Florida International University FIU Digital Commons

\title{
Dynamic Behavior and Fatigue Life of Highway Bridges Due to Doubling Heavy Vehicles
}

Arash Tarighi

atari002@fiu.edu

DOI: $10.25148 /$ etd.FI15032167

Follow this and additional works at: https://digitalcommons.fiu.edu/etd

Part of the Civil Engineering Commons, Structural Engineering Commons, and the Transportation Engineering Commons

\section{Recommended Citation}

Tarighi, Arash, "Dynamic Behavior and Fatigue Life of Highway Bridges Due to Doubling Heavy Vehicles" (2015). FIU Electronic Theses and Dissertations. 1827.

https://digitalcommons.fiu.edu/etd/1827 


\title{
FLORIDA INTERNATIONAL UNIVERSITY
}

Miami, Florida

\section{DYNAMIC BEHAVIOR AND FATIGUE LIFE OF HIGHWAY BRIDGES DUE TO DOUBLING HEAVY VEHICLES}

\author{
A dissertation submitted in partial fulfillment of the \\ requirements for the degree of \\ DOCTOR OF PHILOSOPHY \\ in \\ CIVIL ENGINEERING \\ by \\ Arash Tarighi
}

2015 
To: Dean Amir Mirmiran

College of Engineering and Computing

This dissertation, written by Arash Tarighi, and entitled Dynamic Behavior and Fatigue Life of Highway Bridges Due to Doubling Heavy Vehicles, having been approved in respect to style and intellectual content, is referred to you for judgment.

We have read this dissertation and recommend that it be approved.

Amir Mirmiran

Atorod Azizinamini

Arindam Gan Chowdhury

Yimin Zhu

Ton-Lo Wang, Major Professor

Date of Defense: March 26, 2015

The dissertation of Arash Tarighi is approved.

Dean Amir Mirmiran

College of Engineering and Computing

Dean Lakshmi N. Reddi

University Graduate School

Florida International University, 2015 


\section{DEDICATION}

I would like to dedicate this dissertation to my lovely parents, Sousan and Farhad. Without your unconditional love and sacrifices, this would not have been possible. 


\section{ACKNOWLEDGMENTS}

First, I would like to express my special appreciation and thanks to my advisor, Dr. TonLo Wang for his guidance, kindness and patience throughout the preparation of this dissertation. His knowledge and insightful ideas paved the way for me to complete this work and I will always be thankful to him.

I would especially like to thank Dr. Atorod Azizinamini for his support and guidance as a committee member and also chair of the Department of Civil and Environmental Engineering. Without his help, the completion of the work would not have been possible. I am also very thankful to the other members of my committee, Dr. Amir Mirmiran, Dr. Arindam Gan Chowdhury and Dr. Yimin Zhu for serving as my committee members and for their insightful suggestions and guidance.

This dissertation was funded by a grant from the Georgia Transportation Institute, USDOT Transportation Centers Program.

Last but not least, I would like to express my deepest gratitude to my parents and my brother without whom I would not be where I am today. I am so thankful to have your love and support. 


\section{ABSTRACT OF THE DISSERTATION}

DYNAMIC BEHAVIOR AND FATIGUE LIFE OF HIGHWAY BRIDGES DUE TO

DOUBLING HEAVY VEHICLES

by

Arash Tarighi

Florida International University, 2015

Miami, Florida

Professor Ton-Lo Wang, Major Professor

An increase in the demand for the freight shipping in the United States has been predicted for the near future and Longer Combination Vehicles (LCVs), which can carry more loads in each trip, seem like a good solution for the problem. Currently, utilizing LCVs is not permitted in most states of the US and little research has been conducted on the effects of these heavy vehicles on the roads and bridges. In this research, efforts are made to study these effects by comparing the dynamic and fatigue effects of LCVs with more common trucks.

Ten Steel and prestressed concrete bridges with span lengths ranging from 30' to 140' are designed and modeled using the grid system in MATLAB. Additionally, three more real bridges including two single span simply supported steel bridges and a three span continuous steel bridge are modeled using the same MATLAB code. The equations of motion of three LCVs as well as eight other trucks are derived and these vehicles are subjected to different road surface conditions and bumps on the roads and the designed and real bridges. By forming the bridge equations of motion using the mass, stiffness and damping matrices and considering the interaction between the truck and the bridge, the differential equations are solved using the ODE solver in MATLAB and the results of 
the forces in tires as well as the deflections and moments in the bridge members are obtained.

The results of this study show that for most of the bridges, LCVs result in the smallest values of Dynamic Amplification Factor (DAF) whereas the Single Unit Trucks cause the highest values of DAF when traveling on the bridges. Also in most cases, the values of DAF are observed to be smaller than the $33 \%$ threshold suggested by the design code. Additionally, fatigue analysis of the bridges in this study confirms that by replacing the current truck traffic with higher capacity LCVs, in most cases, the remaining fatigue life of the bridge is only slightly decreased which means that taking advantage of these larger vehicles can be a viable option for decision makers. 


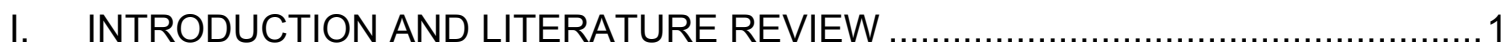

II. METHODOLOGY

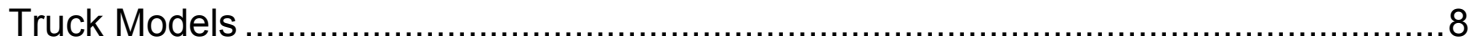

Derivation of Equations of Motion for H20-44 Truck ............................................10

Derivation of Equations of Motion for HS20-44 Truck .......................................... 15

Derivation of Equations of Motion for 9 Axle Turnpike Double ................................22

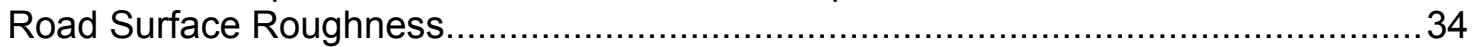

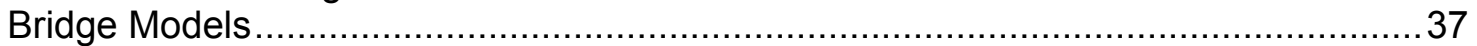

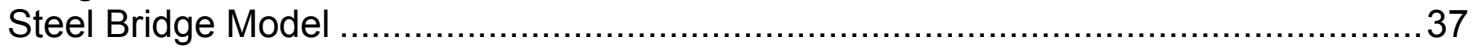

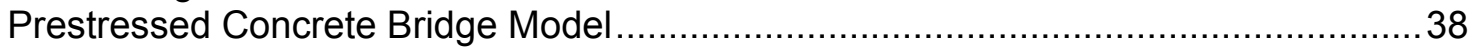

Bridge-Vehicle Interaction and Numerical Methods.............................................43

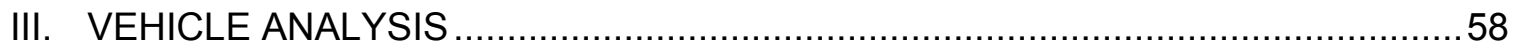

Analysis Results for Different Road Surface Conditions.........................................58

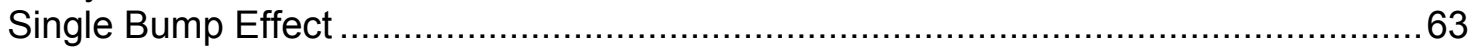

IV. DYNAMIC AMPLIFICATION FACTOR ANALYSIS OF BRIDGES .......................69

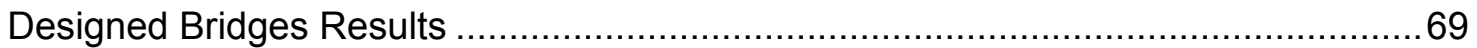

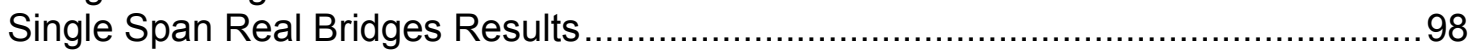

Multiple Span Real Bridge Results ……......................................................... 125

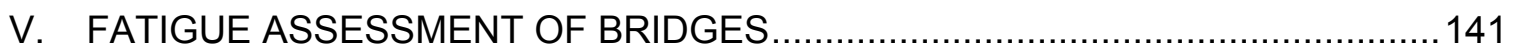

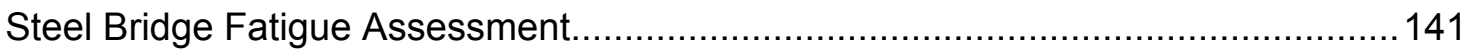

Reinforced Concrete Deck Fatigue Assessment ................................................153

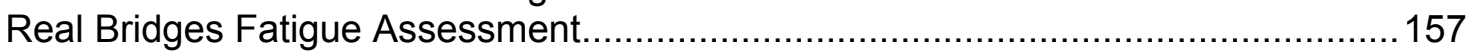

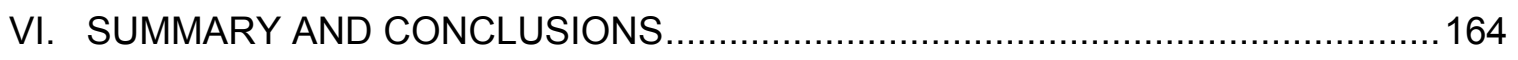

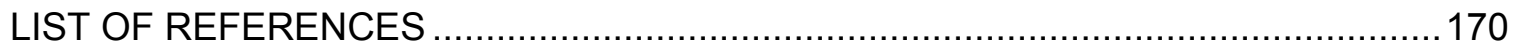

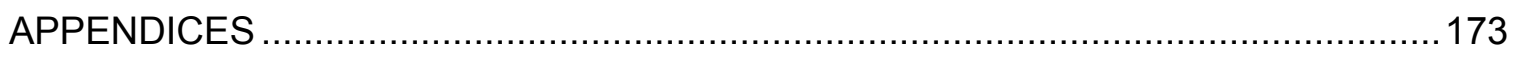

VITA 


\section{LIST OF TABLES}

TABLE

PAGE

Table 1. Trucks Properties for the H-20 and HS-20 Trucks .................................... 10

Table 2. Axle Weights and Gross Vehicle Weight of Trucks .................................. 10

Table 3. Degrees of Freedom of H20-44 Truck ......................................................11

Table 4. Relative Displacements at Spring Locations of H20-44 Truck .......................11

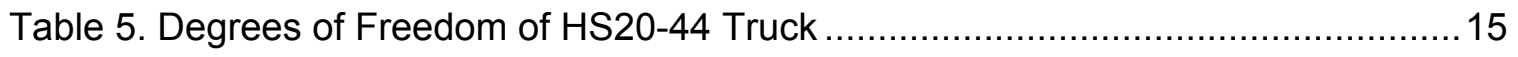

Table 6. Relative Displacements at Spring Locations of HS20-44 Truck .....................17

Table 7. Degrees of Freedom of 9 Axle Turnpike Double ....................................... 24

Table 8. Relative Displacements at Spring Locations of 9 Axle Turnpike Double...........25

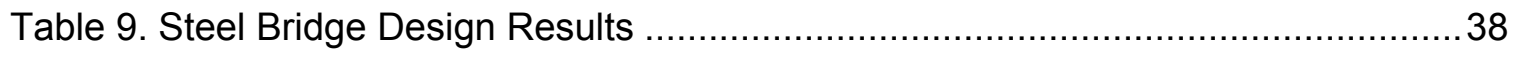

Table 10. Prestressed Concrete Bridge Design Results .............................................. 38

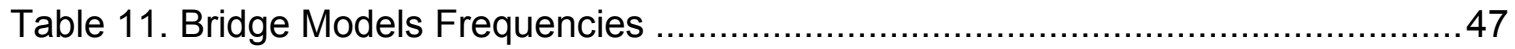

Table 12. Maximum Tire Impact Factors of Single Unit Trucks for the Selected Axle

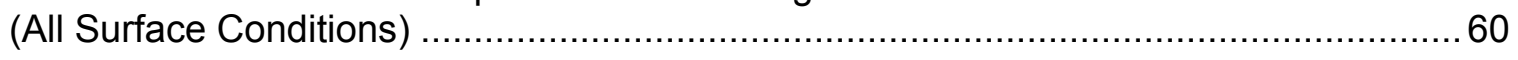

Table 13. Maximum Tire Impact Factors of the Long Combination Vehicles for the Selected Axle (All Bump Sizes).

Table 14. Dynamic Amplification Factor for Prestreesed Concrete Bridges (Good

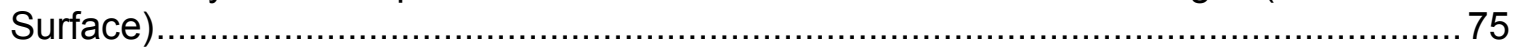

Table 15. Dynamic Amplification Factor for Steel Bridges (Good Surface)...................76

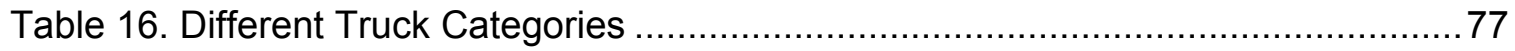

Table 17. Dynamic Amplification Factor for Prestreesed Concrete Bridges (Very

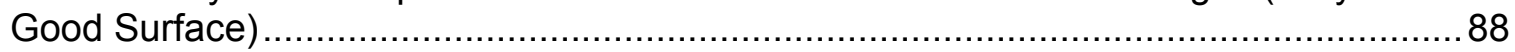

Table 18. Dynamic Amplification Factor for Steel Bridges (Very Good Surface) ............89 
Table 19. Dynamic Amplification Factor for First and Second Real Bridges. 120

Table 20. Dynamic Amplification Factor for the Three Span Real Bridge 138

Table 21. Resistance Factor for Evaluation, Minimum, or Mean Fatigue Life, RR 144

Table 22. Detail Category Constant, A .......................................................... 145

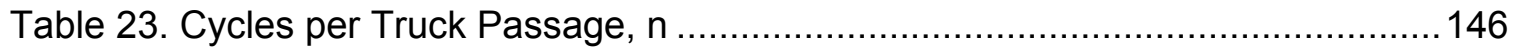

Table 24. Truck Counts Based on WisDOT Data ............................................. 147

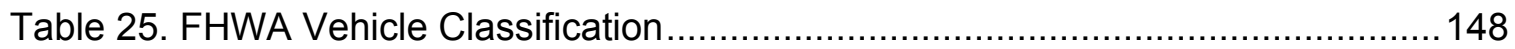

Table 26. Remaining Fatigue Life of the Steel Bridge Based on First and Second Scenarios 148

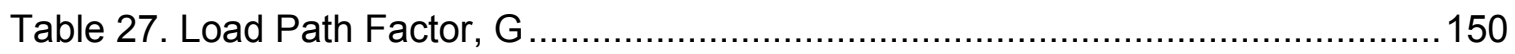

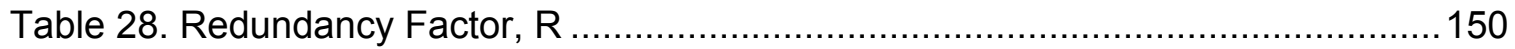

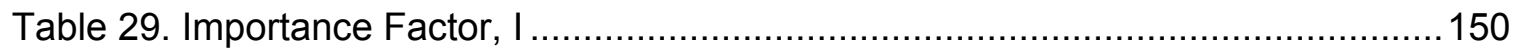

Table 30. Fatigue Rating and Assessment Outcomes ............................................ 151

Table 31. Fatigue Serviceability Index Based on First and Second Scenarios .............151

Table 32. Fatigue Rating Based on First and Second Scenarios............................ 152

Table 33. Remaining Fatigue Life of the Steel Bridge Based on First and Third Scenarios 152

Table 34. Fatigue Serviceability Index Based on First and Third Scenarios ................ 153

Table 35. Fatigue Rating Based on First and Third Scenarios..................................153

Table 36. Remaining Fatigue Life of the Reinforced Concrete Deck Based on First and Second Scenarios

Table 37. Remaining Fatigue Life of the Reinforced Concrete Deck Based on First and Third Scenarios

Table 38. Remaining Fatigue Life of the First Real Bridge for All Scenarios 159 
Table 39. Fatigue Serviceability Index of the First Real Bridge for All Scenarios

Table 40. Remaining Fatigue Life of the Second Real Bridge for All Scenarios 160

Table 41. Fatigue Serviceability Index of the Second Real Bridge for All Scenarios .... 160

Table 42. Remaining Fatigue Life of the Three Span Continuous Real Bridge for All

Scenarios

Table 43. Fatigue Serviceability Index of the Three Span Continuous Real Bridge for All Scenarios 161

Table 44. Fatigue Rating of All Three Real Bridges for All Scenarios 163 


\section{LIST OF FIGURES}

FIGURE

PAGE

Figure 1. Truck Models 8

Figure 2. H20-44 Dynamic Model (a) Truck Side View (b) Truck Front View.................12

Figure 3. HS20-44 Dynamic Model (a) Truck Side View (b) Truck Front View ..............16

Figure 4. Nine Axle Turnpike Double Dynamic Model (a) Truck Side View (b) Truck

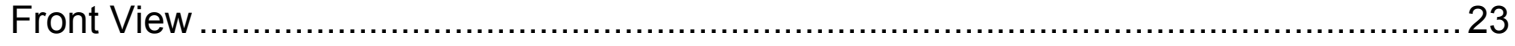

Figure 5. Dodds and Robson Spectrum for Principal Roads.....................................35

Figure 6. Road Surface Profiles for the Right Tire ……..........................................

Figure 7. Steel Girder Bridge Typical Cross Section for (a) 30'-60'-90' (b) 120'-140' .....39

Figure 8. Steel Girder Bridge Plans for (a) 30' (b) 60' (c) 90' ...................................40

Figure 9. Steel Girder Bridge Plans for (a) 120' (b) 140............................................. 41

Figure 10. Prestressed Concrete Bridge Typical Cross Section for (a) 30'-60'-90'

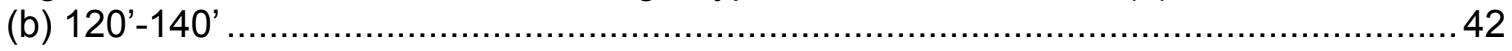

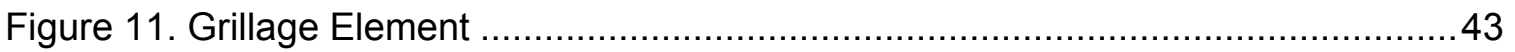

Figure 12. Deflection Due to Dead Load for $60 \mathrm{ft}$. Steel Girder Bridge .........................44

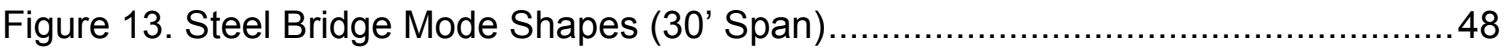

Figure 14. Steel Bridge Mode Shapes (60' Span) ……….......................................49

Figure 15. Steel Bridge Mode Shapes (90' Span) ……...............................................5

Figure 16. Steel Bridge Mode Shapes (120' Span) ……….....................................51

Figure 17. Steel Bridge Mode Shapes (140' Span) .................................................52

Figure 18. Prestressed Concrete Bridge Mode Shapes (30' Span) ................................53

Figure 19. Prestressed Concrete Bridge Mode Shapes (60' Span) ...............................54 
Figure 20. Prestressed Concrete Bridge Mode Shapes (90’ Span) .............................55

Figure 21. Prestressed Concrete Bridge Mode Shapes (120' Span) ..........................56

Figure 22. Prestressed Concrete Bridge Mode Shapes (140' Span) ..........................57

Figure 23. Time History of Different Tire Responses of H-20 Truck Traveling at 15 mph on Very Good Surface Condition

Figure 24. Tire Impact Factors of H-20 Truck for Front and Rear Axles (Very Good and Good Surface Conditions)

Figure 25. Tire Impact Factor of Different Vehicle Categories for the Selected Axle (Very Good Surface Condition)

Figure 26. Tire Impact Factor of Different Vehicle Categories for the Selected Axle (Good Surface Condition)

Figure 27. Tire Impact Factor of Different Vehicle Categories for the Selected Axle (Average Surface Condition).

Figure 28. Tire Impact Factor of Different Vehicle Categories for the Selected Axle (Poor Surface Condition).

Figure 29. Time History of Different Tire Responses of H-20 Truck Traveling at 15 mph (1" Bump)

Figure 30. Time History of Different Tire Responses of H-20 Truck Traveling at 75 mph (1"Bump)

Figure 31. Tire Impact Factors of H-20 Truck for Front and Rear Axles (1" Bump) ........65

Figure 32. Tire Impact Factor of Different Vehicle Categories for the Selected Axle (1/2" Bump)

Figure 33. Tire Impact Factor of Different Vehicle Categories for the Selected Axle (1" Bump)

Figure 34. Tire Impact Factor of Different Vehicle Categories for the Selected Axle (2" Bump)

Figure 35. First Natural Frequency of Designed and Real Bridges 70

Figure 36. Displacement of $30 \mathrm{ft}$. Concrete Bridge due to Single Unit Trucks and HS-20 (Good Surface) 
Figure 37. Displacement of $30 \mathrm{ft}$. Concrete Bridge due to Tractor Semitrailers (Good Surface).

Figure 38. Displacement of $30 \mathrm{ft}$. Concrete Bridge due to Truck and Double Trailers (Good Surface).

Figure 39. Prestressed Concrete Bridges DAF for Different Vehicle Categories (Good Surface)

Figure 40. Steel Bridges DAF for Different Vehicle Categories (Good Surface).....

Figure 41. Moment of $140 \mathrm{ft}$. Concrete Bridge due to Single Unit Trucks and HS-20 (Good Surface).

Figure 42. Moment of $140 \mathrm{ft}$. Concrete Bridge due to Tractor Semitrailers (Good Surface).

Figure 43. Moment of $140 \mathrm{ft}$. Concrete Bridge due to Truck and Double Trailers (Good Surface).

Figure 44. Displacement of $60 \mathrm{ft}$. Steel Bridge due to Single Unit Trucks and HS-20 (Very Good Surface)

Figure 45. Displacement of $60 \mathrm{ft}$. Steel Bridge due to Tractor Semitrailers (Very Good Surface)....

Figure 46. Displacement of $60 \mathrm{ft}$. Steel Bridge due to Truck and Double Trailers (Very Good Surface)

Figure 47. Prestressed Concrete Bridges DAF for Different Vehicle Categories (Very Good Surface)

Figure 48. Steel Bridges DAF for Different Vehicle Categories (Very Good Surface).....91

Figure 49. Moment of $120 \mathrm{ft}$. Steel Bridge due to Single Unit Trucks and HS-20 (Very Good Surface)

Figure 50. Moment of $120 \mathrm{ft}$. Steel Bridge due to Tractor Semitrailers (Very Good Surface).

Figure 51. Moment of $120 \mathrm{ft}$. Steel Bridge due to Truck and Double Trailers (Very Good Surface).

Figure 52. Comparison of the Very Good and Good Surfaces Results (a) 30' Concrete (b) 30' Steel (c) 60' Concrete (d) 60' Steel 
Figure 53. Comparison of the Very Good and Good Surfaces Results (a) 90'

Concrete (b) 90' Steel (c) 120' Concrete (d) 120' Steel

Figure 54. Comparison of the Very Good and Good Surfaces Results (a) 140'

Concrete (b) 140' Steel

Figure 55. First Real Bridge Mode Shapes (189' 8" span).

Figure 56. Displacement of First Real Bridge due to Single Unit Trucks and HS-20 (Good Surface).

Figure 57. Displacement of First Real Bridge due to Tractor Semitrailers (Good Surface)

Figure 58. Displacement of First Real Bridge due to Truck and Double Trailers (Good Surface).

Figure 59. Displacement of First Real Bridge due to Single Unit Trucks and HS-20 (Very Good Surface)

Figure 60. Displacement of First Real Bridge due to Tractor Semitrailers (Very Good Surface).

Figure 61. Displacement of First Real Bridge due to Truck and Double Trailers (Very Good Surface)

Figure 62. Moment of First Real Bridge due to Single Unit Trucks and HS-20 (Good Surface)..... 106

Figure 63. Moment of First Real Bridge due to Tractor Semitrailers (Good Surface) ... 107

Figure 64. Moment of First Real Bridge due to Truck and Double Trailers (Good Surface) 108

Figure 65. Second Real Bridge Mode Shapes (83' 6” span) 110

Figure 66. Displacement of Second Real Bridge due to Single Unit Trucks and HS20 (Good Surface).

Figure 67. Displacement of Second Real Bridge due to Tractor Semitrailers (Good Surface).

Figure 68. Displacement of Second Real Bridge due to Truck and Double Trailers (Good Surface). 
Figure 69. Displacement of Second Real Bridge due to Single Unit Trucks and HS20 (Very Good Surface)

Figure 70. Displacement of Second Real Bridge due to Tractor Semitrailers (Very Good Surface)....

Figure 71. Displacement of Second Real Bridge due to Truck and Double Trailers (Very Good Surface)

Figure 72. Moment of Second Real Bridge due to Single Unit Trucks and HS-20 (Good Surface).

Figure 73. Moment of Second Real Bridge due to Tractor Semitrailers (Good

Surface)

Figure 74. Moment of Second Real Bridge due to Truck and Double Trailers (Good

Surface)

Figure 75. First Real Bridge DAF for Different Vehicle Categories (Very Good Surface)

Figure 76. First Real Bridge DAF for Different Vehicle Categories (Good Surface)......122

Figure 77. Second Real Bridge DAF for Different Vehicle Categories (Very Good Surface).....

Figure 78. Second Real Bridge DAF for Different Vehicle Categories (Good Surface).....

Figure 79. First Real Bridge Comparison of the Very Good and Good Surfaces

Results

Figure 80. Second Real Bridge Comparison of the Very Good and Good Surfaces Results

Figure 81. Three Span Real Bridge Mode Shapes (Three Span Continuous Bridge)... 128

Figure 82. Displacement of Three Span Real Bridge due to Single Unit Trucks and HS-20 (Good Surface)

Figure 83. Displacement of Three Span Real Bridge due to Tractor Semitrailers (Good Surface).

Figure 84. Displacement of Three Span Real Bridge due to Truck and Double Trailers (Good Surface). 
Figure 85. Displacement of Three Span Real Bridge due to Single Unit Trucks and HS-20 (Very Good Surface)

Figure 86. Displacement of Three Span Real Bridge due to Tractor Semitrailers (Very Good Surface)

Figure 87. Displacement of Three Span Real Bridge due to Truck and Double Trailers (Very Good Surface)

Figure 88. Moment of Three Span Real Bridge due to Single Unit Trucks and HS20 (Good Surface).

Figure 89. Moment of Three Span Real Bridge due to Tractor Semitrailers (Good Surface)

Figure 90. Moment of Three Span Real Bridge due to Truck and Double Trailers (Good Surface).

Figure 91. Three Span Real Bridge DAF for Different Vehicle Categories (Very Good Surface)

Figure 92. Three Span Real Bridge DAF for Different Vehicle Categories (Good Surface).

Figure 93. Three Span Real Bridge Comparison of the Very Good and Good Surfaces

Figure 94. Remaining Fatigue Life of All Scenarios for First Real Bridge 162

Figure 95. Remaining Fatigue Life of All Scenarios for Three Span Real Bridge 162 


\section{INTRODUCTION AND LITERATURE REVIEW}

Most of the freight shipping in the United States is done by trucks and it has been predicted that the freight shipping by the use of trucks will be doubled in the next ten years. This growth has to be dealt with, either by increasing the number of trucks or increasing the weight limits of the trucks. Increasing the number of trucks can seriously damage bridges due to repetitive loading, which causes fatigue problems and this can reduce the service life of the bridges. On the other hand, weight limit increase has been a much discussed topic recently and a lot of requests have been reported from different states to allow usage of heavier and longer trucks.

To understand the weight limit problem, it is useful to take a brief look at the history of weight regulations. No limitations on a federal level had been imposed on the truck size and weight, until 1956, when an act was passed in congress, which gave the Federal Government more control over the interstates. As a result, proposed policy by American Association of State Highway Officials (AASHO) in 1946, which limited the gross vehicle weight (GVW) to 73.28 kips and weight of single axles and tandem axles to 18 and 32 kips, respectively, became a federal law. Meanwhile, states with different weight limitations were given the permission to continue their operation under the same old regulations. An amendment to this act was proposed in 1974, which increased the GVW to 80 kips and a 2 kip increase to both single axle and tandem axle weights was also included [1].

As mentioned before, the rising demand for freight shipping can be met by one of the two ways of increasing the number of trucks traveling on the road or using trucks with higher load capacities. A combination of the two solutions, which is adding a smaller 
number of heavier trucks to the system, is also a plausible option. The goal in this research is to study the importance of this issue from the Bridge Engineering standpoint.

The need for more trucks whether in the form of increase in the number of trucks or increase in the gross weight of trucks, is putting significant strain on the current bridges, which were mostly built in accordance with the traffic demands of the seventies. These bridges are experiencing much heavier traffics these days comparing to the days that they were built in. Longevity and durability of bridges are of extreme importance to the bridge owners and using some gauges, such as remaining fatigue life of the bridges or the intensity of the bridge responses due to different types of truck loadings can help quantify the issue. This way, it would be easier to choose between the available options.

In this research, efforts will be made to find out which approach has less detrimental impacts on bridges. In a nutshell, the main question to be answered here is whether the decision makers and DOTs should allow using trucks with higher load capacities (such as longer combination vehicles), which helps save a lot of money on freight in general as well as meeting the increasing freight demands or current bridges are incapable of carrying the loads of larger trucks, so the other solution, which is using more trucks to deal with the increasing freight, has to be used. It should be noted that the severity of the bridge situation under heavier trucks or more number of trucks will also be studied to see whether using heavier trucks is the better solution. In other words, durability and longevity of bridges will be used as some measures for choosing between the options.

Longer Combination Vehicles (LCVs) are referred to trucks with combination of multiple trailers and they are usually bigger in size and capable of carrying more loads comparing to the common types of trucks which includes the Single Unit Trucks such as SU4 Truck and the Truck and Trailer or Truck and Semitrailer such as Type $3 S 2$ (FDOT Truck). 
Currently, according to the state laws in the United Stated, thirteen states allow the operation of Longer Combination Vehicles (LCVs) with some limitations. In addition to that, six states allow these vehicles on Turnpikes only [2].

Using LCVs on the roads can decrease the fuel cost, labor, emission, congestion and also increase the freight shipping efficiency and volume [2]. These benefits altogether make the subject of using these vehicles very appealing to the DOTs. But one should make sure that necessary infrastructures are provided and they are indeed capable of handling the effects of using these vehicles on both roads and bridges.

The interest in utilizing LCVs' benefits has been increased in the recent years with the increase in costs related to the freight shipment, resulting in more willingness among policy makers at DOTs and industry professionals to use other options such as using LCVs. Even though with Intermodal Surface Transportation Efficiency Act which was passed in Congress in 1991 the use of LCVs has been limited due to safety and pavement damages. The only exceptions were the states which had already allowed the use of LCVs [2].

The inconsistency in the literature can be seen when it comes to the effects that LCVs have on the road safety but when it comes to the effects of these vehicles on the road surface, it seems that there is a consensus that with restricting the axle weight limits of LCVs to the axle weight limits of other trucks, the Gross Vehicle Weight (GVW) might not have a huge impact on the road surface damages [2].

It is believed that the number of axles passing over the pavement, the weight of the axles and spacing between the axle groups will determine the damages sustained by the pavement. The relation between the axle weight and the damage to the pavement has 
been found to be an exponential one with the power of four. Generalization in the case of the effects of distance between the axle groups has been found to be a difficult task. The effects of the increase in speed on the pavement also seem to be unpredictable. In order to achieve the purpose of carrying more loads with heavier trucks, two options of heavier axles as well as more number of axles are possible. Studies have shown that while using heavier axles can increase the cost of damages to the pavements, using more number of axles to satisfy the increase of the load demands can even result in a decrease in cost of pavement damages [3].

Sometimes having one more axle can even relieve the pressure on the pavement. As an example, the two cases of 5-axle and 6-axle tractor semitrailer were compared in USDOT (2000). The steering axle, tandem axle and tridem axle were assumed to weigh 12, 34 and 44 kips respectively. In the case of 5-axle truck, two tandem axles were assumed, adding up the total weight to 80 kips. In the case of 6 -axle truck, a tandem and a tridem axle were assumed which made the total weight, 90 kips. It was observed that the 5 -axle truck with the smaller gross vehicle weight caused $\% 18$ more damage to the pavement [4], [5].

Approach slab settlements and movements of the bridge deck might cause bump formation at the end of the bridges. This can cause bridge maintenance costs, bridge deck damages, reduced control for the drivers and inconvenience for the passengers [6]. Heavy trucks passage over the bump can cause significant damages to the infrastructures.

In the first part of this research, the dynamic model and equations of motion of LCVs have been generated. The models have been analyzed under different vehicle speeds and road surface conditions. The effects of the presence of a bump on the road have 
also been studied. The results have been compared to the results of the common truck types to help better understand the effects of LCVs on the roads.

In the second part, five steel girder single span, simply supported bridges and five prestressed concrete single span, simply supported bridges with spans ranging from 30 to 140 feet have been designed in accordance with the AASHTO LRFD design manual [7]. Eleven different trucks have been chosen to be applied to the bridge models to study the effects of different types of truck loadings. The reason to try different trucks is to help understand the effects of additional axles on the response of bridges.

Dynamic amplification factor and fatigue life of the bridges alongside other dynamic responses of the designed bridges shall be calculated. Based on these calculations, the possibility of using heavier trucks instead of more trucks in order to deal with the increasing demand of the freight will be looked into. Obviously, this would be possible only if the stresses, displacements and other indicators of bridge structural health fall within an acceptable range.

Bridge vibration problems due to a moving vehicle have been a subject of many studies in the past. From a general point of view, these studies can be categorized into nine groups: the suspension systems effects, road surface roughness, bridge span length, vehicle braking, axle spacing, gross vehicle weight, vehicle speed, bridge mass and bridge damping. In order to investigate different factors on the bridge dynamic behavior a lot of numerical methods have been developed [8].

There are different approaches to the way that vehicles are modeled. Quarter truck vehicle is the simplest model [9]. The other two common models are the twodimensional models [10]; and the three-dimensional models [8] [11] [12]. 
Also, different ways to model bridge structures have been proposed. Some of them are: grillage method [13], eight-node quadrilateral Kirchhoff plate/shell element and threenode Euler-Bernoulli beam [11], plate elements [12], and assemblage of beam and plate elements [8] [10].

Using the above models, the bridge-vehicle system is formed with the constant interaction between the bridge and the vehicle. The equations of motion of the bridge and the vehicle can be solved separately using iterative procedures or as coupled equations of motion by some methods such as the central difference method [14].

Dynamic load allowance (dynamic impact factor (DAF)) is the dynamic effect of moving vehicles on bridges and is defined as the ratio of the maximum dynamic response to the maximum static response. It can be evaluated from the displacements, strains, or reactions which result in different numbers. In most of the experimental studies published, the computation of DAF is based on the displacements [15]. The AASHTO LRFD design manual suggests a value of $33 \%$ for the dynamic load allowance [7]. In AASHTO standard specifications, it is expressed as a function of the bridge length [16]. Some other codes, like Canada's Ontario Bridge Design Code, define DAF as a function of the first flexural frequency of the bridge [17]. There has been a huge effort in the past decades to investigate the effects of dynamic loading on the bridges through both analytical and field testing methods; the codes' underestimation when it comes to the dynamic load allowance has been suggested in some studies. A reason for this problem might be that, the codes consider good road surface condition, where in fact some of the bridges in the US might experience bad surface conditions at times. 
A complete investigation of the factors affecting DAF, using analytical and experimental methods, was performed by Paultre et al. [18] and they concluded that DAF is related to the surface condition, vehicle suspension system and the fundamental frequency.

A series of investigations using analytical methods were carried out and the results showed that the vehicle speed does not have a big effect on the impact factor when vehicles travel on Good and Very Good surface conditions. Also the impact factors for short span bridges were larger than the impact factors of the long span bridges. It was also observed that an increase in the vehicle weight would result in smaller impact factors [13] [19] [20] [21].

In a research by Brady et al. [22] the DAF was investigated using one simple model as well as another more complicated 3D model. It was observed that the values of DAF for two vehicles on the bridge were smaller than those for one vehicle. In addition, DAF values were larger in a lane in which there is no vehicle comparing to the lane where the vehicle is traveling. 


\section{METHODOLOGY}

\section{Truck Models}

The effects of different trucks on the bridge dynamic responses depend on many factors such as the gross vehicle weight (GVW), number and weight of truck axles, distance between truck axles, etc. To capture the bridge behavior under the traffic, a wide range of trucks needs to be considered. To achieve this goal, many trucks with different lengths and weights have been chosen. These trucks include three Single Unit Trucks (H-20, SU4 and Type 3) and five Tractor Semitrailers (Type 3S2, Type 3S1, Type 2S2, Type $3 S 3$ and HS-20). In addition to these trucks, three longer combination vehicles (LCV) including 7 Axle Rocky Mountain Double, 8 Axle B-Train Double and 9 Axle Turnpike Double are selected. All these trucks can be seen in Figure 1.

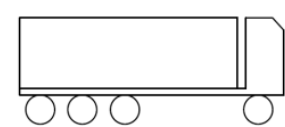

SU4

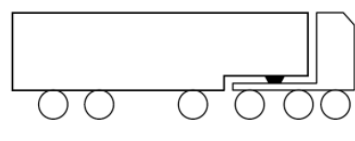

Type 353

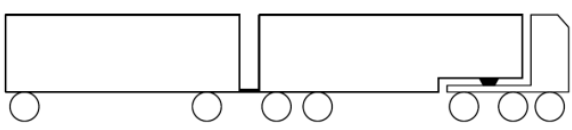

7-Axle Rocky Mountain Double

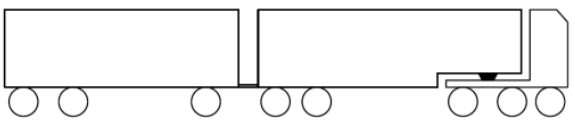

8-Axle B-Train Double

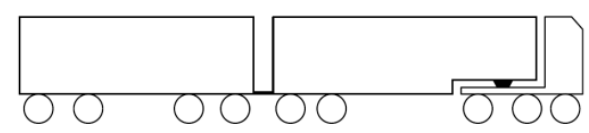

9-Axle Turnpike Double

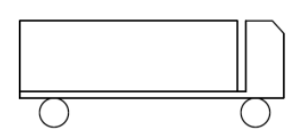

$\mathrm{H}-20$

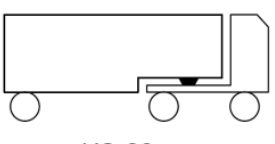

HS-20

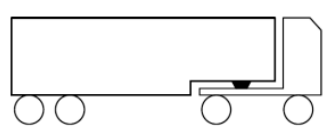

Type 2S2

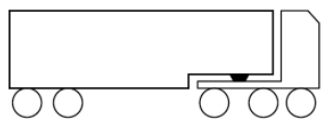

Type 3S2

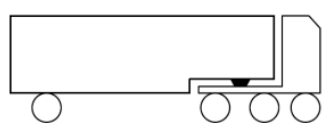

Type 3S1

Figure 1. Truck Models 
The next step is to develop the equations of motion for these trucks. A few different vehicle modeling techniques have been proposed throughout the years. One system which has been used the most was developed and verified by Wang and Huang in several studies [23], [13], [24], [25], [26]. This system and similar systems of modeling have also been used by other researchers to study the dynamic response of bridges due to vehicles. This system comprises of rigid massed as the truck, trailer and axle parts. Each truck or trailer mass has three movements of pitching, rolling and vertical displacements. The axles possess only the vertical and rolling displacements. The springs and dampers have been put together in parallel in a so-called Kelvin model. This model represents the suspension and the tires.

In this research the derivation has been done and extended for different common types of trucks in addition to three longer combination vehicles (LCV). The details of the derivation of equations for the simplest $(\mathrm{H} 20-44)$ and the most complicated case (9 Axle Turnpike Double) are provided here. Data of tractor and trailer lengths in addition to the weights on different axles were gathered from different reports and sources online and for the other cases that no data were found, reasonable assumptions based on the similar cases were made in order to complete the model. The vehicle properties including the stiffness and damping of the suspension and tire for the $\mathrm{H}-20$ and HS-20 trucks can be seen in Table 1. The weights of all axles and the gross vehicle weight of all the trucks which is the sum of the Tare weight and the maximum load that the truck can carry are shown in Table 2.

The vehicle models of the $\mathrm{H} 20-44$ and $\mathrm{HS} 20-44$ were verified with some experimental data in FDOT Report [41] using truck responses due to a single step bump. The results 
showed a good agreement between the experimental and numerical results. Same modeling approach has been extended in this research for the LCVs and other trucks.

Table 1. Trucks Properties for the H-20 and HS-20 Trucks

\begin{tabular}{|c|c|c|c|c|c|}
\hline \multirow{2}{*}{} & \multicolumn{2}{|c|}{$\mathrm{H}-20$} & \multicolumn{3}{c|}{ HS-20 } \\
\cline { 2 - 6 } & $1^{\text {st }}$ Axle & $2^{\text {nd }}$ Axle & $1^{\text {st }}$ Axle & $2^{\text {nd }}$ Axle & $3^{\text {rd }}$ Axle \\
\hline $\begin{array}{c}\text { Suspension Stiffness } \\
\text { (Kips/in) }\end{array}$ & 2.97 & 11.42 & 2.97 & 11.42 & 11.42 \\
\hline $\begin{array}{c}\text { Tire Stiffness } \\
\text { (Kips/in) }\end{array}$ & 4.99 & 19.98 & 4.99 & 19.98 & 19.98 \\
\hline $\begin{array}{c}\text { Suspension Damping } \\
\text { (Kips.Sec/in) }\end{array}$ & 0.06 & 0.23 & 0.06 & 0.23 & 0.23 \\
\hline $\begin{array}{c}\text { Tire Damping } \\
\text { (Kips.Sec/in) }\end{array}$ & 0.006 & 0.02 & 0.006 & 0.02 & 0.02 \\
\hline
\end{tabular}

Table 2. Axle Weights and Gross Vehicle Weight of Trucks

\begin{tabular}{|c|c|c|c|c|c|c|c|c|c|c|c|}
\hline \multirow[b]{2}{*}{ Axle Number } & \multicolumn{11}{|c|}{ Vehicle Type } \\
\hline & $\mathrm{H}-20$ & HS-20 & Type 3 & $\begin{array}{l}\text { Type } \\
3 \text { S2 }\end{array}$ & $\begin{array}{l}\text { Type } \\
\text { 3S3 }\end{array}$ & $\begin{array}{l}\text { Type } \\
2 \text { S2 }\end{array}$ & $\begin{array}{l}\text { Type } \\
3 \text { S1 }\end{array}$ & SU4 & \begin{tabular}{|c|} 
7-Axle \\
Rocky \\
Mountain \\
Double
\end{tabular} & $\begin{array}{c}8 \text { Axle B- } \\
\text { Train } \\
\text { Double }\end{array}$ & $\begin{array}{c}9 \text { Axle } \\
\text { Turnpike } \\
\text { Double }\end{array}$ \\
\hline 1 & 8 & 8 & 16 & 12 & 12 & 12 & 12 & 13.9 & 14 & 12 & 15 \\
\hline 2 & 32 & 32 & 17 & 17 & 17 & 24 & 18 & 18.7 & 18 & 15 & 17 \\
\hline 3 & & 32 & 17 & 17 & 17 & 18 & 18 & 18.7 & 18 & 15 & 17 \\
\hline 4 & & & & 17 & 17 & 18 & 24 & 18.7 & 17 & 14 & 16 \\
\hline 5 & & & & 17 & 17 & & & & 17 & 14 & 16 \\
\hline 6 & & & & & 17 & & & & 18 & 19 & 16 \\
\hline 7 & & & & & & & & & 18 & 17.5 & 16 \\
\hline 8 & & & & & & & & & & 17.5 & 17 \\
\hline 9 & & & & & & & & & & & 17 \\
\hline $\begin{array}{l}\text { Gross Vehicle } \\
\text { Weight [Kips] }\end{array}$ & 40 & 72 & 50 & 80 & 97 & 72 & 72 & 70 & 120 & 124 & 147 \\
\hline
\end{tabular}

\section{Derivation of Equations of Motion for H20-44 Truck}

$\mathrm{H} 20-44$ is the simplest truck model that has been used here. Three degrees of freedom for vertical, roll, and pitch displacements of the truck have been defined. Also each of the 
two axles has two degrees of freedom for vertical and roll displacements. There are seven degrees of freedom in total for this type of truck. The degrees of freedom can be seen in Figure 2 and the description of those degrees of freedom can be found in Table 3. Relative Displacements at the locations of the springs are also calculated using the values given in Table 4 .

The equations of motion will be solved using fourth order Runge-Kutta to determine the state of the vehicle at each instant.

Table 3. Degrees of Freedom of H20-44 Truck

\begin{tabular}{cc|c|l|} 
No. & $\begin{array}{c}\text { Degree of } \\
\text { Freedom }\end{array}$ & $\begin{array}{c}\text { Contributed } \\
\text { Mass }\end{array}$ & \multicolumn{1}{c|}{ Description } \\
$\mathbf{1}$ & $\mathrm{y}_{\mathrm{t} 1}$ & $\mathrm{~m}_{\mathrm{t} 1}$ & Truck vertical displacement and mass \\
$\mathbf{2}$ & $\varphi_{\mathrm{t} 1}$ & $\mathrm{I}_{\mathrm{xt} 1}$ & Truck roll displacement and mass moment of inertia \\
$\mathbf{3}$ & $\theta_{\mathrm{t} 1}$ & $\mathrm{I}_{\mathrm{zt} 1}$ & Truck pitch displacement and mass moment of inertia \\
$\mathbf{4}$ & $\mathrm{y}_{\mathrm{a} 1}$ & $\mathrm{~m}_{\mathrm{a} 1}$ & Front axle vertical displacement and mass \\
$\mathbf{5}$ & $\varphi_{\mathrm{a} 1}$ & $\mathrm{I}_{\mathrm{xa} 1}$ & Front axle roll displacement and mass moment of inertia \\
$\mathbf{6}$ & $\mathrm{y}_{\mathrm{a} 2}$ & $\mathrm{~m}_{\mathrm{a} 2}$ & Rear axle vertical displacement and mass \\
$\mathbf{7}$ & $\varphi_{\mathrm{a} 2}$ & $\mathrm{I}_{\mathrm{xa} 2}$ & Rear axle roll displacement and mass moment of inertia \\
\hline
\end{tabular}

Table 4. Relative Displacements at Spring Locations of H20-44 Truck

\begin{tabular}{|c|c|}
\hline $\mathbf{U}_{\text {sy1 }}$ & $\begin{array}{l}\text { Suspension springs } \\
\left(\mathrm{y}_{\mathrm{t} 1}-\mathrm{y}_{\mathrm{a} 1}\right)+\left(\mathrm{S}_{1} / 2\right)\left(\varphi_{\mathrm{t} 1}-\varphi_{\mathrm{a} 1}\right)+\mathrm{l}_{3} \theta_{\mathrm{t} 1}\end{array}$ \\
\hline $\mathbf{U}_{\text {sy2 }}$ & $\left(\mathrm{y}_{\mathrm{t} 1}-\mathrm{y}_{\mathrm{a} 1}\right)-\left(\mathrm{S}_{1} / 2\right)\left(\varphi_{\mathrm{t} 1}-\varphi_{\mathrm{a} 1}\right)+\mathrm{l}_{3} \theta_{\mathrm{t} 1}$ \\
\hline $\mathbf{U}_{\text {sy3 }}$ & $\left(\mathrm{y}_{\mathrm{t} 1}-\mathrm{y}_{\mathrm{a} 2}\right)+\left(\mathrm{S}_{2} / 2\right)\left(\varphi_{\mathrm{t} 1}-\varphi_{\mathrm{a} 2}\right)-\mathrm{l}_{4} \theta_{\mathrm{t} 1}$ \\
\hline $\mathbf{U}_{\text {sy4 }}$ & $\left(\mathrm{y}_{\mathrm{t} 1}-\mathrm{y}_{\mathrm{a} 2}\right)-\left(\mathrm{S}_{2} / 2\right)\left(\varphi_{\mathrm{t} 1}-\varphi_{\mathrm{a} 2}\right)-\mathrm{l}_{4} \theta_{\mathrm{t} 1}$ \\
\hline & Tire springs \\
\hline $\mathbf{U}_{\mathrm{ty} \mathbf{1}}$ & $\mathrm{y}_{\mathrm{a} 1}+\left(\mathrm{d}_{1} / 2\right) \varphi_{\mathrm{a} 1}+\mathrm{u}_{\mathrm{SR} 1}$ \\
\hline $\mathbf{U}_{\text {ty2 }}$ & $\mathrm{y}_{\mathrm{a} 1}-\left(\mathrm{d}_{1} / 2\right) \varphi_{\mathrm{a} 1}+\mathrm{u}_{\mathrm{SR} 2}$ \\
\hline $\mathbf{U}_{\mathrm{ty} 3}$ & $\mathrm{y}_{\mathrm{a} 2}+\left(\mathrm{d}_{2} / 2\right) \varphi_{\mathrm{a} 2}+\mathrm{u}_{\mathrm{SR} 3}$ \\
\hline $\mathbf{U}_{\mathrm{ty} 4}$ & $\mathrm{y}_{\mathrm{a} 2}-\left(\mathrm{d}_{2} / 2\right) \varphi_{\mathrm{a} 2}+\mathrm{u}_{\mathrm{SR} 4}$ \\
\hline
\end{tabular}




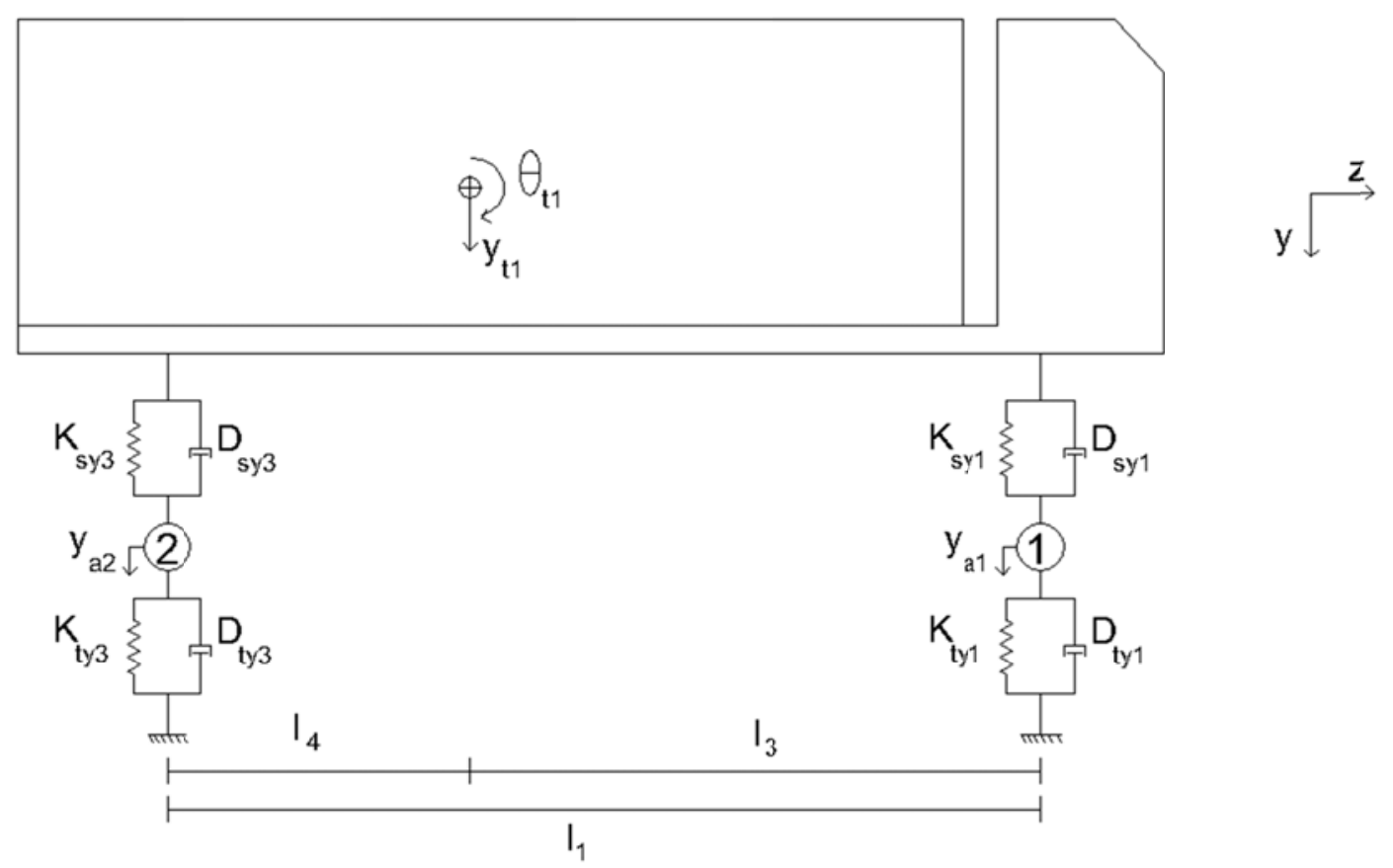

(a)

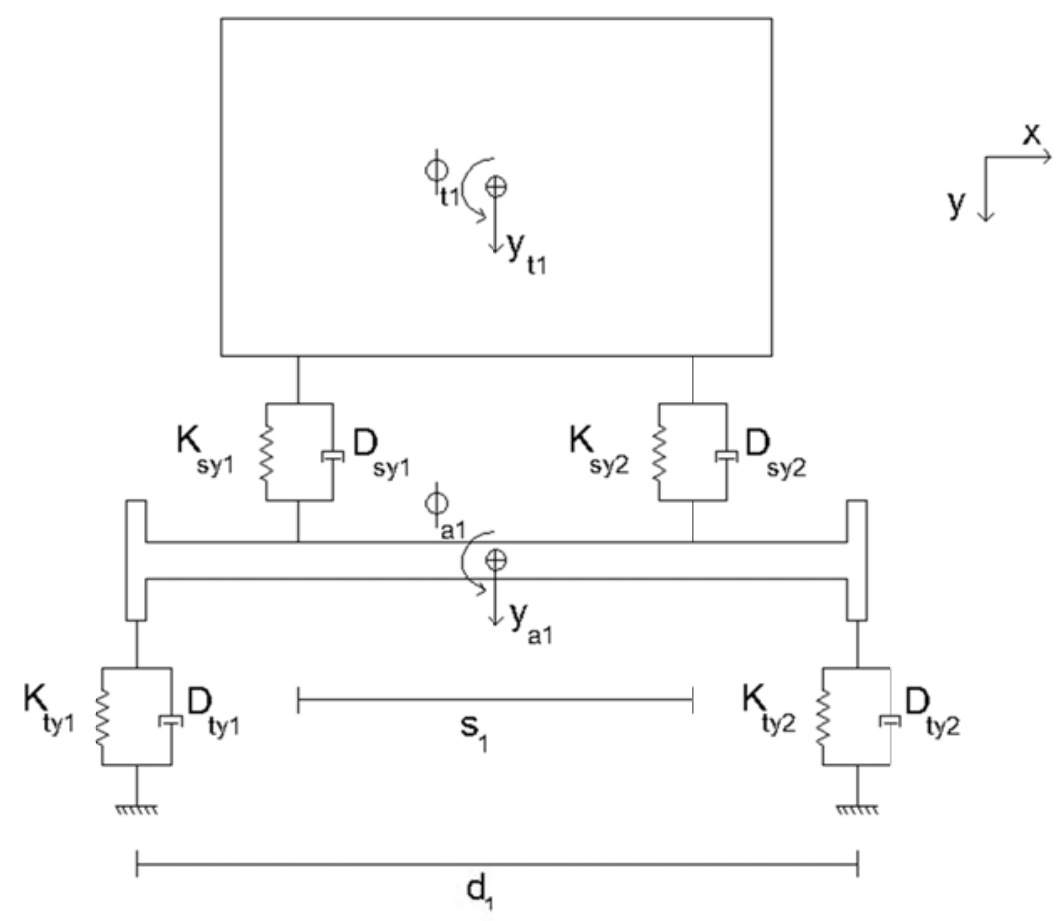

(b)

Figure 2. H20-44 Dynamic Model (a) Truck Side View (b) Truck Front View 
In this table $\mathrm{u}_{\mathrm{SR}}$ is the road surface roughness under the $\mathrm{i}^{\text {th }}$ wheel.

$\mathrm{F}_{\text {syi }}$ and $\mathrm{F}_{\mathrm{dsyi}}$ are defined as the $\mathrm{i}^{\text {th }}$ suspension spring force and suspension damper force, respectively:

$\mathrm{F}_{\mathrm{syi}}=\mathrm{K}_{\mathrm{syi}} \mathrm{U}_{\mathrm{syi}}+\mathrm{F}_{\mathrm{yi}}$

$\mathrm{F}_{\mathrm{dsyi}}=\mathrm{D}_{\mathrm{syi}} \dot{\mathrm{U}}_{\mathrm{syi}}$

Where $\mathrm{F}_{\mathrm{yi}}$ is the friction force at the $\mathrm{i}^{\text {th }}$ suspension. Similarly $\mathrm{F}_{\mathrm{tyi}}$ and $\mathrm{F}_{\mathrm{dtyi}}$ are defined as the spring force and the damper force under the $i^{\text {th }}$ wheel:

$\mathrm{F}_{\mathrm{tyi}}=\mathrm{K}_{\mathrm{tyi}} \mathrm{U}_{\mathrm{tyi}}$

$\mathrm{F}_{\mathrm{dtyi}}=\mathrm{D}_{\mathrm{tyi}} \dot{\mathrm{U}}_{\mathrm{tyi}}$

Lagrange equation has been used to generate the equations of motion of the system:

$\frac{\mathrm{d}}{\mathrm{dt}}\left(\frac{\partial \mathrm{T}}{\partial \dot{\mathrm{q}}_{\mathrm{i}}}\right)-\frac{\partial \mathrm{T}}{\partial \mathrm{q}_{\mathrm{i}}}+\frac{\partial \mathrm{V}}{\partial \mathrm{q}_{\mathrm{i}}}+\frac{\partial \mathrm{D}}{\partial \dot{\mathrm{q}}_{\mathrm{i}}}=0$

Where, $\mathrm{T}$ is the Kinetic Energy of the system:

$\mathrm{T}=\frac{1}{2} \mathrm{~m}_{\mathrm{t} 1} \dot{\mathrm{y}}_{\mathrm{t} 1}{ }^{2}+\frac{1}{2} \mathrm{~m}_{\mathrm{a} 1} \dot{\mathrm{Y}}_{\mathrm{a} 1}{ }^{2}+\frac{1}{2} \mathrm{~m}_{\mathrm{a} 2} \dot{\mathrm{y}}_{\mathrm{a} 2}{ }^{2}+\frac{1}{2} \mathrm{I}_{\mathrm{xt} 1} \dot{\varphi}_{\mathrm{t} 1}{ }^{2}+\frac{1}{2} \mathrm{I}_{\mathrm{zt} 1} \dot{\mathrm{\theta}}_{\mathrm{t} 1}{ }^{2}+\frac{1}{2} \mathrm{I}_{\mathrm{xa} 1} \dot{\varphi}_{\mathrm{a} 1}{ }^{2}+$

$\frac{1}{2} \mathrm{I}_{\mathrm{xa} 2} \dot{\varphi}_{\mathrm{a} 2}^{2}$

$\mathrm{V}$ is the Potential Energy of the system.

$$
\begin{aligned}
& \mathrm{V}=\frac{1}{2} \mathrm{~K}_{\text {sy } 1} \mathrm{U}_{\text {sy } 1}{ }^{2}+\frac{1}{2} \mathrm{~K}_{\text {sy } 2} \mathrm{U}_{\text {sy } 2}{ }^{2}+\frac{1}{2} \mathrm{~K}_{\text {sy } 3} \mathrm{U}_{\text {sy } 3}{ }^{2}+\frac{1}{2} \mathrm{~K}_{\text {sy } 4} \mathrm{U}_{\text {sy } 4}{ }^{2}+\frac{1}{2} \mathrm{~K}_{\mathrm{ty} 1} \mathrm{U}_{\mathrm{ty} 1}{ }^{2}+ \\
& \frac{1}{2} \mathrm{~K}_{\mathrm{ty} 2} \mathrm{U}_{\mathrm{ty} 2}{ }^{2}+\frac{1}{2} \mathrm{~K}_{\mathrm{ty} 3} \mathrm{U}_{\mathrm{ty} 3}{ }^{2}+\frac{1}{2} \mathrm{~K}_{\mathrm{ty} 4} \mathrm{U}_{\mathrm{ty} 4}{ }^{2}-\left(\left(\mathrm{m}_{\mathrm{t} 1} \mathrm{~g}\right) \mathrm{y}_{\mathrm{t} 1}+\left(\mathrm{m}_{\mathrm{a} 1} \mathrm{~g}\right) \mathrm{y}_{\mathrm{a} 1}+\left(\mathrm{m}_{\mathrm{a} 2 \mathrm{~g}} \mathrm{~g}\right) \mathrm{y}_{\mathrm{a} 2}\right)+ \\
& \left(\mathrm{F}_{\mathrm{y} 1} \mathrm{U}_{\mathrm{sy} 1}+\mathrm{F}_{\mathrm{y} 2} \mathrm{U}_{\mathrm{sy} 2}+\mathrm{F}_{\mathrm{y} 3} \mathrm{U}_{\mathrm{sy} 3}+\mathrm{F}_{\mathrm{y} 4} \mathrm{U}_{\mathrm{sy} 4}\right)
\end{aligned}
$$

D is the Damping Energy of the system. 
$\mathrm{D}=\frac{1}{2} \mathrm{D}_{\mathrm{sy} 1} \dot{\mathrm{U}}_{\mathrm{sy} 1}{ }^{2}+\frac{1}{2} \mathrm{D}_{\mathrm{sy} 2} \dot{\mathrm{U}}_{\mathrm{sy} 2}{ }^{2}+\frac{1}{2} \mathrm{D}_{\mathrm{sy} 3} \dot{\mathrm{U}}_{\mathrm{sy} 3}{ }^{2}+\frac{1}{2} \mathrm{D}_{\mathrm{sy} 4} \dot{\mathrm{U}}_{\mathrm{sy} 4}{ }^{2}+\frac{1}{2} \mathrm{D}_{\mathrm{ty} 1} \dot{\mathrm{U}}_{\mathrm{ty} 1}{ }^{2}+$

$\frac{1}{2} \mathrm{D}_{\mathrm{ty} 2} \dot{\mathrm{U}}_{\mathrm{ty} 2}{ }^{2}+\frac{1}{2} \mathrm{D}_{\mathrm{ty} 3} \dot{\mathrm{U}}_{\mathrm{ty} 3}{ }^{2}+\frac{1}{2} \mathrm{D}_{\mathrm{ty} 4} \dot{\mathrm{U}}_{\mathrm{ty} 4}{ }^{2}$

And $\mathrm{q}_{\mathrm{i}}$ is one of the degrees of freedom.

Now the Lagrange equation is applied to $\mathrm{y}_{\mathrm{t} 1}$ :

$\mathrm{m}_{\mathrm{t} 1} \ddot{\mathrm{y}}_{\mathrm{t} 1}+\left[\left(\mathrm{F}_{\mathrm{sy} 1}+\mathrm{F}_{\mathrm{sy} 2}+\mathrm{F}_{\mathrm{sy} 3}+\mathrm{F}_{\mathrm{sy} 4}\right)+\left(\mathrm{F}_{\mathrm{dsy} 1}+\mathrm{F}_{\mathrm{dsy} 2}+\mathrm{F}_{\mathrm{dsy} 3}+\mathrm{F}_{\mathrm{dsy} 4}\right)\right]=\mathrm{m}_{\mathrm{t} 1} \mathrm{~g}$

Also, by applying the Lagrange equation to $\theta_{\mathrm{t} 1}$ :

$\mathrm{I}_{\mathrm{zt} 1} \ddot{\theta}_{\mathrm{t} 1}+\left[\mathrm{l}_{3}\left(\mathrm{~F}_{\mathrm{sy} 1}+\mathrm{F}_{\mathrm{sy} 2}\right)-\mathrm{l}_{4}\left(\mathrm{~F}_{\mathrm{sy} 3}+\mathrm{F}_{\mathrm{sy} 4}\right)\right]+\left[\mathrm{l}_{3}\left(\mathrm{~F}_{\mathrm{dsy} 1}+\mathrm{F}_{\mathrm{dsy} 2}\right)-\mathrm{l}_{4}\left(\mathrm{~F}_{\mathrm{dsy} 3}+\right.\right.$

$\left.\left.\mathrm{F}_{\mathrm{dsy}}\right)\right]=0$

By applying the Lagrange equation to $\varphi_{\mathrm{t} 1}$ :

$\mathrm{I}_{\mathrm{xt} 1} \ddot{\varphi}_{\mathrm{t} 1}+\left[\left(\frac{\mathrm{s}_{1}}{2}\right)\left(\mathrm{F}_{\mathrm{sy} 1}-\mathrm{F}_{\mathrm{sy} 2}\right)+\left(\frac{\mathrm{s}_{2}}{2}\right)\left(\mathrm{F}_{\mathrm{sy} 3}-\mathrm{F}_{\mathrm{sy} 4}\right)\right]+\left[\left(\frac{\mathrm{s}_{1}}{2}\right)\left(\mathrm{F}_{\mathrm{dsy} 1}-\mathrm{F}_{\mathrm{dsy} 2}\right)+\right.$

$\left.\left(\frac{s_{2}}{2}\right)\left(F_{d s y 3}-F_{d s y 4}\right)\right]=0$

Also the rest of degrees of freedom will be as follows:

$\mathrm{m}_{\mathrm{a} 1} \ddot{\mathrm{y}}_{\mathrm{a} 1}-\left(\mathrm{F}_{\mathrm{sy} 1}+\mathrm{F}_{\mathrm{sy} 2}\right)+\left(\mathrm{F}_{\mathrm{ty} 1}+\mathrm{F}_{\mathrm{ty} 2}\right)-\left(\mathrm{F}_{\mathrm{dsy} 1}+\mathrm{F}_{\mathrm{dsy} 2}\right)+\left(\mathrm{F}_{\mathrm{dty} 1}+\mathrm{F}_{\mathrm{dty} 2}\right)=$

$\mathrm{m}_{\mathrm{a} 1} \mathrm{~g}$

$\mathrm{I}_{\mathrm{xa} 1} \ddot{\varphi}_{\mathrm{a} 1}-\left(\frac{\mathrm{s}_{1}}{2}\right)\left(\mathrm{F}_{\mathrm{sy} 1}-\mathrm{F}_{\mathrm{sy} 2}\right)+\left(\frac{\mathrm{d}_{1}}{2}\right)\left(\mathrm{F}_{\mathrm{ty} 1}-\mathrm{F}_{\mathrm{ty} 2}\right)-\left(\frac{\mathrm{s}_{1}}{2}\right)\left(\mathrm{F}_{\mathrm{dsy} 1}-\mathrm{F}_{\mathrm{dsy} 2}\right)+$

$\left(\frac{d_{1}}{2}\right)\left(F_{d t y 1}-F_{d t y 2}\right)=0$

$\mathrm{m}_{\mathrm{a} 2} \ddot{\mathrm{y}}_{\mathrm{a} 2}-\left(\mathrm{F}_{\mathrm{sy} 3}+\mathrm{F}_{\mathrm{sy} 4}\right)+\left(\mathrm{F}_{\mathrm{ty} 3}+\mathrm{F}_{\mathrm{ty} 4}\right)-\left(\mathrm{F}_{\mathrm{dsy} 3}+\mathrm{F}_{\mathrm{dsy} 4}\right)+\left(\mathrm{F}_{\mathrm{dty} 3}+\mathrm{F}_{\mathrm{dty} 4}\right)=$

$\mathrm{m}_{\mathrm{a} 2} \mathrm{~g}$

$\mathrm{I}_{\mathrm{xa} 2} \ddot{\varphi}_{\mathrm{a} 2}-\left(\frac{\mathrm{s}_{2}}{2}\right)\left(\mathrm{F}_{\mathrm{sy} 3}-\mathrm{F}_{\mathrm{sy} 4}\right)+\left(\frac{\mathrm{d}_{2}}{2}\right)\left(\mathrm{F}_{\mathrm{ty} 3}-\mathrm{F}_{\mathrm{ty} 4}\right)-\left(\frac{\mathrm{s}_{2}}{2}\right)\left(\mathrm{F}_{\mathrm{dsy} 3}-\mathrm{F}_{\mathrm{dsy} 4}\right)+$

$\left(\frac{\mathrm{d}_{2}}{2}\right)\left(\mathrm{F}_{\mathrm{dty} 3}-\mathrm{F}_{\mathrm{dty} 4}\right)=0$ 


\section{Derivation of Equations of Motion for HS20-44 Truck}

Same modeling approach as in previous section has been used to formulate the other types of trucks. The only difference for the larger vehicles is the so-called Pivot Point which changes the number of equations of the motion of the whole system by reducing one equation with each pivot point.

Pivot point acts like a vertical restraint between the trailer and the tractor and a relation between the pitch displacements of the trailer and the tractor is generated to deal with this point.

There are twelve degrees of freedom in total for this type of truck. The degrees of freedom can be seen in Figure 3 and the description of those degrees of freedom can be found in Table 5. Relative Displacements at the locations of the springs are also calculated using the values given in Table 6.

Table 5. Degrees of Freedom of HS20-44 Truck

\begin{tabular}{|c|c|l|l|}
$\begin{array}{c}\text { No. } \\
\text { Freedom }\end{array}$ & $\begin{array}{c}\text { Degree of } \\
\text { Mass }\end{array}$ & \multicolumn{1}{c|}{$\begin{array}{c}\text { Contributted } \\
\text { Mescription }\end{array}$} \\
$\mathbf{1}$ & $\mathrm{y}_{\mathrm{t} 1}$ & $\mathrm{~m}_{\mathrm{t} 1}$ & Tractor vertical displacement and mass \\
$\mathbf{2}$ & $\varphi_{\mathrm{t} 1}$ & $\mathrm{I}_{\mathrm{xt} 1}$ & Tractor roll displacement and mass moment of inertia \\
$\mathbf{3}$ & $\theta_{\mathrm{t} 1}$ & $\mathrm{I}_{\mathrm{zt} 1}$ & Tractor pitch displacement and mass moment of inertia \\
$\mathbf{4}$ & $\mathrm{y}_{\mathrm{t} 2}$ & $\mathrm{~m}_{\mathrm{t} 2}$ & Trailer vertical displacement and mass \\
$\mathbf{5}$ & $\varphi_{\mathrm{t} 2}$ & $\mathrm{I}_{\mathrm{xt} 2}$ & Trailer roll displacement and mass moment of inertia \\
$\mathbf{6}$ & $\theta_{\mathrm{t} 2}$ & $\mathrm{I}_{\mathrm{zt} 2}$ & Trailer pitch displacement and mass moment of inertia \\
$\mathbf{7}$ & $\mathrm{y}_{\mathrm{a} 1}$ & $\mathrm{~m}_{\mathrm{a} 1}$ & Steer axle vertical displacement and mass \\
$\mathbf{8}$ & $\varphi_{\mathrm{a} 1}$ & $\mathrm{I}_{\mathrm{xa} 1}$ & Steer axle roll displacement and mass moment of inertia \\
$\mathbf{9}$ & $\mathrm{y}_{\mathrm{a} 2}$ & $\mathrm{~m}_{\mathrm{a} 2}$ & Tractor axle vertical displacement and mass \\
$\mathbf{1 0}$ & $\varphi_{\mathrm{a} 2}$ & $\mathrm{I}_{\mathrm{xa} 2}$ & Tractor axle roll displacement and mass moment of inertia \\
\hline $\mathbf{1 1}$ & $\mathrm{y}_{\mathrm{a} 3}$ & $\mathrm{~m}_{\mathrm{a} 3}$ & Trailer axle vertical displacement and mass \\
$\mathbf{1 2}$ & $\varphi_{\mathrm{a} 3}$ & $\mathrm{I}_{\mathrm{xa} 3}$ & Trailer axle roll displacement and mass moment of inertia \\
\hline
\end{tabular}



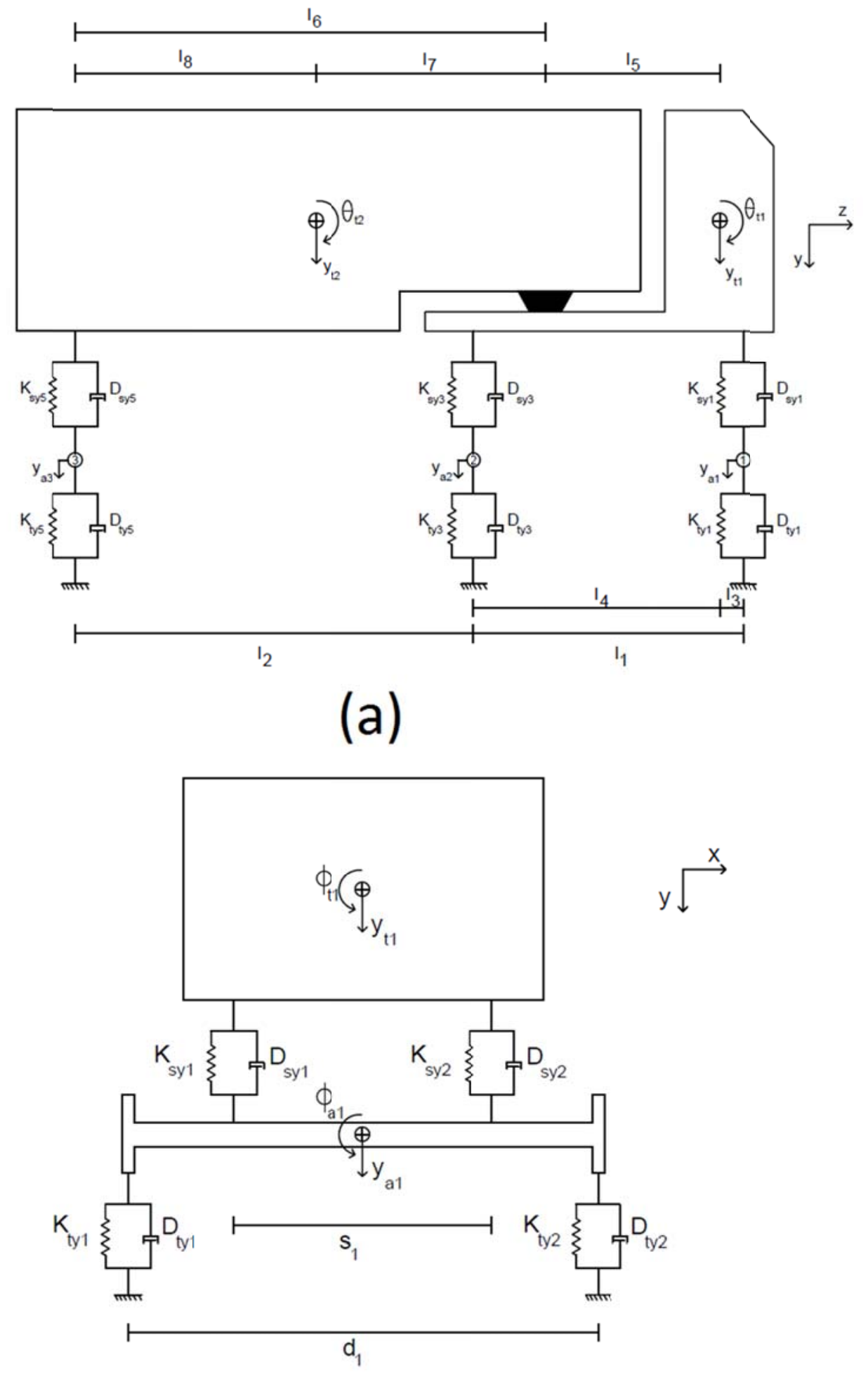

(b)

Figure 3. HS20-44 Dynamic Model (a) Truck Side View (b) Truck Front View 
Table 6. Relative Displacements at Spring Locations of HS20-44 Truck

\begin{tabular}{|c|c|}
\hline & Suspension springs \\
\hline $\mathbf{U}_{\text {sy1 }}$ & $\left(\mathrm{y}_{\mathrm{t} 1}-\mathrm{y}_{\mathrm{a} 1}\right)+\left(\mathrm{S}_{1} / 2\right)\left(\varphi_{\mathrm{t} 1}-\varphi_{\mathrm{a} 1}\right)+\mathrm{l}_{3} \theta_{\mathrm{t} 1}$ \\
\hline $\mathbf{U}_{\text {sy2 }}$ & $\left(\mathrm{y}_{\mathrm{t} 1}-\mathrm{y}_{\mathrm{a} 1}\right)-\left(\mathrm{S}_{1} / 2\right)\left(\varphi_{\mathrm{t} 1}-\varphi_{\mathrm{a} 1}\right)+\mathrm{l}_{3} \theta_{\mathrm{t} 1}$ \\
\hline $\mathbf{U}_{\text {sy3 }}$ & $\left(\mathrm{y}_{\mathrm{t} 1}-\mathrm{y}_{\mathrm{a} 2}\right)+\left(\mathrm{S}_{2} / 2\right)\left(\varphi_{\mathrm{t} 1}-\varphi_{\mathrm{a} 2}\right)-\mathrm{l}_{4} \theta_{\mathrm{t} 1}$ \\
\hline $\mathbf{U}_{\text {sy4 }}$ & $\left(\mathrm{y}_{\mathrm{t} 1}-\mathrm{y}_{\mathrm{a} 2}\right)-\left(\mathrm{S}_{2} / 2\right)\left(\varphi_{\mathrm{t} 1}-\varphi_{\mathrm{a} 2}\right)-\mathrm{l}_{4} \theta_{\mathrm{t} 1}$ \\
\hline $\mathbf{U}_{\text {sy5 }}$ & $\left(\mathrm{y}_{\mathrm{t} 2}-\mathrm{y}_{\mathrm{a} 3}\right)+\left(\mathrm{S}_{3} / 2\right)\left(\varphi_{\mathrm{t} 2}-\varphi_{\mathrm{a} 3}\right)-\mathrm{l}_{8} \theta_{\mathrm{t} 2}$ \\
\hline $\mathbf{U}_{\text {sy6 }}$ & $\left(\mathrm{y}_{\mathrm{t} 2}-\mathrm{y}_{\mathrm{a} 3}\right)-\left(\mathrm{S}_{3} / 2\right)\left(\varphi_{\mathrm{t} 2}-\varphi_{\mathrm{a} 3}\right)-\mathrm{l}_{8} \theta_{\mathrm{t} 2}$ \\
\hline & Tire springs \\
\hline $\mathbf{U}_{\mathrm{ty} 1}$ & $\mathrm{y}_{\mathrm{a} 1}+\left(\mathrm{d}_{1} / 2\right) \varphi_{\mathrm{a} 1}+\mathrm{u}_{\mathrm{SR} 1}$ \\
\hline $\mathbf{U}_{\text {ty2 }}$ & $\mathrm{y}_{\mathrm{a} 1}-\left(\mathrm{d}_{1} / 2\right) \varphi_{\mathrm{a} 1}+\mathrm{u}_{\mathrm{SR} 2}$ \\
\hline $\mathbf{U}_{\text {ty3 }}$ & $\mathrm{y}_{\mathrm{a} 2}+\left(\mathrm{d}_{2} / 2\right) \varphi_{\mathrm{a} 2}+\mathrm{u}_{\mathrm{SR} 3}$ \\
\hline $\mathbf{U}_{\text {ty } 4}$ & $\mathrm{y}_{\mathrm{a} 2}-\left(\mathrm{d}_{2} / 2\right) \varphi_{\mathrm{a} 2}+\mathrm{u}_{\mathrm{SR} 4}$ \\
\hline $\mathbf{U}_{\text {ty5 }}$ & $\mathrm{y}_{\mathrm{a} 3}+\left(\mathrm{d}_{3} / 2\right) \varphi_{\mathrm{a} 3}+\mathrm{u}_{\mathrm{SR} 5}$ \\
\hline $\mathbf{U}_{\text {ty } 6}$ & $\mathrm{y}_{\mathrm{a} 3}-\left(\mathrm{d}_{3} / 2\right) \varphi_{\mathrm{a} 3}+\mathrm{u}_{\mathrm{SR} 6}$ \\
\hline
\end{tabular}

In this table $\mathrm{u}_{\mathrm{SRi}}$ is the road surface roughness under the $\mathrm{i}^{\text {th }}$ wheel.

$\mathrm{F}_{\text {syi }}, \mathrm{F}_{\mathrm{dsyi}}, \mathrm{F}_{\text {tyi }}$ and $\mathrm{F}_{\mathrm{dtyi}}$ have been defined in equations ( 1 ) to ( 4 ). Similarly Lagrange equation ( 5 ) has been used to generate the equations of motion.

Kinetic Energy of the system:

$$
\begin{aligned}
& T=\frac{1}{2} m_{t 1} \dot{y}_{t 1}{ }^{2}+\frac{1}{2} m_{a 1} \dot{y}_{a 1}{ }^{2}+\frac{1}{2} m_{a 2} \dot{y}_{a 2}{ }^{2}+\frac{1}{2} m_{a 3} \dot{y}_{a 3}{ }^{2}+\frac{1}{2} I_{x t 1} \dot{\varphi}_{t 1}{ }^{2}+\frac{1}{2} I_{z t 1} \dot{\theta}_{t 1}{ }^{2}+ \\
& \frac{1}{2} I_{x t 2} \dot{\varphi}_{t 2}{ }^{2}+\frac{1}{2} I_{z t 2} \dot{\theta}_{t 2}{ }^{2}+\frac{1}{2} I_{x a 1} \dot{\varphi}_{a 1}{ }^{2}+\frac{1}{2} I_{x a 2} \dot{\varphi}_{a 2}{ }^{2}+\frac{1}{2} I_{x a 3} \dot{\varphi}_{a 3}{ }^{2}+\frac{1}{2} m_{t 2} \dot{y}_{t 2}{ }^{2}
\end{aligned}
$$

Potential Energy of the system:

$$
\begin{aligned}
& V=\frac{1}{2} K_{s y 1} U_{s y 1}{ }^{2}+\frac{1}{2} K_{s y 2} U_{s y 2}{ }^{2}+\frac{1}{2} K_{s y 3} U_{s y 3}{ }^{2}+\frac{1}{2} K_{s y 4} U_{s y 4}{ }^{2}+\frac{1}{2} K_{s y 5} U_{s y 5}{ }^{2}+ \\
& \frac{1}{2} K_{s y 6} U_{s y 6}{ }^{2}+\frac{1}{2} K_{t y 1} U_{t y 1}{ }^{2}+\frac{1}{2} K_{t y 2} U_{t y 2}{ }^{2}+\frac{1}{2} K_{t y 3} U_{t y 3}{ }^{2}+\frac{1}{2} K_{t y 4} U_{t y 4}{ }^{2}+
\end{aligned}
$$


$\frac{1}{2} K_{t y 5} U_{t y 5}{ }^{2}+\frac{1}{2} K_{t y 6} U_{t y 6}{ }^{2}-\left(\left(m_{t 1} g\right) y_{t 1}+\left(m_{t 2} g\right) y_{t 2}+\left(m_{a 1} g\right) y_{a 1}+\left(m_{a 2} g\right) y_{a 2}+\right.$

$\left.\left(m_{a 3} g\right) y_{a 3}\right)+\left(F_{y 1} U_{s y 1}+F_{y 2} U_{s y 2}+F_{y 3} U_{s y 3}+F_{y 4} U_{s y 4}+F_{y 5} U_{s y 5}+F_{y 6} U_{s y 6}\right)$

Damping Energy of the system:

$D=\frac{1}{2} D_{s y 1} \dot{U}_{s y 1}{ }^{2}+\frac{1}{2} D_{s y 2} \dot{U}_{s y 2}{ }^{2}+\frac{1}{2} D_{s y 3} \dot{U}_{s y 3}{ }^{2}+\frac{1}{2} D_{s y 4} \dot{U}_{s y 4}{ }^{2}+\frac{1}{2} D_{s y 5} \dot{U}_{s y 5}{ }^{2}+$

$\frac{1}{2} D_{s y 6} \dot{U}_{s y 6}{ }^{2}++\frac{1}{2} D_{t y 1} \dot{U}_{t y 1}{ }^{2}+\frac{1}{2} D_{t y 2} \dot{U}_{t y 2}{ }^{2}+\frac{1}{2} D_{t y 3} \dot{U}_{t y 3}{ }^{2}+\frac{1}{2} D_{t y 4} \dot{U}_{t y 4}{ }^{2}+$

$\frac{1}{2} D_{t y 5} \dot{U}_{t y 5}^{2}+\frac{1}{2} D_{t y 6} \dot{U}_{t y 6}^{2}$

The displacement at the pivot point should stay the same, whether it is calculated from the trailer part or the tractor part,

$y_{t 2}+\theta_{t 2} l_{7}=y_{t 1}-\theta_{t 1} l_{5}$

Thus, by calculating $\theta_{\mathrm{t} 2}$ from equation ( 19 ) and substituting in equation ( 16 ),

$$
\begin{aligned}
& T=\frac{1}{2} m_{t 1} \dot{y}_{t 1}{ }^{2}+\frac{1}{2} m_{a 1} \dot{y}_{a 1}^{2}+\frac{1}{2} m_{a 2} \dot{y}_{a 2}{ }^{2}+\frac{1}{2} m_{a 3} \dot{y}_{a 3}{ }^{2}+\frac{1}{2} I_{x t 1} \dot{\varphi}_{t 1}{ }^{2}+\frac{1}{2} I_{z t 1} \dot{\theta}_{t 1}{ }^{2}+ \\
& \frac{1}{2} I_{x t 2} \dot{\varphi}_{t 2}{ }^{2}+\frac{1}{2} I_{z t 2}\left(\frac{\dot{y}_{t 1}-\dot{y}_{t 2}-\dot{\theta}_{t 1} l_{5}}{l_{7}}\right)^{2}+\frac{1}{2} I_{x a 1} \dot{\varphi}_{a 1}{ }^{2}+\frac{1}{2} I_{x a 2} \dot{\varphi}_{a 2}{ }^{2}+\frac{1}{2} I_{x a 3} \dot{\varphi}_{a 3}{ }^{2}+ \\
& \frac{1}{2} m_{t 2} \dot{y}_{t 2}{ }^{2}
\end{aligned}
$$

Same substitution will be applied to the equations ( 17 ) and ( 18 ). Now the Lagrange equation is applied to $y_{\mathrm{t} 2}$ :

$$
\begin{aligned}
& {\left[m_{t 2} \ddot{y}_{t 2}-\frac{I_{z t 2}}{l_{7}^{2}}\left(\ddot{y}_{t 1}-\ddot{y}_{t 2}-\ddot{\theta}_{t 1} l_{5}\right)\right]+\left[\left(1+\frac{l_{8}}{l_{7}}\right)\left(F_{s y 5}+F_{s y 6}\right)-\left(m_{t 2} g\right)\right]+} \\
& {\left[\left(1+\frac{l_{8}}{l_{7}}\right)\left(F_{d s y 5}+F_{d s y 6}\right)\right]=0}
\end{aligned}
$$

To simplify the equation some variables are defined as follows:

$$
S_{a 2}=\frac{I_{z t 2}}{l_{7}^{2}}
$$


$S_{c 2}=\frac{I_{z t 2}}{l_{7}^{2}}+m_{t 2}$

$S_{a 3}=\frac{I_{z t 2}}{l_{7}^{2}} l_{5}$

$B_{t 4}=m_{t 2} g-\left(1+\frac{l_{8}}{l_{7}}\right)\left(F_{s y 5}+F_{s y 6}+F_{d s y 5}+F_{d s y 6}\right)$

Therefore equation ( 21 ) will be simplified to:

$-S_{a 2} \ddot{y}_{t 1}+S_{c 2} \ddot{y}_{t 2}+S_{a 3} \ddot{\theta}_{t 1}=B_{t 4}$

By applying the Lagrange equation to $\mathrm{y}_{\mathrm{t} 1}$ :

$\left[m_{t 1} \ddot{y}_{t 1}+\frac{I_{z t 2}}{l_{7}^{2}}\left(\ddot{y}_{t 1}-\ddot{y}_{t 2}-\ddot{\theta}_{t 1} l_{5}\right)\right]+\left[\left(F_{s y 1}+F_{s y 2}+F_{s y 3}+F_{s y 4}\right)-\frac{l_{8}}{l_{7}}\left(F_{s y 5}+\right.\right.$

$\left.\left.F_{s y 6}\right)-\left(m_{t 1} g\right)\right]+\left[\left(F_{d s y 1}+F_{d s y 2}+F_{d s y 3}+F_{d s y 4}\right)-\frac{l_{8}}{l_{7}}\left(F_{d s y 5}+F_{d s y 6}\right)\right]=0$

Again to simplify the equation some variables are defined as follows:

$S_{a 1}=\frac{I_{z t 2}}{l_{7}^{2}}+m_{t 1}$

$B_{t 1}=m_{t 1} g-\left[\left(F_{s y 1}+F_{s y 2}+F_{s y 3}+F_{s y 4}\right)-\frac{l_{8}}{l_{7}}\left(F_{s y 5}+F_{s y 6}\right)+\left(F_{d s y 1}+F_{d s y 2}+F_{d s y 3}+\right.\right.$

$\left.\left.F_{d s y 4}\right)-\frac{l_{8}}{l_{7}}\left(F_{d s y 5}+F_{d s y 6}\right)\right]$

Therefore equation ( 23 ) will be simplified to:

$S_{a 1} \ddot{y}_{t 1}-S_{a 2} \ddot{y}_{t 2}-S_{a 3} \ddot{\theta}_{t 1}=B_{t 1}$

Also, by applying the Lagrange equation to $\theta_{\mathrm{t} 1}$ :

$\left[I_{z t 1} \ddot{\theta}_{t 1}-\frac{I_{z t 2} l_{5}}{l_{7}^{2}}\left(\ddot{y}_{t 1}-\ddot{y}_{t 2}-\ddot{\theta}_{t 1} l_{5}\right)\right]+\left[l_{3}\left(F_{s y 1}+F_{s y 2}\right)-l_{4}\left(F_{s y 3}+F_{s y 4}\right)+\right.$ 
$\left.\frac{l_{5} I_{8}}{l_{7}}\left(F_{s y 5}+F_{s y 6}\right)\right]+\left[l_{3}\left(F_{d s y 1}+F_{d s y 2}\right)-l_{4}\left(F_{d s y 3}+F_{d s y 4}\right)+\frac{l_{5} I_{8}}{l_{7}}\left(F_{d s y 5}+\right.\right.$

$\left.\left.F_{\text {dsy6 }}\right)\right]=0$

Once again to simplify the equation some variables need to be defined as follows:

$S_{b 3}=I_{z t 1}+\frac{I_{z t 2} l_{5}^{2}}{l_{7}^{2}}$

$B_{t 3}=-\left[\left[l_{3}\left(F_{s y 1}+F_{s y 2}\right)-l_{4}\left(F_{s y 3}+F_{s y 4}\right)+\frac{l_{5} I_{8}}{l_{7}}\left(F_{s y 5}+F_{s y 6}\right)\right]+\left[l_{3}\left(F_{d s y 1}+F_{d s y 2}\right)-\right.\right.$

$\left.\left.l_{4}\left(F_{d s y 3}+F_{d s y 4}\right)+\frac{l_{5} I_{8}}{l_{7}}\left(F_{d s y 5}+F_{d s y 6}\right)\right]\right]$

Therefore equation ( 25 ) will be simplified to:

$-S_{a 3} \ddot{y}_{t 1}+S_{a 3} \ddot{y}_{t 2}+S_{b 3} \ddot{\theta}_{t 1}=B_{t 3}$

By adding equations ( 22 ) and ( 24 ),

$\left(S_{a 1}-S_{a 2}\right) \ddot{y}_{t 1}-\left(S_{a 2}-S_{c 2}\right) \ddot{y}_{t 2}=B_{t 1}+B_{t 4}$

Also by multiplying $\mathrm{S}_{\mathrm{b} 3}$ and $\mathrm{S}_{\mathrm{a} 3}$ to equations ( 24 ) and ( 26 ) respectively,

$\left(S_{a 1} S_{b 3}-S_{a 3}^{2}\right) \ddot{y}_{t 1}-\left(S_{a 2} S_{b 3}-S_{a 3}^{2}\right) \ddot{y}_{t 2}=S_{b 3} B_{t 1}+S_{a 3} B_{t 3}$

By defining the following expressions, equations ( 27 ) and ( 28 ) are simplified to equations ( 29 ) and ( 30 ) respectively,

$$
\begin{aligned}
& e_{1}=S_{a 1}-S_{a 2} \\
& e_{2}=S_{a 2}-S_{c 2} \\
& e_{3}=S_{a 1} S_{b 3}-S_{a 3}^{2} \\
& e_{4}=S_{a 2} S_{b 3}-S_{a 3}^{2}
\end{aligned}
$$


$e_{1} \ddot{y}_{t 1}-e_{2} \ddot{y}_{t 2}=B_{t 1}+B_{t 4}$

$e_{3} \ddot{y}_{t 1}-e_{4} \ddot{y}_{t 2}=S_{b 3} B_{t 1}+S_{a 3} B_{t 3}$

Solving equations ( 29 ) and ( 30 ) for $\ddot{y}_{\mathrm{t} 1}$ and $\ddot{y}_{\mathrm{t} 2}$ will lead to:

$\ddot{y}_{t 1}=\frac{e_{4}\left(B_{t 1}+B_{t 4}\right)-e_{2}\left(S_{b 3} B_{t 1}+S_{a 3} B_{t 3}\right)}{e_{1} e_{4}-e_{2} e_{3}}$

$\ddot{y}_{t 2}=\frac{e_{1}}{e_{2}}\left(\frac{e_{4}\left(B_{t 1}+B_{t 4}\right)-e_{2}\left(S_{b 3} B_{t 1}+S_{a 3} B_{t 3}\right)}{e_{1} e_{4}-e_{2} e_{3}}\right)-\frac{B_{t 1}+B_{t 4}}{e_{2}}$

Substituting equations ( 31 ) and ( 32 ) into equation ( 26 ) will give,

$\ddot{\theta}_{t 1}=$

$\frac{B_{t 3}}{S_{b 3}}+\frac{S_{a 3}}{S_{b 3}}\left(\frac{e_{4}\left(B_{t 1}+B_{t 4}\right)-e_{2}\left(S_{b 3} B_{t 1}+S_{a 3} B_{t 3}\right)}{e_{1} e_{4}-e_{2} e_{3}}\right)-\frac{S_{a 3}}{S_{b 3}}\left(\frac{e_{1}}{e_{2}}\left(\frac{e_{4}\left(B_{t 1}+B_{t 4}\right)-e_{2}\left(S_{b 3} B_{t 1}+S_{a 3} B_{t 3}\right)}{e_{1} e_{4}-e_{2} e_{3}}\right)-\right.$

$\left.\frac{B_{t 1}+B_{t 4}}{e_{2}}\right)$

By applying the Lagrange equation to $\varphi_{\mathrm{t} 1}, \varphi_{\mathrm{t} 2}$ :

$I_{x t 1} \ddot{\varphi}_{t 1}+\left[\left(\frac{s_{1}}{2}\right)\left(F_{s y 1}-F_{s y 2}\right)+\left(\frac{s_{2}}{2}\right)\left(F_{s y 3}-F_{s y 4}\right)\right]+\left[\left(\frac{s_{1}}{2}\right)\left(F_{d s y 1}-F_{d s y 2}\right)+\right.$

$\left.\left(\frac{s_{2}}{2}\right)\left(F_{d s y 3}-F_{d s y 4}\right)\right]=0$

$I_{x t 2} \ddot{\varphi}_{t 2}+\left[\left(\frac{s_{3}}{2}\right)\left(F_{s y 5}-F_{s y 6}\right)\right]+\left[\left(\frac{s_{3}}{2}\right)\left(F_{d s y 5}-F_{d s y 6}\right)\right]=0$

Also the rest of degrees of freedom will be as follows:

$$
\begin{aligned}
& m_{a 1} \ddot{y}_{a 1}-\left(F_{s y 1}+F_{s y 2}\right)+\left(F_{t y 1}+F_{t y 2}\right)-\left(F_{d s y 1}+F_{d s y 2}\right)+\left(F_{d t y 1}+F_{d t y 2}\right)= \\
& m_{a 1} g \\
& I_{x a 1} \ddot{\varphi}_{a 1}-\left(\frac{s_{1}}{2}\right)\left(F_{s y 1}-F_{s y 2}\right)+\left(\frac{d_{1}}{2}\right)\left(F_{t y 1}-F_{t y 2}\right)-\left(\frac{s_{1}}{2}\right)\left(F_{d s y 1}-F_{d s y 2}\right)+ \\
& \left(\frac{d_{1}}{2}\right)\left(F_{d t y 1}-F_{d t y 2}\right)=0 \\
& m_{a 2} \ddot{y}_{a 2}-\left(F_{s y 3}+F_{s y 4}\right)+\left(F_{t y 3}+F_{t y 4}\right)-\left(F_{d s y 3}+F_{d s y 4}\right)+\left(F_{d t y 3}+F_{d t y 4}\right)= \\
& m_{a 2} g
\end{aligned}
$$




$$
\begin{aligned}
& I_{x a 2} \ddot{\varphi}_{a 2}-\left(\frac{s_{2}}{2}\right)\left(F_{s y 3}-F_{s y 4}\right)+\left(\frac{d_{2}}{2}\right)\left(F_{t y 3}-F_{t y 4}\right)-\left(\frac{s_{2}}{2}\right)\left(F_{d s y 3}-F_{d s y 4}\right)+ \\
& \left(\frac{d_{2}}{2}\right)\left(F_{d t y 3}-F_{d t y 4}\right)=0 \\
& m_{a 3} \ddot{y}_{a 3}-\left(F_{s y 5}+F_{s y 6}\right)+\left(F_{t y 5}+F_{t y 6}\right)-\left(F_{d s y 5}+F_{d s y 6}\right)+\left(F_{d t y 5}+F_{d t y 6}\right)= \\
& m_{a 3} g \\
& I_{x a 3} \ddot{\varphi}_{a 3}-\left(\frac{s_{3}}{2}\right)\left(F_{s y 5}-F_{s y 6}\right)+\left(\frac{d_{3}}{2}\right)\left(F_{t y 5}-F_{t y 6}\right)-\left(\frac{s_{3}}{2}\right)\left(F_{d s y 5}-F_{d s y 6}\right)+ \\
& \left(\frac{d_{3}}{2}\right)\left(F_{d t y 5}-F_{d t y 6}\right)=0
\end{aligned}
$$

\section{Derivation of Equations of Motion for 9 Axle Turnpike Double}

The model for 9 Axle Turnpike Double can be seen in Figure 4. This vehicle consists of one tractor, one semitrailer and a trailer, each having three degrees of freedom. Each axle has two degrees of freedom adding up the total number of degrees of freedom to 27 for this particular vehicle. The relative displacement at the spring locations of the tire and the suspension are also calculated using the geometry of the vehicle. Degrees of freedom of this truck and the relative displacements at the spring locations are given in Table 7 and Table 8, respectively.

For the LCV's, it is assumed that the second trailer is traveling at the same speed as the truck and it is connected through a horizontal link to the first trailer which assures the same speed for the second trailer but since the horizontal acceleration of the vehicle is assumed to be zero, this constraint cannot be seen in the equations.

$F_{\text {syi }}, F_{\text {dsyi }}, F_{\text {tyi }}$ and $F_{d t y i}$ have been defined in equations ( 1 ) to ( 4 ). Similarly Lagrange equation ( 5 ) has been used to generate the equations of motion. 


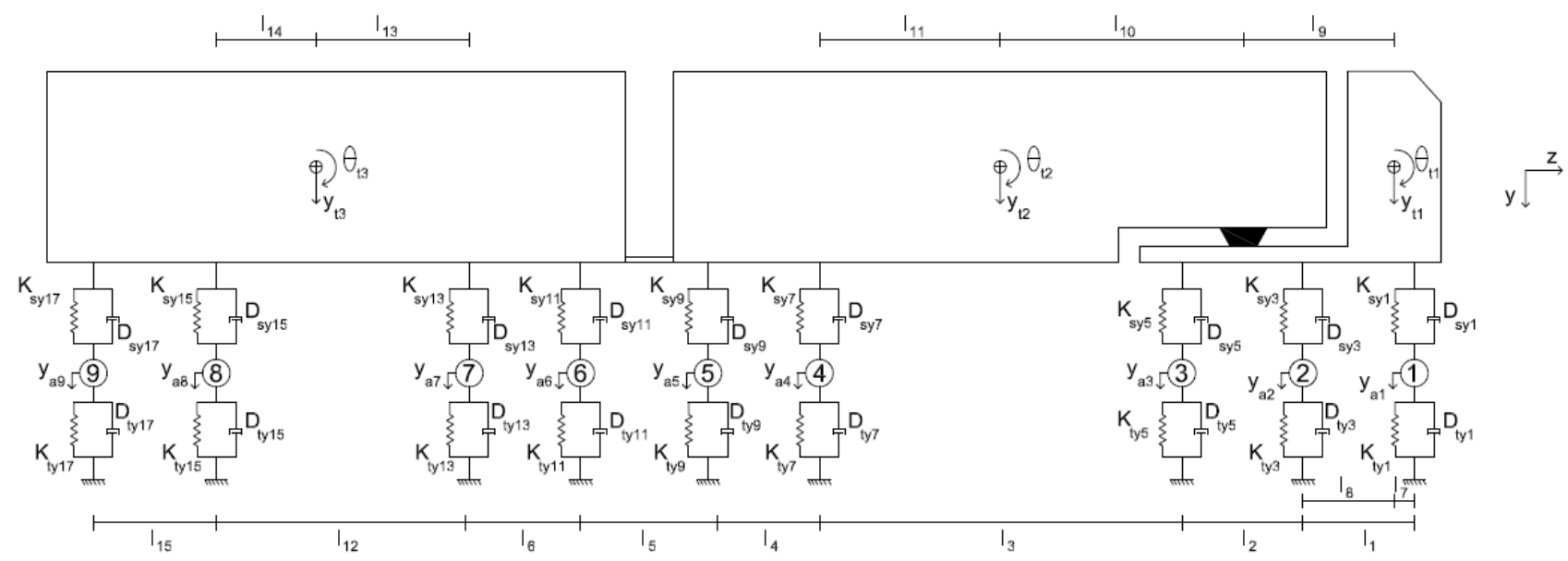

(a)

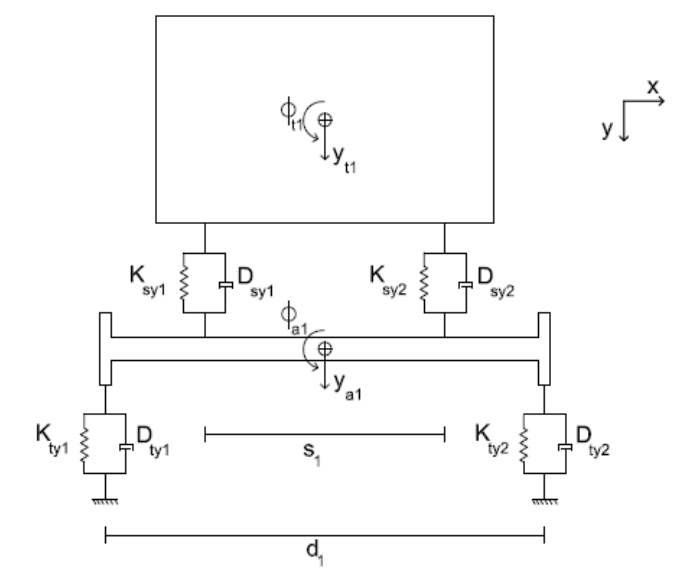

(b)

Figure 4. Nine Axle Turnpike Double Dynamic Model (a) Truck Side View (b) Truck Front View 
Table 7. Degrees of Freedom of 9 Axle Turnpike Double

\begin{tabular}{|c|c|c|c|}
\hline No. & $\begin{array}{l}\text { Degree of } \\
\text { Freedom }\end{array}$ & $\begin{array}{c}\text { Contrib. } \\
\text { Mass }\end{array}$ & Description \\
\hline 1 & $\mathrm{y}_{\mathrm{t} 1}$ & $\mathrm{~m}_{\mathrm{t} 1}$ & Tractor vertical displacement and mass \\
\hline 2 & $\varphi_{\mathrm{t} 1}$ & $\mathrm{I}_{\mathrm{xt} 1}$ & Tractor roll displacement and mass moment of inertia \\
\hline 3 & $\theta_{\mathrm{t} 1}$ & $\mathrm{I}_{\mathrm{zt} 1}$ & Tractor pitch displacement and mass moment of inertia \\
\hline 4 & $\mathrm{y}_{\mathrm{t} 2}$ & $\mathrm{~m}_{\mathrm{t} 2}$ & Semi-trailer vertical displacement and mass \\
\hline 5 & $\varphi_{\mathrm{t} 2}$ & $\mathrm{I}_{\mathrm{xt} 2}$ & Semi-trailer roll displacement and mass moment of inertia \\
\hline 6 & $\theta_{\mathrm{t} 2}$ & $\mathrm{I}_{\mathrm{zt} 2}$ & Semi-trailer pitch displacement and mass moment of inertia \\
\hline 7 & $\mathrm{y}_{\mathrm{t} 3}$ & $\mathrm{~m}_{\mathrm{t} 3}$ & Trailer vertical displacement and mass \\
\hline 8 & $\varphi_{\mathrm{t} 3}$ & $\mathrm{I}_{\mathrm{xt} 3}$ & Trailer roll displacement and mass moment of inertia \\
\hline 9 & $\theta_{\mathrm{t} 3}$ & $\mathrm{I}_{\mathrm{zt} 3}$ & Trailer pitch displacement and mass moment of inertia \\
\hline 10 & $\mathrm{y}_{\mathrm{a} 1}$ & $\mathrm{~m}_{\mathrm{a} 1}$ & Steer axle vertical displacement and mass \\
\hline 11 & $\varphi_{\mathrm{a} 1}$ & $\mathrm{I}_{\mathrm{xa} 1}$ & Steer axle roll displacement and mass moment of inertia \\
\hline 12 & $\mathrm{y}_{\mathrm{a} 2}$ & $\mathrm{~m}_{\mathrm{a} 2}$ & Vertical displacement and mass of forward axle of tractor tandem \\
\hline 13 & $\varphi_{\mathrm{a} 2}$ & $\mathrm{I}_{\mathrm{xa} 2}$ & $\begin{array}{l}\text { Roll displacement and mass moment of inertia of forward axle of } \\
\text { tractor tandem }\end{array}$ \\
\hline 14 & $\mathrm{y}_{\mathrm{a} 3}$ & $\mathrm{~m}_{\mathrm{a} 3}$ & Vertical displacement and mass of aft axle of tractor tandem \\
\hline 15 & $\varphi_{\mathrm{a} 3}$ & $\mathrm{I}_{\mathrm{xa} 3}$ & $\begin{array}{l}\text { Roll displacement and mass moment of inertia of aft axle of tractor } \\
\text { tandem }\end{array}$ \\
\hline 16 & $\mathrm{y}_{\mathrm{a} 4}$ & $\mathrm{~m}_{\mathrm{a} 4}$ & Vertical displacement and mass of 1 st axle of semi-trailer \\
\hline 17 & $\varphi_{\mathrm{a} 4}$ & $\mathrm{I}_{\mathrm{xa} 4}$ & $\begin{array}{l}\text { Roll displacement and mass moment of inertia of } 1 \text { st axle of semi- } \\
\text { trailer }\end{array}$ \\
\hline 18 & $\mathrm{y}_{\mathrm{a} 5}$ & $\mathrm{~m}_{\mathrm{a} 5}$ & Vertical displacement and mass of 2nd axle of semi-trailer \\
\hline 19 & $\varphi_{\mathrm{a} 5}$ & $\mathrm{I}_{\mathrm{xa} 5}$ & $\begin{array}{l}\text { Roll displacement and mass moment of inertia of } 2 \text { nd axle of semi- } \\
\text { trailer }\end{array}$ \\
\hline 20 & $\mathrm{y}_{\mathrm{a} 6}$ & $\mathrm{~m}_{\mathrm{a} 6}$ & Vertical displacement and mass of 1st axle of trailer \\
\hline 21 & $\varphi_{\mathrm{a} 6}$ & $\mathrm{I}_{\mathrm{xa} 6}$ & Roll displacement and mass moment of inertia of 1 st axle of trailer \\
\hline 22 & $\mathrm{y}_{\mathrm{a} 7}$ & $\mathrm{~m}_{\mathrm{a} 7}$ & Vertical displacement and mass of second axle of trailer \\
\hline 23 & $\varphi_{\mathrm{a} 7}$ & $\mathrm{I}_{\mathrm{xa} 7}$ & Roll displacement and mass moment of inertia of 2 nd axle of trailer \\
\hline 24 & $\mathrm{y}_{\mathrm{a} 8}$ & $\mathrm{~m}_{\mathrm{a} 8}$ & Vertical displacement and mass of 3rd axle of trailer \\
\hline 25 & $\varphi_{\mathrm{a} 8}$ & $\mathrm{I}_{\mathrm{xa} 8}$ & Roll displacement and mass moment of inertia of 3rd axle of trailer \\
\hline 26 & $\mathrm{y}_{\mathrm{a} 9}$ & $\mathrm{~m}_{\mathrm{a} 9}$ & Vertical displacement and mass of 4th axle of trailer \\
\hline 27 & $\varphi_{\mathrm{a} 9}$ & $\mathrm{I}_{\mathrm{xa9}}$ & Roll displacement and mass moment of inertia of 4 th axle of trailer \\
\hline
\end{tabular}


Table 8. Relative Displacements at Spring Locations of 9 Axle Turnpike Double

\begin{tabular}{|c|c|}
\hline & Suspension springs \\
\hline $\mathbf{U}_{\text {sy1 }}$ & $\left(\mathrm{y}_{\mathrm{t} 1}-\mathrm{y}_{\mathrm{a} 1}\right)+\left(\mathrm{S}_{1} / 2\right)\left(\varphi_{\mathrm{t} 1}-\varphi_{\mathrm{a} 1}\right)+\mathrm{l}_{7} \theta_{\mathrm{t} 1}$ \\
\hline $\mathbf{U}_{\text {sy2 }}$ & $\left(\mathrm{y}_{\mathrm{t} 1}-\mathrm{y}_{\mathrm{a} 1}\right)-\left(\mathrm{S}_{1} / 2\right)\left(\varphi_{\mathrm{t} 1}-\varphi_{\mathrm{a} 1}\right)+\mathrm{l}_{7} \theta_{\mathrm{t} 1}$ \\
\hline $\mathbf{U}_{\mathrm{sy} 3}$ & $\left(\mathrm{y}_{\mathrm{t} 1}-\mathrm{y}_{\mathrm{a} 2}\right)+\left(\mathrm{S}_{2} / 2\right)\left(\varphi_{\mathrm{t} 1}-\varphi_{\mathrm{a} 2}\right)-\mathrm{l}_{8} \theta_{\mathrm{t} 1}$ \\
\hline $\mathbf{U}_{\text {sy4 }}$ & $\left(\mathrm{y}_{\mathrm{t} 1}-\mathrm{y}_{\mathrm{a} 2}\right)-\left(\mathrm{S}_{2} / 2\right)\left(\varphi_{\mathrm{t} 1}-\varphi_{\mathrm{a} 2}\right)-\mathrm{l}_{8} \theta_{\mathrm{t} 1}$ \\
\hline $\mathbf{U}_{\text {sy5 }}$ & $\left(y_{\mathrm{t} 1}-\mathrm{y}_{\mathrm{a} 3}\right)+\left(\mathrm{S}_{3} / 2\right)\left(\varphi_{\mathrm{t} 1}-\varphi_{\mathrm{a} 3}\right)-\left(\mathrm{l}_{2}+\mathrm{l}_{8}\right) \theta_{\mathrm{t} 1}$ \\
\hline $\mathbf{U}_{\text {sy } 6}$ & $\left(\mathrm{y}_{\mathrm{t} 1}-\mathrm{y}_{\mathrm{a} 3}\right)-\left(\mathrm{S}_{3} / 2\right)\left(\varphi_{\mathrm{t} 1}-\varphi_{\mathrm{a} 3}\right)-\left(\mathrm{l}_{2}+\mathrm{l}_{8}\right) \theta_{\mathrm{t} 1}$ \\
\hline $\mathbf{U}_{\text {sy7 }}$ & $\left(\mathrm{y}_{\mathrm{t} 2}-\mathrm{y}_{\mathrm{a} 4}\right)+\left(\mathrm{S}_{4} / 2\right)\left(\varphi_{\mathrm{t} 2}-\varphi_{\mathrm{a} 4}\right)-\mathrm{l}_{11} \theta_{\mathrm{t} 2}$ \\
\hline $\mathbf{U}_{\text {sy8 }}$ & $\left(\mathrm{y}_{\mathrm{t} 2}-\mathrm{y}_{\mathrm{a} 4}\right)-\left(\mathrm{S}_{4} / 2\right)\left(\varphi_{\mathrm{t} 2}-\varphi_{\mathrm{a} 4}\right)-\mathrm{l}_{11} \theta_{\mathrm{t} 2}$ \\
\hline $\mathbf{U}_{\text {sy9 }}$ & $\left(\mathrm{y}_{\mathrm{t} 2}-\mathrm{y}_{\mathrm{a} 5}\right)+\left(\mathrm{S}_{5} / 2\right)\left(\varphi_{\mathrm{t} 2}-\varphi_{\mathrm{a} 5}\right)-\left(\mathrm{l}_{4}+\mathrm{l}_{11}\right) \theta_{\mathrm{t} 2}$ \\
\hline $\mathbf{U}_{\text {sy10 }}$ & $\left(\mathrm{y}_{\mathrm{t} 2}-\mathrm{y}_{\mathrm{a} 5}\right)-\left(\mathrm{S}_{5} / 2\right)\left(\varphi_{\mathrm{t} 2}-\varphi_{\mathrm{a} 5}\right)-\left(\mathrm{l}_{4}+\mathrm{l}_{11}\right) \theta_{\mathrm{t} 2}$ \\
\hline $\mathbf{U}_{\text {sy11 }}$ & $\left(\mathrm{y}_{\mathrm{t} 3}-\mathrm{y}_{\mathrm{a} 6}\right)+\left(\mathrm{S}_{6} / 2\right)\left(\varphi_{\mathrm{t} 3}-\varphi_{\mathrm{a} 6}\right)+\left(\mathrm{l}_{6}+\mathrm{l}_{13}\right) \theta_{\mathrm{t} 3}$ \\
\hline $\mathbf{U}_{\mathrm{sy} 12}$ & $\left(\mathrm{y}_{\mathrm{t} 3}-\mathrm{y}_{\mathrm{a} 6}\right)-\left(\mathrm{S}_{6} / 2\right)\left(\varphi_{\mathrm{t} 3}-\varphi_{\mathrm{a} 6}\right)+\left(\mathrm{l}_{6}+\mathrm{l}_{13}\right) \theta_{\mathrm{t} 3}$ \\
\hline $\mathbf{U}_{\mathrm{sy} 13}$ & $\left(\mathrm{y}_{\mathrm{t} 3}-\mathrm{y}_{\mathrm{a} 7}\right)+\left(\mathrm{S}_{7} / 2\right)\left(\varphi_{\mathrm{t} 3}-\varphi_{\mathrm{a} 7}\right)+\mathrm{l}_{13} \theta_{\mathrm{t} 3}$ \\
\hline $\mathbf{U}_{\text {sy14 }}$ & $\left(\mathrm{y}_{\mathrm{t} 3}-\mathrm{y}_{\mathrm{a} 7}\right)-\left(\mathrm{S}_{7} / 2\right)\left(\varphi_{\mathrm{t} 3}-\varphi_{\mathrm{a} 7}\right)+\mathrm{l}_{13} \theta_{\mathrm{t} 3}$ \\
\hline $\mathbf{U}_{\text {sy15 }}$ & $\left(\mathrm{y}_{\mathrm{t} 3}-\mathrm{y}_{\mathrm{a} 8}\right)+\left(\mathrm{S}_{8} / 2\right)\left(\varphi_{\mathrm{t} 3}-\varphi_{\mathrm{a} 8}\right)-\mathrm{l}_{14} \theta_{\mathrm{t} 3}$ \\
\hline $\mathbf{U}_{\text {sy16 }}$ & $\left(\mathrm{y}_{\mathrm{t} 3}-\mathrm{y}_{\mathrm{a} 8}\right)-\left(\mathrm{S}_{8} / 2\right)\left(\varphi_{\mathrm{t} 3}-\varphi_{\mathrm{a} 8}\right)-\mathrm{l}_{14} \theta_{\mathrm{t} 3}$ \\
\hline $\mathbf{U}_{\text {sy17 }}$ & $\left(\mathrm{y}_{\mathrm{t} 3}-\mathrm{y}_{\mathrm{a} 9}\right)+\left(\mathrm{S}_{9} / 2\right)\left(\varphi_{\mathrm{t} 3}-\varphi_{\mathrm{a} 9}\right)-\left(\mathrm{l}_{14}+\mathrm{l}_{15}\right) \theta_{\mathrm{t} 3}$ \\
\hline $\mathbf{U}_{\text {sy18 }}$ & $\left(\mathrm{y}_{\mathrm{t} 3}-\mathrm{y}_{\mathrm{a} 9}\right)-\left(\mathrm{S}_{9} / 2\right)\left(\varphi_{\mathrm{t} 3}-\varphi_{\mathrm{a} 9}\right)-\left(\mathrm{l}_{14}+\mathrm{l}_{15}\right) \theta_{\mathrm{t} 3}$ \\
\hline
\end{tabular}

\section{Tire springs}

$\mathbf{U}_{\mathrm{ty} 1}$

$\mathbf{U}_{\text {ty2 }}$

$\mathbf{U}_{\text {ty3 }}$

$\mathbf{U}_{\mathrm{ty} 4}$

$\mathbf{U}_{\text {ty5 }}$

$\mathbf{U}_{\text {ty } 6}$

$\mathbf{U}_{\text {ty7 }}$

$\mathbf{U}_{\text {ty8 }}$

$\mathrm{U}_{\text {ty9 }}$

$\mathrm{y}_{\mathrm{a} 1}+\left(\mathrm{d}_{1} / 2\right) \varphi_{\mathrm{a} 1}+\mathrm{u}_{\mathrm{SR} 1}$

$\mathrm{y}_{\mathrm{a} 1}-\left(\mathrm{d}_{1} / 2\right) \varphi_{\mathrm{a} 1}+\mathrm{u}_{\mathrm{SR} 2}$

$\mathrm{y}_{\mathrm{a} 2}+\left(\mathrm{d}_{2} / 2\right) \varphi_{\mathrm{a} 2}+\mathrm{u}_{\mathrm{SR} 3}$

$\mathrm{y}_{\mathrm{a} 2}-\left(\mathrm{d}_{2} / 2\right) \varphi_{\mathrm{a} 2}+\mathrm{u}_{\mathrm{SR} 4}$

$\mathrm{y}_{\mathrm{a} 3}+\left(\mathrm{d}_{3} / 2\right) \varphi_{\mathrm{a} 3}+\mathrm{u}_{\mathrm{SR} 5}$

$\mathrm{y}_{\mathrm{a} 3}-\left(\mathrm{d}_{3} / 2\right) \varphi_{\mathrm{a} 3}+\mathrm{u}_{\mathrm{SR} 6}$

$\mathrm{y}_{\mathrm{a} 4}+\left(\mathrm{d}_{4} / 2\right) \varphi_{\mathrm{a} 4}+\mathrm{u}_{\mathrm{SR} 7}$

$\mathrm{y}_{\mathrm{a} 4}-\left(\mathrm{d}_{4} / 2\right) \varphi_{\mathrm{a} 4}+\mathrm{u}_{\mathrm{SR} 8}$

$\mathrm{y}_{\mathrm{a} 5}+\left(\mathrm{d}_{5} / 2\right) \varphi_{\mathrm{a} 5}+\mathrm{u}_{\mathrm{SR} 9}$ 


\begin{tabular}{|c|c|}
\hline $\mathbf{U}_{\text {ty10 }}$ & $\mathrm{y}_{\mathrm{a} 5}-\left(\mathrm{d}_{5} / 2\right) \varphi_{\mathrm{a} 5}+\mathrm{u}_{\mathrm{SR} 10}$ \\
\cline { 2 - 2 } $\mathbf{U}_{\mathrm{ty} 11}$ & $\mathrm{y}_{\mathrm{a} 6}+\left(\mathrm{d}_{6} / 2\right) \varphi_{\mathrm{a} 6}+\mathrm{u}_{\mathrm{SR} 11}$ \\
$\mathbf{U}_{\mathrm{ty} 12}$ & $\mathrm{y}_{\mathrm{a} 6}-\left(\mathrm{d}_{6} / 2\right) \varphi_{\mathrm{a} 6}+\mathrm{u}_{\mathrm{SR} 12}$ \\
\hline $\mathbf{U}_{\mathrm{ty} 13}$ & $\mathrm{y}_{\mathrm{a} 7}+\left(\mathrm{d}_{7} / 2\right) \varphi_{\mathrm{a} 7}+\mathrm{u}_{\mathrm{SR} 13}$ \\
\hline $\mathbf{U}_{\mathrm{ty} 14}$ & $\mathrm{y}_{\mathrm{a} 7}-\left(\mathrm{d}_{7} / 2\right) \varphi_{\mathrm{a} 7}+\mathrm{u}_{\mathrm{SR} 14}$ \\
\hline $\mathbf{U}_{\mathrm{ty} 15}$ & $\mathrm{y}_{\mathrm{a} 8}+\left(\mathrm{d}_{8} / 2\right) \varphi_{\mathrm{a} 8}+\mathrm{u}_{\mathrm{SR} 15}$ \\
$\mathbf{U}_{\mathrm{ty} 16}$ & $\mathrm{y}_{\mathrm{a} 8}-\left(\mathrm{d}_{8} / 2\right) \varphi_{\mathrm{a} 8}+\mathrm{u}_{\mathrm{SR} 16}$ \\
\hline $\mathbf{U}_{\mathrm{ty} 17}$ & $\mathrm{y}_{\mathrm{a} 9}+\left(\mathrm{d}_{9} / 2\right) \varphi_{\mathrm{a} 9}+\mathrm{u}_{\mathrm{SR} 17}$ \\
\hline $\mathbf{U}_{\mathrm{ty} 18}$ & $\mathrm{y}_{\mathrm{a} 9}-\left(\mathrm{d}_{9} / 2\right) \varphi_{\mathrm{a} 9}+\mathrm{u}_{\mathrm{SR} 18}$ \\
\hline
\end{tabular}

Kinetic Energy of the system:

$$
\begin{aligned}
& \mathrm{T}=\frac{1}{2} \mathrm{~m}_{\mathrm{t} 1} \dot{\mathrm{Y}}_{\mathrm{t} 1}{ }^{2}+\frac{1}{2} \mathrm{~m}_{\mathrm{a} 1} \dot{\mathrm{y}}_{\mathrm{a} 1}{ }^{2}+\frac{1}{2} \mathrm{~m}_{\mathrm{a} 2} \dot{\mathrm{Y}}_{\mathrm{a} 2}{ }^{2}+\frac{1}{2} \mathrm{~m}_{\mathrm{a} 3} \dot{\mathrm{Y}}_{\mathrm{a} 3}{ }^{2}+\frac{1}{2} \mathrm{~m}_{\mathrm{a} 4} \dot{\mathrm{Y}}_{\mathrm{a} 4}{ }^{2}+\frac{1}{2} \mathrm{~m}_{\mathrm{a} 5} \dot{\mathrm{Y}}_{\mathrm{a} 5}{ }^{2}+ \\
& \frac{1}{2} \mathrm{~m}_{\mathrm{a} 6} \dot{\mathrm{Y}}_{\mathrm{a} 6}{ }^{2}+\frac{1}{2} \mathrm{~m}_{\mathrm{a} 7} \dot{\mathrm{Y}}_{\mathrm{a} 7}{ }^{2}+\frac{1}{2} \mathrm{~m}_{\mathrm{a} 8} \dot{\mathrm{Y}}_{\mathrm{a} 8}{ }^{2}+\frac{1}{2} \mathrm{~m}_{\mathrm{a} 9} \dot{\mathrm{Y}}_{\mathrm{a} 9}{ }^{2}+\frac{1}{2} \mathrm{I}_{\mathrm{xt} 1} \dot{\varphi}_{\mathrm{t} 1}{ }^{2}+\frac{1}{2} \mathrm{I}_{\mathrm{zt} 1} \dot{\theta}_{\mathrm{t} 1}{ }^{2}+ \\
& \frac{1}{2} \mathrm{I}_{\mathrm{xt} 2} \dot{\varphi}_{\mathrm{t} 2}{ }^{2}+\frac{1}{2} \mathrm{I}_{\mathrm{zt} 2} \dot{\theta}_{\mathrm{t} 2}{ }^{2}+\frac{1}{2} \mathrm{I}_{\mathrm{xt} 3} \dot{\varphi}_{\mathrm{t} 3}{ }^{2}+\frac{1}{2} \mathrm{I}_{\mathrm{zt} 3} \dot{\theta}_{\mathrm{t} 3}{ }^{2}+\frac{1}{2} \mathrm{I}_{\mathrm{x} a 1} \dot{\varphi}_{\mathrm{a} 1}{ }^{2}+\frac{1}{2} \mathrm{I}_{\mathrm{xa} 2} \dot{\varphi}_{\mathrm{a} 2}{ }^{2}+ \\
& \frac{1}{2} \mathrm{I}_{\mathrm{xa} 3} \dot{\varphi}_{\mathrm{a} 3}{ }^{2}+\frac{1}{2} \mathrm{I}_{\mathrm{xa} 4} \dot{\varphi}_{\mathrm{a} 4}{ }^{2}+\frac{1}{2} \mathrm{I}_{\mathrm{xa} 5} \dot{\varphi}_{\mathrm{a} 5}{ }^{2}+\frac{1}{2} \mathrm{I}_{\mathrm{xa} 6} \dot{\varphi}_{\mathrm{a} 6}{ }^{2}+\frac{1}{2} \mathrm{I}_{\mathrm{xa} 7} \dot{\varphi}_{\mathrm{a} 7}{ }^{2}+\frac{1}{2} \mathrm{I}_{\mathrm{xa} 8} \dot{\varphi}_{\mathrm{a} 8}{ }^{2}+ \\
& \frac{1}{2} \mathrm{I}_{\mathrm{xa} 9} \dot{\varphi}_{\mathrm{a} 9}^{2}+\frac{1}{2} \mathrm{~m}_{\mathrm{t} 2} \dot{\mathrm{y}}_{\mathrm{t} 2}^{2}+\frac{1}{2} \mathrm{~m}_{\mathrm{t} 3} \dot{\mathrm{y}}_{\mathrm{t} 3}^{2}
\end{aligned}
$$

Potential Energy of the system:

$$
\begin{aligned}
& \mathrm{V}=\frac{1}{2} \mathrm{~K}_{\mathrm{sy} 1} \mathrm{U}_{\mathrm{sy} 1}{ }^{2}+\frac{1}{2} \mathrm{~K}_{\mathrm{sy} 2} \mathrm{U}_{\mathrm{sy} 2}{ }^{2}+\frac{1}{2} \mathrm{~K}_{\mathrm{sy} 3} \mathrm{U}_{\mathrm{sy} 3}{ }^{2}+\frac{1}{2} \mathrm{~K}_{\mathrm{sy} 4} \mathrm{U}_{\mathrm{sy} 4}{ }^{2}+\frac{1}{2} \mathrm{~K}_{\mathrm{sy} 5} \mathrm{U}_{\mathrm{sy} 5}{ }^{2}+ \\
& \frac{1}{2} \mathrm{~K}_{\mathrm{sy} 6} \mathrm{U}_{\mathrm{sy} 6}{ }^{2}+\frac{1}{2} \mathrm{~K}_{\mathrm{sy} 7} \mathrm{U}_{\mathrm{sy} 7}{ }^{2}+\frac{1}{2} \mathrm{~K}_{\mathrm{sy} 8} \mathrm{U}_{\mathrm{sy} 8}{ }^{2}+\frac{1}{2} \mathrm{~K}_{\mathrm{sy} 9} \mathrm{U}_{\mathrm{sy} 9}{ }^{2}+\frac{1}{2} \mathrm{~K}_{\mathrm{sy} 10} \mathrm{U}_{\mathrm{sy} 10}{ }^{2}+ \\
& \frac{1}{2} \mathrm{~K}_{\mathrm{sy} 11} \mathrm{U}_{\mathrm{sy} 11}{ }^{2}+\frac{1}{2} \mathrm{~K}_{\mathrm{sy} 12} \mathrm{U}_{\mathrm{sy} 12}{ }^{2}+\frac{1}{2} \mathrm{~K}_{\mathrm{sy} 13} \mathrm{U}_{\mathrm{sy} 13}{ }^{2}+\frac{1}{2} \mathrm{~K}_{\mathrm{sy} 14} \mathrm{U}_{\mathrm{sy} 14}{ }^{2}+ \\
& \frac{1}{2} \mathrm{~K}_{\mathrm{sy} 15} \mathrm{U}_{\mathrm{sy} 15}{ }^{2}+\frac{1}{2} \mathrm{~K}_{\mathrm{sy} 16} \mathrm{U}_{\mathrm{sy} 16}{ }^{2}+\frac{1}{2} \mathrm{~K}_{\mathrm{sy} 17} \mathrm{U}_{\mathrm{sy} 17}{ }^{2}+\frac{1}{2} \mathrm{~K}_{\mathrm{sy} 18} \mathrm{U}_{\mathrm{sy} 18}{ }^{2}+\frac{1}{2} \mathrm{~K}_{\mathrm{ty} 1} \mathrm{U}_{\mathrm{ty} 1}{ }^{2}+ \\
& \frac{1}{2} \mathrm{~K}_{\mathrm{ty} 2} \mathrm{U}_{\mathrm{ty} 2}{ }^{2}+\frac{1}{2} \mathrm{~K}_{\mathrm{ty} 3} \mathrm{U}_{\mathrm{ty} 3}{ }^{2}+\frac{1}{2} \mathrm{~K}_{\mathrm{ty} 4} \mathrm{U}_{\mathrm{ty} 4}{ }^{2}+\frac{1}{2} \mathrm{~K}_{\mathrm{ty} 5} \mathrm{U}_{\mathrm{ty} 5}{ }^{2}+\frac{1}{2} \mathrm{~K}_{\mathrm{ty} 6} \mathrm{U}_{\mathrm{ty} 6}{ }^{2}+
\end{aligned}
$$




$$
\begin{aligned}
& \frac{1}{2} \mathrm{~K}_{\mathrm{ty} 7} \mathrm{U}_{\mathrm{sy} 7}{ }^{2}+\frac{1}{2} \mathrm{~K}_{\mathrm{ty} 8} \mathrm{U}_{\mathrm{ty} 8}{ }^{2}+\frac{1}{2} \mathrm{~K}_{\mathrm{ty} 9} \mathrm{U}_{\mathrm{ty} 9}{ }^{2}+\frac{1}{2} \mathrm{~K}_{\mathrm{ty} 10} \mathrm{U}_{\mathrm{ty} 10}{ }^{2}+\frac{1}{2} \mathrm{~K}_{\mathrm{ty} 11} \mathrm{U}_{\mathrm{ty} 11}{ }^{2}+ \\
& \frac{1}{2} \mathrm{~K}_{\mathrm{ty} 12} \mathrm{U}_{\mathrm{ty} 12}{ }^{2}+\frac{1}{2} \mathrm{~K}_{\mathrm{ty} 13} \mathrm{U}_{\mathrm{ty} 13}{ }^{2}+\frac{1}{2} \mathrm{~K}_{\mathrm{ty} 14} \mathrm{U}_{\mathrm{ty} 14}{ }^{2}+\frac{1}{2} \mathrm{~K}_{\mathrm{ty} 15} \mathrm{U}_{\mathrm{ty} 15}{ }^{2}+\frac{1}{2} \mathrm{~K}_{\mathrm{ty} 16} \mathrm{U}_{\mathrm{ty} 16}{ }^{2}+ \\
& \frac{1}{2} \mathrm{~K}_{\mathrm{ty} 17} \mathrm{U}_{\mathrm{ty} 17}{ }^{2}+\frac{1}{2} \mathrm{~K}_{\mathrm{ty} 18} \mathrm{U}_{\mathrm{ty} 18}{ }^{2}-\left(\left(\mathrm{m}_{\mathrm{t} 1} \mathrm{~g}\right) \mathrm{y}_{\mathrm{t} 1}+\left(\mathrm{m}_{\mathrm{t} 2} \mathrm{~g}\right) \mathrm{y}_{\mathrm{t} 2}+\left(\mathrm{m}_{\mathrm{t} 3} \mathrm{~g}\right) \mathrm{y}_{\mathrm{t} 3}+\right. \\
& \left(\mathrm{m}_{\mathrm{a} 1} \mathrm{~g}\right) \mathrm{y}_{\mathrm{a} 1}+\left(\mathrm{m}_{\mathrm{a} 2} \mathrm{~g}\right) \mathrm{y}_{\mathrm{a} 2}+\left(\mathrm{m}_{\mathrm{a} 3} \mathrm{~g}\right) \mathrm{y}_{\mathrm{a} 3}+\left(\mathrm{m}_{\mathrm{a} 4} \mathrm{~g}\right) \mathrm{y}_{\mathrm{a} 4}+\left(\mathrm{m}_{\mathrm{a} 5} \mathrm{~g}\right) \mathrm{y}_{\mathrm{a} 5}+\left(\mathrm{m}_{\mathrm{a} 6} \mathrm{~g}\right) \mathrm{y}_{\mathrm{a} 6}+ \\
& \left.\left(\mathrm{m}_{\mathrm{a} 7} \mathrm{~g}\right) \mathrm{y}_{\mathrm{a} 7}+\left(\mathrm{m}_{\mathrm{a} 8} \mathrm{~g}\right) \mathrm{y}_{\mathrm{a} 8}+\left(\mathrm{m}_{\mathrm{a} 9} \mathrm{~g}\right) \mathrm{y}_{\mathrm{a} 9}\right)+\left(\mathrm{F}_{\mathrm{y} 1} \mathrm{U}_{\mathrm{sy} 1}+\mathrm{F}_{\mathrm{y} 2} \mathrm{U}_{\mathrm{sy} 2}+\mathrm{F}_{\mathrm{y} 3} \mathrm{U}_{\mathrm{sy} 3}+\right. \\
& \mathrm{F}_{\mathrm{y} 4} \mathrm{U}_{\mathrm{sy} 4}+\mathrm{F}_{\mathrm{y} 5} \mathrm{U}_{\mathrm{sy} 5}+\mathrm{F}_{\mathrm{y} 6} \mathrm{U}_{\mathrm{sy} 6}+\mathrm{F}_{\mathrm{y} 7} \mathrm{U}_{\mathrm{sy} 7}+\mathrm{F}_{\mathrm{y} 8} \mathrm{U}_{\mathrm{sy} 8}+\mathrm{F}_{\mathrm{y} 9} \mathrm{U}_{\mathrm{sy} 9}+\mathrm{F}_{\mathrm{y} 10} \mathrm{U}_{\mathrm{sy} 10}+ \\
& \mathrm{F}_{\mathrm{y} 11} \mathrm{U}_{\mathrm{sy} 11}+\mathrm{F}_{\mathrm{y} 12} \mathrm{U}_{\mathrm{sy} 12}+\mathrm{F}_{\mathrm{y} 13} \mathrm{U}_{\mathrm{sy} 13}+\mathrm{F}_{\mathrm{y} 14} \mathrm{U}_{\mathrm{sy} 14}+\mathrm{F}_{\mathrm{y} 15} \mathrm{U}_{\mathrm{sy} 15}+\mathrm{F}_{\mathrm{y} 16} \mathrm{U}_{\mathrm{sy} 16}+ \\
& \left.\mathrm{F}_{\mathrm{y} 17} \mathrm{U}_{\mathrm{sy} 17}+\mathrm{F}_{\mathrm{y} 18} \mathrm{U}_{\mathrm{sy} 18}\right)
\end{aligned}
$$

\section{Damping Energy of the system:}

$$
\begin{aligned}
& \mathrm{D}=\frac{1}{2} \mathrm{D}_{\mathrm{sy} 1} \dot{\mathrm{U}}_{\mathrm{sy} 1}{ }^{2}+\frac{1}{2} \mathrm{D}_{\mathrm{sy} 2} \dot{\mathrm{U}}_{\mathrm{sy} 2}{ }^{2}+\frac{1}{2} \mathrm{D}_{\mathrm{sy} 3} \dot{\mathrm{U}}_{\mathrm{sy} 3}{ }^{2}+\frac{1}{2} \mathrm{D}_{\mathrm{sy} 4} \dot{\mathrm{U}}_{\mathrm{sy} 4}{ }^{2}+\frac{1}{2} \mathrm{D}_{\mathrm{sy} 5} \dot{\mathrm{U}}_{\mathrm{sy} 5}{ }^{2}+ \\
& \frac{1}{2} \mathrm{D}_{\mathrm{sy} 6} \dot{\mathrm{U}}_{\mathrm{sy} 6}{ }^{2}+\frac{1}{2} \mathrm{D}_{\mathrm{sy} 7} \dot{\mathrm{U}}_{\mathrm{sy} 7}{ }^{2}+\frac{1}{2} \mathrm{D}_{\mathrm{sy} 8} \dot{\mathrm{U}}_{\mathrm{sy} 8}{ }^{2}+\frac{1}{2} \mathrm{D}_{\mathrm{sy} 9} \dot{\mathrm{U}}_{\mathrm{sy} 9}{ }^{2}+\frac{1}{2} \mathrm{D}_{\mathrm{sy} 10} \dot{\mathrm{U}}_{\mathrm{sy} 10}{ }^{2}+ \\
& \frac{1}{2} \mathrm{D}_{\mathrm{sy} 11} \dot{\mathrm{U}}_{\mathrm{sy} 11}{ }^{2}+\frac{1}{2} \mathrm{D}_{\mathrm{sy} 12} \dot{\mathrm{U}}_{\mathrm{sy} 12}{ }^{2}+\frac{1}{2} \mathrm{D}_{\mathrm{sy} 13} \dot{\mathrm{U}}_{\mathrm{sy} 13}{ }^{2}+\frac{1}{2} \mathrm{D}_{\mathrm{sy} 14} \dot{\mathrm{U}}_{\mathrm{sy} 14}{ }^{2}+\frac{1}{2} \mathrm{D}_{\mathrm{sy} 15} \dot{\mathrm{U}}_{\mathrm{sy} 15}{ }^{2}+ \\
& \frac{1}{2} \mathrm{D}_{\mathrm{sy} 16} \dot{\mathrm{U}}_{\mathrm{sy} 16}{ }^{2}+\frac{1}{2} \mathrm{D}_{\mathrm{sy} 17} \dot{\mathrm{U}}_{\mathrm{sy} 17}{ }^{2}+\frac{1}{2} \mathrm{D}_{\mathrm{sy} 18} \dot{\mathrm{U}}_{\mathrm{sy} 18}{ }^{2}+\frac{1}{2} \mathrm{D}_{\mathrm{ty} 1} \dot{\mathrm{U}}_{\mathrm{ty} 1}{ }^{2}+\frac{1}{2} \mathrm{D}_{\mathrm{ty} 2} \dot{\mathrm{U}}_{\mathrm{ty} 2}{ }^{2}+ \\
& \frac{1}{2} \mathrm{D}_{\mathrm{ty} 3} \dot{\mathrm{U}}_{\mathrm{ty} 3}{ }^{2}+\frac{1}{2} \mathrm{D}_{\mathrm{ty} 4} \dot{\mathrm{U}}_{\mathrm{ty} 4}{ }^{2}+\frac{1}{2} \mathrm{D}_{\mathrm{ty} 5} \dot{\mathrm{U}}_{\mathrm{ty} 5}{ }^{2}+\frac{1}{2} \mathrm{D}_{\mathrm{ty} 6} \dot{\mathrm{U}}_{\mathrm{ty} 6}{ }^{2}+\frac{1}{2} \mathrm{D}_{\mathrm{ty} 7} \dot{\mathrm{U}}_{\mathrm{ty} 7}{ }^{2}+{ }_{\mathrm{ty} 8}{ }^{2}+\frac{1}{2} \mathrm{D}_{\mathrm{ty} 9} \dot{\mathrm{U}}_{\mathrm{ty} 9}{ }^{2}+\frac{1}{2} \mathrm{D}_{\mathrm{ty} 10} \dot{\mathrm{U}}_{\mathrm{ty} 10}{ }^{2}+\frac{1}{2} \mathrm{D}_{\mathrm{ty} 11} \dot{\mathrm{U}}_{\mathrm{ty} 11}{ }^{2}+\frac{1}{2} \mathrm{D}_{\mathrm{ty} 12} \dot{\mathrm{U}}_{\mathrm{ty} 12}{ }^{2}+ \\
& \frac{1}{2} \mathrm{D}_{\mathrm{ty} 13} \dot{\mathrm{U}}_{\mathrm{ty} 13}{ }^{2}+\frac{1}{2} \mathrm{D}_{\mathrm{ty} 14} \dot{\mathrm{U}}_{\mathrm{ty} 14}{ }^{2}+\frac{1}{2} \mathrm{D}_{\mathrm{ty} 15} \dot{\mathrm{U}}_{\mathrm{ty} 15}{ }^{2}+\frac{1}{2} \mathrm{D}_{\mathrm{ty} 16} \dot{\mathrm{U}}_{\mathrm{ty} 16}{ }^{2}+\frac{1}{2} \mathrm{D}_{\mathrm{ty} 17} \dot{\mathrm{U}}_{\mathrm{ty} 177}{ }^{2}+ \\
& \frac{1}{2} \mathrm{D}_{\mathrm{ty} 18} \dot{\mathrm{U}}_{\mathrm{ty} 18}{ }^{2}
\end{aligned}
$$

The displacement at the pivot point should stay the same, whether it is calculated from the trailer part or the tractor part,

$y_{t 2}+\theta_{t 2} l_{10}=y_{t 1}-\theta_{t 1} l_{9}$

Thus, by substituting $\theta_{\mathrm{t} 2}$ from equation ( 45 ) in equation ( 42 ), 


$$
\begin{aligned}
& \mathrm{T}=\frac{1}{2} \mathrm{~m}_{\mathrm{t} 1} \dot{\mathrm{Y}}_{\mathrm{t} 1}{ }^{2}+\frac{1}{2} \mathrm{~m}_{\mathrm{a} 1} \dot{\mathrm{y}}_{\mathrm{a} 1}{ }^{2}+\frac{1}{2} \mathrm{~m}_{\mathrm{a} 2} \dot{\mathrm{Y}}_{\mathrm{a} 2}{ }^{2}+\frac{1}{2} \mathrm{~m}_{\mathrm{a} 3} \dot{\mathrm{Y}}_{\mathrm{a} 3}{ }^{2}+\frac{1}{2} \mathrm{~m}_{\mathrm{a} 4} \dot{\mathrm{Y}}_{\mathrm{a} 4}{ }^{2}+\frac{1}{2} \mathrm{~m}_{\mathrm{a} 5} \dot{\mathrm{y}}_{\mathrm{a} 5}{ }^{2}+ \\
& \frac{1}{2} \mathrm{~m}_{\mathrm{a} 6} \dot{\mathrm{Y}}_{\mathrm{a} 6}{ }^{2}+\frac{1}{2} \mathrm{~m}_{\mathrm{a} 7} \dot{\mathrm{Y}}_{\mathrm{a} 7}{ }^{2}+\frac{1}{2} \mathrm{~m}_{\mathrm{a} 8} \dot{\mathrm{Y}}_{\mathrm{a} 8}{ }^{2}+\frac{1}{2} \mathrm{~m}_{\mathrm{a} 9} \dot{\mathrm{Y}}_{\mathrm{a} 9}{ }^{2}+\frac{1}{2} \mathrm{I}_{\mathrm{xt} 1} \dot{\varphi}_{\mathrm{t} 1}{ }^{2}+\frac{1}{2} \mathrm{I}_{\mathrm{zt} 1} \dot{\theta}_{\mathrm{t} 1}{ }^{2}+ \\
& \frac{1}{2} \mathrm{I}_{\mathrm{xt} 2} \dot{\varphi}_{\mathrm{t} 2}{ }^{2}+\frac{1}{2} \mathrm{I}_{\mathrm{zt} 2}\left(\frac{\dot{\mathrm{y}}_{\mathrm{t} 1}-\dot{\mathrm{y}}_{\mathrm{t} 2}-\dot{\theta}_{\mathrm{t} 1} \mathrm{l}_{\mathrm{g}}}{\mathrm{l}_{10}}\right)^{2}+\frac{1}{2} \mathrm{I}_{\mathrm{xt} 3} \dot{\varphi}_{\mathrm{t} 3}{ }^{2}+\frac{1}{2} \mathrm{I}_{\mathrm{zt} 3} \dot{\theta}_{t 3}{ }^{2}+\frac{1}{2} \mathrm{I}_{\mathrm{xa} 1} \dot{\varphi}_{\mathrm{a} 1}{ }^{2}+ \\
& \frac{1}{2} \mathrm{I}_{\mathrm{xa} 2} \dot{\varphi}_{\mathrm{a} 2}{ }^{2}+\frac{1}{2} \mathrm{I}_{\mathrm{xa} 3} \dot{\varphi}_{\mathrm{a} 3}{ }^{2}+\frac{1}{2} \mathrm{I}_{\mathrm{xa} 4} \dot{\varphi}_{\mathrm{a} 4}{ }^{2}+\frac{1}{2} \mathrm{I}_{\mathrm{xa} 5} \dot{\varphi}_{\mathrm{a} 5}{ }^{2}+\frac{1}{2} \mathrm{I}_{\mathrm{xa} 6} \dot{\varphi}_{\mathrm{a} 6}{ }^{2}+\frac{1}{2} \mathrm{I}_{\mathrm{xa} 7} \dot{\varphi}_{\mathrm{a} 7}{ }^{2}+ \\
& \frac{1}{2} \mathrm{I}_{\mathrm{xa} 8} \dot{\varphi}_{\mathrm{a} 8}^{2}+\frac{1}{2} \mathrm{I}_{\mathrm{xa} 9} \dot{\varphi}_{\mathrm{a} 9}{ }^{2}+\frac{1}{2} \mathrm{~m}_{\mathrm{t} 2} \dot{\mathrm{y}}_{\mathrm{t} 2}{ }^{2}+\frac{1}{2} \mathrm{~m}_{\mathrm{t} 3} \dot{\mathrm{y}}_{\mathrm{t} 3}{ }^{2}
\end{aligned}
$$

Same substitution will be applied to the equations ( 43 ) and ( 44 ). Now the Lagrange equation is applied to $\mathrm{y}_{\mathrm{t} 2}$ :

$$
\begin{aligned}
& {\left[\mathrm{m}_{\mathrm{t} 2} \ddot{\mathrm{y}}_{\mathrm{t} 2}-\frac{\mathrm{I}_{\mathrm{zt} 2}}{\mathrm{l}_{10}{ }^{2}}\left(\ddot{\mathrm{y}}_{\mathrm{t} 1}-\ddot{\mathrm{y}}_{\mathrm{t} 2}-\ddot{\theta}_{\mathrm{t} 1} \mathrm{l}_{9}\right)\right]+\left[\left(1+\frac{\mathrm{l}_{11}}{\mathrm{l}_{10}}\right)\left(\mathrm{F}_{\mathrm{sy} 7}+\mathrm{F}_{\mathrm{sy} 8}\right)+\left(1+\frac{\mathrm{l}_{4}+\mathrm{l}_{11}}{\mathrm{l}_{10}}\right)\left(\mathrm{F}_{\mathrm{sy} 9}+\right.\right.} \\
& \left.\left.\mathrm{F}_{\mathrm{sy} 10}\right)-\left(\mathrm{m}_{\mathrm{t} 2} \mathrm{~g}\right)\right]+\left[\left(1+\frac{\mathrm{l}_{11}}{\mathrm{l}_{10}}\right)\left(\mathrm{F}_{\mathrm{dsy} 7}+\mathrm{F}_{\mathrm{dsy8}}\right)+\left(1+\frac{\mathrm{l}_{4}+\mathrm{l}_{11}}{\mathrm{l}_{10}}\right)\left(\mathrm{F}_{\mathrm{dsy} 9}+\mathrm{F}_{\mathrm{dsy} 10}\right)\right]=0
\end{aligned}
$$

To simplify the equation some variables are defined as follows:

$$
\begin{aligned}
& \mathrm{S}_{\mathrm{a} 2}=\frac{\mathrm{I}_{\mathrm{zt} 2}}{\mathrm{l}_{10}{ }^{2}} \\
& \mathrm{~S}_{\mathrm{c} 2}=\frac{\mathrm{I}_{\mathrm{zt} 2}}{\mathrm{l}_{10}{ }^{2}}+\mathrm{m}_{\mathrm{t} 2} \\
& \mathrm{~S}_{\mathrm{a} 3}=\frac{\mathrm{I}_{\mathrm{zt} 2}}{\mathrm{l}_{10}{ }^{2}} \mathrm{l}_{9}
\end{aligned}
$$

$\mathrm{B}_{\mathrm{t} 4}=\mathrm{m}_{\mathrm{t} 2 \mathrm{~g}} \mathrm{~g}\left(1+\frac{\mathrm{l}_{11}}{\mathrm{l}_{10}}\right)\left(\mathrm{F}_{\mathrm{sy} 7}+\mathrm{F}_{\mathrm{sy} 8}+\mathrm{F}_{\mathrm{dsy} 7}+\mathrm{F}_{\mathrm{dsy8}}\right)-\left(1+\frac{\mathrm{l}_{4}+\mathrm{l}_{11}}{\mathrm{l}_{10}}\right)\left(\mathrm{F}_{\mathrm{sy} 9}+\mathrm{F}_{\mathrm{sy} 10}+\mathrm{F}_{\mathrm{dsy} 9}+\right.$ $\left.\mathrm{F}_{\mathrm{dsy} 10}\right)$

Therefore equation ( 48 ) will be simplified to:

$$
-\mathrm{S}_{\mathrm{a} 2} \ddot{\mathrm{y}}_{\mathrm{t} 1}+\mathrm{S}_{\mathrm{c} 2} \ddot{\mathrm{y}}_{\mathrm{t} 2}+\mathrm{S}_{\mathrm{a} 3} \ddot{\theta}_{\mathrm{t} 1}=\mathrm{B}_{\mathrm{t} 4}
$$

By applying the Lagrange equation to $\mathrm{y}_{\mathrm{t} 1}$ : 


$$
\begin{aligned}
& {\left[\mathrm{m}_{\mathrm{t} 1} \ddot{\mathrm{y}}_{\mathrm{t} 1}+\frac{\mathrm{I}_{\mathrm{zt} 2}}{\mathrm{l}_{10}}\left(\ddot{\mathrm{y}}_{\mathrm{t} 1}-\ddot{\mathrm{y}}_{\mathrm{t} 2}-\ddot{\theta}_{\mathrm{t} 1} \mathrm{l}_{9}\right)\right]+\left[\left(\mathrm{F}_{\mathrm{sy} 1}+\mathrm{F}_{\mathrm{sy} 2}+\mathrm{F}_{\mathrm{sy} 3}+\mathrm{F}_{\mathrm{sy} 4}+\mathrm{F}_{\mathrm{sy} 5}+\mathrm{F}_{\mathrm{sy} 6}\right)-\right.} \\
& \left.\frac{\mathrm{l}_{11}}{\mathrm{l}_{10}}\left(\mathrm{~F}_{\mathrm{sy} 7}+\mathrm{F}_{\mathrm{sy} 8}\right)-\frac{\mathrm{l}_{4}+\mathrm{l}_{11}}{\mathrm{l}_{10}}\left(\mathrm{~F}_{\mathrm{sy} 9}+\mathrm{F}_{\mathrm{sy} 10}\right)-\left(\mathrm{m}_{\mathrm{t} 1 \mathrm{~g}} \mathrm{~g}\right)\right]+\left[\left(\mathrm{F}_{\mathrm{dsy} 1}+\mathrm{F}_{\mathrm{dsy} 2}+\mathrm{F}_{\mathrm{dsy} 3}+\right.\right. \\
& \left.\left.\mathrm{F}_{\mathrm{dsy} 4}+\mathrm{F}_{\mathrm{dsy} 5}+\mathrm{F}_{\mathrm{dsy} 6}\right)-\frac{\mathrm{l}_{11}}{\mathrm{l}_{10}}\left(\mathrm{~F}_{\mathrm{dsy} 7}+\mathrm{F}_{\mathrm{dsy} 8}\right)-\frac{\mathrm{l}_{4}+\mathrm{l}_{11}}{\mathrm{l}_{10}}\left(\mathrm{~F}_{\mathrm{dsy} 9}+\mathrm{F}_{\mathrm{dsy} 10}\right)\right]=0
\end{aligned}
$$

Again to simplify the equation some variables are defined as follows:

$$
\begin{aligned}
& \mathrm{S}_{\mathrm{a} 1}=\frac{\mathrm{I}_{\mathrm{zt} 2}}{\mathrm{l}_{10}^{2}}+\mathrm{m}_{\mathrm{t} 1} \\
& \mathrm{~B}_{\mathrm{t} 1}=\mathrm{m}_{\mathrm{t} 1} \mathrm{~g}-\left[\left(\mathrm{F}_{\mathrm{sy} 1}+\mathrm{F}_{\mathrm{sy} 2}+\mathrm{F}_{\mathrm{sy} 3}+\mathrm{F}_{\mathrm{sy} 4}+\mathrm{F}_{\mathrm{sy} 5}+\mathrm{F}_{\mathrm{sy} 6}\right)-\frac{\mathrm{l}_{11}}{\mathrm{l}_{10}}\left(\mathrm{~F}_{\mathrm{sy} 7}+\mathrm{F}_{\mathrm{sy} 8}\right)-\frac{\mathrm{l}_{4}+\mathrm{l}_{11}}{\mathrm{l}_{10}}\left(\mathrm{~F}_{\mathrm{sy} 9}+\right.\right. \\
& \left.\mathrm{F}_{\mathrm{sy} 10}\right)+\left(\mathrm{F}_{\mathrm{dsy} 1}+\mathrm{F}_{\mathrm{dsy} 2}+\mathrm{F}_{\mathrm{dsy} 3}+\mathrm{F}_{\mathrm{dsy} 4}+\mathrm{F}_{\mathrm{dsy} 5}+\mathrm{F}_{\mathrm{dsy} 6}\right)-\frac{\mathrm{l}_{11}}{\mathrm{l}_{10}}\left(\mathrm{~F}_{\mathrm{dsy} 7}+\mathrm{F}_{\mathrm{dsy} 8}\right)- \\
& \left.\frac{\mathrm{l}_{4}+\mathrm{l}_{11}}{\mathrm{l}_{10}}\left(\mathrm{~F}_{\mathrm{dsy} 9}+\mathrm{F}_{\mathrm{dsy} 10}\right)\right]
\end{aligned}
$$

Therefore equation ( 49 ) will be simplified to:

$\mathrm{S}_{\mathrm{a} 1} \ddot{\mathrm{y}}_{\mathrm{t} 1}-\mathrm{S}_{\mathrm{a} 2} \ddot{\mathrm{y}}_{\mathrm{t} 2}-\mathrm{S}_{\mathrm{a} 3} \ddot{\theta}_{\mathrm{t} 1}=\mathrm{B}_{\mathrm{t} 1}$

Also, by applying the Lagrange equation to $\theta_{\mathrm{t} 1}$ :

$$
\begin{aligned}
& {\left[I_{z t 1} \ddot{\theta}_{t 1}-\frac{I_{z t 2} l_{9}}{l_{10}{ }^{2}}\left(\ddot{y}_{t 1}-\ddot{y}_{t 2}-\ddot{\theta}_{t 1} l_{9}\right)\right]+\left[l_{7}\left(F_{s y 1}+F_{s y 2}\right)-l_{8}\left(F_{s y 3}+F_{s y 4}\right)-\right.} \\
& \left.\left(l_{2}+l_{8}\right)\left(F_{s y 5}+F_{s y 6}\right)+\frac{l_{9} I_{11}}{l_{10}}\left(F_{s y 7}+F_{s y 8}\right)+\frac{l_{9}\left(l_{4}+I_{11}\right)}{l_{10}}\left(F_{s y 9}+F_{s y 10}\right)\right]+ \\
& {\left[l_{7}\left(F_{d s y 1}+F_{d s y 2}\right)-l_{8}\left(F_{d s y 3}+F_{d s y 4}\right)-\left(l_{2}+l_{8}\right)\left(F_{d s y 5}+F_{d s y 6}\right)+\frac{l_{9} I_{11}}{l_{10}}\left(F_{d s y 7}+\right.\right.} \\
& \left.\left.F_{d s y 8}\right)+\frac{l_{9}\left(l_{4}+I_{11}\right)}{l_{10}}\left(F_{d s y 9}+F_{d s y 10}\right)\right]=0
\end{aligned}
$$

Once again to simplify the equation some variables need to be defined as follows:

$$
\mathrm{S}_{\mathrm{b} 3}=\mathrm{I}_{\mathrm{zt} 1}+\frac{\mathrm{I}_{\mathrm{zt} 2} \mathrm{l}_{9}}{\mathrm{l}_{10}^{2}}
$$




$$
\begin{aligned}
& \mathrm{B}_{\mathrm{t} 3}=-\left[\left[\mathrm{l}_{7}\left(\mathrm{~F}_{\mathrm{sy} 1}+\mathrm{F}_{\mathrm{sy} 2}\right)-\mathrm{l}_{8}\left(\mathrm{~F}_{\mathrm{sy} 3}+\mathrm{F}_{\mathrm{sy} 4}\right)-\left(\mathrm{l}_{2}+\mathrm{l}_{8}\right)\left(\mathrm{F}_{\mathrm{sy} 5}+\mathrm{F}_{\mathrm{sy} 6}\right)+\frac{\mathrm{l}_{9} \mathrm{I}_{11}}{\mathrm{l}_{10}}\left(\mathrm{~F}_{\mathrm{sy} 7}+\mathrm{F}_{\mathrm{sy} 8}\right)+\right.\right. \\
& \left.\frac{\mathrm{l}_{9}\left(\mathrm{l}_{4}+\mathrm{I}_{11}\right)}{\mathrm{l}_{10}}\left(\mathrm{~F}_{\mathrm{sy} 9}+\mathrm{F}_{\mathrm{sy} 10}\right)\right]+\left[\mathrm{l}_{7}\left(\mathrm{~F}_{\mathrm{dsy} 1}+\mathrm{F}_{\mathrm{dsy} 2}\right)-\mathrm{l}_{8}\left(\mathrm{~F}_{\mathrm{dsy} 3}+\mathrm{F}_{\mathrm{dsy} 4}\right)-\left(\mathrm{l}_{2}+\mathrm{l}_{8}\right)\left(\mathrm{F}_{\mathrm{dsy} 5}+\right.\right. \\
& \left.\left.\left.\mathrm{F}_{\mathrm{dsy} 6}\right)+\frac{\mathrm{l}_{9} \mathrm{I}_{11}}{\mathrm{l}_{10}}\left(\mathrm{~F}_{\mathrm{dsy} 7}+\mathrm{F}_{\mathrm{dsy} 8}\right)+\frac{\mathrm{l}_{9}\left(\mathrm{l}_{4}+\mathrm{I}_{11}\right)}{\mathrm{l}_{10}}\left(\mathrm{~F}_{\mathrm{dsy} 9}+\mathrm{F}_{\mathrm{dsy} 10}\right)\right]\right]
\end{aligned}
$$

Therefore equation ( 51 ) will be simplified to:

$-\mathrm{S}_{\mathrm{a} 3} \ddot{\mathrm{y}}_{\mathrm{t} 1}+\mathrm{S}_{\mathrm{a} 3} \ddot{\mathrm{y}}_{\mathrm{t} 2}+\mathrm{S}_{\mathrm{b} 3} \ddot{\theta}_{\mathrm{t} 1}=\mathrm{B}_{\mathrm{t} 3}$

By adding equations ( 48 ) and ( 50 ),

$$
\left(S_{\mathrm{a} 1}-\mathrm{S}_{\mathrm{a} 2}\right) \ddot{y}_{\mathrm{t} 1}-\left(\mathrm{S}_{\mathrm{a} 2}-\mathrm{S}_{\mathrm{c} 2}\right) \ddot{y}_{\mathrm{t} 2}=\mathrm{B}_{\mathrm{t} 1}+\mathrm{B}_{\mathrm{t} 4}
$$

Also by multiplying $S_{\mathrm{b} 3}$ and $S_{\mathrm{a} 3}$ to equations ( 50 ) and ( 52 ), respectively,

$$
\left(\mathrm{S}_{\mathrm{a} 1} \mathrm{~S}_{\mathrm{b} 3}-\mathrm{S}_{\mathrm{a} 3}^{2}\right) \ddot{\mathrm{y}}_{\mathrm{t} 1}-\left(\mathrm{S}_{\mathrm{a} 2} \mathrm{~S}_{\mathrm{b} 3}-\mathrm{S}_{\mathrm{a} 3}^{2}\right) \ddot{\mathrm{y}}_{\mathrm{t} 2}=\mathrm{S}_{\mathrm{b} 3} \mathrm{~B}_{\mathrm{t} 1}+\mathrm{S}_{\mathrm{a} 3} \mathrm{~B}_{\mathrm{t} 3}
$$

By defining the following expressions, equations ( 53 ) and ( 54 ) are simplified to equations ( 55 ) and ( 56 ), respectively,

$$
\begin{aligned}
& \mathrm{e}_{1}=\mathrm{S}_{\mathrm{a} 1}-\mathrm{S}_{\mathrm{a} 2} \\
& \mathrm{e}_{2}=\mathrm{S}_{\mathrm{a} 2}-\mathrm{S}_{\mathrm{c} 2} \\
& \mathrm{e}_{3}=\mathrm{S}_{\mathrm{a} 1} \mathrm{~S}_{\mathrm{b} 3}-\mathrm{S}_{\mathrm{a} 3}^{2} \\
& \mathrm{e}_{4}=\mathrm{S}_{\mathrm{a} 2} \mathrm{~S}_{\mathrm{b} 3}-\mathrm{S}_{\mathrm{a} 3}^{2} \\
& \mathrm{e}_{1} \ddot{\mathrm{y}}_{\mathrm{t} 1}-\mathrm{e}_{2} \ddot{\mathrm{y}}_{\mathrm{t} 2}=\mathrm{B}_{\mathrm{t} 1}+\mathrm{B}_{\mathrm{t} 4} \\
& \mathrm{e}_{3} \ddot{\mathrm{y}}_{\mathrm{t} 1}-\mathrm{e}_{4} \ddot{\mathrm{y}}_{\mathrm{t} 2}=\mathrm{S}_{\mathrm{b} 3} \mathrm{~B}_{\mathrm{t} 1}+\mathrm{S}_{\mathrm{a} 3} \mathrm{~B}_{\mathrm{t} 3}
\end{aligned}
$$

Solving equations ( 55 ) and ( 56 ) for $\ddot{y}_{\mathrm{t} 1}$ and $\ddot{y}_{\mathrm{t} 2}$ will lead to: 
$\ddot{y}_{\mathrm{t} 1}=\frac{\mathrm{e}_{4}\left(\mathrm{~B}_{\mathrm{t} 1}+\mathrm{B}_{\mathrm{t} 4}\right)-\mathrm{e}_{2}\left(\mathrm{~S}_{\mathrm{b} 3} \mathrm{~B}_{\mathrm{t} 1}+\mathrm{S}_{\mathrm{a} 3} \mathrm{~B}_{\mathrm{t} 3}\right)}{\mathrm{e}_{1} \mathrm{e}_{4}-\mathrm{e}_{2} \mathrm{e}_{3}}$

$\ddot{y}_{\mathrm{t} 2}=\frac{\mathrm{e}_{1}}{\mathrm{e}_{2}}\left(\frac{\mathrm{e}_{4}\left(\mathrm{~B}_{\mathrm{t} 1}+\mathrm{B}_{\mathrm{t} 4}\right)-\mathrm{e}_{2}\left(\mathrm{~S}_{\mathrm{b} 3} \mathrm{~B}_{\mathrm{t} 1}+\mathrm{S}_{\mathrm{a} 3} \mathrm{~B}_{\mathrm{t} 3}\right)}{\mathrm{e}_{1} \mathrm{e}_{4}-\mathrm{e}_{2} \mathrm{e}_{3}}\right)-\frac{\mathrm{B}_{\mathrm{t} 1}+\mathrm{B}_{\mathrm{t} 4}}{\mathrm{e}_{2}}$

Substituting equations ( 57 ) and ( 58 ) into equation ( 52 ) will give,

$$
\begin{aligned}
\ddot{\theta}_{\mathrm{t} 1}=\frac{\mathrm{B}_{\mathrm{t} 3}}{\mathrm{~S}_{\mathrm{b} 3}}+\frac{\mathrm{S}_{\mathrm{a} 3}}{\mathrm{~S}_{\mathrm{b} 3}}( & \left.\frac{\mathrm{e}_{4}\left(\mathrm{~B}_{\mathrm{t} 1}+\mathrm{B}_{\mathrm{t} 4}\right)-\mathrm{e}_{2}\left(\mathrm{~S}_{\mathrm{b} 3} \mathrm{~B}_{\mathrm{t} 1}+\mathrm{S}_{\mathrm{a} 3} \mathrm{~B}_{\mathrm{t} 3}\right)}{\mathrm{e}_{1} \mathrm{e}_{4}-\mathrm{e}_{2} \mathrm{e}_{3}}\right) \\
& -\frac{\mathrm{S}_{\mathrm{a} 3}}{\mathrm{~S}_{\mathrm{b} 3}}\left(\frac{\mathrm{e}_{1}}{\mathrm{e}_{2}}\left(\frac{\mathrm{e}_{4}\left(\mathrm{~B}_{\mathrm{t} 1}+\mathrm{B}_{\mathrm{t} 4}\right)-\mathrm{e}_{2}\left(\mathrm{~S}_{\mathrm{b} 3} \mathrm{~B}_{\mathrm{t} 1}+\mathrm{S}_{\mathrm{a} 3} \mathrm{~B}_{\mathrm{t} 3}\right)}{\mathrm{e}_{1} \mathrm{e}_{4}-\mathrm{e}_{2} \mathrm{e}_{3}}\right)-\frac{\mathrm{B}_{\mathrm{t} 1}+\mathrm{B}_{\mathrm{t} 4}}{\mathrm{e}_{2}}\right)
\end{aligned}
$$

By applying the Lagrange equation to $\varphi_{\mathrm{t} 1}, \varphi_{\mathrm{t} 2}, \varphi_{\mathrm{t} 3}, \mathrm{y}_{\mathrm{t} 3}, \theta_{\mathrm{t} 3}$ :

$$
\begin{aligned}
& \mathrm{I}_{\mathrm{xt} 1} \ddot{\varphi}_{\mathrm{t} 1}+\left[\left(\frac{\mathrm{s}_{1}}{2}\right)\left(\mathrm{F}_{\mathrm{sy} 1}-\mathrm{F}_{\mathrm{sy} 2}\right)+\left(\frac{\mathrm{s}_{2}}{2}\right)\left(\mathrm{F}_{\mathrm{sy} 3}-\mathrm{F}_{\mathrm{sy} 4}\right)+\left(\frac{\mathrm{s}_{3}}{2}\right)\left(\mathrm{F}_{\mathrm{sy} 5}-\mathrm{F}_{\mathrm{sy} 6}\right)\right]+ \\
& {\left[\left(\frac{s_{1}}{2}\right)\left(F_{d s y 1}-F_{d s y 2}\right)+\left(\frac{s_{2}}{2}\right)\left(F_{d s y 3}-F_{d s y 4}\right)+\left(\frac{s_{3}}{2}\right)\left(F_{d s y 5}-F_{d s y 6}\right)\right]=0} \\
& \mathrm{I}_{\mathrm{xt} 2} \ddot{\varphi}_{\mathrm{t} 2}+\left[\left(\frac{\mathrm{s}_{4}}{2}\right)\left(\mathrm{F}_{\mathrm{sy} 7}-\mathrm{F}_{\mathrm{sy} 8}\right)+\left(\frac{\mathrm{s}_{5}}{2}\right)\left(\mathrm{F}_{\mathrm{sy} 9}-\mathrm{F}_{\mathrm{sy} 10}\right)\right]+\left[\left(\frac{\mathrm{s}_{4}}{2}\right)\left(\mathrm{F}_{\mathrm{dsy} 7}-\mathrm{F}_{\mathrm{dsy} 8}\right)+\right. \\
& \left.\left(\frac{s_{5}}{2}\right)\left(F_{d s y 9}-F_{d s y 10}\right)\right]=0 \\
& \mathrm{I}_{\mathrm{xt} 3} \ddot{\varphi}_{\mathrm{t} 3}+\left[\left(\frac{\mathrm{s}_{6}}{2}\right)\left(\mathrm{F}_{\mathrm{sy} 11}-\mathrm{F}_{\mathrm{sy} 12}\right)+\left(\frac{\mathrm{s}_{7}}{2}\right)\left(\mathrm{F}_{\mathrm{sy} 13}-\mathrm{F}_{\mathrm{sy} 14}\right)+\left(\frac{\mathrm{s}_{8}}{2}\right)\left(\mathrm{F}_{\mathrm{sy} 15}-\mathrm{F}_{\mathrm{sy} 16}\right)+\right. \\
& \left.\left(\frac{s_{9}}{2}\right)\left(F_{s y 17}-F_{s y 18}\right)\right]+\left[\left(\frac{s_{6}}{2}\right)\left(F_{d s y 11}-F_{d s y 12}\right)+\left(\frac{s_{7}}{2}\right)\left(F_{d s y 13}-F_{d s y 14}\right)+\right. \\
& \left.\left(\frac{s_{8}}{2}\right)\left(F_{\mathrm{dsy} 15}-\mathrm{F}_{\mathrm{dsy} 16}\right)+\left(\frac{\mathrm{s}_{9}}{2}\right)\left(\mathrm{F}_{\mathrm{dsy} 17}-\mathrm{F}_{\mathrm{dsy} 18}\right)\right]=0 \\
& \mathrm{~m}_{\mathrm{t} 3} \ddot{\mathrm{y}}_{\mathrm{t} 3}+\left(\mathrm{F}_{\mathrm{sy} 11}+\mathrm{F}_{\mathrm{sy} 12}+\mathrm{F}_{\mathrm{sy} 13}+\mathrm{F}_{\mathrm{sy} 14}+\mathrm{F}_{\mathrm{sy} 15}+\mathrm{F}_{\mathrm{sy} 16}+\mathrm{F}_{\mathrm{sy} 17}+\mathrm{F}_{\mathrm{sy} 18}\right)+ \\
& \left(F_{d s y 11}+F_{d s y 12}+F_{d s y 13}+F_{d s y 14}+F_{d s y 15}+F_{d s y 16}+F_{d s y 17}+F_{d s y 18}\right)=m_{t 3} g \\
& \mathrm{I}_{\mathrm{zt} 3} \ddot{\theta}_{\mathrm{t} 3}+\left[\left(\mathrm{l}_{6}+\mathrm{l}_{13}\right)\left(\mathrm{F}_{\mathrm{sy} 11}+\mathrm{F}_{\mathrm{sy} 12}\right)+\mathrm{l}_{13}\left(\mathrm{~F}_{\mathrm{sy} 13}+\mathrm{F}_{\mathrm{sy} 14}\right)-\mathrm{l}_{14}\left(\mathrm{~F}_{\mathrm{sy} 15}+\mathrm{F}_{\mathrm{sy} 16}\right)-\right. \\
& \left.\left(\mathrm{l}_{14}+\mathrm{l}_{15}\right)\left(\mathrm{F}_{\mathrm{sy} 17}+\mathrm{F}_{\mathrm{sy} 18}\right)\right]+\left[\left(\mathrm{l}_{6}+\mathrm{l}_{13}\right)\left(\mathrm{F}_{\mathrm{dsy} 11}+\mathrm{F}_{\mathrm{dsy} 12}\right)+\mathrm{l}_{13}\left(\mathrm{~F}_{\mathrm{dsy} 13}+\mathrm{F}_{\mathrm{dsy} 14}\right)-\right. \\
& \left.\mathrm{l}_{14}\left(\mathrm{~F}_{\mathrm{dsy} 15}+\mathrm{F}_{\mathrm{dsy} 16}\right)-\left(\mathrm{l}_{14}+\mathrm{l}_{15}\right)\left(\mathrm{F}_{\mathrm{dsy} 17}+\mathrm{F}_{\mathrm{dsy} 18}\right)\right]=0
\end{aligned}
$$

The rest of degrees of freedom will be as follow: 


$$
\begin{aligned}
& \mathrm{m}_{\mathrm{a} 1} \ddot{\mathrm{y}}_{\mathrm{a} 1}-\left(\mathrm{F}_{\mathrm{sy} 1}+\mathrm{F}_{\mathrm{sy} 2}\right)+\left(\mathrm{F}_{\mathrm{ty} 1}+\mathrm{F}_{\mathrm{ty} 2}\right)-\left(\mathrm{F}_{\mathrm{dsy} 1}+\mathrm{F}_{\mathrm{dsy} 2}\right)+\left(\mathrm{F}_{\mathrm{dty} 1}+\mathrm{F}_{\mathrm{dty} 2}\right)= \\
& \mathrm{m}_{\mathrm{a} 1} \mathrm{~g} \\
& \mathrm{I}_{\mathrm{xa} 1} \ddot{\varphi}_{\mathrm{a} 1}-\left(\frac{\mathrm{s}_{1}}{2}\right)\left(\mathrm{F}_{\mathrm{sy} 1}-\mathrm{F}_{\mathrm{sy} 2}\right)+\left(\frac{\mathrm{d}_{1}}{2}\right)\left(\mathrm{F}_{\mathrm{ty} 1}-\mathrm{F}_{\mathrm{ty} 2}\right)-\left(\frac{\mathrm{s}_{1}}{2}\right)\left(\mathrm{F}_{\mathrm{dsy} 1}-\mathrm{F}_{\mathrm{dsy} 2}\right)+\left(\frac{\mathrm{d}_{1}}{2}\right)\left(\mathrm{F}_{\mathrm{dty} 1}-\mathrm{F}_{\mathrm{dty} 2}\right)= \\
& 0 \\
& \mathrm{~m}_{\mathrm{a} 2} \ddot{\mathrm{y}}_{\mathrm{a} 2}-\left(\mathrm{F}_{\mathrm{sy} 3}+\mathrm{F}_{\mathrm{sy} 4}\right)+\left(\mathrm{F}_{\mathrm{ty} 3}+\mathrm{F}_{\mathrm{ty} 4}\right)-\left(\mathrm{F}_{\mathrm{dsy} 3}+\mathrm{F}_{\mathrm{dsy} 4}\right)+\left(\mathrm{F}_{\mathrm{dty} 3}+\mathrm{F}_{\mathrm{dty} 4}\right)= \\
& \mathrm{m}_{\mathrm{a} 2} \mathrm{~g} \\
& \mathrm{I}_{\mathrm{xa} 2} \ddot{\varphi}_{\mathrm{a} 2}-\left(\frac{\mathrm{s}_{2}}{2}\right)\left(\mathrm{F}_{\mathrm{sy} 3}-\mathrm{F}_{\mathrm{sy} 4}\right)+\left(\frac{\mathrm{d}_{2}}{2}\right)\left(\mathrm{F}_{\mathrm{ty} 3}-\mathrm{F}_{\mathrm{ty} 4}\right)-\left(\frac{\mathrm{s}_{2}}{2}\right)\left(\mathrm{F}_{\mathrm{dsy} 3}-\mathrm{F}_{\mathrm{dsy} 4}\right)+ \\
& \left(\frac{\mathrm{d}_{2}}{2}\right)\left(\mathrm{F}_{\mathrm{dty} 3}-\mathrm{F}_{\mathrm{dty} 4}\right)=0 \\
& \mathrm{~m}_{\mathrm{a} 3} \ddot{\mathrm{y}}_{\mathrm{a} 3}-\left(\mathrm{F}_{\mathrm{sy} 5}+\mathrm{F}_{\mathrm{sy} 6}\right)+\left(\mathrm{F}_{\mathrm{ty} 5}+\mathrm{F}_{\mathrm{ty} 6}\right)-\left(\mathrm{F}_{\mathrm{dsy} 5}+\mathrm{F}_{\mathrm{dsy} 6}\right)+\left(\mathrm{F}_{\mathrm{dty} 5}+\mathrm{F}_{\mathrm{dty} 6}\right)= \\
& \mathrm{m}_{\mathrm{a} 3} \mathrm{~g} \\
& \mathrm{I}_{\mathrm{xa} 3} \ddot{\varphi}_{\mathrm{a} 3}-\left(\frac{\mathrm{s}_{3}}{2}\right)\left(\mathrm{F}_{\mathrm{sy} 5}-\mathrm{F}_{\mathrm{sy} 6}\right)+\left(\frac{\mathrm{d}_{3}}{2}\right)\left(\mathrm{F}_{\mathrm{ty} 5}-\mathrm{F}_{\mathrm{ty} 6}\right)-\left(\frac{\mathrm{s}_{3}}{2}\right)\left(\mathrm{F}_{\mathrm{dsy} 5}-\mathrm{F}_{\mathrm{dsy} 6}\right)+ \\
& \left(\frac{d_{3}}{2}\right)\left(F_{d t y 5}-F_{d t y 6}\right)=0 \\
& \mathrm{~m}_{\mathrm{a} 4} \ddot{\mathrm{y}}_{\mathrm{a} 4}-\left(\mathrm{F}_{\mathrm{sy} 7}+\mathrm{F}_{\mathrm{sy} 8}\right)+\left(\mathrm{F}_{\mathrm{ty} 7}+\mathrm{F}_{\mathrm{ty} 8}\right)-\left(\mathrm{F}_{\mathrm{dsy} 7}+\mathrm{F}_{\mathrm{dsy} 8}\right)+\left(\mathrm{F}_{\mathrm{dty} 7}+\mathrm{F}_{\mathrm{dty} 8}\right)= \\
& \mathrm{m}_{\mathrm{a} 4} \mathrm{~g} \\
& \mathrm{I}_{\mathrm{xa} 4} \ddot{\varphi}_{\mathrm{a} 4}-\left(\frac{\mathrm{s}_{4}}{2}\right)\left(\mathrm{F}_{\mathrm{sy} 7}-\mathrm{F}_{\mathrm{sy} 8}\right)+\left(\frac{\mathrm{d}_{4}}{2}\right)\left(\mathrm{F}_{\mathrm{ty} 7}-\mathrm{F}_{\mathrm{ty} 8}\right)-\left(\frac{\mathrm{s}_{4}}{2}\right)\left(\mathrm{F}_{\mathrm{dsy} 7}-\mathrm{F}_{\mathrm{dsy} 8}\right)+ \\
& \left(\frac{\mathrm{d}_{4}}{2}\right)\left(\mathrm{F}_{\mathrm{dty} 7}-\mathrm{F}_{\mathrm{dty} 8}\right)=0 \\
& \mathrm{~m}_{\mathrm{a} 5} \ddot{\mathrm{y}}_{\mathrm{a} 5}-\left(\mathrm{F}_{\mathrm{sy} 9}+\mathrm{F}_{\mathrm{sy} 10}\right)+\left(\mathrm{F}_{\mathrm{ty} 9}+\mathrm{F}_{\mathrm{ty} 10}\right)-\left(\mathrm{F}_{\mathrm{dsy} 9}+\mathrm{F}_{\mathrm{dsy} 10}\right)+\left(\mathrm{F}_{\mathrm{dty} 9}+\mathrm{F}_{\mathrm{dty} 10}\right)= \\
& \mathrm{m}_{\mathrm{a} 5} \mathrm{~g} \\
& \mathrm{I}_{\mathrm{xa} 5} \ddot{\varphi}_{\mathrm{a} 5}-\left(\frac{\mathrm{s}_{5}}{2}\right)\left(\mathrm{F}_{\mathrm{sy} 9}-\mathrm{F}_{\mathrm{sy} 10}\right)+\left(\frac{\mathrm{d}_{5}}{2}\right)\left(\mathrm{F}_{\mathrm{ty} 9}-\mathrm{F}_{\mathrm{ty} 10}\right)-\left(\frac{\mathrm{s}_{5}}{2}\right)\left(\mathrm{F}_{\mathrm{dsy} 9}-\mathrm{F}_{\mathrm{dsy} 10}\right)+ \\
& \left(\frac{d_{5}}{2}\right)\left(F_{d t y 9}-F_{d t y 10}\right)=0
\end{aligned}
$$




$$
\begin{aligned}
& \mathrm{m}_{\mathrm{a} 6} \ddot{\mathrm{y}}_{\mathrm{a} 6}-\left(\mathrm{F}_{\mathrm{sy} 11}+\mathrm{F}_{\mathrm{sy} 12}\right)+\left(\mathrm{F}_{\mathrm{ty} 11}+\mathrm{F}_{\mathrm{ty} 12}\right)-\left(\mathrm{F}_{\mathrm{dsy} 11}+\mathrm{F}_{\mathrm{dsy} 12}\right)+\left(\mathrm{F}_{\mathrm{dty} 11}+\right. \\
& \left.\mathrm{F}_{\mathrm{dty} 12}\right)=\mathrm{m}_{\mathrm{a} 6} \mathrm{~g} \\
& \mathrm{I}_{\mathrm{xa} 6} \ddot{\varphi}_{\mathrm{a} 6}-\left(\frac{\mathrm{s}_{6}}{2}\right)\left(\mathrm{F}_{\mathrm{sy} 11}-\mathrm{F}_{\mathrm{sy} 12}\right)+\left(\frac{\mathrm{d}_{6}}{2}\right)\left(\mathrm{F}_{\mathrm{ty} 11}-\mathrm{F}_{\mathrm{ty} 12}\right)-\left(\frac{\mathrm{s}_{6}}{2}\right)\left(\mathrm{F}_{\mathrm{dsy} 11}-\mathrm{F}_{\mathrm{dsy} 12}\right)+ \\
& \left(\frac{d_{6}}{2}\right)\left(F_{d t y 11}-F_{d t y 12}\right)=0 \\
& \mathrm{~m}_{\mathrm{a} 7} \ddot{\mathrm{y}}_{\mathrm{a} 7}-\left(\mathrm{F}_{\mathrm{sy} 13}+\mathrm{F}_{\mathrm{sy} 14}\right)+\left(\mathrm{F}_{\mathrm{ty} 13}+\mathrm{F}_{\mathrm{ty} 14}\right)-\left(\mathrm{F}_{\mathrm{dsy} 13}+\mathrm{F}_{\mathrm{dsy} 14}\right)+\left(\mathrm{F}_{\mathrm{dty} 13}+\right. \\
& \left.\mathrm{F}_{\mathrm{dty} 14}\right)=\mathrm{m}_{\mathrm{a} 7} \mathrm{~g} \\
& \mathrm{I}_{\mathrm{xa} 7} \ddot{\varphi}_{\mathrm{a} 7}-\left(\frac{\mathrm{s}_{7}}{2}\right)\left(\mathrm{F}_{\mathrm{sy} 13}-\mathrm{F}_{\mathrm{sy} 14}\right)+\left(\frac{\mathrm{d}_{7}}{2}\right)\left(\mathrm{F}_{\mathrm{ty} 13}-\mathrm{F}_{\mathrm{ty} 14}\right)-\left(\frac{\mathrm{s}_{7}}{2}\right)\left(\mathrm{F}_{\mathrm{dsy} 13}-\mathrm{F}_{\mathrm{dsy} 14}\right)+ \\
& \left(\frac{d_{7}}{2}\right)\left(F_{d t y 13}-F_{d t y 14}\right)=0 \\
& \mathrm{~m}_{\mathrm{a} 8} \ddot{\mathrm{y}}_{\mathrm{a} 8}-\left(\mathrm{F}_{\mathrm{sy} 15}+\mathrm{F}_{\mathrm{sy} 16}\right)+\left(\mathrm{F}_{\mathrm{ty} 15}+\mathrm{F}_{\mathrm{ty} 16}\right)-\left(\mathrm{F}_{\mathrm{dsy} 15}+\mathrm{F}_{\mathrm{dsy} 16}\right)+\left(\mathrm{F}_{\mathrm{dty} 15}+\right. \\
& \left.\mathrm{F}_{\mathrm{dty} 16}\right)=\mathrm{m}_{\mathrm{a} 8} \mathrm{~g} \\
& \mathrm{I}_{\mathrm{xa} 8} \ddot{\varphi}_{\mathrm{a} 8}-\left(\frac{\mathrm{s}_{8}}{2}\right)\left(\mathrm{F}_{\mathrm{sy} 15}-\mathrm{F}_{\mathrm{sy} 16}\right)+\left(\frac{\mathrm{d}_{8}}{2}\right)\left(\mathrm{F}_{\mathrm{ty} 15}-\mathrm{F}_{\mathrm{ty} 16}\right)-\left(\frac{\mathrm{s}_{8}}{2}\right)\left(\mathrm{F}_{\mathrm{dsy} 15}-\mathrm{F}_{\mathrm{dsy} 16}\right)+ \\
& \left(\frac{\mathrm{d}_{8}}{2}\right)\left(\mathrm{F}_{\mathrm{dty} 15}-\mathrm{F}_{\mathrm{dty} 16}\right)=0 \\
& \mathrm{~m}_{\mathrm{a} 9} \ddot{\mathrm{y}}_{\mathrm{a} 9}-\left(\mathrm{F}_{\mathrm{sy} 17}+\mathrm{F}_{\mathrm{sy} 18}\right)+\left(\mathrm{F}_{\mathrm{ty} 17}+\mathrm{F}_{\mathrm{ty} 18}\right)-\left(\mathrm{F}_{\mathrm{dsy} 17}+\mathrm{F}_{\mathrm{dsy} 18}\right)+\left(\mathrm{F}_{\mathrm{dty} 17}+\right. \\
& \left.\mathrm{F}_{\mathrm{dty} 18}\right)=\mathrm{m}_{\mathrm{a} 9 \mathrm{~g}} \\
& \mathrm{I}_{\mathrm{xa} 9} \ddot{\varphi}_{\mathrm{a} 9}-\left(\frac{\mathrm{s}_{9}}{2}\right)\left(\mathrm{F}_{\mathrm{sy} 17}-\mathrm{F}_{\mathrm{sy} 18}\right)+\left(\frac{\mathrm{d}_{9}}{2}\right)\left(\mathrm{F}_{\mathrm{ty} 17}-\mathrm{F}_{\mathrm{ty} 18}\right)-\left(\frac{\mathrm{s}_{9}}{2}\right)\left(\mathrm{F}_{\mathrm{dsy} 17}-\mathrm{F}_{\mathrm{dsy} 18}\right)+ \\
& \left(\frac{d_{9}}{2}\right)\left(F_{d t y 17}-F_{d t y 18}\right)=0
\end{aligned}
$$

Twenty seven equations of motion were developed here to capture the real behavior of the 9-Axle Turnpike Double. 


\section{Road Surface Roughness}

Road surface roughness is an important factor when it comes to the dynamic response of bridges and roadways and their interaction with the moving vehicles. The more uneven a surface is, the bigger the strain which will be put on the pavement.

Many different methods for road profile generation have been proposed during the past decades but there have been two main methods used by the most of researchers trying to capture the real behavior of bridge-vehicle interaction.

In this research the same road surface roughness which was used by Wang and Huang in several studies [23], [13], [24], [25], [26] have been used. In these studies, the Power Spectral Density (PSD) function, which was proposed by Dodds and Robson [27], was used.

Dodds and Robson [27] developed power spectral density (PSD) functions and validated these functions with the data recorded at the field. The function that they came up with is,

$\varphi(\mathrm{n})= \begin{cases}\varphi\left(\mathrm{n}_{0}\right)\left(\frac{\mathrm{n}}{\mathrm{n}_{0}}\right)^{-\mathrm{w}_{1}}, & \mathrm{n} \leq \mathrm{n}_{0} \\ \varphi\left(\mathrm{n}_{0}\right)\left(\frac{\mathrm{n}}{\mathrm{n}_{0}}\right)^{-\mathrm{w}_{2}}, & \mathrm{n} \geq \mathrm{n}_{0}\end{cases}$

In this equation,

$\varphi(n)$ is the PSD and has the unit of $\mathrm{m}^{2} /$ cycle $/ \mathrm{m}$

$\mathrm{n}$ is the wave number and has the unit of cycle/m

$\mathrm{n}_{0}$ is the discontinuity frequency and has the value of $\mathrm{n}_{0}=\frac{1}{2 \pi}$ cycle $/ \mathrm{m}$ 
$\varphi\left(\mathrm{n}_{0}\right)$ is the roughness coefficient or the value of the power spectral density at the discontinuity frequency point $\left(\mathrm{n}_{0}\right)$ and has the unit of $\mathrm{m}^{2} /$ cycle $/ \mathrm{m}$

And $w_{1}$ and $w_{2}$ are roughness exponents.

According to Dodds and Robson [27], $\varphi\left(\mathrm{n}_{0}\right)$ depends on the road type and road surface condition and the values of $\mathrm{w}_{1}$ and $\mathrm{w}_{2}$ are only related to the type of the road. In this study, Good surface condition for the Principal Roads is assumed and mean values of $20,2.05,1.44$ are chosen for $\varphi\left(\mathrm{n}_{0}\right), \mathrm{w}_{1}$ and $\mathrm{w}_{2}$, respectively. By plugging the values of $\mathrm{n}_{0}, \varphi\left(\mathrm{n}_{0}\right), \mathrm{w}_{1}$ and $\mathrm{w}_{2}$ in to the equation ( 83 ) and drawing the graph of the given function in a log-log scale Figure 5 is obtained which is a bilinear presentation of the PSD and the point of discontinuity is shown on the graph [28].

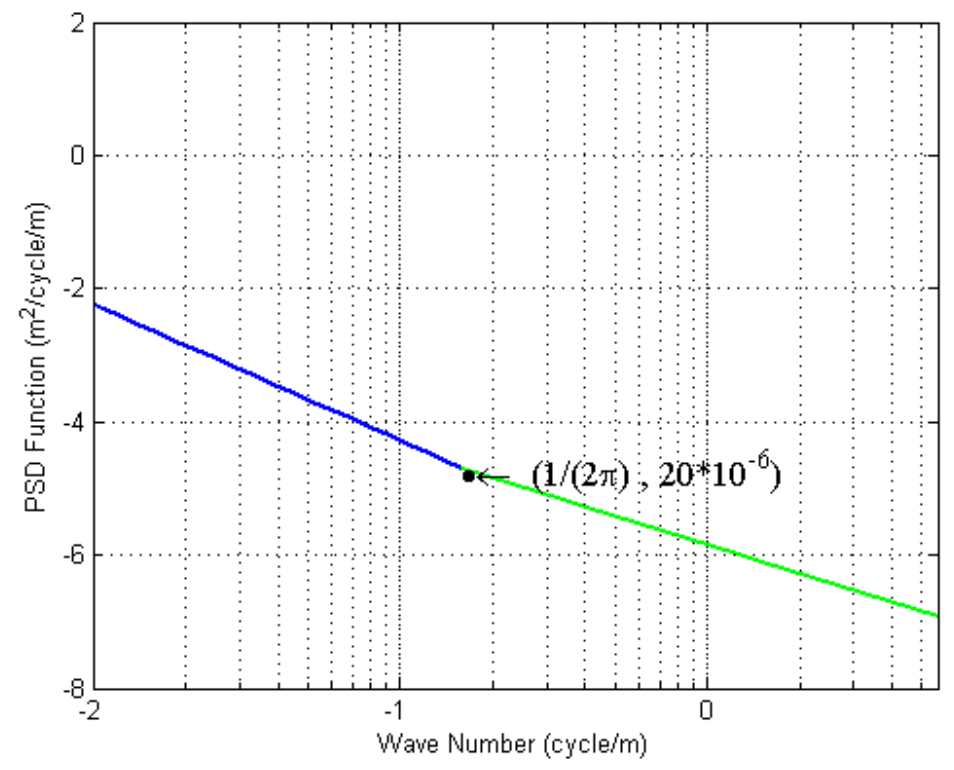

Figure 5. Dodds and Robson Spectrum for Principal Roads

In order to create road profiles, some random numbers with Gaussian distribution and zero mean should be generated. This can be done by different methods such as the random numbers generation tools in Matlab software [29]. These numbers then should 
be passed through some filters to get the form of equation ( 83 ). Four different road surface conditions of Very Good, Good, Average and Poor are generated. Road surfaces are defined over an 800 foot distance and the surface profile was reported in every 5 inches along the road. Two different sets of road profile are selected for the right and left tires. The road surface profile for the right tire is shown in Figure 6 . The obtained numbers show the road surface profile of the bridge and they can present the actual behavior of a road surface.

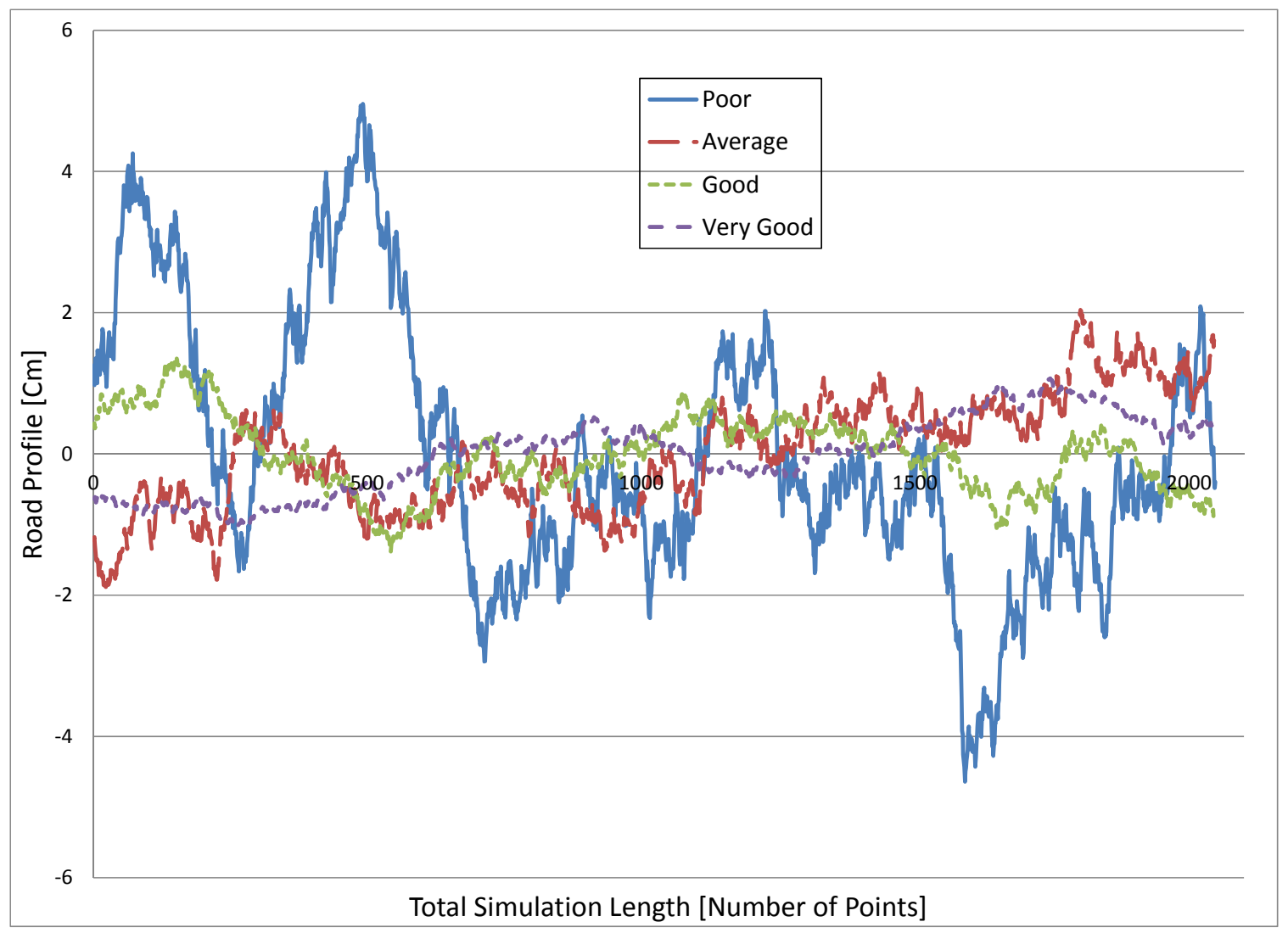

Figure 6. Road Surface Profiles for the Right Tire

The second method which was proposed by Honda et al. [28] involves a different power spectral density (PSD) function with different values for the exponent and the coefficient which were calculated using least square method. It should also be noted that recently some new methods using non-Gaussian process and also using Laplace model have 
been proposed by some researchers in Sweden but since the reliability of these models have not been verified by any other researchers around the world they are not used in this research. All the methods so far can be used to generate a road profile for a bridge in the longitudinal direction but there have been some studies such as Liu et al. [20] in which efforts have been made to investigate the effects of transverse undulation in bridges. But since no significant effects have been reported by these studies on the importance of considering changes of road surface in the transverse direction, only one direction road surface profile has been taken into consideration in this research.

\section{Bridge Models}

Two different sets of bridges (thirteen bridges in total) have been used in this study; In the first set, designed simply supported single span bridges consisting of five steel girder bridges and five prestressed concrete bridges and in the second set, built bridges including two simply supported single span bridges and a multiple span bridge. The first set of bridges has been designed based on AASHTO LRFD Design Specifications [7].

\section{Steel Bridge Model}

Five single span steel girder bridges with the lengths of 30',60', 90', 120' and 140' have been selected and designed in accordance with the AASHTO LRFD Design Specifications [7]. These designed bridge models have been verified with the real bridges based on the first natural frequency results. This comparison is shown in chapter IV. The typical cross section of the bridges can be seen in Figure 7. The floor plans can be seen in Figure 8 and Figure 9. The results of the design which include the girder sections, diaphragm sections and diaphragm spacings can be found in Table 9. It was observed that the moment in the exterior girder in most of the cases has been the controlling factor of the design. 
Table 9. Steel Bridge Design Results

\begin{tabular}{|c|c|c|c|c|c|c|c|c|}
\hline $\begin{array}{l}\text { Girder } \\
\text { Section }\end{array}$ & $\begin{array}{l}\text { Diaphragm } \\
\text { Section }\end{array}$ & $\begin{array}{l}\text { Diaphragm } \\
\text { Spacing (ft) }\end{array}$ & $\begin{array}{l}\text { Span } \\
\text { Length } \\
\text { (ft) }\end{array}$ & Girder & $\begin{array}{c}\mathrm{M}_{\mathrm{n}} \\
\text { (kip-ft) }\end{array}$ & $\begin{array}{c}\mathrm{M}_{\mathrm{u}} \\
\text { (kip-ft) }\end{array}$ & $\begin{array}{c}V_{n} \\
\text { (kip-ft) }\end{array}$ & $\begin{array}{c}V_{u} \\
\text { (kip-ft) }\end{array}$ \\
\hline \multirow{2}{*}{ W16X57 } & \multirow{2}{*}{ W10X30 } & \multirow{2}{*}{15} & \multirow{2}{*}{30} & Interior & 901 & 770 & 187 & 134 \\
\hline & & & & Exterior & 901 & 870 & 187 & 127 \\
\hline \multirow{2}{*}{ W24X146 } & \multirow{2}{*}{ W16X77 } & \multirow{2}{*}{20} & \multirow{2}{*}{60} & Interior & 2664 & 2326 & 425 & 199 \\
\hline & & & & Exterior & 2664 & 2660 & 425 & 190 \\
\hline \multirow{2}{*}{ W30X292 } & \multirow{2}{*}{ W21X101 } & \multirow{2}{*}{30} & \multirow{2}{*}{90} & Interior & 5763 & 4725 & 837 & 257 \\
\hline & & & & Exterior & 5763 & 5345 & 837 & 246 \\
\hline \multirow{2}{*}{ W40X372 } & \multirow{2}{*}{ W24X131 } & \multirow{2}{*}{30} & \multirow{2}{*}{120} & Interior & 8964 & 7792 & 1228 & 311 \\
\hline & & & & Exterior & 8964 & 8793 & 1228 & 300 \\
\hline \multirow{2}{*}{ W40X431 } & \multirow{2}{*}{ W24X131 } & \multirow{2}{*}{35} & \multirow{2}{*}{140} & Interior & 13239 & 10220 & 1421 & 349 \\
\hline & & & & Exterior & 13239 & 11589 & 1421 & 337 \\
\hline
\end{tabular}

\section{Prestressed Concrete Bridge Model}

The design of the prestressed concrete bridges was done for five bridges with the span lengths of 30',60', 90', 120' and 140' and according to the specifications of the AASHTO LRFD Design Specifications [7]. The results are shown in Table 10. The cross sections of these bridges can be seen in Figure 10 and the floor plans are the same as the floor plans of the steel bridges which have been shown in Figure 8 and Figure 9.

Table 10. Prestressed Concrete Bridge Design Results

\begin{tabular}{|c|c|c|c|c|c|c|c|}
\hline $\begin{array}{c}\text { Girder } \\
\text { Section }\end{array}$ & $\begin{array}{c}\text { Diaphragm } \\
\text { Section }\end{array}$ & $\begin{array}{c}\text { Diaphragm } \\
\text { Spacing }\end{array}$ & $\begin{array}{c}\text { Span } \\
\text { Length (ft) }\end{array}$ & $\begin{array}{c}\text { No. of } \\
\text { Strands }\end{array}$ & $\begin{array}{c}\text { No. of } \\
\text { Harped } \\
\text { Strands }\end{array}$ & $\begin{array}{c}\text { Slab } \\
\text { Thickness }\end{array}$ & $\begin{array}{c}\text { Concrete } \\
f^{\prime}\end{array}$ \\
\hline III & W10X30 & 15 & 30 & 12 & 4 & 8 & 5000 \\
\hline III & W16X77 & 20 & 60 & 18 & 4 & 8 & 5000 \\
\hline V & W21X101 & 30 & 90 & 30 & 6 & 8 & 5000 \\
\hline VI & W24X131 & 30 & 120 & 38 & 8 & 9 & 6000 \\
\hline VI & W24X131 & 35 & 140 & 56 & 10 & 9 & 6000 \\
\hline
\end{tabular}




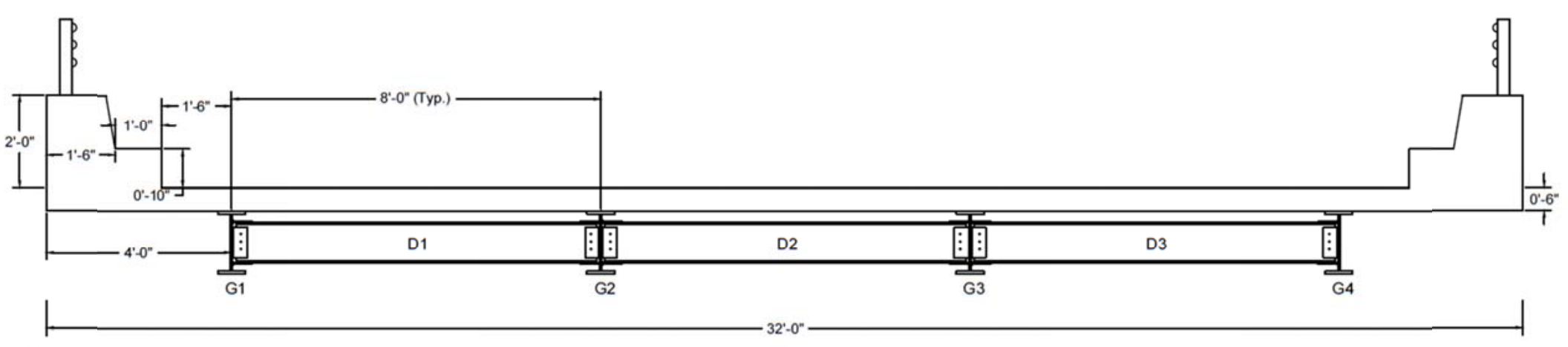

(a)

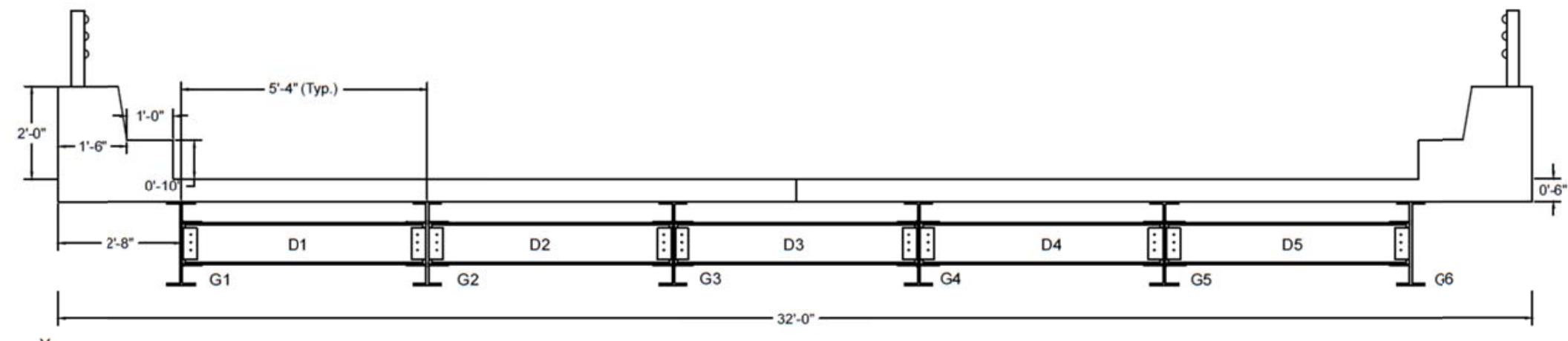

(b)

Figure 7. Steel Girder Bridge Typical Cross Section for (a) 30'-60'-90' (b) 120'-140' 

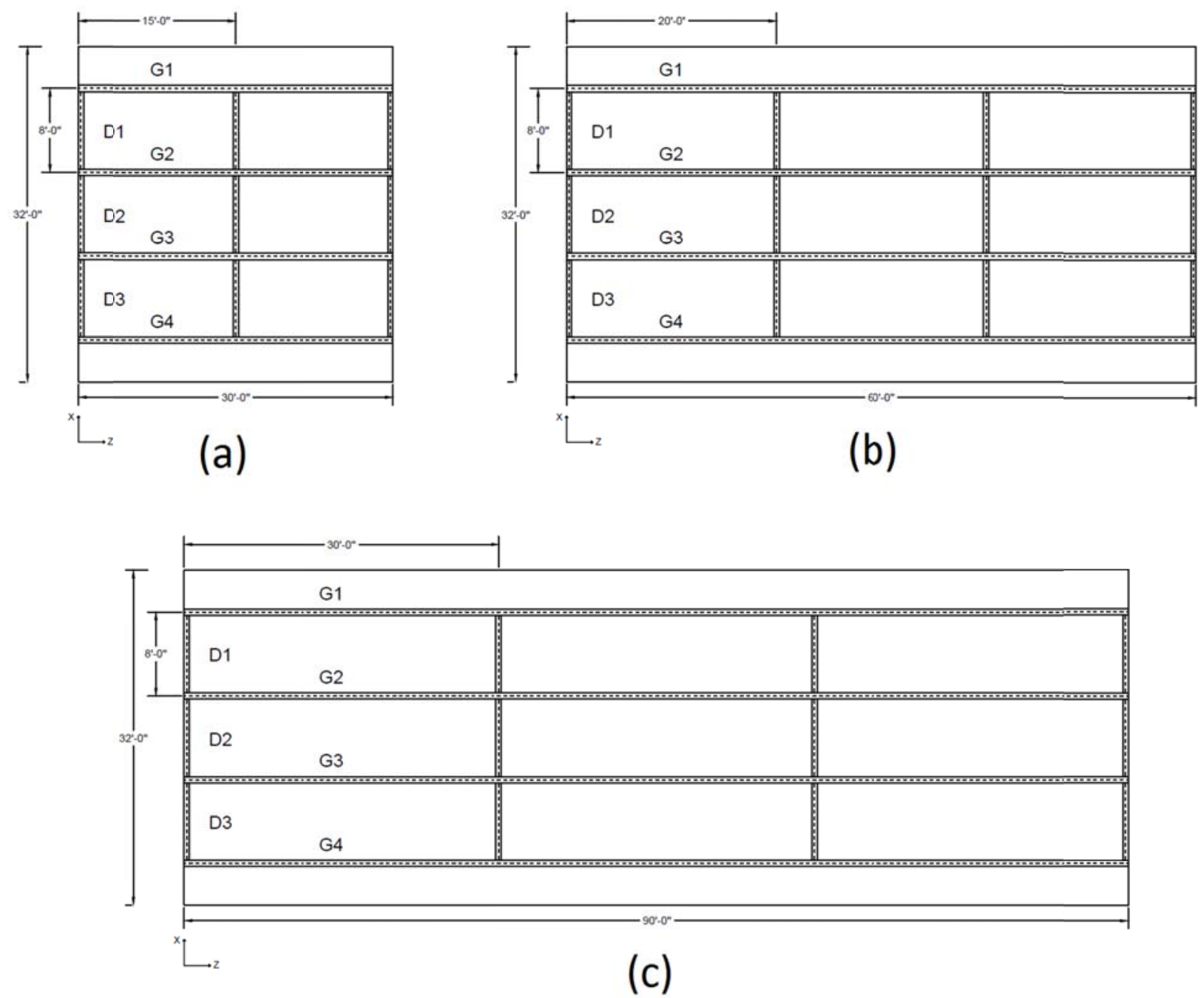

Figure 8. Steel Girder Bridge Plans for (a) 30' (b) 60' (c) 90' 


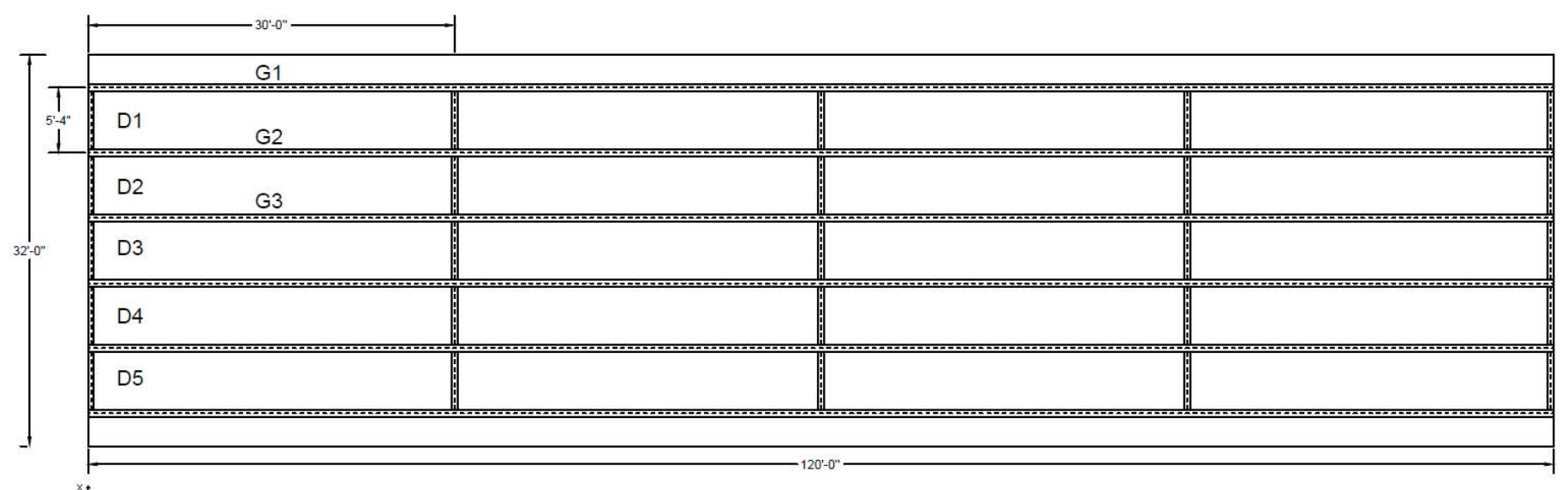

(a)

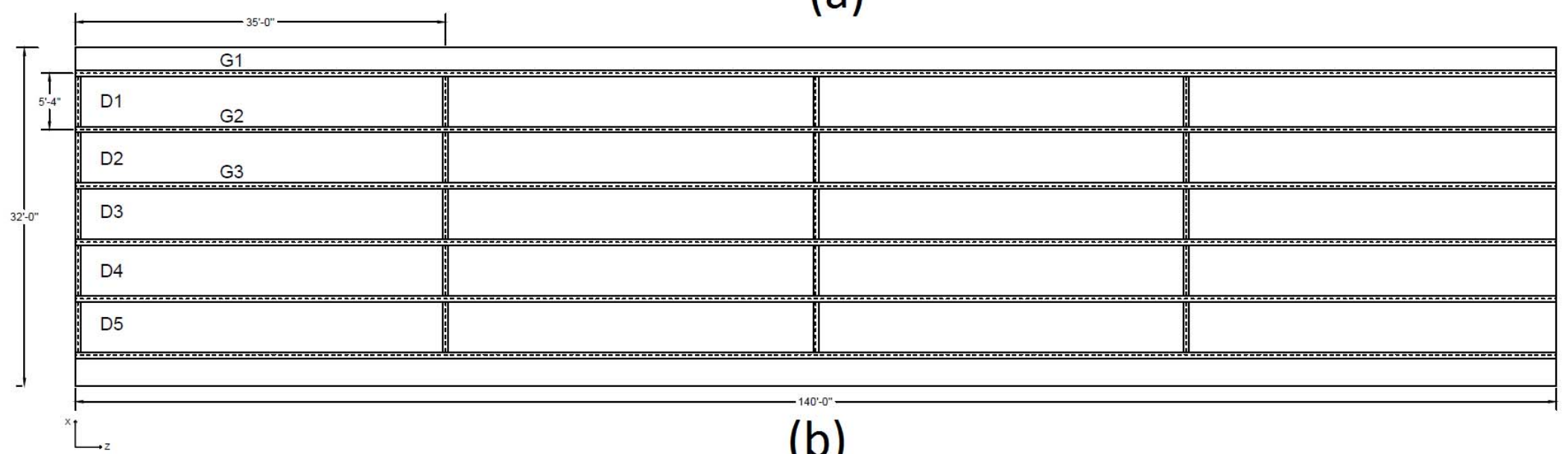

Figure 9. Steel Girder Bridge Plans for (a) 120' (b) 140 


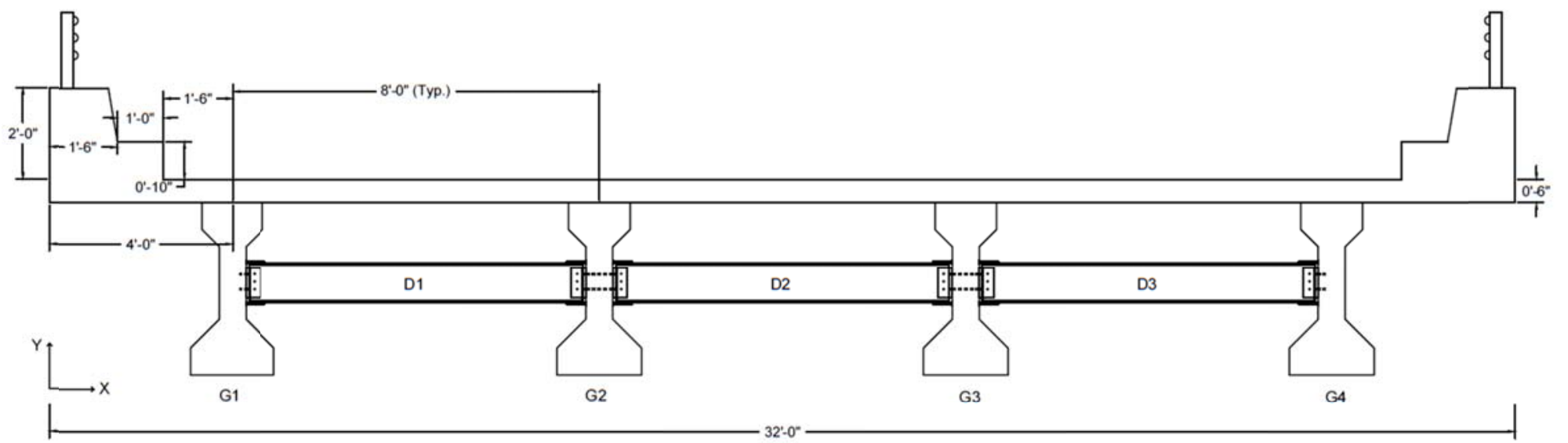

(a)

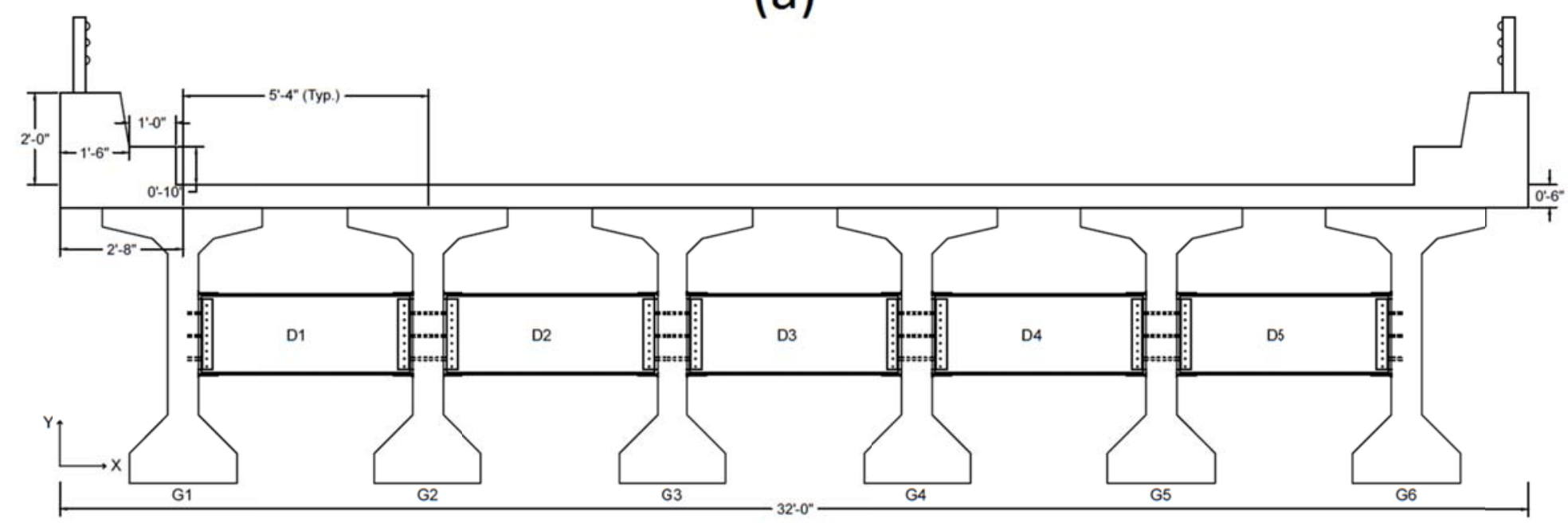

(b)

Figure 10. Prestressed Concrete Bridge Typical Cross Section for (a) 30'-60'-90' (b) 120'-140' 


\section{Bridge-Vehicle Interaction and Numerical Methods}

Designed bridges in the previous two sections are modeled as grillage beam systems. The grillage model (also called Grid Model) is a group of beam elements put together as one system. These elements are defined with two nodes as shown in Figure 11 and they are connected at their joints.

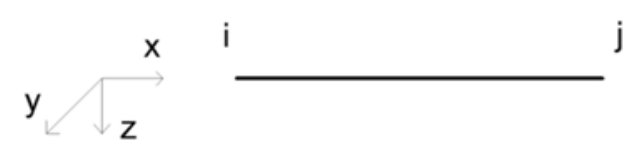

Figure 11. Grillage Element

The node parameters are:

$\delta^{\mathrm{e}}=\left\{\begin{array}{ll}\delta_{\mathrm{i}} & \delta_{\mathrm{j}}\end{array}\right\}^{\mathrm{T}}$

Where,

$\delta_{\mathrm{i}}=\left\{\begin{array}{lll}\mathrm{w}_{\mathrm{zi}} & \theta_{\mathrm{xi}} & \theta_{\mathrm{yi}}\end{array}\right\}^{\mathrm{T}}$ is the left joint displacement vector.

$\delta_{\mathrm{j}}=\left\{\begin{array}{lll}\mathrm{w}_{\mathrm{zj}} & \theta_{\mathrm{xj}} & \theta_{\mathrm{yj}}\end{array}\right\}^{\mathrm{T}}$ is the right joint displacement vector.

$\mathrm{w}_{\mathrm{z}}$ is the vertical displacement in the $\mathrm{z}$ direction.

$\theta_{\mathrm{x}}$ and $\theta_{\mathrm{y}}$ are the rotational displacements about the $\mathrm{x}$ and $\mathrm{y}$ direction, respectively.

Each beam element represents the moment of inertia and torsional stiffness of the girder and the deck above the girder and these elements are usually chosen in a way that they coincide with the girders. The starting and the ending elements are restrained by hinged supports at each node. Since the axial component of the elements or the force along the $\mathrm{x}$-axis is not usually modeled in the grillage model, using hinged or roller supports would not make any difference. The transverse elements are modeled in a manner to represent 
the flexural and torsional behavior of the concrete deck in the transverse direction but at the place of the diaphragms, these elements also include the properties of the diaphragm section in addition to the concrete deck. As for the spacing of the transverse elements, they should be around 1.5 to 2 times the distance between the longitudinal members.

Matrix structural analysis method has been used here to model the bridge system. First, the local mass and stiffness matrices of each element are formed and then these matrices are assembled together using the transfer matrices to form the global stiffness and mass matrices. Then the force matrix will be formed based on the degree of freedom in which the load is being applied to and finally the displacements, moments and stresses at each node can be calculated. The deflection of the bridge due to the dead load weight of the bridge is shown in Figure 12 for the case of $60 \mathrm{ft}$. concrete bridge,

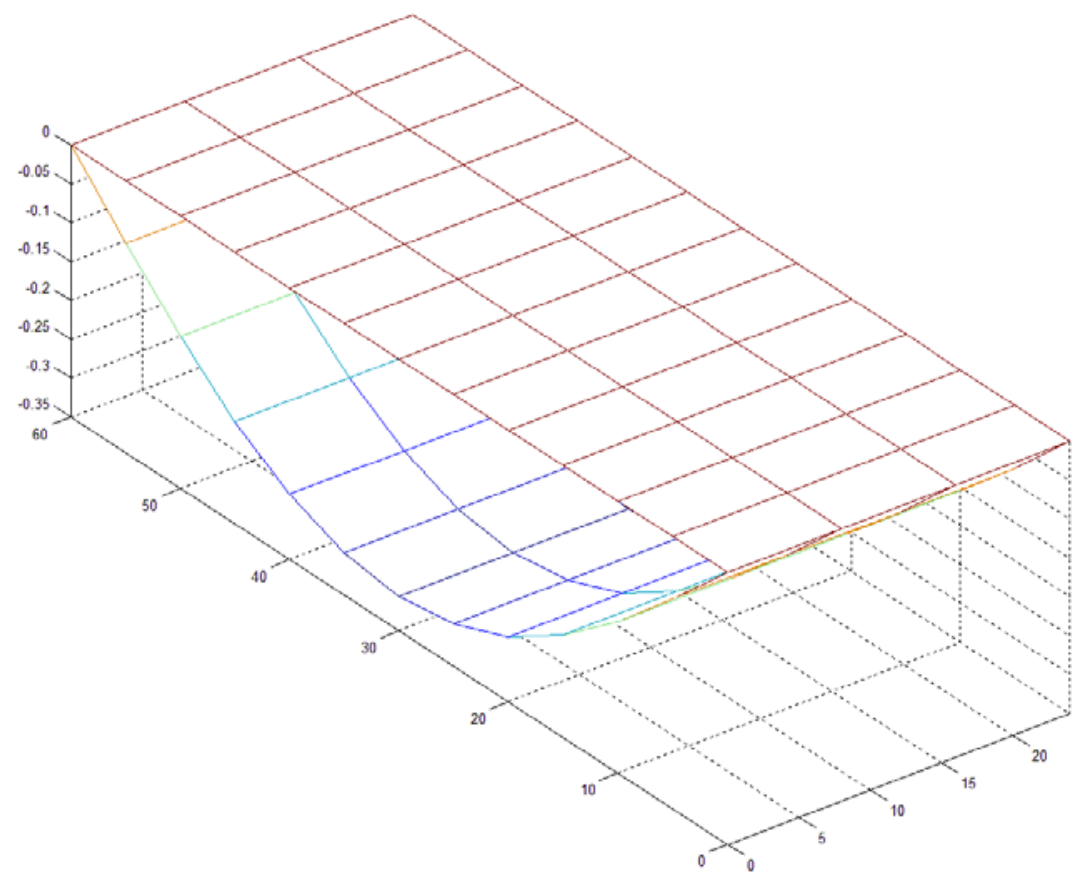

Figure 12. Deflection Due to Dead Load for $60 \mathrm{ft}$. Steel Girder Bridge 
For the dynamic analysis of the bridge, damping matrix for the bridge needs to be determined. Rayleigh Damping [38] has been used in this research, to model the damping behavior of the bridge. In this type of damping, the damping matrix can be obtained from the mass matrix or the stiffness matrix. It can also be found using the combination of the stiffness and the mass matrices which is shown in equation ( 85 ),

$[C]=\alpha[M]+\beta[K]$

$\alpha$ and $\beta$ can be calculated using the frequency values of two selected modes,

$\alpha=\frac{2 \xi w_{i} w_{j}}{w_{i}+w_{j}}$

$\beta=\frac{2 \xi}{w_{i}+w_{j}}$

$2-5 \%$ of damping is generally used [39] and here, fixed value of $5 \%$ damping [40] has been selected for the bridge and the frequencies of the first two modes have been used to find the damping matrix. The equation of motion for bridge-vehicle system is:

$\left[\mathrm{M}_{\mathrm{b}}\right]\{\ddot{\delta}\}+\left[\mathrm{C}_{\mathrm{b}}\right]\{\dot{\delta}\}+\left[\mathrm{K}_{\mathrm{b}}\right]\{\delta\}=\mathrm{F}_{\mathrm{b}}$

Where,

$M_{b}$ is the global mass matrix of the bridge.

$\mathrm{C}_{\mathrm{b}}$ is the global damping matrix of the bridge.

$\mathrm{K}_{\mathrm{b}}$ is the global stiffness matrix of the bridge.

$\delta$ is the nodal displacement.

And $\mathrm{F}_{\mathrm{b}}$ is the global load vector due to the bridge-vehicle interaction. This interaction force can be calculated using equation ( 89 ). 
$\mathrm{F}_{\mathrm{bt}}^{\mathrm{i}}=\mathrm{K}_{\mathrm{tzi}} \mathrm{U}_{\mathrm{tzi}}+\mathrm{C}_{\mathrm{tzi}} \dot{\mathrm{U}}_{\mathrm{tzi}}$

Where,

$\mathrm{F}_{\mathrm{bt}}^{\mathrm{i}}$ is the force between the $\mathrm{i}^{\text {th }}$ wheel and the bridge.

$\mathrm{K}_{\mathrm{tzi}}$ is the tire stiffness of the $\mathrm{i}^{\text {th }}$ wheel.

$\mathrm{C}_{\mathrm{tzi}}$ is the tire damping of the $\mathrm{i}^{\text {th }}$ wheel.

$\dot{\mathrm{U}}_{\mathrm{tzi}}$ is the relative velocity between the bridge and the $\mathrm{i}^{\text {th }}$ wheel.

$\mathrm{U}_{\mathrm{tzi}}=\mathrm{z}_{\mathrm{wi}}-\left(-\mathrm{u}_{\mathrm{sri}}\right)-\left(-\mathrm{z}_{\mathrm{bi}}\right)$ is the relative displacement of the bridge and the $\mathrm{i}^{\text {th }}$ wheel.

$z_{w i}$ is the vertical displacement of the $i^{\text {th }}$ wheel.

$\mathrm{u}_{\text {sri }}$ is the road surface roughness under the $\mathrm{i}^{\text {th }}$ wheel. (Positive upwards)

And $z_{\mathrm{bi}}$ is the bridge vertical displacement under the $\mathrm{i}^{\text {th }}$ wheel. (Positive upwards)

Numerical methods need to be used to solve the equations of motion given in equation ( 88 ). Fourth order Runge-Kutta (with 0.00025 second integration time step) has been used to solve the equations of motion for the trucks at each time step to get the tire forces. Then the tire forces have been used as the forcing vector in equation ( 88 ). Now the equation ( 88 ), which is a coupled system of second degree differential equations, needs to be solved. The number of equations in this system is equal to the number of the degrees of freedom of the bridge grid model. These equations can be solved using the ODE Solver in MATLAB and the results would be the deflection, velocity and acceleration of the bridge for each degree of freedom. In the next step, the new state of the bridge will be imposed on the vehicle which changes the initial values for solving the equations of motion of the vehicle. These equations will be solved using the new initial 
state and the results for the tire forces will be applied to the bridge in the next step. This cycle of interaction between the bridge and the vehicle will be continued until the vehicle passes the bridge and at that time the bridge starts to vibrate and the damping of the bridge will eventually stop the bridge movement.

Modal analysis of the bridge models was performed using the eig command in MATLAB and the first six frequencies of the bridges were calculated. This command finds the eigenvalues and eigenvectors of an eignvalue problem. The results have been shown in Table 11. It can be observed from this table that the prestressed concrete bridges have higher frequencies comparing to the steel bridges which shows the higher stiffness to mass ratio in these bridges. All the mode shapes can be seen in Figure 13 to Figure 22.

Table 11. Bridge Models Frequencies

\begin{tabular}{|c|c|c|c|c|c|}
\hline \multirow{2}{*}{$\begin{array}{c}\text { Mode } \\
\text { Number }\end{array}$} & \multicolumn{5}{|c|}{ Span Length [ft] } \\
\cline { 2 - 6 } & 30 & 60 & 90 & 120 & 140 \\
\hline $1^{\text {st }}$ & 8.81 & 4.24 & 3.17 & 2.52 & 2.31 \\
\hline $2^{\text {nd }}$ & 9.03 & 4.34 & 3.21 & 2.52 & 2.33 \\
\hline $3^{\text {rd }}$ & 11.87 & 9.55 & 9.05 & 8.25 & 4.51 \\
\hline $4^{\text {th }}$ & 22.85 & 17.39 & 12.81 & 10.00 & 9.11 \\
\hline $5^{\text {th }}$ & 38.95 & 17.46 & 12.87 & 10.17 & 9.28 \\
\hline $6^{\text {th }}$ & 39.10 & 19.38 & 15.03 & 12.30 & 9.38 \\
\hline \multirow{5}{*}{ Prestressed Concrete Bridge } \\
\hline Mode $^{\text {Number }}$ & \multicolumn{5}{|c|}{ Span Length [ft] } \\
\hline & 30 & 60 & 90 & 120 & 140 \\
\hline $1^{\text {st }}$ & 14.76 & 6.35 & 4.07 & 2.77 & 2.05 \\
\hline $2^{\text {nd }}$ & 15.16 & 6.64 & 4.31 & 3.03 & 2.32 \\
\hline $3^{\text {rd }}$ & 17.18 & 9.11 & 6.74 & 5.86 & 5.13 \\
\hline $4^{\text {th }}$ & 24.22 & 16.93 & 13.29 & 11.20 & 8.23 \\
\hline $5^{\text {th }}$ & 61.30 & 26.04 & 16.47 & 11.21 & 8.33 \\
\hline $6^{\text {th }}$ & 63.56 & 26.10 & 16.55 & 12.09 & 9.53 \\
\hline & \multicolumn{5}{|c}{} \\
\hline
\end{tabular}




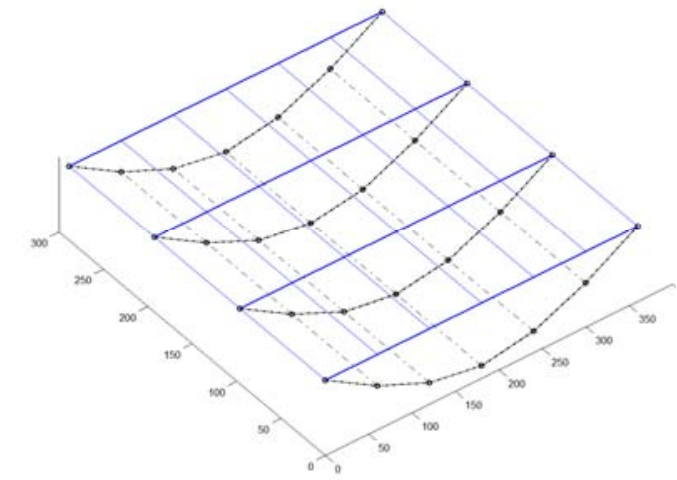

(a) $1^{\text {st }}$ Mode $\left(\mathrm{f}_{1}=8.81 \mathrm{~Hz}\right)$

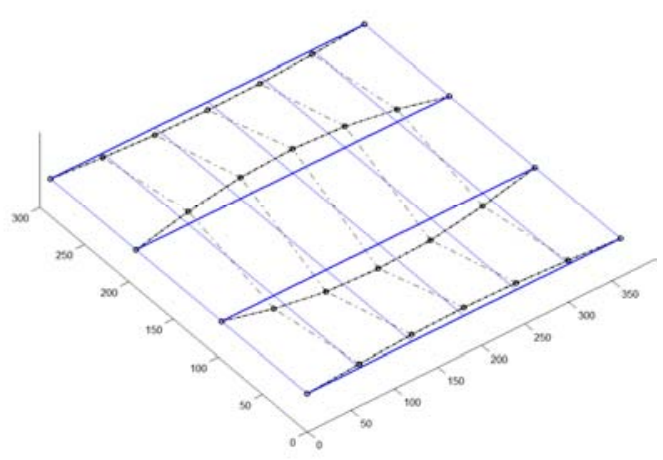

(d) $4^{\text {th }}$ Mode $\left(f_{4}=22.85 \mathrm{~Hz}\right)$

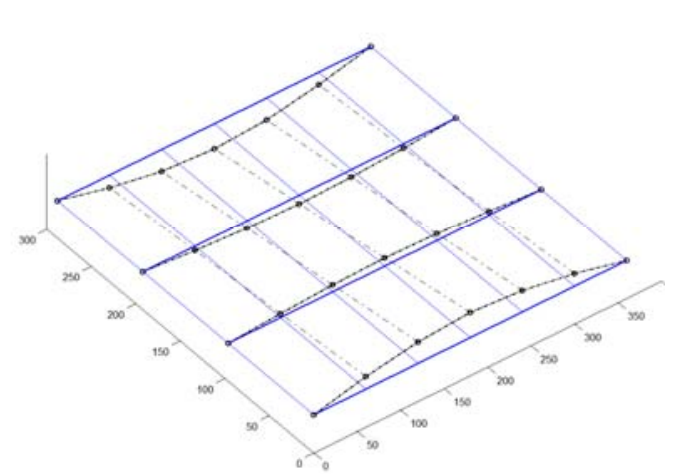

(b) $2^{\text {nd }}$ Mode $\left(f_{2}=9.03 \mathrm{~Hz}\right)$

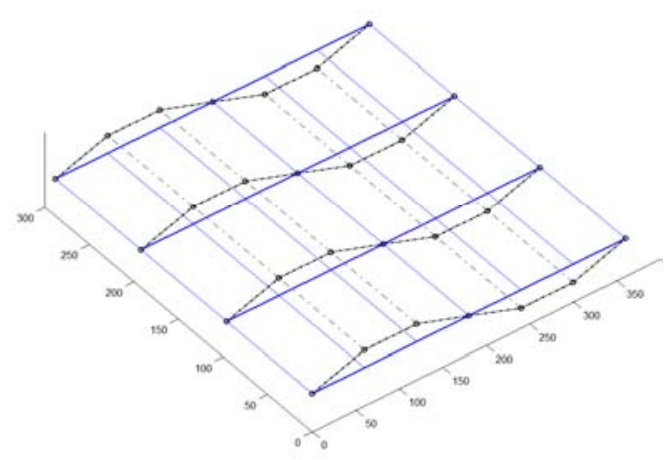

(e) $5^{\text {th }}$ Mode $\left(f_{5}=38.95 \mathrm{~Hz}\right)$

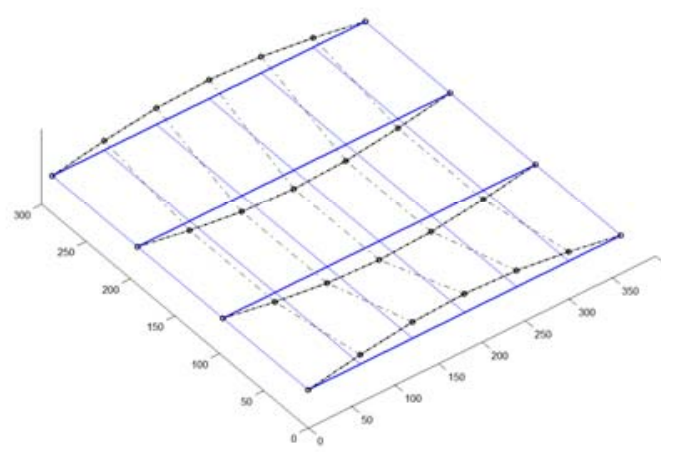

(c) $3^{\text {rd }}$ Mode $\left(f_{3}=11.87 \mathrm{~Hz}\right)$

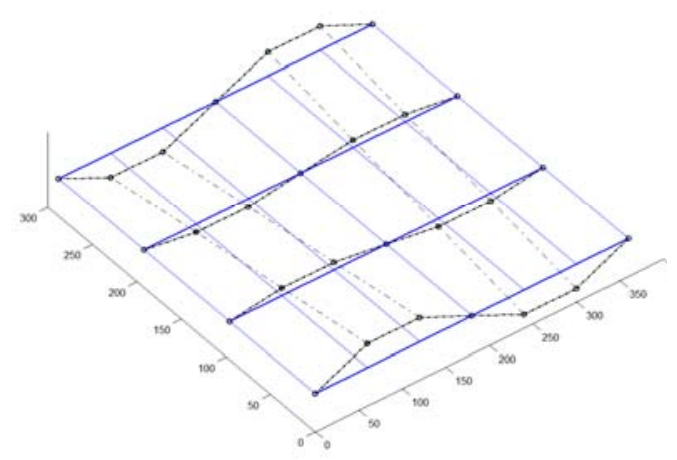

(f) $6^{\text {th }}$ Mode $\left(\mathrm{f}_{6}=39.10 \mathrm{~Hz}\right)$

Figure 13. Steel Bridge Mode Shapes (30’ Span) 


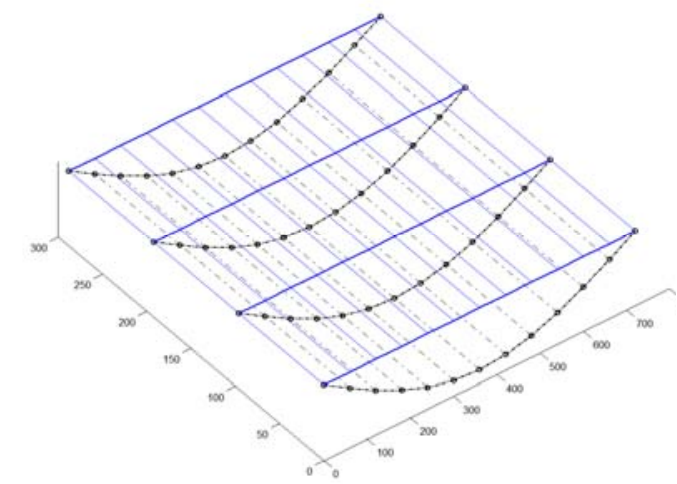

(a) $1^{\text {st }}$ Mode $\left(\mathrm{f}_{1}=4.24 \mathrm{~Hz}\right)$

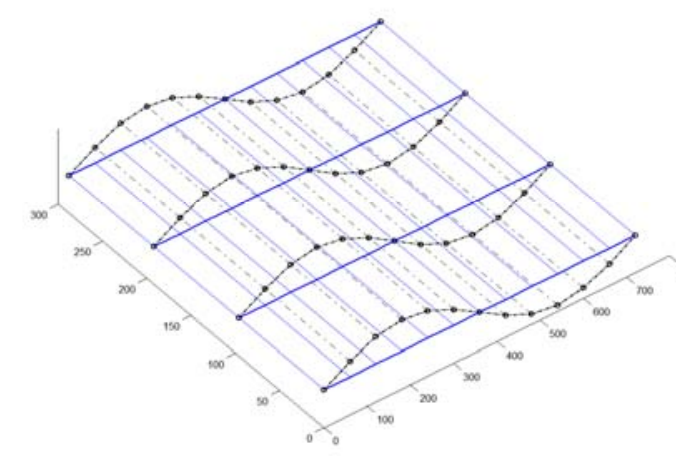

(d) $4^{\text {th }}$ Mode $\left(\mathrm{f}_{4}=17.39 \mathrm{~Hz}\right)$

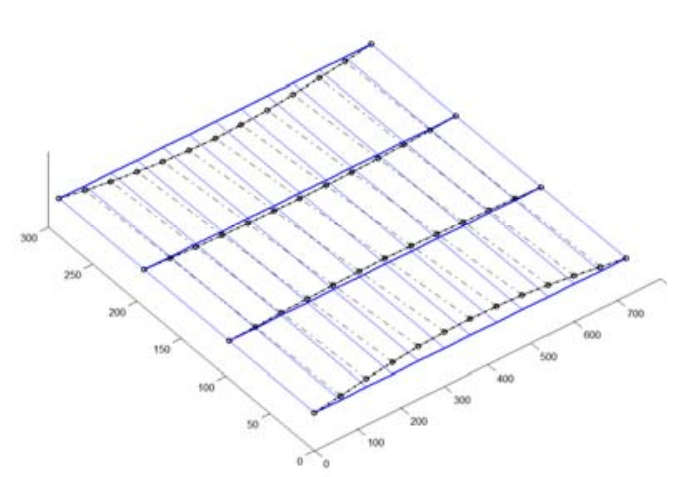

(b) $2^{\text {nd }}$ Mode $\left(\mathrm{f}_{2}=4.34 \mathrm{~Hz}\right)$

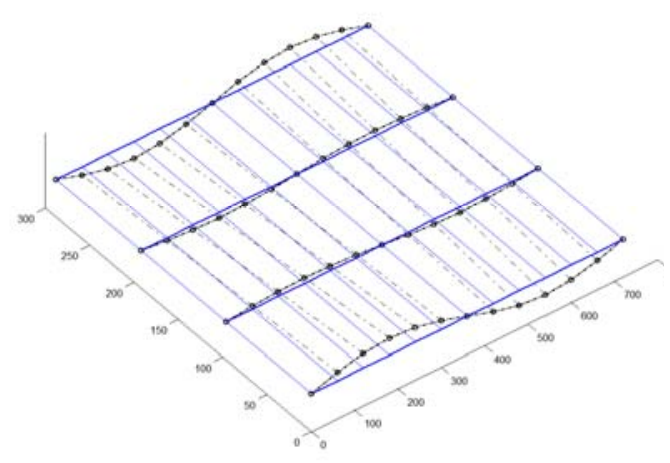

(e) $5^{\text {th }}$ Mode $\left(\mathrm{f}_{5}=17.46 \mathrm{~Hz}\right)$

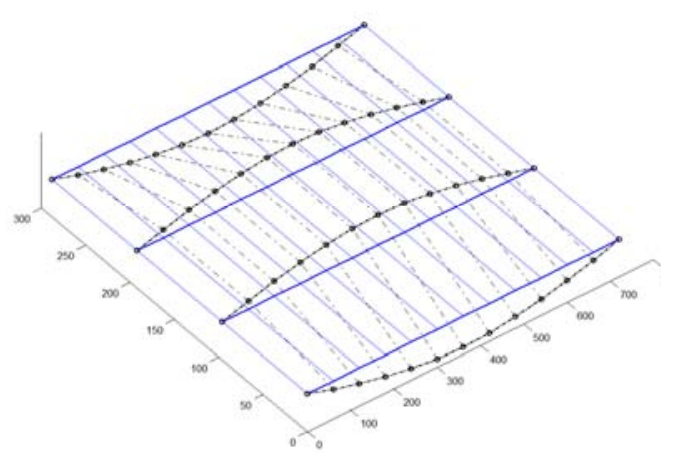

(c) $3^{\text {rd }}$ Mode $\left(\mathrm{f}_{3}=9.55 \mathrm{~Hz}\right)$

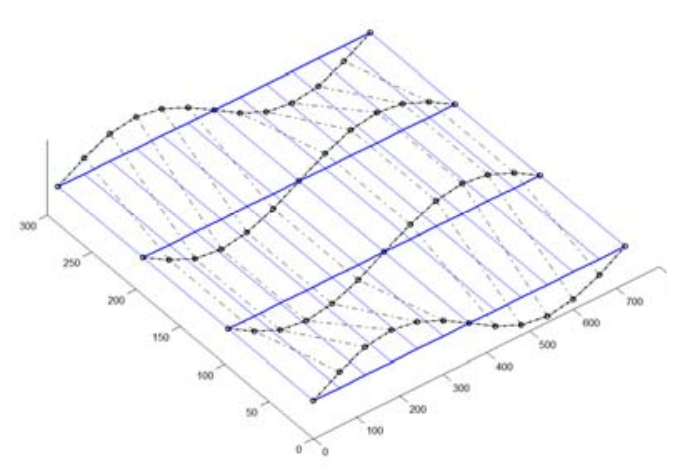

(f) $6^{\text {th }}$ Mode $\left(\mathrm{f}_{6}=19.38 \mathrm{~Hz}\right)$

Figure 14. Steel Bridge Mode Shapes (60' Span) 


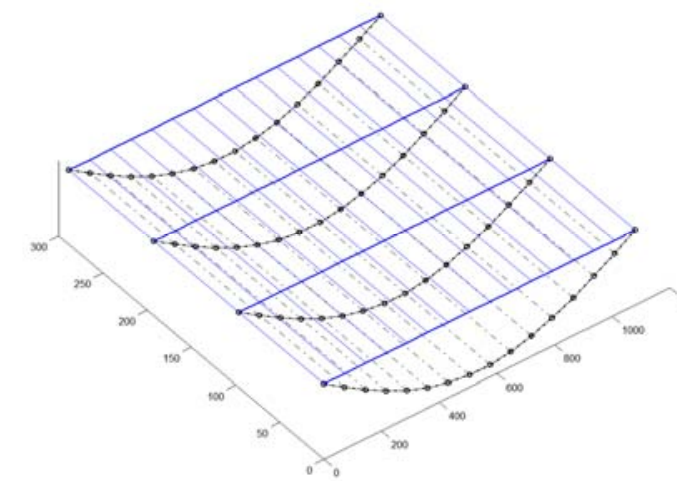

(a) $1^{\text {st }}$ Mode $\left(\mathrm{f}_{1}=3.17 \mathrm{~Hz}\right)$

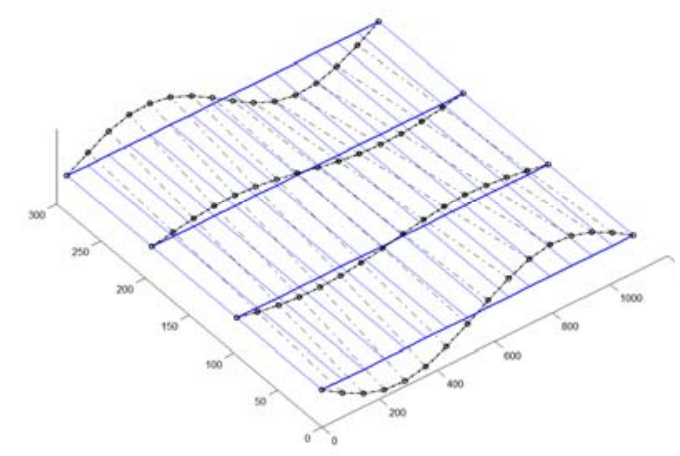

(d) $4^{\text {th }}$ Mode $\left(\mathrm{f}_{4}=12.81 \mathrm{~Hz}\right)$

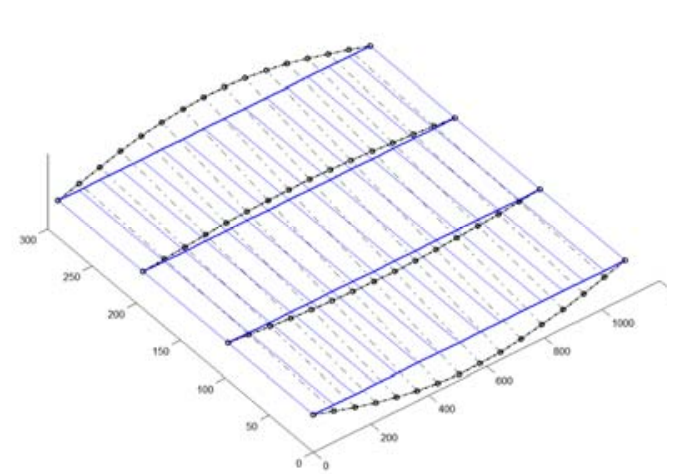

(b) $2^{\text {nd }}$ Mode $\left(\mathrm{f}_{2}=3.21 \mathrm{~Hz}\right)$

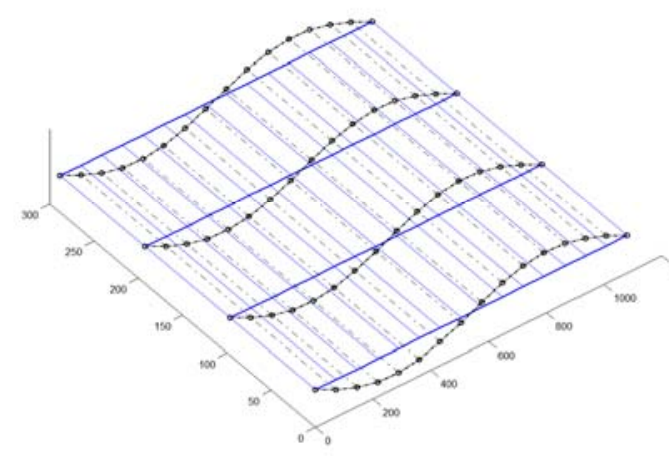

(e) $5^{\text {th }}$ Mode $\left(f_{5}=12.87 \mathrm{~Hz}\right)$

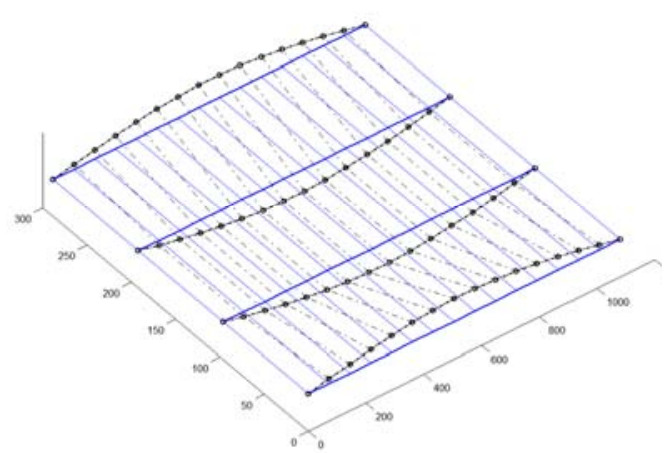

(c) $3^{\text {rd }}$ Mode $\left(f_{3}=9.05 \mathrm{~Hz}\right)$

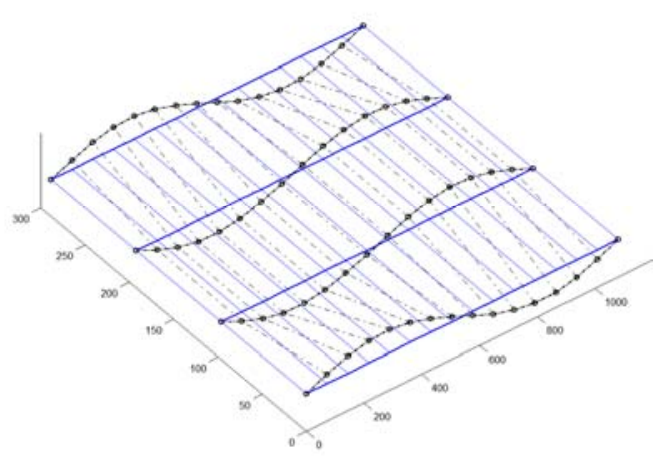

(f) $6^{\text {th }}$ Mode $\left(\mathrm{f}_{6}=15.03 \mathrm{~Hz}\right)$

Figure 15. Steel Bridge Mode Shapes (90’ Span) 


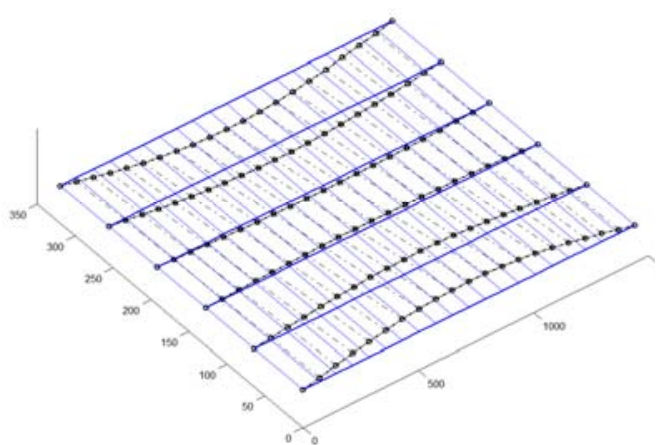

(a) $1^{\text {st }}$ Mode $\left(\mathrm{f}_{1}=2.52 \mathrm{~Hz}\right)$

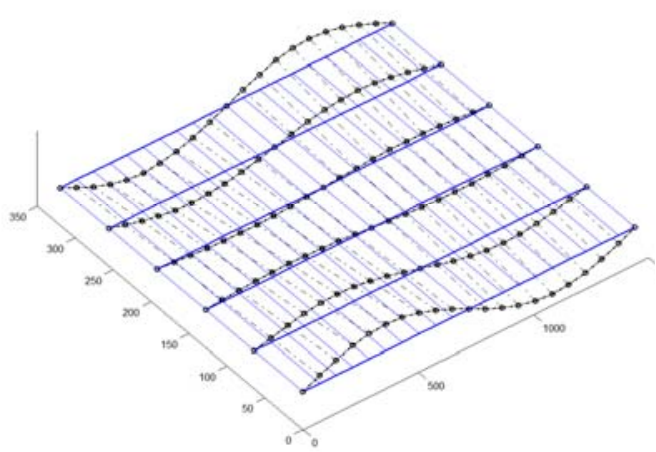

(d) $4^{\text {th }}$ Mode $\left(\mathrm{f}_{4}=10.00 \mathrm{~Hz}\right)$

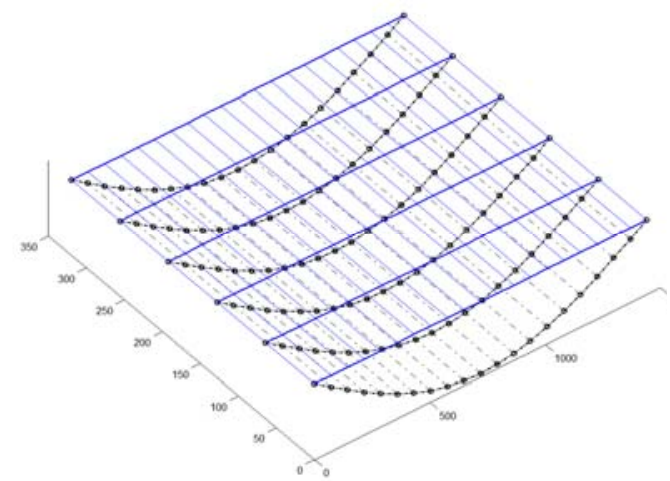

(b) $2^{\text {nd }}$ Mode $\left(\mathrm{f}_{2}=2.52 \mathrm{~Hz}\right)$

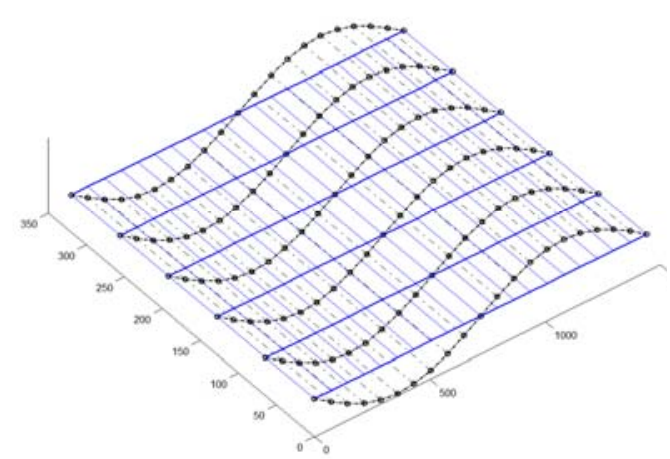

(e) $5^{\text {th }}$ Mode $\left(f_{5}=10.17 \mathrm{~Hz}\right)$

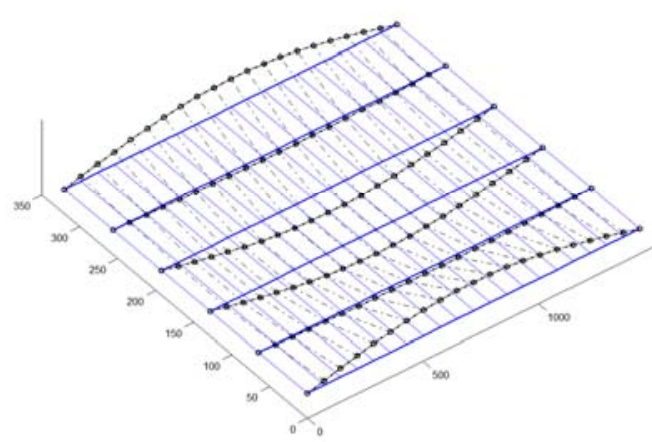

(c) $3^{\text {rd }}$ Mode $\left(\mathrm{f}_{3}=8.25 \mathrm{~Hz}\right)$

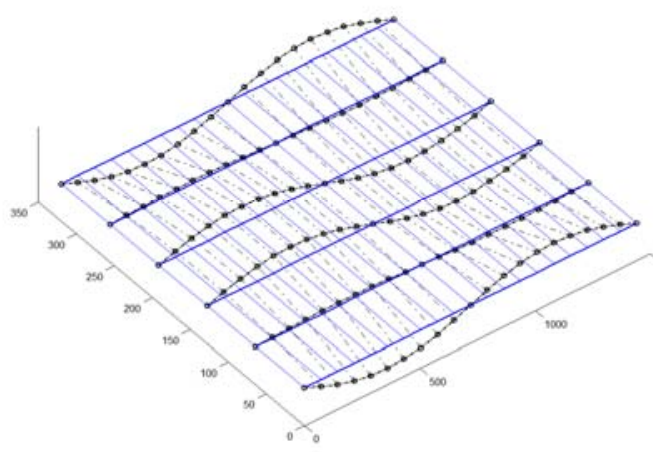

(f) $6^{\text {th }}$ Mode $\left(f_{6}=12.30 \mathrm{~Hz}\right)$

Figure 16. Steel Bridge Mode Shapes (120’ Span) 


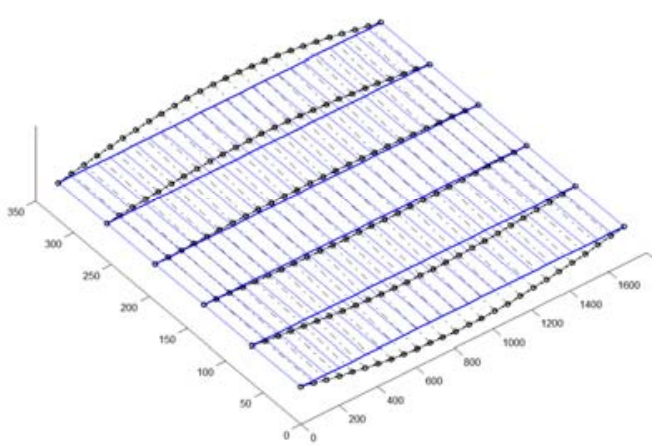

(a) $1^{\text {st }}$ Mode $\left(\mathrm{f}_{1}=2.31 \mathrm{~Hz}\right)$

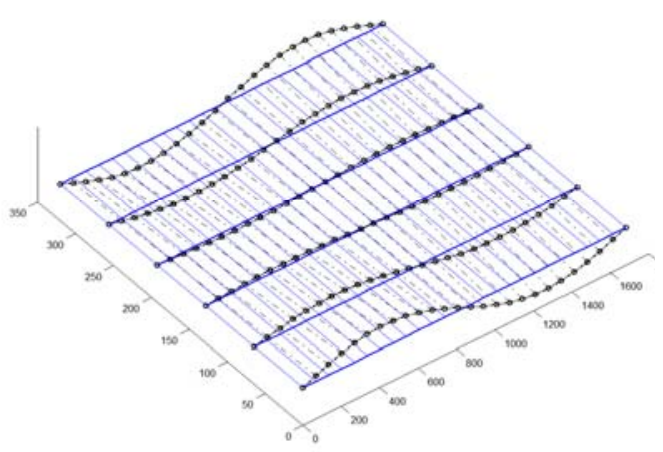

(d) $4{ }^{\text {th }}$ Mode $\left(f_{4}=9.11 \mathrm{~Hz}\right)$

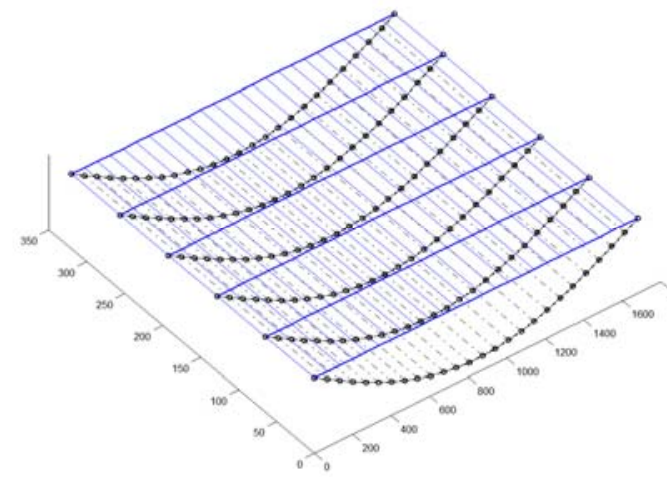

(b) $2^{\text {nd }}$ Mode $\left(\mathrm{f}_{2}=2.33 \mathrm{~Hz}\right)$

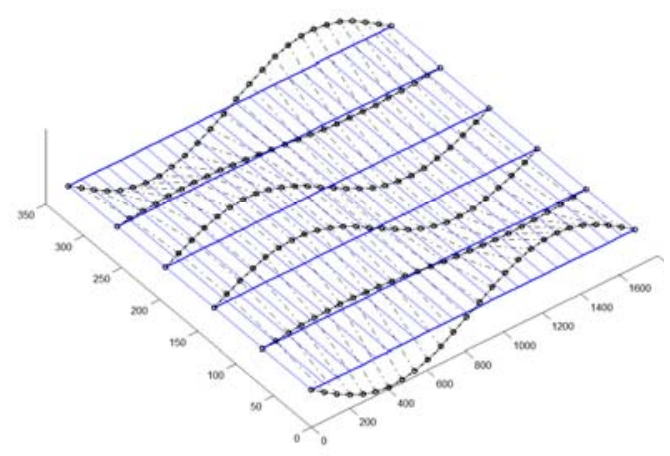

(e) $5^{\text {tn }}$ Mode $\left(f_{5}=9.28 \mathrm{~Hz}\right)$

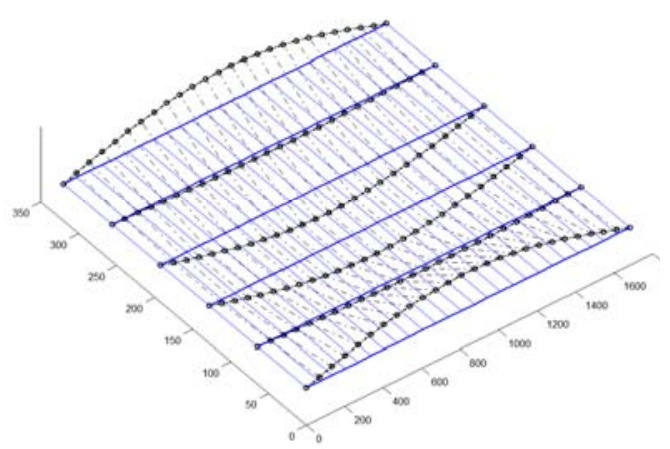

(c) $3^{\text {rd }}$ Mode $\left(\mathrm{f}_{3}=4.51 \mathrm{~Hz}\right)$

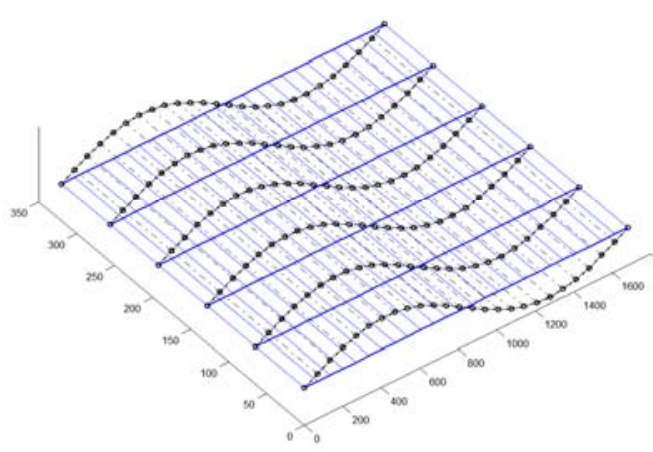

(f) $6^{\text {th }}$ Mode $\left(\mathrm{f}_{6}=9.38 \mathrm{~Hz}\right)$

Figure 17. Steel Bridge Mode Shapes (140’ Span) 


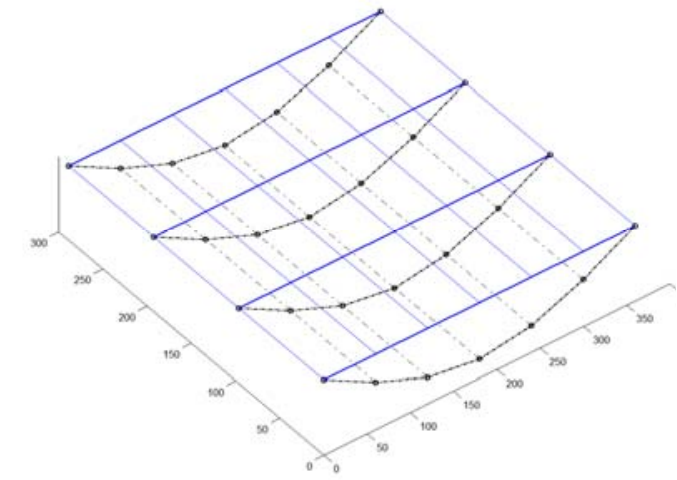

(a) $1^{\text {st }}$ Mode $\left(\mathrm{f}_{1}=14.76 \mathrm{~Hz}\right)$

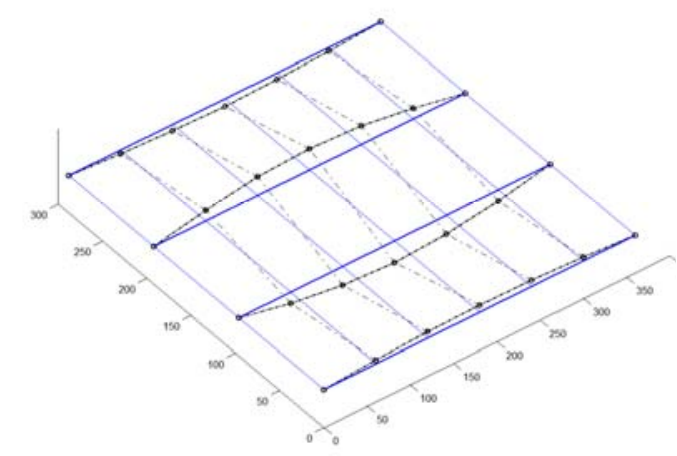

(d) $4^{\text {th }}$ Mode $\left(\mathrm{f}_{4}=24.22 \mathrm{~Hz}\right)$

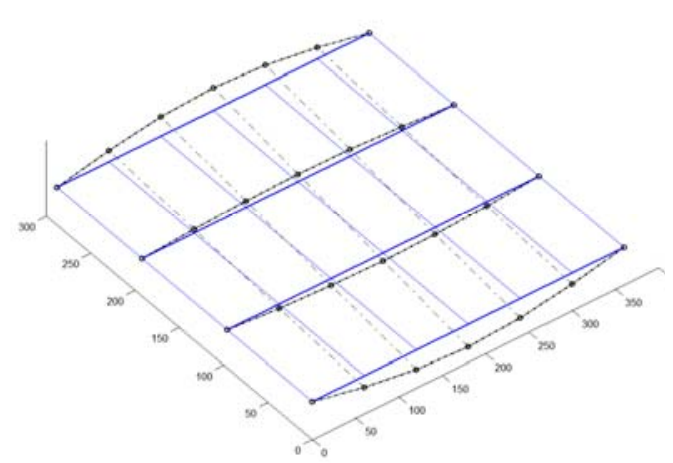

(b) $2^{\text {nd }}$ Mode $\left(f_{2}=15.16 \mathrm{~Hz}\right)$

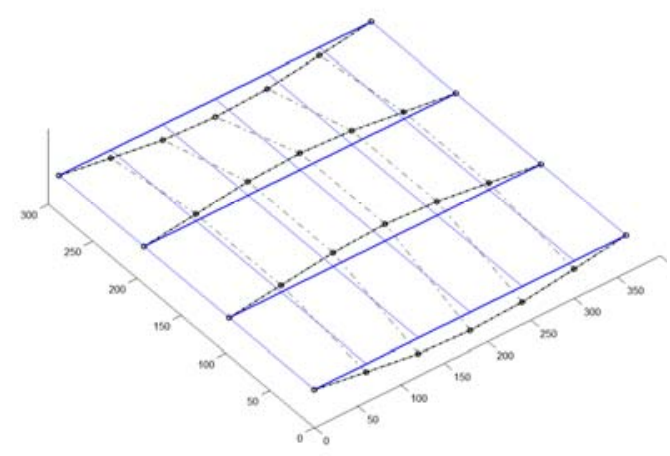

(e) $5^{\text {th }}$ Mode $\left(f_{5}=61.30 \mathrm{~Hz}\right)$

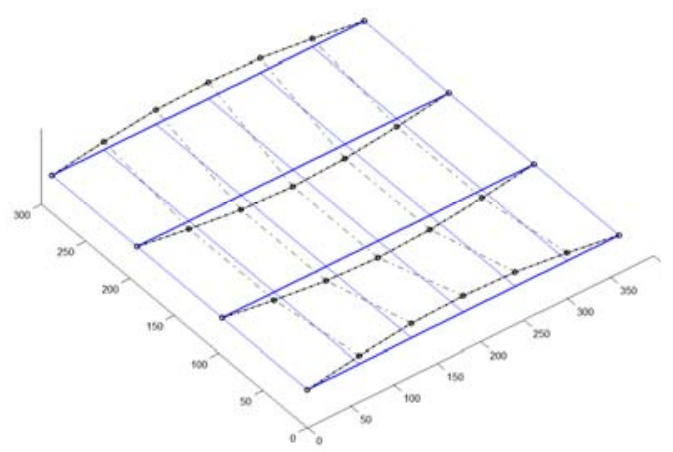

(c) $3^{\text {rd }}$ Mode $\left(f_{3}=17.18 \mathrm{~Hz}\right)$

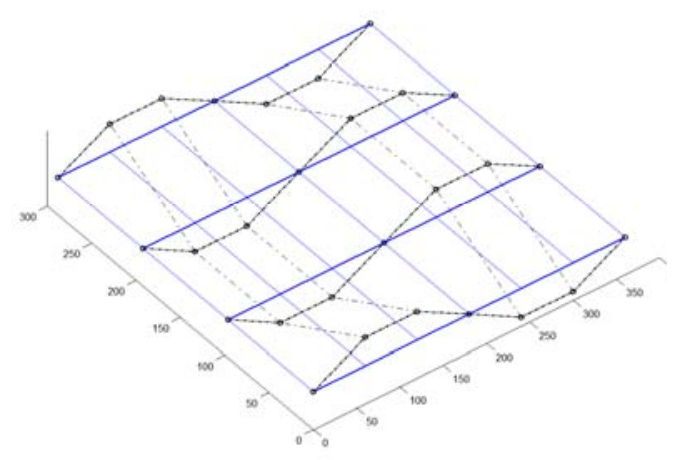

(f) $6^{\text {th }}$ Mode $\left(\mathrm{f}_{6}=63.56 \mathrm{~Hz}\right)$

Figure 18. Prestressed Concrete Bridge Mode Shapes (30’ Span) 


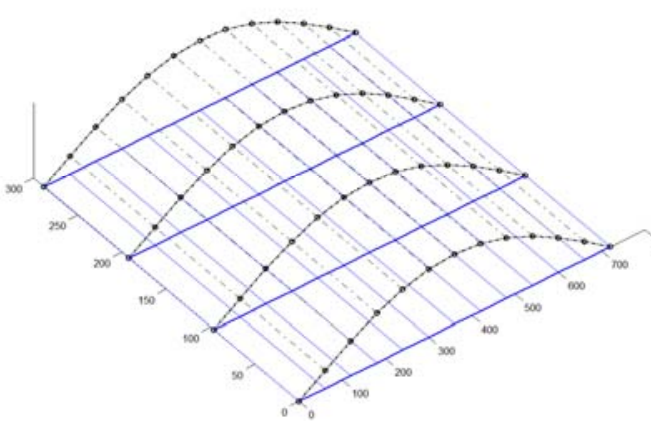

(a) $1^{\text {st }}$ Mode $\left(\mathrm{f}_{1}=6.35 \mathrm{~Hz}\right)$

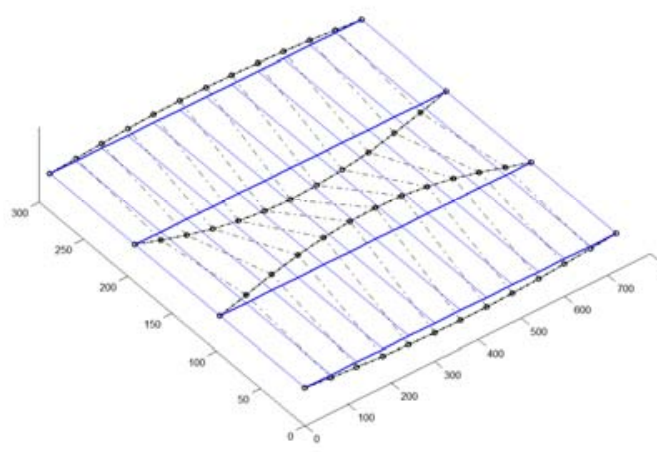

(d) $4^{\text {th }}$ Mode $\left(f_{4}=16.93 \mathrm{~Hz}\right)$

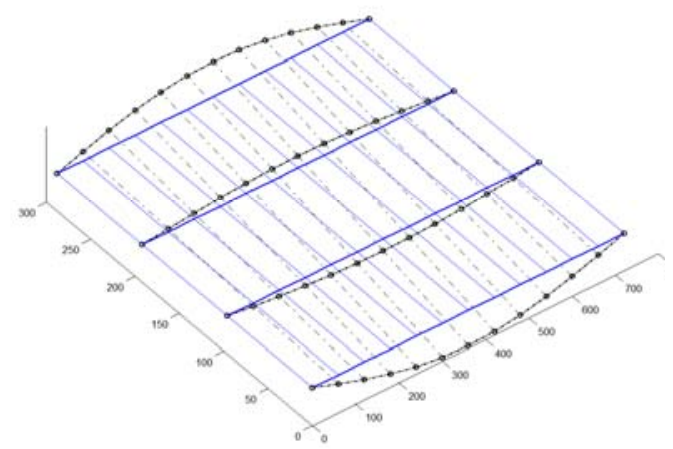

(b) $2^{\text {nd }}$ Mode $\left(\mathrm{f}_{2}=6.64 \mathrm{~Hz}\right)$

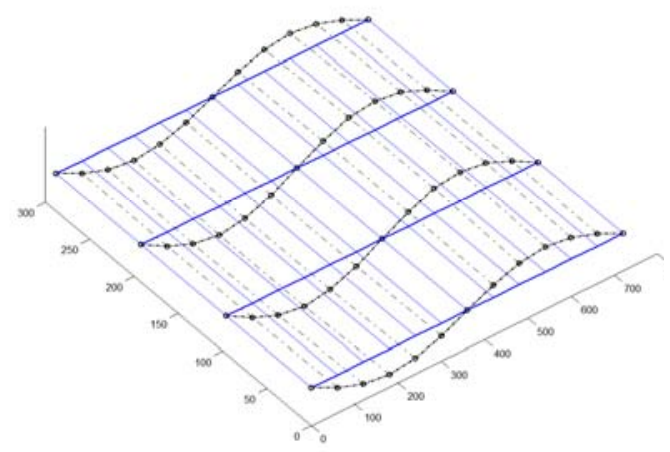

(e) $5^{\text {th }}$ Mode $\left(f_{5}=26.04 \mathrm{~Hz}\right)$

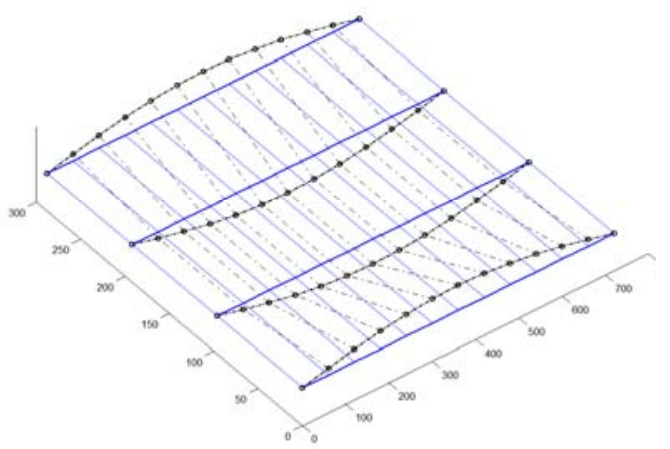

(c) $3^{\text {rd }}$ Mode $\left(f_{3}=9.11 \mathrm{~Hz}\right)$

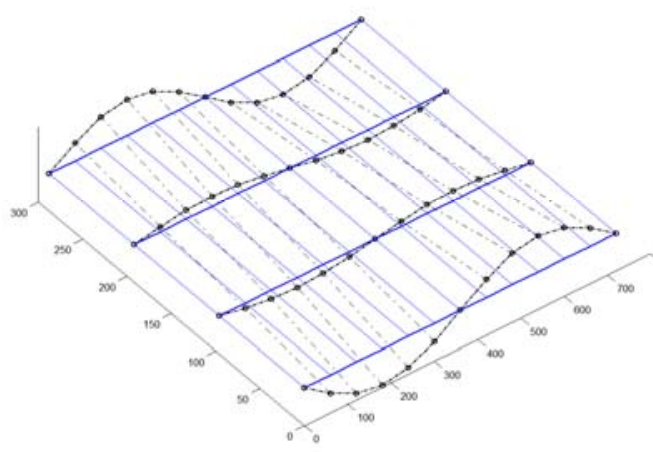

(f) $6^{\text {th }}$ Mode $\left(\mathrm{f}_{6}=26.10 \mathrm{~Hz}\right)$

Figure 19. Prestressed Concrete Bridge Mode Shapes (60’ Span) 


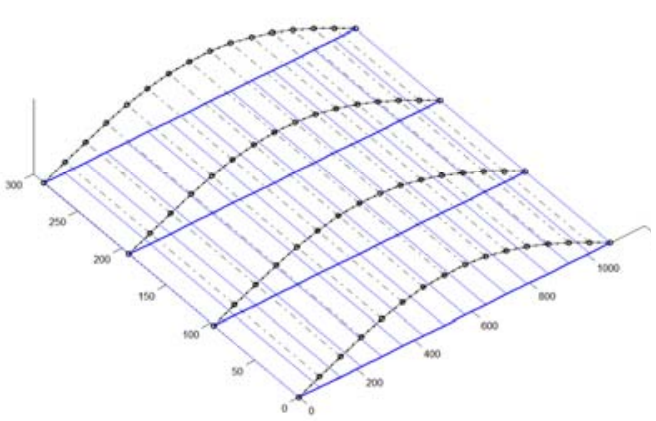

(a) $1^{\text {st }}$ Mode $\left(\mathrm{f}_{1}=4.07 \mathrm{~Hz}\right)$

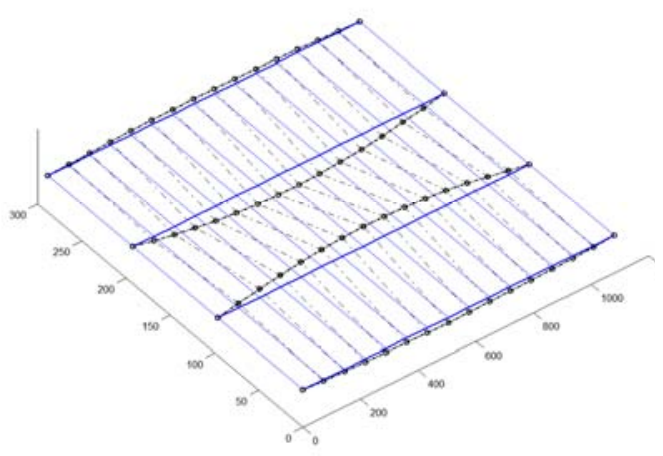

(d) $4^{\text {th }}$ Mode $\left(\mathrm{f}_{4}=13.29 \mathrm{~Hz}\right)$

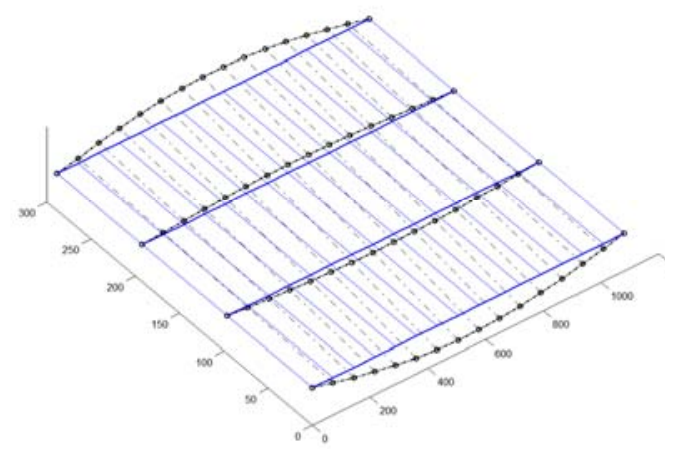

(b) $2^{\text {nd }}$ Mode $\left(\mathrm{f}_{2}=4.31 \mathrm{~Hz}\right)$

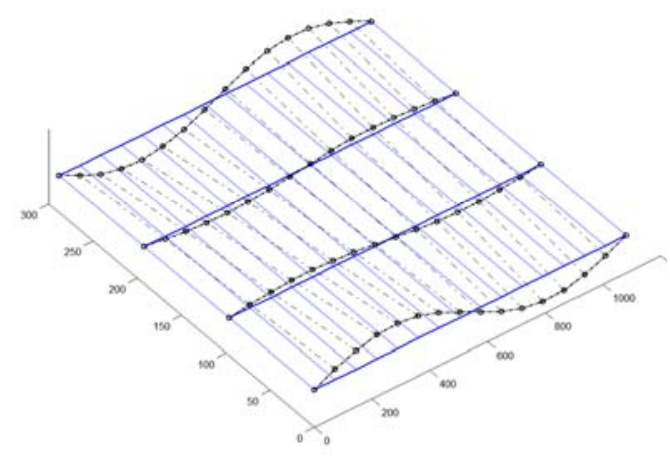

(e) $5^{\text {th }}$ Mode $\left(f_{5}=16.47 \mathrm{~Hz}\right)$

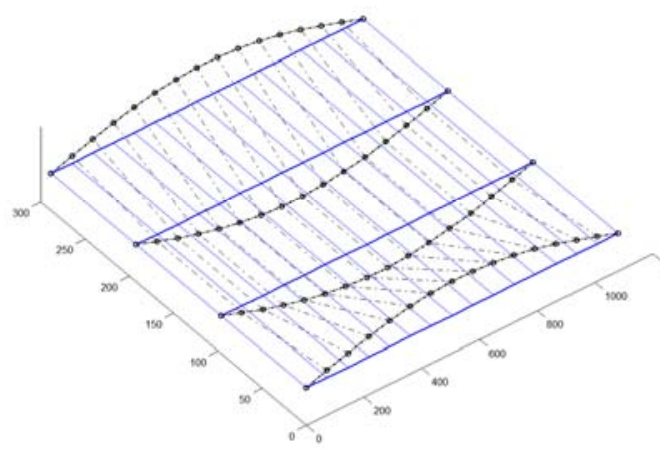

(c) $3^{\text {rd }}$ Mode $\left(\mathrm{f}_{3}=6.74 \mathrm{~Hz}\right)$

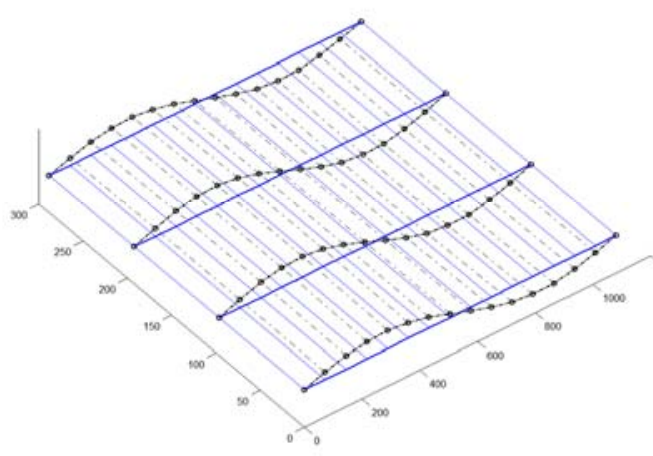

(f) $6^{\text {th }}$ Mode $\left(\mathrm{f}_{6}=16.55 \mathrm{~Hz}\right)$

Figure 20. Prestressed Concrete Bridge Mode Shapes (90’ Span) 


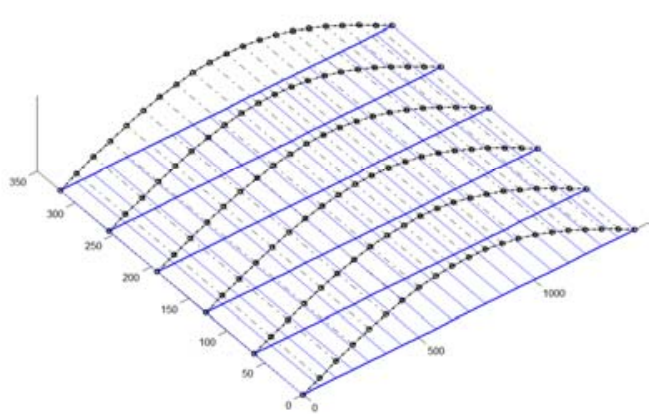

(a) $1^{\text {st }}$ Mode $\left(\mathrm{f}_{1}=2.77 \mathrm{~Hz}\right)$

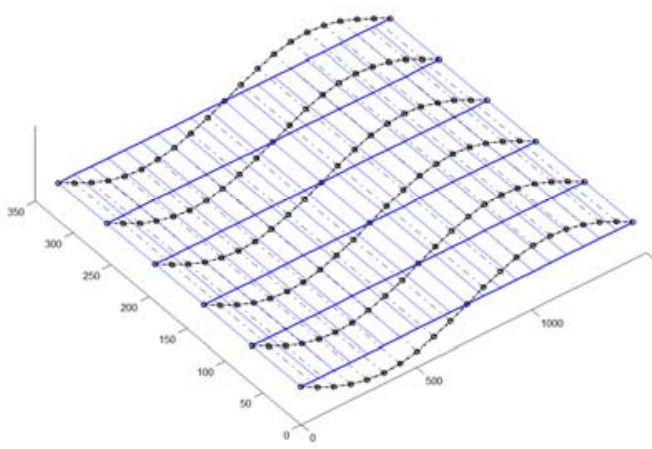

(d) $4^{\text {th }}$ Mode $\left(\mathrm{f}_{4}=11.20 \mathrm{~Hz}\right)$

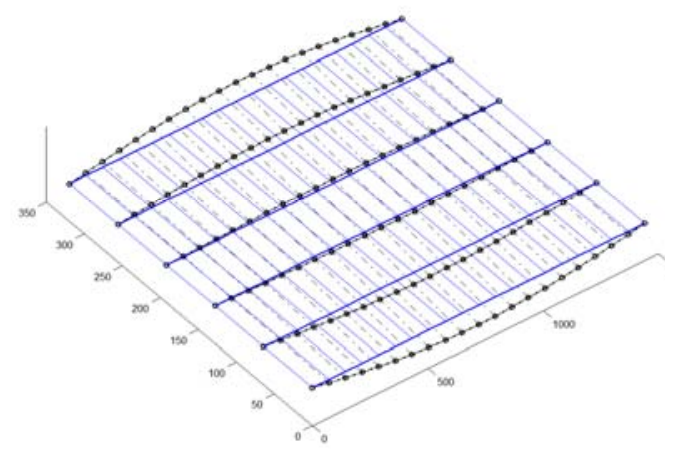

(b) $2^{\text {nd }}$ Mode $\left(f_{2}=3.03 \mathrm{~Hz}\right)$

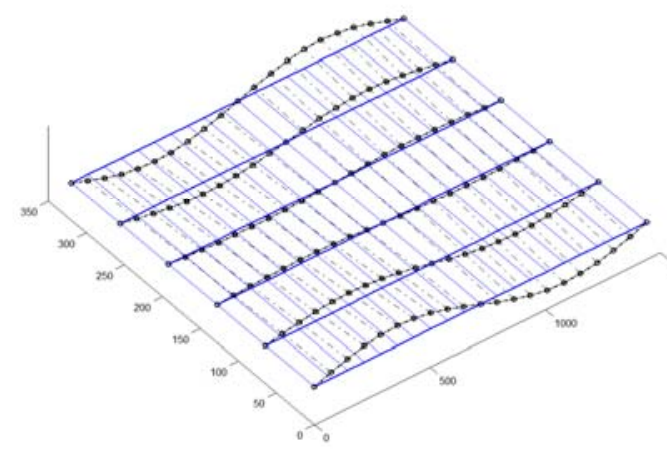

(e) $5^{\text {tn }}$ Mode $\left(f_{5}=11.21 \mathrm{~Hz}\right)$

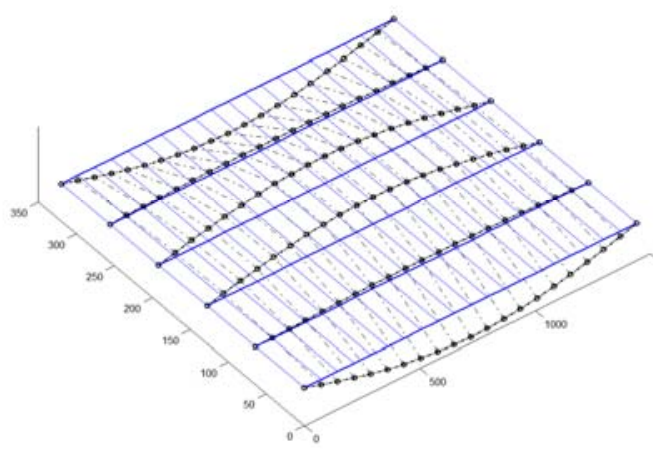

(c) $3^{\text {rd }}$ Mode $\left(\mathrm{f}_{3}=5.86 \mathrm{~Hz}\right)$

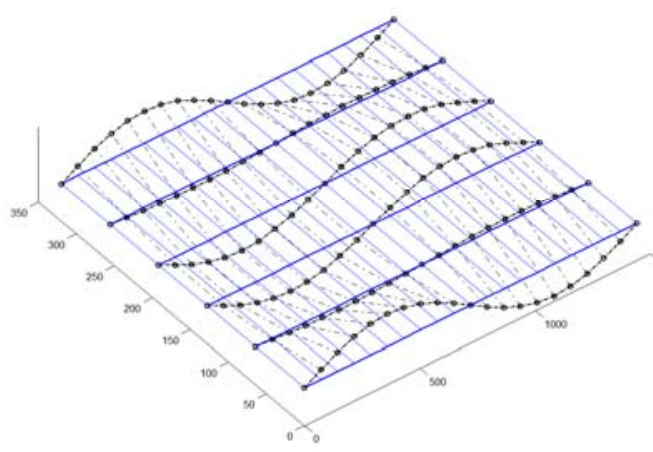

(f) $6^{\text {th }}$ Mode $\left(\mathrm{f}_{6}=12.09 \mathrm{~Hz}\right)$

Figure 21. Prestressed Concrete Bridge Mode Shapes (120’ Span) 


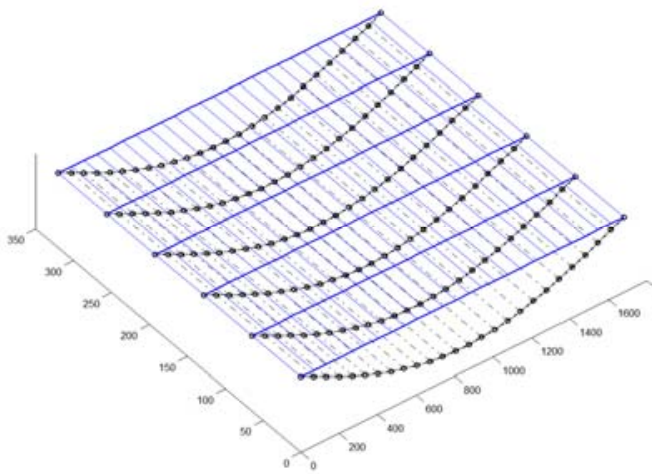

(a) $1^{\text {st }}$ Mode $\left(\mathrm{f}_{1}=2.05 \mathrm{~Hz}\right)$

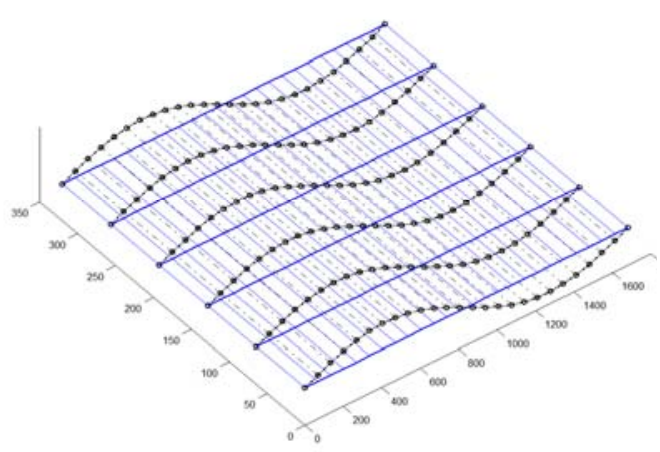

(d) $4^{\text {tn }}$ Mode $\left(\mathrm{f}_{4}=8.23 \mathrm{~Hz}\right)$

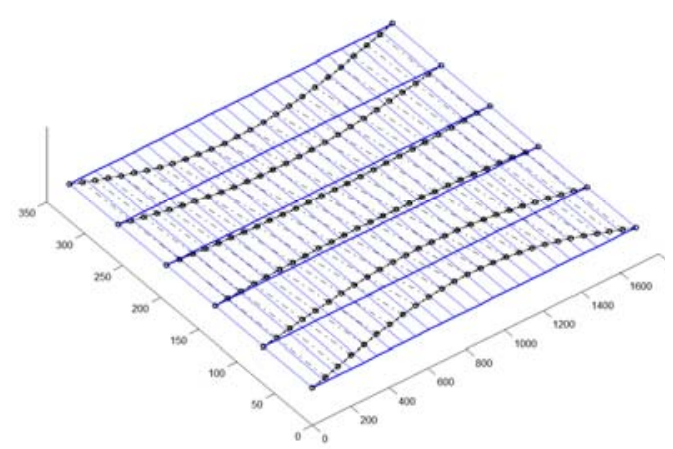

(b) $2^{\text {nd }}$ Mode $\left(\mathrm{f}_{2}=2.32 \mathrm{~Hz}\right)$

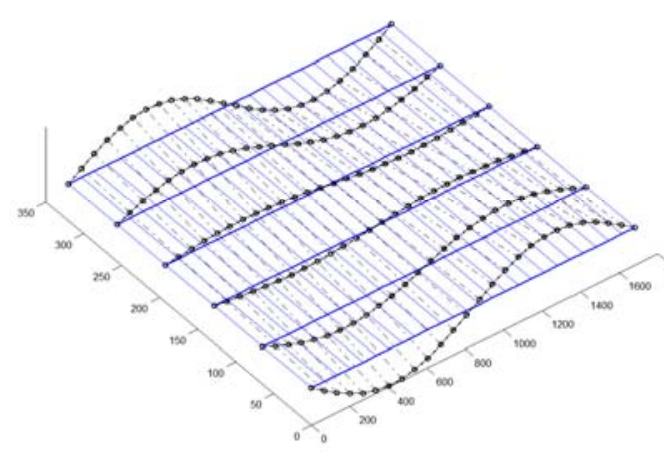

(e) $5^{\text {th }}$ Mode $\left(\mathrm{f}_{5}=8.33 \mathrm{~Hz}\right)$

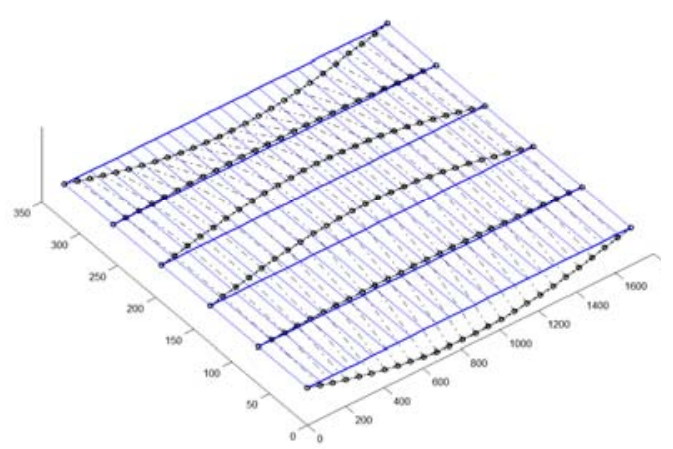

(c) $3^{\text {rd }}$ Mode $\left(\mathrm{f}_{3}=5.13 \mathrm{~Hz}\right)$

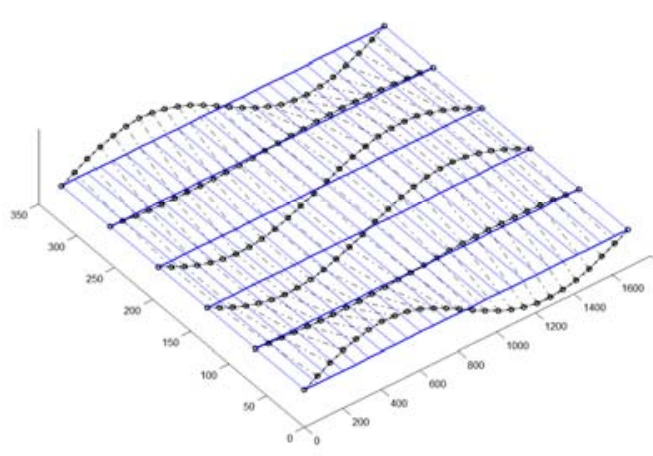

(f) $6^{\text {th }}$ Mode $\left(\mathrm{f}_{6}=9.53 \mathrm{~Hz}\right)$

Figure 22. Prestressed Concrete Bridge Mode Shapes (140’ Span) 


\section{VEHICLE ANALYSIS}

The dynamic response of the vehicles due to different road surface profiles has been calculated and compared to the results of the other types of trucks such as the Single Unit Trucks and Tractor Semitrailers. In addition, the effects of a single bump on the road, when different vehicles are traveling, have been studied. The results can help understand the effects of these trucks on the road overlays. The models and the results from the models can also prepare the first step to study the effects of larger vehicles on roadway bridges.

In order to solve the equations of motion, MATLAB software [29] has been used. MATLAB ODE function (ode45) which is designed to solve Ordinary Differential Equations has been used to solve these equations. This solver uses fourth order Rungekutta (with 0.005 second integration time step) to solve the ordinary differential equations. It was assumed that the vehicle starts at the state of rest and as the vehicle moves forward, the road surface condition displaces the vehicle suspension therefore the initial condition of each state changes.

\section{Analysis Results for Different Road Surface Conditions}

Impact Factor is a good criterion to understand the dynamic effects of vehicles on the road surface. Impact Factor is defined in equation ( 90 ) and it can be calculated for the suspension or the tire. The tire impact factor is of more importance here and it can be used as an indicator of the strain which is being put on the pavement.

$$
\text { Impact Factor }(\%)=\frac{\text { Maximum Dynamic Response }- \text { Maximum Static Response }}{\text { Maximum Static Response }} * 100
$$

In order to study the responses of different vehicles, the dynamic equations of motion of the trucks were analyzed while traveling on different surface conditions. Eleven different 
vehicles traveling at different speeds ranging from 15 to $75 \mathrm{mph}$ on four different road surface roughness conditions were studied. The Impact Factor can be calculated for each truck tire.

The time history results of $\mathrm{H}-20$ truck traveling at $15 \mathrm{mph}$ on the Very Good surface condition are shown in Figure 23. The results have been reported for all four front and rear tires. The results of the maximum tire impact factors for the last axle of the Single Unit Trucks are shown in Table 12.

By collecting the analysis results of all the vehicles and averaging these results for the three groups of vehicles (Single Unit Trucks, Tractor Semitrailers and LCVs), Figure 24 to Figure 28 are created based on different road surface roughness conditions.

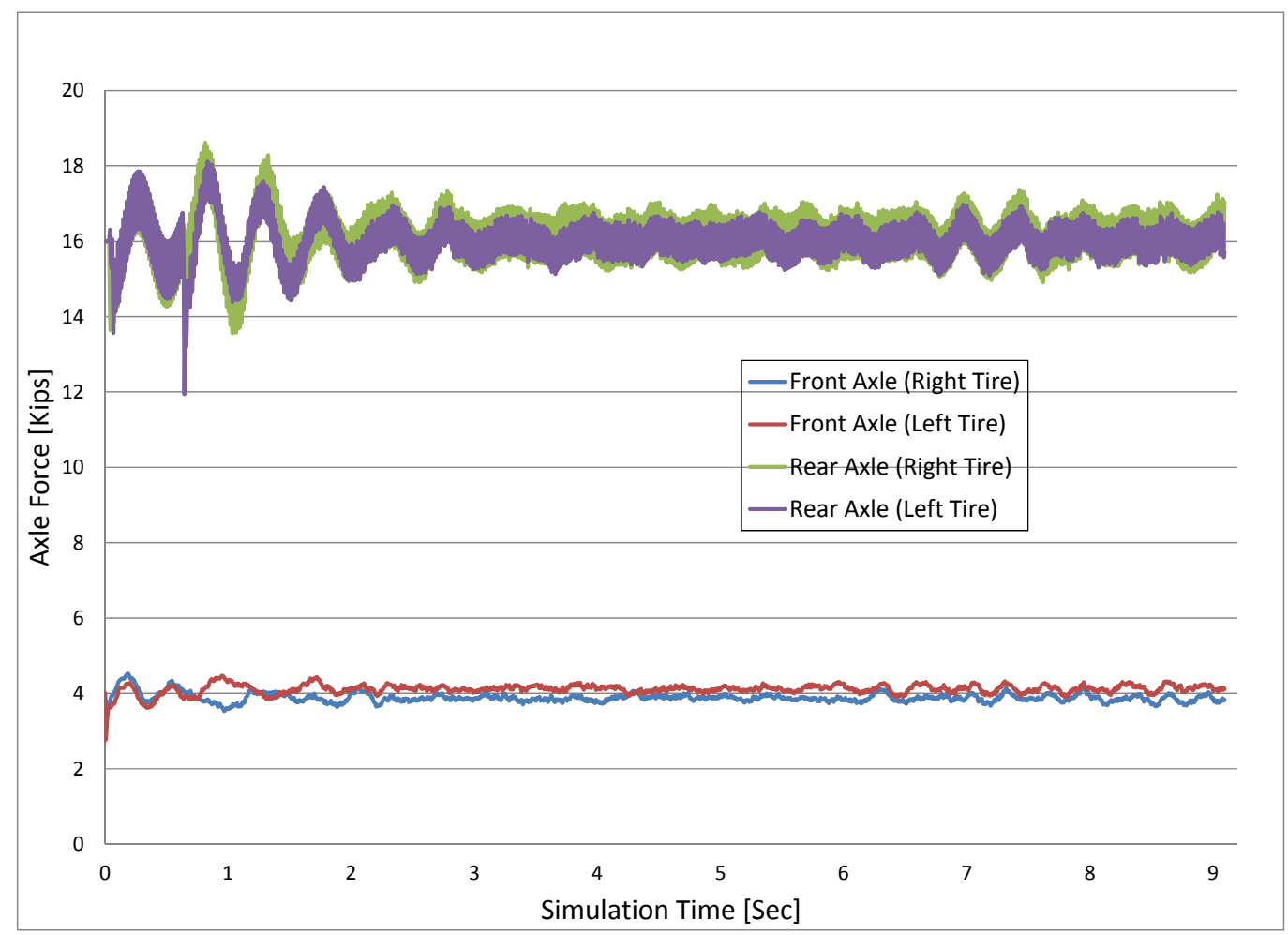

Figure 23. Time History of Different Tire Responses of H-20 Truck Traveling at $15 \mathrm{mph}$ on Very Good Surface Condition 
Table 12. Maximum Tire Impact Factors of Single Unit Trucks for the Selected Axle (All Surface Conditions)

\begin{tabular}{|c|c|c|c|c|c|c|c|c|c|c|c|c|}
\hline \multirow{3}{*}{$\begin{array}{l}\text { Vehicle } \\
\text { Speed } \\
\text { [mph] }\end{array}$} & \multicolumn{12}{|c|}{ Tire Impact Factor [\%] } \\
\hline & \multicolumn{4}{|c|}{$\mathrm{H}-20$} & \multicolumn{4}{|c|}{ SU4 } & \multicolumn{4}{|c|}{ Type 3} \\
\hline & "Very Good" & "Good" & "Average" & "Poor" & "Very Good" & "Good" & "Average" & "Poor" & "Very Good" & "Good" & "Average" & "Poor" \\
\hline 15 & 16.4 & 27.9 & \begin{tabular}{|l|}
32.8 \\
\end{tabular} & 53.9 & 32.9 & 44.4 & 42.6 & 76.6 & 41.3 & 43.8 & 37.0 & 98.8 \\
\hline 25 & 11.9 & 28.1 & 33.1 & 52.7 & 43.1 & 48.9 & 55.0 & 76.7 & 26.0 & 54.9 & 45.0 & 102.2 \\
\hline 35 & 10.2 & 20.0 & 32.2 & 66.6 & 42.9 & 47.3 & 51.0 & 55.1 & 30.8 & 38.1 & 69.4 & 91.0 \\
\hline 45 & 25.7 & 22.6 & 37.3 & 64.2 & 42.4 & 49.7 & 52.1 & 77.3 & 26.8 & 41.4 & 56.3 & 113.5 \\
\hline 55 & 15.9 & 40.7 & 36.3 & 54.0 & 34.6 & 62.6 & 54.1 & 86.3 & 22.5 & 58.8 & 57.3 & 92.5 \\
\hline 65 & 16.2 & 25.2 & 38.8 & 57.4 & 40.6 & 64.6 & 66.8 & 85.7 & 32.7 & 61.7 & 56.1 & 107.8 \\
\hline 75 & 16.4 & 24.4 & 40.0 & 48.3 & 42.4 & 49.7 & 68.0 & 99.8 & 34.4 & 51.5 & 65.9 & 106.5 \\
\hline
\end{tabular}

The results shown in the next three pages are for the last axle of the Single Unit Trucks, last axle of the Tractor Semitrailers and last axle of the first trailer (Semitrailer) of the LCVs. It can be seen from these figures that the values of impact factor can get very high as the road surface condition goes from Very Good to Poor. In terms of the effects of the vehicle speed on the values of impact factor, it is not easy to find a generalized rule for these effects and an increase in the vehicle speed can result in higher or lower values of impact factor.

But the most important conclusion which should be drawn from these results is about the LCVs. They tend to have slightly higher results for the cases of better surface conditions such as the Very Good and Good but in the case of the Poor surface condition they show smaller values of impact factor. In general the results from the LCVs are not that different from the other two types of the vehicles.

It should be noted that this might not be necessarily true for the case of vehicles traveling on the bridges because the nature of the problem is different in that case and the interaction between the vehicles and the bridge could have an important role in that problem. 


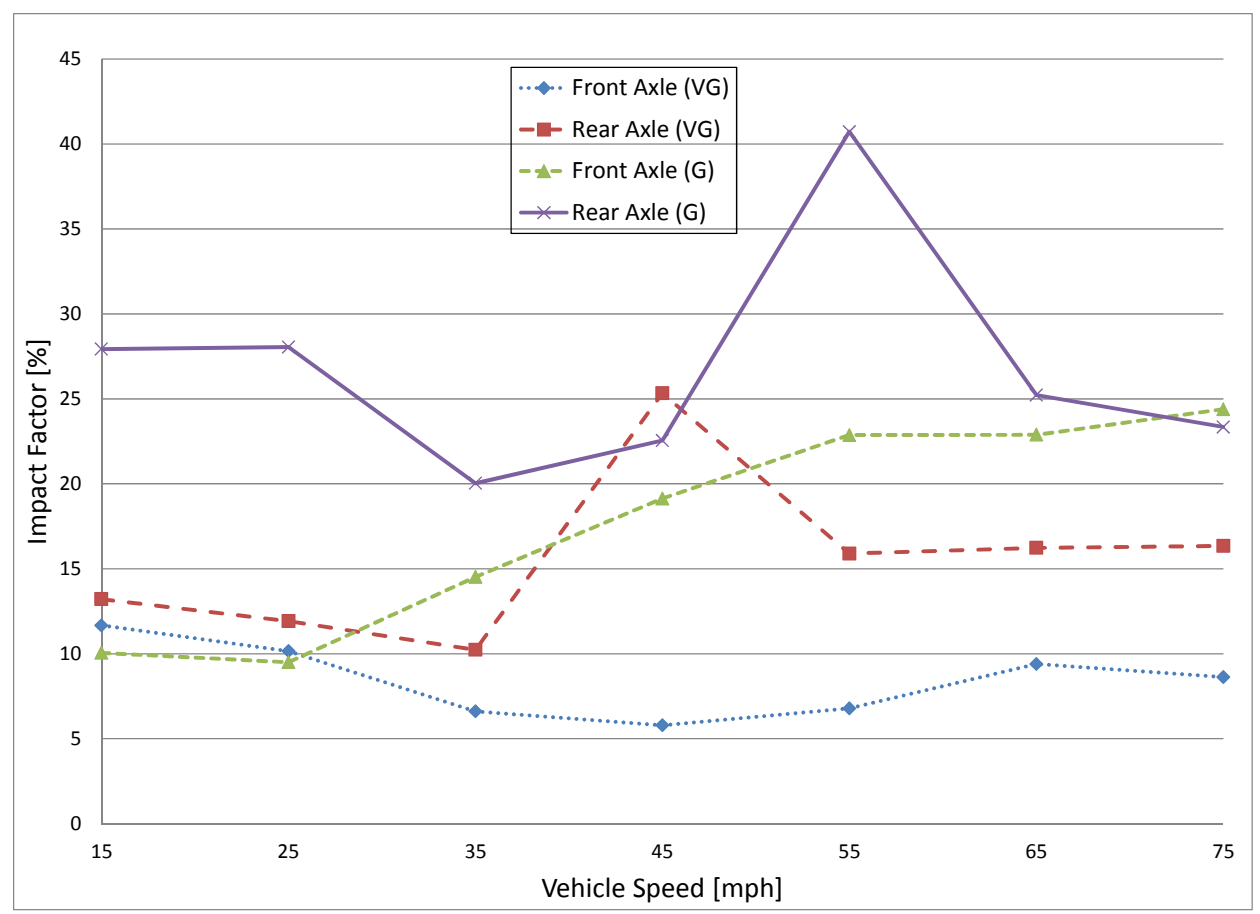

Figure 24. Tire Impact Factors of H-20 Truck for Front and Rear Axles (Very Good and Good Surface Conditions)

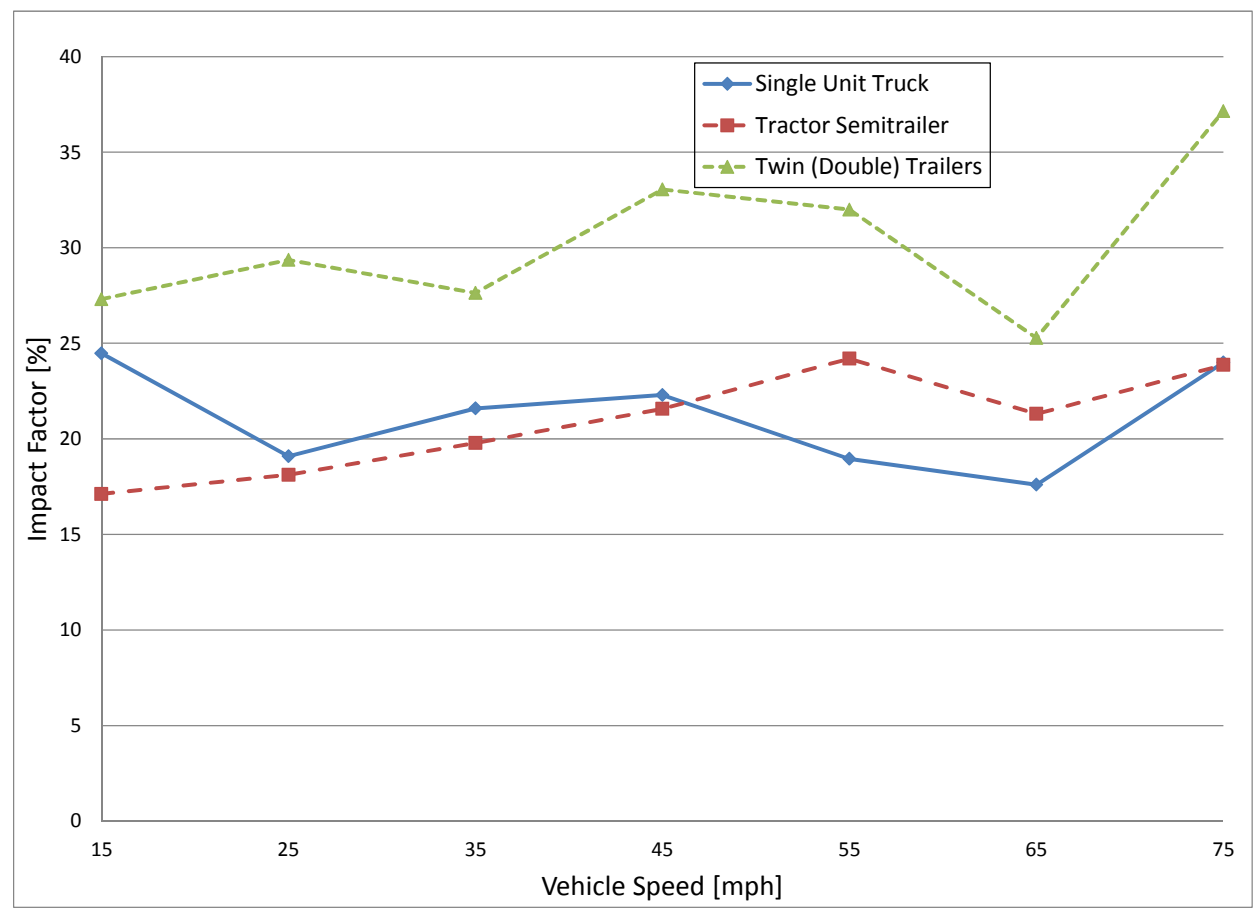

Figure 25. Tire Impact Factor of Different Vehicle Categories for the Selected Axle (Very Good Surface Condition) 


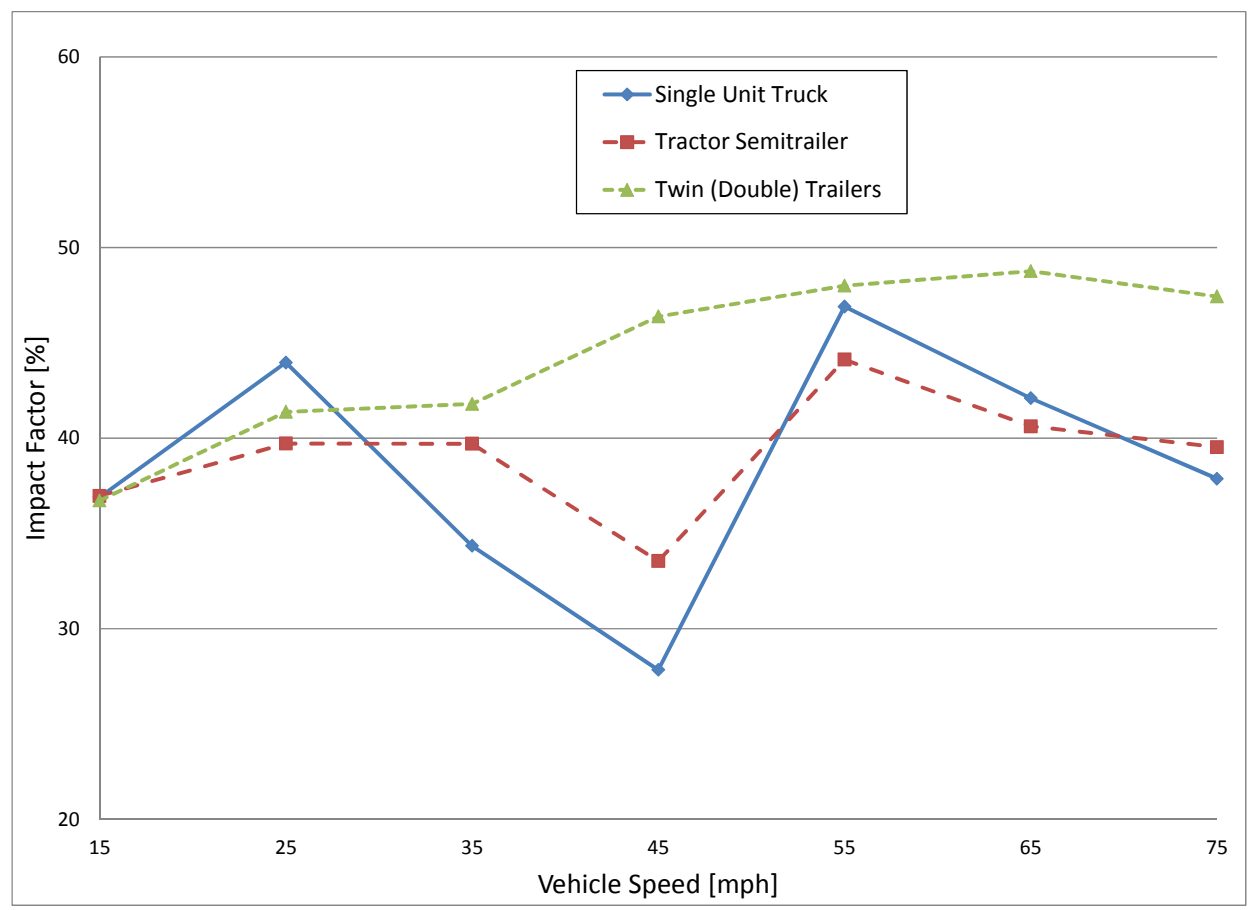

Figure 26. Tire Impact Factor of Different Vehicle Categories for the Selected Axle (Good Surface Condition)

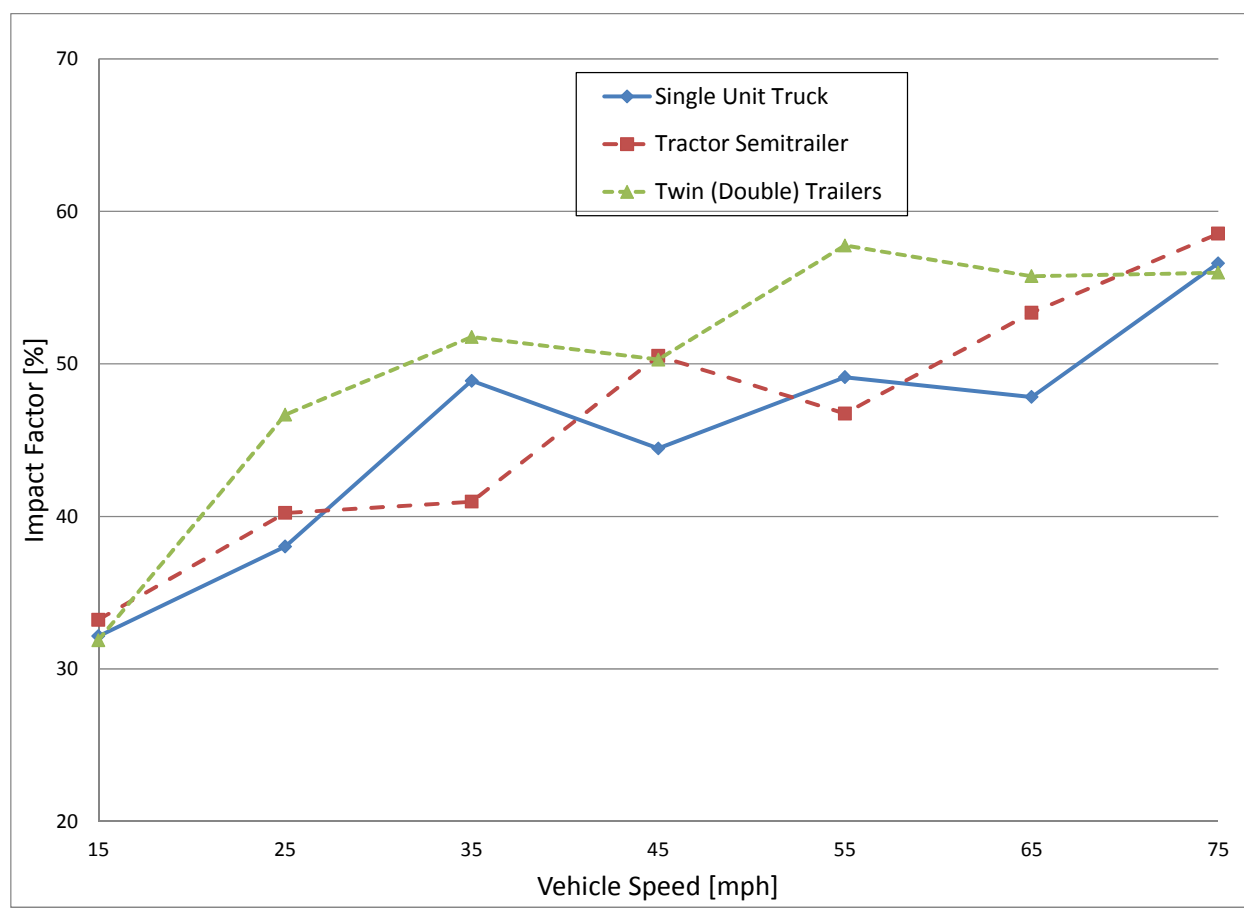

Figure 27. Tire Impact Factor of Different Vehicle Categories for the Selected Axle (Average Surface Condition) 


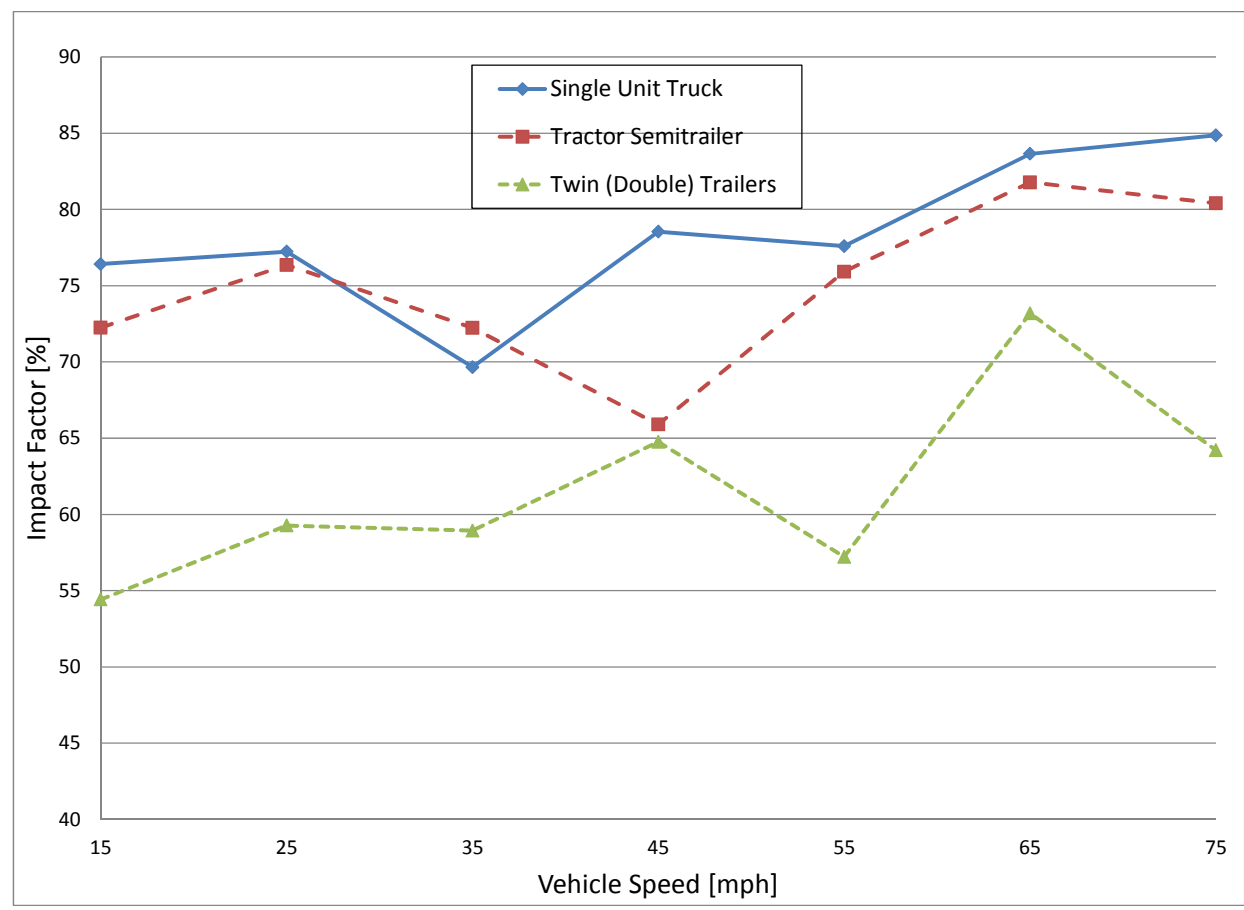

Figure 28. Tire Impact Factor of Different Vehicle Categories for the Selected Axle (Poor Surface Condition)

\section{Single Bump Effect}

In order to study the effects of vehicle stability, instead of the road surface generated using the PSD function, a smooth road surface profile with a single bump of different sizes was assumed for the road surface condition. Three different bump sizes of $1 / 2,1$ and 2 inches were assumed. Larger bump sizes seem to be unrealistic so 2 inches was chosen as the maximum bump size.

The time history of different tire responses of $\mathrm{H}-20$ truck traveling at $15 \mathrm{mph}$ and $75 \mathrm{mph}$ when a single 1" Bump is present is shown in Figure 29 and Figure 30. Since the length that vehicle travels in is equal in both cases, it can be seen that the truck traveling at 15 mph has enough time to go back to its original state whereas in the case of the truck traveling at $75 \mathrm{mph}$, it is still vibrating at the end of the simulated length of 200 feet. In 
both cases the front axle (light axle) goes back to its original state much faster than the rear axle (heavy axle). Also by comparing the peaks of the forces between the front and rear axles, it is evident that there is a time lag between the two peaks which shows the time difference between the two axles passing over the bump. It should also be noted that unlike the previous results for different road surface conditions where the left and right tires had different road surface conditions, here the input of both left and right tires are the same, therefore the two tires show identical behaviors and the vehicle does not show any rolling motions.

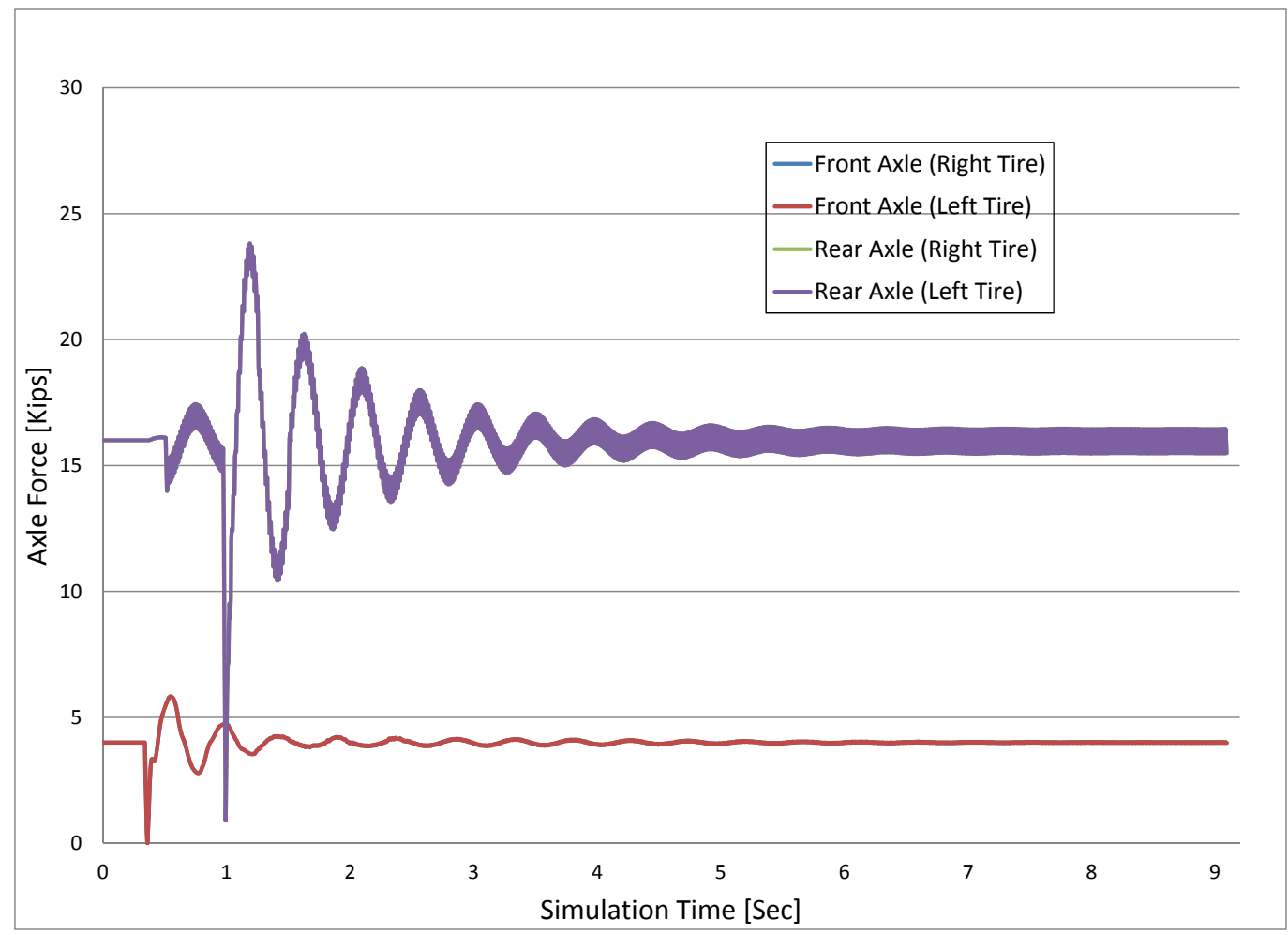

Figure 29. Time History of Different Tire Responses of H-20 Truck Traveling at 15 mph (1" Bump)

The tire impact factors of $\mathrm{H}-20$ truck for front and rear axles when passing over the 1" bump has been shown in Figure 31. Slightly higher numbers for the rear axle can be seen in this graph which was also the case in the results of the previous section. 


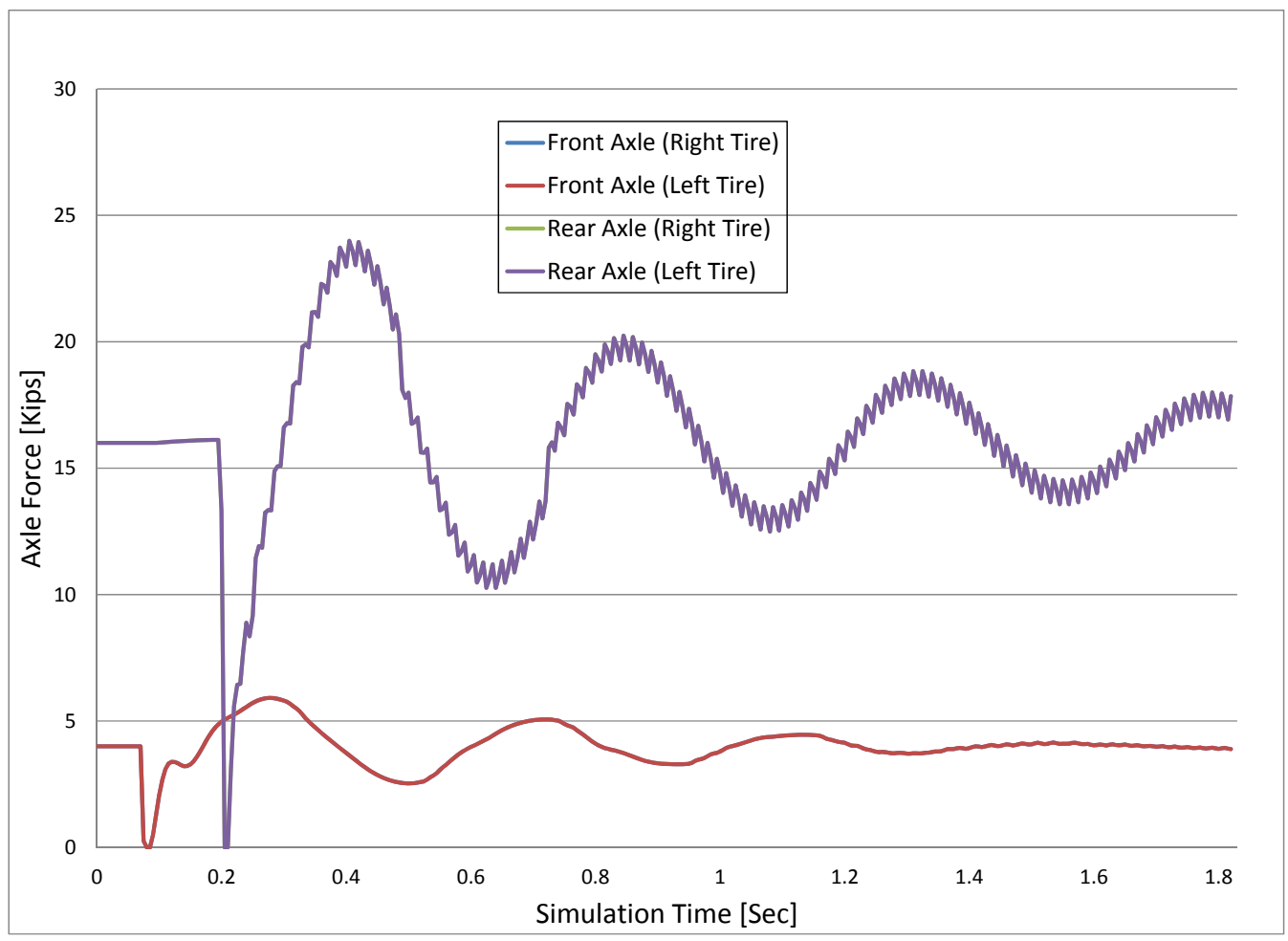

Figure 30. Time History of Different Tire Responses of H-20 Truck Traveling at 75 mph (1" Bump)

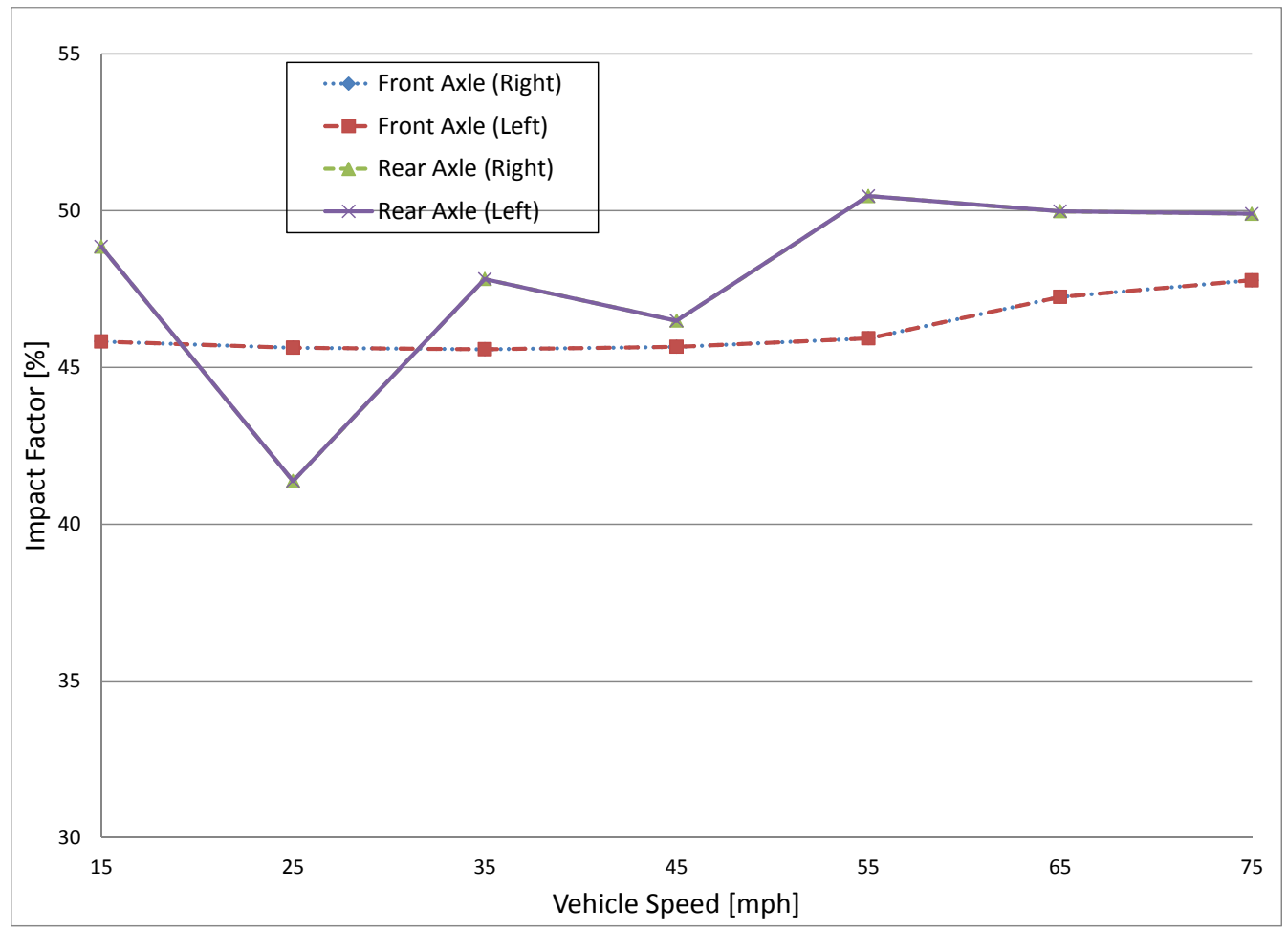

Figure 31. Tire Impact Factors of H-20 Truck for Front and Rear Axles (1" Bump) 
The averaged tire impact factor results of all vehicles, categorized in three groups of vehicles, when traveling over a 1/2", 1" and 2" bump have been shown in Figure 32 to Figure 34. The results have been reported for the last axle of Single Unit Trucks, last axle of Tractor Semitrailers and last axle of the first trailer of LCVs.

These results show an increase in the impact factors as the height of the bump increases. The impact factors can be very high for the case of 2 " bump which shows the strain that big potholes or height differentials between the surfaces can put on the roads. One can also observe the same trend as the different road surface conditions in the previous section in these figures. In the cases of 1/2" and 1" bumps the LCVs result in higher impact factors but as the road surface condition gets worse (i.e. the case of 2" bump) the LCVs result in the lowest impact factors. All in all, the results from the LCVs are not that different from the other types of vehicles.

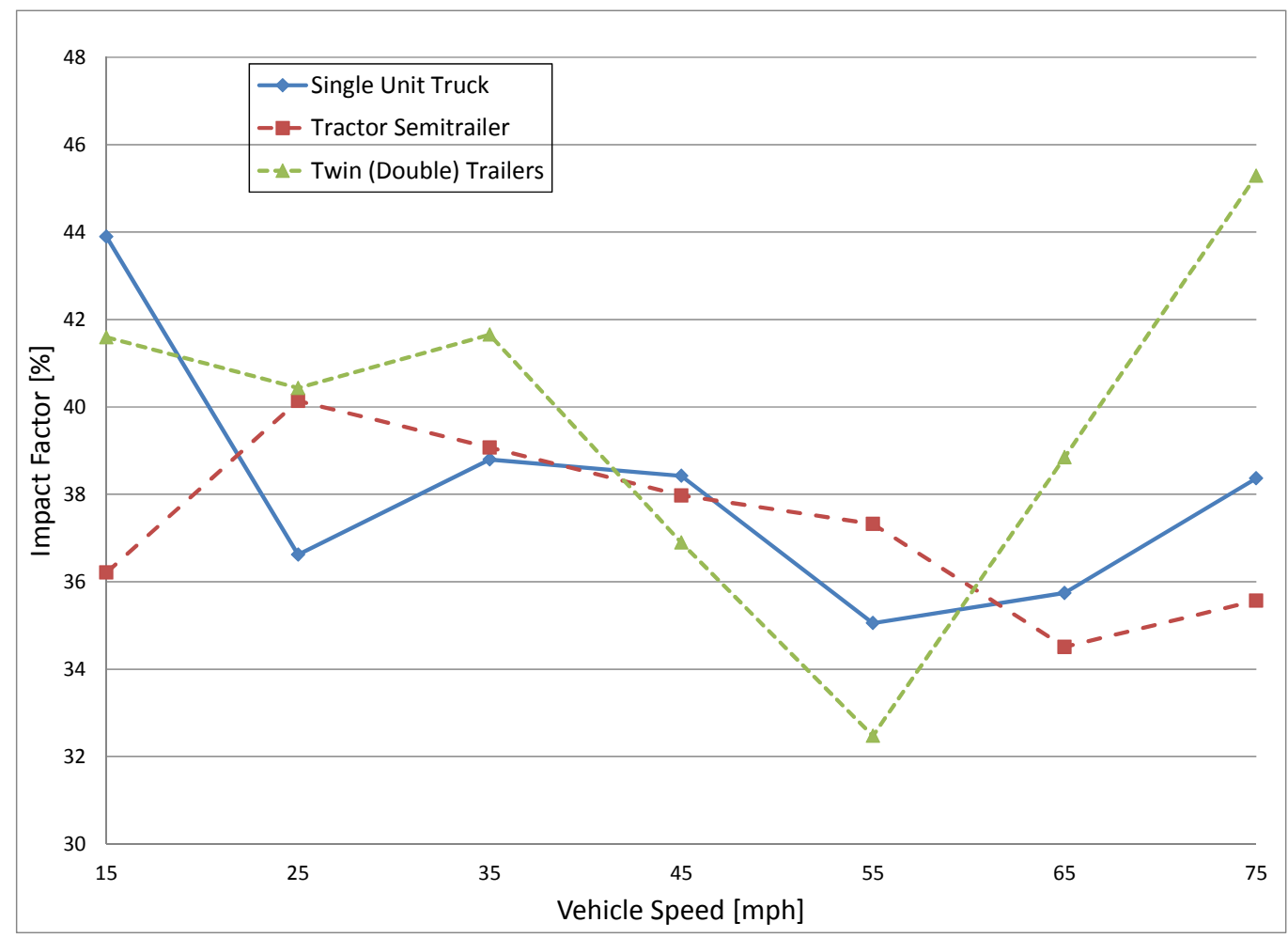

Figure 32. Tire Impact Factor of Different Vehicle Categories for the Selected Axle (1/2" Bump) 


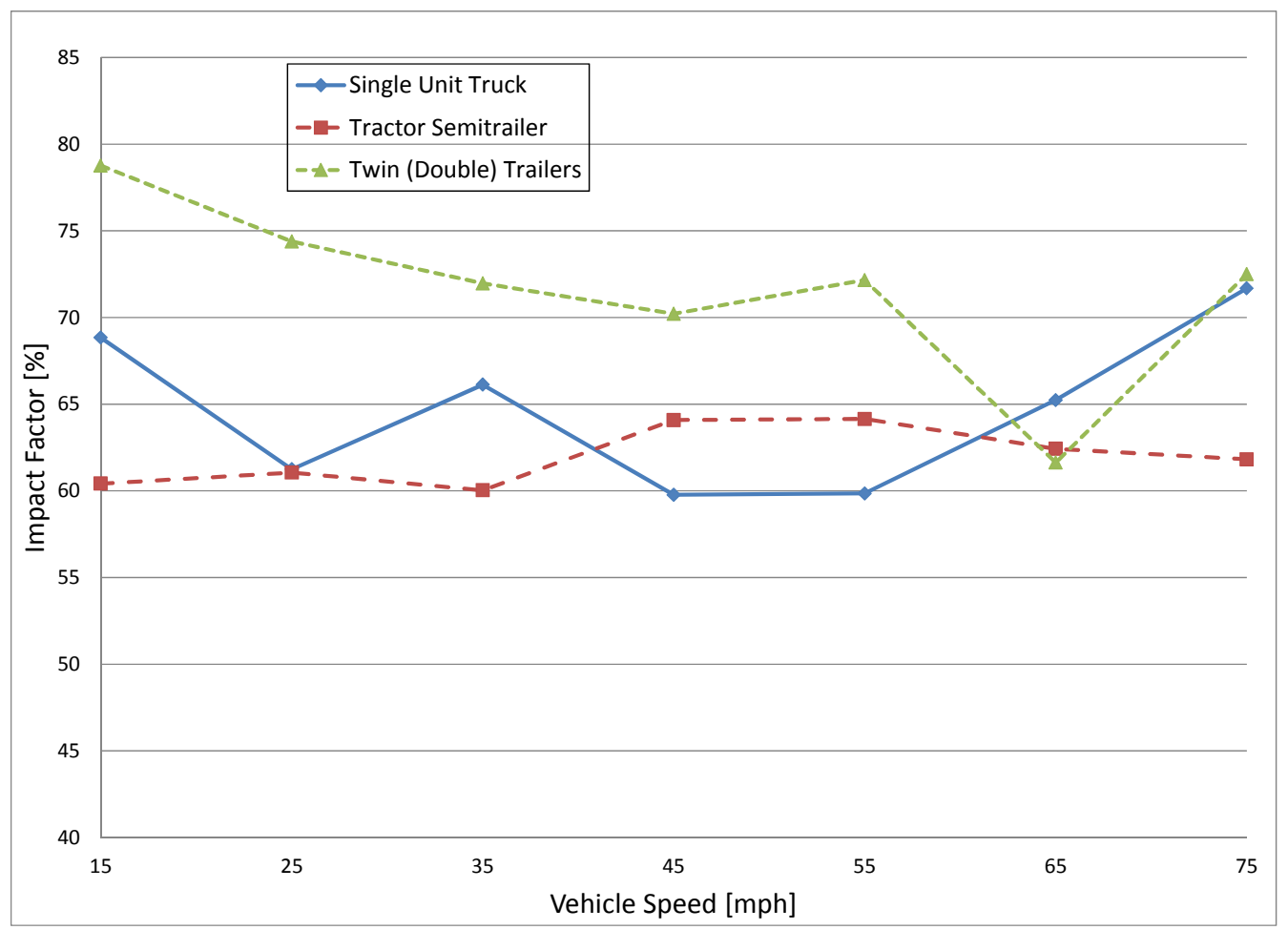

Figure 33. Tire Impact Factor of Different Vehicle Categories for the Selected Axle (1" Bump)

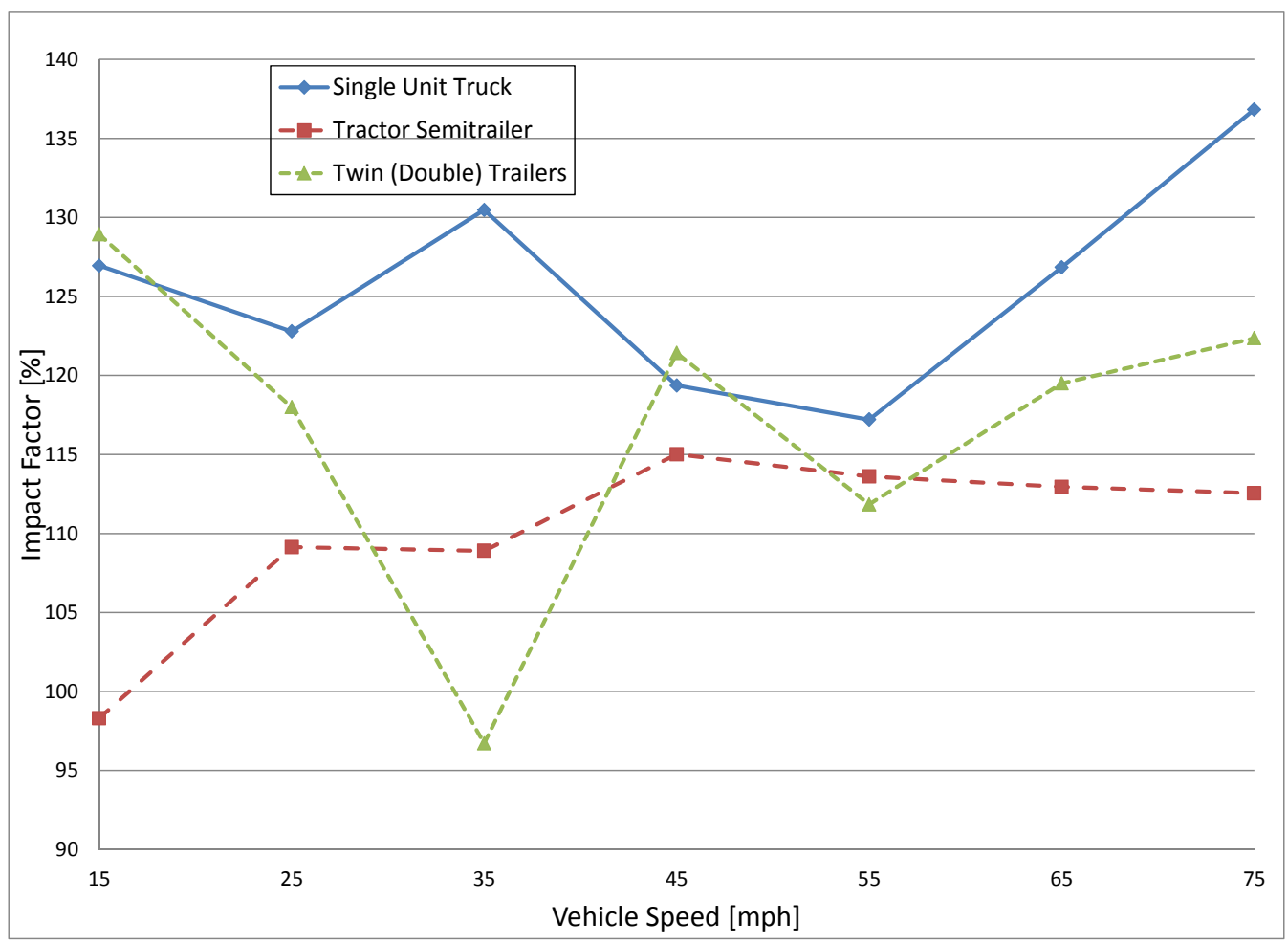

Figure 34. Tire Impact Factor of Different Vehicle Categories for the Selected Axle (2" Bump) 
The results for the tire impact factors of the last axle of the first trailer of Long Combination Vehicles for all bump sizes have also been shown in Table 13. Extremely high values of impact factors can be seen in the case of the largest bump.

Table 13. Maximum Tire Impact Factors of the Long Combination Vehicles for the Selected Axle (All Bump Sizes)

\begin{tabular}{|c|c|c|c|c|c|c|c|c|c|}
\hline \multirow{2}{*}{$\begin{array}{c}\text { Vehicle } \\
\text { Speed } \\
\text { [mph] }\end{array}$} & \multicolumn{9}{|c|}{ Tire Impact Factor [\%] } \\
\cline { 2 - 11 } & $\mathbf{7}$ Axle Rocky Mountain Double & \multicolumn{2}{|c|}{ 8 Axle B-Train Double } & \multicolumn{3}{|c|}{ 9 Axle Turnpike Double } \\
\hline $\mathbf{1 / 2}$ inch & $\mathbf{1}$ inch & $\mathbf{2}$ inches & $\mathbf{1 / 2}$ inch & $\mathbf{1}$ inch & $\mathbf{2}$ inches & $\mathbf{1 / 2}$ inch & $\mathbf{1}$ inch & $\mathbf{2}$ inches \\
\hline $\mathbf{1 5}$ & 38.9 & 79.8 & 136.1 & 39.3 & 71.3 & 109.3 & 46.5 & 85.2 & 141.4 \\
\hline $\mathbf{2 5}$ & 44.2 & 77.5 & 125.6 & 34.4 & 60.3 & 96.1 & 42.7 & 85.4 & 132.3 \\
\hline $\mathbf{3 5}$ & 37.6 & 79.7 & 102.0 & 41.7 & 67.3 & 86.8 & 45.7 & 69.0 & 101.4 \\
\hline $\mathbf{4 5}$ & 28.9 & 68.4 & 116.6 & 49.5 & 65.0 & 116.3 & 32.3 & 77.3 & 131.4 \\
\hline $\mathbf{5 5}$ & 33.6 & 68.7 & 108.1 & 34.0 & 66.2 & 117.4 & 29.8 & 81.7 & 110.1 \\
\hline $\mathbf{6 5}$ & 37.8 & 55.2 & 116.7 & 43.7 & 61.9 & 115.9 & 35.0 & 67.9 & 125.9 \\
\hline $\mathbf{7 5}$ & 52.0 & 75.4 & 129.8 & 42.6 & 61.6 & 103.6 & 41.2 & 80.5 & 133.6 \\
\hline
\end{tabular}

In order to comprehend the effects of different trucks on the bridges it is necessary to compare the results of all different trucks but it should be noted that the gross vehicle weight should also be taken into account. Also determining that which truck has more detrimental effects on the bridges without actually putting the loads on the bridge and calculating resulted moments and stresses is not possible.

One of the main tasks in this project is to study the effects of different vehicle speeds on the dynamic response of bridges. Another important factor affecting the dynamic response of the bridges is the type of the vehicle traveling on the bridge. For this reason, effects of the different types of vehicles shown in Figure 1 shall be studied. These tasks will be done for the steel girder and prestressed concrete bridges and the effects of span length shall be incorporated into this research. Moreover, the influence of different classes of road surface roughness on the bridge dynamic response will be researched. 


\section{DYNAMIC AMPLIFICATION FACTOR ANALYSIS OF BRIDGES}

\section{Designed Bridges Results}

In this section, the effects of different types of vehicles on different types of bridges will be studied and the Dynamic Amplification Factor (DAF) i.e. the Dynamic Load Allowance will be calculated and compared for different cases of analysis.

But first the validity of the designed bridges is checked using the two real steel bridges which will be analyzed in the next section of this chapter. Both bridges are located in the state of Florida, one in Volusia County and the other one in the Broward County. The first real bridge is a $189^{\prime}-8^{\prime \prime}$ long, single span straight bridge with five girders and the second one is the first span of a three span bridge which is $83^{\prime}-6$ " long with seven girders.

In order to make a comparison between the five steel bridges which were designed and the two real bridges which have been used here, the first natural frequencies of these bridges have been shown in Figure 35. It can be seen that the first natural frequencies of the two real bridges lie within a reasonable range. In the same figure, the first natural frequency results of the prestressed concrete bridges which were designed can be seen.

The cases here are based on the Good and Very Good road surface condition and four different vehicle speeds of $15,35,55,75 \mathrm{mph}$ have been considered. The analysis was carried out for two different types of bridges (Steel Bridge and Prestressed Concrete Bridge) with five different span lengths of $30,60,90,120,140$ feet.

To eliminate the effects of initial vibrations of trucks, it was assumed that each truck started to move from a distance which is equal to five times of its length before reaching the bridge. 


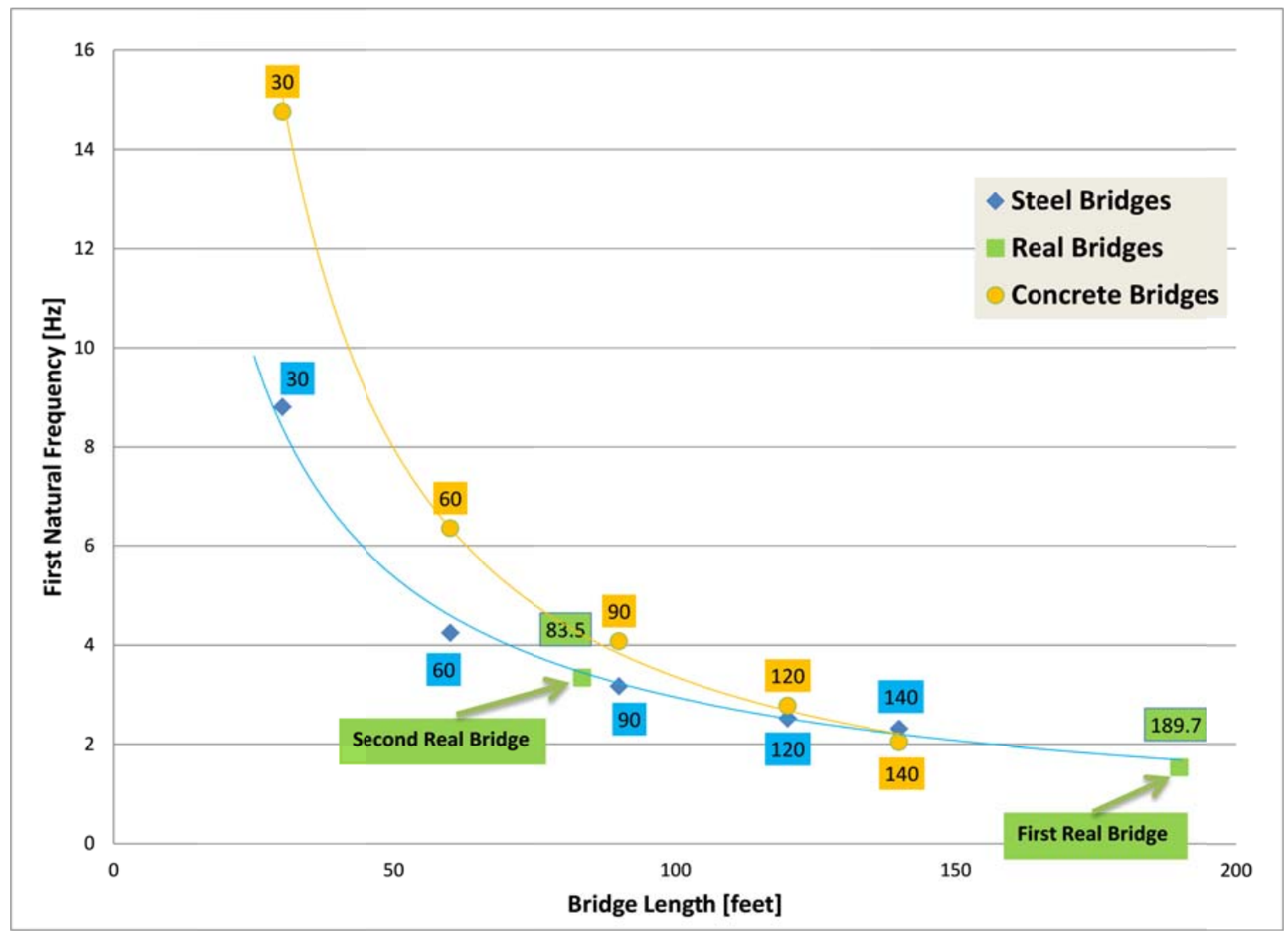

Figure 35. First Natural Frequency of Designed and Real Bridges

The results of the deflection for the case of Good surface condition at a middle point of the bridge (one of the grid points) which has the highest displacement are shown in Figure 36 to Figure 38 for all eleven types of trucks traveling on the prestressed concrete bridge with the span length of 30 feet. The transverse vehicle location was assumed to be at the far right end of the bridge with a distance of 30 inches from the curb. 


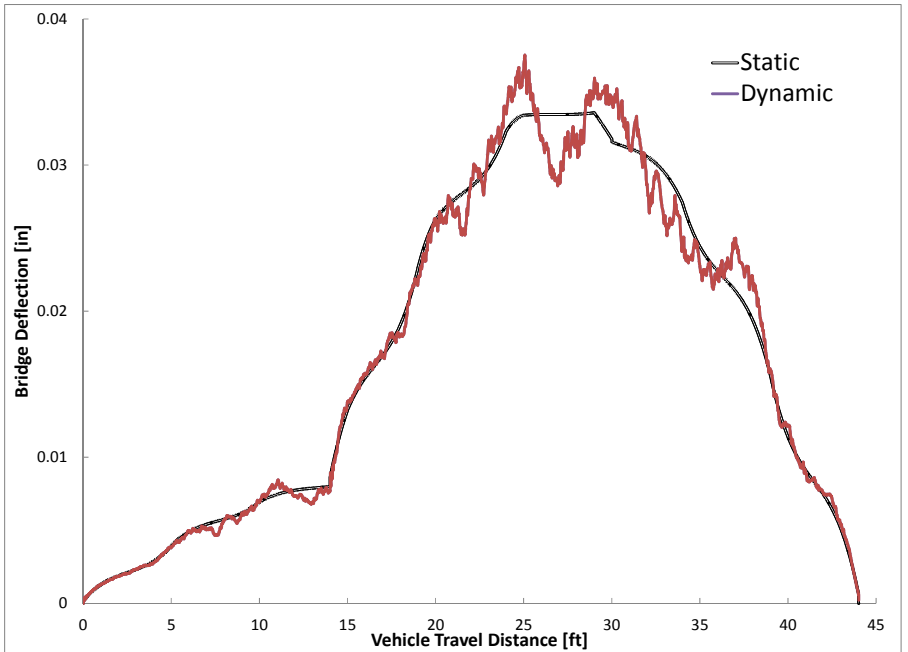

(a) $\mathrm{H}-20$

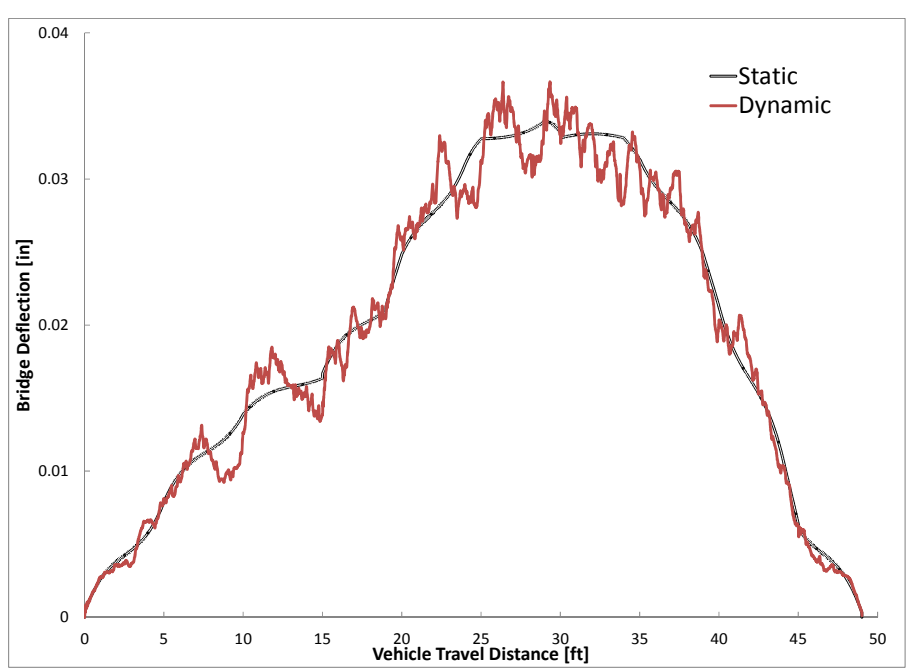

(c) Type 3

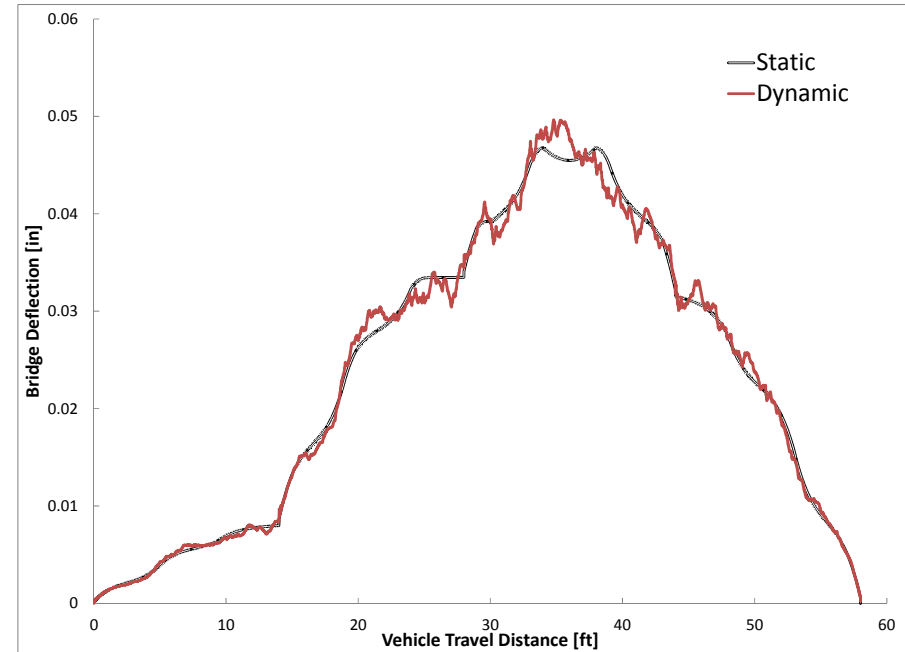

(b) HS-20

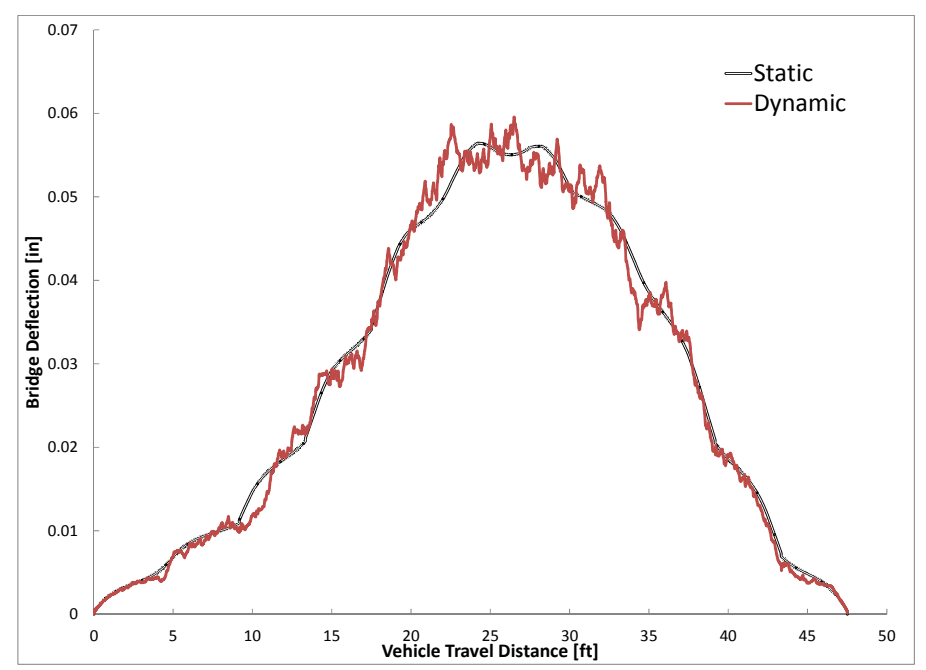

(d) SU4

Figure 36. Displacement of $30 \mathrm{ft}$. Concrete Bridge due to Single Unit Trucks and HS-20 (Good Surface) 


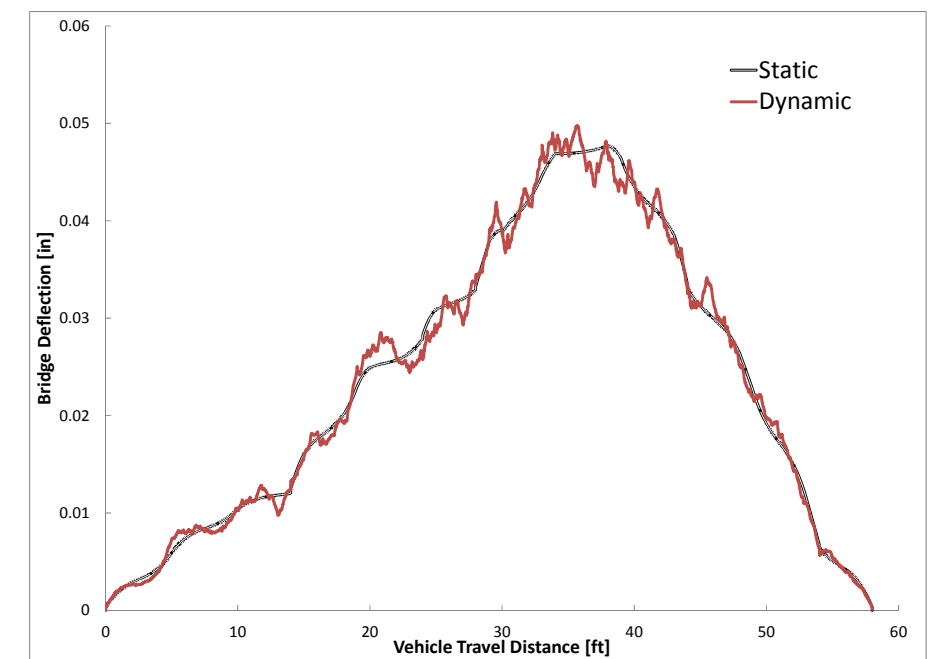

(e) Type 2S2

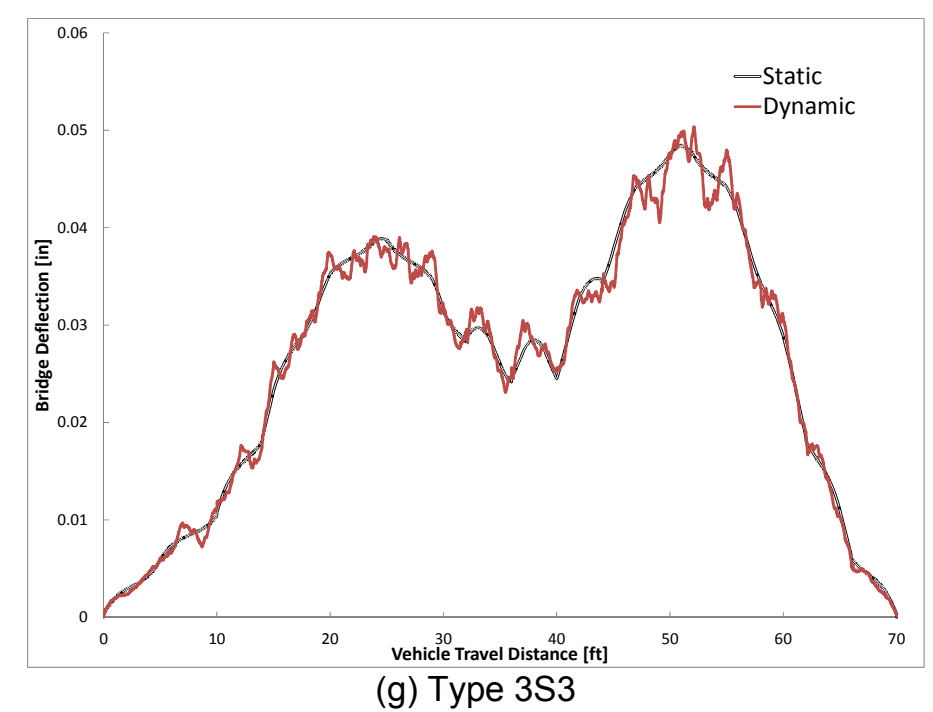

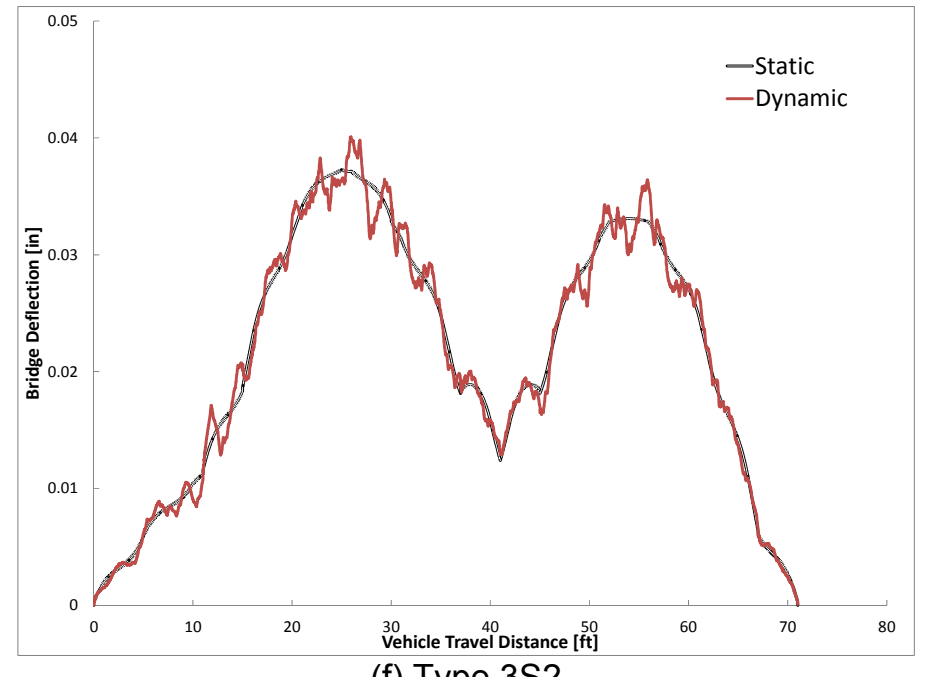

(f) Type 3S2

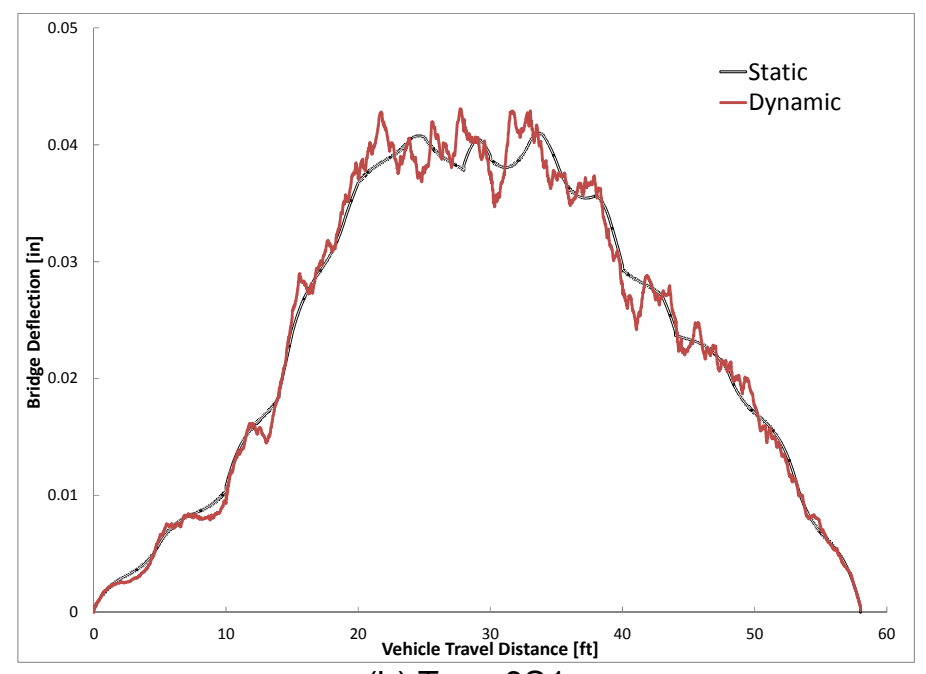

(h) Type 3S1

Figure 37. Displacement of $30 \mathrm{ft}$. Concrete Bridge due to Tractor Semitrailers (Good Surface) 


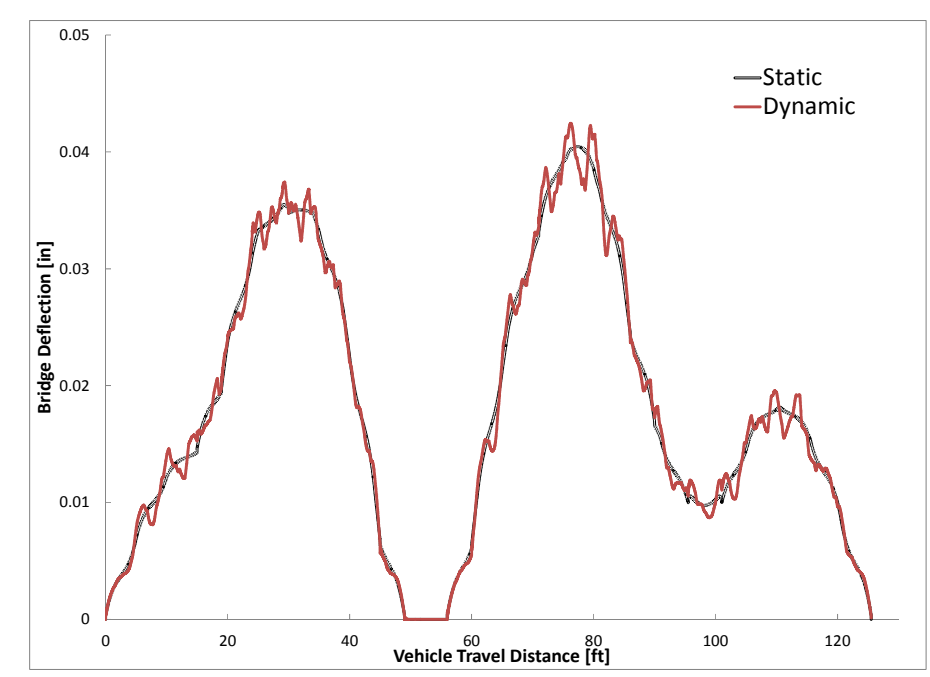

(i) 7-Axle Rocky Mountain Double
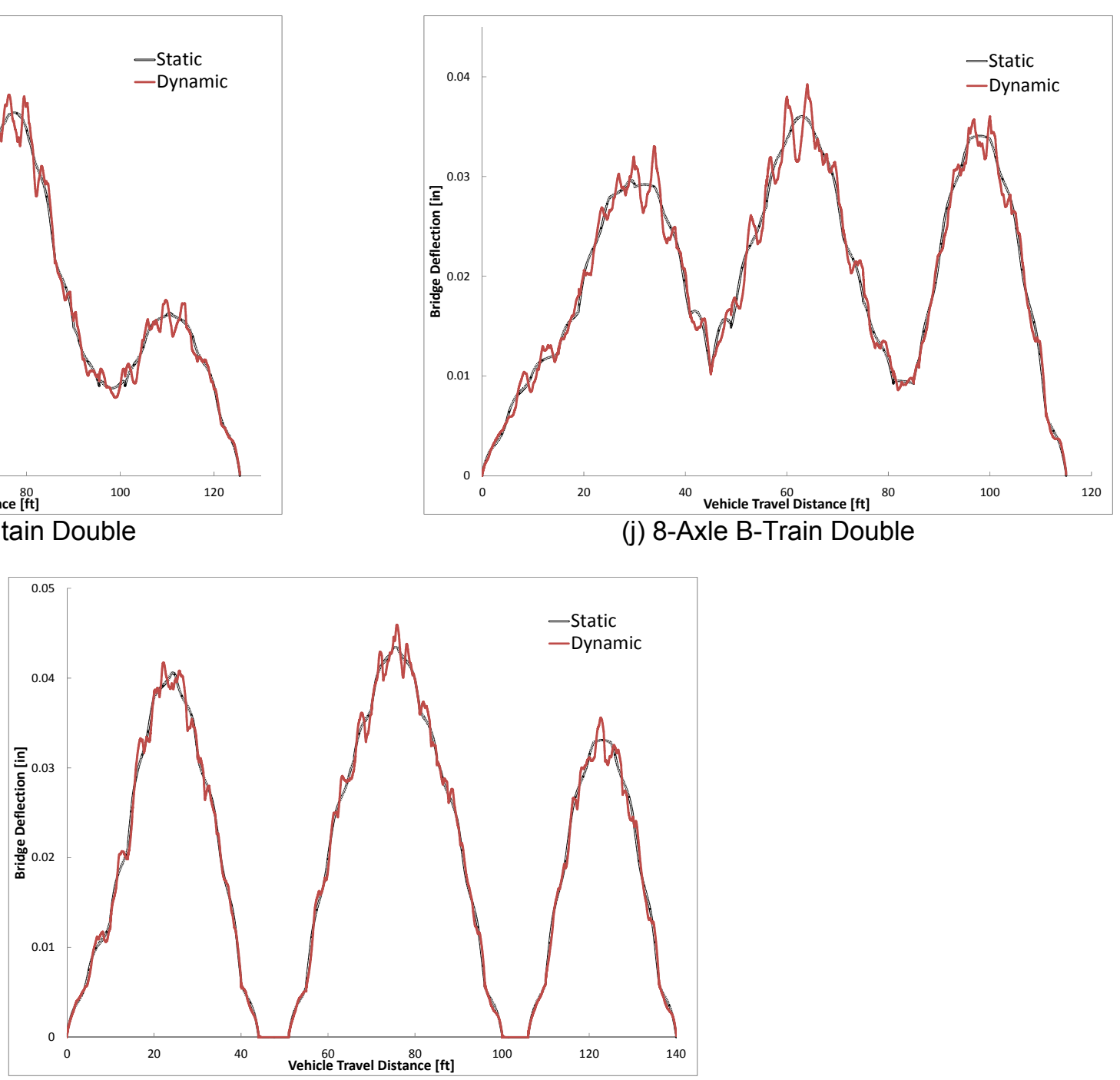

(k) 9-Axle Turnpike Double

Figure 38. Displacement of $30 \mathrm{ft}$. Concrete Bridge due to Truck and Double Trailers (Good Surface) 
The results are shown as the static and dynamic response of the bridge. The static response of the bridge means that the vehicle is moving along the bridge without vibrating due to the effects of suspensions and tires so the loading would be static and the interaction of the bridge and vehicle does not have a role in this case while in the case of dynamic response of the bridge, the interaction of the bridge and vehicle has a significant role in the response of the bridge.

The horizontal axis which shows the vehicle travel distance is the distance which the truck travels when it has at least one set of wheels on the bridge. The total vehicle distance would be equal to the length of the bridge plus the length of the vehicle.

Dynamic Amplification Factor (DAF) or the dynamic load allowance is defined as,

$D A F(\%)=\frac{\text { Maximum Dynamic Response-Maximum Static Response }}{\text { Maximum Static Response }} * 100$

The values of DAF for different vehicle speeds are given in Table 14 and Table 15 for Steel and Prestressed Concrete bridges, respectively. All these numbers shown here are for the case of Good road surface condition. The reason for choosing the Good road surface condition is that the maintenance of road surface of bridges is an important issue and usually the old surfaces are replaced by new surfaces before their complete deterioration. It can be observed that almost all these numbers are below $33 \%$ which was suggested by the AASHTO LRFD Bridge Design Specification [7]. In order to understand the effects of different trucks on bridges in terms of the dynamic amplification factor, all the trucks have been categorized into three groups of Single Unit Trucks, Tractor Semitrailers and Twin (Double) Trailers. These categories can be seen in Table 16. Now by averaging the values of dynamic amplification factor for each of these categories for all the vehicle speeds and bridge lengths, a comparison can be made. 
Table 14. Dynamic Amplification Factor for Prestreesed Concrete Bridges (Good Surface)

\begin{tabular}{|c|c|c|c|c|c|c|c|c|c|c|c|c|c|c|}
\hline \multirow[b]{2}{*}{$\begin{array}{c}\text { Bridge } \\
\text { Type }\end{array}$} & \multirow[b]{2}{*}{$\begin{array}{c}\text { Span } \\
\text { Length } \\
\text { [feet] }\end{array}$} & \multirow[b]{2}{*}{$\begin{array}{l}\text { Surface } \\
\text { Condition }\end{array}$} & \multirow[b]{2}{*}{$\begin{array}{l}\text { Speed } \\
{[\mathrm{mph}]}\end{array}$} & \multicolumn{11}{|c|}{ Vehicle Type } \\
\hline & & & & $\mathrm{H}-20$ & HS-20 & $\begin{array}{c}\text { Type } \\
3\end{array}$ & $\begin{array}{l}\text { Type } \\
\text { 3S2 }\end{array}$ & $\begin{array}{l}\text { Type } \\
\text { 3S3 }\end{array}$ & $\begin{array}{l}\text { Type } \\
2 \text { S2 }\end{array}$ & $\begin{array}{l}\text { Type } \\
3 \text { S1 }\end{array}$ & SU4 & $\begin{array}{c}\text { 7-Axle } \\
\text { Rocky } \\
\text { Mountain } \\
\text { Double }\end{array}$ & $\begin{array}{l}8 \text { Axle } \\
\text { B-Train } \\
\text { Double }\end{array}$ & $\begin{array}{c}9 \text { Axle } \\
\text { Turnpike } \\
\text { Double }\end{array}$ \\
\hline \multirow{20}{*}{ (4) } & \multirow{4}{*}{30} & \multirow{4}{*}{ Good } & 15 & 11.8 & 6.1 & 8.0 & 7.6 & 3.9 & 4.3 & 5.1 & 5.6 & 5.0 & 8.9 & 5.8 \\
\hline & & & 35 & 12.3 & 10.7 & 7.7 & 3.0 & 8.8 & 14.5 & 13.5 & 10.4 & 2.4 & 4.6 & 3.7 \\
\hline & & & 55 & 9.5 & 10.1 & 10.8 & 1.1 & 0.9 & 13.8 & 9.3 & 9.5 & 2.3 & 9.0 & 4.3 \\
\hline & & & 75 & 6.4 & 7.4 & 7.7 & 3.2 & 3.0 & 11.5 & 7.5 & 3.8 & 6.0 & 15.7 & 1.3 \\
\hline & \multirow{4}{*}{60} & \multirow{4}{*}{ Good } & 15 & 6.6 & 2.8 & 14.9 & 5.9 & 5.1 & 4.4 & 6.8 & 14.6 & 3.7 & 5.3 & 4.5 \\
\hline & & & 35 & 6.9 & 7.8 & 12.5 & 5.9 & 6.9 & 14.7 & 12.8 & 17.1 & 5.1 & 3.3 & 6.0 \\
\hline & & & 55 & 4.4 & 6.9 & 8.7 & 6.1 & 10.9 & 10.3 & 8.5 & 13.3 & 7.1 & 1.9 & 10.6 \\
\hline & & & 75 & 1.9 & 7.0 & 5.5 & 3.8 & 8.6 & 10.2 & 2.3 & 13.1 & 10.3 & 3.0 & 13.1 \\
\hline & \multirow{4}{*}{90} & \multirow{4}{*}{ Good } & 15 & 5.9 & 8.4 & 12.9 & 10.1 & 10.4 & 8.6 & 6.4 & 14.5 & 3.3 & 3.9 & 5.5 \\
\hline & & & 35 & 5.9 & 7.5 & 18.4 & 7.9 & 7.4 & 14.1 & 12.2 & 14.3 & 4.7 & 6.3 & 4.5 \\
\hline & & & 55 & 7.4 & 7.6 & 12.5 & 12.1 & 8.3 & 8.2 & 6.4 & 9.5 & 5.5 & 8.7 & 9.3 \\
\hline & & & 75 & 8.7 & 3.5 & 18.9 & 7.8 & 9.6 & 4.9 & 3.9 & 10.8 & 8.1 & 8.9 & 11.0 \\
\hline & \multirow{4}{*}{120} & \multirow{4}{*}{ Good } & 15 & 8.2 & 9.0 & 13.0 & 18.5 & 11.7 & 8.8 & 9.8 & 9.7 & 4.0 & 4.1 & 5.6 \\
\hline & & & 35 & 8.2 & 9.0 & 11.1 & 9.3 & 11.4 & 13.7 & 17.7 & 8.7 & 6.8 & 6.6 & 6.0 \\
\hline & & & 55 & 10.5 & 8.3 & 12.6 & 14.2 & 10.3 & 10.3 & 6.8 & 10.7 & 8.2 & 5.8 & 5.2 \\
\hline & & & 75 & 16.7 & 6.0 & 21.1 & 15.9 & 14.4 & 11.0 & 7.9 & 20.2 & 14.3 & 6.9 & 9.2 \\
\hline & \multirow{4}{*}{140} & \multirow{4}{*}{ Good } & 15 & 9.8 & 9.6 & 16.7 & 12.8 & 19.5 & 12.7 & 12.5 & 10.2 & 6.4 & 4.9 & 8.5 \\
\hline & & & 35 & 7.7 & 7.5 & 13.6 & 11.7 & 21.4 & 12.6 & 16.2 & 13.7 & 5.8 & 4.8 & 6.1 \\
\hline & & & 55 & 13.6 & 9.7 & 22.8 & 11.8 & 17.2 & 12.6 & 11.5 & 15.7 & 5.6 & 6.9 & 7.7 \\
\hline & & & 75 & 6.7 & 9.5 & 12.9 & 14.7 & 18.0 & 13.3 & 14.2 & 11.1 & 7.3 & 4.5 & 4.6 \\
\hline
\end{tabular}


Table 15. Dynamic Amplification Factor for Steel Bridges (Good Surface)

\begin{tabular}{|c|c|c|c|c|c|c|c|c|c|c|c|c|c|c|}
\hline \multirow[b]{2}{*}{$\begin{array}{c}\text { Bridge } \\
\text { Type }\end{array}$} & \multirow[b]{2}{*}{$\begin{array}{c}\text { Span } \\
\text { Length } \\
\text { [feet] }\end{array}$} & \multirow[b]{2}{*}{$\begin{array}{l}\text { Surface } \\
\text { Condition }\end{array}$} & \multirow[b]{2}{*}{$\begin{array}{l}\text { Speed } \\
{[\mathrm{mph}]}\end{array}$} & \multicolumn{11}{|c|}{ Vehicle Type } \\
\hline & & & & $\mathrm{H}-20$ & HS-20 & $\begin{array}{c}\text { Type } \\
3\end{array}$ & $\begin{array}{l}\text { Type } \\
\text { 3S2 }\end{array}$ & $\begin{array}{l}\text { Type } \\
\text { 3S3 }\end{array}$ & $\begin{array}{l}\text { Type } \\
2 S 2\end{array}$ & $\begin{array}{l}\text { Type } \\
\text { 3S1 }\end{array}$ & SU4 & $\begin{array}{c}\text { 7-Axle } \\
\text { Rocky } \\
\text { Mountain } \\
\text { Double }\end{array}$ & $\begin{array}{l}8 \text { Axle } \\
\text { B-Train } \\
\text { Double }\end{array}$ & $\begin{array}{c}9 \text { Axle } \\
\text { Turnpike } \\
\text { Double }\end{array}$ \\
\hline \multirow{20}{*}{$\begin{array}{c}4 \\
4 \\
0 \\
0\end{array}$} & \multirow{4}{*}{30} & \multirow{4}{*}{ Good } & 15 & 11.3 & 6.3 & 9.6 & 8.4 & 3.8 & 5.3 & 8.5 & 9.6 & 5.8 & 9.6 & 6.3 \\
\hline & & & 35 & 12.9 & 11.1 & 14.1 & 4.3 & 6.8 & 13.3 & 15.7 & 12.9 & 1.6 & 5.1 & 4.5 \\
\hline & & & 55 & 9.2 & 11.0 & 13.6 & 1.8 & 2.1 & 15.9 & 10.5 & 7.0 & 2.4 & 9.3 & 4.3 \\
\hline & & & 75 & 1.7 & 6.6 & 7.1 & 3.6 & 3.0 & 14.3 & 6.1 & 6.0 & 6.4 & 16.7 & 1.2 \\
\hline & \multirow{4}{*}{60} & \multirow{4}{*}{ Good } & 15 & 7.1 & 5.5 & 18.9 & 8.4 & 8.0 & 13.7 & 9.6 & 16.6 & 5.7 & 5.5 & 4.5 \\
\hline & & & 35 & 5.5 & 10.3 & 13.3 & 12.2 & 8.9 & 14.0 & 17.4 & 21.8 & 5.5 & 3.5 & 5.5 \\
\hline & & & 55 & 8.9 & 5.5 & 13.0 & 8.7 & 12.7 & 17.0 & 8.6 & 14.1 & 6.2 & 4.5 & 10.9 \\
\hline & & & 75 & 5.4 & 7.6 & 15.7 & 12.6 & 9.5 & 11.4 & 4.6 & 15.8 & 9.3 & 8.2 & 12.7 \\
\hline & \multirow{4}{*}{90} & \multirow{4}{*}{ Good } & 15 & 5.8 & 10.1 & 16.5 & 15.7 & 9.5 & 12.7 & 10.7 & 18.6 & 6.1 & 6.4 & 11.5 \\
\hline & & & 35 & 8.5 & 10.3 & 15.7 & 16.9 & 14.7 & 16.8 & 15.2 & 26.7 & 8.0 & 10.3 & 6.9 \\
\hline & & & 55 & 13.0 & 5.5 & 22.1 & 22.4 & 14.0 & 22.7 & 7.9 & 21.8 & 12.3 & 13.1 & 8.4 \\
\hline & & & 75 & 14.9 & 6.8 & 20.6 & 24.7 & 24.2 & 10.8 & 9.2 & 22.8 & 12.9 & 10.7 & 17.4 \\
\hline & \multirow{4}{*}{120} & \multirow{4}{*}{ Good } & 15 & 8.1 & 10.1 & 13.4 & 18.9 & 16.6 & 11.9 & 12.0 & 18.5 & 9.0 & 6.1 & 7.8 \\
\hline & & & 35 & 8.8 & 9.2 & 18.4 & 15.1 & 18.0 & 11.9 & 15.3 & 18.4 & 10.3 & 9.1 & 7.6 \\
\hline & & & 55 & 17.2 & 5.8 & 26.3 & 16.4 & 18.1 & 15.2 & 11.2 & 18.2 & 11.9 & 10.0 & 9.5 \\
\hline & & & 75 & 15.3 & 11.7 & 23.5 & 16.9 & 21.0 & 14.5 & 13.7 & 18.8 & 13.1 & 10.2 & 11.5 \\
\hline & \multirow{4}{*}{140} & \multirow{4}{*}{ Good } & 15 & 10.3 & 9.2 & 19.9 & 13.2 & 19.0 & 14.4 & 13.2 & 12.9 & 6.7 & 5.0 & 8.8 \\
\hline & & & 35 & 9.9 & 7.5 & 15.4 & 11.3 & 20.8 & 12.1 & 14.5 & 20.2 & 6.0 & 6.1 & 7.8 \\
\hline & & & 55 & 16.1 & 8.5 & 21.0 & 14.6 & 21.5 & 16.9 & 11.6 & 14.7 & 7.0 & 6.6 & 7.3 \\
\hline & & & 75 & 8.0 & 10.8 & 21.0 & 14.5 & 14.0 & 9.8 & 10.0 & 13.3 & 8.1 & 4.6 & 8.3 \\
\hline
\end{tabular}


The results of this averaging have been shown in Figure 39 and Figure 40.

Table 16. Different Truck Categories

\begin{tabular}{|c|c|c|}
\hline $\begin{array}{c}\text { Single Unit } \\
\text { Trucks }\end{array}$ & $\begin{array}{c}\text { Tractor } \\
\text { Semitrailers }\end{array}$ & Twin (Double) Trailers \\
\hline \hline H-20 & HS-20 & $\begin{array}{c}\text { 7-Axle Rocky Mountain } \\
\text { Double }\end{array}$ \\
\hline Type 3 & Type 3S2 & 8-Axle B-Train Double \\
\hline SU4 & Type 3S3 & 9-Axle Turnpike Double \\
\hline & Type 2S2 & \\
\cline { 2 - 2 } & Type 3S1 & \\
\hline
\end{tabular}

It can be observed from the results of these two figures that the dynamic amplification factor is always below $33 \%$ when considering the Good surface condition for the bridge.

It can also be said that the highest values of the dynamic amplification factor belong to the cases of Single Unit Trucks. Cases of Tractor Semitrailer also have higher dynamic amplification factor comparing to the cases of Twin (Double) Trailers. These results show consistency with the results obtained from the previous section where the heavier trucks generated the lowest dynamic amplification factors.

Another observation from these results is that the increase in the vehicle speed does not always result in higher dynamic amplification. For the case of Twin (Double) Trailers in most cases there is a direct relation between the vehicle speed and the dynamic amplification factor and the highest values of the DAF are achieved when the vehicle speed is at its most. (i.e. $75 \mathrm{mph}$ ) For the case of Tractor Semitrailer the increasing trend for the DAF cannot be seen but the maximum values of DAF in this case mostly happen when the vehicle speed is around the average speed of $35 \mathrm{mph}$. 
A closer look at the results for different span lengths also shows that as the span length increases, in some but not all cases, the values of dynamic amplification factor also increase.

The reason for this increase is that, with the increase in the span length, the maximum deflection in the middle of the bridge also increases and more fluctuations of the bridge would happen. These extra vibrations would result in larger differences between the cases of static and dynamic responses.

Value of moment at different grid points of the bridge was also calculated as a measure to calculate the stresses which were endured by the bridge. These values were recorded for the static and dynamic truck loading at each time step and the results for the prestressed concrete bridge with the span length of $140 \mathrm{ft}$. for the Good road surface condition and $15 \mathrm{mph}$ vehicle speed is shown in Figure 41 to Figure 43.

It can be observed from these graphs that the maximum moment in the bridge is resulted when the heaviest trucks (Longer Combination Vehicles such as 9 Axle Turnpike Double and 8 Axle B-Train Double) pass the bridge.

The results when Very Good road surface condition was used, is also shown here to make a comparison between the two cases of surface condition. The displacement at the midspan of the $60 \mathrm{ft}$. span Steel Bridge when different trucks travel on the bridge is shown in Figure 44 to Figure 46. All these figures show the static and dynamic responses as it was explained before and these responses have been recorded for a point in the middle of the bridge which has the largest deflection.

Using the relationship given in equation ( 91 ), the Dynamic Amplification Factor (DAF) for all the vehicle speeds and all the bridge cases were calculated. The summary of all 
the DAFs for the case of Very Good surface condition is given in Table 17 and Table 18. It can be observed from these tables that the DAF values are still smaller than the 0.33 suggested by AASHTO LRFD and these numbers are even smaller comparing to the case of Good surface condition.

Using the same truck categories which were given in Table 16, the results for all the eleven trucks were summarized and shown in the graphs of Figure 47 and Figure 48. Comparing the results in those figures and of Figure 39 and Figure 40, shows that the values of the Dynamic Amplification Factor for the case of Very Good road surface condition are generally smaller than the values of DAF for the case of Good surface condition which is sensible.

The results for the moment at the midpoint of $120 \mathrm{ft}$. steel bridge was also recorded for the case of Very Good surface condition and the comparison between the static and dynamic responses are shown in Figure 49 to Figure 51.

Finally, all results for the discussed cases were grouped and shown in Figure 52 to Figure 54. It can be seen that in the majority of cases the Dynamic Amplification Factor (DAF) is higher in the case of Good surface condition and the values are below $33 \%$. Also the highest values of DAF happen when the Single Unit Trucks is on the road.

One reason that can be mentioned for getting the highest values of DAF for the Single Unit Trucks group is that the weight of a single axle in the trucks under this category can be as high as 34 kips and also the distance between the axles are smaller because the total length of the truck is small comparing to the other two cases. So with the heavy trucks, the distribution of the loads over more number of axles and more distance between these axles result in smaller values for DAF. 


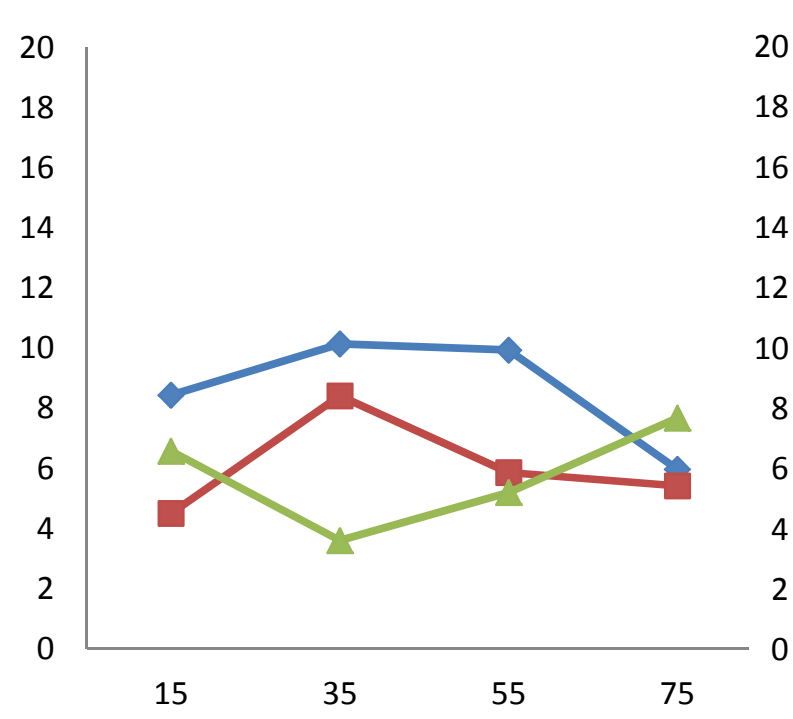

(a) 30' Span Length

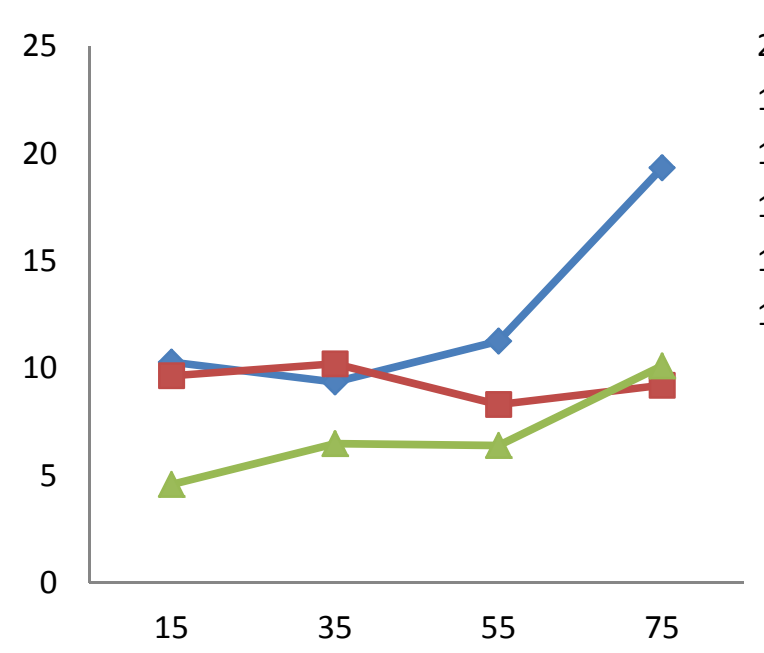

(d) 120' Span Length

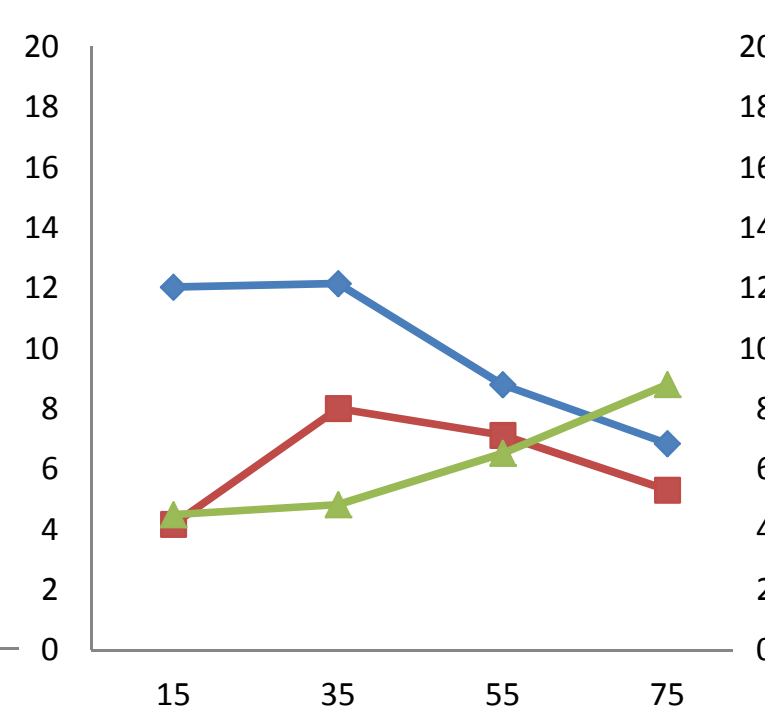

(b) 60' Span Length

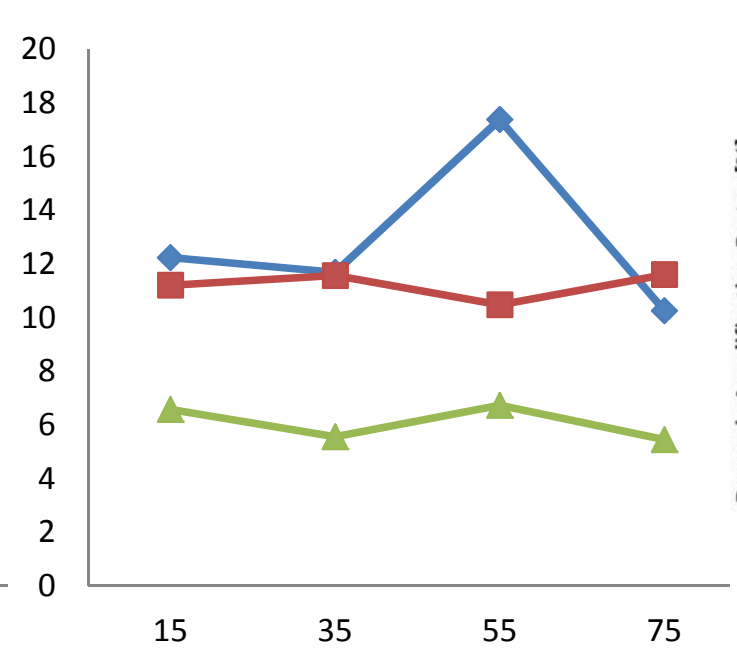

(e) 140 ' Span Length

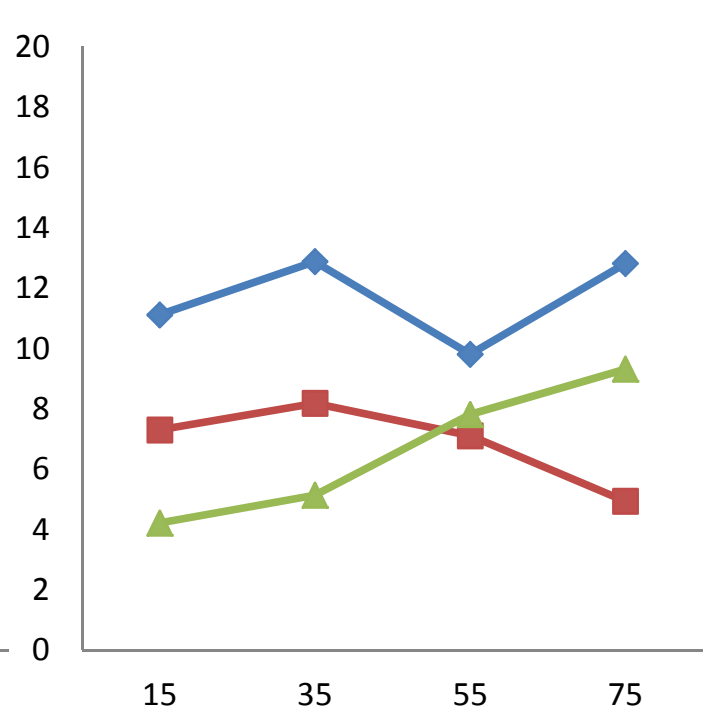

(c) 90' Span Length

Figure 39. Prestressed Concrete Bridges DAF for Different Vehicle Categories (Good Surface) 


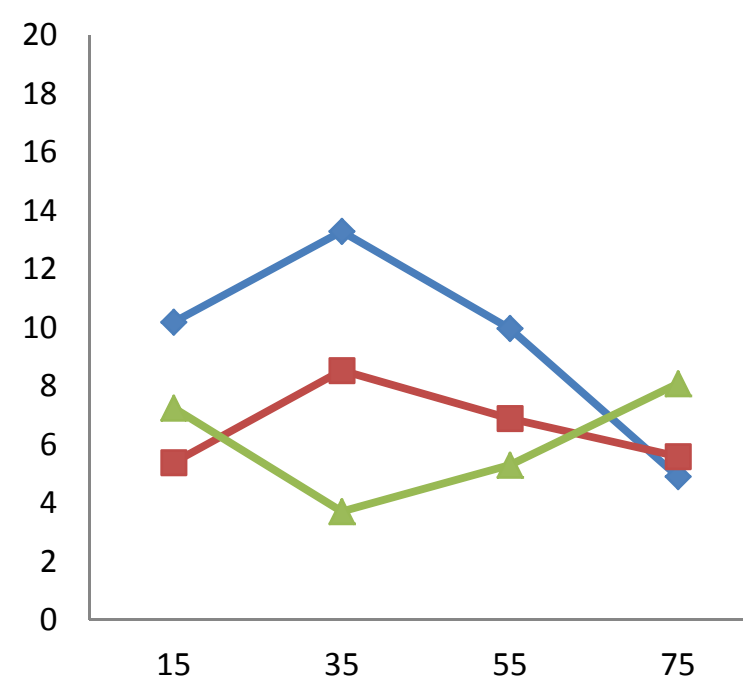

(a) 30' Span Length

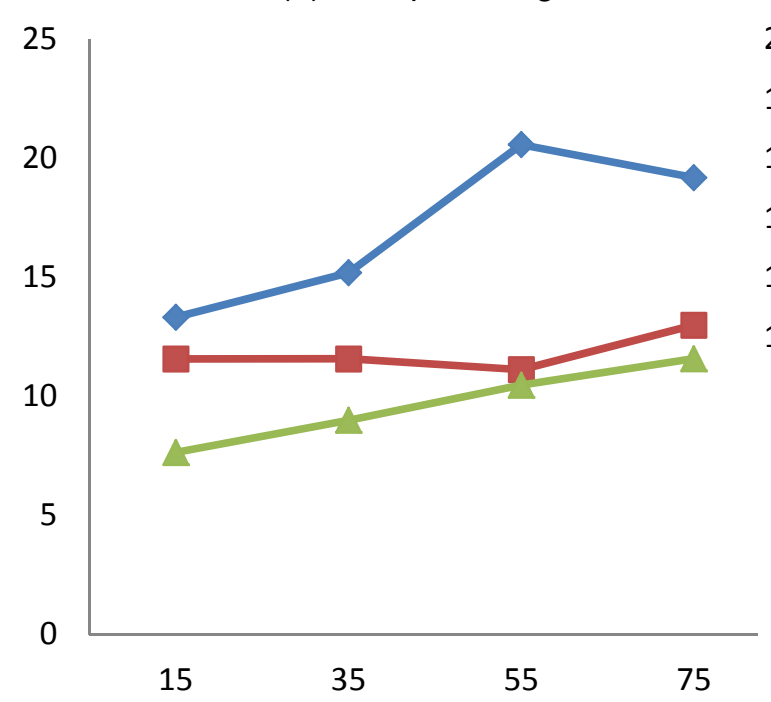

(d) 120 ' Span Length

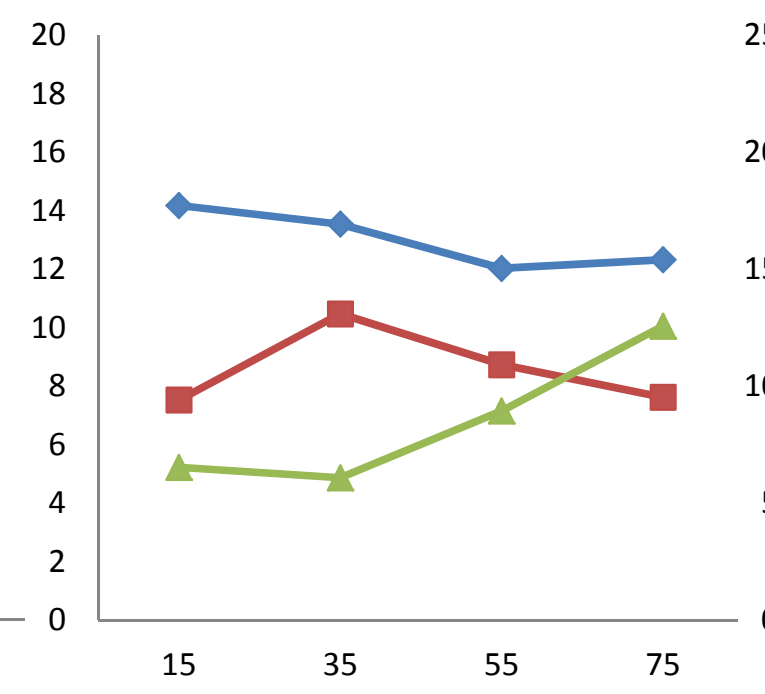

(b) 60' Span Length

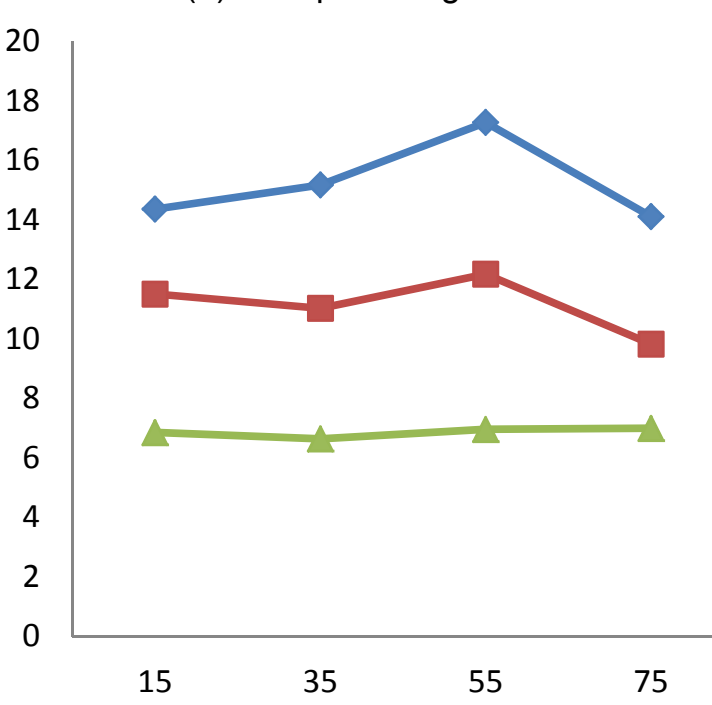

(e) 140' Span Length

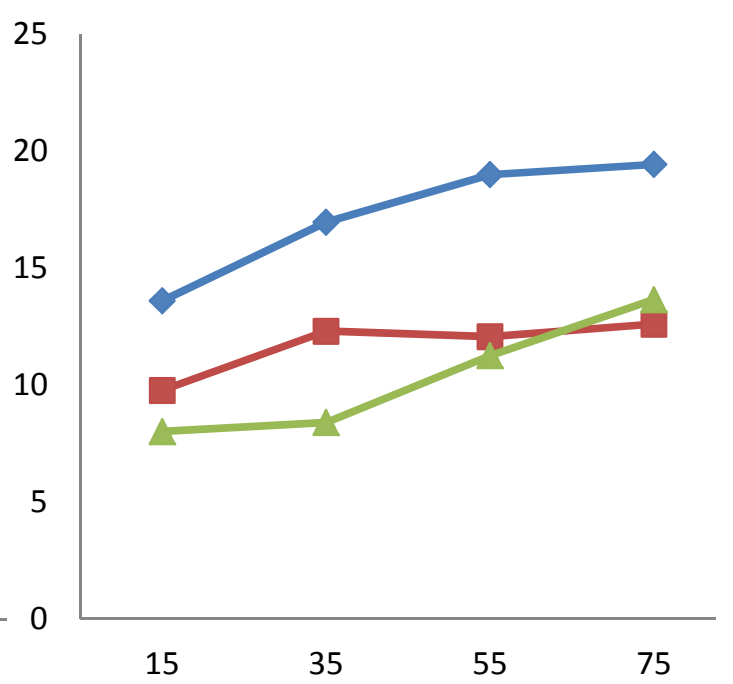

(c) 90' Span Length

Figure 40. Steel Bridges DAF for Different Vehicle Categories (Good Surface) 


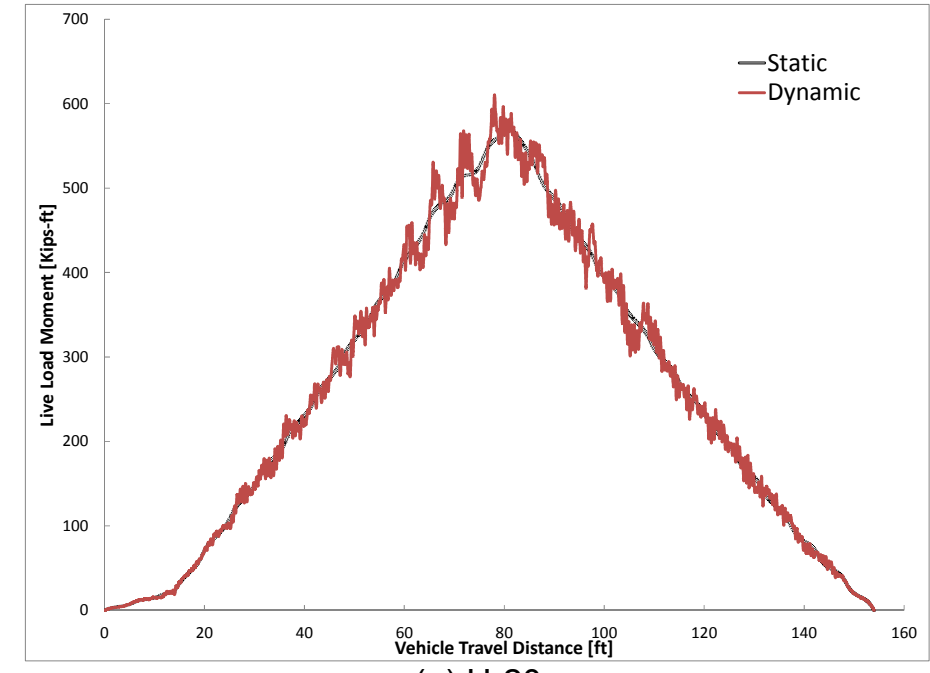

(a) $\mathrm{H}-20$

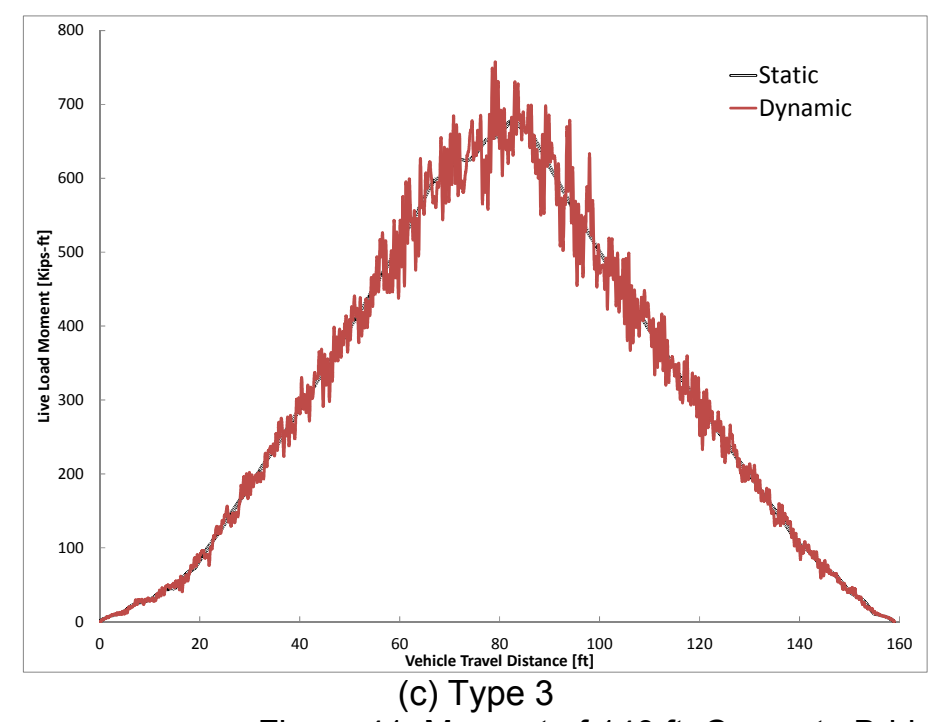

Figure 41. Moment of $140 \mathrm{ft}$. Concrete Bridge due to Single Unit Trucks and HS-20 (Good Surface)

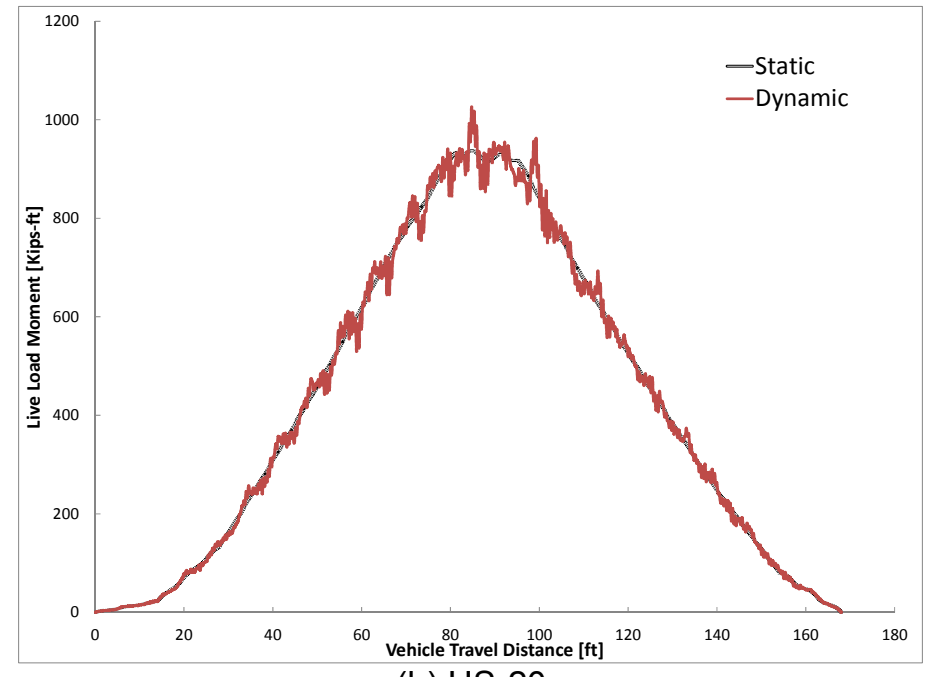

(b) HS-20

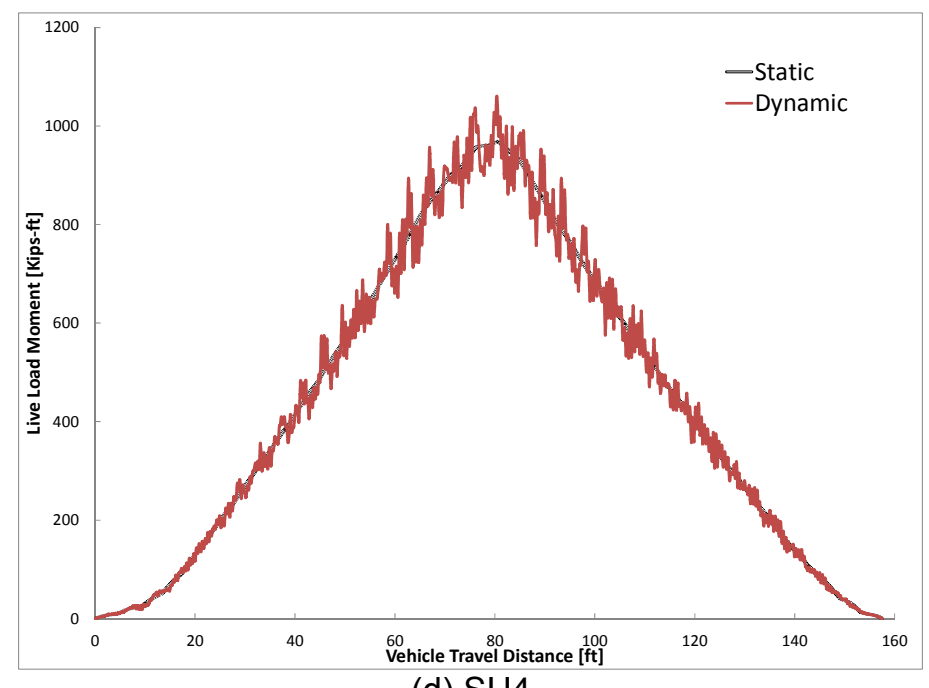

(d) SU4 


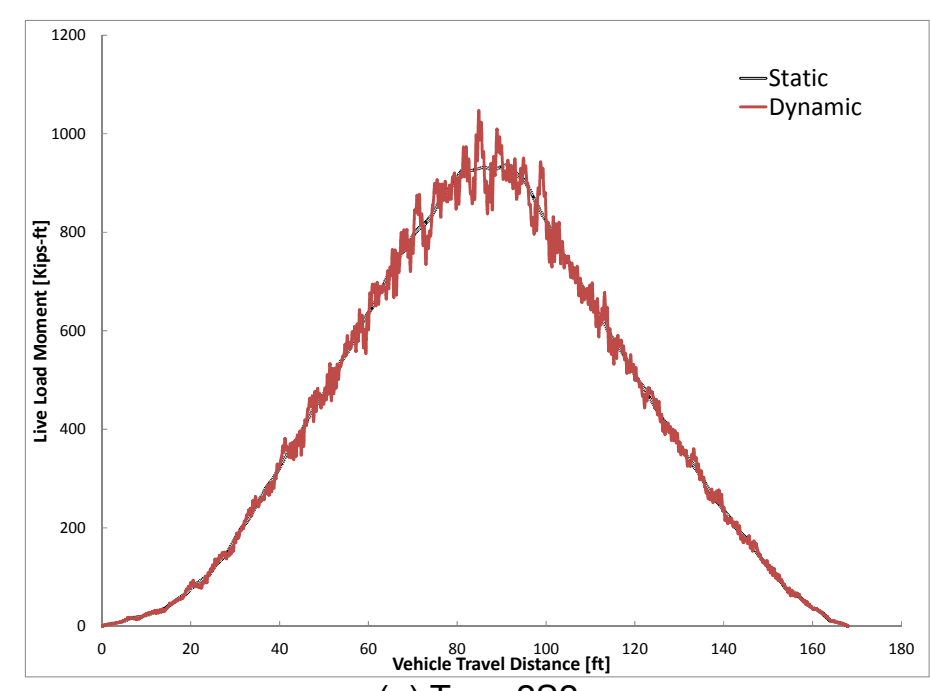

(e) Type 2S2

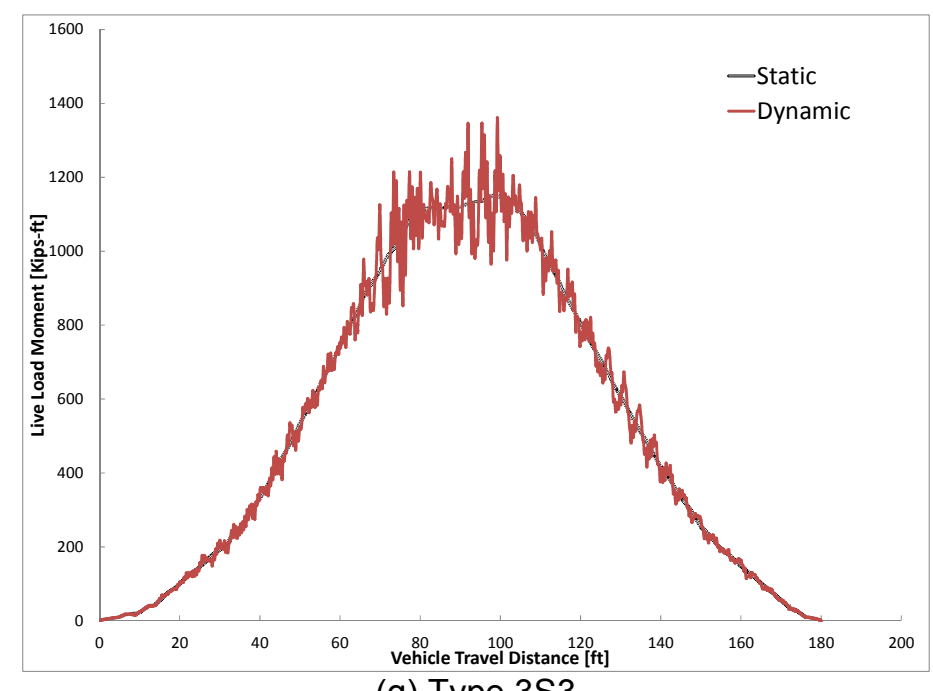

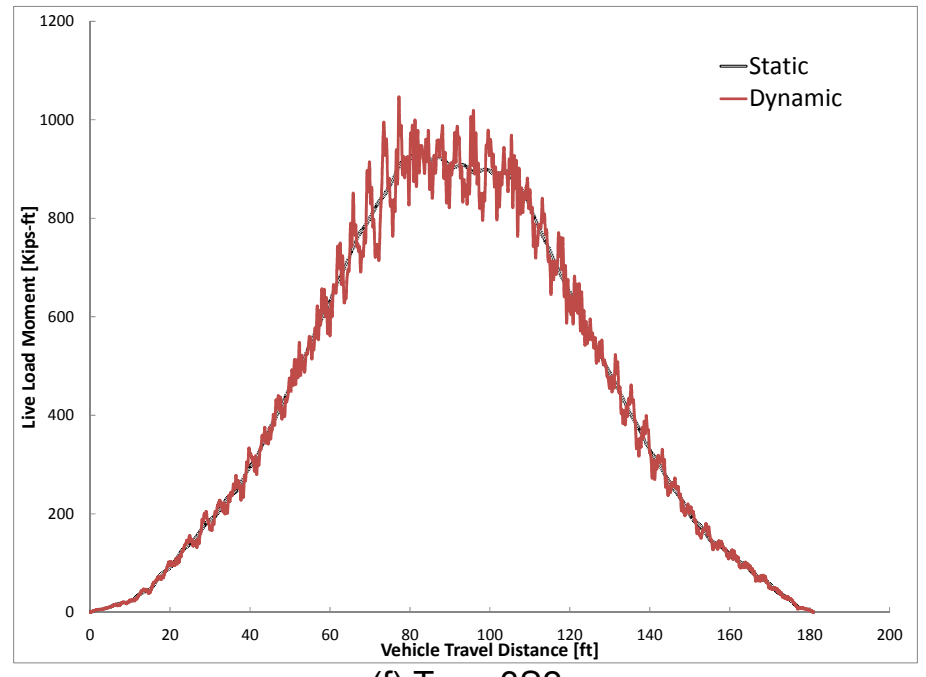

(f) Type 3S2

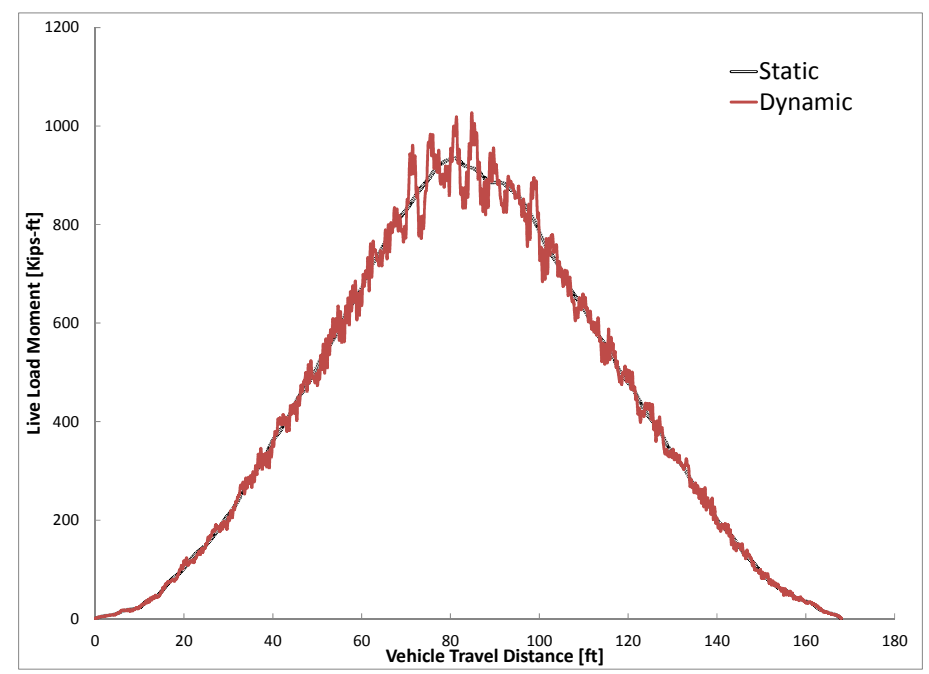

(h) Type 3S1

Figure 42. Moment of $140 \mathrm{ft}$. Concrete Bridge due to Tractor Semitrailers (Good Surface) 


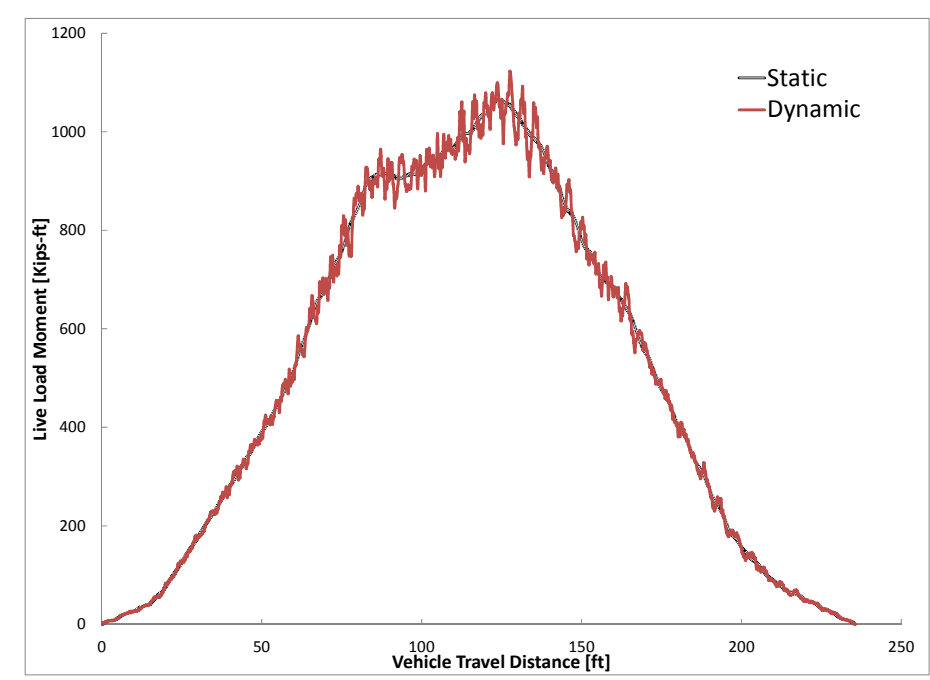

(i) 7-Axle Rocky Mountain Double

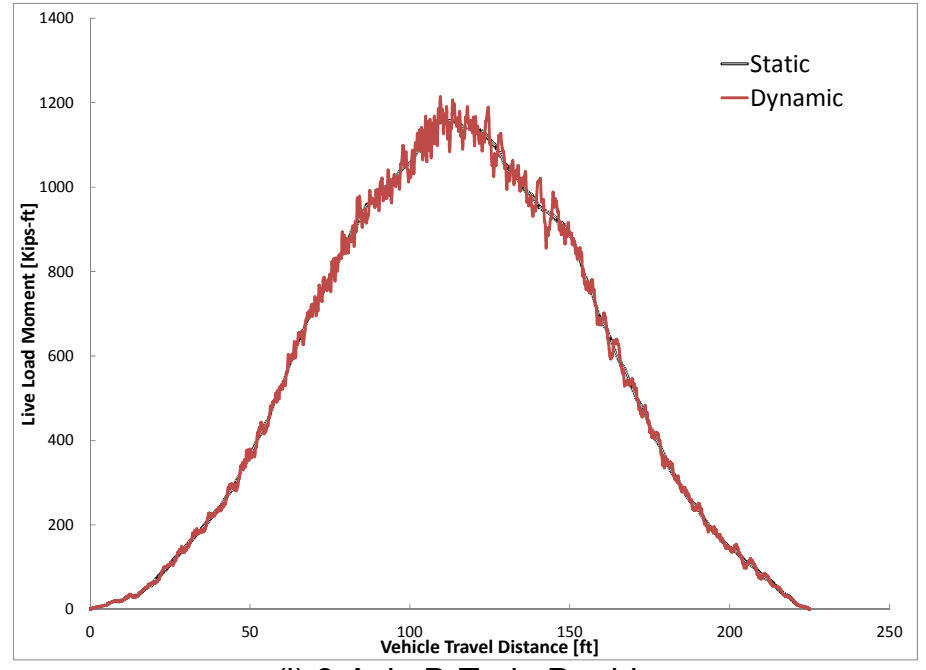

(j) 8-Axle B-Train Double

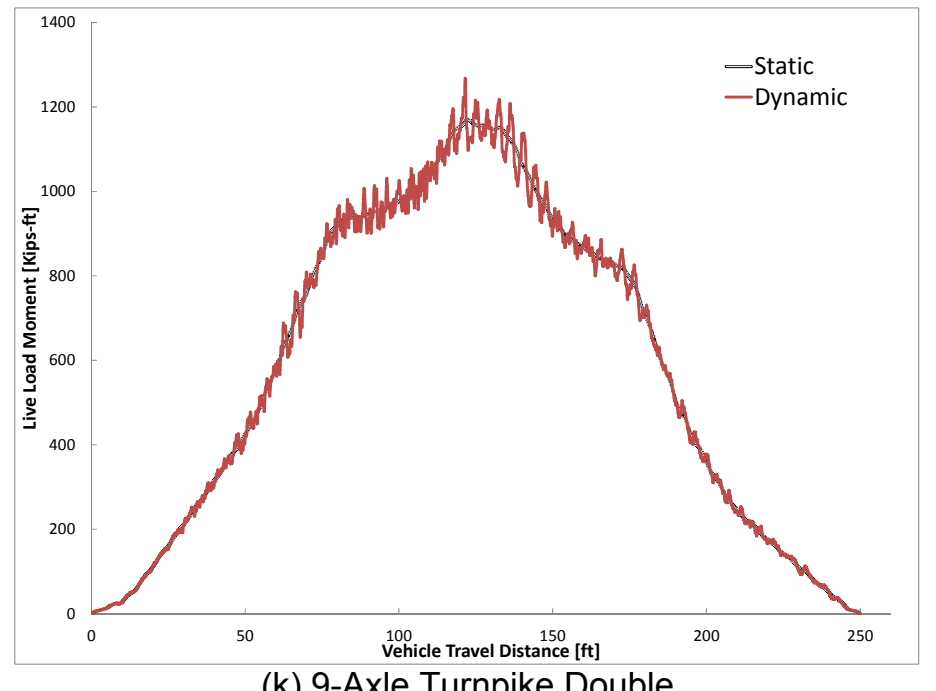

(k) 9-Axle Turnpike Double

Figure 43. Moment of $140 \mathrm{ft}$. Concrete Bridge due to Truck and Double Trailers (Good Surface) 


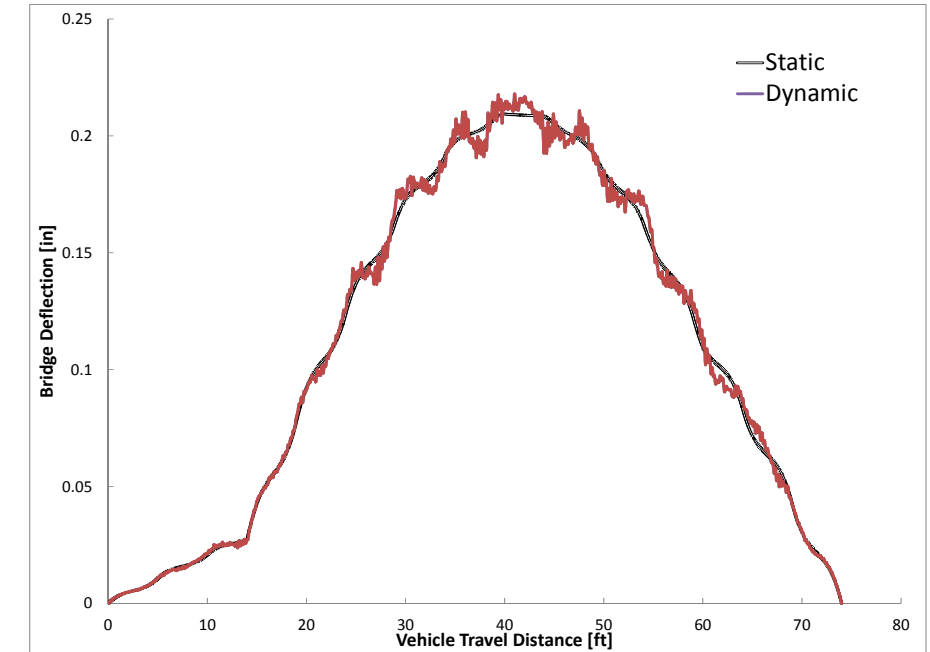

(a) $\mathrm{H}-2 \mathrm{O}$

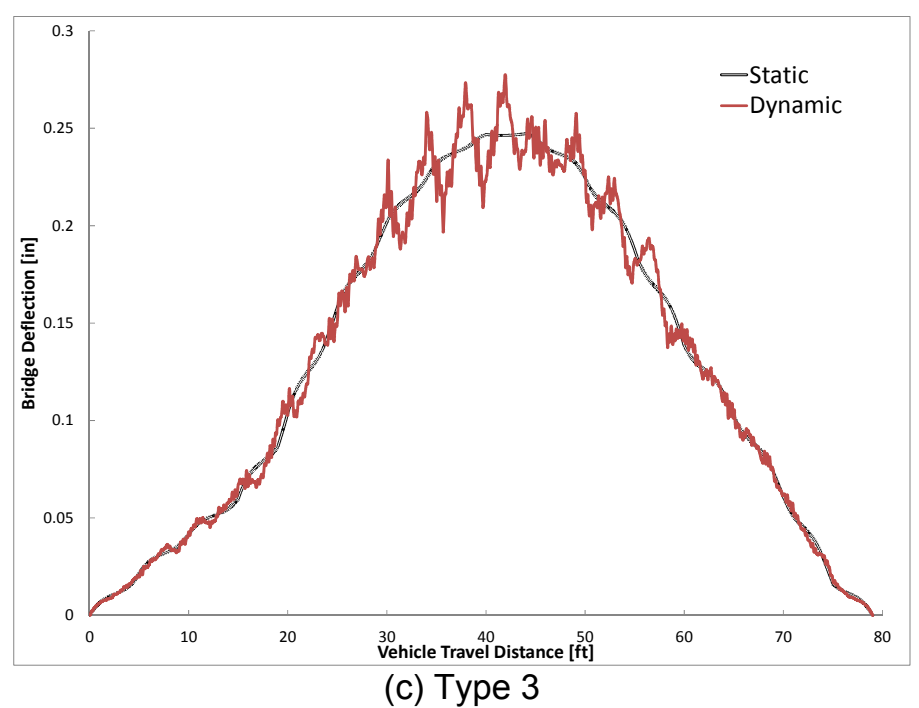

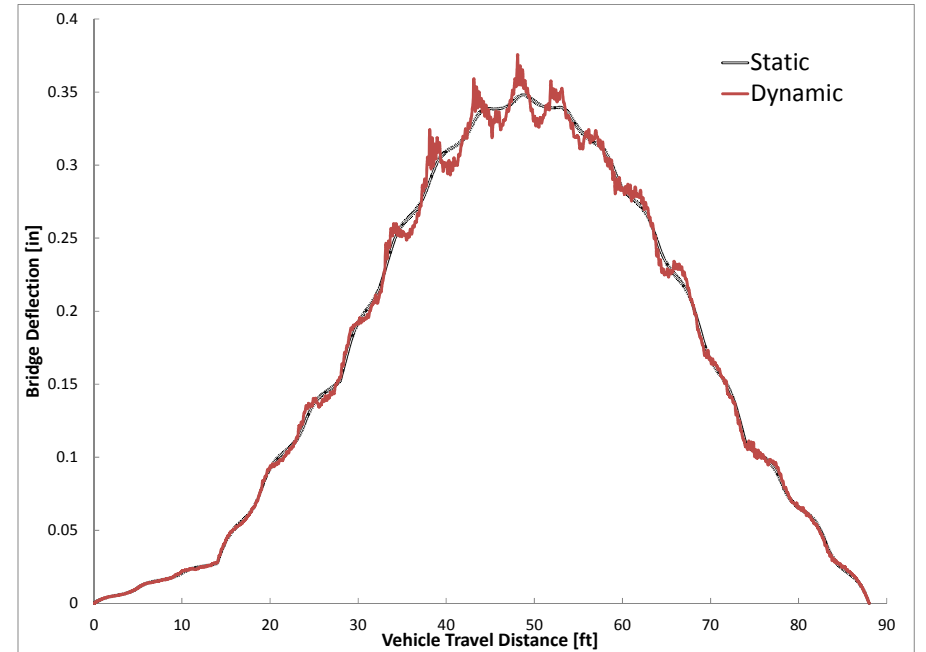

(b) HS-20

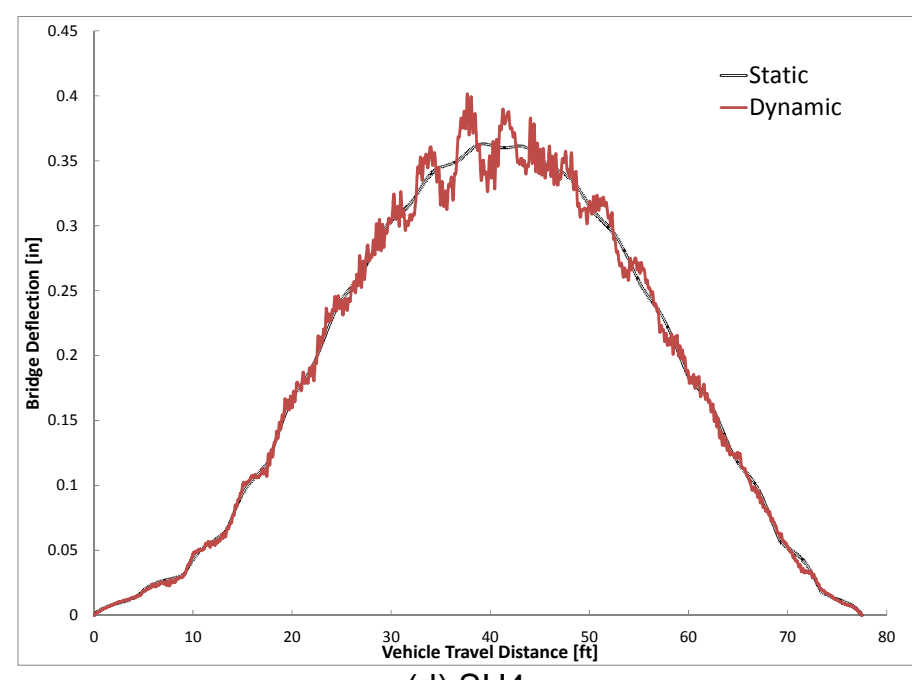

(d) SU4

Figure 44. Displacement of $60 \mathrm{ft}$. Steel Bridge due to Single Unit Trucks and HS-20 (Very Good Surface) 


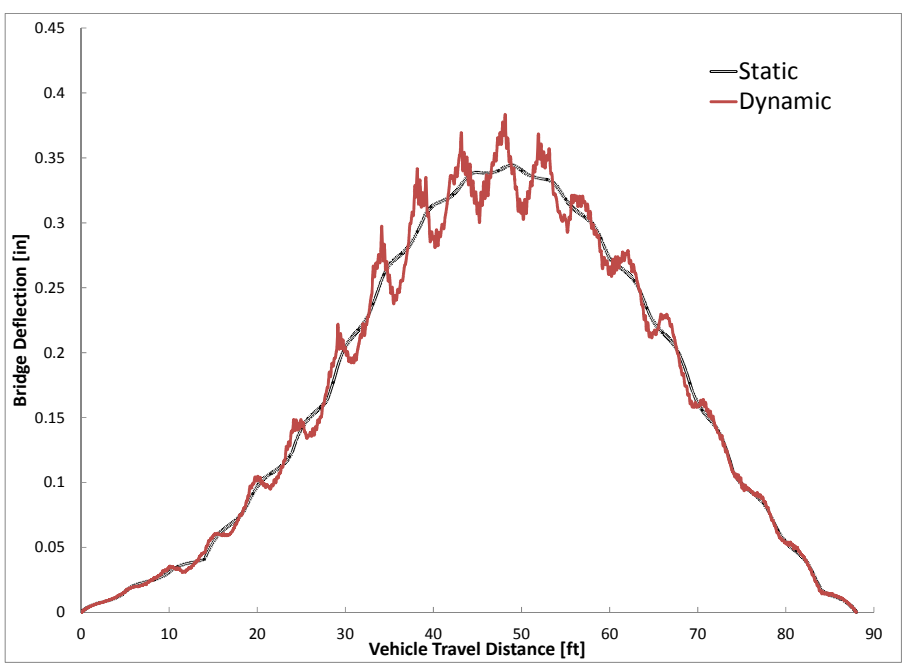

(e) Type 2S2

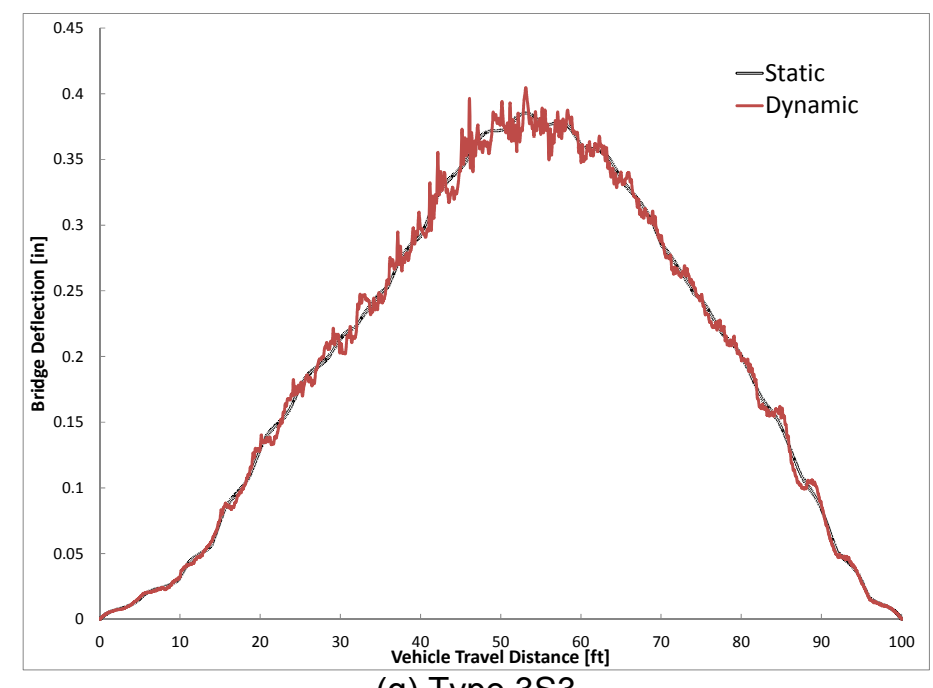

(g) Type 353

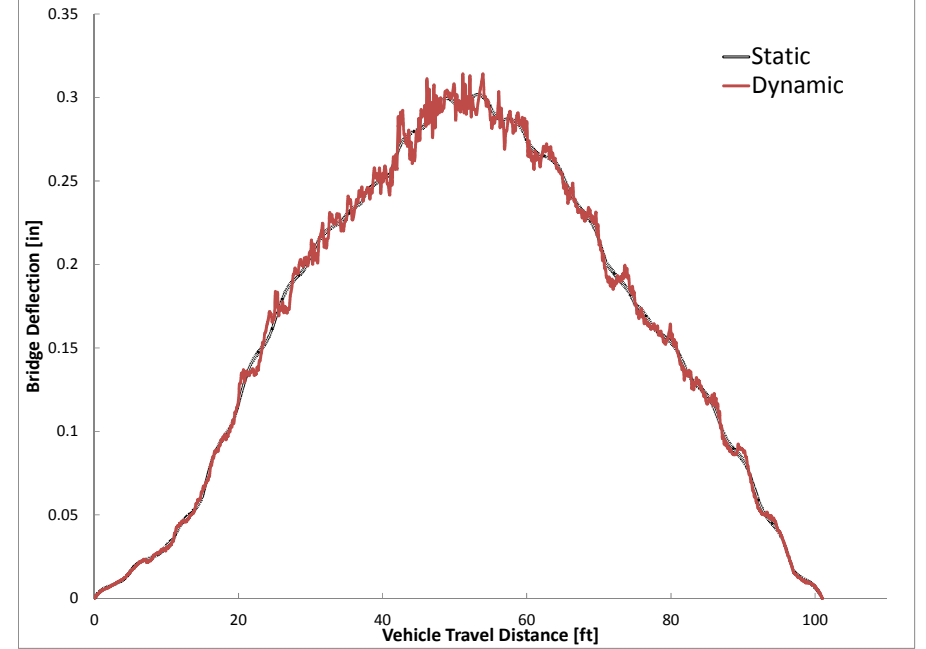

(f) Type 3S2

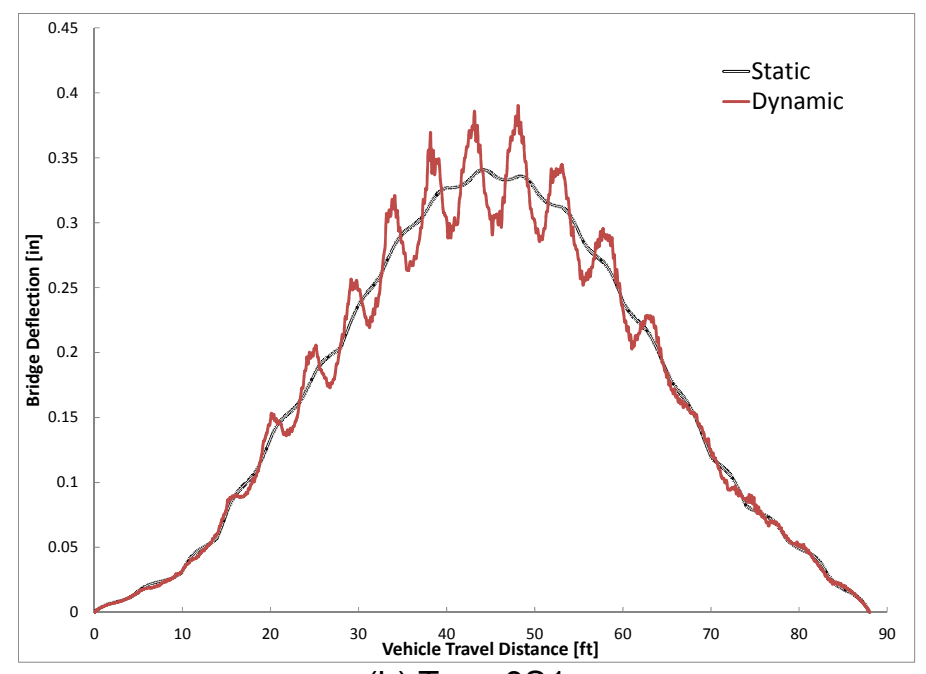

(h) Type 3S1

Figure 45. Displacement of $60 \mathrm{ft}$. Steel Bridge due to Tractor Semitrailers (Very Good Surface) 


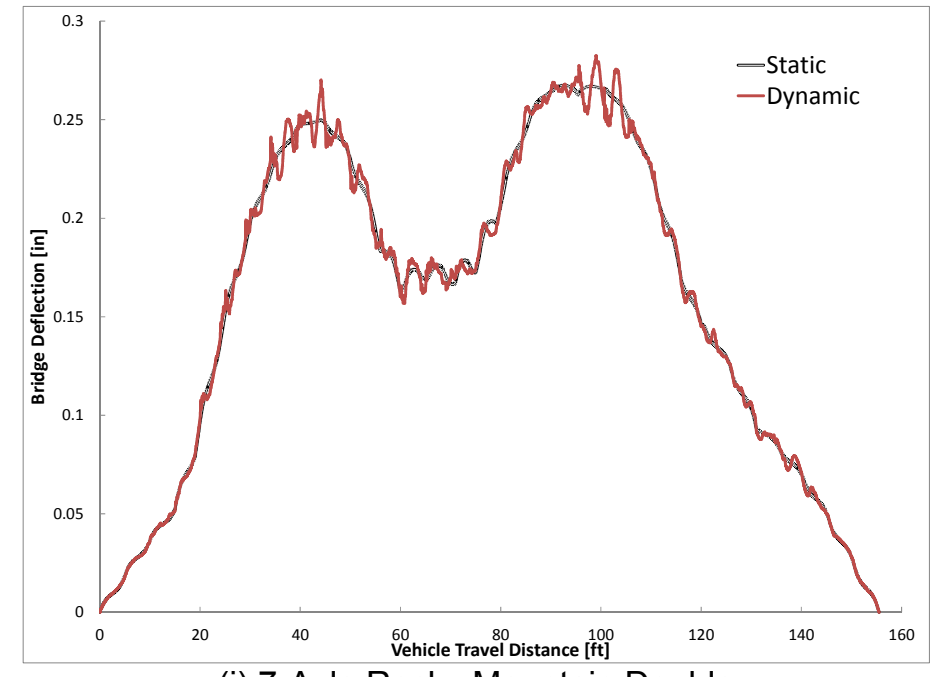

(i) 7-Axle Rocky Mountain Double
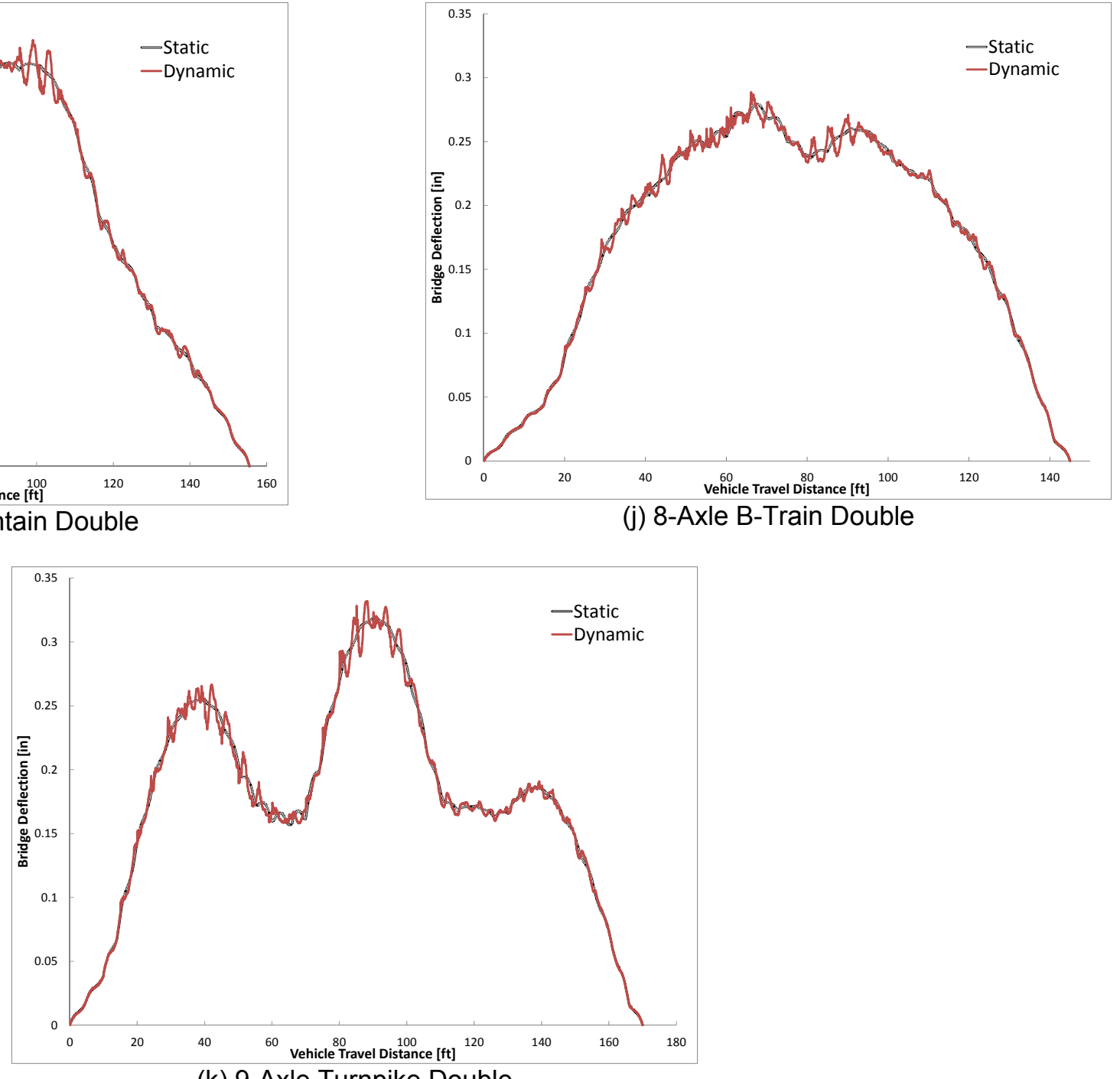

(k) 9-Axle Turnpike Double

Figure 46. Displacement of $60 \mathrm{ft}$. Steel Bridge due to Truck and Double Trailers (Very Good Surface) 
Table 17. Dynamic Amplification Factor for Prestreesed Concrete Bridges (Very Good Surface)

\begin{tabular}{|c|c|c|c|c|c|c|c|c|c|c|c|c|c|c|}
\hline \multirow[b]{2}{*}{$\begin{array}{c}\text { Bridge } \\
\text { Type }\end{array}$} & \multirow[b]{2}{*}{$\begin{array}{l}\text { Span } \\
\text { Length } \\
\text { [feet] }\end{array}$} & \multirow[b]{2}{*}{$\begin{array}{l}\text { Surface } \\
\text { Condition }\end{array}$} & \multirow[b]{2}{*}{$\begin{array}{l}\text { Speed } \\
{[\mathrm{mph}]}\end{array}$} & \multicolumn{11}{|c|}{ Vehicle Type } \\
\hline & & & & $\mathrm{H}-20$ & HS-20 & $\begin{array}{c}\text { Type } \\
3\end{array}$ & $\begin{array}{l}\text { Type } \\
\text { 3S2 }\end{array}$ & $\begin{array}{l}\text { Type } \\
\text { 3S3 }\end{array}$ & $\begin{array}{l}\text { Type } \\
2 \text { 2S2 }\end{array}$ & $\begin{array}{l}\text { Type } \\
\text { 3S1 }\end{array}$ & SU4 & $\begin{array}{l}\text { 7-Axle } \\
\text { Rocky } \\
\text { Mountain } \\
\text { Double }\end{array}$ & $\begin{array}{l}8 \text { Axle } \\
\text { B-Train } \\
\text { Double }\end{array}$ & $\begin{array}{c}9 \text { Axle } \\
\text { Turnpike } \\
\text { Double }\end{array}$ \\
\hline \multirow{20}{*}{$\begin{array}{l}\frac{1}{0} \\
\frac{1}{0} \\
\frac{0}{0}\end{array}$} & \multirow{4}{*}{30} & \multirow{4}{*}{$\begin{array}{l}\text { Very } \\
\text { Good }\end{array}$} & 15 & 4.0 & 4.0 & 2.9 & 5.5 & 6.5 & 4.4 & 5.7 & 5.5 & 1.7 & 2.5 & 1.8 \\
\hline & & & 35 & 6.6 & 1.5 & 5.0 & 9.4 & 0.7 & 1.5 & 5.7 & 3.3 & 1.9 & 3.3 & 1.3 \\
\hline & & & 55 & 10.9 & 5.1 & 4.3 & 6.7 & 1.1 & 1.6 & 2.4 & 2.5 & 6.2 & 8.9 & 1.7 \\
\hline & & & 75 & 17.8 & 5.2 & 1.6 & 3.4 & 7.3 & 1.9 & 6.4 & 4.1 & 1.6 & 1.1 & 1.2 \\
\hline & \multirow{4}{*}{60} & \multirow{4}{*}{$\begin{array}{l}\text { Very } \\
\text { Good }\end{array}$} & 15 & 3.6 & 3.7 & 9.5 & 3.4 & 2.2 & 7.7 & 9.1 & 7.3 & 4.0 & 1.6 & 3.7 \\
\hline & & & 35 & 3.6 & 3.7 & 8.3 & 5.8 & 2.5 & 3.1 & 6.6 & 5.6 & 4.0 & 0.9 & 2.8 \\
\hline & & & 55 & 4.1 & 2.9 & 9.6 & 5.4 & 5.0 & 4.1 & 2.2 & 5.0 & 4.5 & 8.0 & 6.6 \\
\hline & & & 75 & 8.9 & 0.9 & 7.9 & 1.8 & 1.5 & 2.4 & 5.3 & 4.3 & 3.1 & 5.3 & 4.7 \\
\hline & \multirow{4}{*}{90} & \multirow{4}{*}{$\begin{array}{l}\text { Very } \\
\text { Good }\end{array}$} & 15 & 5.3 & 2.0 & 8.1 & 4.6 & 4.0 & 3.7 & 6.6 & 9.7 & 2.1 & 1.0 & 2.7 \\
\hline & & & 35 & 4.6 & 3.0 & 6.9 & 5.3 & 4.1 & 5.7 & 8.0 & 8.3 & 2.7 & 3.2 & 3.3 \\
\hline & & & 55 & 7.3 & 3.1 & 6.3 & 10.7 & 6.1 & 4.0 & 3.2 & 5.2 & 6.2 & 5.1 & 5.8 \\
\hline & & & 75 & 11.0 & 1.4 & 4.2 & 9.1 & 6.0 & 4.1 & 2.0 & 4.8 & 5.4 & 6.8 & 7.5 \\
\hline & \multirow{4}{*}{120} & \multirow{4}{*}{$\begin{array}{l}\text { Very } \\
\text { Good }\end{array}$} & 15 & 4.6 & 4.9 & 9.3 & 4.3 & 4.1 & 4.0 & 5.5 & 7.5 & 4.7 & 2.2 & 3.0 \\
\hline & & & 35 & 4.6 & 4.4 & 10.4 & 6.4 & 5.8 & 5.1 & 9.5 & 6.6 & 3.2 & 4.9 & 4.6 \\
\hline & & & 55 & 4.1 & 3.2 & 6.8 & 7.7 & 6.5 & 4.1 & 4.0 & 5.2 & 5.3 & 4.8 & 5.4 \\
\hline & & & 75 & 12.1 & 2.5 & 11.9 & 5.8 & 7.2 & 4.3 & 5.2 & 11.4 & 4.4 & 7.8 & 6.7 \\
\hline & \multirow{4}{*}{140} & \multirow{4}{*}{$\begin{array}{l}\text { Very } \\
\text { Good }\end{array}$} & 15 & 6.0 & 5.4 & 7.2 & 4.8 & 4.0 & 6.4 & 6.6 & 8.3 & 5.6 & 4.3 & 8.7 \\
\hline & & & 35 & 7.7 & 7.5 & 13.6 & 11.7 & 21.4 & 12.6 & 16.2 & 13.7 & 5.8 & 4.8 & 6.1 \\
\hline & & & 55 & 5.0 & 4.4 & 12.0 & 8.8 & 8.3 & 4.1 & 3.3 & 6.3 & 5.6 & 6.6 & 5.6 \\
\hline & & & 75 & 6.9 & 6.1 & 5.8 & 7.1 & 9.5 & 4.9 & 9.1 & 6.7 & 8.4 & 6.8 & 6.3 \\
\hline
\end{tabular}


Table 18. Dynamic Amplification Factor for Steel Bridges (Very Good Surface)

\begin{tabular}{|c|c|c|c|c|c|c|c|c|c|c|c|c|c|c|}
\hline \multirow[b]{2}{*}{$\begin{array}{l}\text { Bridge } \\
\text { Type }\end{array}$} & \multirow[b]{2}{*}{$\begin{array}{l}\text { Span } \\
\text { Length } \\
\text { [feet] }\end{array}$} & \multirow[b]{2}{*}{$\begin{array}{l}\text { Surface } \\
\text { Condition }\end{array}$} & \multirow[b]{2}{*}{$\begin{array}{l}\text { Speed } \\
{[\mathrm{mph}]}\end{array}$} & \multicolumn{11}{|c|}{ Vehicle Type } \\
\hline & & & & $\mathrm{H}-20$ & HS-20 & $\begin{array}{c}\text { Type } \\
3\end{array}$ & $\begin{array}{l}\text { Type } \\
3 S 2\end{array}$ & $\begin{array}{l}\text { Type } \\
\text { 3S3 }\end{array}$ & $\begin{array}{l}\text { Type } \\
2 \mathrm{~S} 2\end{array}$ & $\begin{array}{l}\text { Type } \\
\text { 3S1 }\end{array}$ & SU4 & $\begin{array}{l}\text { 7-Axle } \\
\text { Rocky } \\
\text { Mountain } \\
\text { Double }\end{array}$ & $\begin{array}{l}8 \text { Axle } \\
\text { B-Train } \\
\text { Double }\end{array}$ & $\begin{array}{l}9 \text { Axle } \\
\text { Turnpike } \\
\text { Double }\end{array}$ \\
\hline \multirow{20}{*}{$\begin{array}{l}0 \\
0 \\
0 \\
0\end{array}$} & \multirow{4}{*}{30} & \multirow{4}{*}{$\begin{array}{l}\text { Very } \\
\text { Good }\end{array}$} & 15 & 3.5 & 4.9 & 4.2 & 6.9 & 8.2 & 5.0 & 9.4 & 8.9 & 1.2 & 3.2 & 3.9 \\
\hline & & & 35 & 6.8 & 3.5 & 6.0 & 10.5 & 0.2 & 1.6 & 6.4 & 5.1 & 1.8 & 3.5 & 2.4 \\
\hline & & & 55 & 7.7 & 6.9 & 6.8 & 6.3 & 0.6 & 1.1 & 3.5 & 3.4 & 6.8 & 9.3 & 2.2 \\
\hline & & & 75 & 18.0 & 7.3 & 5.8 & 2.5 & 6.3 & 7.5 & 5.5 & 4.4 & 1.3 & 0.6 & 2.1 \\
\hline & \multirow{4}{*}{60} & \multirow{4}{*}{$\begin{array}{l}\text { Very } \\
\text { Good }\end{array}$} & 15 & 4.1 & 7.9 & 12.3 & 4.2 & 5.1 & 11.3 & 14.5 & 10.6 & 5.7 & 3.3 & 4.2 \\
\hline & & & 35 & 5.8 & 6.1 & 9.0 & 6.3 & 4.6 & 8.0 & 9.6 & 8.3 & 6.9 & 3.2 & 5.2 \\
\hline & & & 55 & 3.1 & 3.6 & 9.8 & 10.3 & 7.6 & 6.3 & 5.4 & 7.7 & 7.6 & 7.8 & 11.0 \\
\hline & & & 75 & 7.5 & 3.5 & 10.9 & 3.3 & 1.1 & 4.1 & 7.0 & 4.0 & 6.3 & 7.8 & 4.3 \\
\hline & \multirow{4}{*}{90} & \multirow{4}{*}{$\begin{array}{l}\text { Very } \\
\text { Good }\end{array}$} & 15 & 5.0 & 3.6 & 8.2 & 7.7 & 7.1 & 5.4 & 9.0 & 8.8 & 6.5 & 4.5 & 5.6 \\
\hline & & & 35 & 4.9 & 4.2 & 17.0 & 11.0 & 9.1 & 6.4 & 6.3 & 12.4 & 7.9 & 5.2 & 5.9 \\
\hline & & & 55 & 4.9 & 2.3 & 6.7 & 15.4 & 11.4 & 5.3 & 3.0 & 9.8 & 8.0 & 10.6 & 9.4 \\
\hline & & & 75 & 14.2 & 1.5 & 8.8 & 13.2 & 11.2 & 4.6 & 3.3 & 8.7 & 10.5 & 12.5 & 10.0 \\
\hline & \multirow{4}{*}{120} & \multirow{4}{*}{$\begin{array}{l}\text { Very } \\
\text { Good }\end{array}$} & 15 & 5.9 & 4.4 & 12.1 & 6.1 & 6.4 & 4.0 & 8.4 & 7.7 & 8.2 & 4.4 & 5.7 \\
\hline & & & 35 & 4.8 & 5.5 & 15.0 & 12.6 & 12.7 & 6.7 & 9.1 & 10.6 & 4.4 & 7.1 & 5.2 \\
\hline & & & 55 & 4.9 & 4.1 & 10.8 & 10.0 & 10.6 & 6.1 & 5.9 & 11.9 & 9.9 & 6.0 & 8.3 \\
\hline & & & 75 & 11.4 & 2.0 & 9.8 & 10.0 & 9.5 & 4.0 & 4.1 & 6.2 & 9.4 & 5.8 & 7.7 \\
\hline & \multirow{4}{*}{140} & \multirow{4}{*}{$\begin{array}{l}\text { Very } \\
\text { Good }\end{array}$} & 15 & 4.3 & 5.2 & 8.2 & 4.9 & 4.7 & 6.1 & 7.0 & 6.9 & 6.3 & 4.6 & 9.2 \\
\hline & & & 35 & 5.3 & 6.1 & 7.5 & 12.7 & 7.5 & 5.3 & 8.1 & 11.6 & 4.6 & 7.0 & 5.2 \\
\hline & & & 55 & 6.1 & 5.3 & 11.8 & 12.0 & 8.6 & 6.5 & 4.4 & 6.6 & 6.9 & 7.9 & 6.6 \\
\hline & & & 75 & 7.7 & 4.4 & 7.1 & 6.6 & 8.1 & 6.6 & 7.0 & 6.2 & 9.9 & 8.4 & 6.9 \\
\hline
\end{tabular}




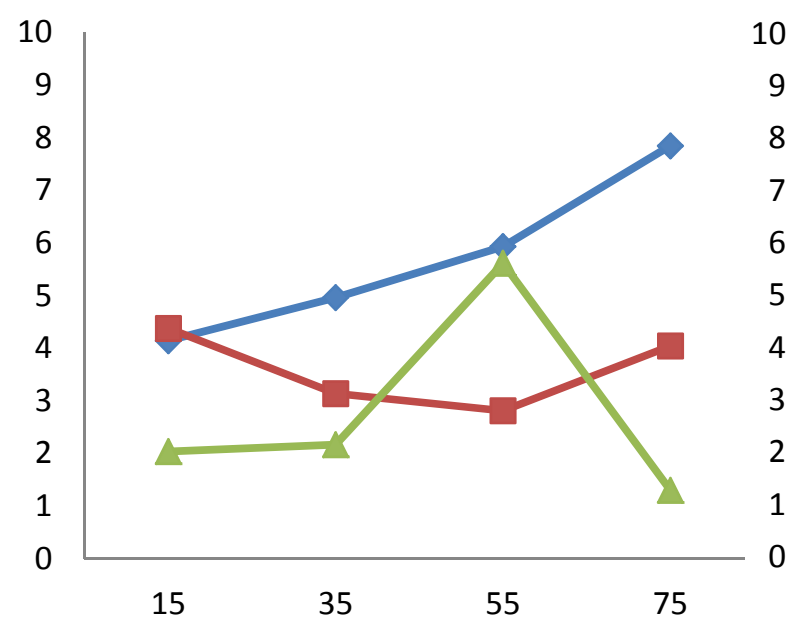

(a) 30' Span Length

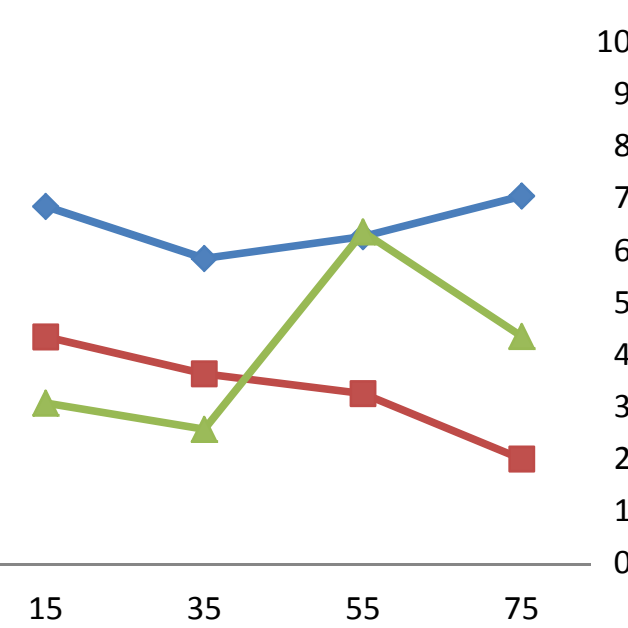

(b) 60' Span Length

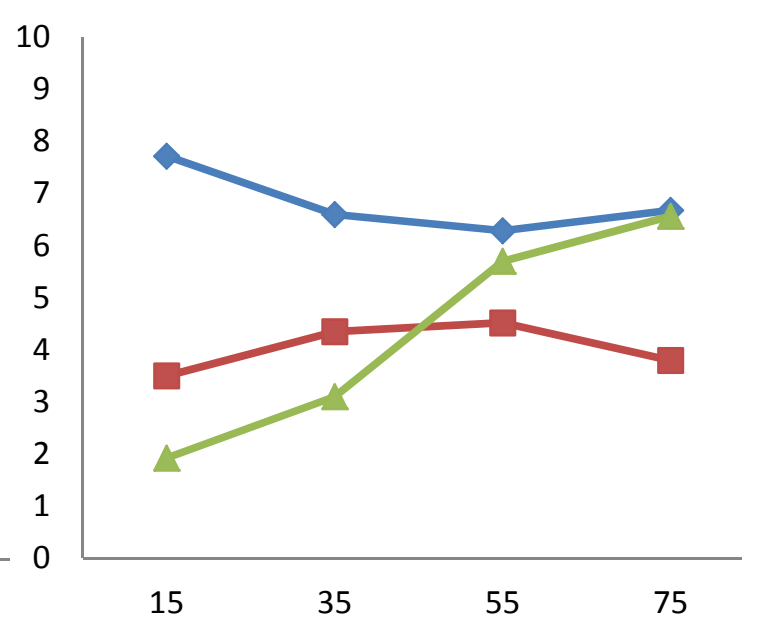

(c) 90' Span Length

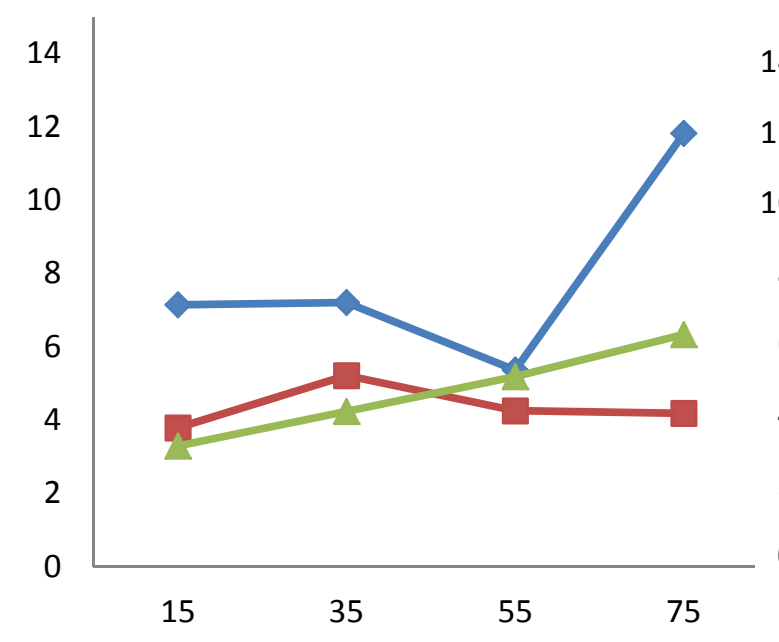

(d) 120' Span Length

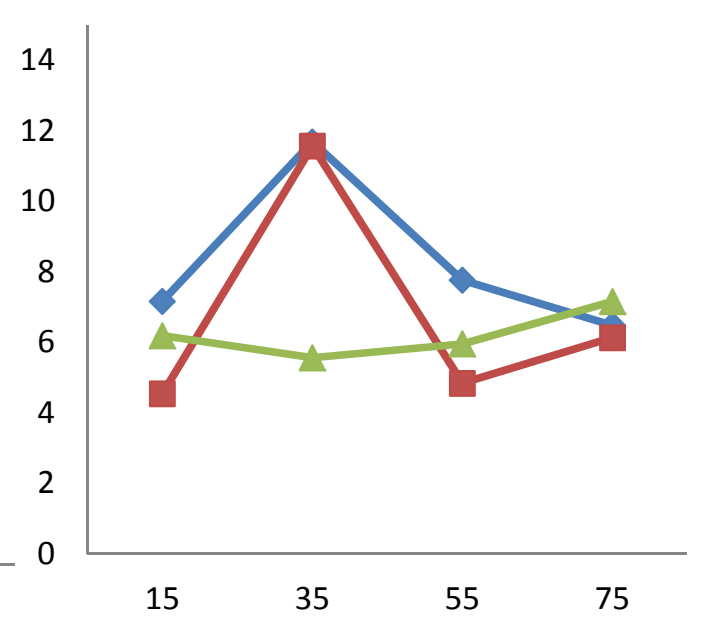

(e) 140 ' Span Length

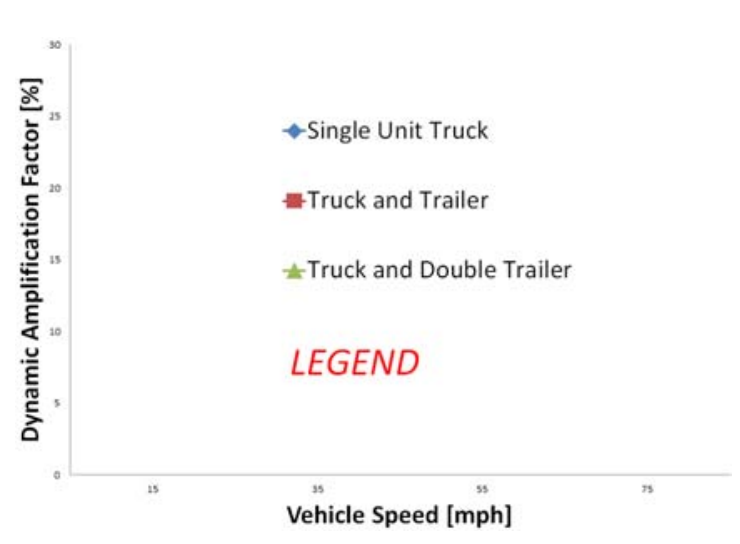

Figure 47. Prestressed Concrete Bridges DAF for Different Vehicle Categories (Very Good Surface) 


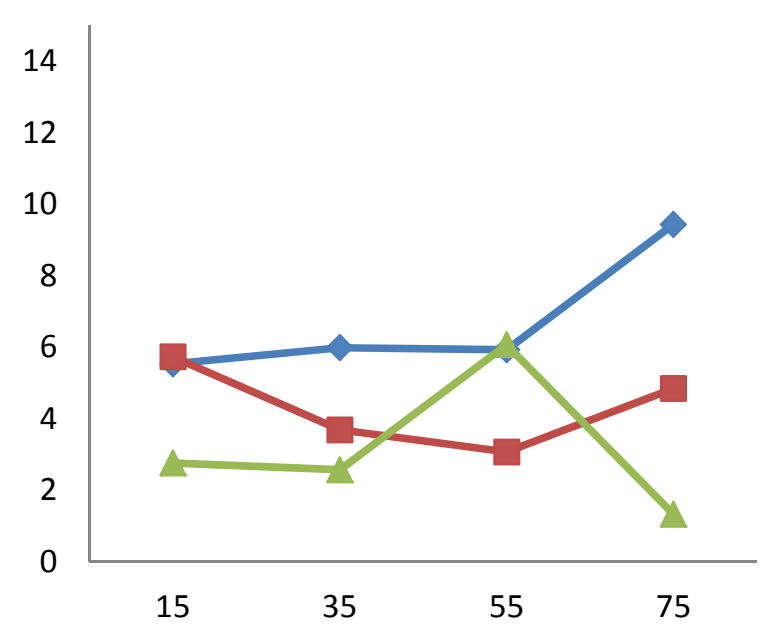

(a) 30' Span Length

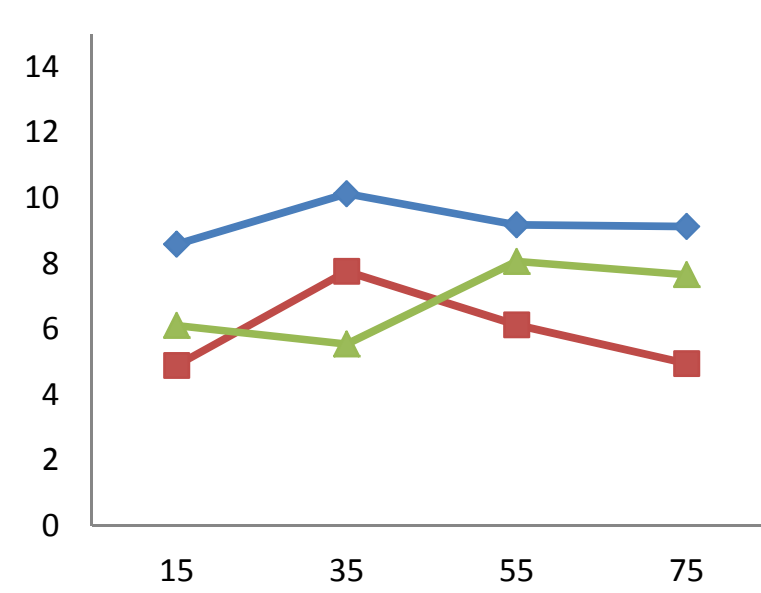

(d) 120' Span Length

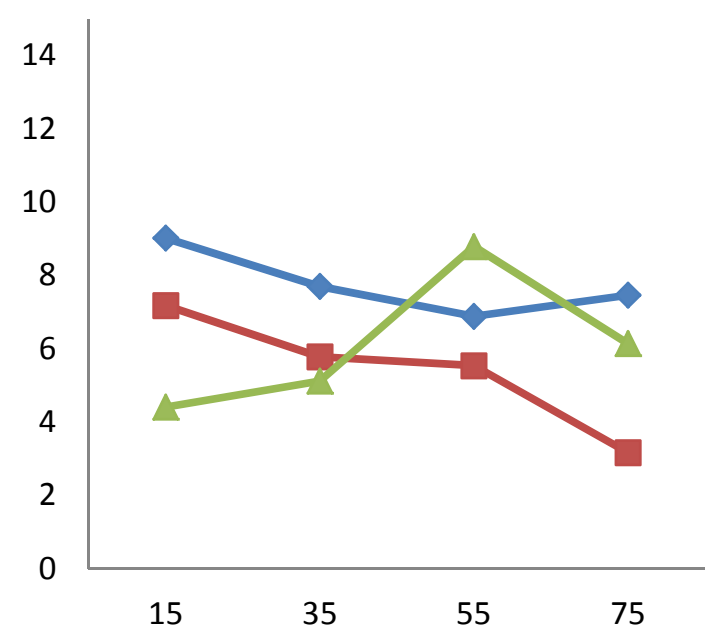

(b) 60' Span Length

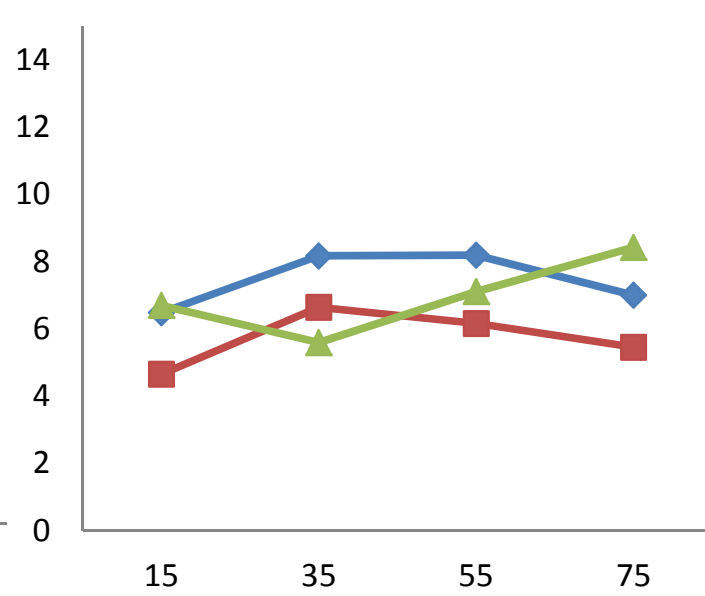

(e) 140' Span Length

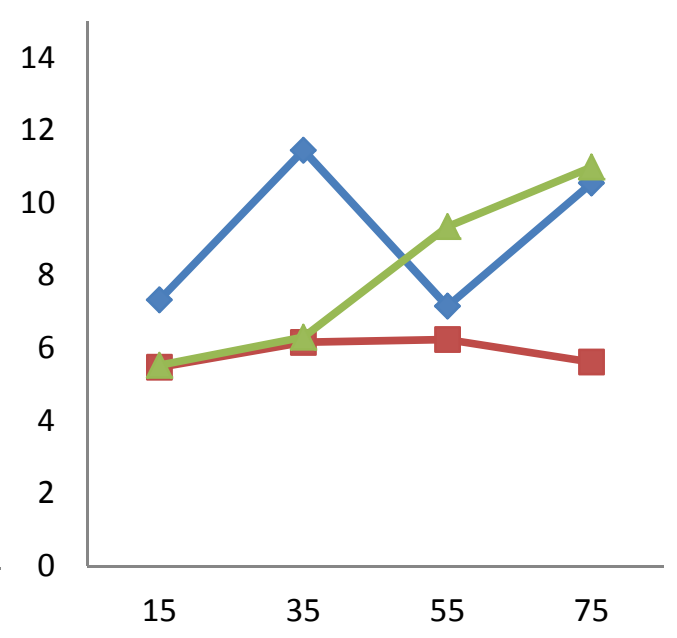

(c) 90 ' Span Length

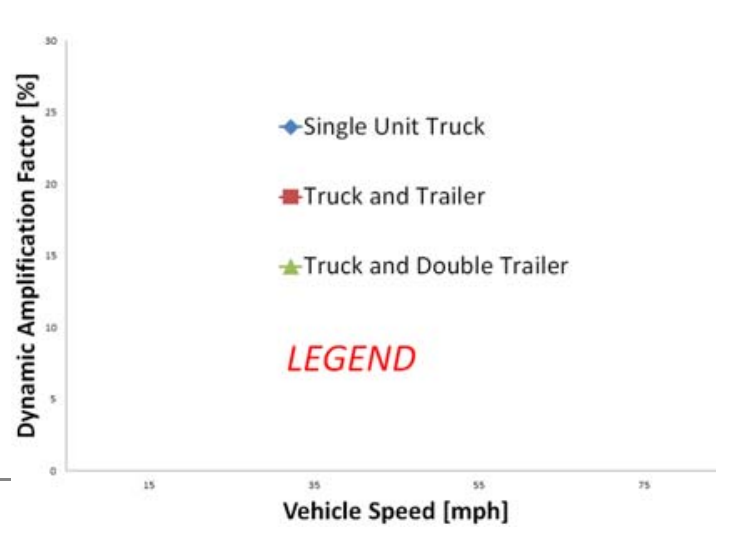

Figure 48. Steel Bridges DAF for Different Vehicle Categories (Very Good Surface) 


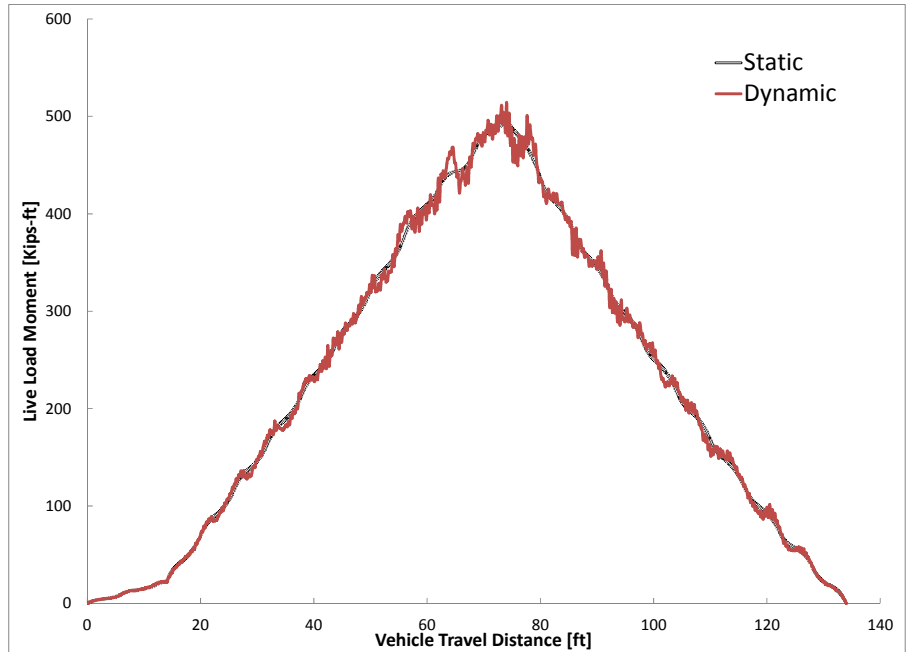

(a) $\mathrm{H}-2 \mathrm{O}$

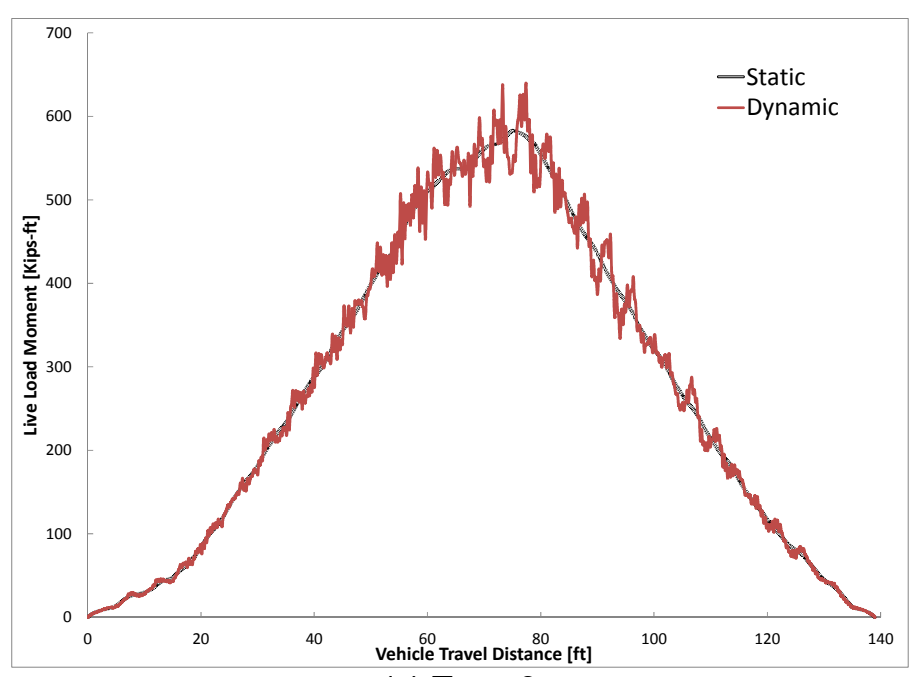

(c) Type 3
Figure 49. Moment of $120 \mathrm{ft}$. Steel Bridge due to Single Unit Trucks and HS-20 (Very Good Surface)

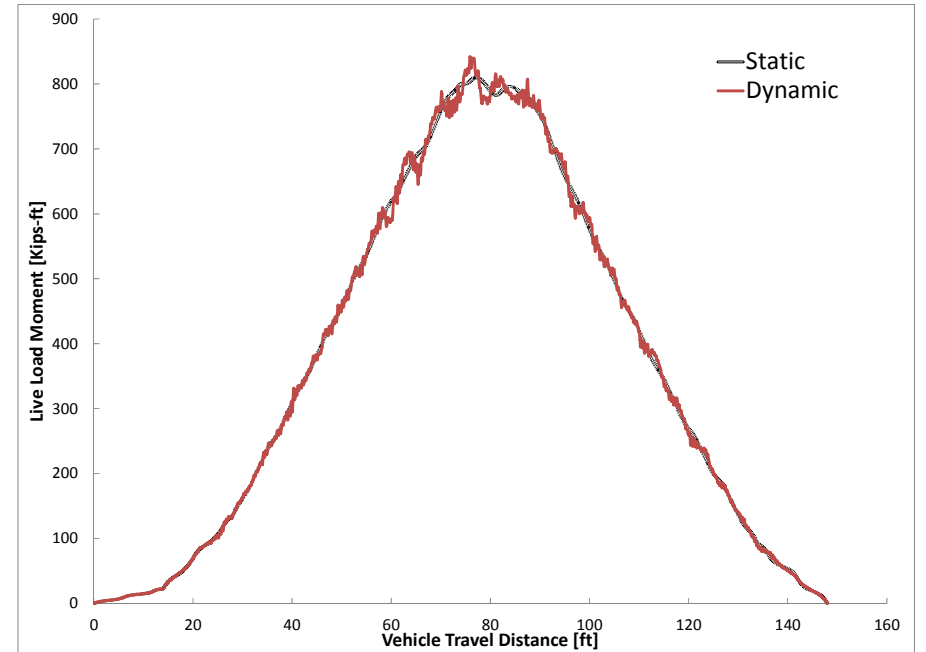

(b) HS-20

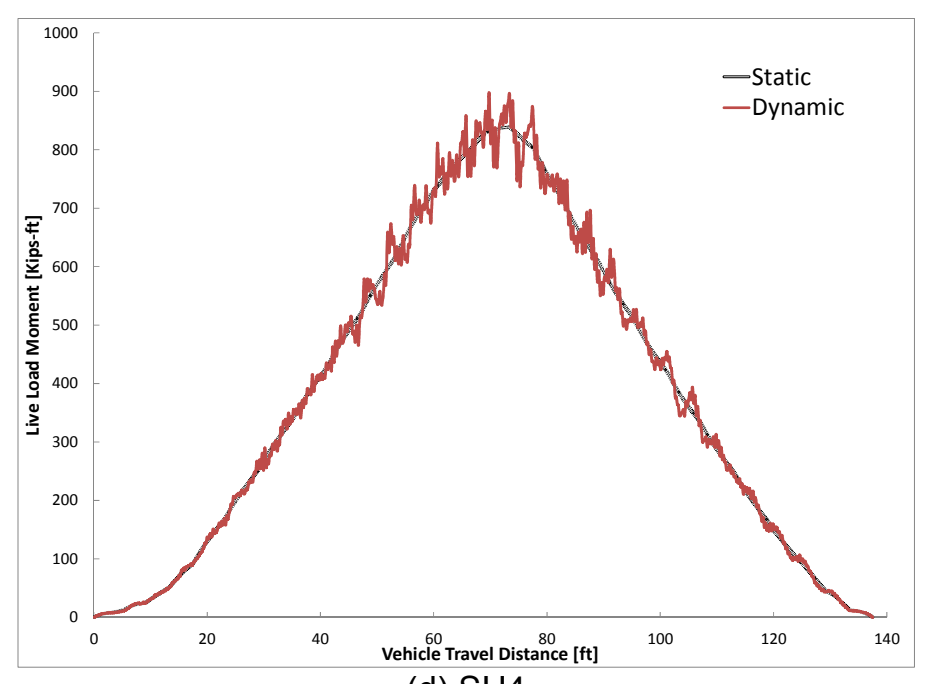




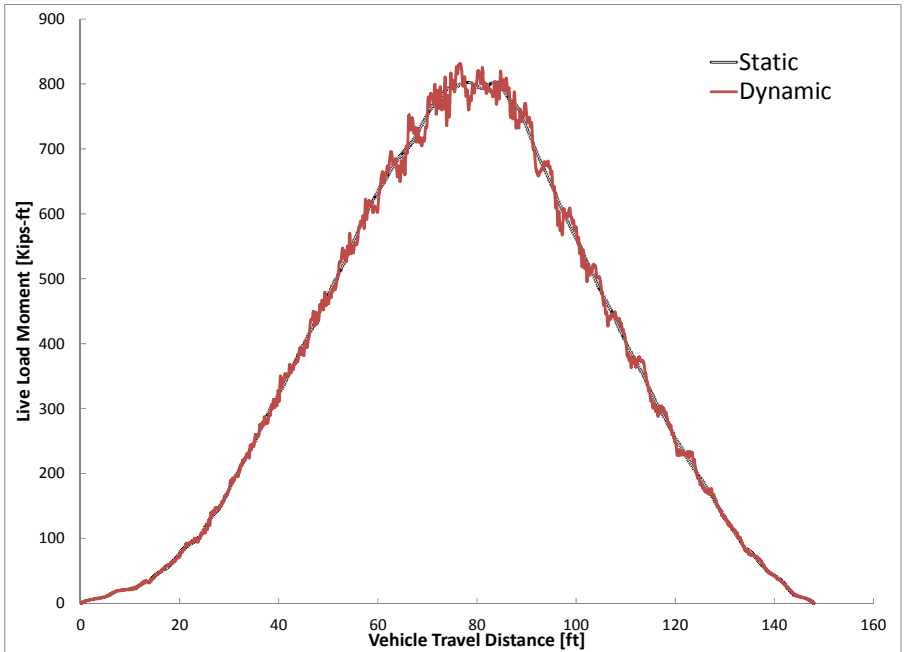

(e) Type 2S2

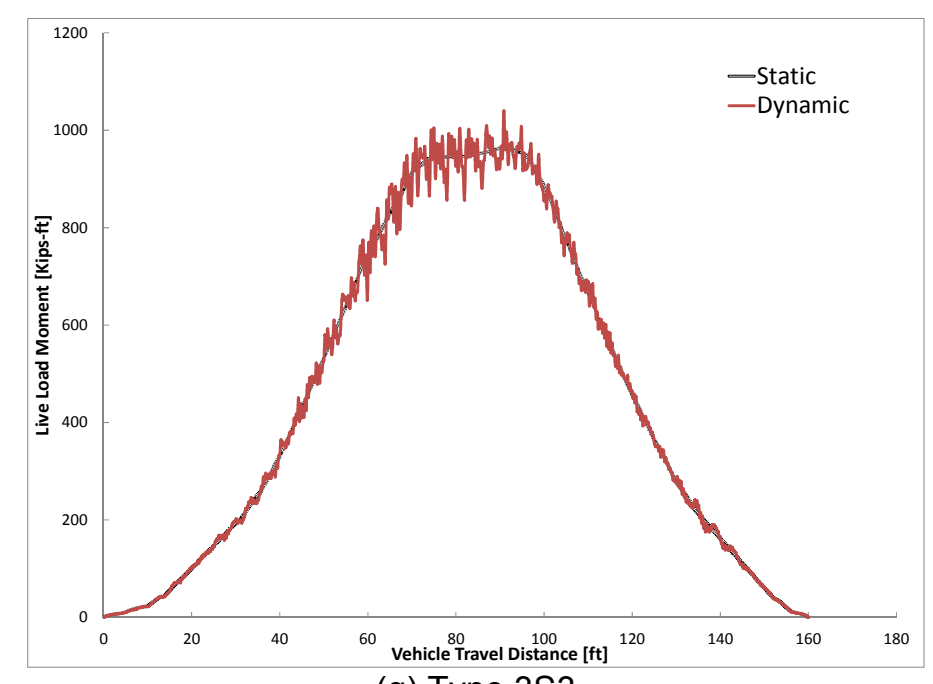

(g) Type 3S3

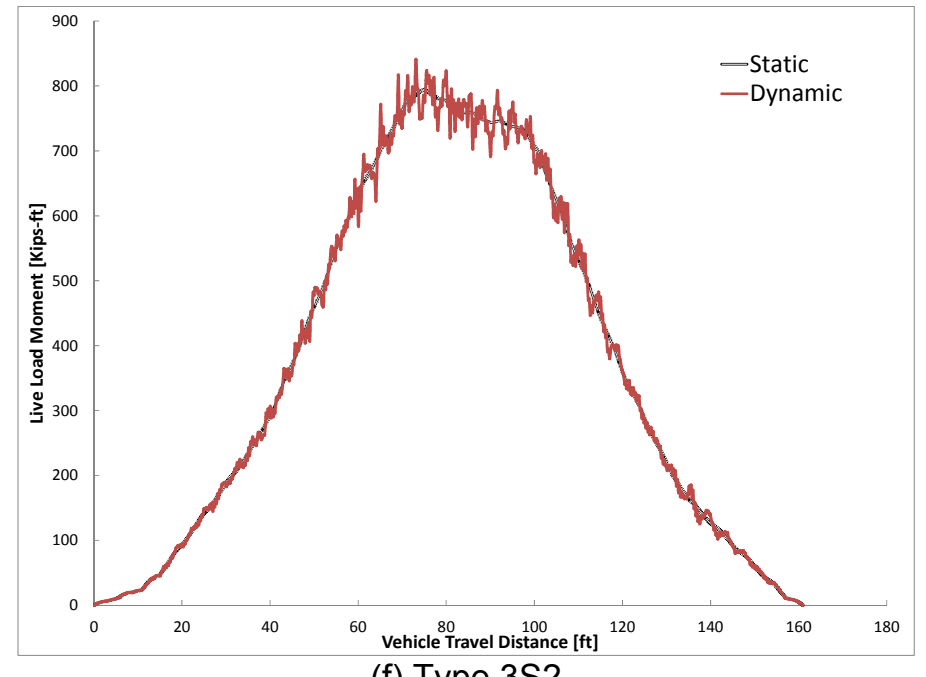

(f) Type 3S2

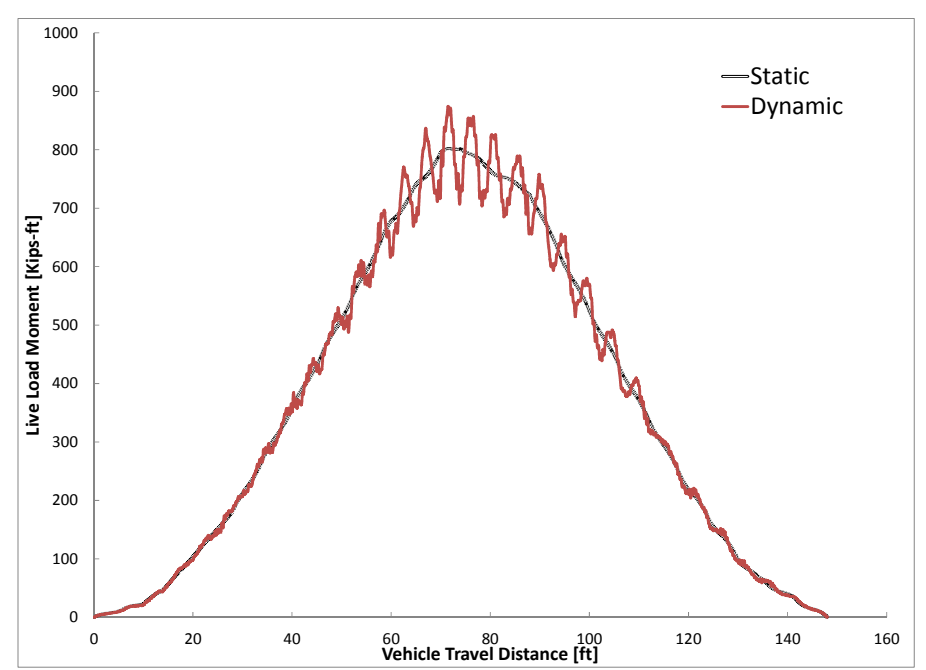

(h) Type 3S1

Figure 50. Moment of $120 \mathrm{ft}$. Steel Bridge due to Tractor Semitrailers (Very Good Surface) 


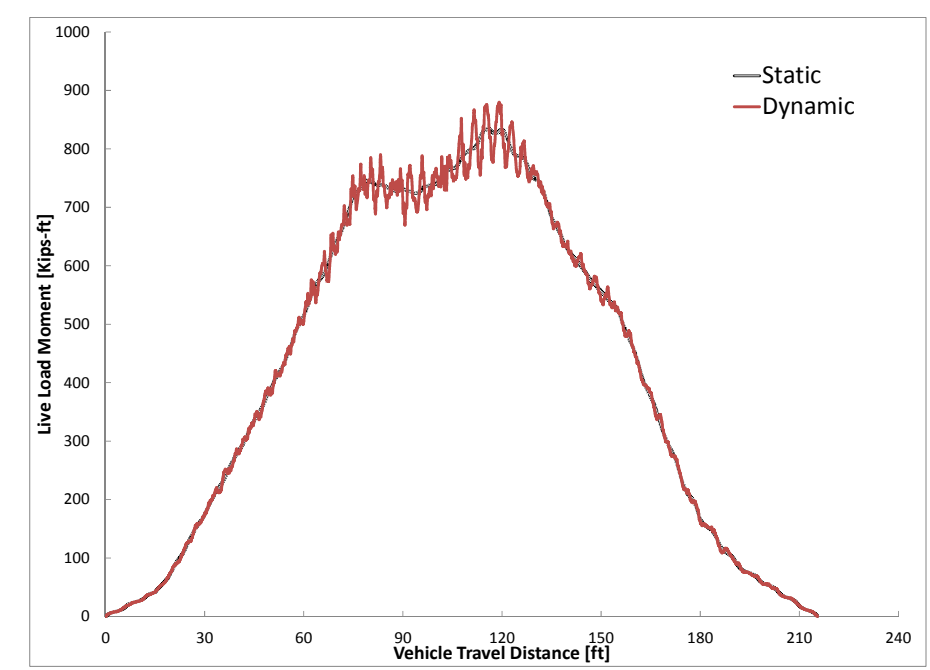

(i) 7-Axle Rocky Mountain Double

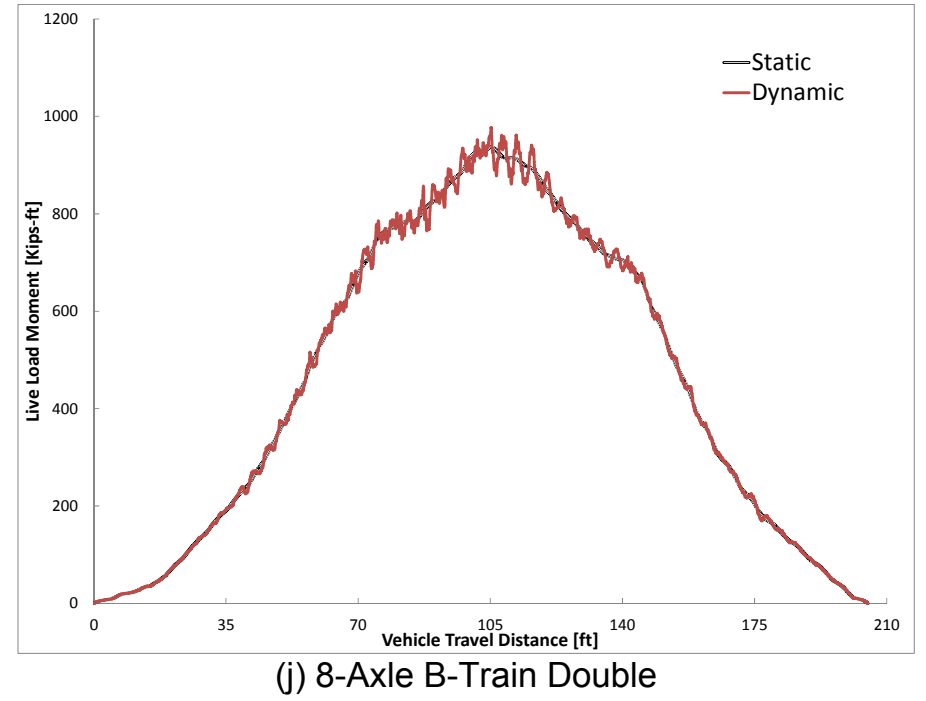

(j) 8-Axle B-Train Double

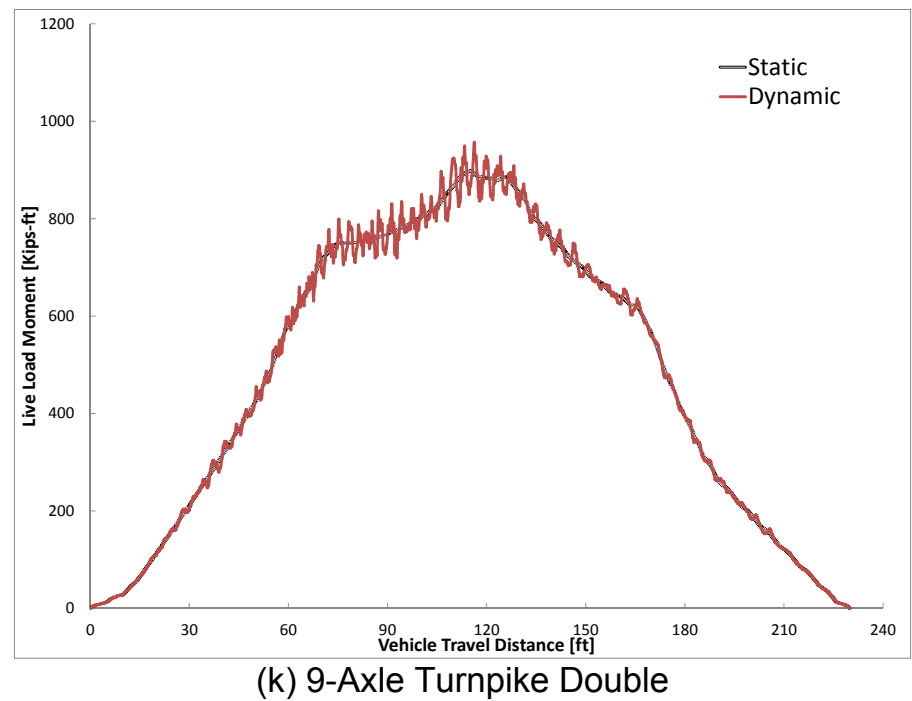

Figure 51. Moment of $120 \mathrm{ft}$. Steel Bridge due to Truck and Double Trailers (Very Good Surface) 

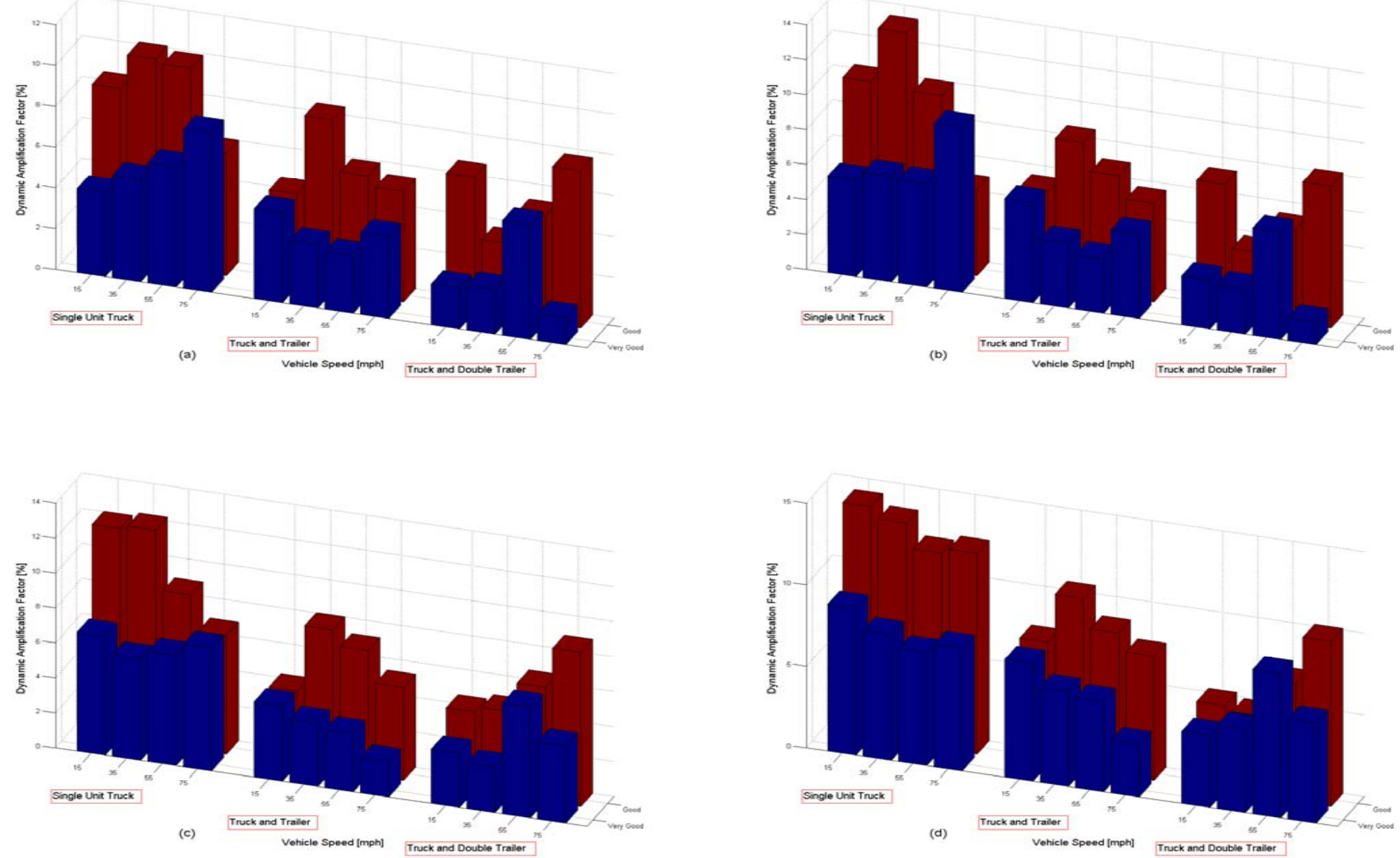

Figure 52. Comparison of the Very Good and Good Surfaces Results (a) 30' Concrete (b) 30' Steel (c) 60' Concrete (d) 60' Steel 

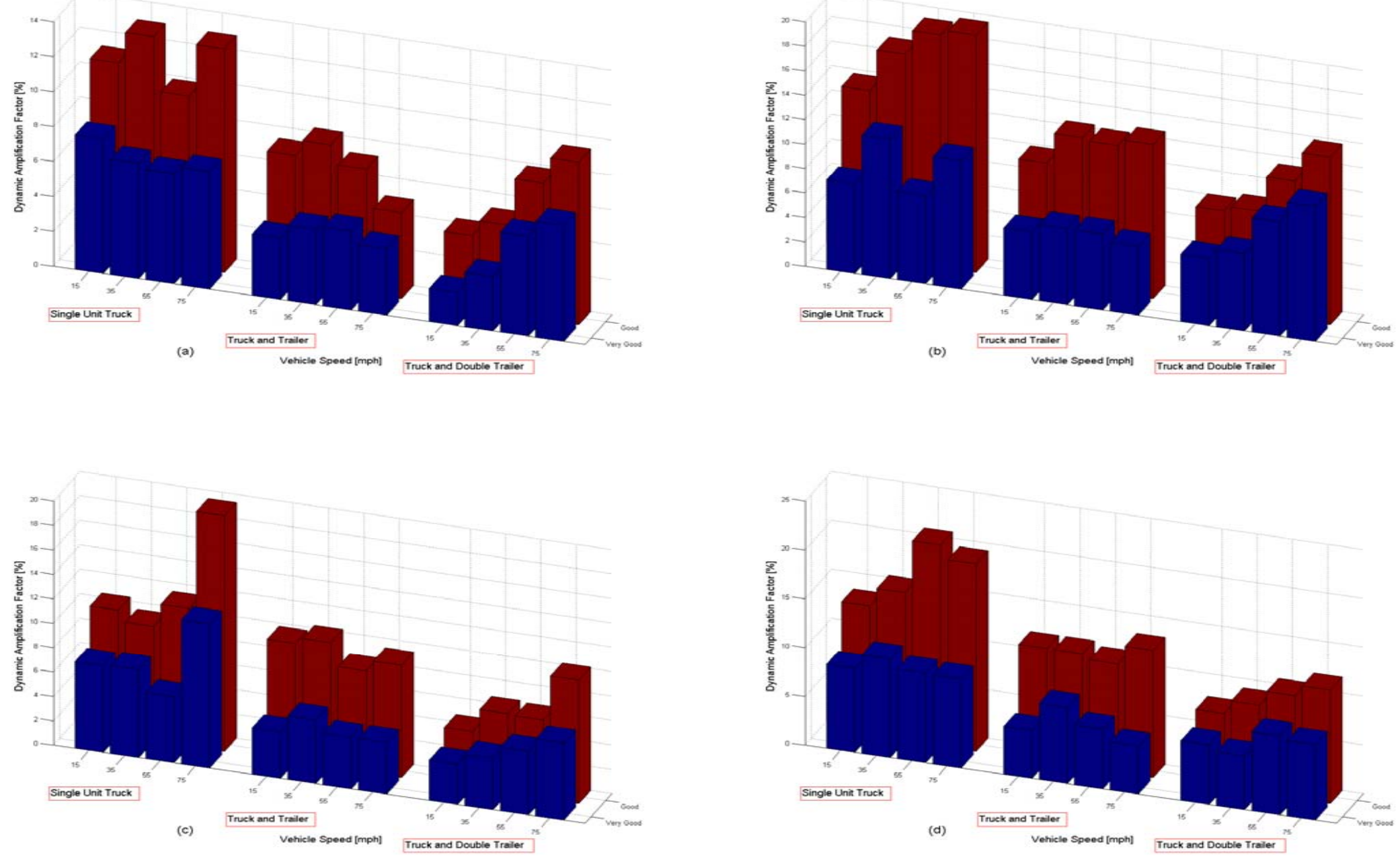

Figure 53. Comparison of the Very Good and Good Surfaces Results (a) 90' Concrete (b) 90' Steel (c) 120' Concrete (d) 120' Steel 

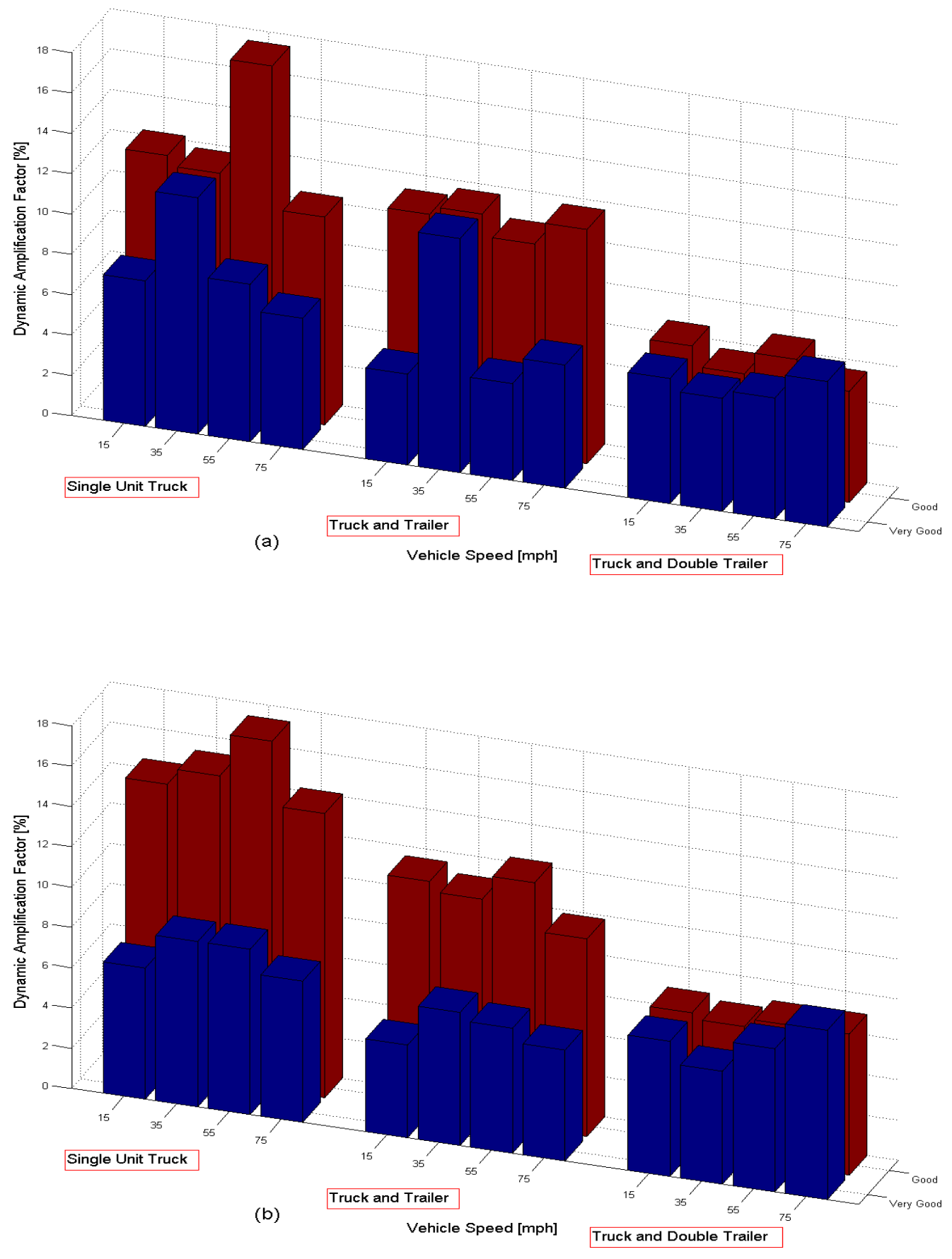

Figure 54. Comparison of the Very Good and Good Surfaces Results (a) 140' Concrete (b) 140' Steel 


\section{Single Span Real Bridges Results}

In this section, three different bridges which have been previously constructed are modeled. The drawings of all three bridges can be found in appendix 1 . The same approach which was used for the designed bridges has been used and the same type of analysis as the previous section has been performed. Two of these bridges are single span simply supported bridges and the third one is a three span continuous bridge.

The first bridge which is located on Interstate 95 close to Daytona Beach in Volusia County is $189^{\prime}-8^{\prime \prime}$ long. This bridge has a single Span and is straight with 7 degree skew which is negligible and it has been modeled as a straight bridge. This I-girder steel bridge has five girders in total.

The first six mode shapes and their corresponding natural frequencies of this bridge can be seen in Figure 55. The displacement of this bridge at the midpoint due to the passage of all eleven trucks is recorded and shown in Figure 56 to Figure 58 for the Good surface condition and in Figure 59 to Figure 61 for the Very Good surface condition. The results show more high frequency dynamic responses for the lighter Single Unit Trucks and lower frequency dynamic responses for the heavier trucks. It can also be seen that the highest deflections in the middle point of the bridge is caused by the Long Combination Vehicles. The heaviest, longest truck which is 9-Axle Turnpike Double, results in the highest deflection in the bridge. The results also show slightly higher responses for the Good surface condition in comparison with the Very Good surface condition which is as expected. The results for the moment at the midpoint of this bridge can also be seen in Figure 62 to Figure 64. Again high frequency dynamic results for the lighter trucks can be seen in LCVs and 9-Axle Turnpike Double in particular, resulted in highest value of moment in the midpoint of the bridge. 


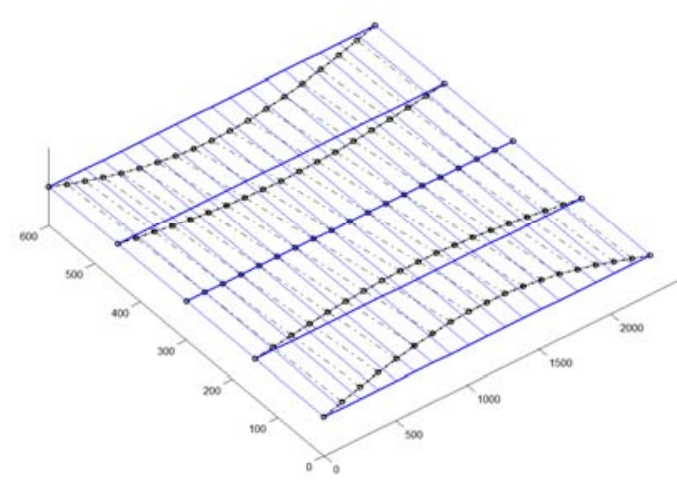

(a) $1^{\text {st }}$ Mode $\left(\mathrm{f}_{1}=1.53 \mathrm{~Hz}\right)$

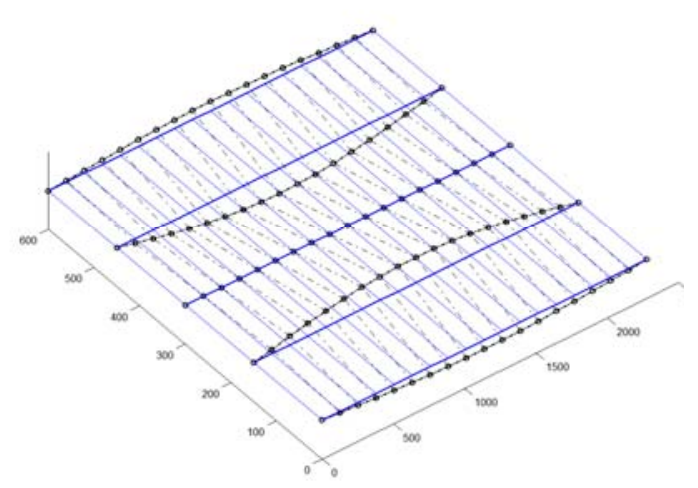

(d) $4^{\text {th }}$ Mode $\left(\mathrm{f}_{4}=6.08 \mathrm{~Hz}\right)$

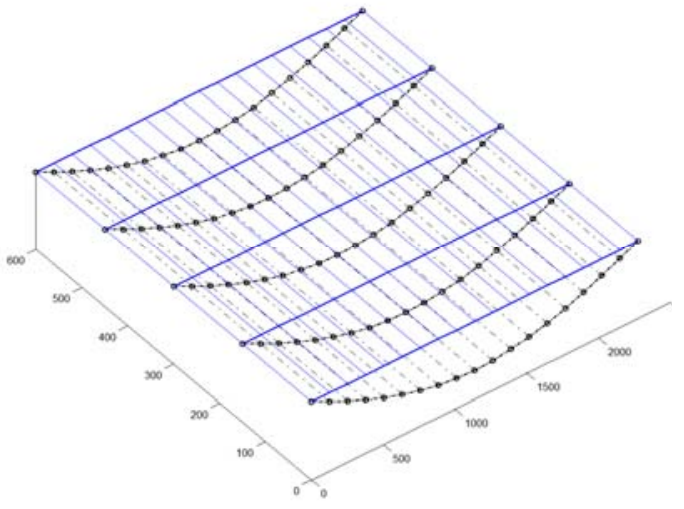

(b) $2^{\text {nd }}$ Mode $\left(\mathrm{f}_{2}=1.54 \mathrm{~Hz}\right)$

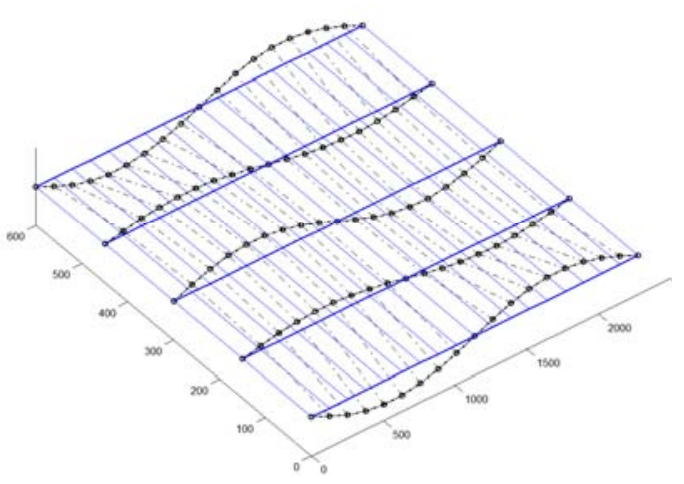

(e) $5^{\text {th }}$ Mode $\left(\mathrm{f}_{5}=6.16 \mathrm{~Hz}\right)$

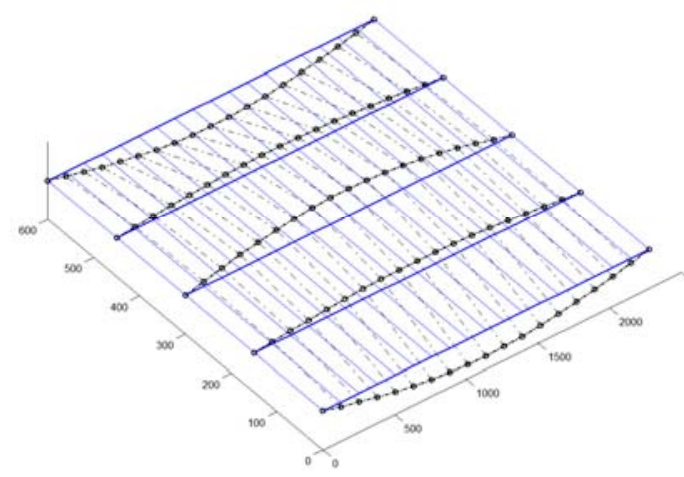

(c) $3^{\text {rd }}$ Mode $\left(\mathrm{f}_{3}=3.38 \mathrm{~Hz}\right)$

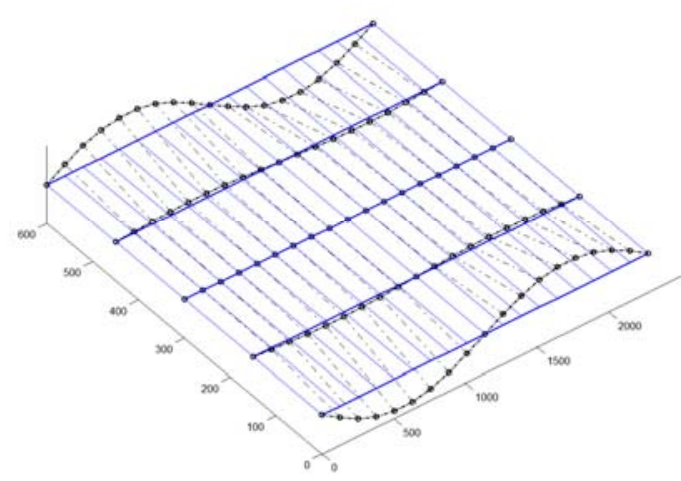

(f) $6^{\text {th }}$ Mode $\left(\mathrm{f}_{6}=6.61 \mathrm{~Hz}\right)$

Figure 55. First Real Bridge Mode Shapes (189' 8" span) 


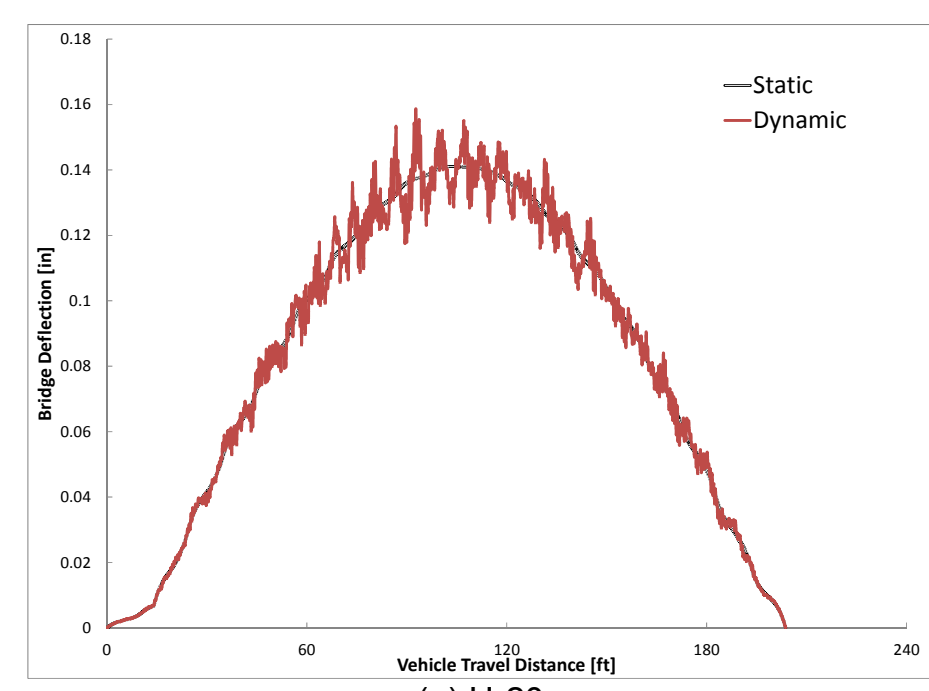

(a) $\mathrm{H}-20$

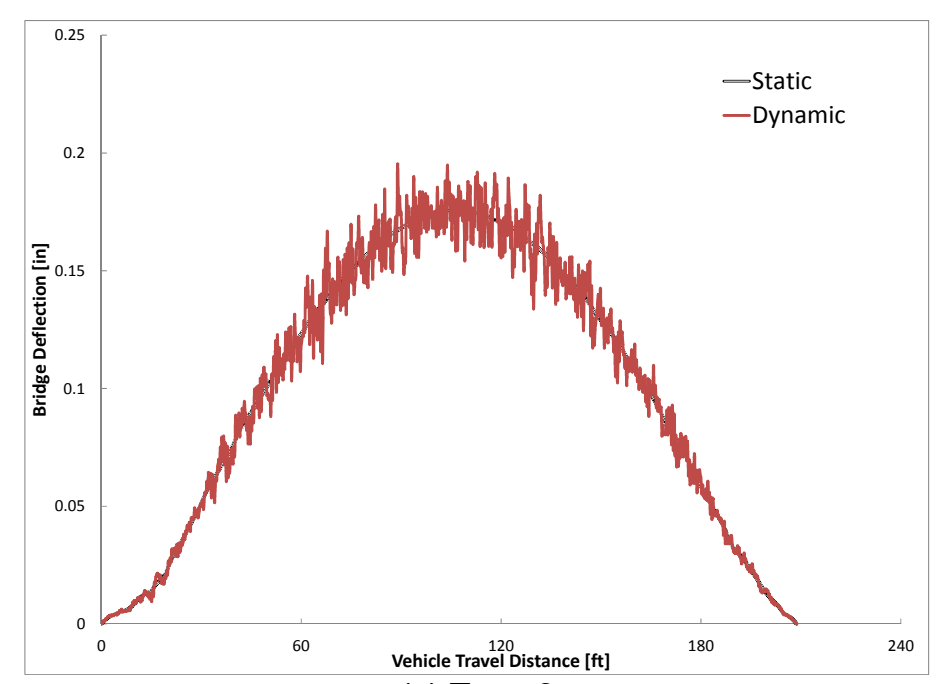

(c) Type 3

Figure 56. Displacement of First Real Bridge due to Single Unit Trucks and HS-20 (Good Surface)

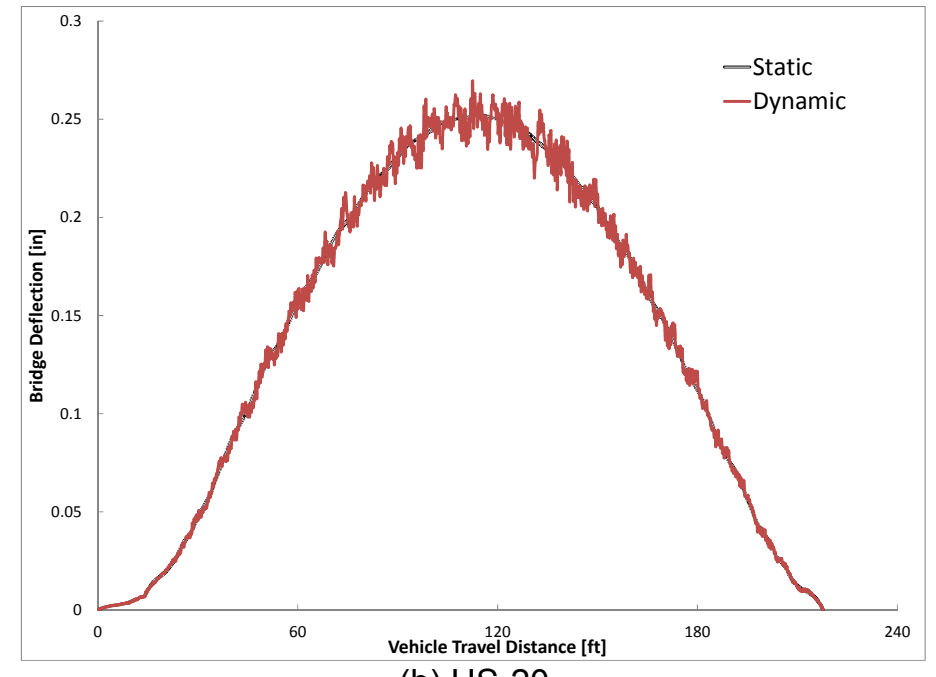

(b) HS-20

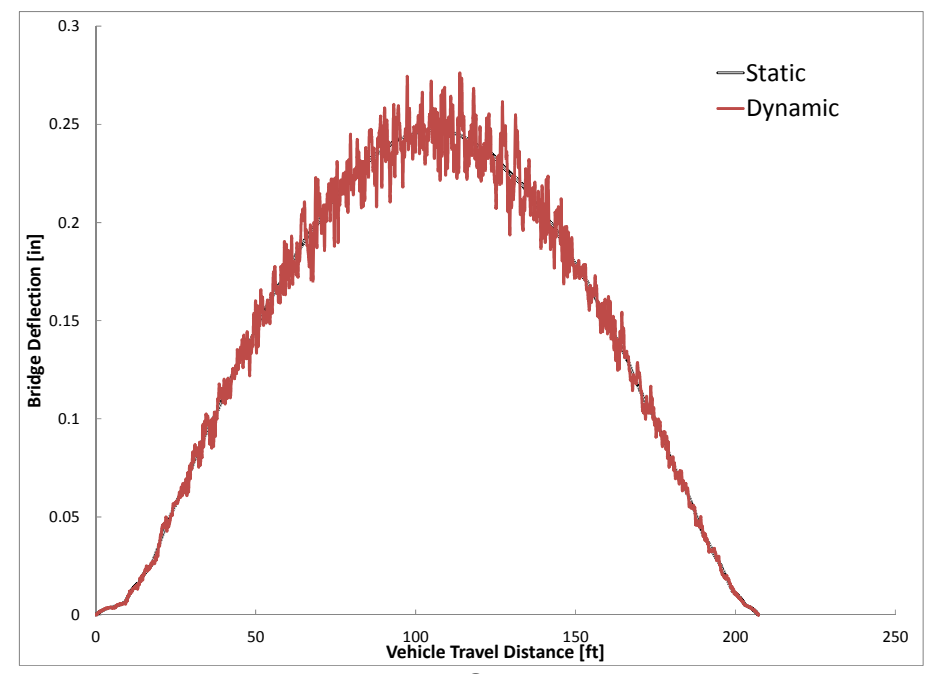

(d) SU4
250 


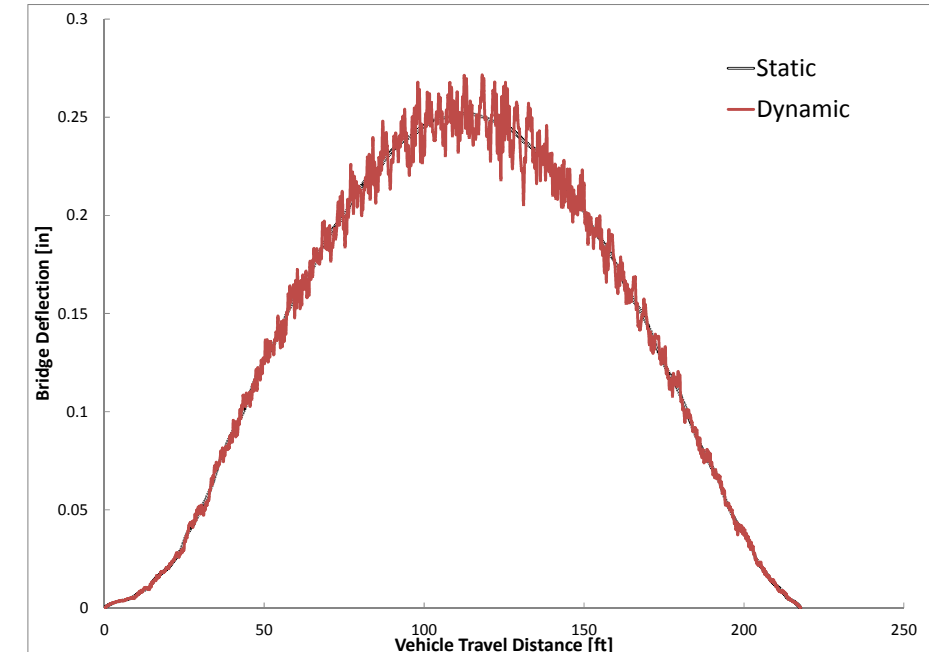

(e) Type 2S2

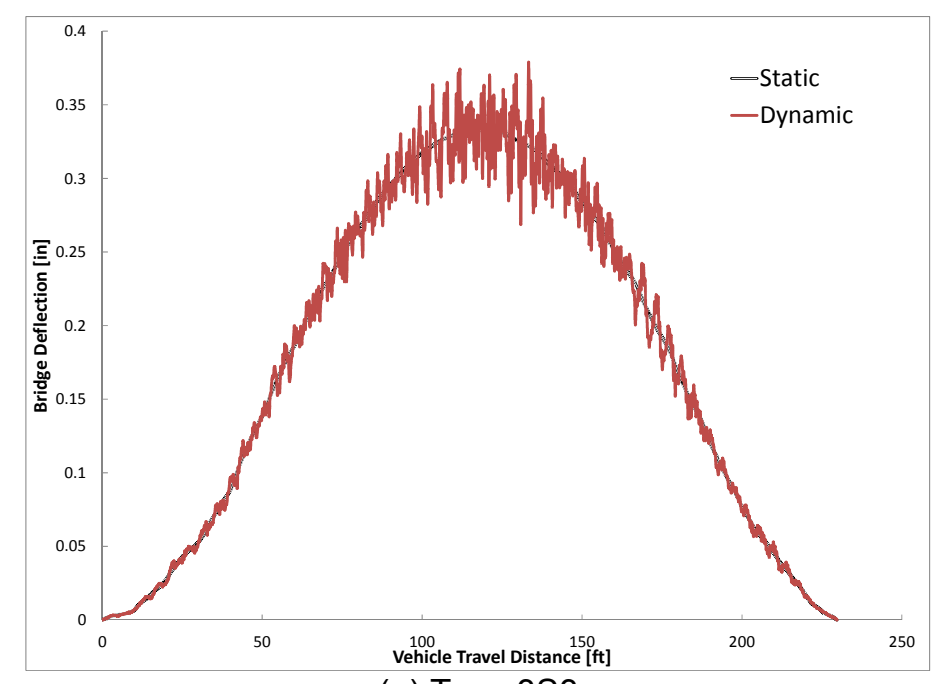

(g) Type $3 \mathrm{S3}$

250

Figure 57. Displacement of First Real Bridge due to Tractor Semitrailers (Good Surface) 


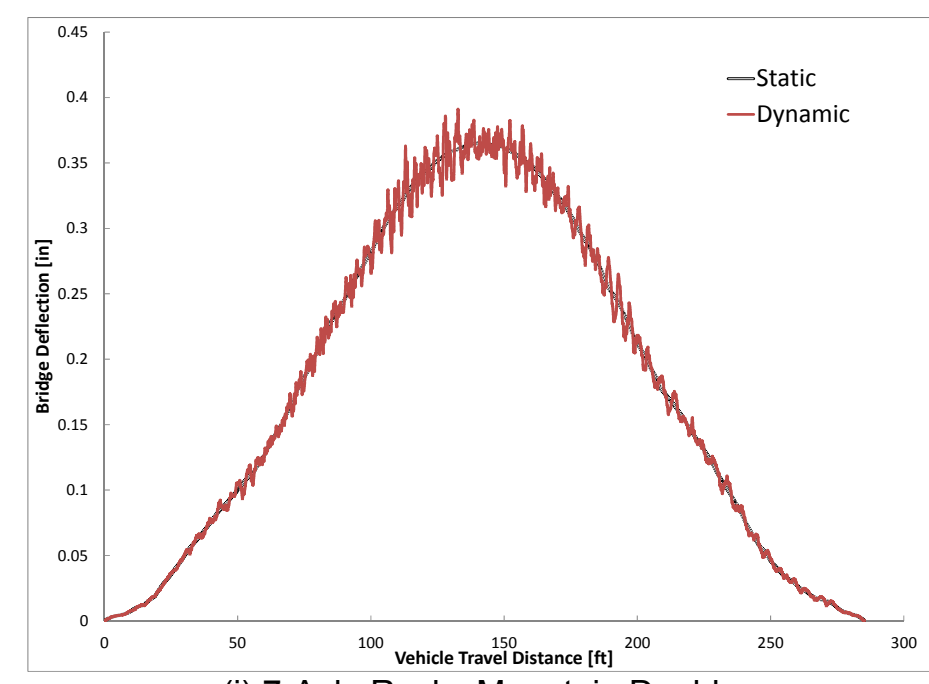

(i) 7-Axle Rocky Mountain Double
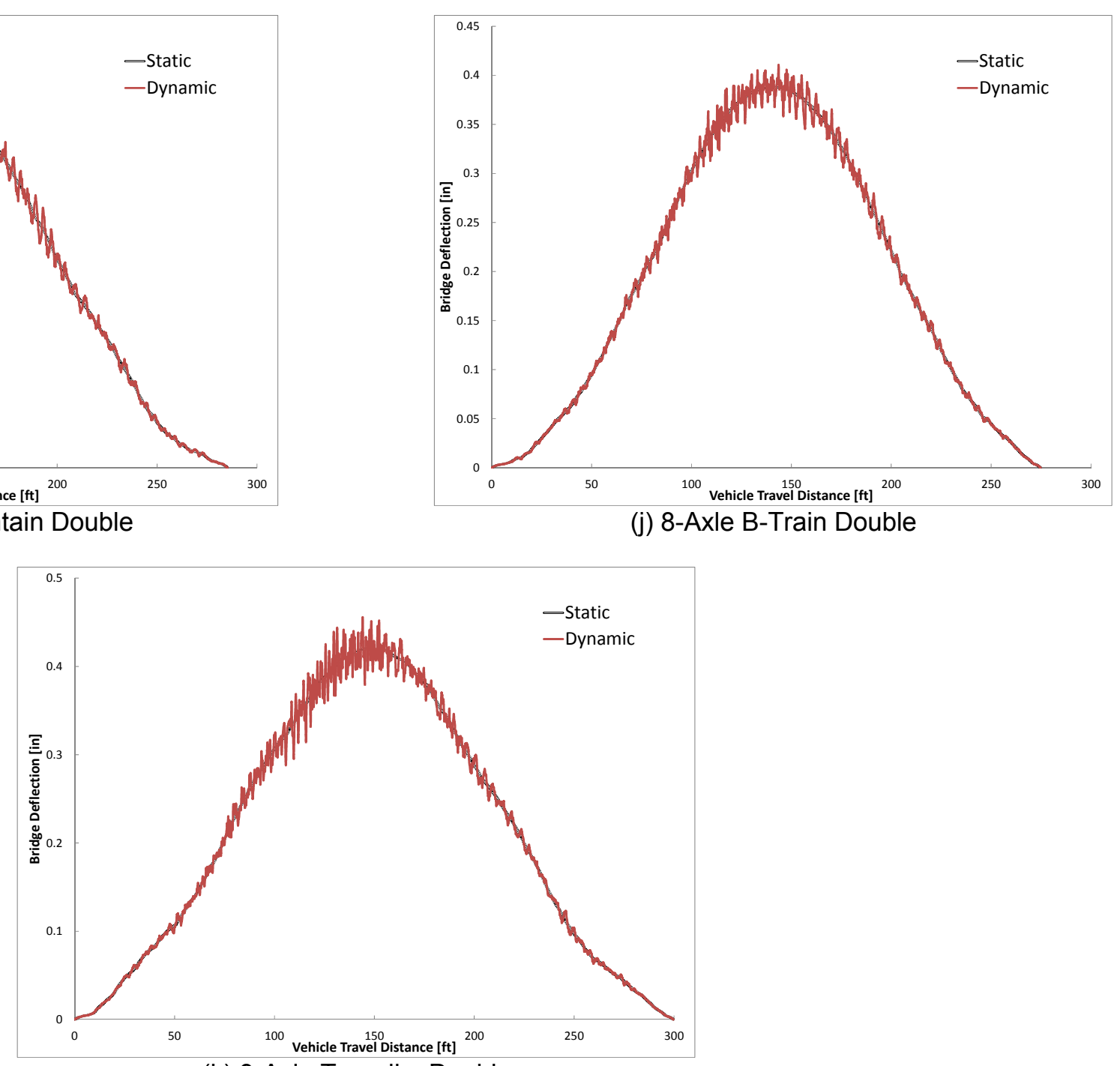

(k) 9-Axle Turnpike Double

Figure 58. Displacement of First Real Bridge due to Truck and Double Trailers (Good Surface) 


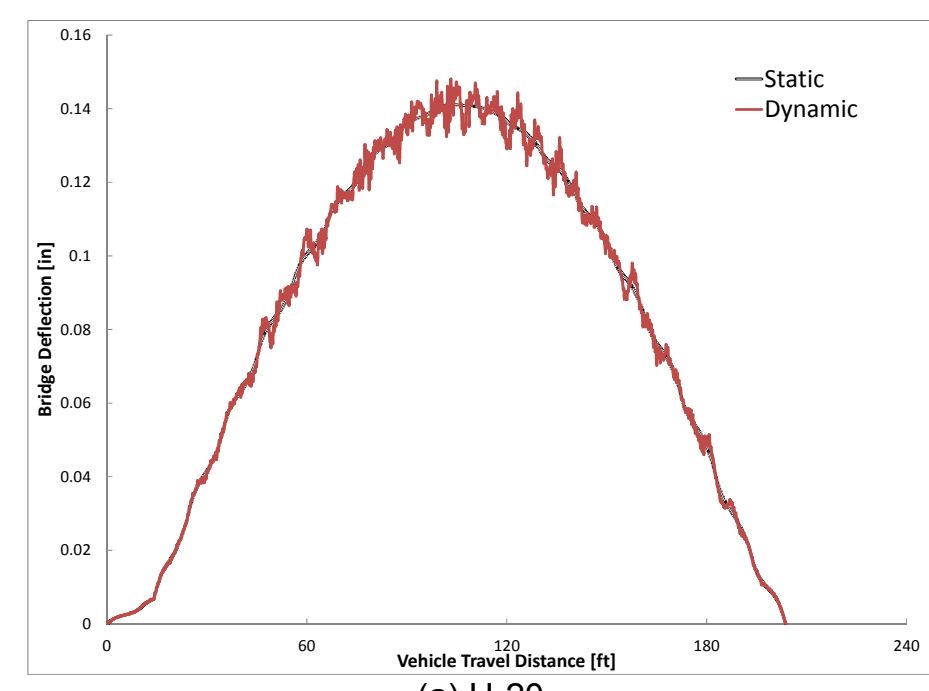

(a) $\mathrm{H}-20$

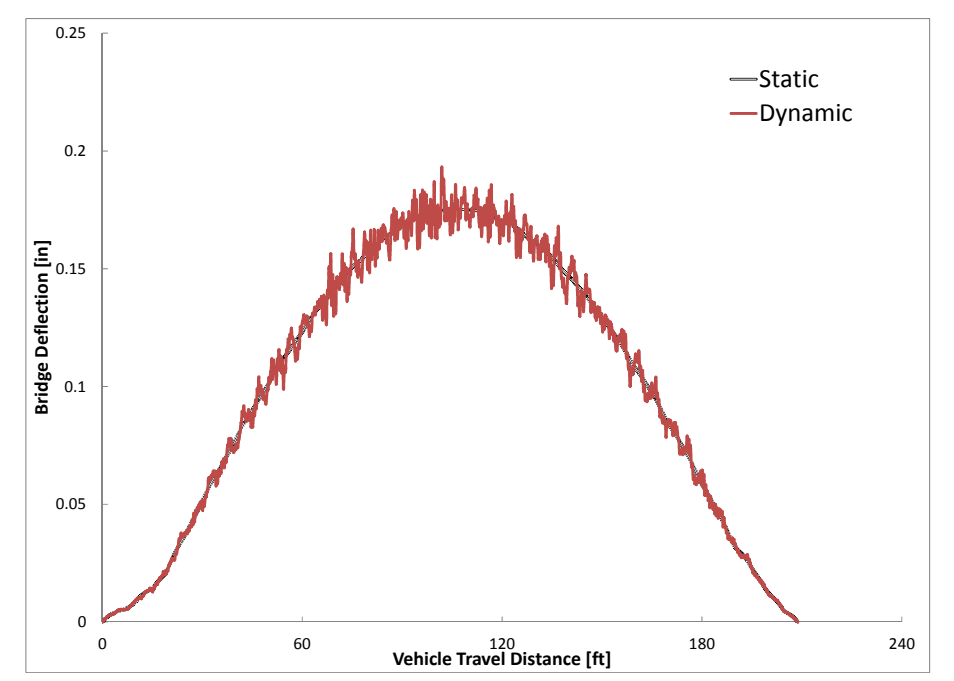

(c) Type 3

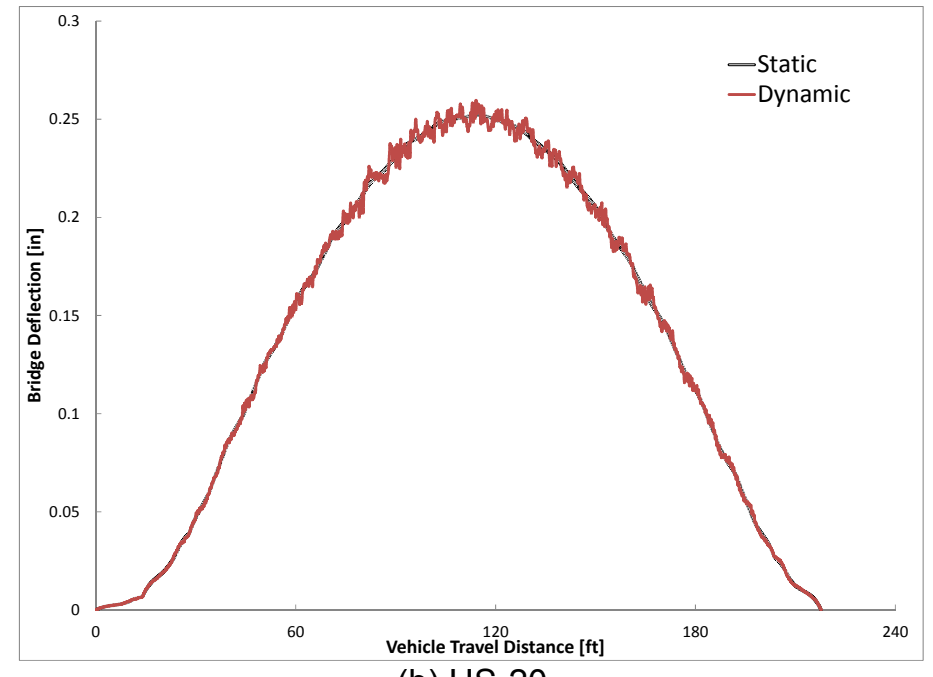

(b) HS-20

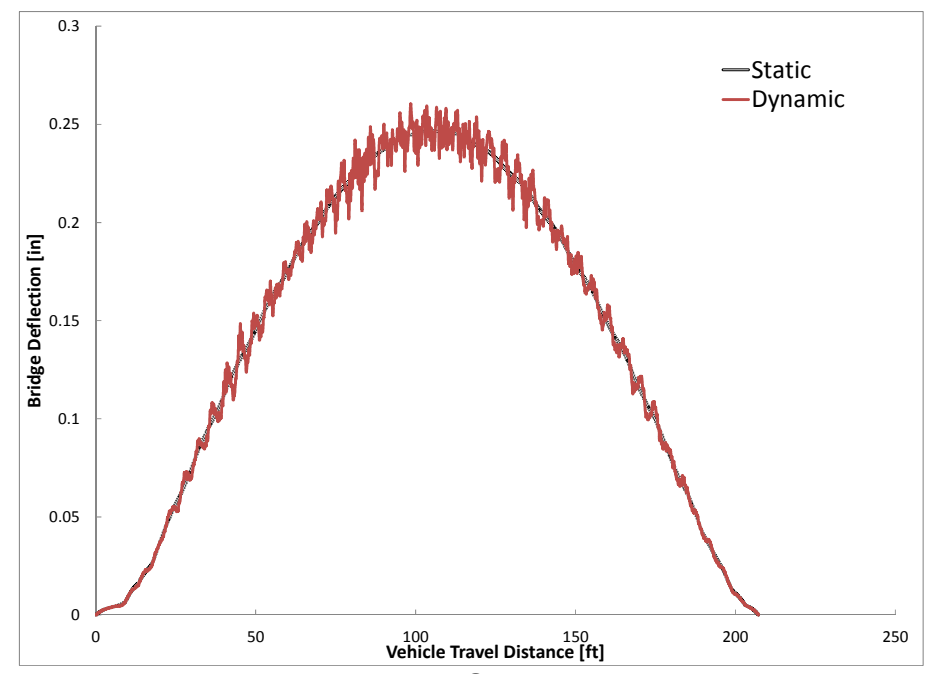

(d) SU4

Figure 59. Displacement of First Real Bridge due to Single Unit Trucks and HS-20 (Very Good Surface) 


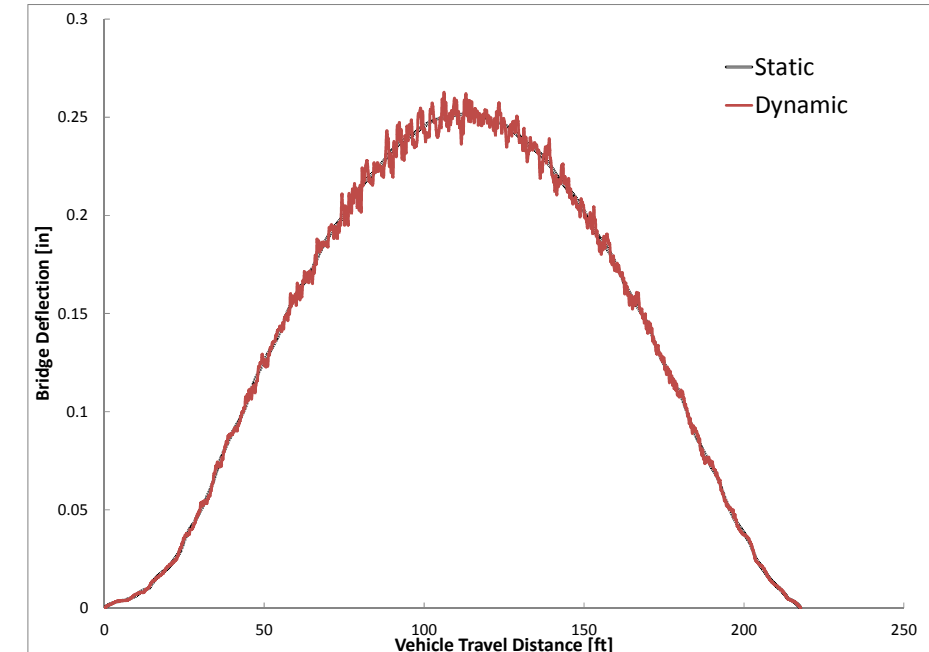

(e) Type 2S2

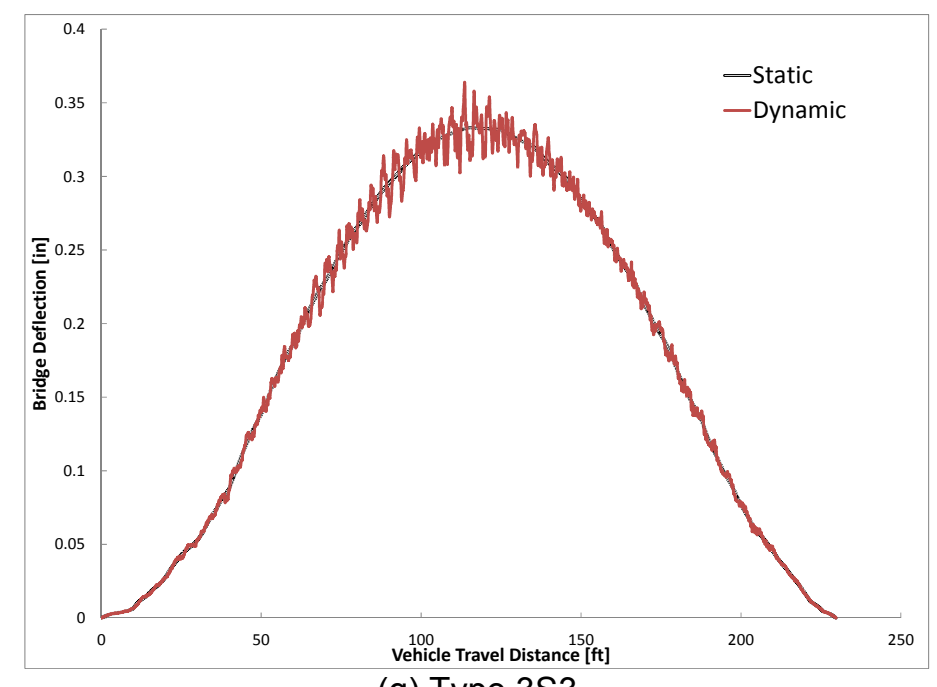

(g) Type 3S3

Figure 60. Displacement of First Real Bridge due to Tractor Semitrailers (Very Good Surface)

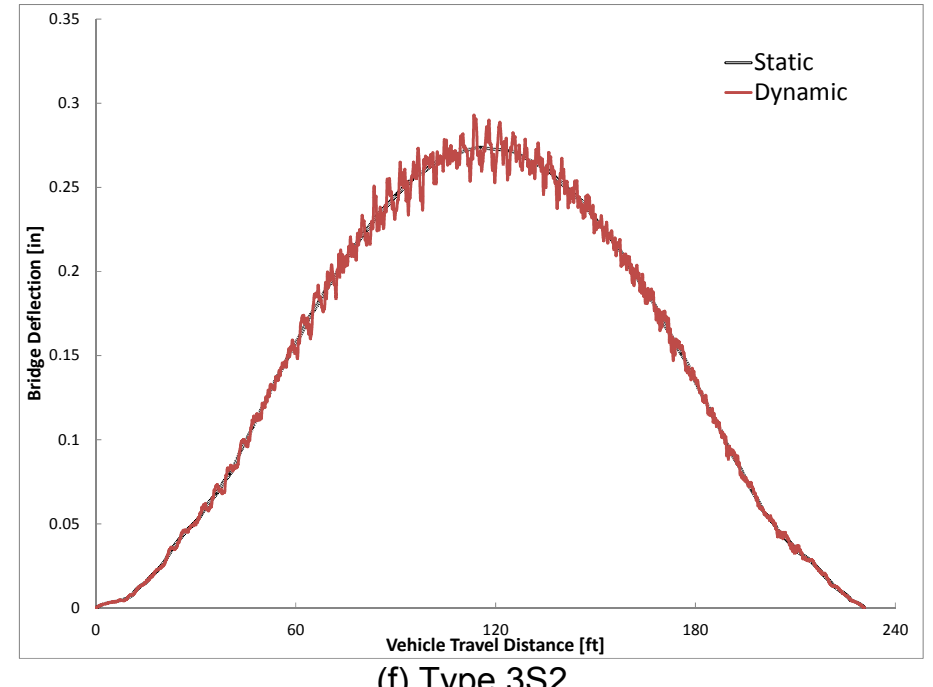

(f) Type 3S2

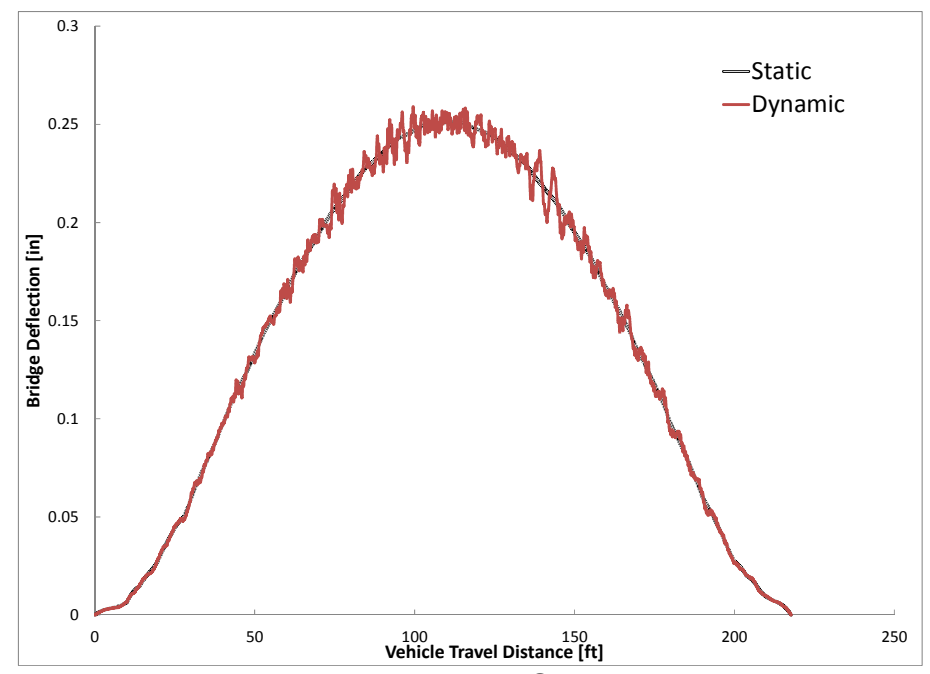

(h) Type $3 \mathrm{~S} 1$ 


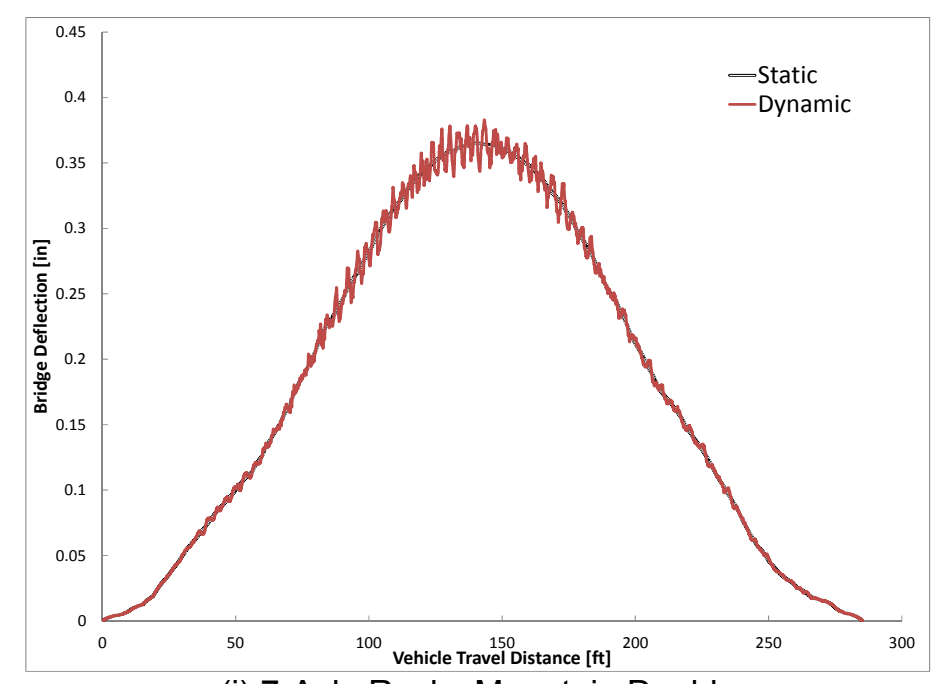

(i) 7-Axle Rocky Mountain Double

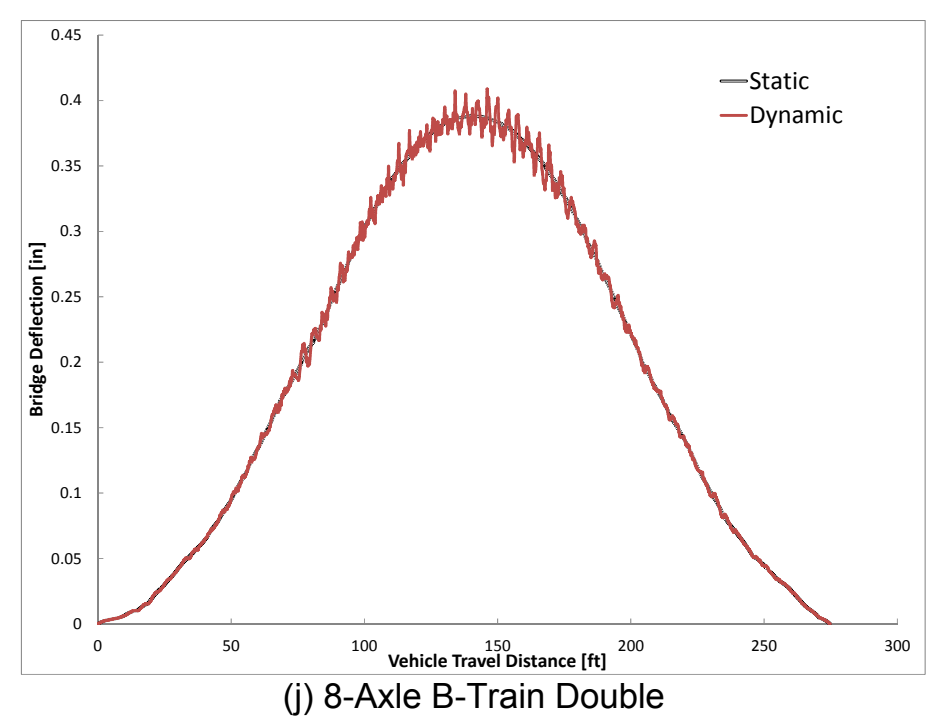

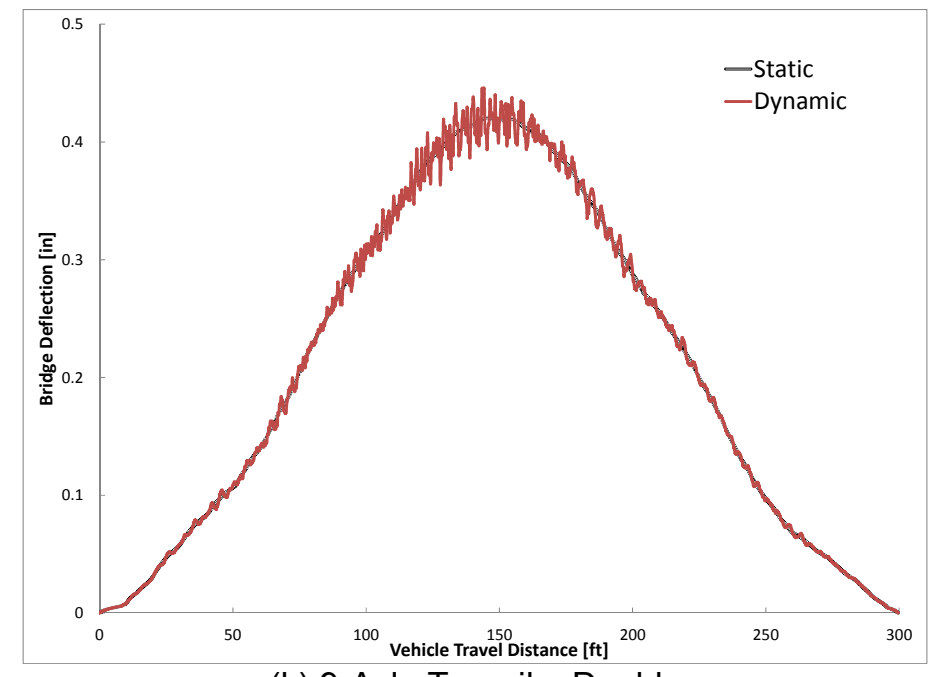

(k) 9-Axle Turnpike Double

Figure 61. Displacement of First Real Bridge due to Truck and Double Trailers (Very Good Surface) 


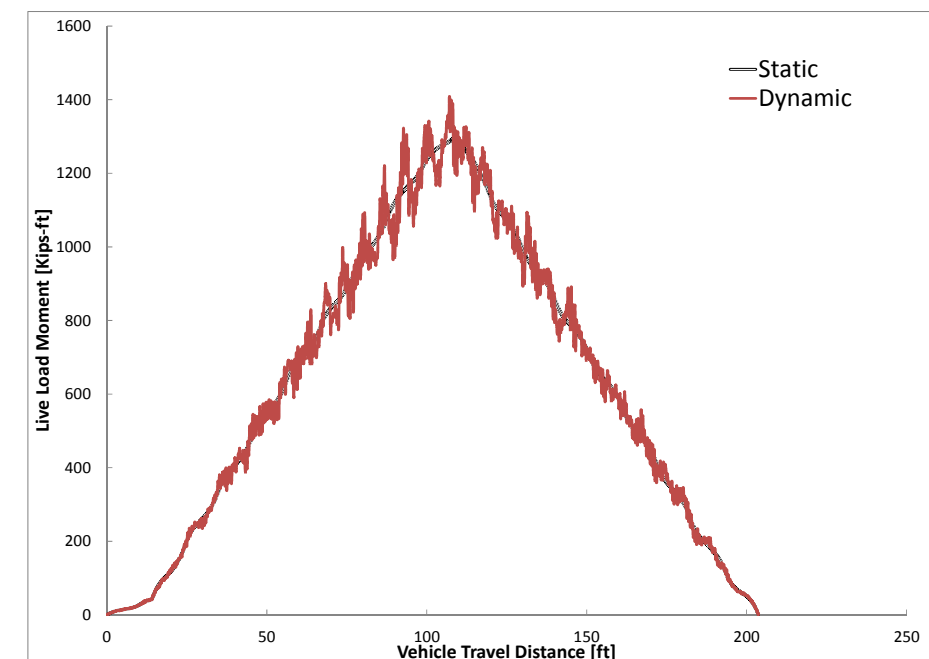

(a) $\mathrm{H}-20$

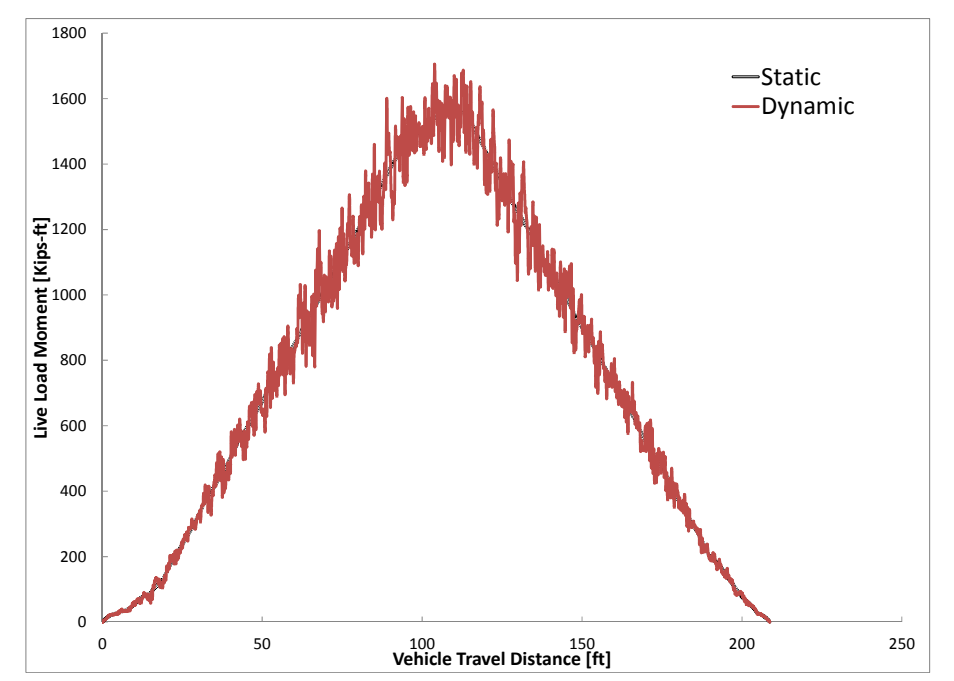

(c) Type 3

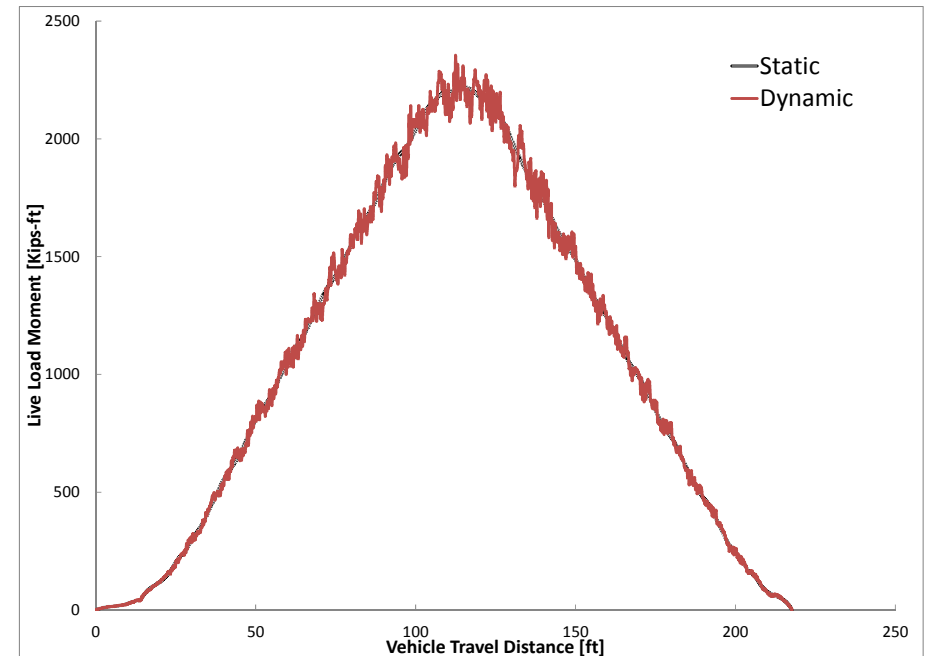

(b) HS-20

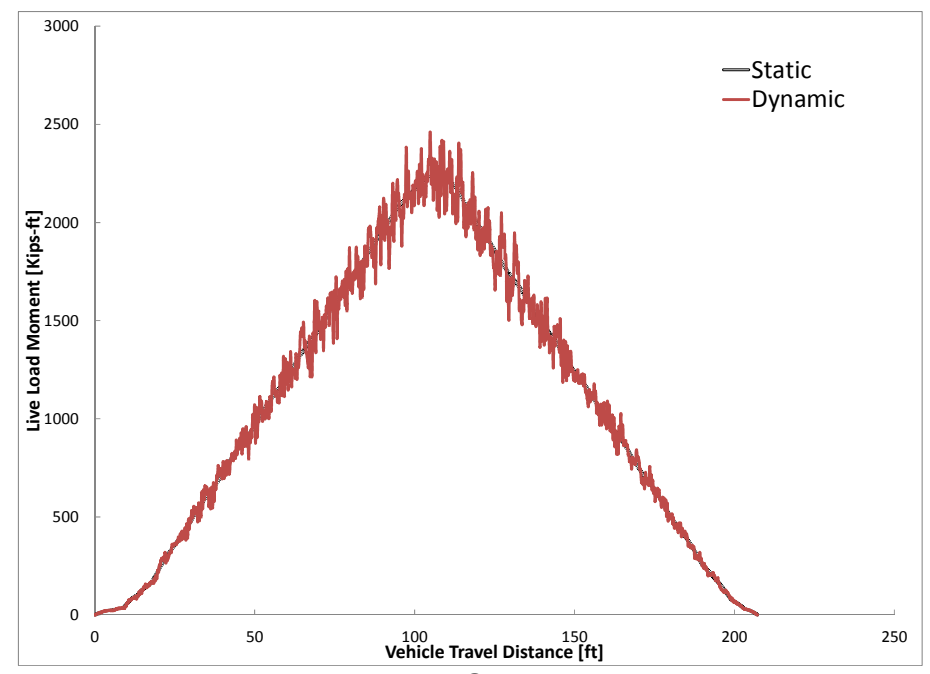

(d) SU4

Figure 62. Moment of First Real Bridge due to Single Unit Trucks and HS-20 (Good Surface) 


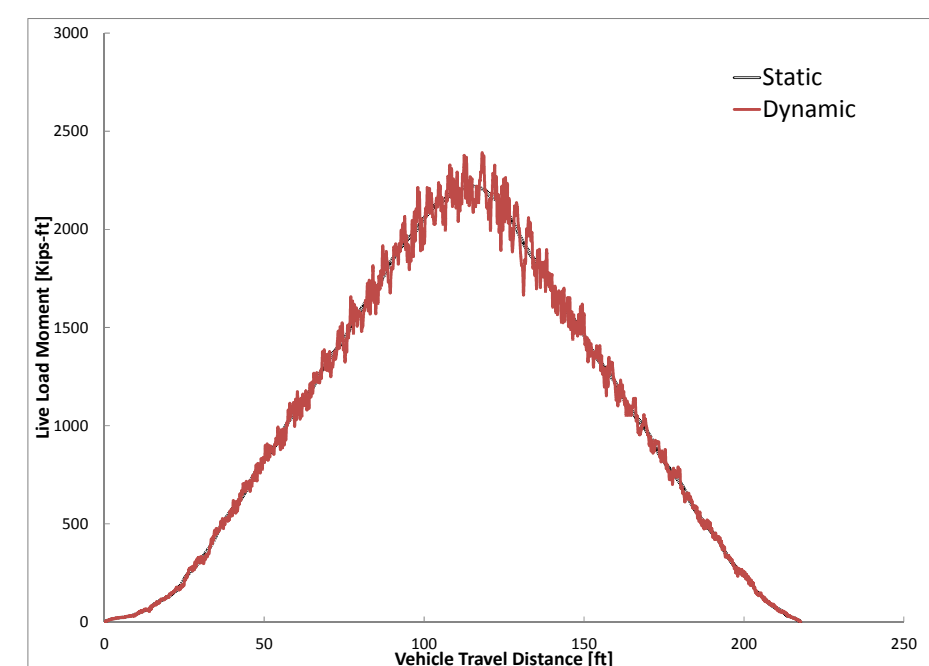

(e) Type 2S2

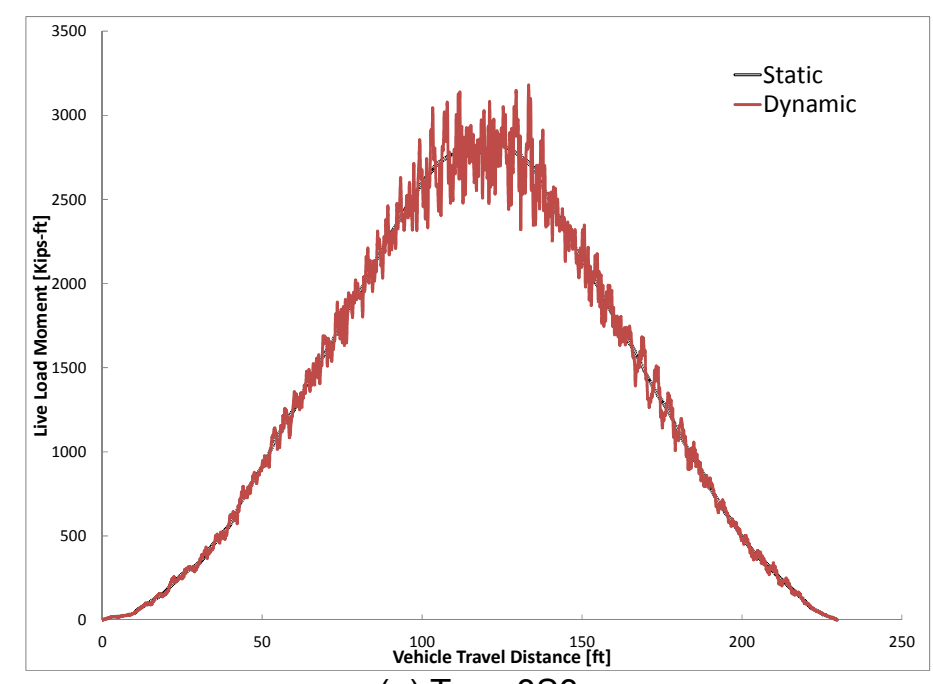

(g) Type 3S3

Figure 63. Moment of First Real Bridge due to Tractor Semitrailers (Good Surface)

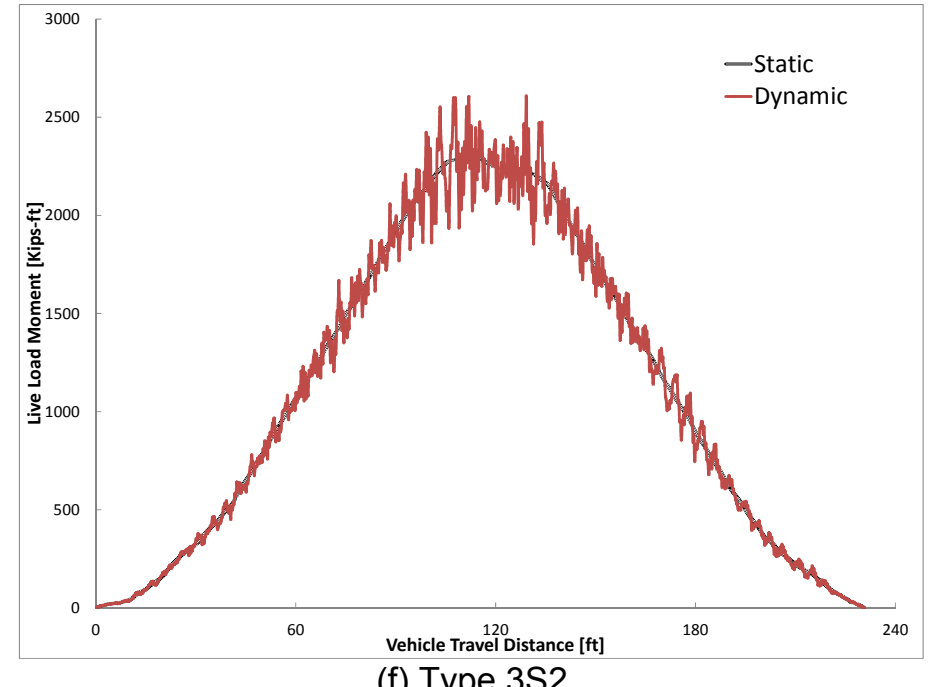

(f) Type 3S2

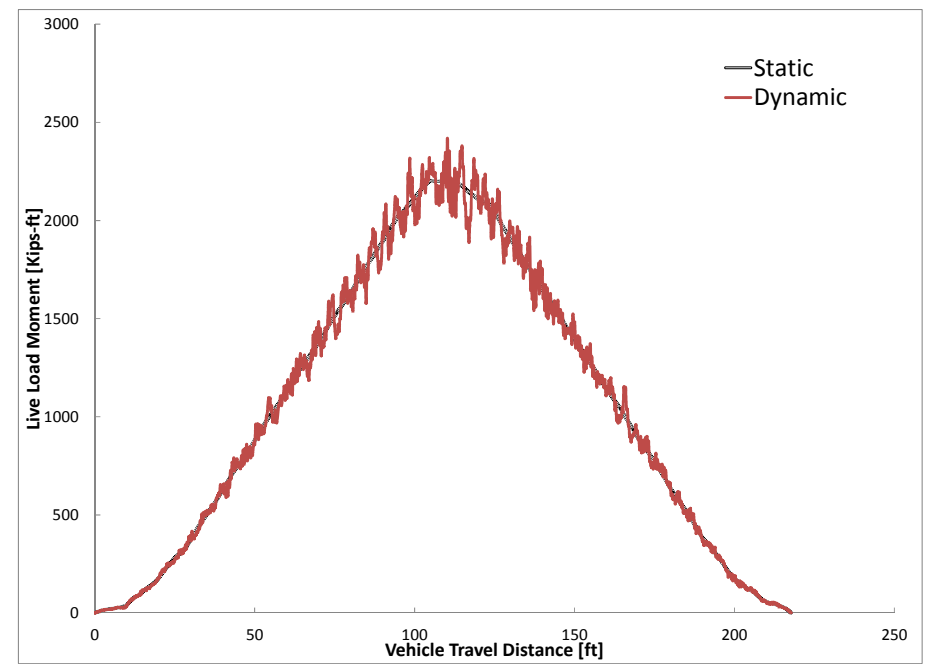

(h) Type 3S1 


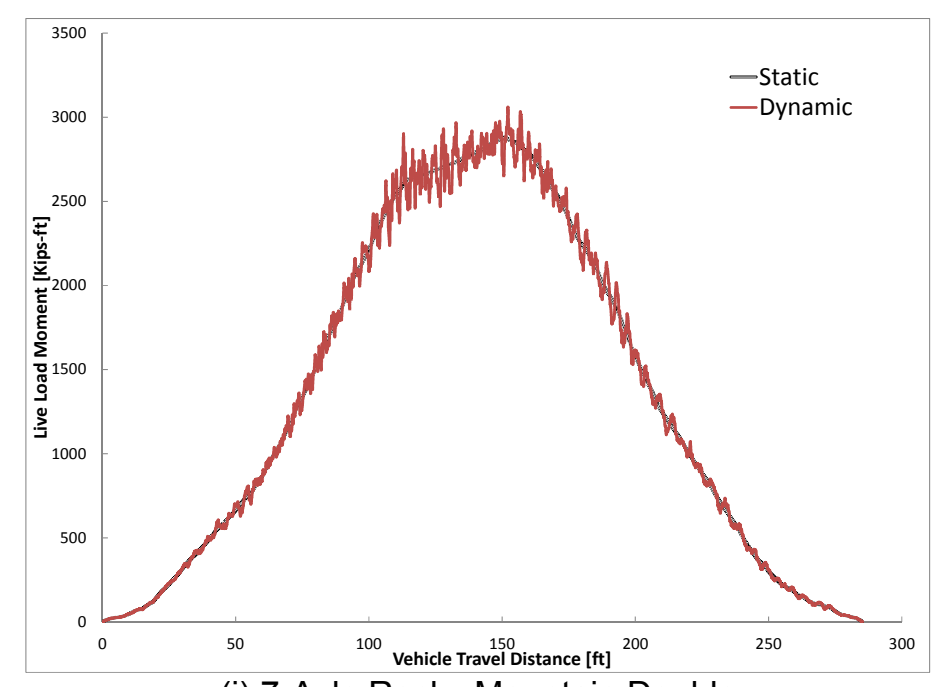

(i) 7-Axle Rocky Mountain Double

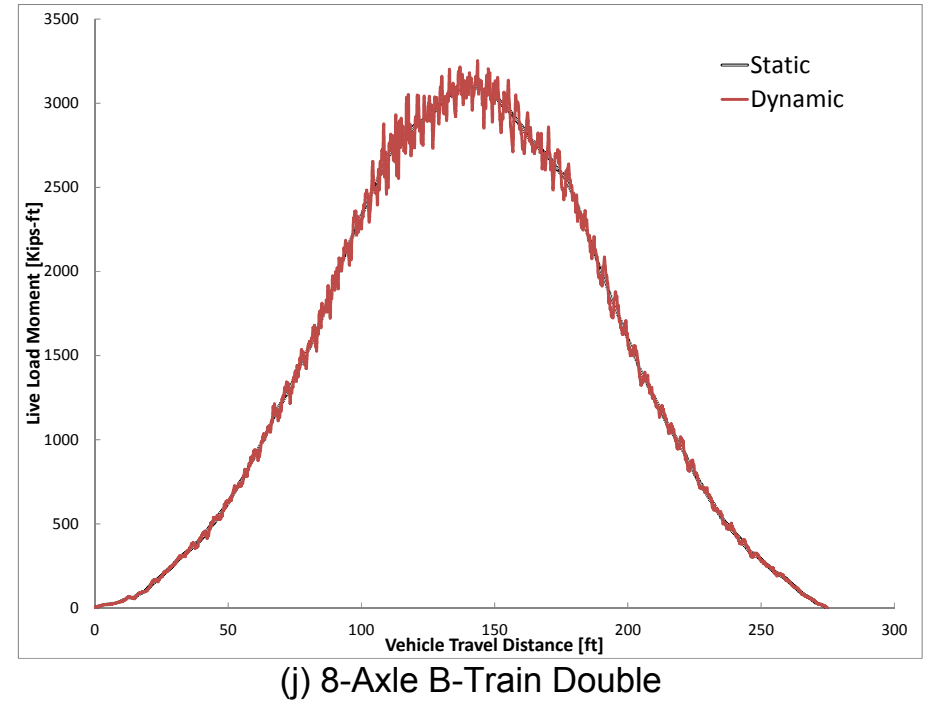

(j) 8-Axle B-Train Double

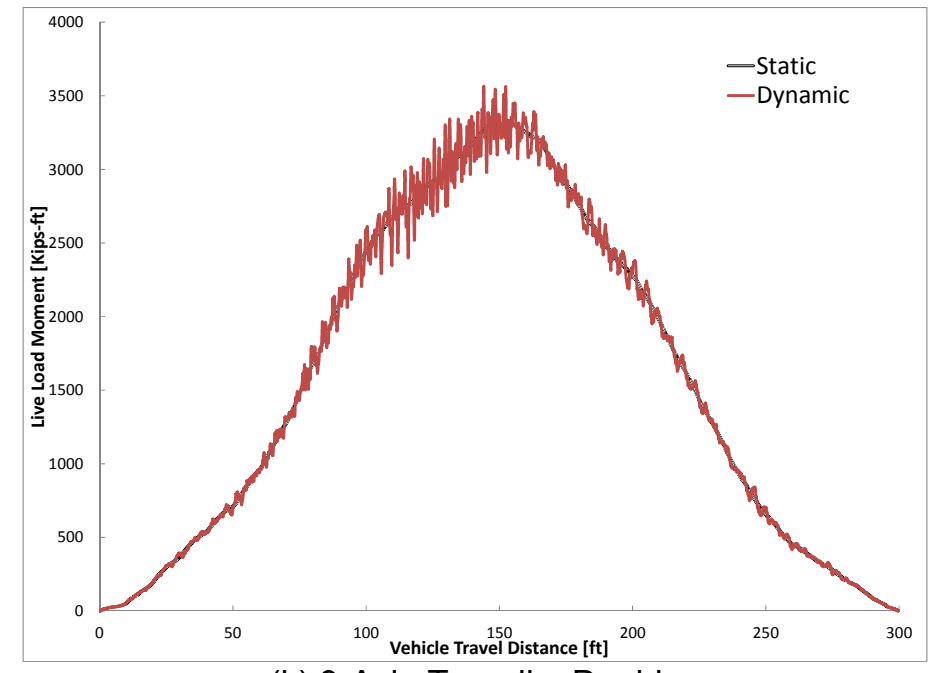

(k) 9-Axle Turnpike Double

Figure 64. Moment of First Real Bridge due to Truck and Double Trailers (Good Surface) 
The second bridge is located on Interstate 595 in Davie, Broward County. This is a three span simply supported bridge and the first span (same as the third span) is chosen and modeled here. This span is 83 '-6" long and it has seven girders. The I-girder system is also used as the deck system of this bridge. This bridge is also slightly skewed with 3 degrees which has not been taken into account in the model.

The first six mode shapes of the second real bridge can be seen in Figure 65. The static and dynamic responses of the midpoint of this bridge have been shown in the Figure 66 to Figure 68 for the Good surface condition and in Figure 69 to Figure 71 for the Very Good surface condition. The Good surface condition dynamic results are slightly higher than the Very Good surface condition. Higher frequency dynamic results can be observed for the Single Unit Trucks comparing to the LCVs. Another difference which can be observed is that the static response of Single Unit Trucks peaks at some point and then decreases whereas in the case of LCVs the maximum static response stays at the top for a while before decreasing. This is due to the length of this bridge and was not seen in the case of the first real bridge which was longer. Another observation which can be made from these figures is that the maximum displacement at the middle of the bridge does not happen when the heaviest trucks (LCVs) are on the bridge but in fact the maximum happens when Type $3 S 3$ is on the bridge. The reason for that can be found in the ratio of the length of the bridge to the vehicle and the fact that in Type $3 S 3$ the density of the weight over the length is higher (weight distributed over one trailer) than the LCVs (weight distributed over two trailers) even though the total weight of Type $3 S 3$ is smaller. The static and dynamic moment at the midpoint of the bridge are also shown in Figure 72 to Figure 74 and same point about the high frequency results in the case of Single Unit Trucks comparing to the LCVs can be made here. 


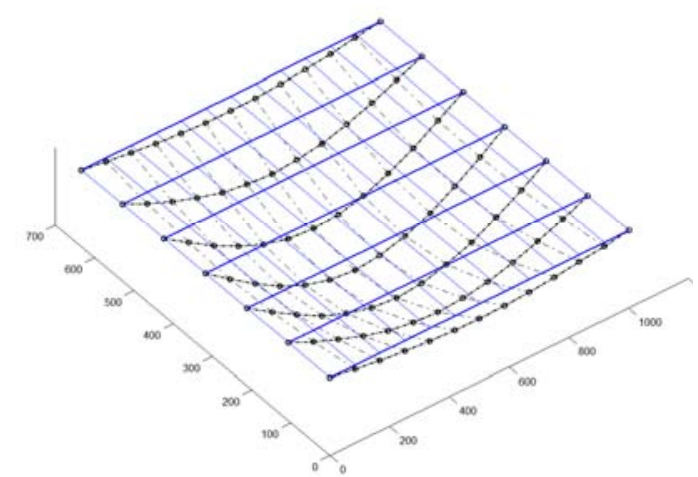

(a) $1^{\text {st }}$ Mode $\left(\mathrm{f}_{1}=3.34 \mathrm{~Hz}\right)$

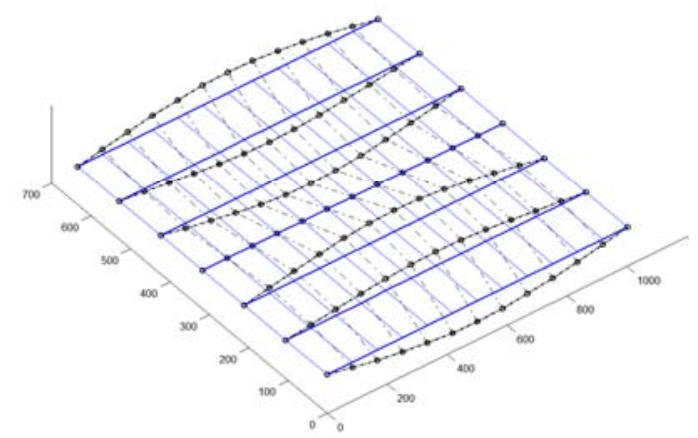

(d) $4^{\text {th }}$ Mode $\left(\mathrm{f}_{4}=9.09 \mathrm{~Hz}\right)$

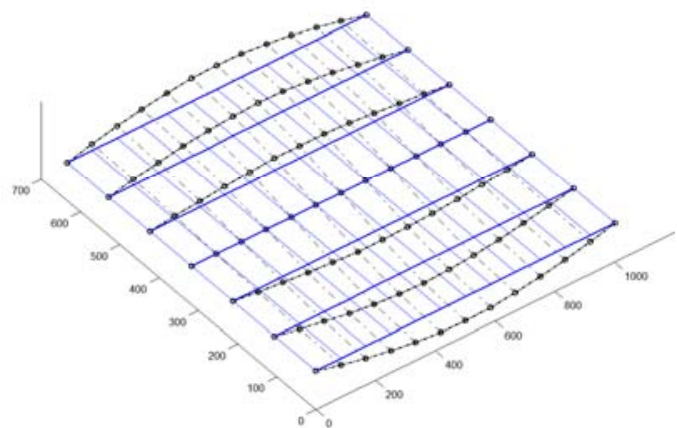

(b) $2^{\text {nd }}$ Mode $\left(\mathrm{f}_{2}=4.84 \mathrm{~Hz}\right)$

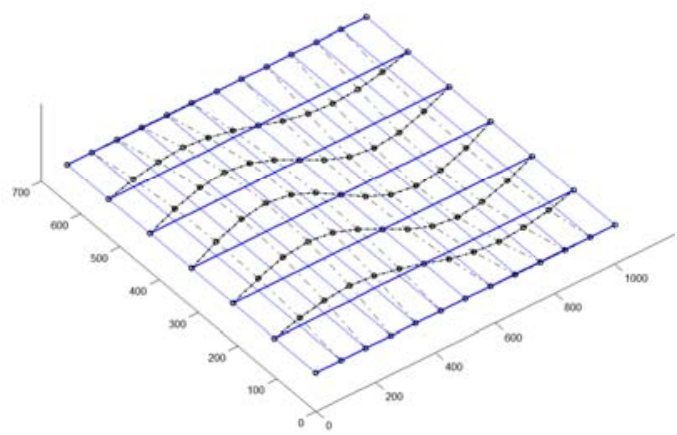

(e) $5^{\text {th }}$ Mode $\left(f_{5}=12.03 \mathrm{~Hz}\right)$

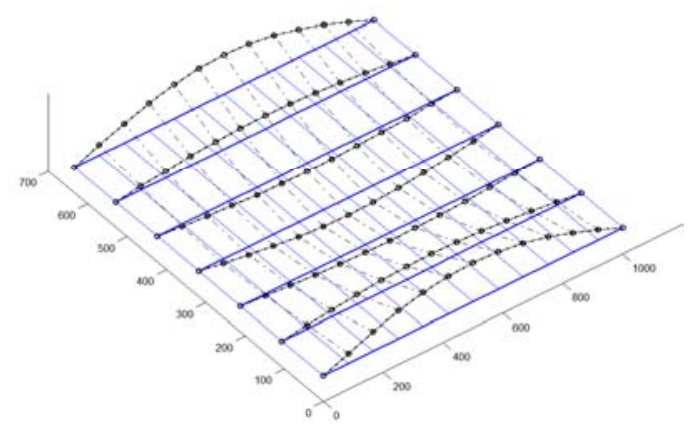

(c) $3^{\text {rd }}$ Mode $\left(f_{3}=5.97 \mathrm{~Hz}\right)$

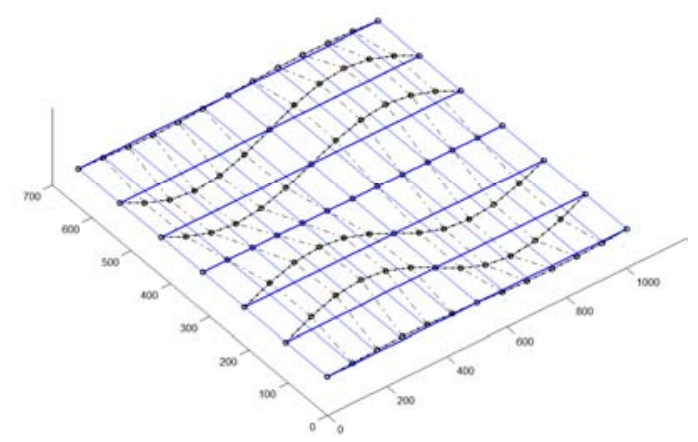

(f) $6^{\text {th }}$ Mode $\left(\mathrm{f}_{6}=14.22 \mathrm{~Hz}\right)$

Figure 65. Second Real Bridge Mode Shapes (83' 6" span) 


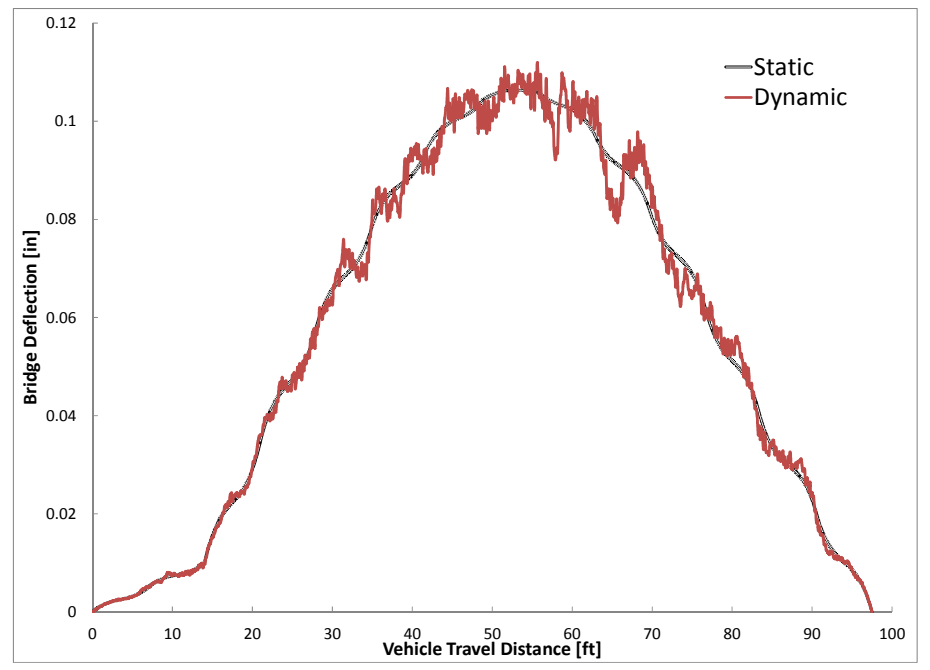

(a) $\mathrm{H}-20$

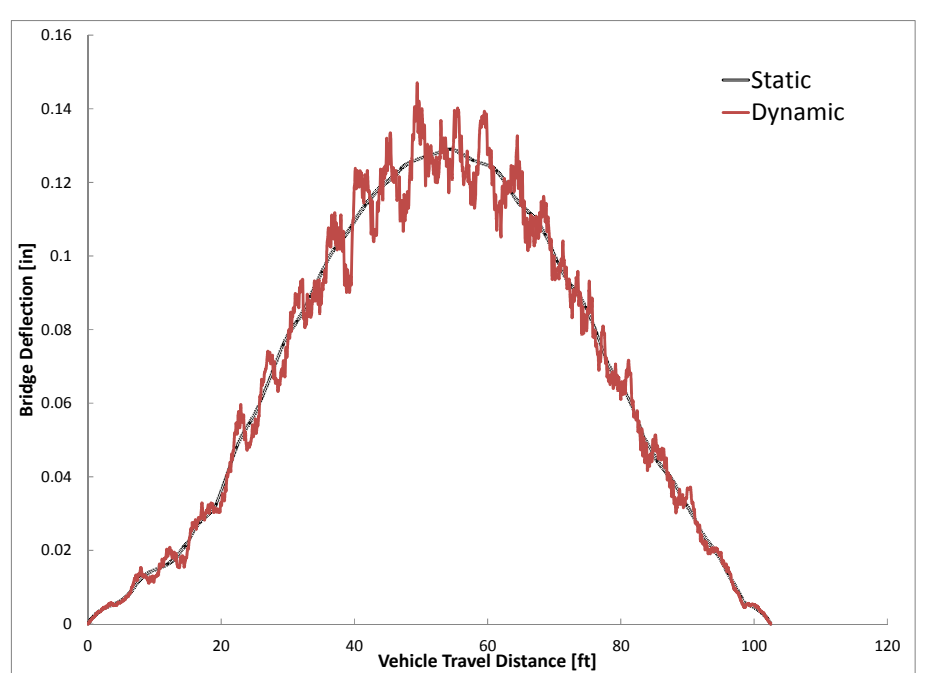

(c) Type 3

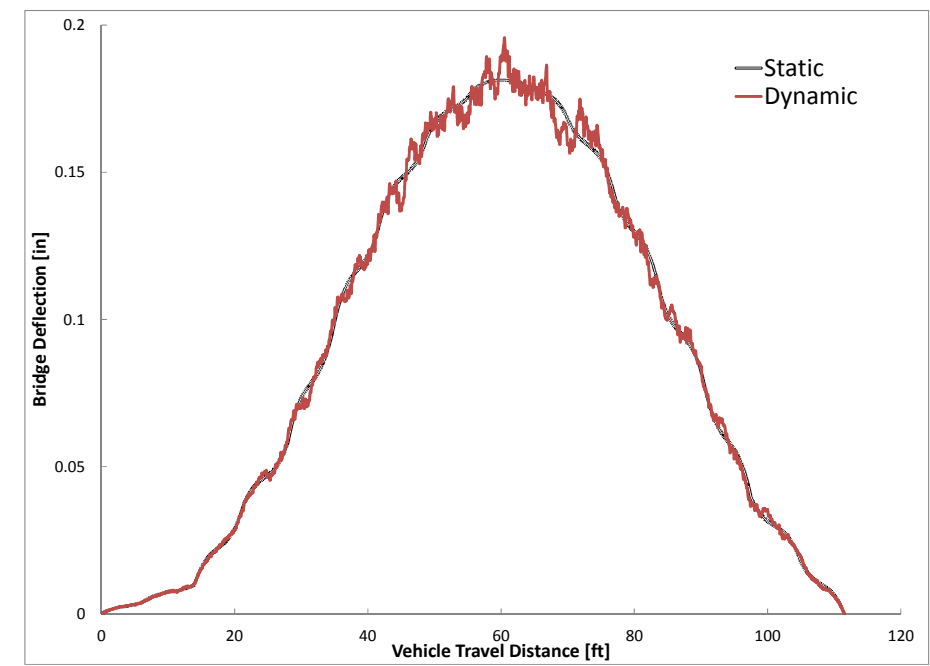

(b) HS-20

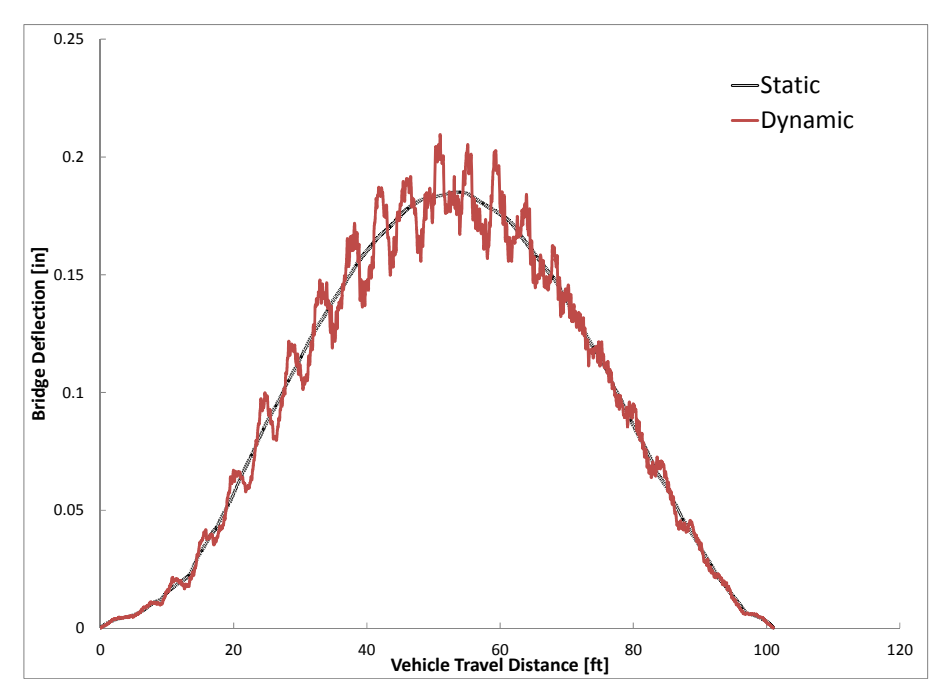

(d) SU4

Figure 66. Displacement of Second Real Bridge due to Single Unit Trucks and HS-20 (Good Surface) 


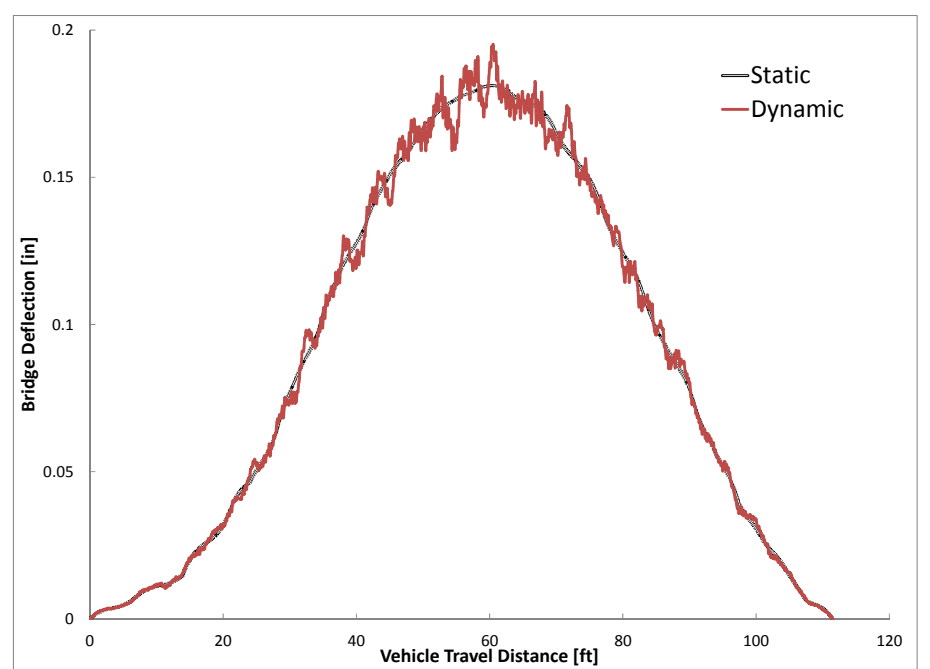

(e) Type $2 S 2$

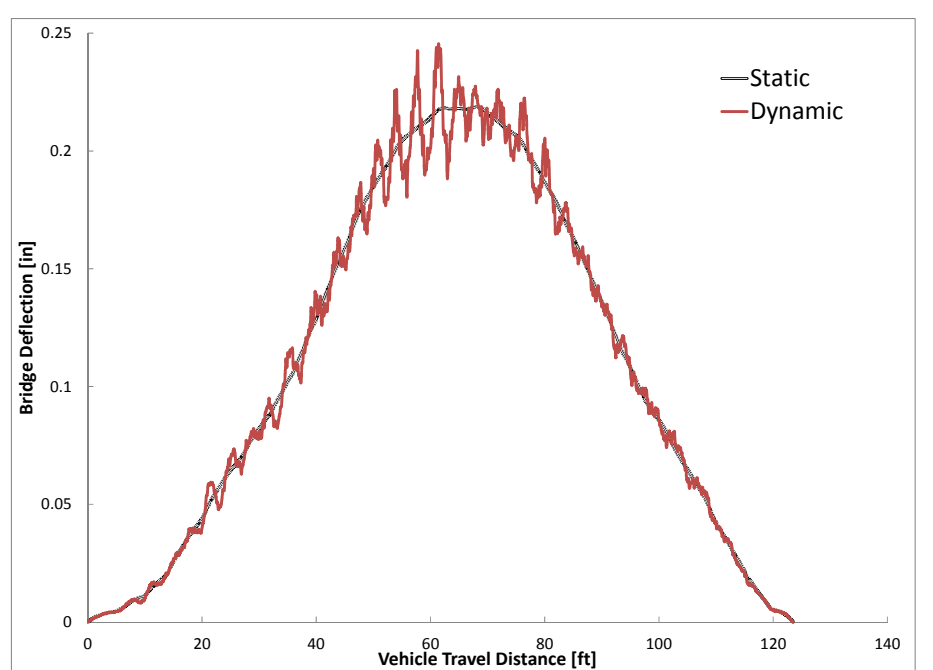

(g) Type 3S3 140

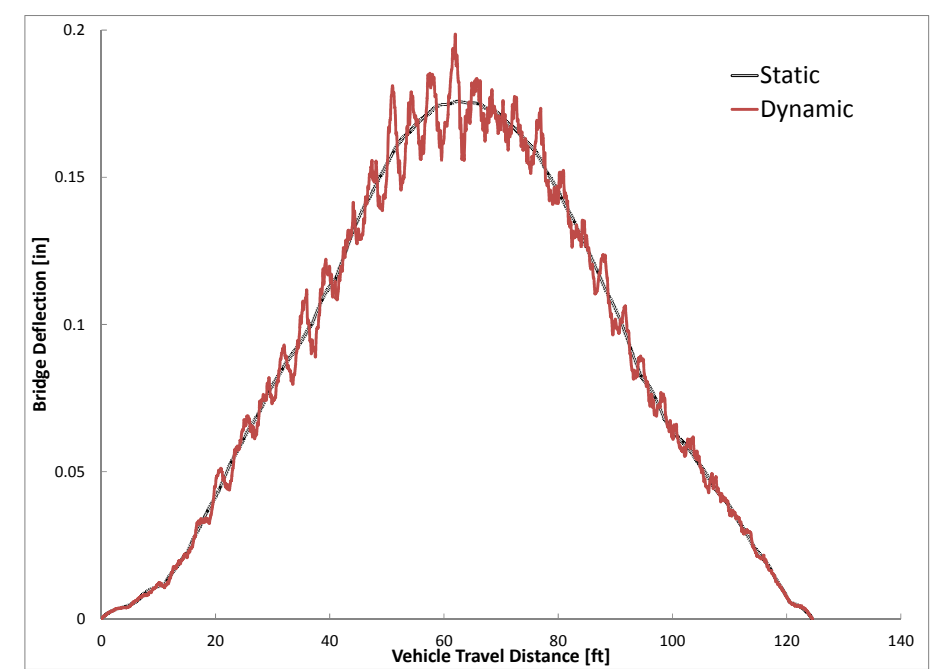

(f) Type 3S2

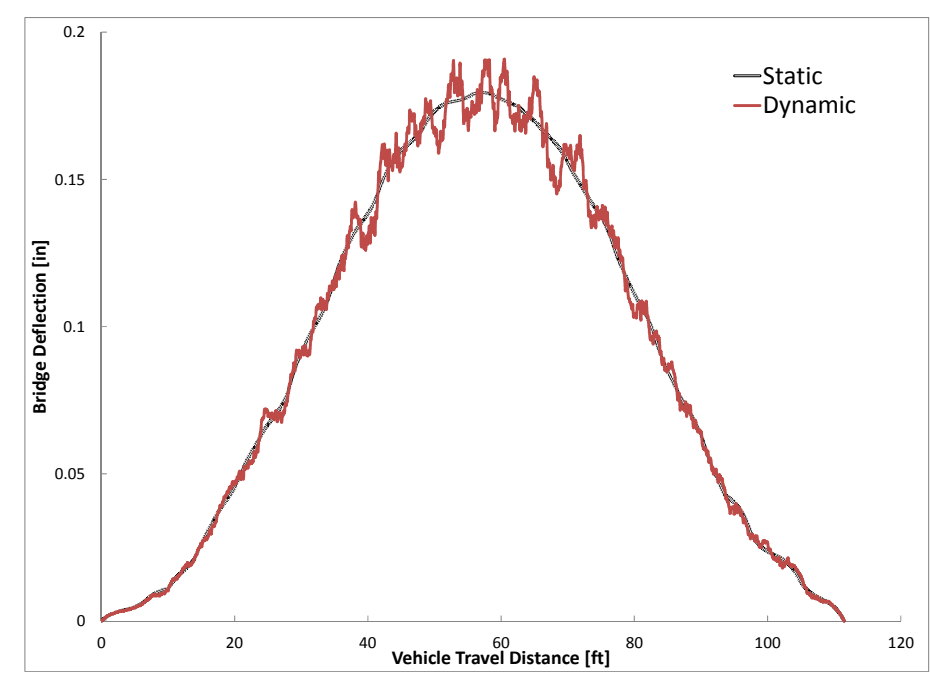

(h) Type 3S1

Figure 67. Displacement of Second Real Bridge due to Tractor Semitrailers (Good Surface) 

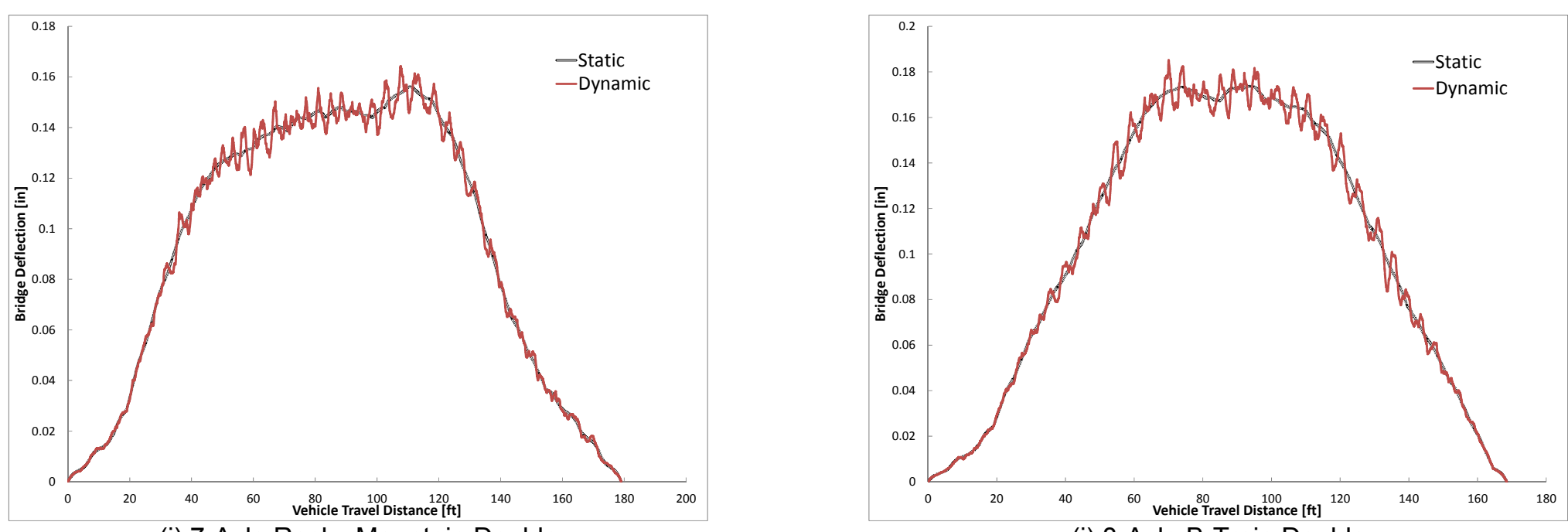

(i) 7-Axle Rocky Mountain Double

(j) 8-Axle B-Train Double

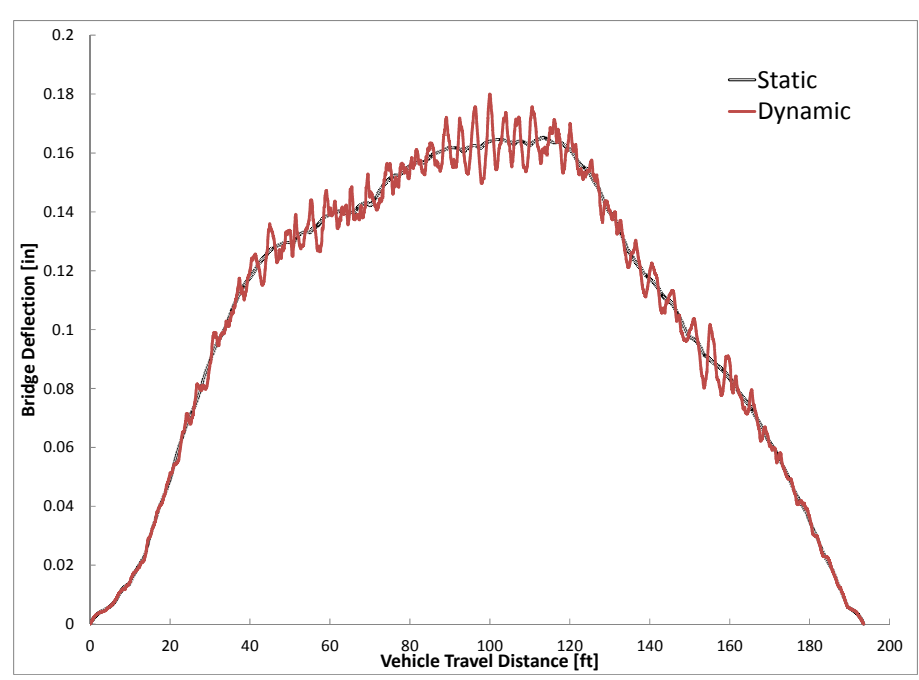

(k) 9-Axle Turnpike Double

Figure 68. Displacement of Second Real Bridge due to Truck and Double Trailers (Good Surface) 


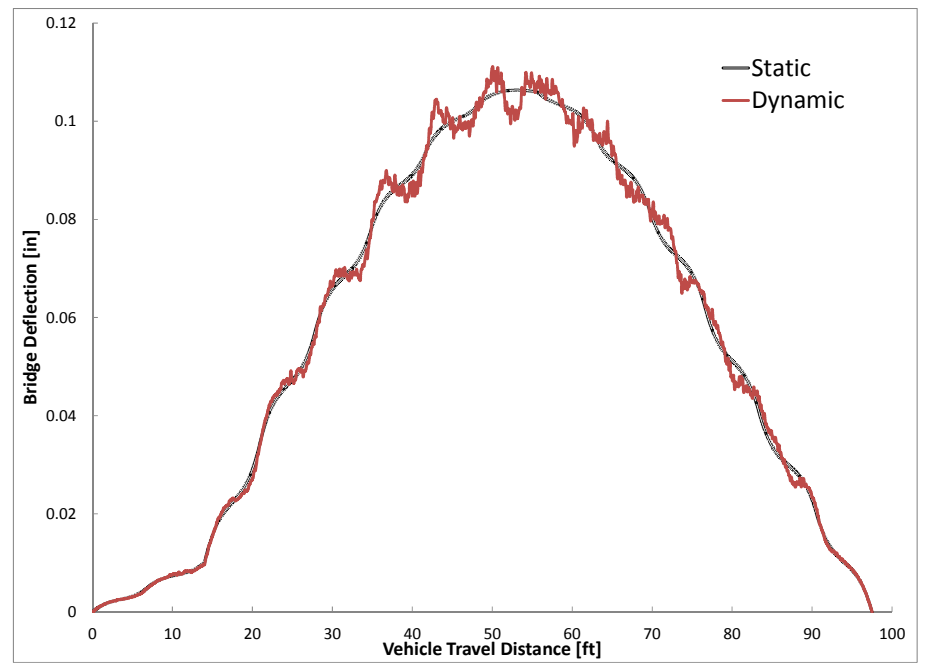

(a) $\mathrm{H}-20$

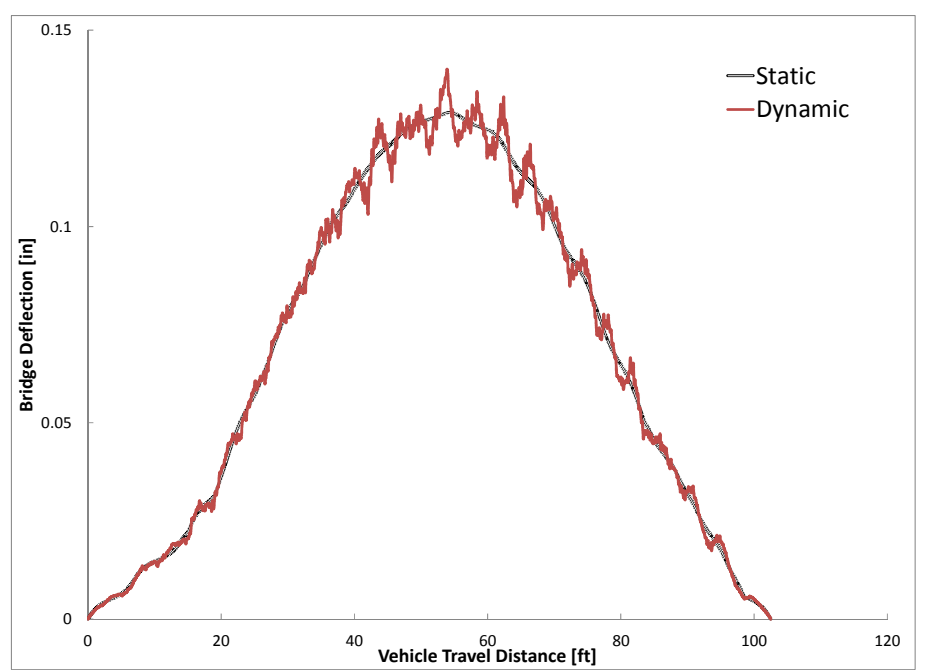

(c) Type 3

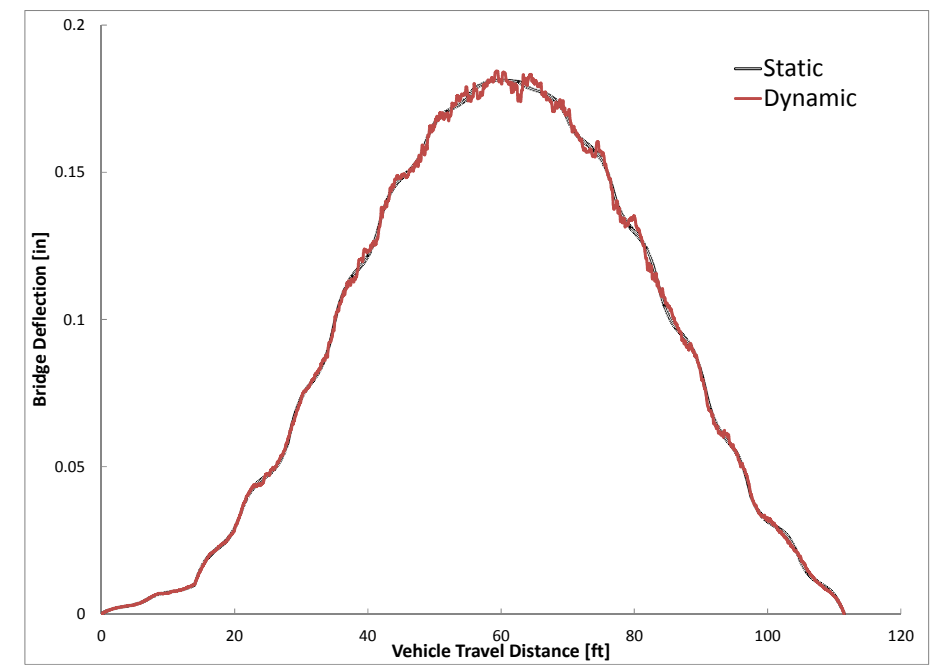

(b) HS-20

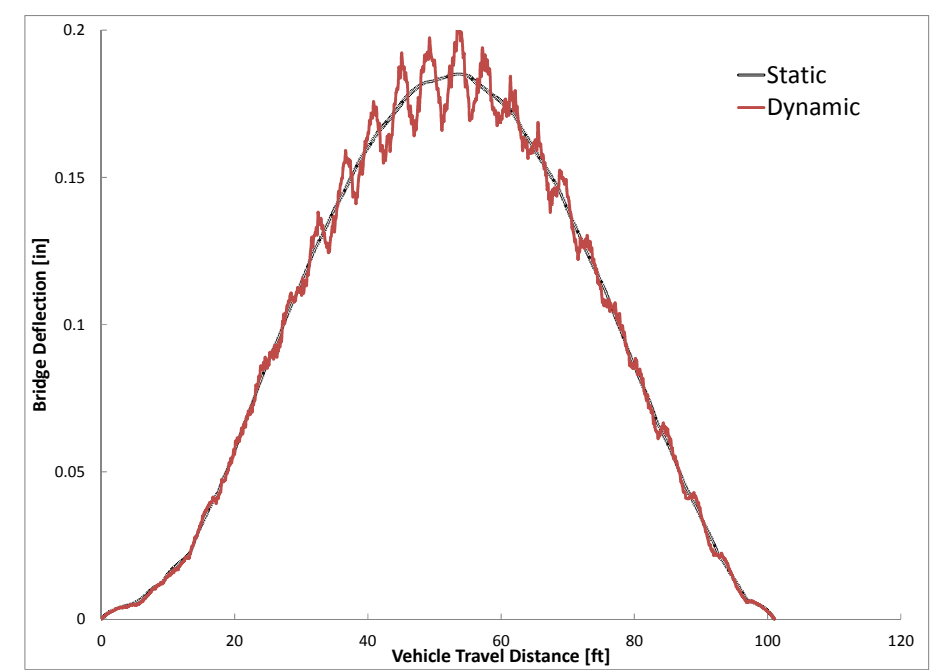

(d) SU4

Figure 69. Displacement of Second Real Bridge due to Single Unit Trucks and HS-20 (Very Good Surface) 


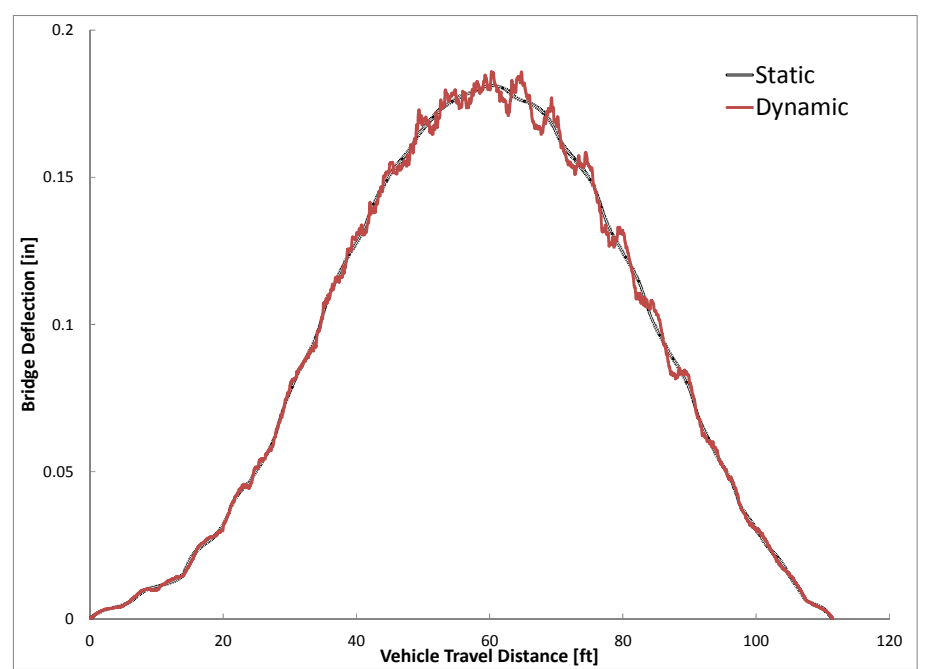

(e) Type 2S2

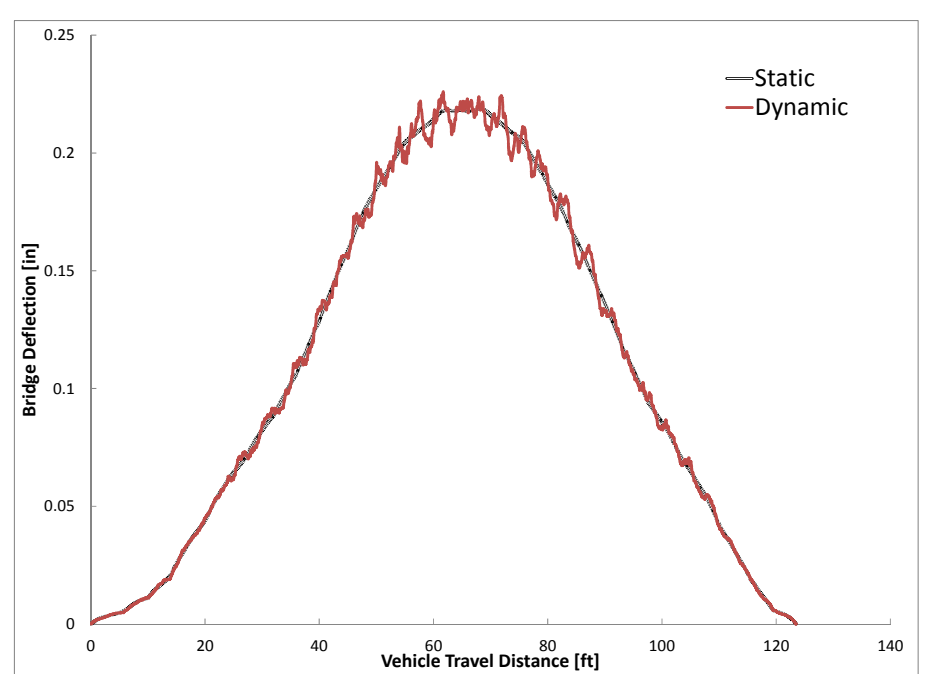

(g) Type 3S3

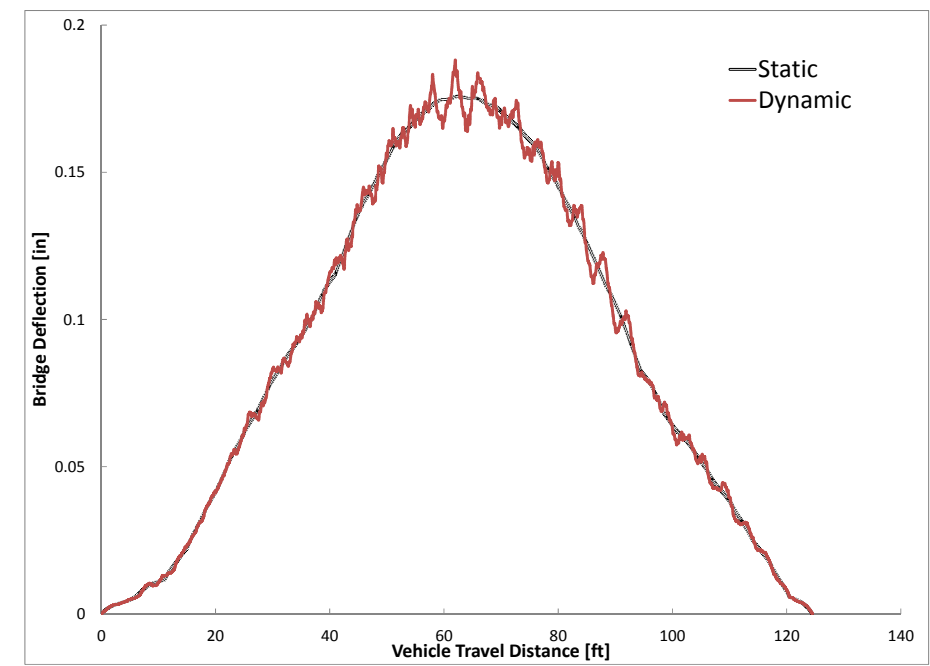

(f) Type 3S2

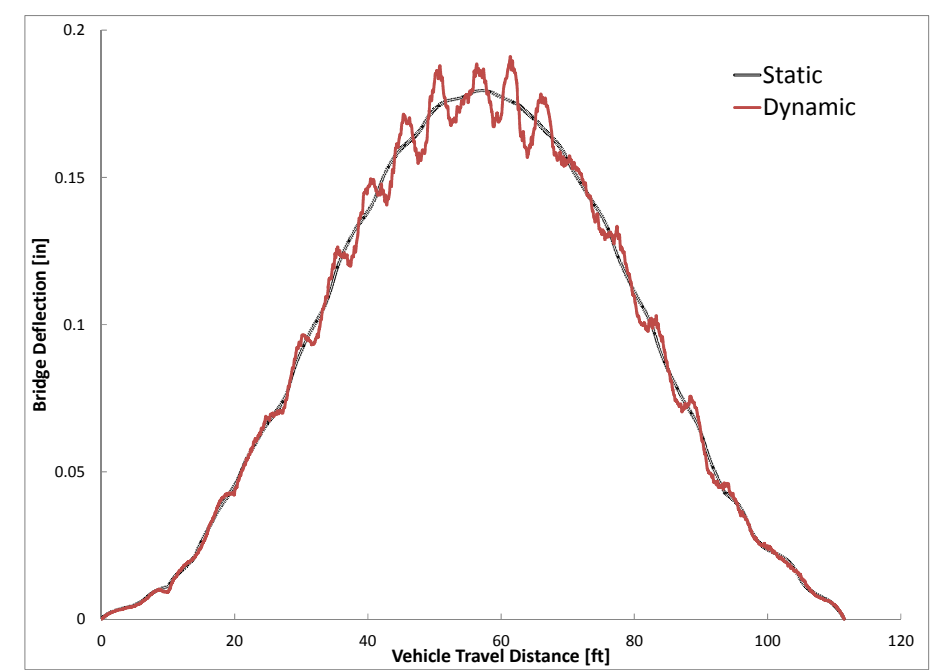

(h) Type 3S1

Figure 70. Displacement of Second Real Bridge due to Tractor Semitrailers (Very Good Surface) 

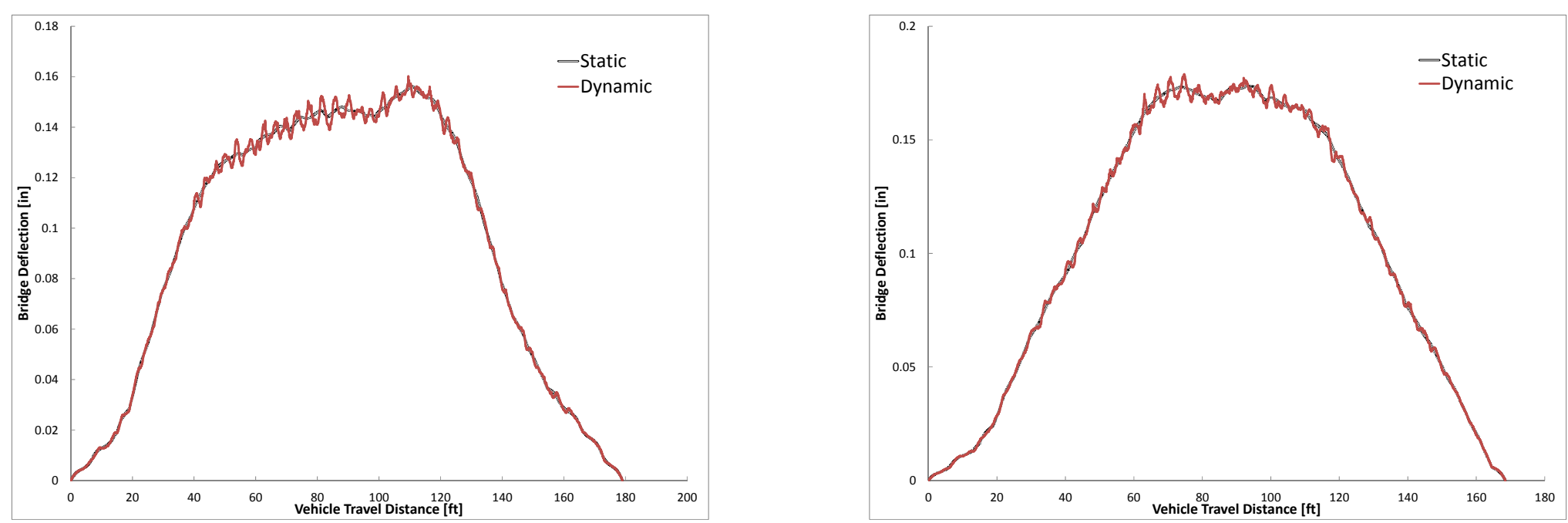

(i) 7-Axle Rocky Mountain Double

(j) 8-Axle B-Train Double

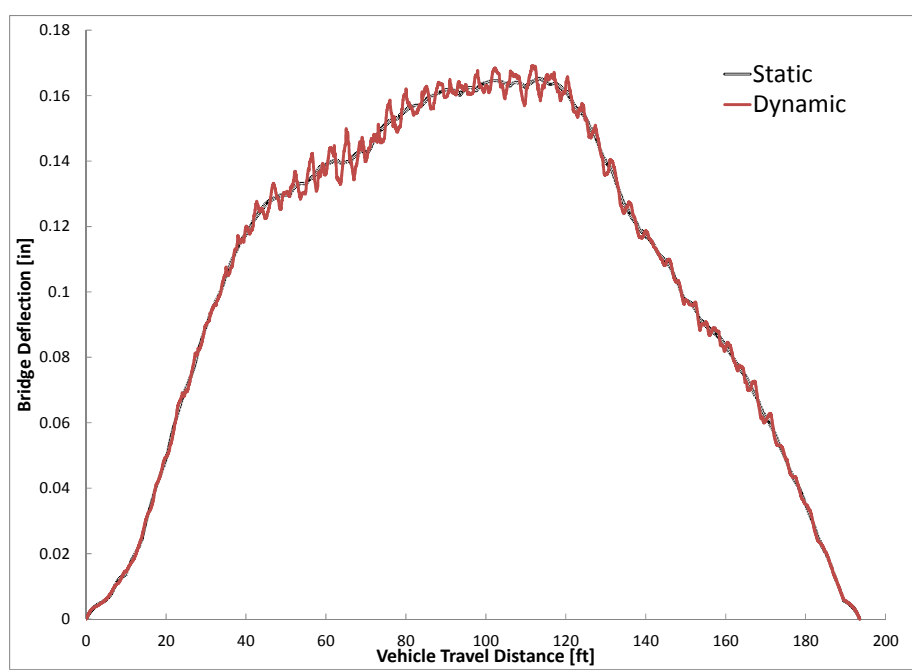

(k) 9-Axle Turnpike Double

Figure 71. Displacement of Second Real Bridge due to Truck and Double Trailers (Very Good Surface) 


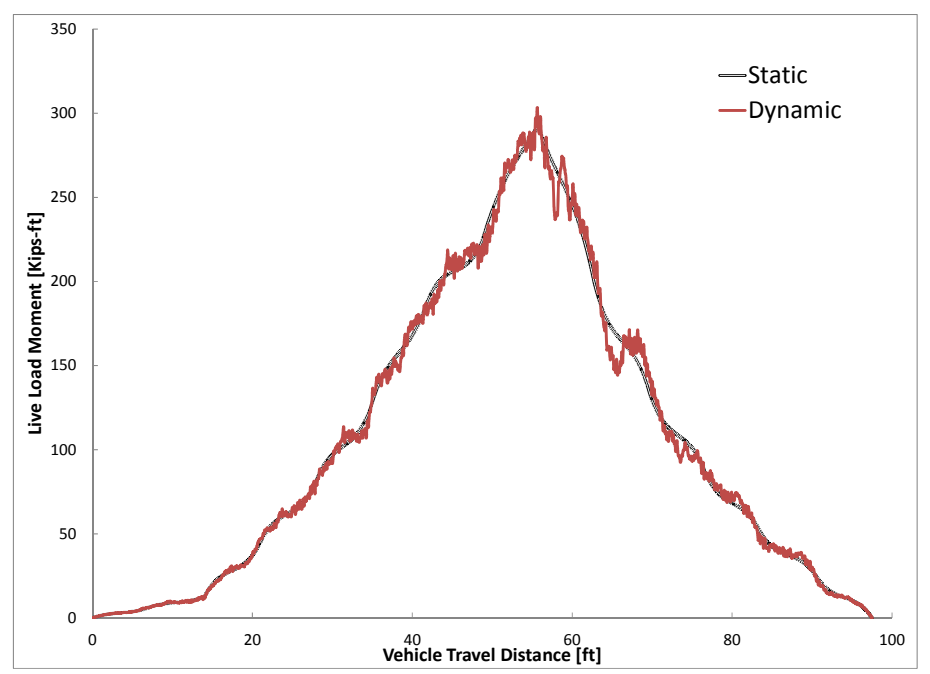

(a) $\mathrm{H}-20$

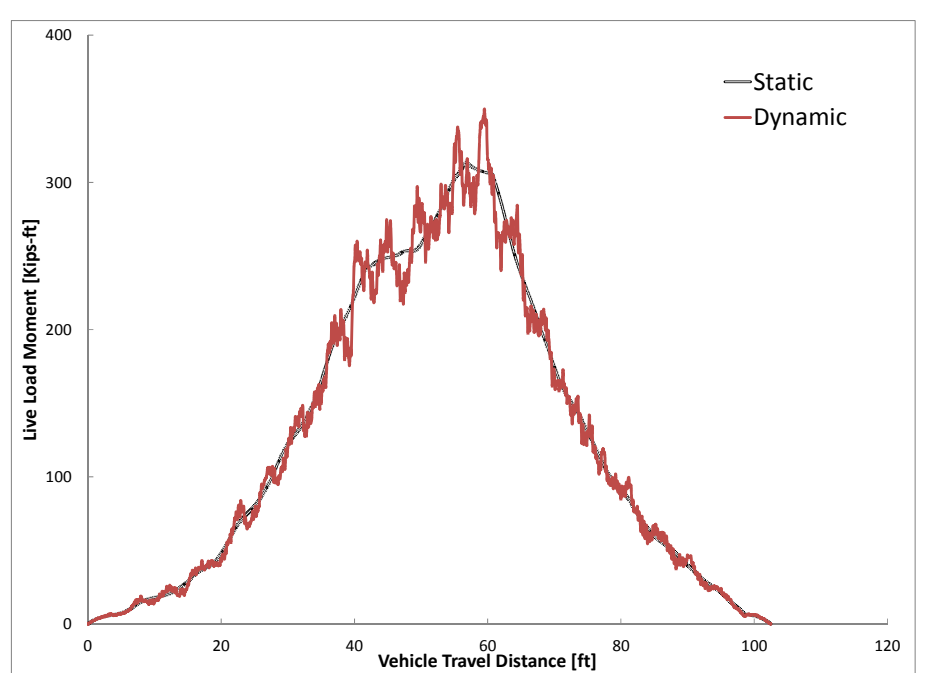

(c) Type 3

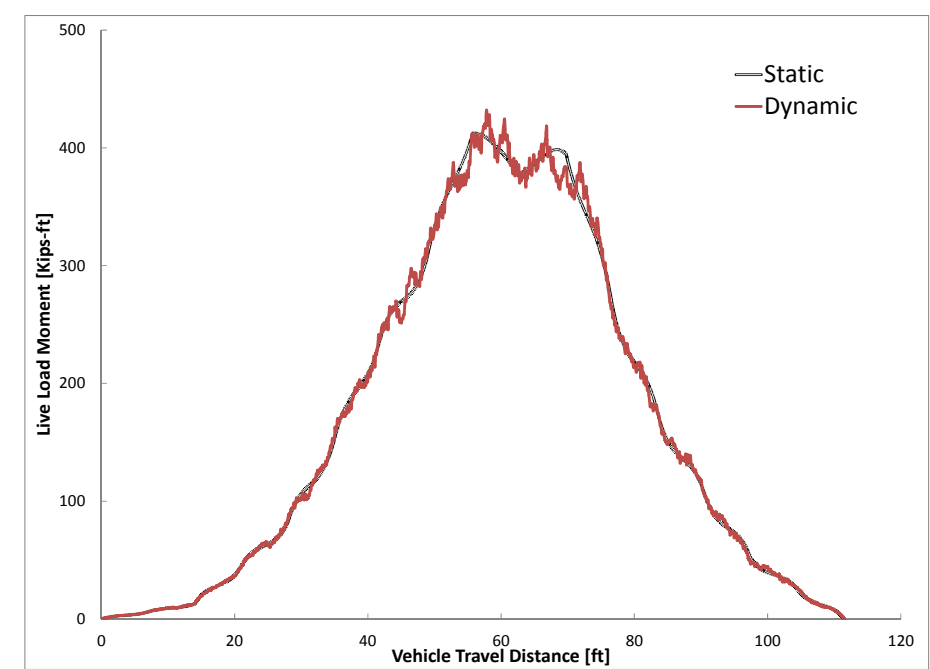

(b) HS-20

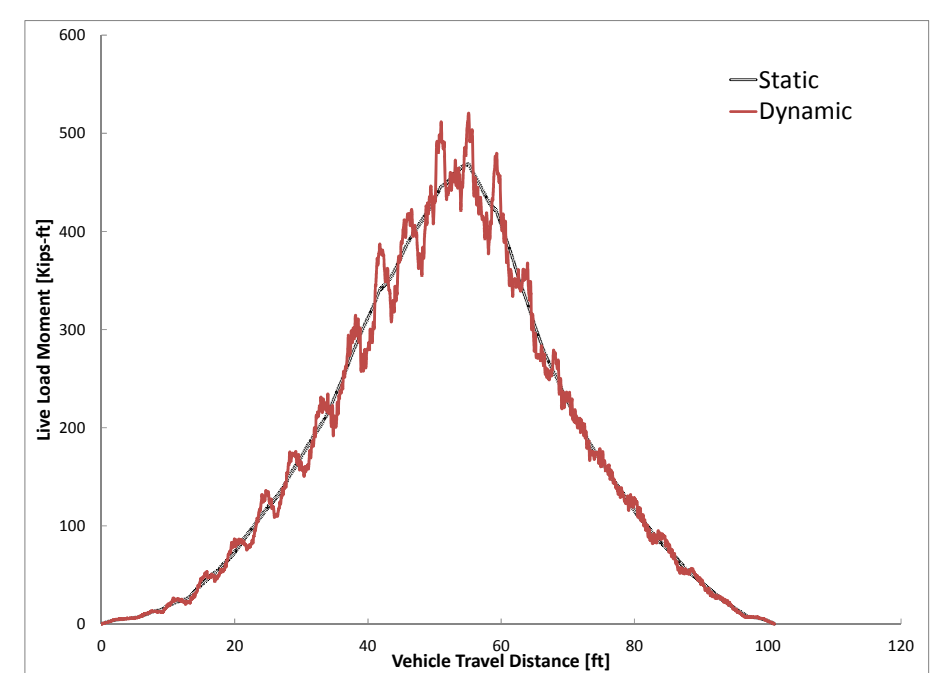

(d) SU4

Figure 72. Moment of Second Real Bridge due to Single Unit Trucks and HS-20 (Good Surface) 


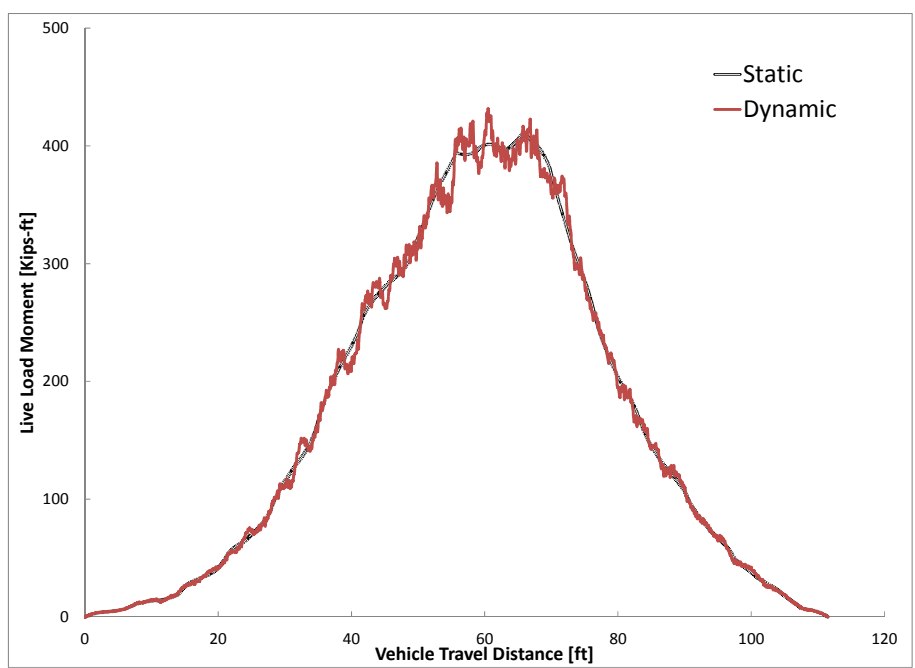

(e) Type 2S2

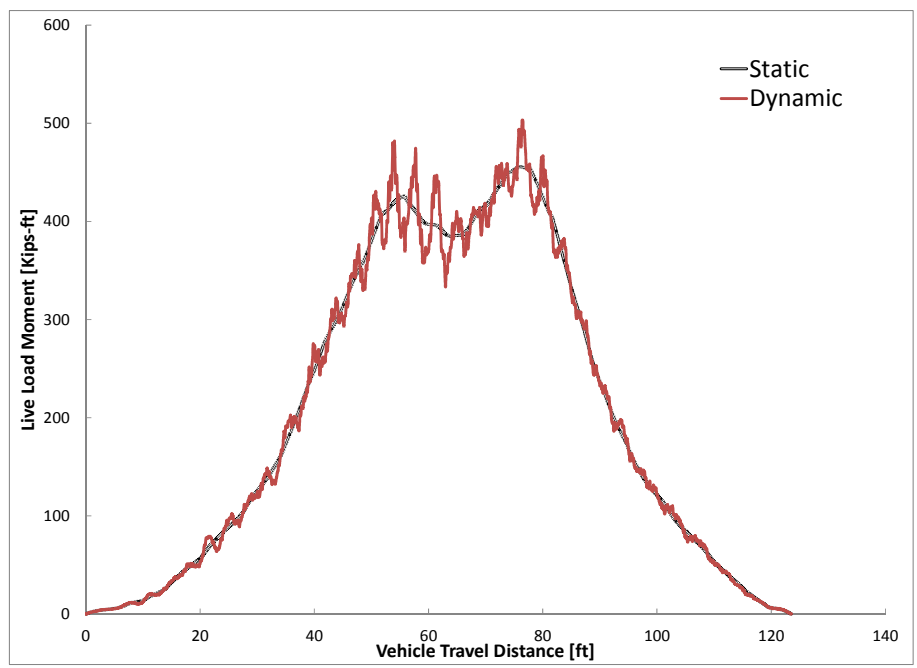

(g) Type $3 \mathrm{S3}$

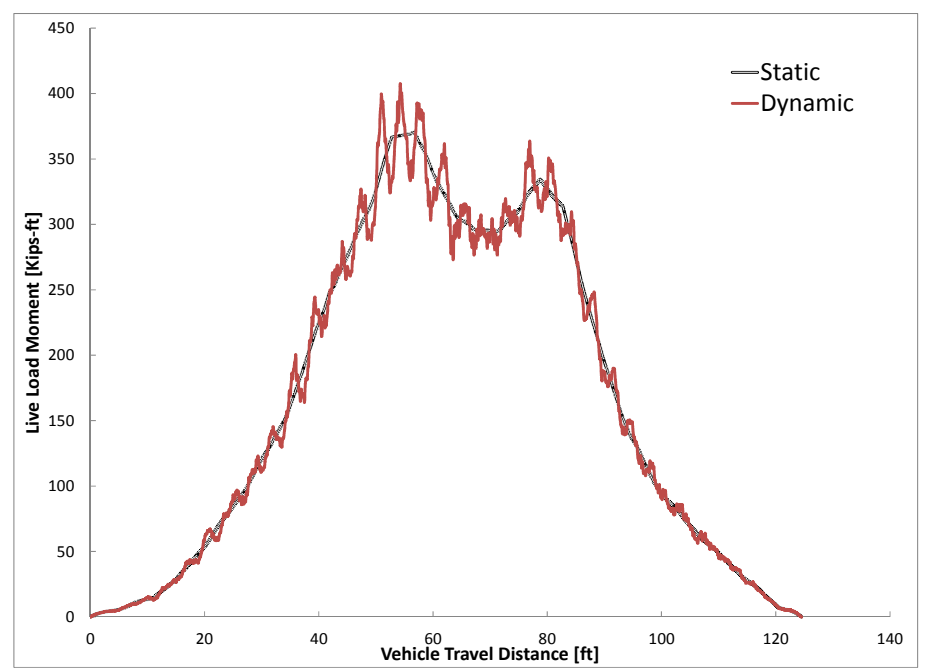

(f) Type 3S2

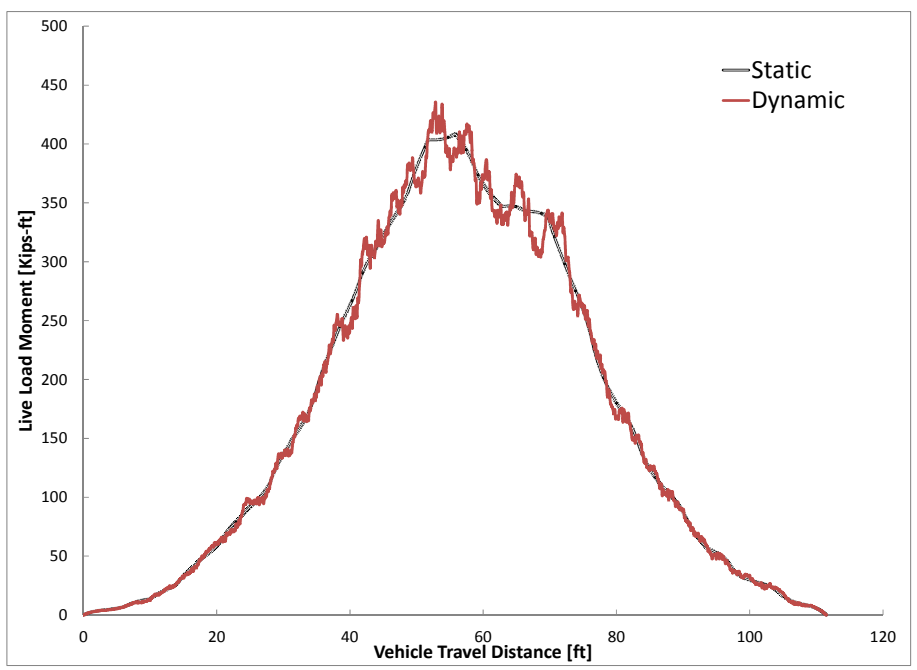

(h) Type 3S1

Figure 73. Moment of Second Real Bridge due to Tractor Semitrailers (Good Surface)

118 


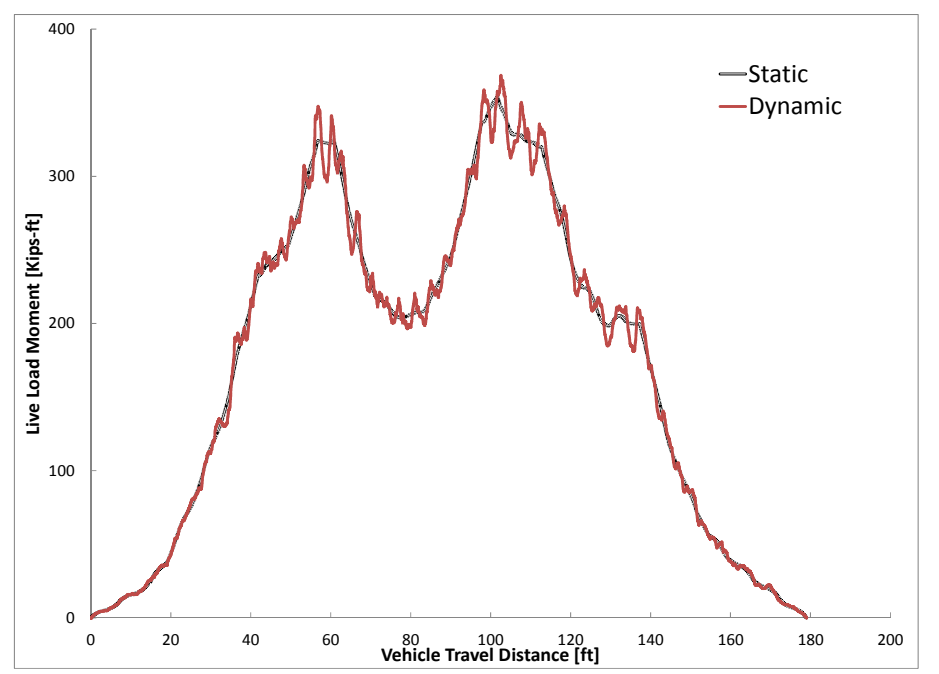

(i) 7-Axle Rocky Mountain Double

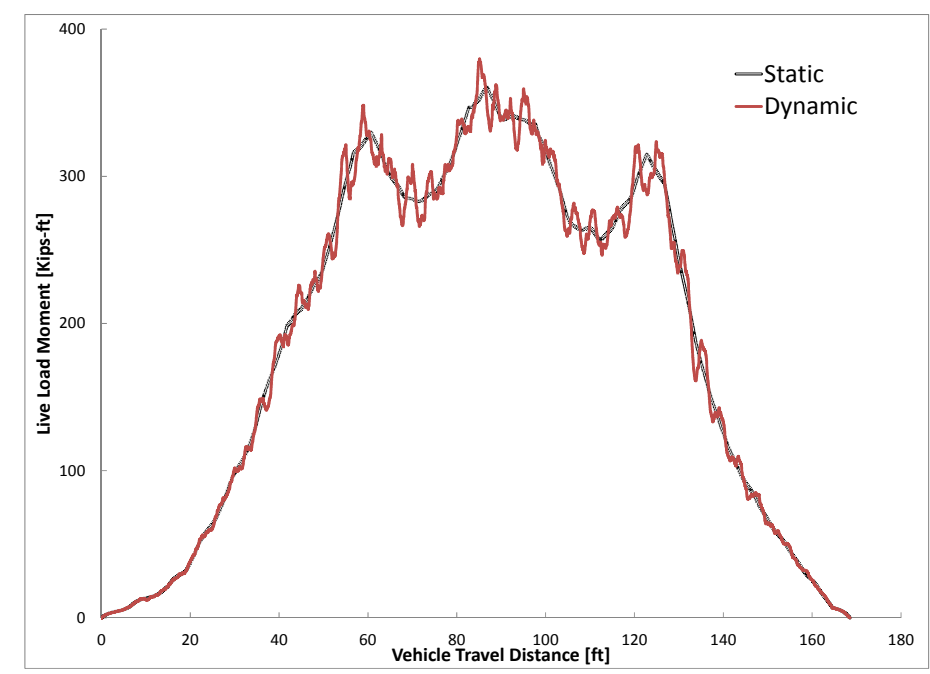

(j) 8-Axle B-Train Double

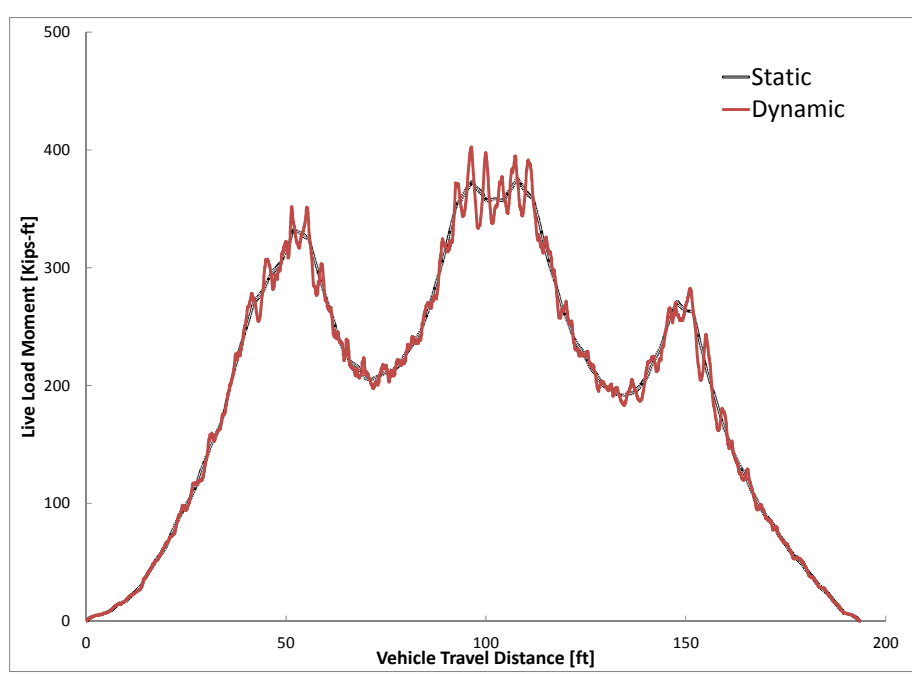

(k) 9-Axle Turnpike Double

Figure 74. Moment of Second Real Bridge due to Truck and Double Trailers (Good Surface) 
Table 19. Dynamic Amplification Factor for First and Second Real Bridges

\begin{tabular}{|c|c|c|c|c|c|c|c|c|c|c|c|c|c|}
\hline \multirow[b]{2}{*}{$\begin{array}{l}\text { Bridge } \\
\text { Type }\end{array}$} & \multirow[b]{2}{*}{$\begin{array}{c}\text { Surface } \\
\text { Condition }\end{array}$} & \multirow[b]{2}{*}{$\begin{array}{l}\text { Speed } \\
{[\mathrm{mph}]}\end{array}$} & \multicolumn{11}{|c|}{ Vehicle Type } \\
\hline & & & $\mathrm{H}-20$ & HS-20 & Type 3 & $\begin{array}{c}\text { Type } \\
352\end{array}$ & $\begin{array}{c}\text { Type } \\
353\end{array}$ & $\begin{array}{c}\text { Type } \\
\text { 2S2 }\end{array}$ & $\begin{array}{c}\text { Type } \\
\text { 3S1 }\end{array}$ & SU4 & $\begin{array}{c}\text { 7-Axle Rocky } \\
\text { Mountain } \\
\text { Double }\end{array}$ & $\begin{array}{l}8 \text { Axle } \\
\text { B-Train } \\
\text { Double }\end{array}$ & $\begin{array}{l}9 \text { Axle } \\
\text { Turnpike } \\
\text { Double }\end{array}$ \\
\hline \multirow{8}{*}{ 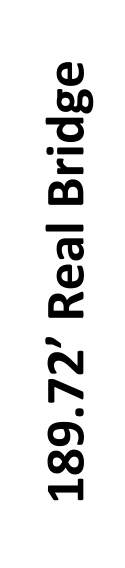 } & \multirow{4}{*}{$\begin{array}{l}\text { Very } \\
\text { Good }\end{array}$} & 15 & 5.0 & 3.0 & 10.1 & 7.0 & 9.3 & 7.9 & 10.2 & 11.9 & 7.1 & 5.3 & 6.1 \\
\hline & & 35 & 7.1 & 6.2 & 11.6 & 7.9 & 8.6 & 6.0 & 7.5 & 6.0 & 5.6 & 5.0 & 6.0 \\
\hline & & 55 & 4.8 & 5.7 & 11.3 & 10.5 & 14.2 & 7.6 & 9.6 & 7.3 & 6.5 & 5.2 & 8.5 \\
\hline & & 75 & 8.1 & 4.9 & 11.1 & 7.6 & 8.9 & 5.2 & 7.7 & 8.8 & 6.9 & 6.9 & 10.2 \\
\hline & \multirow{4}{*}{ Good } & 15 & 12.5 & 6.9 & 11.3 & 14.7 & 13.8 & 4.3 & 3.0 & 5.5 & 7.1 & 5.8 & 8.5 \\
\hline & & 35 & 10.0 & 6.2 & 18.8 & 13.9 & 14.0 & 10.3 & 12.2 & 16.2 & 9.4 & 6.9 & 11.7 \\
\hline & & 55 & 12.9 & 6.6 & 18.4 & 17.2 & 12.5 & 11.3 & 10.1 & 17.3 & 14.1 & 9.7 & 16.3 \\
\hline & & 75 & 15.4 & 11.6 & 23.6 & 18.5 & 21.0 & 12.9 & 14.8 & 17.1 & 15.0 & 9.1 & 17.4 \\
\hline \multirow{8}{*}{ 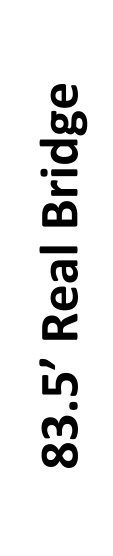 } & \multirow{4}{*}{$\begin{array}{l}\text { Very } \\
\text { Good }\end{array}$} & 15 & 4.5 & 1.7 & 8.6 & 7.0 & 3.3 & 2.6 & 6.5 & 9.3 & 2.6 & 3.0 & 2.4 \\
\hline & & 35 & 4.9 & 3.3 & 6.2 & 7.0 & 7.1 & 2.9 & 5.5 & 4.2 & 2.0 & 3.2 & 2.7 \\
\hline & & 55 & 6.3 & 1.4 & 4.9 & 12.6 & 4.2 & 3.7 & 2.8 & 3.3 & 4.7 & 4.1 & 6.9 \\
\hline & & 75 & 11.5 & 0.8 & 4.3 & 8.7 & 5.7 & 3.3 & 2.6 & 3.1 & 2.8 & 7.5 & 8.1 \\
\hline & \multirow{4}{*}{ Good } & 15 & 5.3 & 7.9 & 14.0 & 13.0 & 12.3 & 7.8 & 6.4 & 13.2 & 5.3 & 6.6 & 8.9 \\
\hline & & 35 & 5.7 & 9.0 & 11.4 & 8.4 & 11.9 & 11.0 & 10.1 & 11.5 & 3.5 & 7.9 & 5.6 \\
\hline & & 55 & 4.3 & 10.7 & 9.7 & 7.1 & 7.3 & 7.1 & 4.7 & 10.2 & 6.6 & 10.0 & 10.6 \\
\hline & & 75 & 4.5 & 5.6 & 11.5 & 5.9 & 8.7 & 2.9 & 0.8 & 8.8 & 13.0 & 12.4 & 13.9 \\
\hline
\end{tabular}


The results for the Dynamic Amplification Factors of First and Second Real Bridges due to all the vehicles and four different vehicle speeds are shown in Table 19. The results for the two real bridges show similar results as the results of the designed bridges. The DAF values for the cases of Very Good and Good conditions are generally smaller than the $33 \%$ threshold suggested by AASHTO LRFD design manual. It is difficult to find a common trend for the DAF values with respect to the vehicle speed value for different types of vehicles and road surface conditions.

Using the vehicle categories in Table 16 the DAFs calculated from all the vehicles have been grouped and presented for the first real bridge in Figure 75 and Figure 76 for the Very Good and Good surface conditions respectively. The results of the second bridge have been shown in Figure 77 and Figure 78 for the Very Good and Good surface conditions respectively as well. It can be observed that except for some higher speeds in which the LCVs result in higher results, in most cases the highest values of the DAF happen when the Single Unit Trucks travel on the bridge and the Tractor Semitrailers DAF results usually lie between the Single Unit Trucks and the LCVs.

Figure 79 and Figure 80 show the results of the comparison between the two surface conditions for the first and second real bridges, respectively. From the first real bridge results, it can be seen that the Single Unit Trucks generally result in higher values of DAF comparing to the LCVs. The same thing cannot be said, as strongly, for the second real bridge since in some cases (higher vehicle speeds for the Good surface condition), the values of DAFs due to the passage of LCVs are higher than the values of the DAF in the case of Single Unit Trucks. Also the difference between the two surface conditions and their results is pretty meaningful. Finally, finding a general trend for the relation between the vehicle speed and the DAF values does not seem easy and possible. 


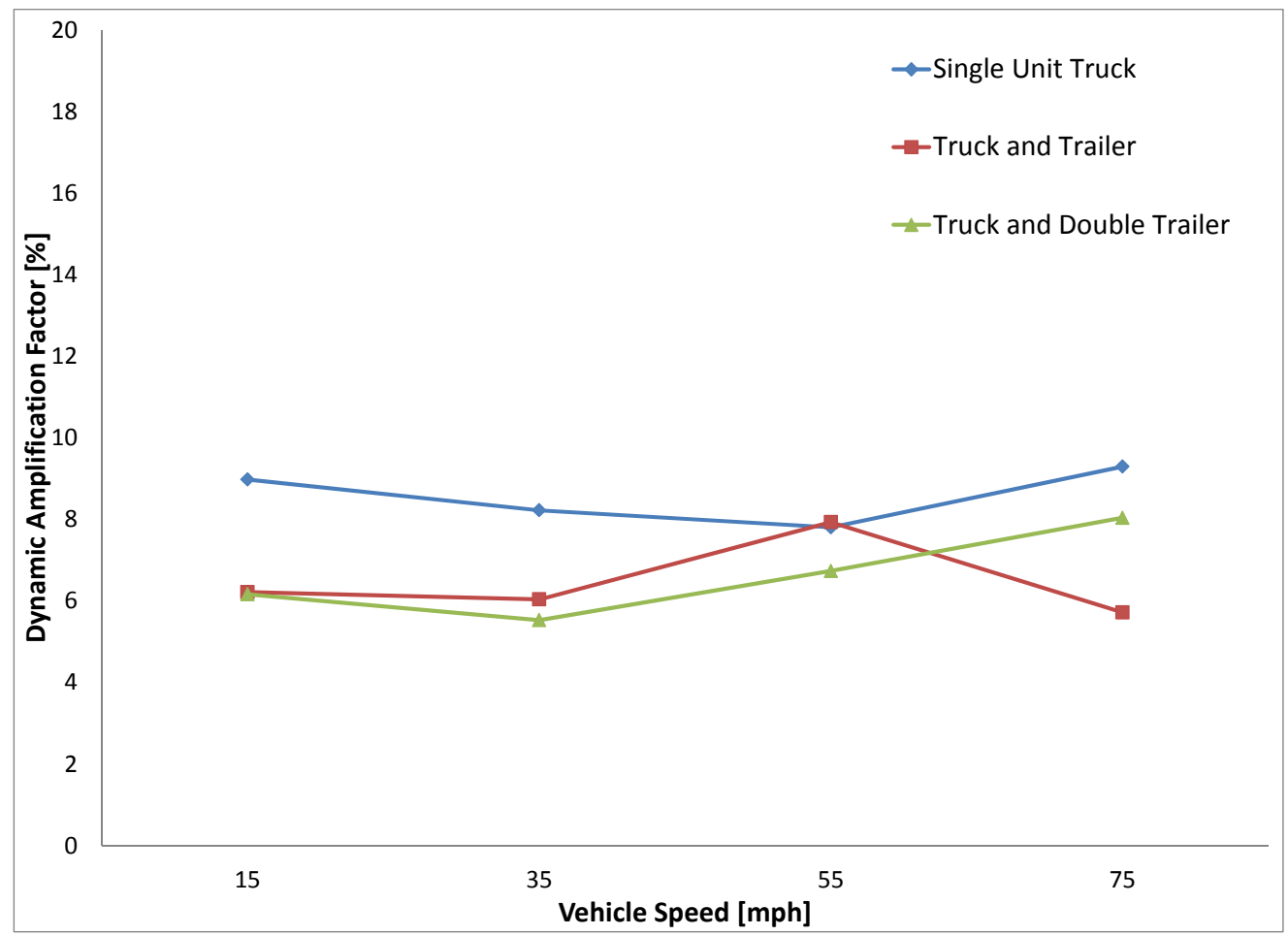

Figure 75. First Real Bridge DAF for Different Vehicle Categories (Very Good Surface)

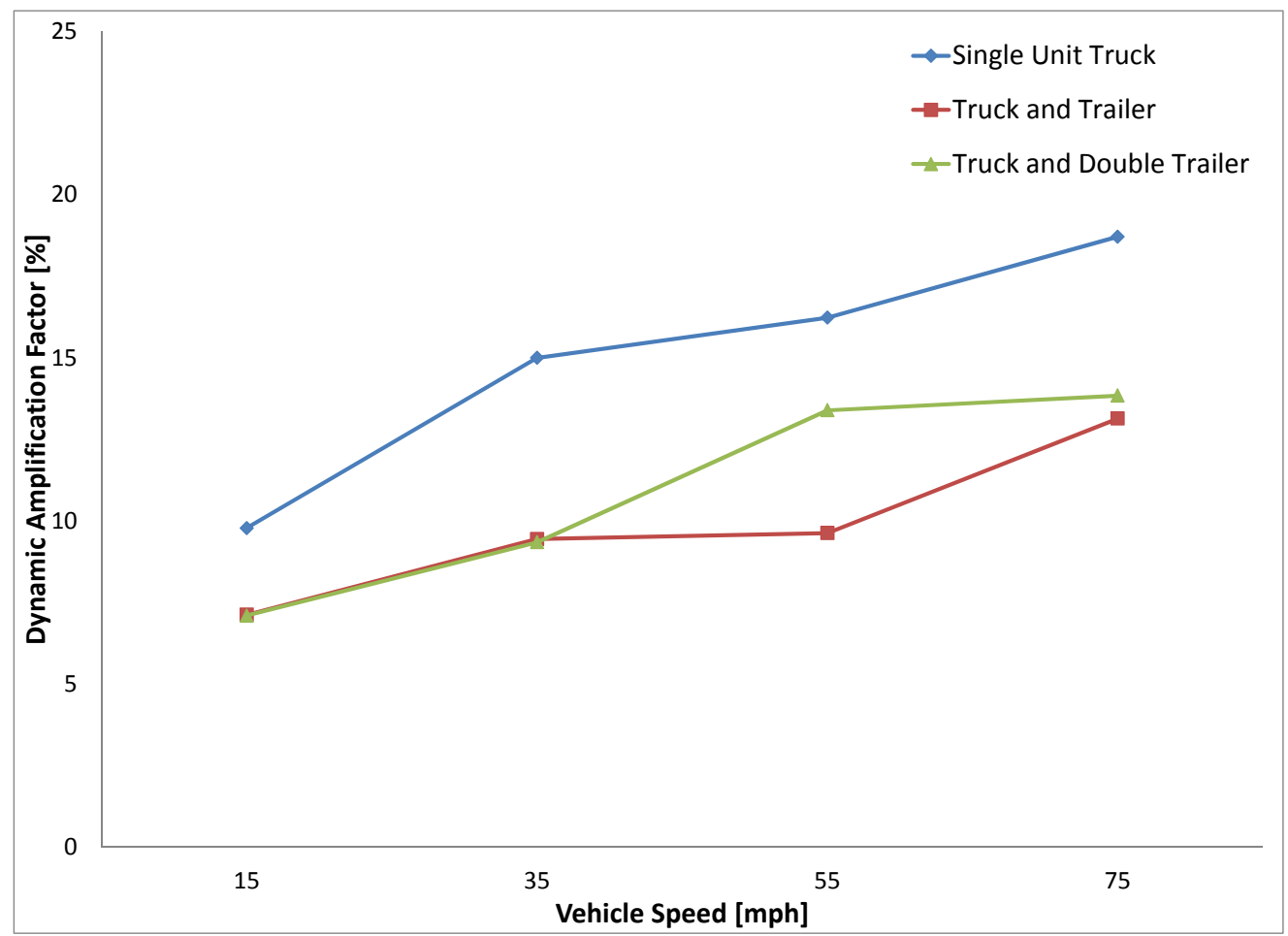

Figure 76. First Real Bridge DAF for Different Vehicle Categories (Good Surface) 


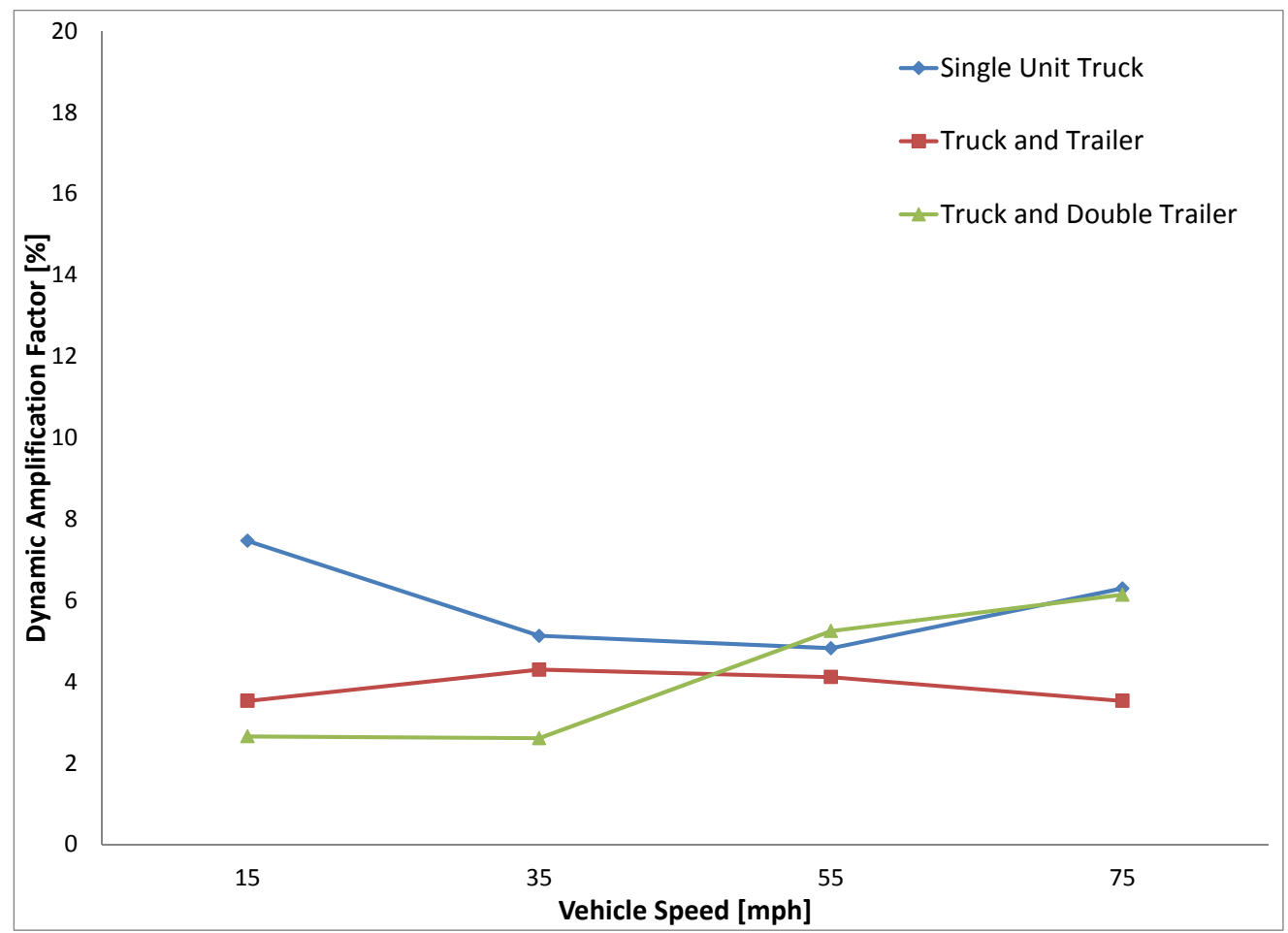

Figure 77. Second Real Bridge DAF for Different Vehicle Categories (Very Good Surface)

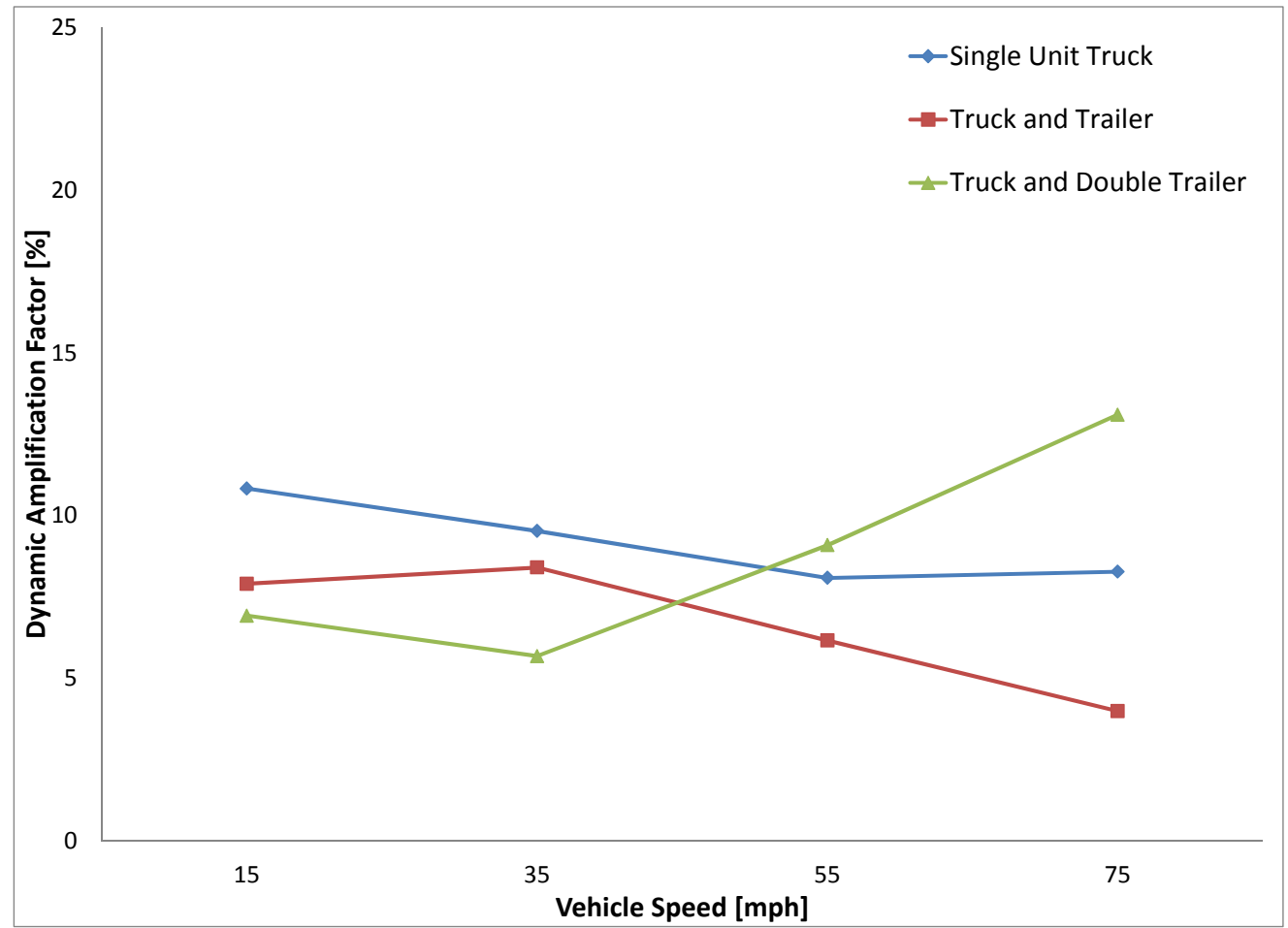

Figure 78. Second Real Bridge DAF for Different Vehicle Categories (Good Surface) 


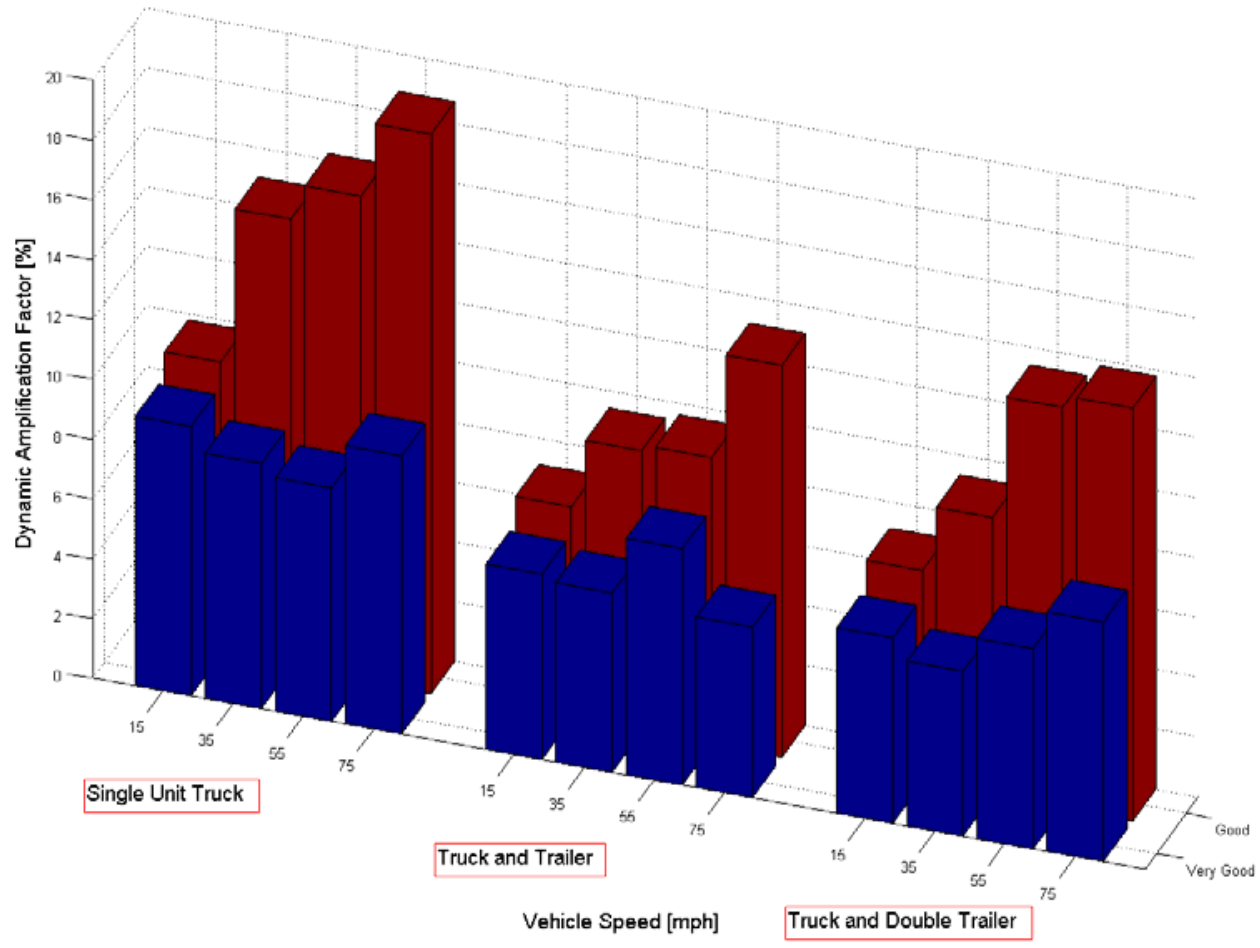

Figure 79. First Real Bridge Comparison of the Very Good and Good Surfaces Results

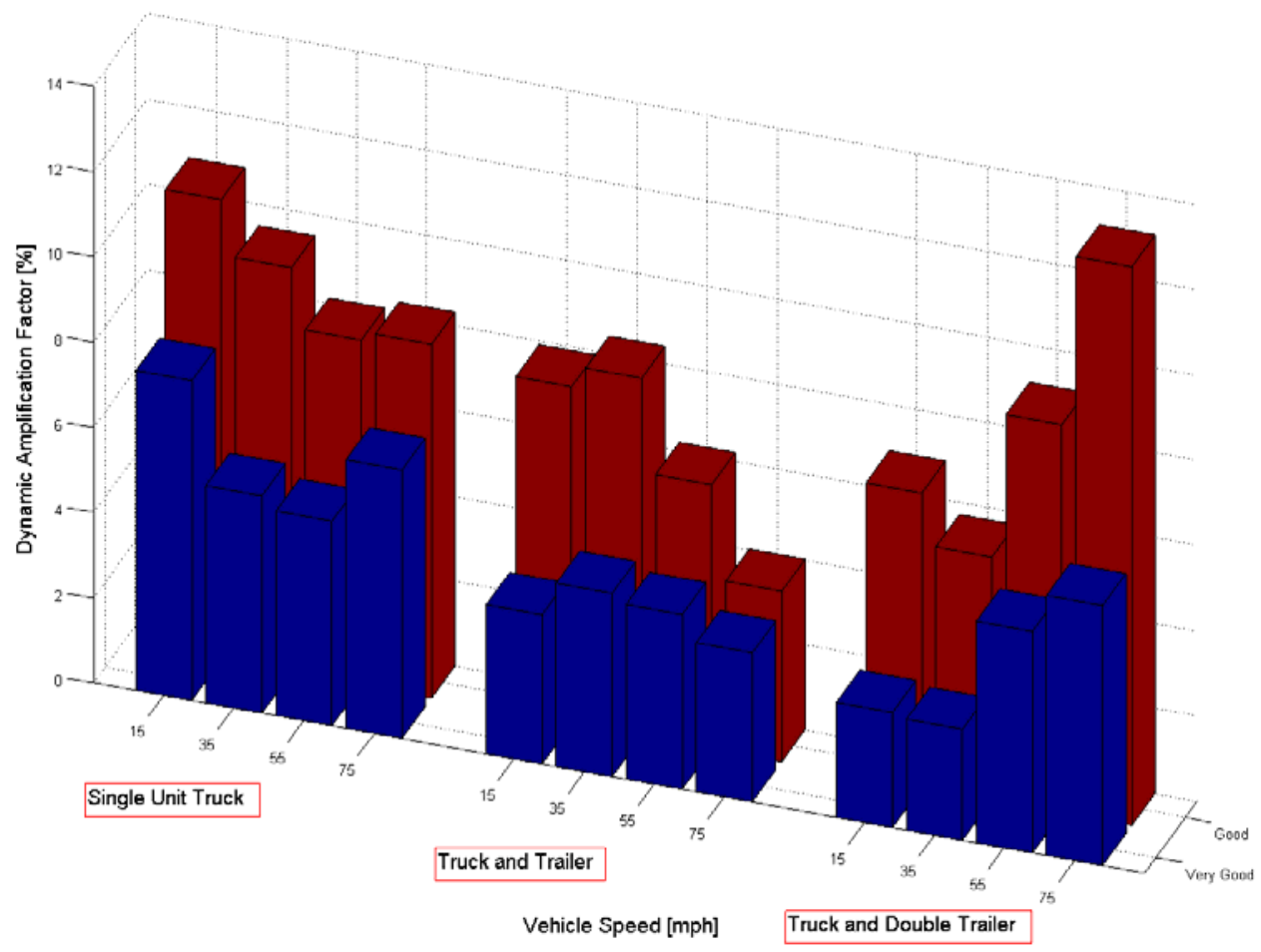

Figure 80. Second Real Bridge Comparison of the Very Good and Good Surfaces Results 


\section{Multiple Span Real Bridge Results}

In this section, the model is modified and extended so that it can be used to analyze the multiple span continuous bridges. A three span continuous straight I-girder real bridge taken from an NHI Course is used [30]. The span lengths are 140, 175 and 140 feet and the bridge has four girders. The bridge is skewed at 60 degrees but since lateral loading, lateral movement and diaphragm behavior are not in the scope of this research, it was assumed that the bridge is not skewed.

The first six mode shapes of the three span real bridge can be seen in Figure 81 . The displacement of the middle point of the second span of the bridge has been recorded due to the static and dynamic loading of all the different trucks and the results are shown in Figure 82 to Figure 84 for the Good surface condition and in Figure 85 to Figure 87 for the Very Good surface conditions.

Three different sections can be detected for the deflection curves of the midpoint for all the vehicles. In the first section, the vehicle has just entered the bridge, so there is no load in the second span and since the bridge is a continuous one, the second span will deform upwards (in the negative direction). When the bigger part of the truck weight enters the second span of the bridge, the deflection of the middle span starts to go downwards (in the positive direction) and finally when the heavier part of the truck leaves the second span and enters the last span, the middle span starts to go upwards (in the negative direction) again. One can also observe from these figures that the third segment of the deflection response gives higher negative response comparing to the first segment of the deflection response. The reason for this can be found in the fact that usually in the first segment, the truck has just entered the bridge and the first few axles are lighter than the last axles in almost all the cases that have been considered here. 
Whereas in the third segment, the truck has started to leave the bridge and the last axles of the truck are present on the bridge and these axles are heavier than the first axles so they cause more deflections in the bridge.

The results of the deflection of the midpoint show that the Single Unit Trucks display more high frequency results comparing to the other two truck categories. Due to the largeness of the ratio of the total length of the bridge to all vehicles, it can be seen that all the displacement curves look similar in terms of the shape and length of the peaks and valleys.

The moment at the middle point of the middle span due to static and dynamic loading is also recorded and shown in Figure 88 to Figure 90. Moment curve also shows the same pattern as the displacement curves. The first segment also shows smaller moment values comparing to the third segment which is again due to the lighter weights of the first few axles comparing to the last axles.

Table 20 shows the dynamic amplification factor for the three span real bridge. The numbers in the table show that the values of DAF are generally smaller than $33 \%$ suggested by AASHTO LRFD design manual.

Figure 91 and Figure 92 show the values of Dynamic Amplification Factor recorded for the bridge on Very Good and Good surface conditions, respectively. These values are presented for different vehicle speeds and different vehicle categories based on Table 16. It can be seen that for the case of Very Good surface condition, the Truck and Double Trailers category shows slightly higher results comparing to the other two truck types specifically in the cases of high $(75 \mathrm{mph})$ and low $(15 \mathrm{mph})$ truck speeds. But Single Unit Trucks also show close results to the LCVs particularly in the case of 
medium (35 and $55 \mathrm{mph}$ ) truck speeds. In the case of the Good surface condition though, Single Unit Trucks show highest values of DAF between all the truck categories. The Truck and Double Trailers category shows smaller results especially in the case of middle truck speeds. This category and the truck and trailer category show pretty similar results specifically in the case of medium truck speeds. 


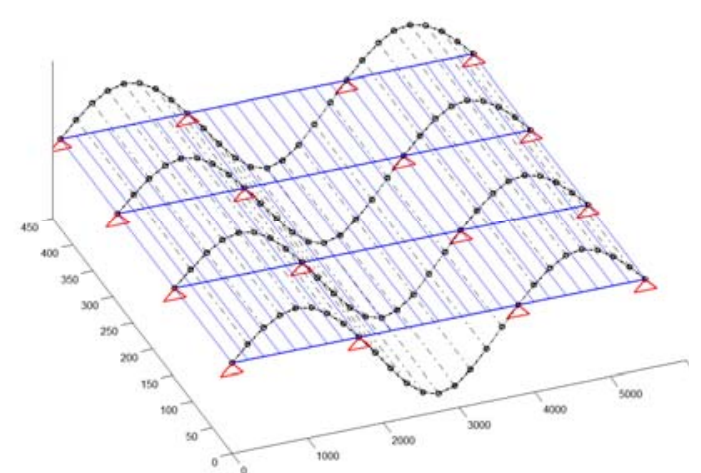

(a) $1^{\text {st }}$ Mode $\left(\mathrm{f}_{1}=1.64 \mathrm{~Hz}\right)$

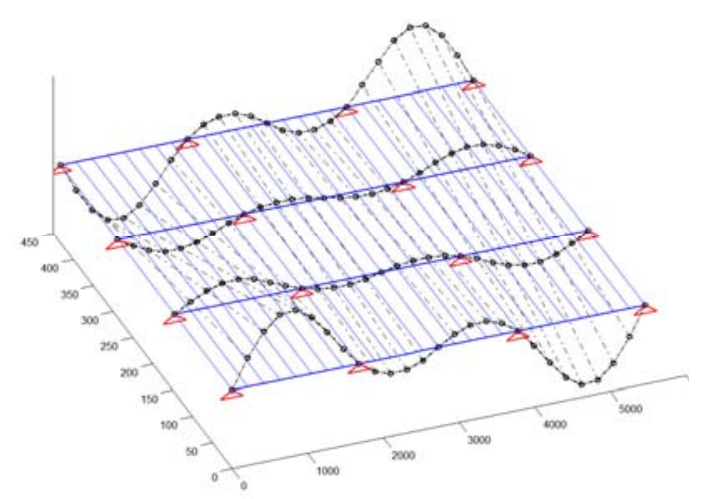

(d) $4^{\text {th }}$ Mode $\left(\mathrm{f}_{4}=2.76 \mathrm{~Hz}\right)$

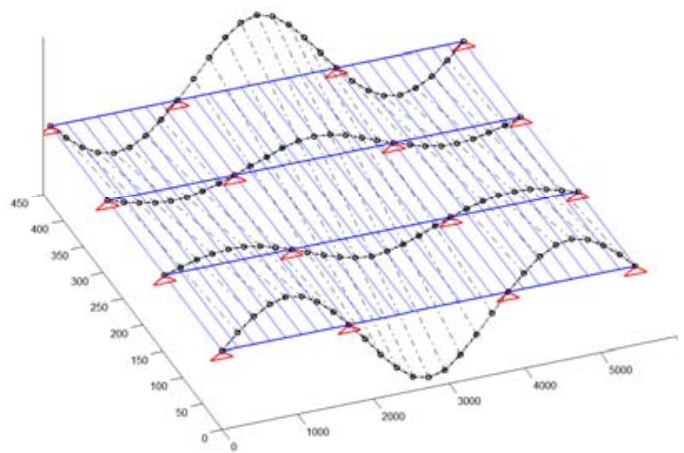

(b) $2^{\text {nd }}$ Mode $\left(\mathrm{f}_{2}=1.73 \mathrm{~Hz}\right)$

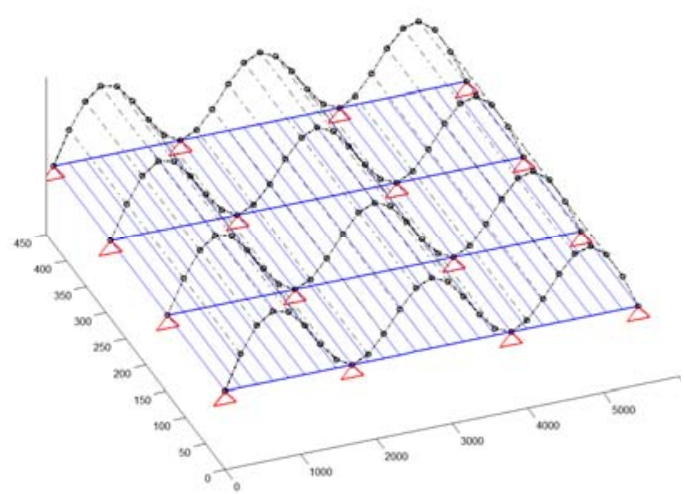

(e) $5^{\text {th }}$ Mode $\left(\mathrm{f}_{5}=3.45 \mathrm{~Hz}\right)$

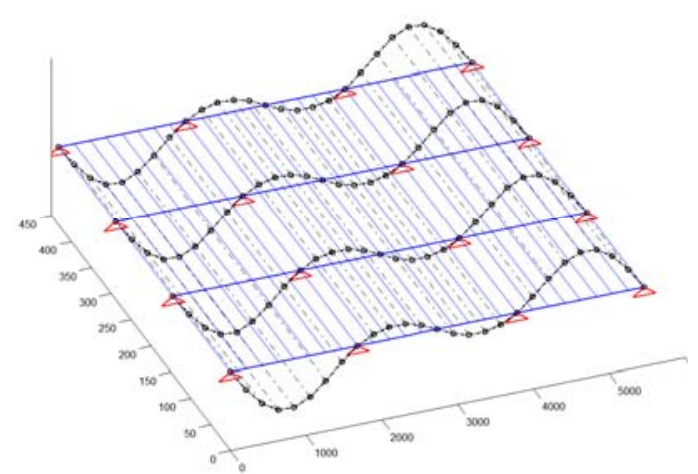

(c) $3^{\text {rd }}$ Mode $\left(\mathrm{f}_{3}=2.68 \mathrm{~Hz}\right)$

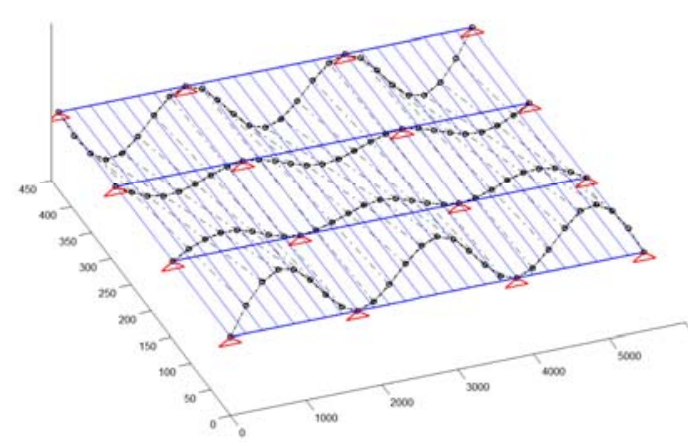

(f) $6^{\text {th }}$ Mode $\left(\mathrm{f}_{6}=3.52 \mathrm{~Hz}\right)$

Figure 81. Three Span Real Bridge Mode Shapes (Three Span Continuous Bridge) 


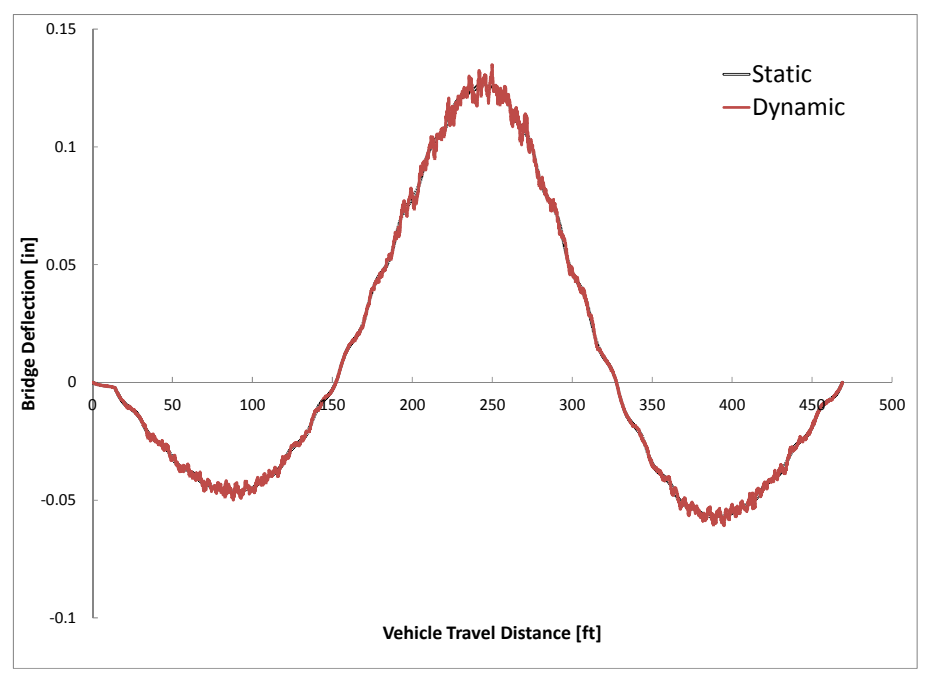

(a) $\mathrm{H}-20$

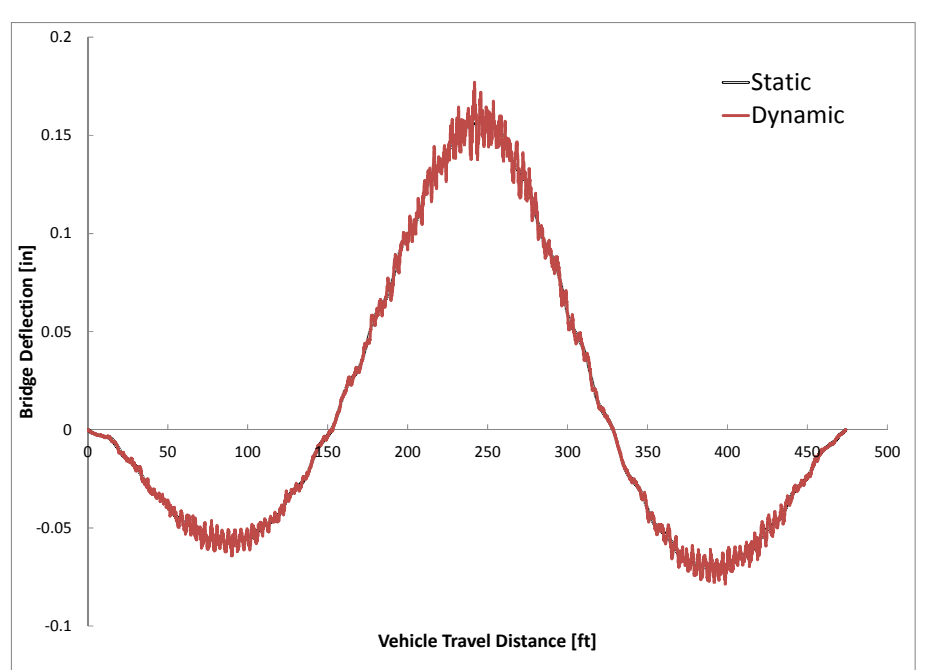

(c) Type 3

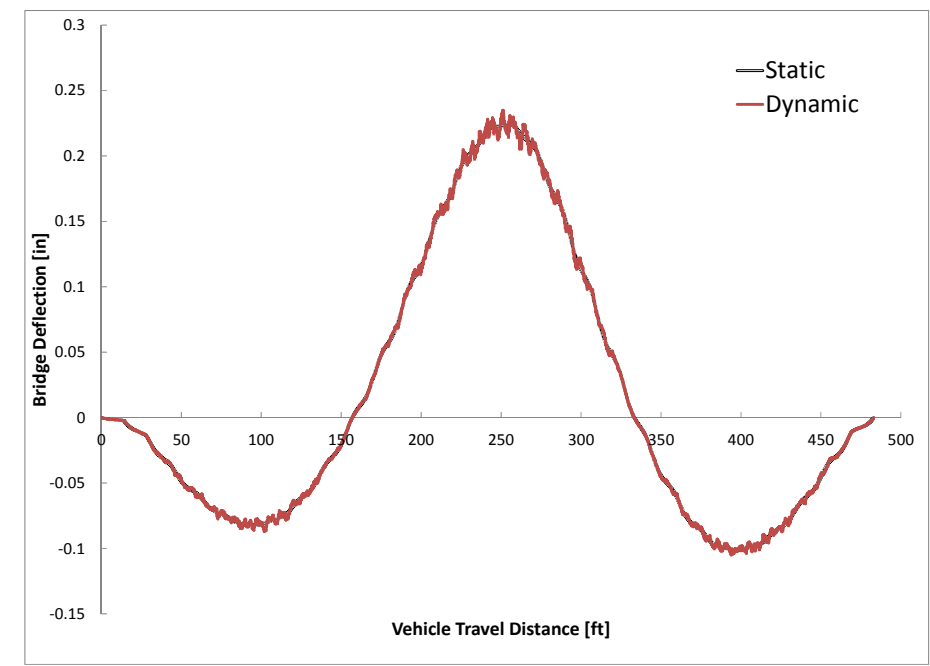

(b) HS-20

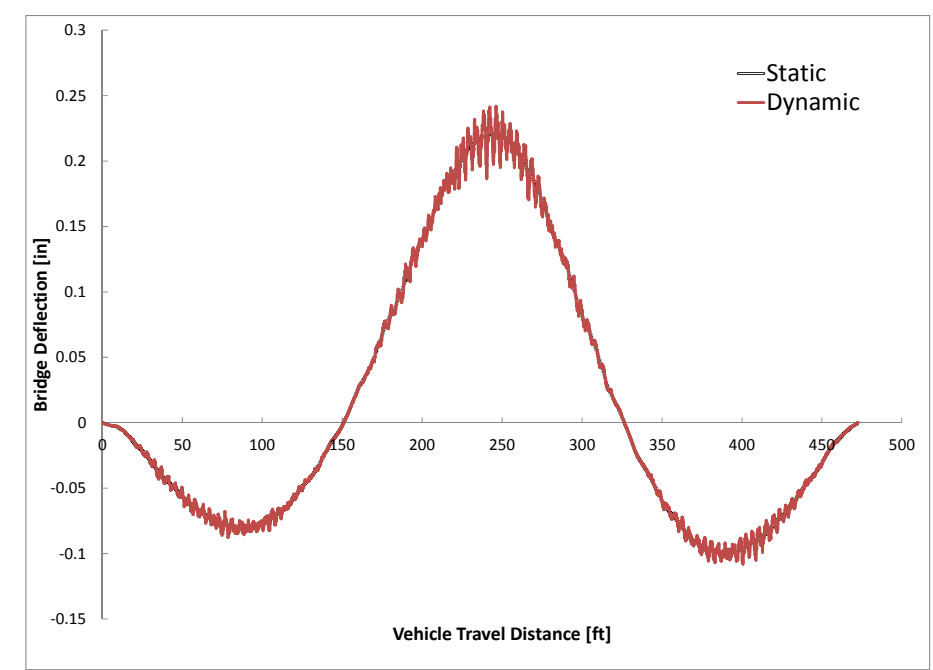

(d) SU4

Figure 82. Displacement of Three Span Real Bridge due to Single Unit Trucks and HS-20 (Good Surface) 


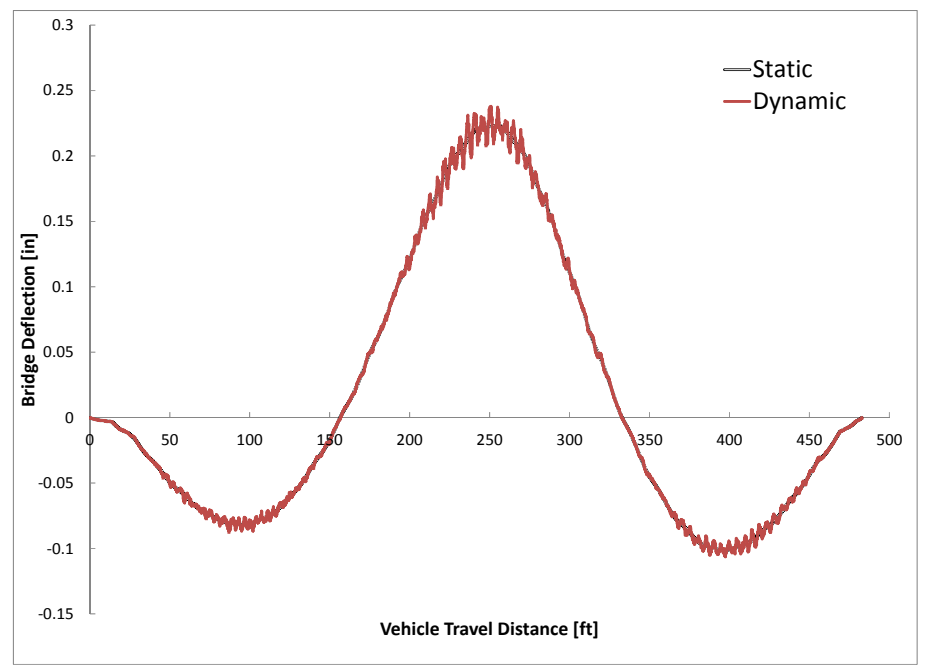

(e) Type 2S2

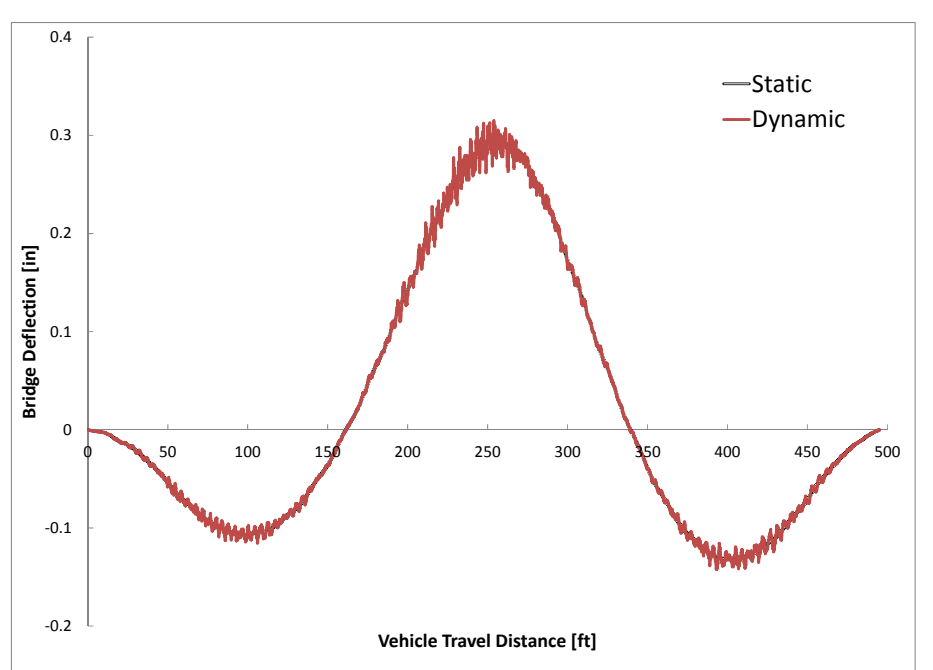

(g) Type 3S3

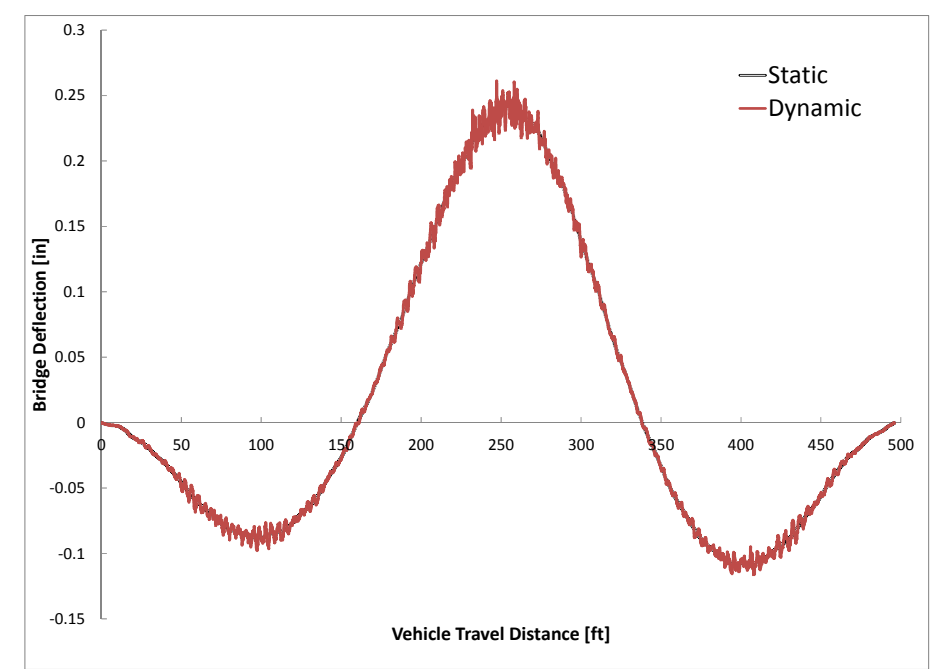

(f) Type 3S2

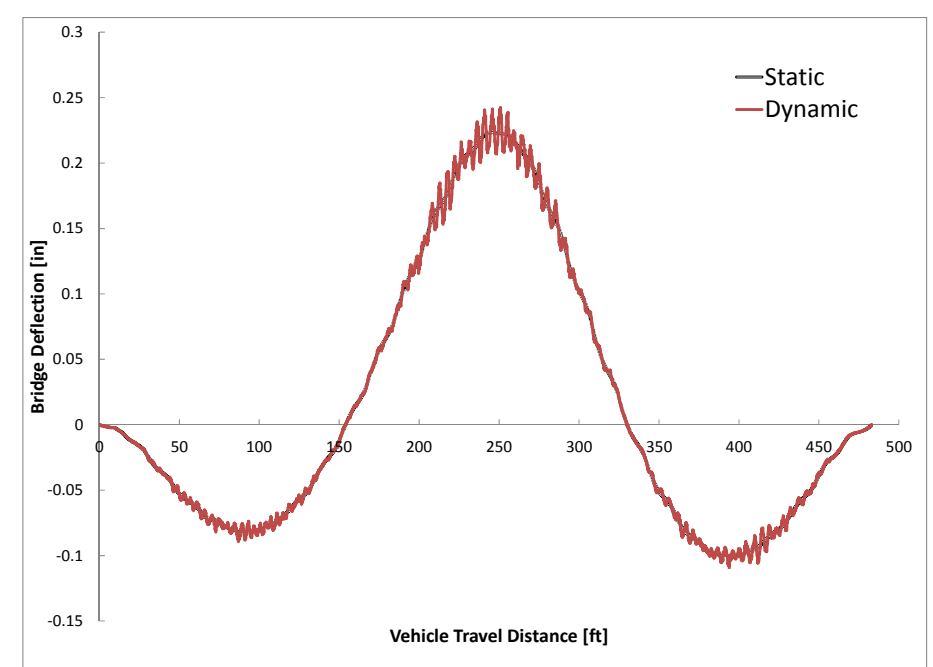

(h) Type 3S1

Figure 83. Displacement of Three Span Real Bridge due to Tractor Semitrailers (Good Surface) 


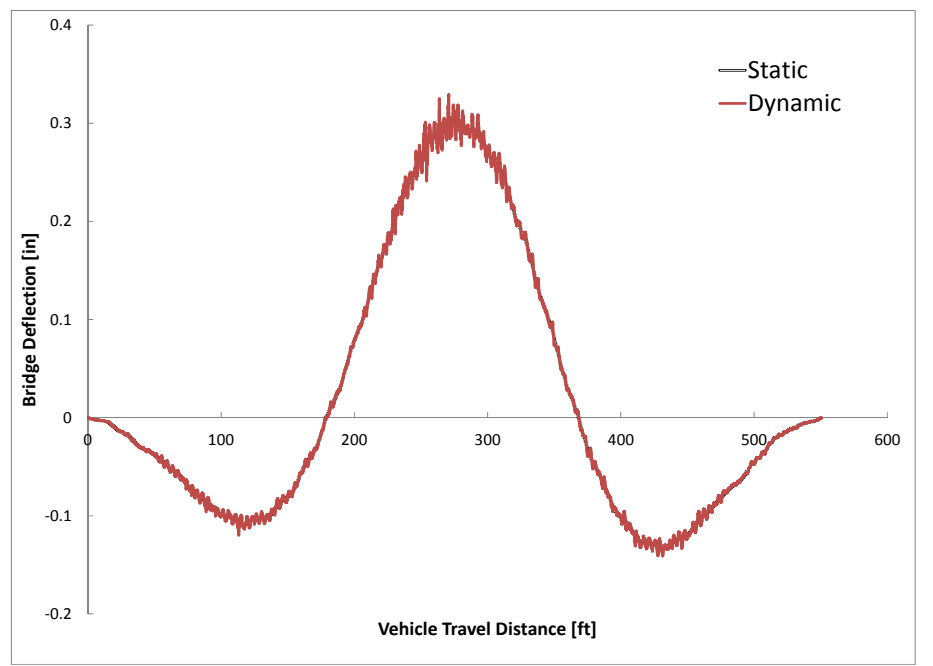

(i) 7-Axle Rocky Mountain Double

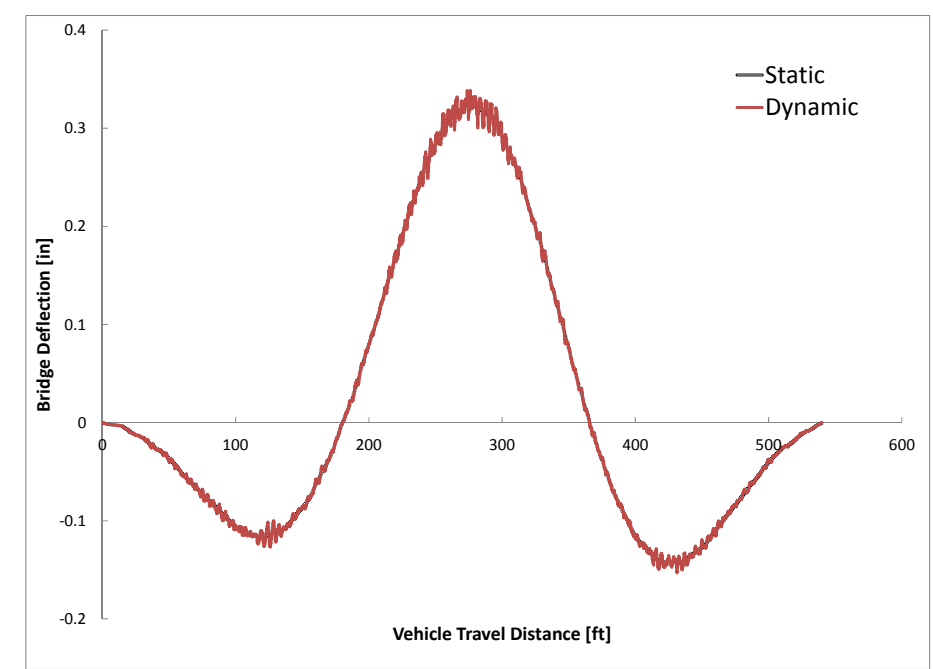

(j) 8-Axle B-Train Double

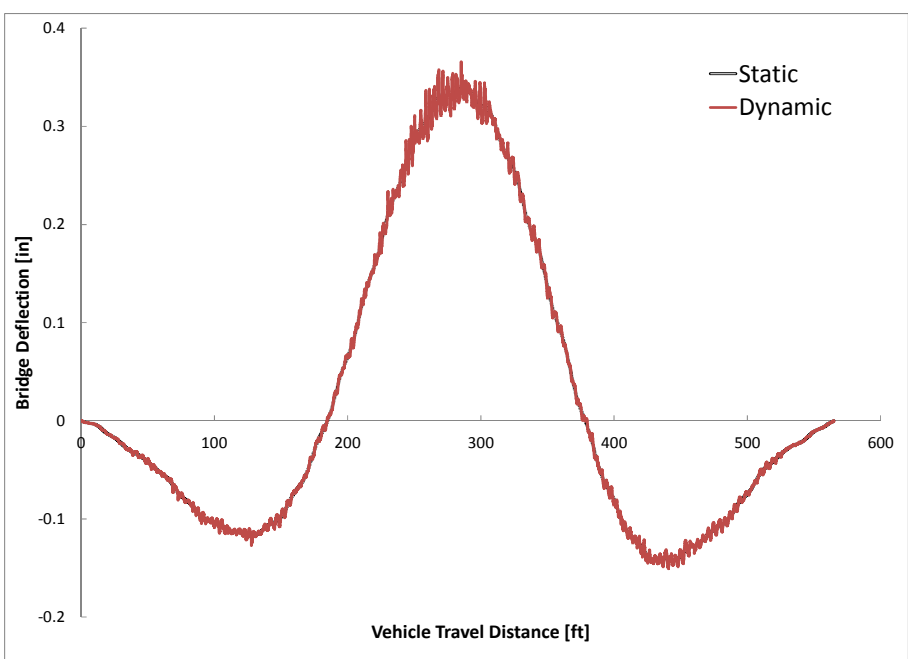

(k) 9-Axle Turnpike Double

Figure 84. Displacement of Three Span Real Bridge due to Truck and Double Trailers (Good Surface) 


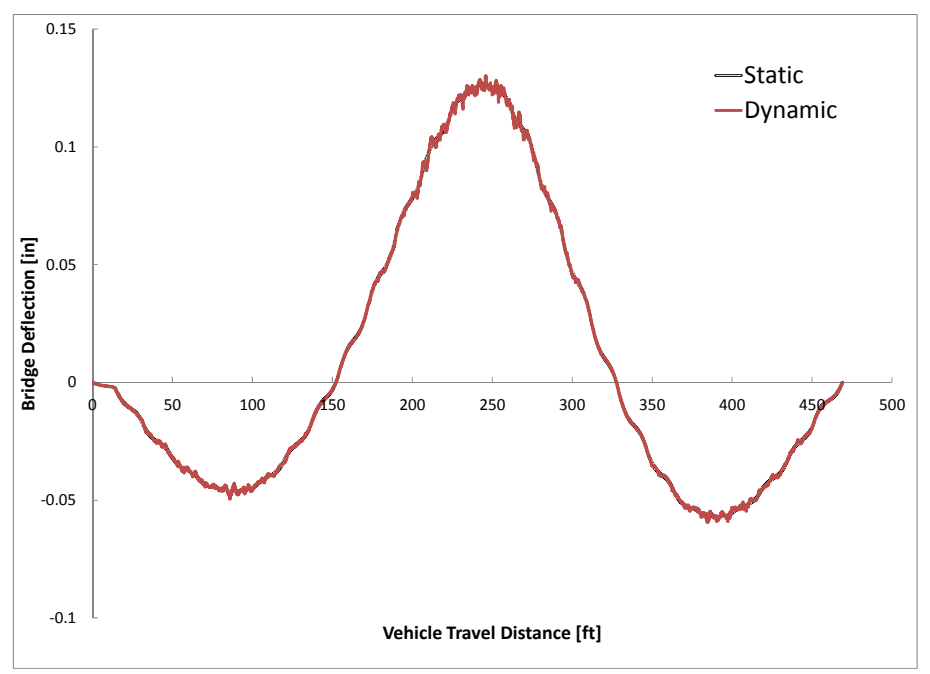

(a) $\mathrm{H}-20$

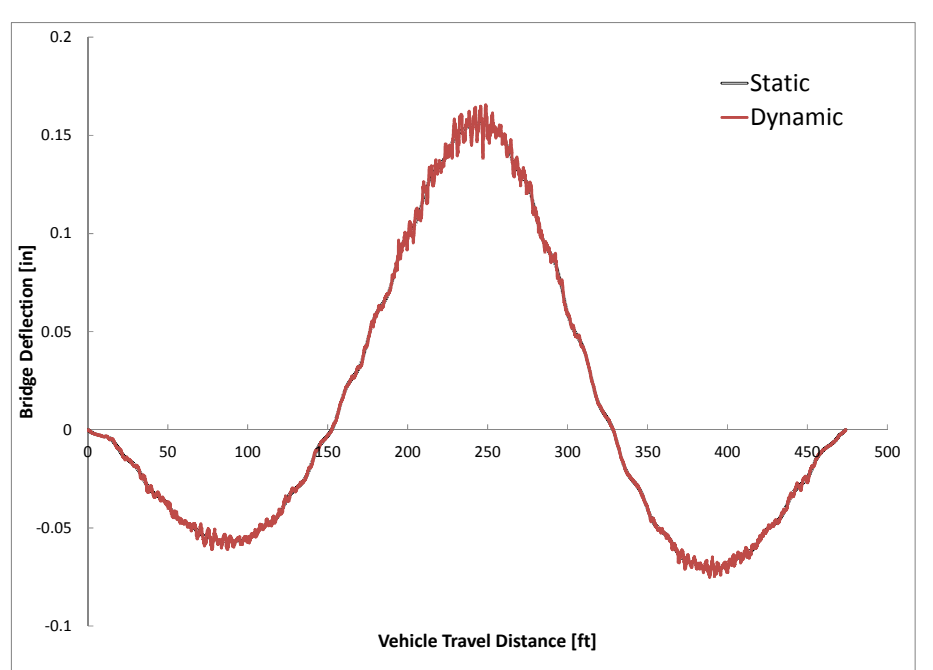

(c) Type 3

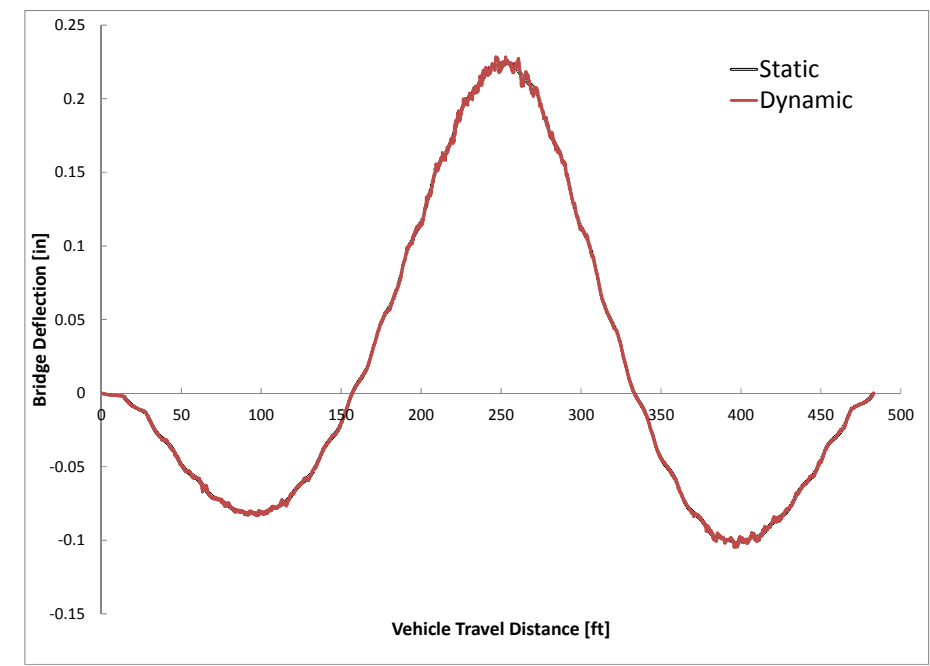

(b) HS-20

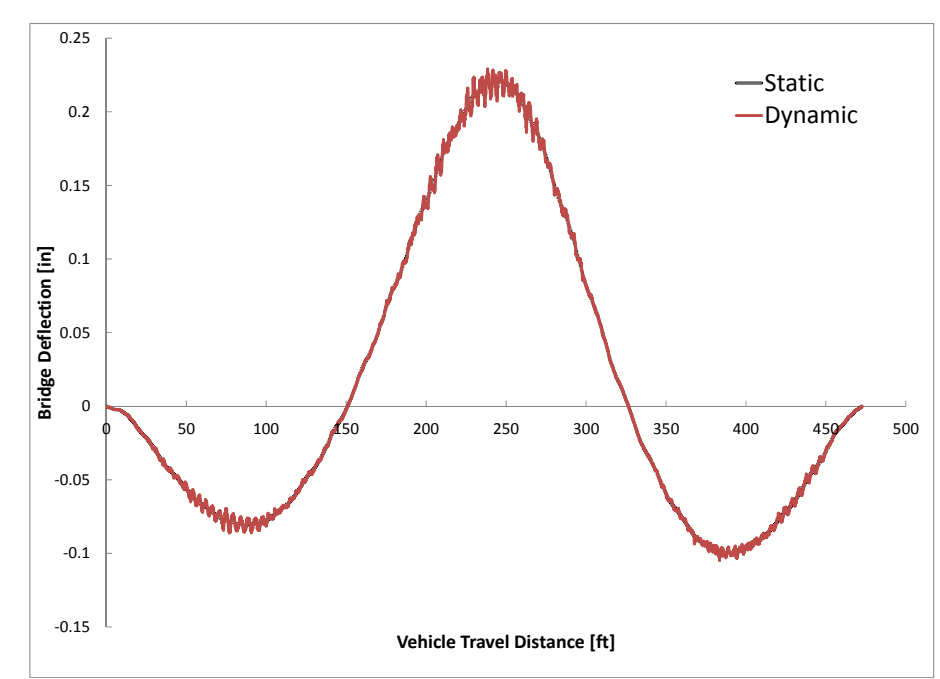

(d) SU4

Figure 85. Displacement of Three Span Real Bridge due to Single Unit Trucks and HS-20 (Very Good Surface) 


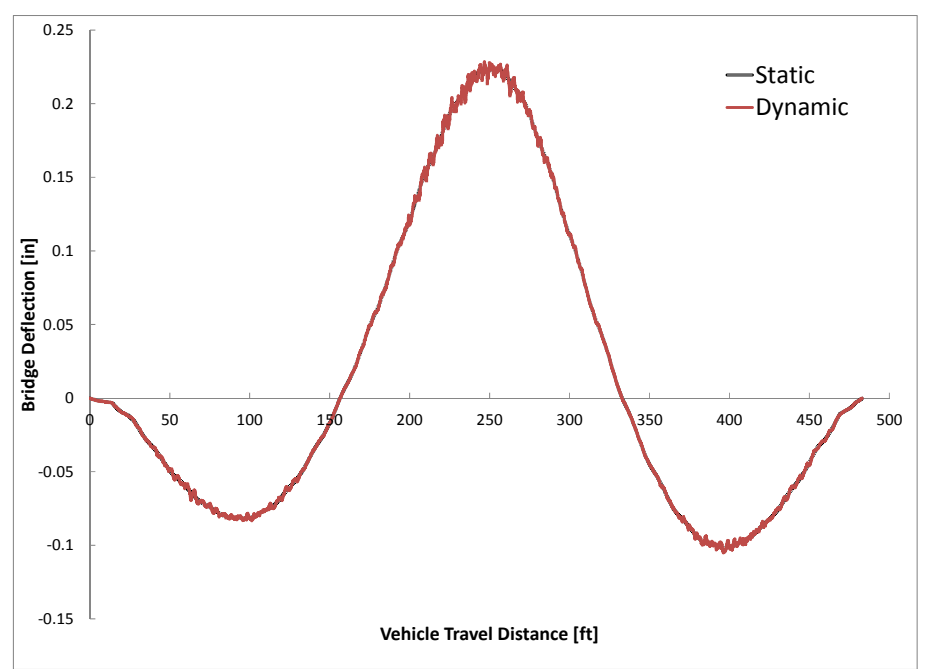

(e) Type 2S2

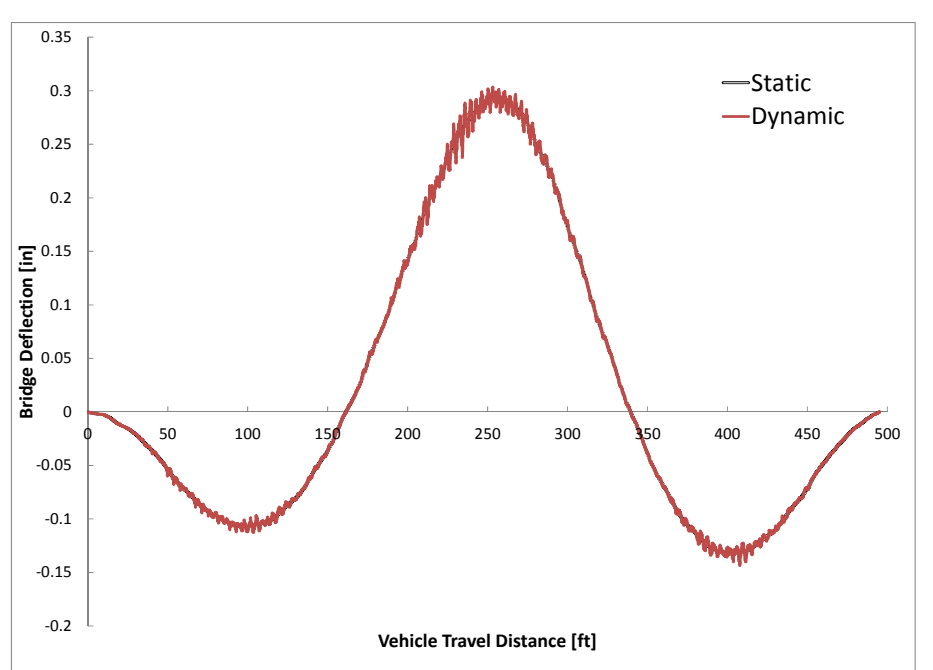

(g) Type 3S3

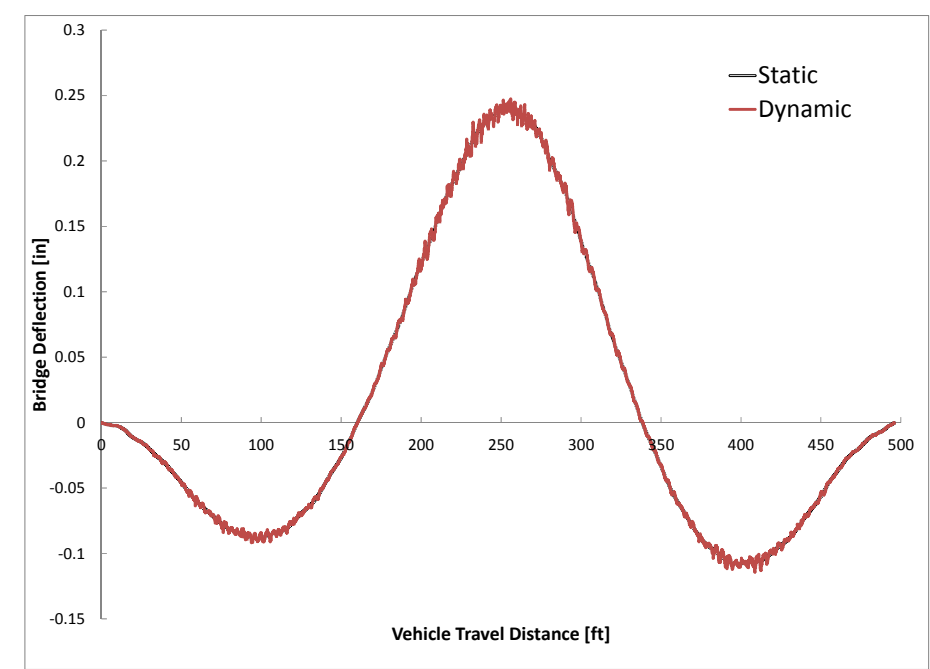

(f) Type 3S2

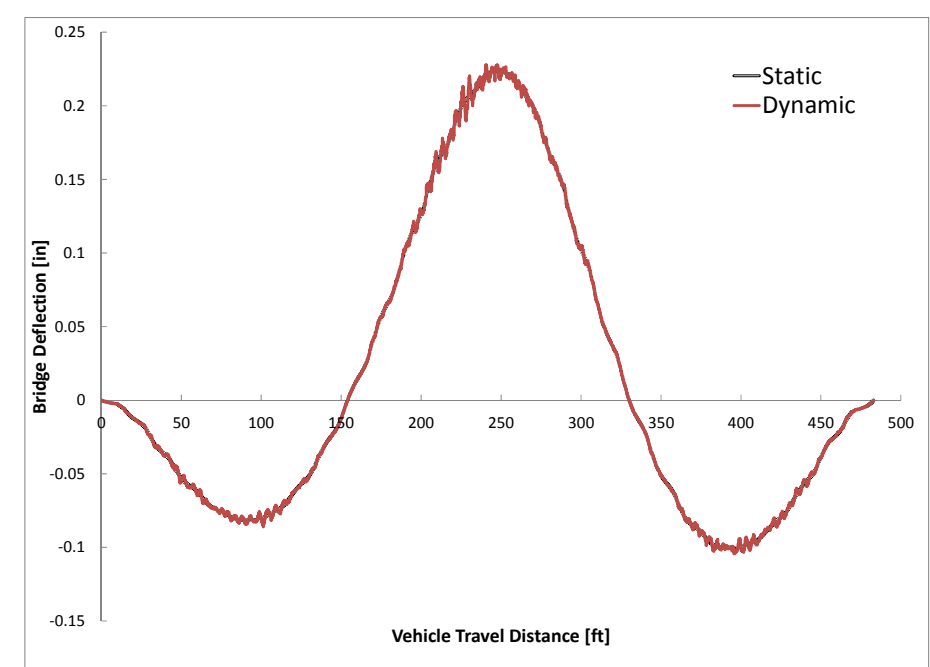

(h) Type 3S1

Figure 86. Displacement of Three Span Real Bridge due to Tractor Semitrailers (Very Good Surface) 


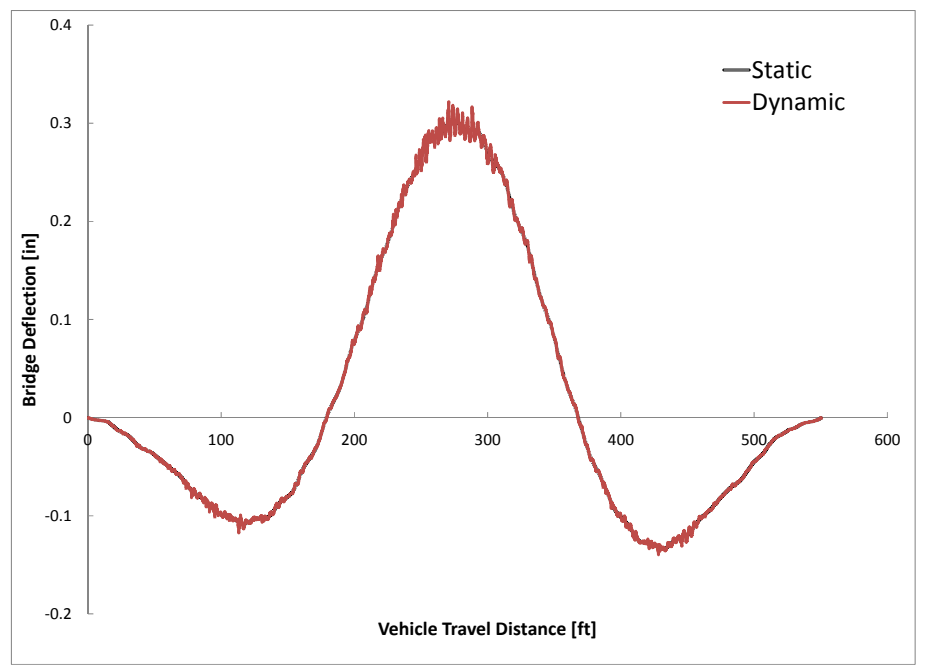

(i) 7-Axle Rocky Mountain Double

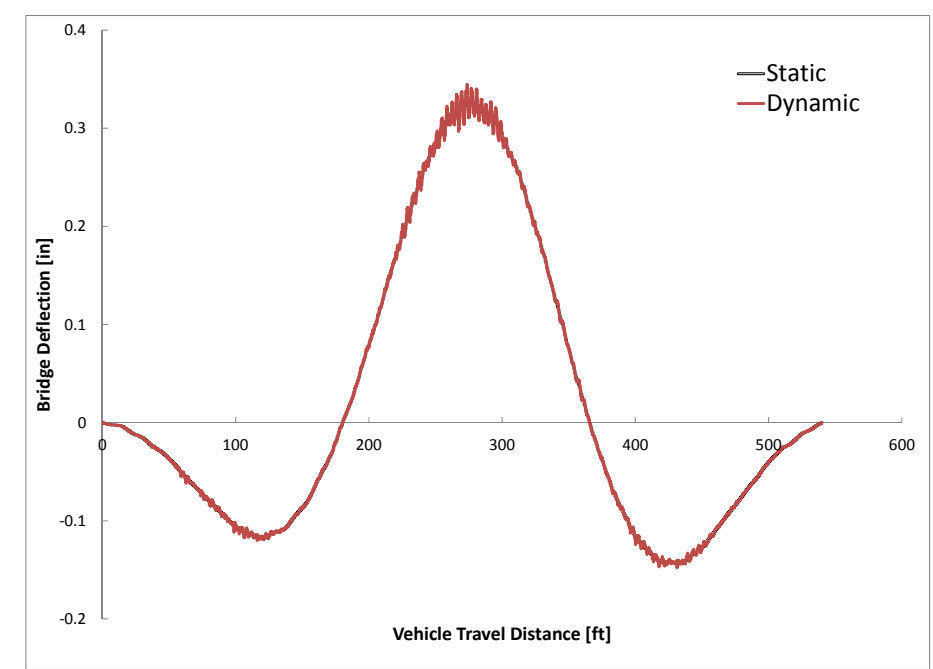

(j) 8-Axle B-Train Double

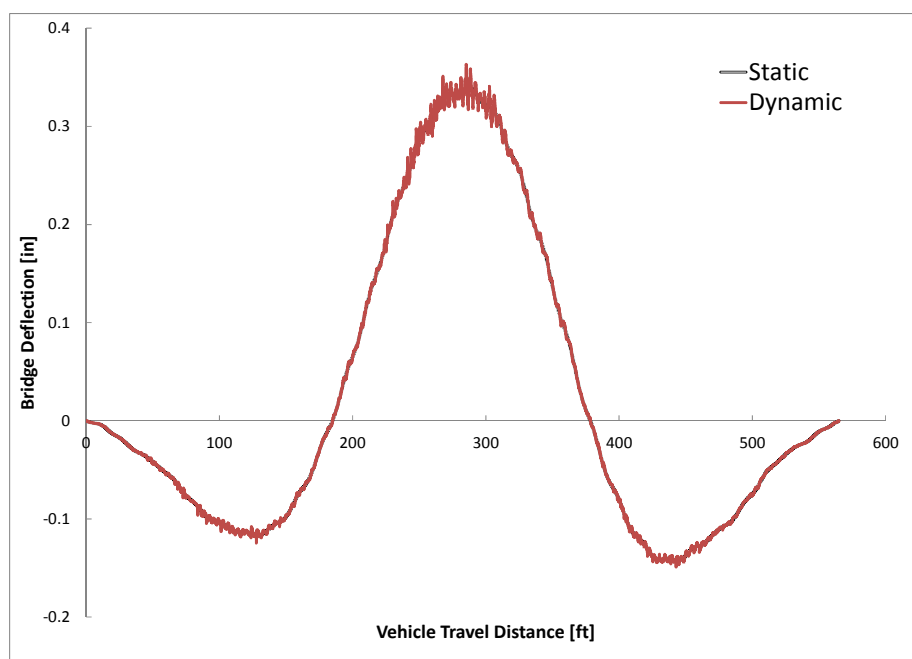

(k) 9-Axle Turnpike Double

Figure 87. Displacement of Three Span Real Bridge due to Truck and Double Trailers (Very Good Surface) 


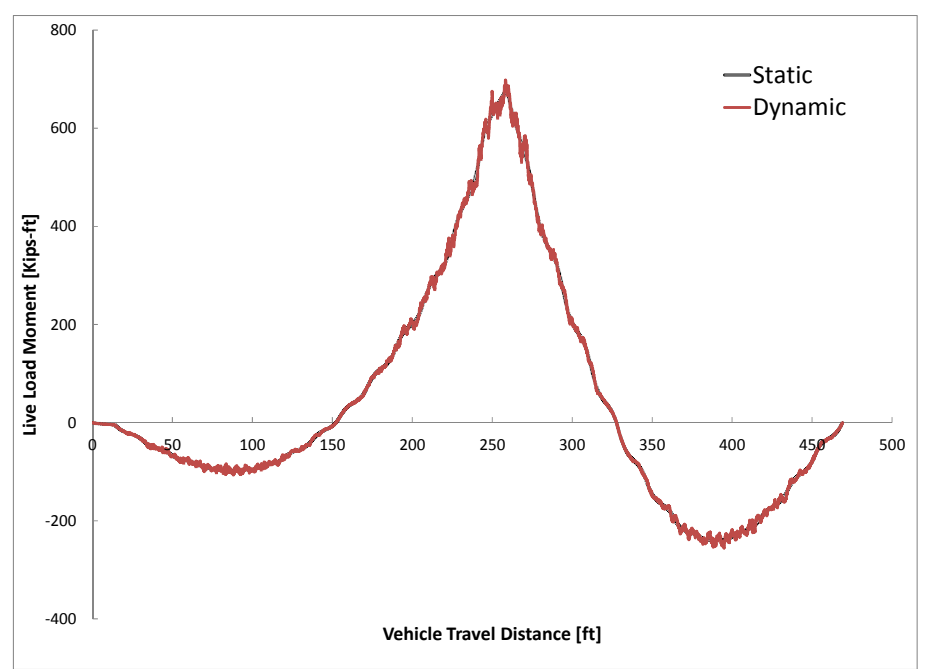

(a) $\mathrm{H}-20$

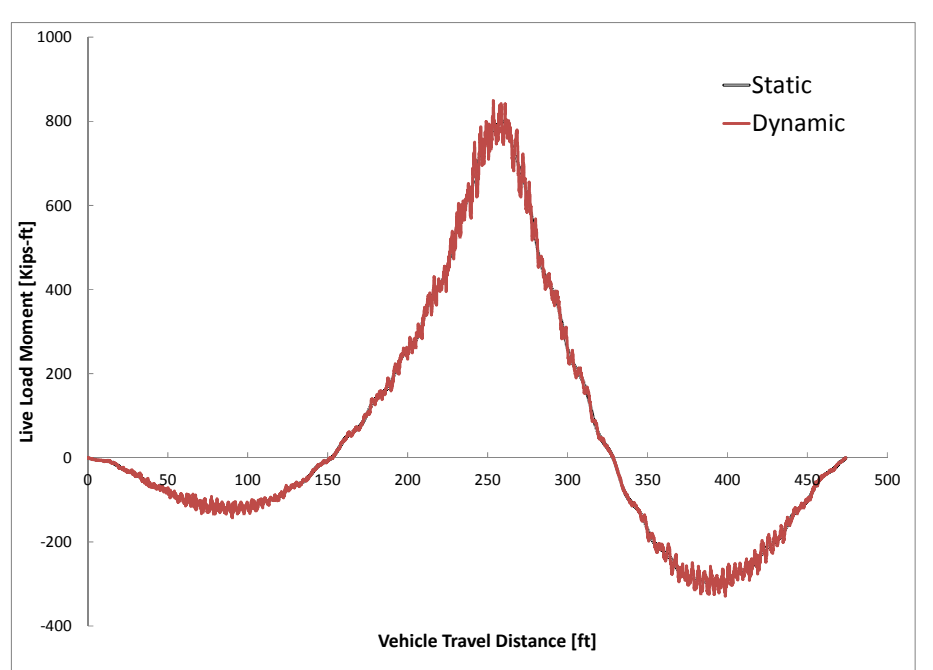

(c) Type 3

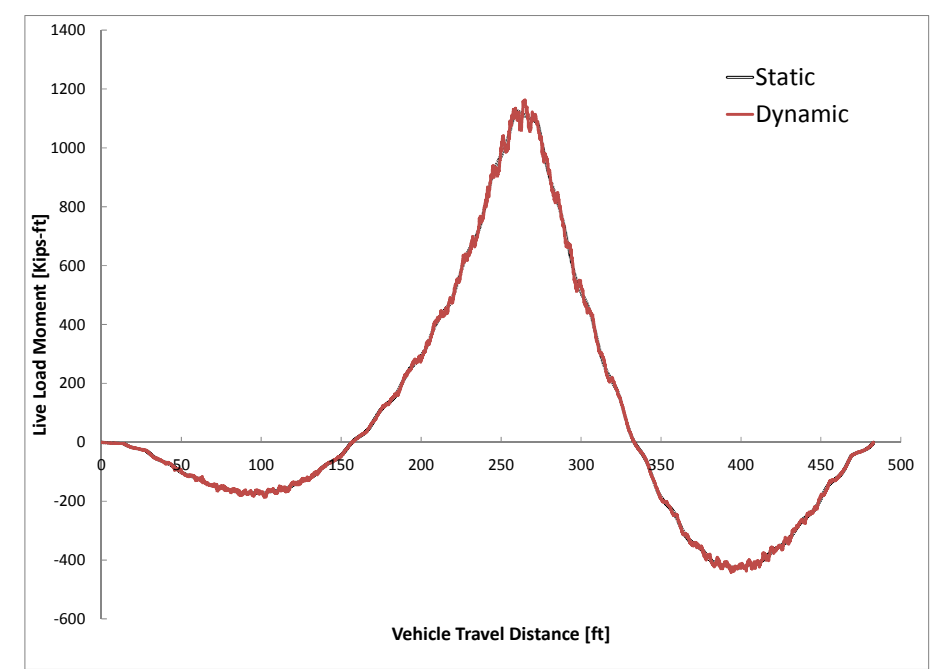

(b) HS-20

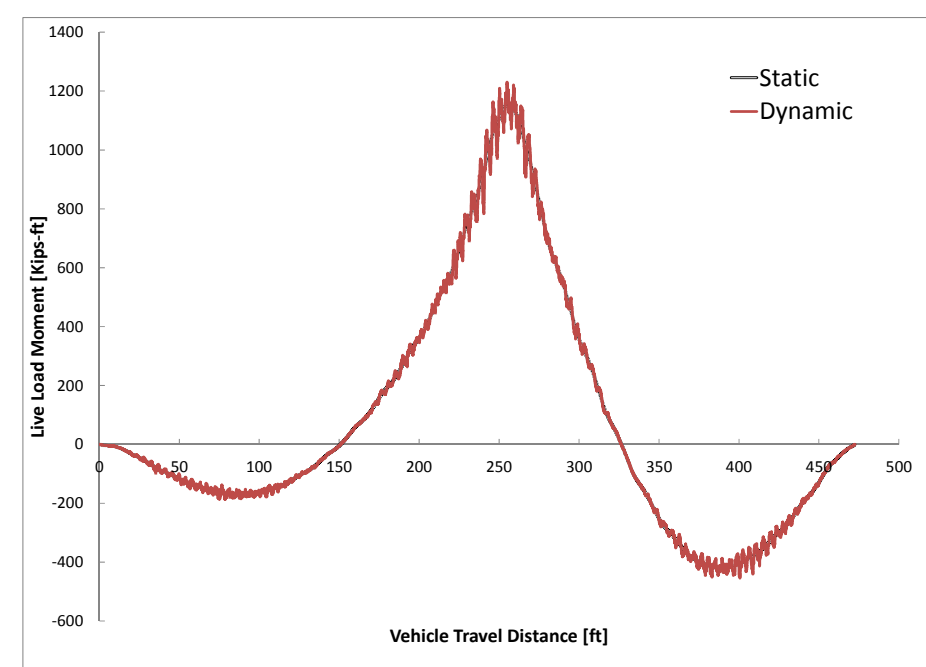

(d) SU4

Figure 88. Moment of Three Span Real Bridge due to Single Unit Trucks and HS-20 (Good Surface) 


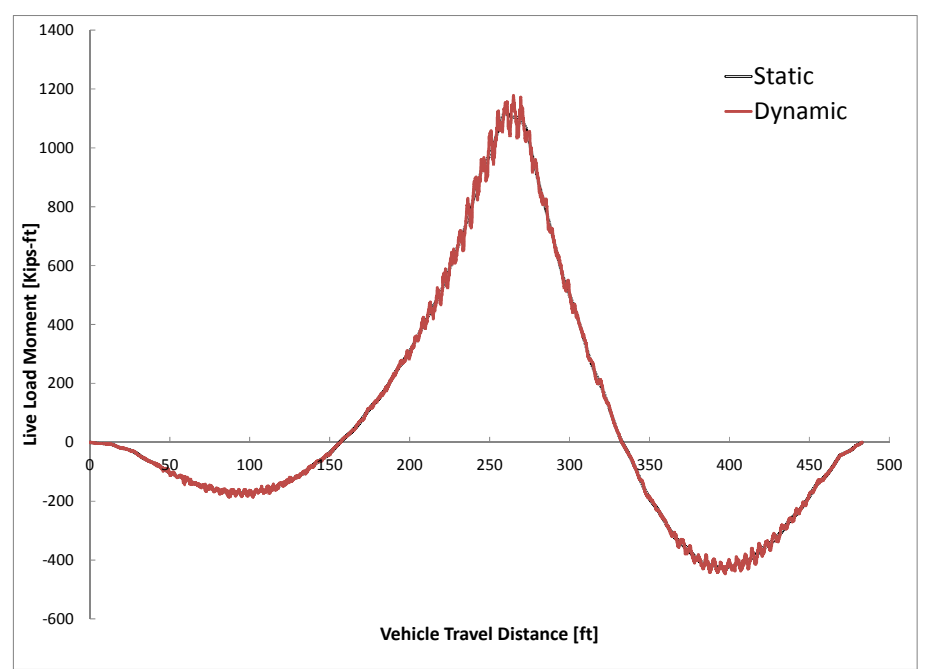

(e) Type 2S2

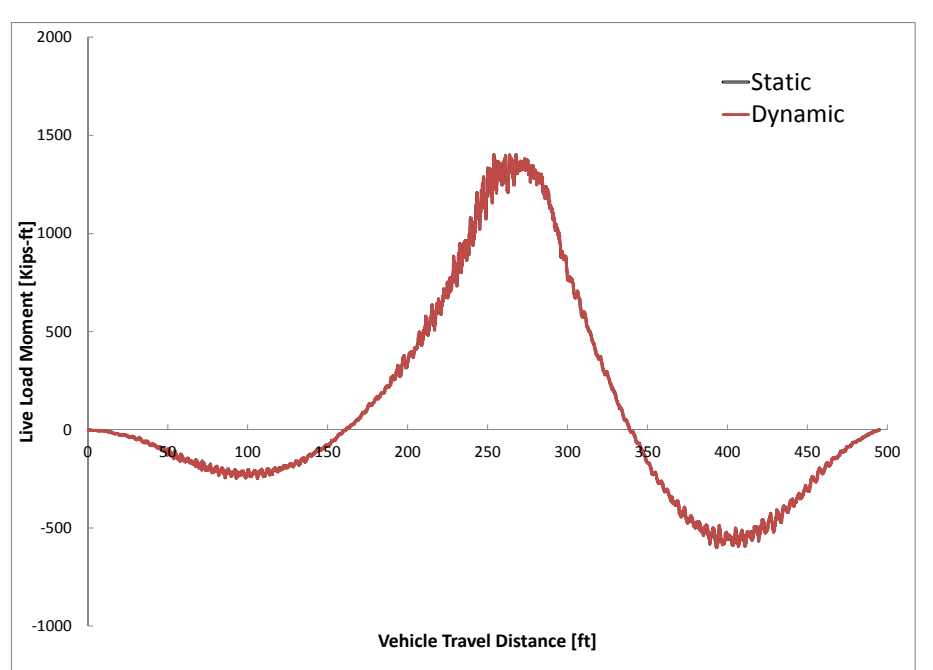

(g) Type 353

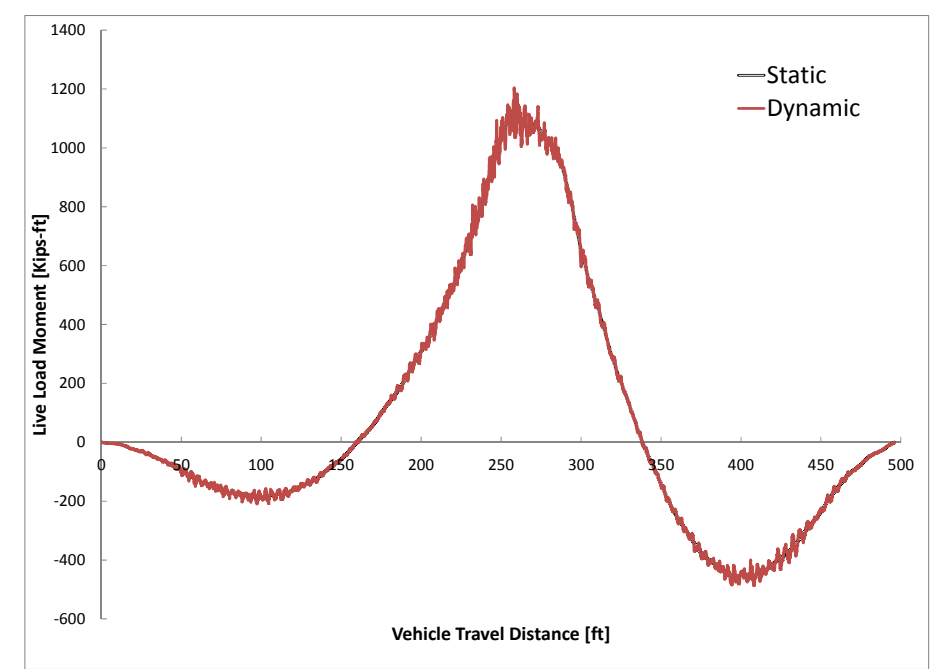

(f) Type 3S2

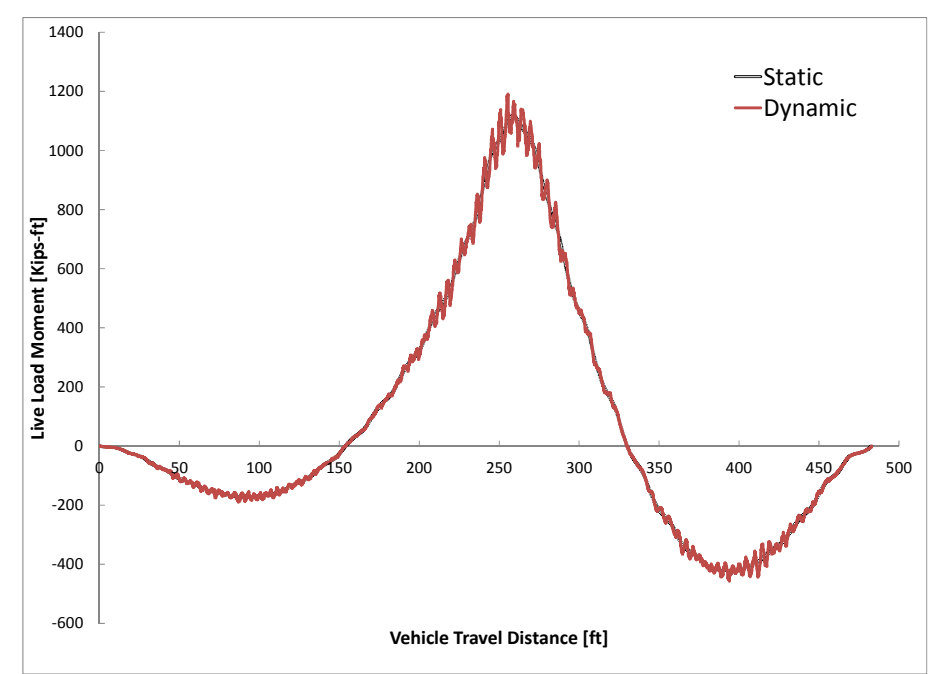

(h) Type 3S1

Figure 89. Moment of Three Span Real Bridge due to Tractor Semitrailers (Good Surface) 


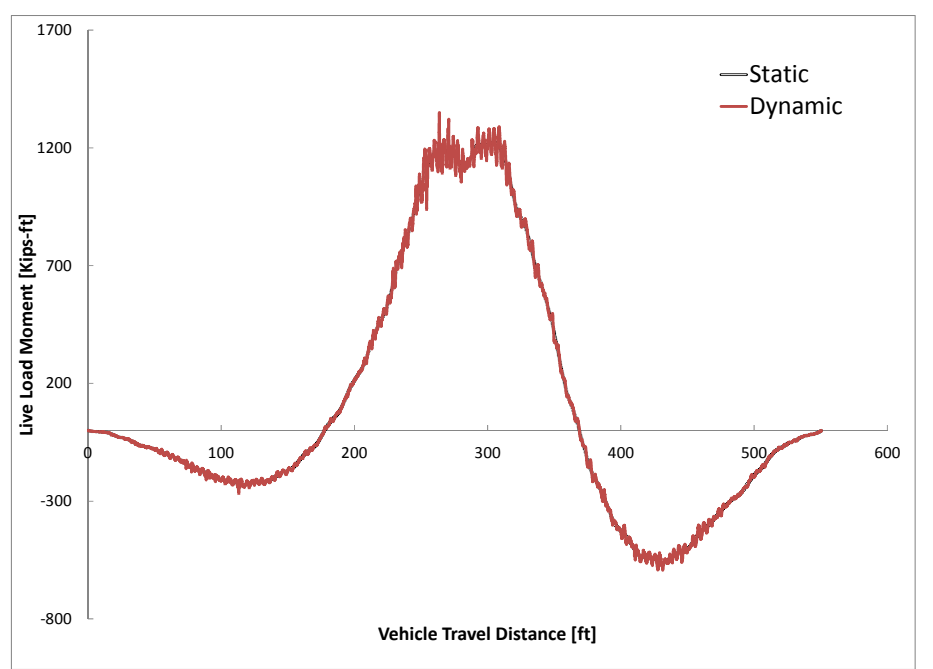

(i) 7-Axle Rocky Mountain Double

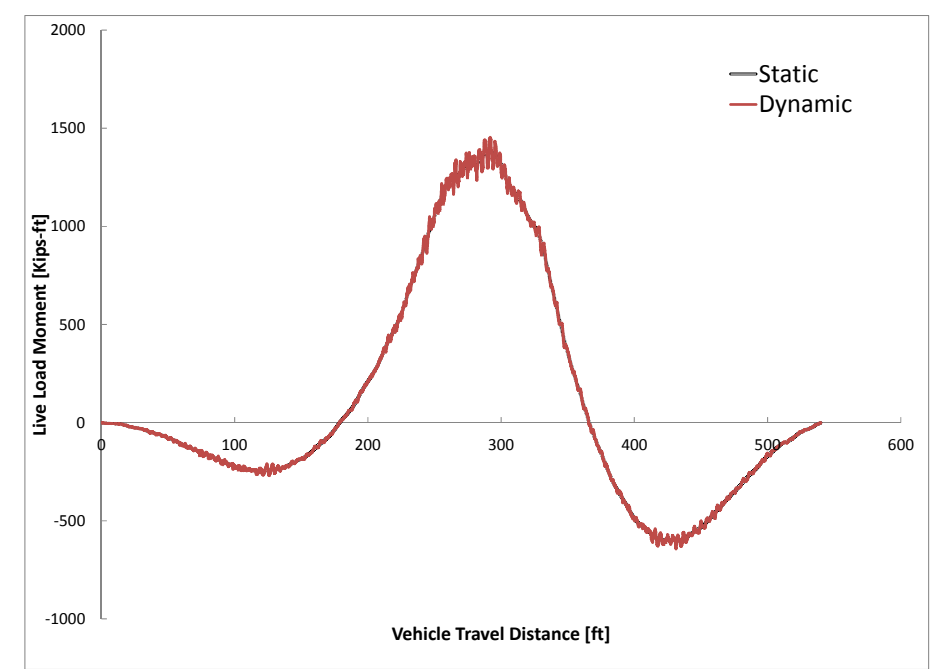

(j) 8-Axle B-Train Double

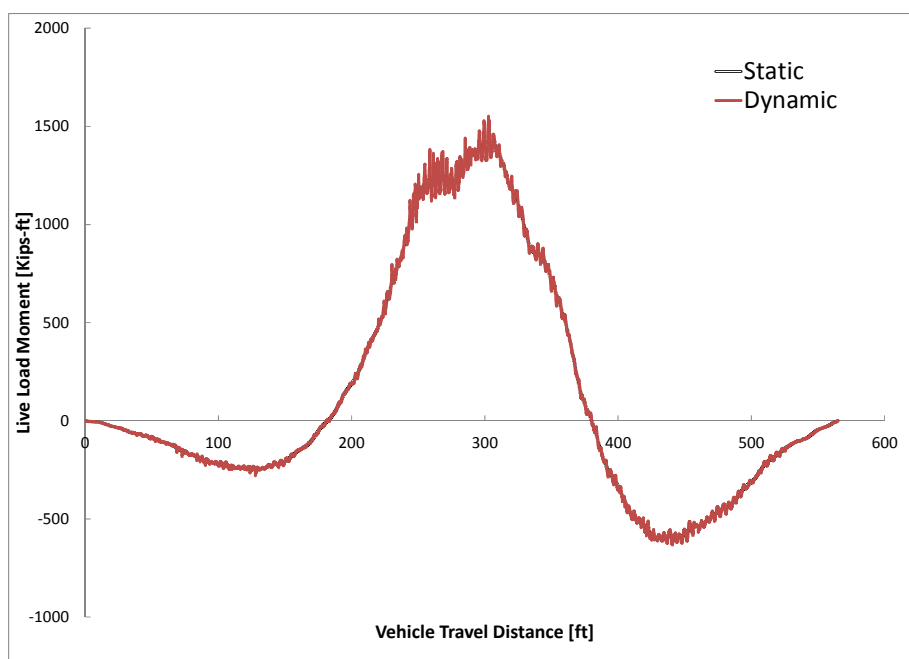

(k) 9-Axle Turnpike Double

Figure 90. Moment of Three Span Real Bridge due to Truck and Double Trailers (Good Surface) 
Table 20. Dynamic Amplification Factor for the Three Span Real Bridge

\begin{tabular}{|c|c|c|c|c|c|c|c|c|c|c|c|c|c|}
\hline \multirow[b]{2}{*}{$\begin{array}{l}\text { Bridge } \\
\text { Type }\end{array}$} & \multirow[b]{2}{*}{$\begin{array}{l}\text { Surface } \\
\text { Condition }\end{array}$} & \multirow[b]{2}{*}{$\begin{array}{l}\text { Speed } \\
\text { [mph] }\end{array}$} & \multicolumn{11}{|c|}{ Vehicle Type } \\
\hline & & & H-20 & HS-20 & Type 3 & $\begin{array}{c}\text { Type } \\
352\end{array}$ & $\begin{array}{c}\text { Type } \\
3 S 3\end{array}$ & $\begin{array}{c}\text { Type } \\
2 S 2\end{array}$ & $\begin{array}{c}\text { Type } \\
3 S 1\end{array}$ & SU4 & $\begin{array}{c}\text { 7-Axle Rocky } \\
\text { Mountain } \\
\text { Double }\end{array}$ & $\begin{array}{l}8 \text { Axle } \\
\text { B-Train } \\
\text { Double }\end{array}$ & $\begin{array}{c}9 \text { Axle } \\
\text { Turnpike } \\
\text { Double }\end{array}$ \\
\hline \multirow{8}{*}{ 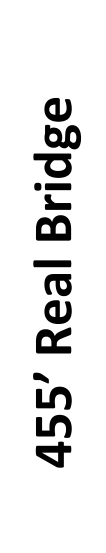 } & \multirow{4}{*}{$\begin{array}{l}\text { Very } \\
\text { Good }\end{array}$} & 15 & 3.0 & 1.8 & 5.9 & 2.3 & 3.2 & 2.3 & 2.0 & 3.7 & 6.0 & 5.4 & 6.9 \\
\hline & & 35 & 4.3 & 5.0 & 4.9 & 3.7 & 3.8 & 5.6 & 9.5 & 4.2 & 5.3 & 5.6 & 5.0 \\
\hline & & 55 & 7.1 & 4.0 & 6.8 & 4.7 & 2.9 & 5.7 & 9.7 & 5.1 & 9.0 & 3.8 & 5.3 \\
\hline & & 75 & 6.6 & 3.7 & 11.5 & 6.8 & 4.3 & 10.1 & 8.2 & 6.2 & 14.2 & 7.2 & 11.7 \\
\hline & \multirow{4}{*}{ Good } & 15 & 6.8 & 4.7 & 13.3 & 8.0 & 7.2 & 6.5 & 8.5 & 9.5 & 8.4 & 3.6 & 7.7 \\
\hline & & 35 & 8.4 & 5.9 & 13.9 & 7.8 & 9.1 & 8.0 & 9.3 & 13.7 & 7.0 & 8.1 & 5.0 \\
\hline & & 55 & 8.8 & 6.5 & 15.6 & 18.7 & 7.2 & 12.6 & 11.7 & 16.1 & 11.1 & 7.3 & 10.2 \\
\hline & & 75 & 10.4 & 6.2 & 13.7 & 11.1 & 9.0 & 6.0 & 10.5 & 12.2 & 10.3 & 9.3 & 13.6 \\
\hline
\end{tabular}




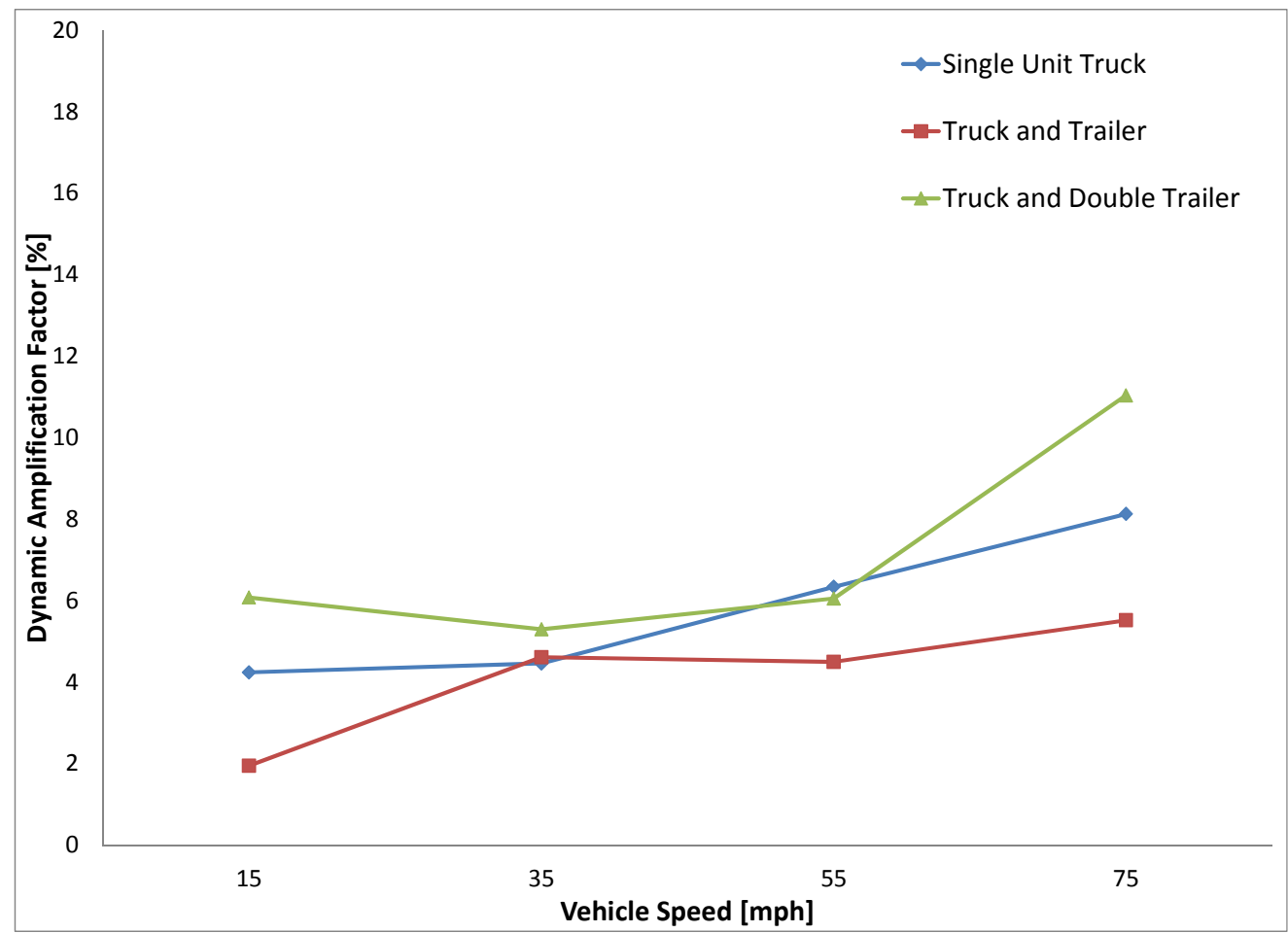

Figure 91. Three Span Real Bridge DAF for Different Vehicle Categories (Very Good Surface)

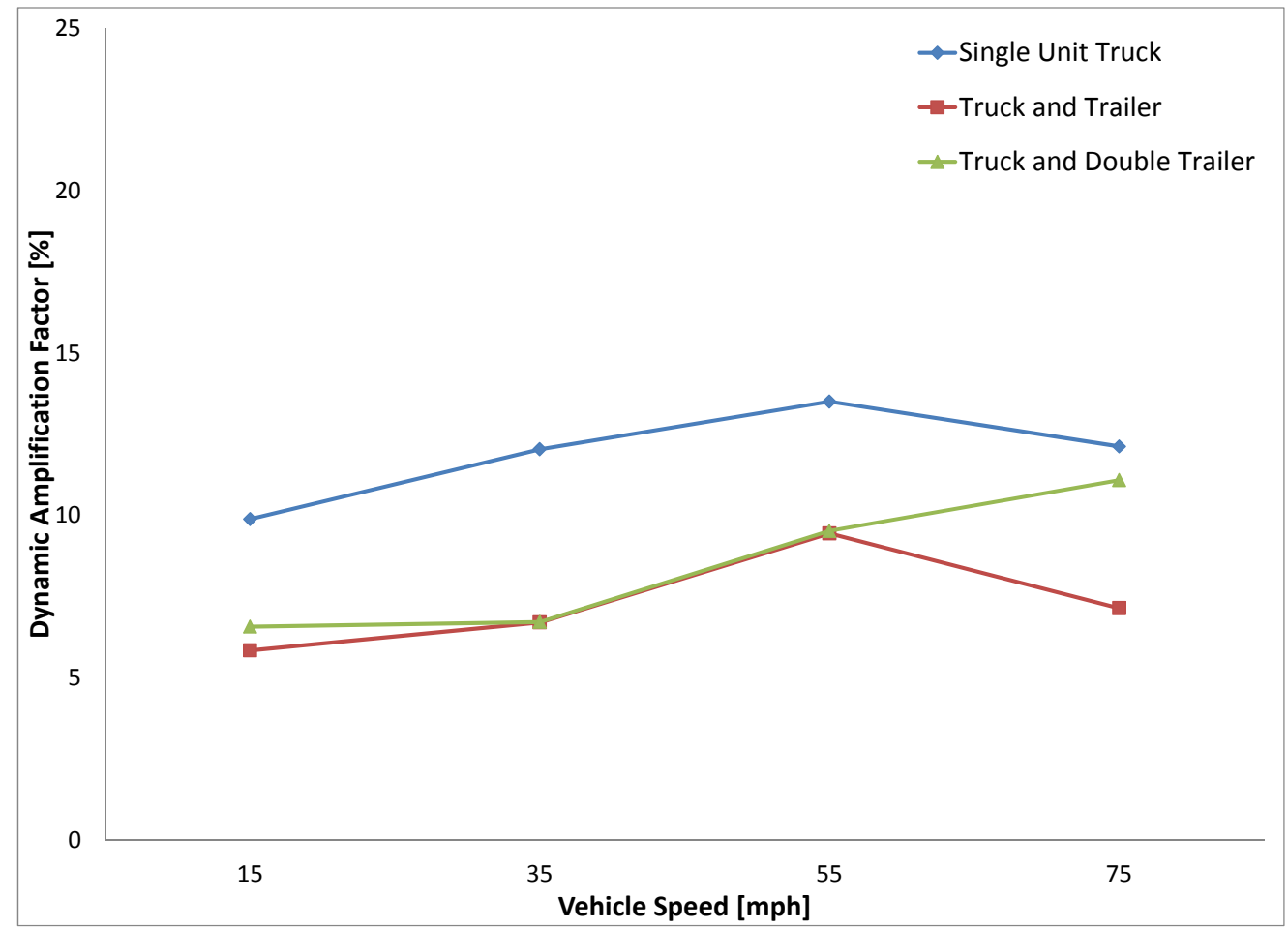

Figure 92. Three Span Real Bridge DAF for Different Vehicle Categories (Good Surface) 
The comparison of all the values for the three span continuous bridge is shown in Figure 93 for the two road surface conditions and four different vehicle speeds.

The bar graphs show noticeable higher values for the Good surface condition comparing to the Very Good surface condition.

By looking at the graphs, it is also evident that for the Very Good surface condition, the Truck and Double Trailers category has a slightly higher results comparing to the other two categories and when the surface condition is Good, the DAF values are much higher for the Single Unit Trucks.

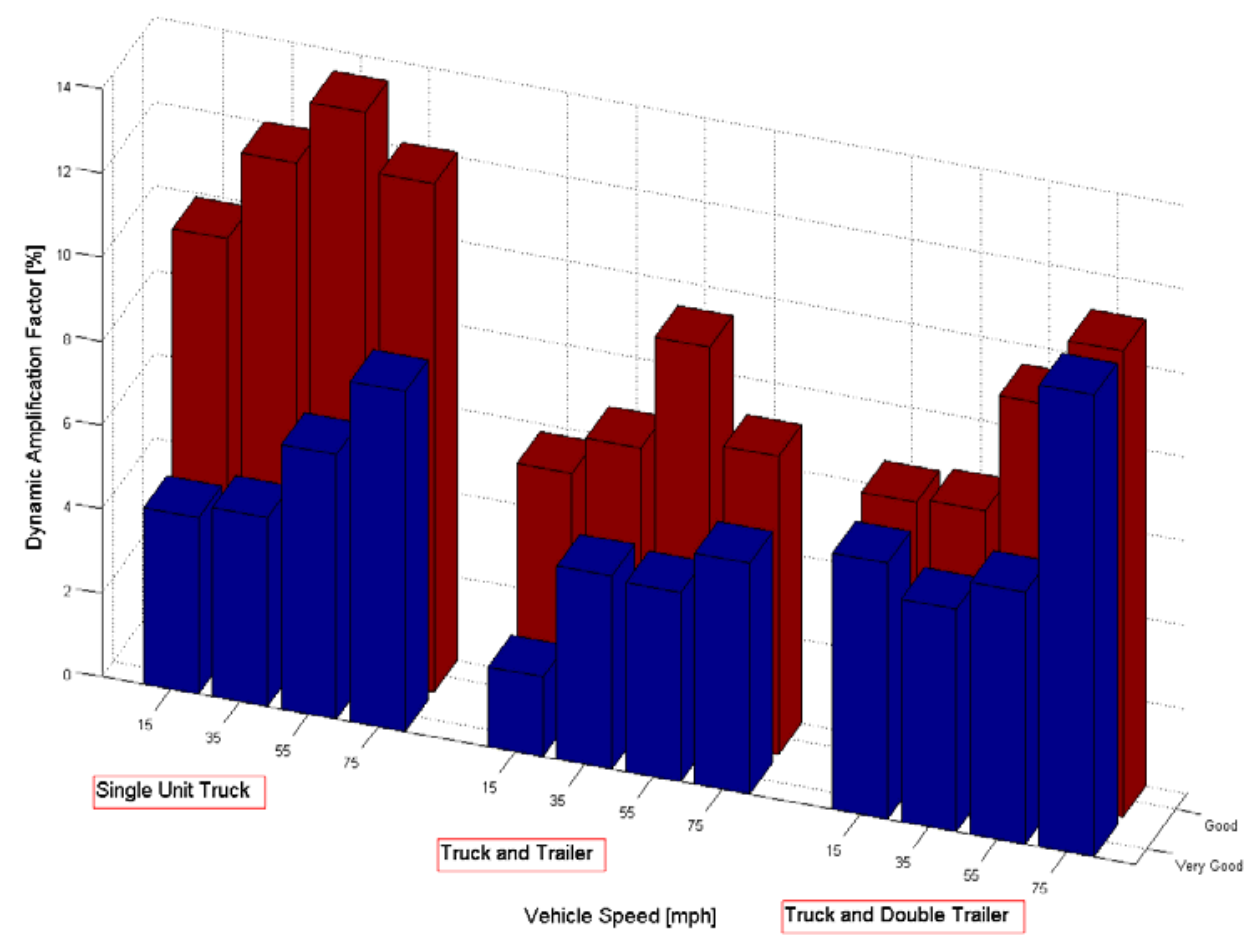

Figure 93. Three Span Real Bridge Comparison of the Very Good and Good Surfaces 


\section{FATIGUE ASSESSMENT OF BRIDGES}

Fatigue assessment is a way to evaluate the current status and remaining life of bridges. Fatigue can decrease the life of bridges significantly so close attention should be paid to the fatigue evaluation of the steel bridges and reinforced concrete decks.

\section{Steel Bridge Fatigue Assessment}

Based on AASHTO Guide Specifications for Fatigue Evaluation of Existing Steel Bridges [31], the fatigue life of a bridge is: (Same formula has been mentioned in NCHRP Report 495 [32])

$\mathrm{Y}=\frac{\mathrm{fK} \times 10^{6}}{\mathrm{~T}_{\mathrm{a}} \mathrm{C}\left(\mathrm{R}_{\mathrm{s}} \mathrm{S}_{\mathrm{r}}\right)^{3}}$

Where,

$\mathrm{Y}=$ Total life in years

$\mathrm{f}=$ Factor specified for evaluation, 1 for safe life and 2 for mean life

$\mathrm{K}=$ Constant tabulated for each type of fatigue sensitive detail

$\mathrm{T}_{\mathrm{a}}=$ Estimated lifetime-average daily truck volume

$\mathrm{C}=$ Number of cycles for a passage of the fatigue truck

$R_{s}=$ Reliability factor $=1.35$ for a reliability index $(\beta=0.94)$

$S_{r}=$ Stress range for a passage of the fatigue truck

$\mathrm{T}_{\mathrm{a}}$ can be expressed in terms of current annual daily truck volume $(\mathrm{T})$, constant annual growth rate $(u)$, current age of the bridge $(A)$, and $Y$. Substituting the new $T_{a}$ in equation 
( 92 ) and solving for Y, equation ( 92 ) will yield to equation ( 93 ) as in NCHRP Report 495 [32]:

$\mathrm{Y}=\frac{\log \left[\frac{\mathrm{fK} \times 10^{6}}{\mathrm{TC}\left(\mathrm{R}_{\mathrm{S}} \mathrm{S}^{3}\right)^{3}} \mathrm{u}(1+\mathrm{u})^{\mathrm{A}-1}+1\right]}{\log (1+\mathrm{u})}$

The following equation was adopted by AASHTO Manual for Bridge Evaluation (MBE) [33],

$\mathrm{Y}=\frac{\mathrm{R}_{\mathrm{R}} \mathrm{A}}{365 \mathrm{n}(\mathrm{ADTT})_{\mathrm{sL}}\left[(\Delta \mathrm{f})_{\mathrm{eff}}\right]^{3}}$

Where,

$Y=$ Total finite fatigue life in years

$R_{R}=$ Resistant factor specified for evaluation, minimum or mean fatigue life as given in

Table 7.2.5.2-1 of the MBE [33]

A = Detail category constant given in LRFD Design Table 6.6.1.2.5-1 [7]

$n=$ Number of stress-range cycles per truck passage estimated according to Article

7.2.5.2 of the MBE [33]

$(\mathrm{ADTT})_{\mathrm{SL}}=$ Average number of trucks per day in a single lane averaged over the fatigue life as specified in LRFD Design, Section 3.6.1.4.2 [7]

$(\Delta \mathrm{f})_{\mathrm{eff}}=$ The effective stress range as specified in Section 7.2.2 of the MBE [33]

Equation ( 94 ) is similar to equation ( 92 ). By replacing T with $365\left[(\mathrm{ADTT})_{\mathrm{SL}}\right]_{\text {Present }}$ (i.e. the average number of trucks per day in a single lane averaged until present), equation ( 93 ) can be rewritten in the form of equation ( 95 ). Equation ( 95 ) which is also given in 
NCHRP Report 721 [34], gives a closed form solution for $Y$, as opposed to the previous formula in the AASHTO MBE (2011) [33] which had to be solved either by using iterations or estimated using a graph in the commentary section of the manual.

$\mathrm{Y}=\frac{\log \left[\frac{\mathrm{R}_{\mathrm{R}} \mathrm{A}}{365 \mathrm{n}\left[(\mathrm{ADTT}) \mathrm{SL}_{\operatorname{Present}}\left[(\Delta \mathrm{ff})_{\mathrm{eff}}\right]^{\mathrm{g}} \mathrm{g}(1+\mathrm{g})^{\mathrm{a}-1}+1\right]}\right.}{\log (1+\mathrm{g})}$

Where,

$\mathrm{Y} \quad=$ Total finite fatigue life in years

$\mathrm{R}_{\mathrm{R}} \quad=$ Resistant factor specified for evaluation, minimum or mean fatigue life as given in Table 7.2.5.2-1 of the MBE [33]

A = Detail category constant given in LRFD Design, Table 6.6.1.2.5-1 [7]

$(\mathrm{ADTT})_{\mathrm{SL}}=$ Average number of trucks per day in a single lane averaged over the fatigue life as specified in LRFD Design, Section 3.6.1.4.2 [7]

$\mathrm{n} \quad=$ Number of stress-range cycles per truck passage estimated according to Article 7.2.5.2 of the MBE [33]

$(\Delta \mathrm{f})_{\mathrm{eff}} \quad=$ The effective stress range as specified in Section 7.2.2 of MBE [33]

g = Estimated annual traffic-volume growth rate

a $\quad=$ Present age of the bridge

In this research, equation ( 95 ) shall be used to determine the remaining fatigue life of steel bridges. In order to do the fatigue analysis, the effective stress range needs to be calculated. After analyzing the responses of eleven different trucks traveling at 55 and $75 \mathrm{mph}$ on different bridge lengths ranging from $30 \mathrm{ft}$. to $140 \mathrm{ft}$. with Good surface 
condition and obtaining the value of flexural stress for each time step at the midspan of each bridge, the effective stress range was calculated using the difference between the maximum flexural stress due to dynamic loading. For the cases with multiple peaks and valleys for the flexural stress due to static loading, the Miner's rule [35] was used to calculate the effective stress range of all the peaks.

$S_{r \text { Miner }}=\left[\sum \alpha_{i} S_{r i}^{n}\right]^{1 / n}$

Where,

$\mathrm{S}_{\mathrm{r} \text { Miner }}=$ The effective stress range calculated using the Miner's rule [35]

$\alpha_{\mathrm{i}} \quad=$ Number of cycles of stress with stress range within the stress bin $\mathrm{S}_{\mathrm{ri}}$ divided by the total number of stress cycles

$\mathrm{S}_{\mathrm{ri}} \quad=$ Average value of each stress bin

$\mathrm{n} \quad=$ An exponent which is taken as 3 for structural steel details

$R_{R}$, or the resistant factor is given in Table 7.2.5.2-1 of the MBE [33] and is shown in Table 21.

Table 21. Resistance Factor for Evaluation, Minimum, or Mean Fatigue Life, $R_{R}$

\begin{tabular}{|c|c|c|c|}
\hline \multirow{2}{*}{$\begin{array}{c}\text { Detail } \\
\text { Category }\end{array}$} & \multicolumn{3}{|c|}{$\mathbf{R}_{\mathbf{R}}$} \\
\cline { 2 - 4 } & $\begin{array}{c}\text { Evaluation } \\
\text { Life }\end{array}$ & $\begin{array}{c}\text { Minimum } \\
\text { Life }\end{array}$ & $\begin{array}{c}\text { Mean } \\
\text { Life }\end{array}$ \\
\hline \hline A & 1.7 & 1.0 & 2.8 \\
\hline B & 1.4 & 1.0 & 2.0 \\
\hline$B^{\prime}$ & 4.5 & 1.0 & 2.4 \\
\hline C & 1.2 & 1.0 & 1.3 \\
\hline C' $^{\prime}$ & 1.2 & 1.0 & 1.3 \\
\hline D & 1.3 & 1.0 & 1.6 \\
\hline E & 1.3 & 1.0 & 1.6 \\
\hline$E^{\prime}$ & 1.6 & 1.0 & 2.5 \\
\hline
\end{tabular}


The value of $R_{R}$ is given for three different fatigue lives of Mean, Evaluation and Minimum fatigue life which is corresponding to the mean fatigue resistance, one standard deviation below the mean fatigue resistance and two standard deviations below the mean fatigue resistance.

For the design, the conservative value for the minimum life should be assumed and the same assumption is applicable to the analysis, herein. So the value of $R_{R}$ shall be taken as one.

A, or the detail category constant is given in Table 22 , and the results will be calculated for different detail categories.

Table 22. Detail Category Constant, A

\begin{tabular}{|c|c|}
\hline $\begin{array}{c}\text { Detail } \\
\text { Category }\end{array}$ & $\begin{array}{c}\text { Constant, A } \\
\text { times } \mathbf{~ 1 0}^{\mathbf{8}} \\
\left(\mathbf{k s i}^{\mathbf{3}} \mathbf{)}\right.\end{array}$ \\
\hline \hline $\mathrm{A}$ & 250.0 \\
\hline $\mathrm{B}$ & 120.0 \\
\hline $\mathrm{B}^{\prime}$ & 61.0 \\
\hline $\mathrm{C}$ & 44.0 \\
\hline $\mathrm{C}^{\prime}$ & 44.0 \\
\hline $\mathrm{D}$ & 22.0 \\
\hline $\mathrm{E}$ & 11.0 \\
\hline $\mathrm{E}^{\prime}$ & 3.9 \\
\hline
\end{tabular}

$\mathrm{n}$, or the Number of stress-range cycles per truck passage shall be evaluated from Table 23.

All bridges here are designed as simple span girder bridges and in four cases of bridge lengths of $60,90,120,140 \mathrm{ft}$. the value of $\mathrm{n}$ should be taken as 1 and in the case of $30 \mathrm{ft}$. span bridge, this factor should be taken as 2 . 
Table 23. Cycles per Truck Passage, $n$

\begin{tabular}{|c|c|c|}
\hline \multirow{2}{*}{ Longitudinal Members } & \multicolumn{2}{|c|}{ Span Length } \\
\cline { 2 - 3 } & $>40.0 \mathrm{ft}$. & $\leq 40.0 \mathrm{ft}$. \\
\hline \hline Simple Span Girders & 1.0 & 2.0 \\
\hline Continuous Girders & \multicolumn{2}{|c|}{} \\
\hline 1) near interior support & 1.5 & 2.0 \\
\hline 2) elsewhere & 1.0 & 2.0 \\
\hline Cantilever Girders & \multicolumn{2}{|c|}{5.0} \\
\hline Trusses & \multicolumn{2}{|c|}{1.0} \\
\hline \multirow{2}{*}{ Transverse Members } & \multicolumn{2}{|c|}{ Spacing } \\
\cline { 2 - 3 } & $>20.0 \mathrm{ft}$. & $\leq 20.0 \mathrm{ft}$. \\
\cline { 2 - 3 } & 1.0 & 2.0 \\
\hline
\end{tabular}

For $(\text { ADTT })_{\text {SL }}$ the data given in Report, Statistical Analysis of Heavy Truck Loads Using Wisconsin Weigh-In-Motion Data [36] is used for each category of trucks. Data of close to 6 million vehicles was gathered in 2007 in the state of Wisconsin. This data was obtained from Wisconsin Department of Transportation for total of 17 different locations. In order to understand the data gathered from the report, categorization of the vehicles is needed. Eleven different types of trucks have been selected which fall under different categories of Federal Highway Administration category scheme.

FHWA Category Scheme for the vehicle classification which is shown in Table 25. The data obtained from the report is then categorized based on the eleven different types of the vehicle used in the study which can be seen in the Table 24.

The aim of this research is to understand the effects of using higher capacity trucks instead of smaller trucks on the bridges and this will be viewed considering the fatigue behavior of bridges. The question is, whether using higher capacity trucks, which results in using less number of trucks, have more detrimental effects on the fatigue behavior of 
bridges or, since the counts of the trucks on bridges decrease, this will not cause more damages to the bridges.

Table 24. Truck Counts Based on WisDOT Data

\begin{tabular}{|c|c|c|c|}
\hline $\begin{array}{c}\text { Vehicle } \\
\text { Class }\end{array}$ & Vehicle Type & $\begin{array}{c}\text { Total Number } \\
\text { of Counts } \\
\text { [Year] }\end{array}$ & $\begin{array}{l}\% \text { of } \\
\text { Total }\end{array}$ \\
\hline Class 5 & $\mathrm{H}-20$ & 748658 & 13 \\
\hline Class 6 & Type 3 & 251795 & 4.37 \\
\hline Class 7 & SU4 & 25753 & 1.27 \\
\hline \multirow{2}{*}{ Class 8} & HS-20 & 634745 & 11.02 \\
\hline & Type 3S1 \& 2S2 & 213738 & 3.71 \\
\hline Class 9 & Type 3S2 & 3553613 & 61.72 \\
\hline Class 10 & Type 3S3 & 72939 & 1.27 \\
\hline \multirow{4}{*}{ Class 13} & 7 Axle Rocky Mountain Double & 9738 & 0.17 \\
\hline & 8 Axle B-Train Double & 680 & 0.01 \\
\hline & 9 Axle Turnpike Double & 75 & 0 \\
\hline & Total & 5511734 & \\
\hline
\end{tabular}

In order to answer the above question, different scenarios can be considered. As shown in the table above, the number of vehicles with higher number of axles which can carry more load are very small in the data gathered from the Wisconsin DOT and this number for the whole group of class 13 is below $0.2 \%$ of the total number of trucks.

One can also observe from the same table that the majority of the freight shipping in this state is done by class 9 vehicles with the staggering percentage of 60. 9-Axle Turnpike Double can carry up to $50 \%$ more load than the Type 3S2, so using Turnpike Double instead of Type $3 S 2$ can result in 33\% reduction in the number of trucks on the bridges. This decrease can be applied to $(\mathrm{ADTT})_{\mathrm{SL}}$ and effective stress range which was calculated for all the vehicles should also be updated. Results for the detail C' are given in Table 26 as an example for different growth rates and current age of the bridge. 
Table 25. FHWA Vehicle Classification

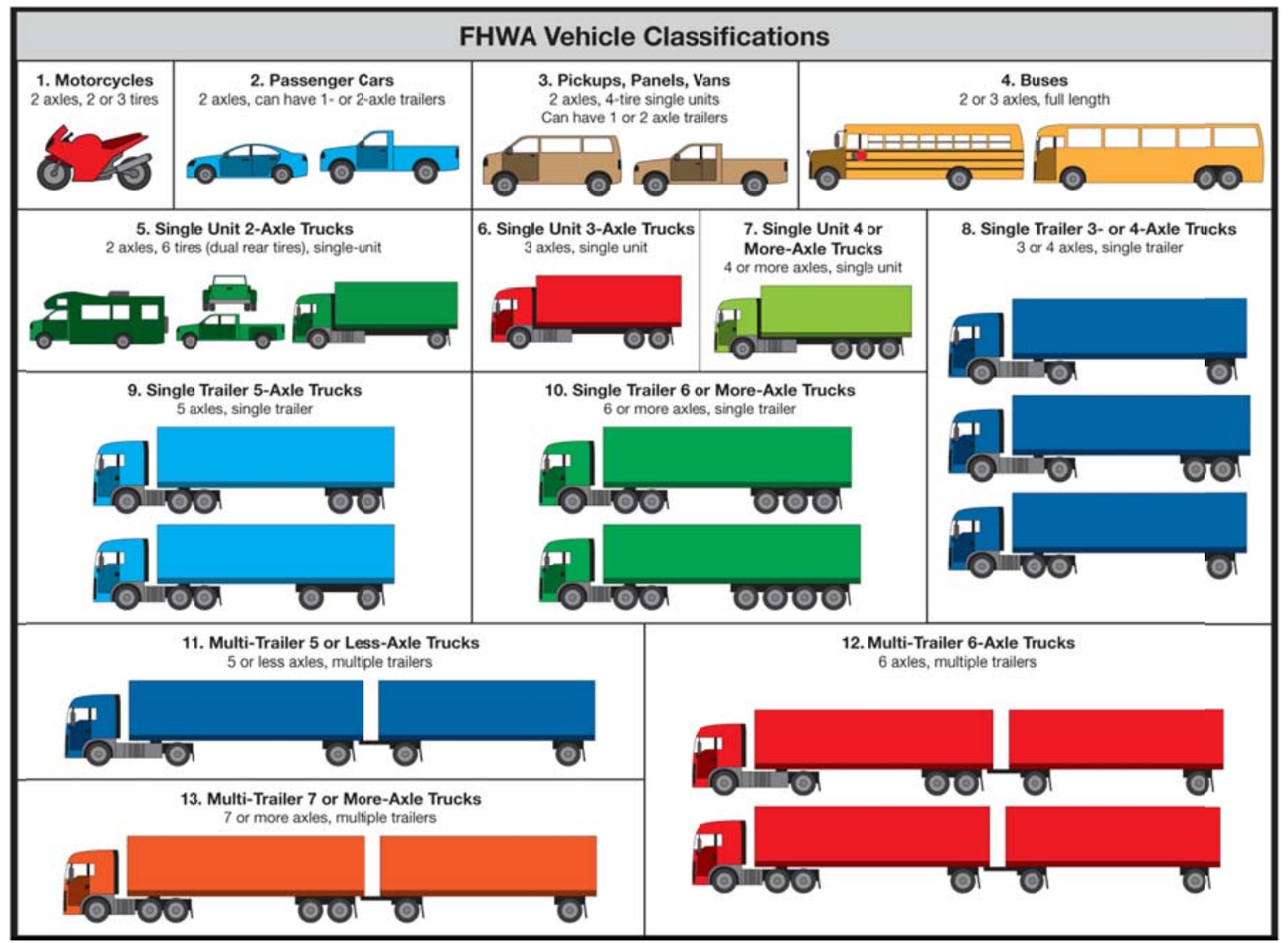

Taken from Texas DOT website (http://onlinemanuals.txdot.gov/txdotmanuals/trilimages/FHWA Classification Chart FINAL.png)

Table 26. Remaining Fatigue Life of the Steel Bridge Based on First and Second Scenarios

\begin{tabular}{|c|c|c|c|c|c|c|c|c|}
\hline \multicolumn{8}{|c|}{ Remaining Fatigue Life in years } \\
\hline & \multicolumn{7}{|c|}{ Type 3S2 } & \multicolumn{3}{c|}{ 9-Axle Turnpike Double } \\
\hline & 0.02 & 0.04 & 0.06 & 0.08 & 0.02 & 0.04 & 0.06 & 0.08 \\
\hline 5 & 75 & 52 & 41 & 34 & 72 & 50 & 40 & 33 \\
\hline 10 & 74 & 52 & 41 & 34 & 71 & 50 & 39 & 33 \\
\hline 20 & 72 & 51 & 40 & 34 & 69 & 49 & 39 & 33 \\
\hline 30 & 71 & 50 & 40 & 34 & 67 & 48 & 39 & 33 \\
\hline 40 & 69 & 50 & 40 & 34 & 66 & 48 & 38 & 33 \\
\hline 50 & 68 & 50 & 40 & 34 & 65 & 48 & 38 & 32 \\
\hline
\end{tabular}


It can be seen that by using heavier vehicles, the Remaining Fatigue Life has slightly decreased. This shows that, using less number of trucks to carry the same load might not have an extremely bad effect on the overall stresses due to fatigue loading on the bridge even though higher stresses will be present at the bridge when these trucks pass.

A new measure for the fatigue life evaluation of steel bridges has also been proposed in NCHRP Report 721 [34]. This measure which is called Fatigue Serviceability Index (FSI or $\mathrm{Q}$ ) provides a relative evaluation of fatigue serviceability of different structural details. This index is dimensionless and is a good measure for the engineers to evaluate the current status of bridges. In the remaining fatigue life approach, the fatigue life can be negative in some cases which means that the bridge which is currently in use, was supposed to be fixed or replaced earlier. This shows that the formula is over conservative. One advantage of the FSI measure over the the remaining fatigue life procedure is that the negative values for the index would actually mean that the bridge is in critical situation in terms of the fatigue status and prompt action is needed to deal with the situation. FSI is given in equation ( 97 ):

$Q=\left(\frac{Y-a}{N}\right) G R I$

Where:

$Y \quad=$ Calculated total fatigue life of the detail

$N=$ Greater of $Y$ or 100 years

G = Load Path Factor

$R \quad=$ Redundancy Factor

I $\quad=$ Importance Factor 
$Q \quad=$ Fatigue Serviceability Index (Also called FSI)

$a \quad=$ Current Age of the Bridge

G, R and I can be obtained from Table 27, Table 28, Table 29 respectively [34]:

Table 27. Load Path Factor, G

\begin{tabular}{|c|c|}
\hline $\begin{array}{c}\text { Number of Load Path } \\
\text { Members }\end{array}$ & G \\
\hline \hline 1 or 2 members & 0.8 \\
\hline 3 members & 0.9 \\
\hline 4 or more members & 1 \\
\hline
\end{tabular}

Table 28. Redundancy Factor, $\mathrm{R}$

\begin{tabular}{|c|c|}
\hline Type of Span & $\mathbf{R}$ \\
\hline \hline Simple & 0.9 \\
\hline Continuous & 1 \\
\hline
\end{tabular}

Table 29. Importance Factor, I

\begin{tabular}{|c|c|}
\hline $\begin{array}{c}\text { Structure or } \\
\text { Location }\end{array}$ & $\begin{array}{c}\text { Importance } \\
\text { Factor, I }\end{array}$ \\
\hline \hline $\begin{array}{c}\text { Interstate Highway } \\
\text { Main Arterial State } \\
\text { Route }\end{array}$ & 0.90 \\
\hline $\begin{array}{c}\text { Secondary Arterial } \\
\text { Urban Areas }\end{array}$ & 0.95 \\
\hline $\begin{array}{c}\text { Rural Roads } \\
\text { Low ADTT routes }\end{array}$ & 1.00 \\
\hline
\end{tabular}

From the above tables, values of $G, R$ and $I$ in this research will be $1,0.9,0.9$ respectively. After the calculation of FSI, the values will be assessed using Table 30 given in NCHRP Report 721 [34]. 
Table 30. Fatigue Rating and Assessment Outcomes

\begin{tabular}{|c|c|c|}
\hline $\begin{array}{c}\text { Fatigue Serviceability } \\
\text { Index, } Q\end{array}$ & $\begin{array}{c}\text { Fatigue } \\
\text { Rating }\end{array}$ & Assessment Outcome \\
\hline \hline 1.00 to 0.50 & Excellent & Continue Regular Inspection \\
\hline 0.50 to 0.35 & Good & Continue Regular Inspection \\
\hline 0.35 to 0.20 & Moderate & Continue Regular Inspection \\
\hline 0.20 to 0.10 & Fair & Increase Inspection Frequency \\
\hline 0.10 to 0.00 & Poor & Assess Frequently \\
\hline$<0.00$ & Critical & $\begin{array}{c}\text { Consider Retrofit, } \\
\text { Replacement or } \\
\text { Reassessment }\end{array}$ \\
\hline
\end{tabular}

For the same case that was discussed earlier, the values of Fatigue Serviceability Index were calculated and the results are given in Table 31 and Table 32. It can be seen from these tables that the fatigue rating for the case of using longer combination vehicles, such as 9-Axle Turnpike Double, on the bridge, results in slightly worse FSI but not big enough to change the fatigue rating of the bridge which remains the same for two cases.

In addition to these two scenarios of using Type 3S2 trucks or using 9-Axle Turnpike Double, a third scenario which is using Single Unit Trucks instead of Typpe 3S2 trucks has also been investigated here. The truck from Single Unit Trucks category which has been selected here is SU4 which can almost carry the same weight as Type 3S2 truck.

Table 31. Fatigue Serviceability Index Based on First and Second Scenarios

\begin{tabular}{|c|c|c|c|c|c|c|c|c|}
\hline \multicolumn{9}{|c|}{ Fatigue Serviceability Index } \\
\hline & \multicolumn{4}{|c|}{ Type 3S2 } & \multicolumn{4}{|c|}{ 9-Axle Turnpike Double } \\
\hline$a^{g}$ & 0.02 & 0.04 & 0.06 & 0.08 & 0.02 & 0.04 & 0.06 & 0.08 \\
\hline 5 & 0.61 & 0.42 & 0.33 & 0.28 & 0.58 & 0.41 & 0.32 & 0.27 \\
\hline 10 & 0.60 & 0.42 & 0.33 & 0.28 & 0.58 & 0.41 & 0.32 & 0.27 \\
\hline 20 & 0.58 & 0.41 & 0.32 & 0.28 & 0.56 & 0.40 & 0.32 & 0.27 \\
\hline 30 & 0.57 & 0.41 & 0.32 & 0.28 & 0.54 & 0.39 & 0.32 & 0.27 \\
\hline 40 & 0.51 & 0.41 & 0.32 & 0.28 & 0.50 & 0.39 & 0.31 & 0.27 \\
\hline 50 & 0.47 & 0.41 & 0.32 & 0.28 & 0.46 & 0.39 & 0.31 & 0.26 \\
\hline
\end{tabular}


Table 32. Fatigue Rating Based on First and Second Scenarios

\begin{tabular}{|c|c|c|c|c|c|c|c|c|}
\hline \multicolumn{70}{|c|}{ Type 3S2 } & \multicolumn{3}{c|}{ 9-Axle Turnpike Double } \\
\hline \multicolumn{1}{|c|}{0.02} & 0.04 & 0.06 & 0.08 & 0.02 & 0.04 & 0.06 & 0.08 \\
\hline 5 & Excellent & Good & Moderate & Moderate & Excellent & Good & Moderate & Moderate \\
\hline 10 & Excellent & Good & Moderate & Moderate & Excellent & Good & Moderate & Moderate \\
\hline 20 & Excellent & Good & Moderate & Moderate & Excellent & Good & Moderate & Moderate \\
\hline 30 & Excellent & Good & Moderate & Moderate & Excellent & Good & Moderate & Moderate \\
\hline 40 & Excellent & Good & Moderate & Moderate & Excellent & Good & Moderate & Moderate \\
\hline 50 & Good & Good & Moderate & Moderate & Good & Good & Moderate & Moderate \\
\hline
\end{tabular}

Using the same WIM data, and replacing the Type 3S2 trucks with the SU4 trucks, the results of remaing fatigue life, Fatigue Serviceability Index and Fatigue Rating were obtained and shown in Table 33, Table 34 and Table 35.

It can be conclude from these three tables that using SU4 truck instead of Type 3S2 can have bad effects of the fatigue life of the bridge. This might be due to the fact that SU4 causes higher stress ranges as a result of having heavy axles located very close to each other. So the third scenario is not a good option.

Table 33. Remaining Fatigue Life of the Steel Bridge Based on First and Third Scenarios

\begin{tabular}{|c|c|c|c|c|c|c|c|c|}
\hline \multicolumn{9}{|c|}{ Remaining Fatigue Life in years } \\
\hline & \multicolumn{4}{|c|}{ Type 3S2 } & \multicolumn{4}{|c|}{ SU4 Truck } \\
\hline a & 0.02 & 0.04 & 0.06 & 0.08 & 0.02 & 0.04 & 0.06 & 0.08 \\
\hline 5 & 75 & 52 & 41 & 34 & 55 & 40 & 33 & 28 \\
\hline 10 & 74 & 52 & 41 & 34 & 53 & 40 & 32 & 27 \\
\hline 20 & 72 & 51 & 40 & 34 & 51 & 38 & 31 & 27 \\
\hline 30 & 71 & 50 & 40 & 34 & 49 & 38 & 31 & 27 \\
\hline 40 & 69 & 50 & 40 & 34 & 47 & 37 & 31 & 27 \\
\hline 50 & 68 & 50 & 40 & 34 & 45 & 37 & 31 & 27 \\
\hline
\end{tabular}


Table 34. Fatigue Serviceability Index Based on First and Third Scenarios

\begin{tabular}{|c|c|c|c|c|c|c|c|c|}
\hline \multicolumn{9}{|c|}{ Type 3S2 } \\
\hline \multicolumn{1}{|c|}{} & \multicolumn{9}{|c|}{ SU4 Truck } \\
\hline $\mathrm{g}$ & 0.02 & 0.04 & 0.06 & 0.08 & 0.02 & 0.04 & 0.06 & 0.08 \\
\hline 5 & 0.61 & 0.42 & 0.33 & 0.28 & 0.45 & 0.32 & 0.27 & 0.23 \\
\hline 10 & 0.60 & 0.42 & 0.33 & 0.28 & 0.43 & 0.32 & 0.26 & 0.22 \\
\hline 20 & 0.58 & 0.41 & 0.32 & 0.28 & 0.41 & 0.31 & 0.25 & 0.22 \\
\hline 30 & 0.57 & 0.41 & 0.32 & 0.28 & 0.40 & 0.31 & 0.25 & 0.22 \\
\hline 40 & 0.51 & 0.41 & 0.32 & 0.28 & 0.38 & 0.30 & 0.25 & 0.22 \\
\hline 50 & 0.47 & 0.41 & 0.32 & 0.28 & 0.36 & 0.30 & 0.25 & 0.22 \\
\hline
\end{tabular}

Table 35. Fatigue Rating Based on First and Third Scenarios

\begin{tabular}{|c|c|c|c|c|c|c|c|c|}
\hline \multicolumn{9}{|c|}{ Fatigue Rating } \\
\hline & \multicolumn{4}{|c|}{ Type 3S2 } & \multicolumn{4}{|c|}{ SU4 Truck } \\
\hline$a^{9}$ & 0.02 & 0.04 & 0.06 & 0.08 & 0.02 & 0.04 & 0.06 & 0.08 \\
\hline 5 & Excellent & Good & Moderate & Moderate & Good & Moderate & Moderate & Moderate \\
\hline 10 & Excellent & Good & Moderate & Moderate & Good & Moderate & Moderate & Moderate \\
\hline 20 & Excellent & Good & Moderate & Moderate & Good & Moderate & Moderate & Moderate \\
\hline 30 & Excellent & Good & Moderate & Moderate & Good & Moderate & Moderate & Moderate \\
\hline 40 & Excellent & Good & Moderate & Moderate & Good & Moderate & Moderate & Moderate \\
\hline 50 & Good & Good & Moderate & Moderate & Good & Moderate & Moderate & Moderate \\
\hline
\end{tabular}

\section{Reinforced Concrete Deck Fatigue Assessment}

According to NCHRP Report 495 [32], a procedure similar to what was discussed in the previous section can be used to evaluate fatigue in RC decks [32]:

$\mathrm{Y}_{\mathrm{d}}=\frac{\log \left[\frac{\mathrm{K}_{\mathrm{d}} \mathrm{K}_{\mathrm{P}}}{\left.\mathrm{TC}_{\mathrm{d}}\left(\mathrm{R}_{\mathrm{d}} \mathrm{IP}_{\mathrm{S}} \mathrm{P} / \mathrm{Pu}_{\mathrm{u}}\right)^{17.95} \mathrm{u}(1+\mathrm{u})^{\mathrm{A}-1}+1\right]}\right.}{\log (1+\mathrm{u})}$

Equation ( 98 ) can be rewritten using the terms used in AASHTO Manual for Bridge Evaluation (MBE) [33] : 
$Y_{d}=\frac{\log \left[\frac{K_{d} K_{P}}{\left[(\text { ADTT })_{S L}\right]_{P r e s e n t} C_{d}\left(R_{d} I_{P} P / P_{u}\right)^{17.95}} g(1+g)^{a-1}+1\right]}{\log (1+g)}$

Where:

$\mathrm{R}_{\mathrm{d}} \quad=$ Reliability factor

$Y_{d} \quad=$ Mean service life of the deck in years for $R_{d}=1$

Evaluation life of the deck in years for $R_{d}=1.35$

$\left[(\mathrm{ADTT})_{\mathrm{SL}}\right]_{\text {Present }}=$ Average number of trucks per day in a single day in a single lane averaged until present

g = Estimated annual traffic-volume growth rate

a $\quad$ Present age of the bridge

$\mathrm{K}_{\mathrm{d}}=$ Coefficient to cover model uncertainty $=2.09 \times 10^{-6}$

$\mathrm{K}_{\mathrm{P}} \quad$ = Coefficient to consider time difference between deck failure and treatment

$=3.16 \times 10^{-7}$

$\mathrm{P}_{\mathrm{S}} \quad=$ Axle-group factor $=1.04$

$\mathrm{C}_{\mathrm{d}} \quad=$ Average number of axles per truck

I $\quad=$ Impact factor

$\mathrm{P}_{\mathrm{u}} \quad$ = Ultimate shear capacity of the deck [32]

$=\left(2+\frac{4}{\alpha}\right)\left(\mathrm{f}_{\mathrm{c}}^{\prime}\right)^{1 / 2} \mathrm{~b}_{0} \mathrm{~d} \gamma<4\left(\mathrm{f}_{\mathrm{c}}^{\prime}\right)^{1 / 2} \mathrm{~b}_{0} \mathrm{~d} \gamma$

Where, 


$$
\begin{aligned}
& \mathrm{f}_{\mathrm{c}}^{\prime}=\text { Concrete compressive strength in psi } \\
& \alpha=\text { Ratio of tire print's long side to short side }=2.5 \text { for dual tires } \\
& \mathrm{d}=\text { Deck's effective thickness }=\text { total thickness }- \text { bottom cover thickness } \\
& \mathrm{b}_{0}=\text { Perimeter of the critical section } \\
& \gamma=\text { Model correction parameter }=1.55 \\
& \mathrm{P}=\text { Equivalent fatigue load [32] } \\
&=\left(\sum \mathrm{f}_{\mathrm{i}}\left(\mathrm{P}_{\mathrm{i}}\right) \mathrm{P}_{\mathrm{i}}^{17.95}\right)^{1 / 17.95} \\
& \quad W h e r e \\
& \mathrm{P}_{\mathrm{i}}= \text { Mid-interval value of the } \mathrm{i}^{\text {th }} \text { interval in the Wheel Weight Histograms } \\
& \mathrm{f}_{\mathrm{i}}\left(\mathrm{P}_{\mathrm{i}}\right)=\text { frequency of that interval }
\end{aligned}
$$

In order to calculate the service life of the reinforced concrete decks, the details of the analyses of prestressed concrete bridges with reinforced concrete decks have been used. Similar to the previous section, three scenarios of trucks have been assumed. First, the current traffic recorded from the WIM data in the Wisconsin DOT report [36]. In the second scenario, in order to determine the effects of using heavy vehicles instead of doubling the number of current vehicles, all Type $3 S 2$ vehicles have been replaced by the longer combination vehicle, 9-Axle Turnpike Double which can carry almost twice as much as the Type $3 S 2$ vehicle.

In the third scenario, the Type $3 \mathrm{~S} 2$ vehicles were replaced by single unit SU4 trucks. By using the WIM data and the vehicle axle weights, the equivalent fatigue load (P) was 
calculated. Using equation ( 99 ), the service life of bridge decks and therefore the remaining fatigue life of the $\mathrm{RC}$ decks can be calculated. The results for the comparison of the three cases for $30 \mathrm{ft}$. prestressed concrete bridge, have been shown in Table 36 and Table 37.

Table 36. Remaining Fatigue Life of the Reinforced Concrete Deck Based on First and Second Scenarios

\begin{tabular}{|c|c|c|c|c|c|c|c|c|}
\hline \multicolumn{8}{|c|}{ Remaining Fatigue Life in years } \\
\hline & \multicolumn{7}{|c|}{ Ty2 } & \multicolumn{3}{c|}{9 9-Axle Turnpike Double } \\
\hline & 0.02 & 0.04 & 0.06 & 0.08 & 0.02 & 0.04 & 0.06 & 0.08 \\
\hline 5 & 81 & 56 & 43 & 36 & 87 & 59 & 46 & 38 \\
\hline 10 & 80 & 55 & 43 & 36 & 87 & 59 & 46 & 38 \\
\hline 20 & 79 & 55 & 43 & 36 & 85 & 58 & 45 & 38 \\
\hline 30 & 78 & 54 & 43 & 36 & 84 & 58 & 45 & 38 \\
\hline 40 & 77 & 54 & 43 & 36 & 83 & 57 & 45 & 38 \\
\hline 50 & 76 & 54 & 43 & 36 & 82 & 57 & 45 & 38 \\
\hline
\end{tabular}

It can be observed from the table above that the second scenario which is the case of using heavier vehicles with higher load capacity in giving more fatigue life comparing to the regular case of using smaller trucks with lower load capacity.

Table 37. Remaining Fatigue Life of the Reinforced Concrete Deck Based on First and Third Scenarios

\begin{tabular}{|c|c|c|c|c|c|c|c|c|}
\hline \multicolumn{8}{|c|}{ Remaining Fatigue Life in years } \\
\hline & \multicolumn{9}{|c|}{ Type 3S2 } & \multicolumn{4}{c|}{ SU4 Truck } \\
\hline & 0.02 & 0.04 & 0.06 & 0.08 & 0.02 & 0.04 & 0.06 & 0.08 \\
\hline 5 & 81 & 56 & 43 & 36 & 74 & 52 & 41 & 34 \\
\hline 10 & 80 & 55 & 43 & 36 & 73 & 51 & 40 & 34 \\
\hline 20 & 79 & 55 & 43 & 36 & 72 & 51 & 40 & 34 \\
\hline 30 & 78 & 54 & 43 & 36 & 70 & 50 & 40 & 34 \\
\hline 40 & 77 & 54 & 43 & 36 & 69 & 50 & 40 & 33 \\
\hline 50 & 76 & 54 & 43 & 36 & 68 & 49 & 40 & 33 \\
\hline
\end{tabular}


Also from Table 37, one can observe that using Single Unit Trucks such as SU4 can lower the remaining fatigue life of the bridges. As mentioned before, having many axles with small spacing can result in higher stresses on the bridge and the concrete deck which results in shorter fatigue life.

\section{Real Bridges Fatigue Assessment}

In this section the fatigue assessment of the three real bridges introduced in Chapter IV is carried out. In order to do this assessment, same approach as the previous section has been used and the Weigh-In-Motion data recorded for the state of Wisconsin and shown in Table 24 has been used. Using the same approach, three different scenarios have been assumed for the vehicle traffic over the three bridges. Equation ( 95 ) has been used to evaluate the remaining life of the real steel bridges. Fatigue Serviceability Index (FSI) and Fatigue Rating [34] have also been used to make the evaluation more qualitative.

The results for the remaining fatigue life and the Fatigue Serviceability Index (FSI) of the first real bridge (189'-8" long, single span bridge) for all scenarios have been shown in Table 38 and Table 39, respectively. It can be observed from these two tables that the difference between the first (current traffic i.e. using Type $3 S 2$ trucks) and second (replacing all Type 352 trucks with larger 9-Axle Turnpike Double trucks) scenarios is significant. The second scenario is resulting in much smaller remaining fatigue lives comparing to the first scenario. The results for the third scenario (replacing all Type $3 S 2$ trucks with Single Unit Trucks, in this case SU4) are pretty close and even slightly better than the results from the first scenario.

For the second real bridge (83'-6" long, single span bridge) the results for the remaining fatigue life and FSI are shown in Table 40 and Table 41 respectively. The results show 
that the first scenario gives the highest values of the reaming fatigue life among the three scenarios. Second and third scenarios give almost the same values for the remaining fatigue life and they are significantly lower than the first scenario.

The three span continuous real bridge analysis results for the remaining fatigue life and FSI can be seen in Table 42 and Table 43. Also in this case the first scenario shows the highest values of the remaining fatigue life. The third scenario is in the second place in terms of the remaining fatigue life and the second scenario which is using the larger vehicles results in the smallest fatigue life. The difference between the three cases is not that high though.

The comparison of the remaining fatigue life of the first real bridge for two annual growth rates and current bridge ages of 5, 20 and 50 years have been shown in Figure 94 . The same comparison for the three span continuous real bridge is shown in Figure 95.

The Fatigue Ratings of all three real bridges based on all three scenarios can be seen in Table 44. Fatigue ratings for the first real bridge are almost the same for the first and third scenarios but for the second scenario, observed fatigue ratings are lower than the other two cases.

Fatigue ratings for the second real bridge are almost the same for the three different scenarios. For the annual growth rates of $0.02,0.04$ and 0.08 the fatigue rating is Excellent, Excellent and Good, respectively, for all three scenarios and for $\mathrm{g}$ of 0.06 it is Excellent for the first scenario and Good for the second and third scenarios.

Fatigue ratings for the three span continuous real bridge are also the same for all three scenarios. For annual growth rate of 0.02 the bridge condition is Good and for all other annual growth rates the bridge condition is moderate. 
Table 38. Remaining Fatigue Life of the First Real Bridge for All Scenarios

\begin{tabular}{|c|c|c|c|c|c|c|c|c|c|c|c|c|}
\hline \multicolumn{10}{|c|}{ Temaining Fatigue Life in years } \\
\hline & \multicolumn{10}{|c|}{ Type 3S2 (Scenario I) } & \multicolumn{1}{c|}{ S-Axle Turnpike Double (Scenario II) } & \multicolumn{4}{c|}{ (Scenario III) } \\
\hline & 0.02 & 0.04 & 0.06 & 0.08 & 0.02 & 0.04 & 0.06 & 0.08 & 0.02 & 0.04 & 0.06 & 0.08 \\
\hline 5 & 64 & 46 & 37 & 31 & 44 & 34 & 28 & 24 & 67 & 47 & 38 & 32 \\
\hline 10 & 63 & 45 & 36 & 31 & 43 & 33 & 27 & 24 & 66 & 47 & 37 & 31 \\
\hline 20 & 61 & 44 & 36 & 30 & 39 & 31 & 26 & 23 & 64 & 46 & 37 & 31 \\
\hline 30 & 59 & 44 & 35 & 30 & 36 & 30 & 26 & 23 & 62 & 45 & 37 & 31 \\
\hline 40 & 57 & 43 & 35 & 30 & 34 & 29 & 26 & 23 & 60 & 45 & 36 & 31 \\
\hline 50 & 56 & 43 & 35 & 30 & 32 & 29 & 25 & 23 & 59 & 45 & 36 & 31 \\
\hline
\end{tabular}

Table 39. Fatigue Serviceability Index of the First Real Bridge for All Scenarios

\begin{tabular}{|c|c|c|c|c|c|c|c|c|c|c|c|c|}
\hline \multicolumn{19}{|c|}{ Tatigue Serviceability Index } \\
\hline & \multicolumn{9}{|c|}{ 9-Axle Turnpike Double (Scenario II) } & \multicolumn{5}{c|}{ SU4 (Scenario III) } \\
\hline & 0.02 & 0.04 & 0.06 & 0.08 & 0.02 & 0.04 & 0.06 & 0.08 & 0.02 & 0.04 & 0.06 & 0.08 \\
\hline 5 & 0.52 & 0.37 & 0.30 & 0.25 & 0.36 & 0.28 & 0.23 & 0.19 & 0.54 & 0.38 & 0.31 & 0.26 \\
\hline 10 & 0.51 & 0.36 & 0.29 & 0.25 & 0.35 & 0.27 & 0.22 & 0.19 & 0.53 & 0.38 & 0.30 & 0.25 \\
\hline 20 & 0.49 & 0.36 & 0.29 & 0.24 & 0.32 & 0.25 & 0.21 & 0.19 & 0.52 & 0.37 & 0.30 & 0.25 \\
\hline 30 & 0.48 & 0.36 & 0.28 & 0.24 & 0.29 & 0.24 & 0.21 & 0.19 & 0.50 & 0.36 & 0.30 & 0.25 \\
\hline 40 & 0.46 & 0.35 & 0.28 & 0.24 & 0.28 & 0.23 & 0.21 & 0.19 & 0.49 & 0.36 & 0.29 & 0.25 \\
\hline 50 & 0.43 & 0.35 & 0.28 & 0.24 & 0.26 & 0.23 & 0.20 & 0.19 & 0.48 & 0.36 & 0.29 & 0.25 \\
\hline
\end{tabular}


Table 40. Remaining Fatigue Life of the Second Real Bridge for All Scenarios

\begin{tabular}{|c|c|c|c|c|c|c|c|c|c|c|c|c|}
\hline \multicolumn{10}{|c|}{ Temaining Fatigue Life in years } \\
\hline & \multicolumn{10}{|c|}{ 9-Axle Turnpike Double (Scenario II) } & \multicolumn{5}{c|}{ SU4 (Scenario III) } \\
\hline & 0.02 & 0.04 & 0.06 & 0.08 & 0.02 & 0.04 & 0.06 & 0.08 & 0.02 & 0.04 & 0.06 & 0.08 \\
\hline & & & & & & & & & & & & \\
\hline
\end{tabular}

Table 41. Fatigue Serviceability Index of the Second Real Bridge for All Scenarios

\begin{tabular}{|c|c|c|c|c|c|c|c|c|c|c|c|c|}
\hline \multicolumn{19}{|c|}{ Tatigue Serviceability Index } \\
\hline & \multicolumn{9}{|c|}{ 9-Axle Turnpike Double (Scenario II) } & \multicolumn{5}{c|}{ SU4 (Scenario III) } \\
\hline & 0.02 & 0.04 & 0.06 & 0.08 & 0.02 & 0.04 & 0.06 & 0.08 & 0.02 & 0.04 & 0.06 & 0.08 \\
\hline 5 & 0.78 & 0.71 & 0.53 & 0.43 & 0.78 & 0.62 & 0.47 & 0.38 & 0.78 & 0.62 & 0.46 & 0.38 \\
\hline 10 & 0.76 & 0.71 & 0.53 & 0.43 & 0.75 & 0.62 & 0.46 & 0.38 & 0.75 & 0.61 & 0.46 & 0.38 \\
\hline 20 & 0.71 & 0.66 & 0.53 & 0.43 & 0.69 & 0.62 & 0.46 & 0.38 & 0.69 & 0.61 & 0.46 & 0.38 \\
\hline 30 & 0.67 & 0.60 & 0.53 & 0.43 & 0.64 & 0.58 & 0.46 & 0.38 & 0.64 & 0.58 & 0.46 & 0.38 \\
\hline 40 & 0.63 & 0.56 & 0.50 & 0.43 & 0.60 & 0.53 & 0.46 & 0.38 & 0.60 & 0.53 & 0.46 & 0.38 \\
\hline 50 & 0.60 & 0.52 & 0.46 & 0.42 & 0.57 & 0.49 & 0.43 & 0.38 & 0.57 & 0.49 & 0.43 & 0.38 \\
\hline
\end{tabular}


Table 42. Remaining Fatigue Life of the Three Span Continuous Real Bridge for All Scenarios

\begin{tabular}{|c|c|c|c|c|c|c|c|c|c|c|c|c|}
\hline \multicolumn{13}{|c|}{ Remaining Fatigue Life in years } \\
\hline & \multicolumn{4}{|c|}{ Type 3S2 (Scenario I) } & \multicolumn{4}{|c|}{ 9-Axle Turnpike Double (Scenario II) } & \multicolumn{4}{|c|}{ SU4 (Scenario III) } \\
\hline $\mathrm{a}$ & 0.02 & 0.04 & 0.06 & 0.08 & 0.02 & 0.04 & 0.06 & 0.08 & 0.02 & 0.04 & 0.06 & 0.08 \\
\hline 5 & 60 & 43 & 35 & 29 & 51 & 38 & 31 & 26 & 57 & 42 & 34 & 29 \\
\hline 10 & 59 & 43 & 34 & 29 & 49 & 37 & 30 & 26 & 56 & 41 & 33 & 28 \\
\hline 20 & 56 & 42 & 34 & 29 & 46 & 36 & 30 & 26 & 54 & 40 & 33 & 28 \\
\hline 30 & 54 & 41 & 33 & 29 & 44 & 35 & 29 & 25 & 51 & 39 & 32 & 28 \\
\hline 40 & 52 & 40 & 33 & 29 & 42 & 34 & 29 & 25 & 50 & 39 & 32 & 28 \\
\hline 50 & 51 & 40 & 33 & 29 & 40 & 34 & 29 & 25 & 48 & 38 & 32 & 28 \\
\hline
\end{tabular}

Table 43. Fatigue Serviceability Index of the Three Span Continuous Real Bridge for All Scenarios

\begin{tabular}{|c|c|c|c|c|c|c|c|c|c|c|c|c|}
\hline \multicolumn{13}{|c|}{ Fatigue Serviceability Index } \\
\hline & \multicolumn{4}{|c|}{ Type 3 S2 (Scenario I) } & \multicolumn{4}{|c|}{ 9-Axle Turnpike Double (Scenario II) } & \multicolumn{4}{|c|}{ SU4 (Scenario III) } \\
\hline a $\quad g$ & 0.02 & 0.04 & 0.06 & 0.08 & 0.02 & 0.04 & 0.06 & 0.08 & 0.02 & 0.04 & 0.06 & 0.08 \\
\hline 5 & 0.49 & 0.35 & 0.28 & 0.23 & 0.41 & 0.31 & 0.25 & 0.21 & 0.46 & 0.34 & 0.28 & 0.23 \\
\hline 10 & 0.48 & 0.35 & 0.28 & 0.23 & 0.40 & 0.30 & 0.24 & 0.21 & 0.45 & 0.33 & 0.27 & 0.23 \\
\hline 20 & 0.45 & 0.34 & 0.28 & 0.23 & 0.37 & 0.29 & 0.24 & 0.21 & 0.44 & 0.32 & 0.27 & 0.23 \\
\hline 30 & 0.44 & 0.33 & 0.27 & 0.23 & 0.36 & 0.28 & 0.23 & 0.20 & 0.41 & 0.32 & 0.26 & 0.23 \\
\hline 40 & 0.42 & 0.32 & 0.27 & 0.23 & 0.34 & 0.28 & 0.23 & 0.20 & 0.41 & 0.32 & 0.26 & 0.23 \\
\hline 50 & 0.41 & 0.32 & 0.27 & 0.23 & 0.32 & 0.28 & 0.23 & 0.20 & 0.39 & 0.31 & 0.26 & 0.23 \\
\hline
\end{tabular}




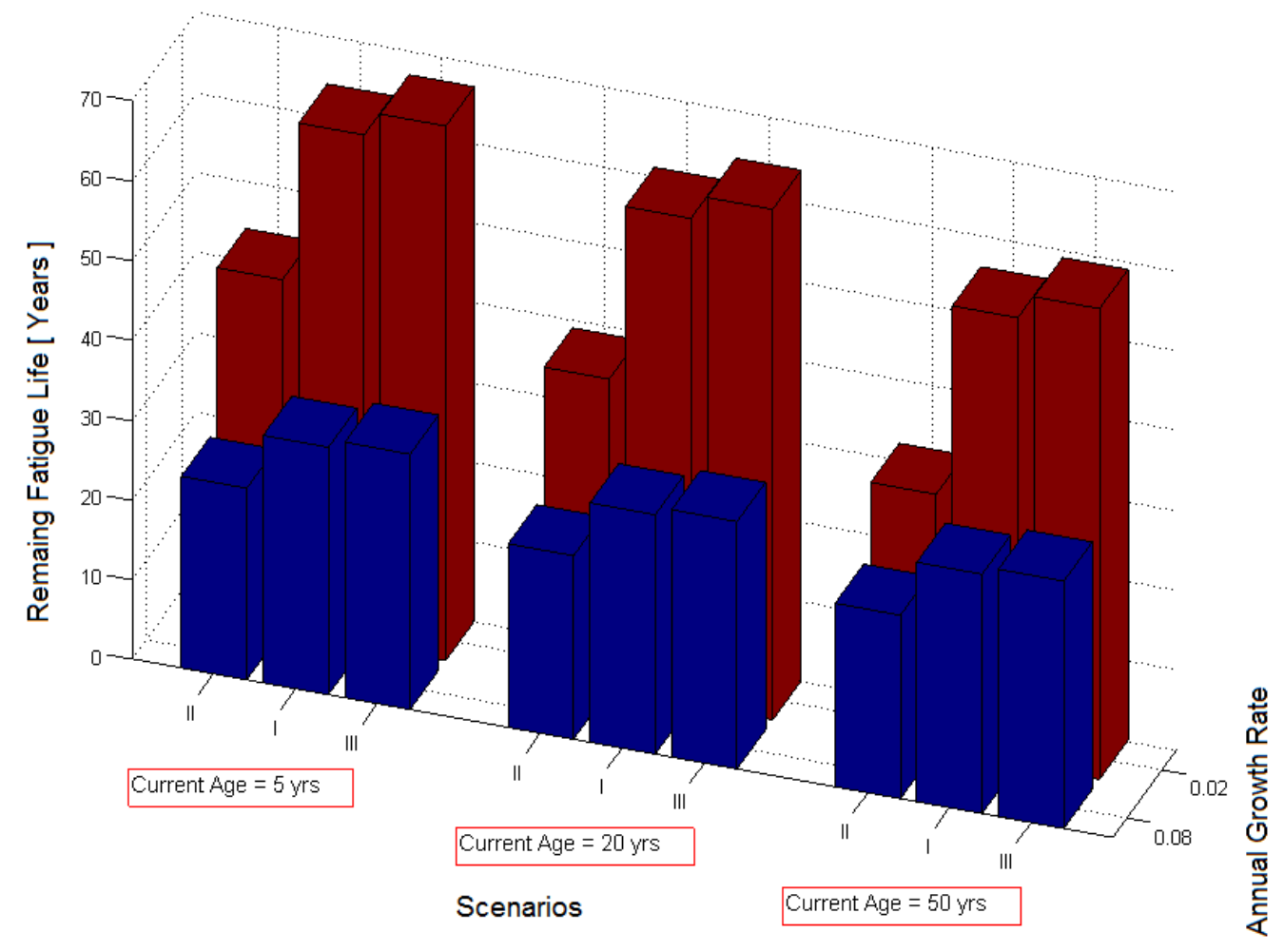

Figure 94. Remaining Fatigue Life of All Scenarios for First Real Bridge

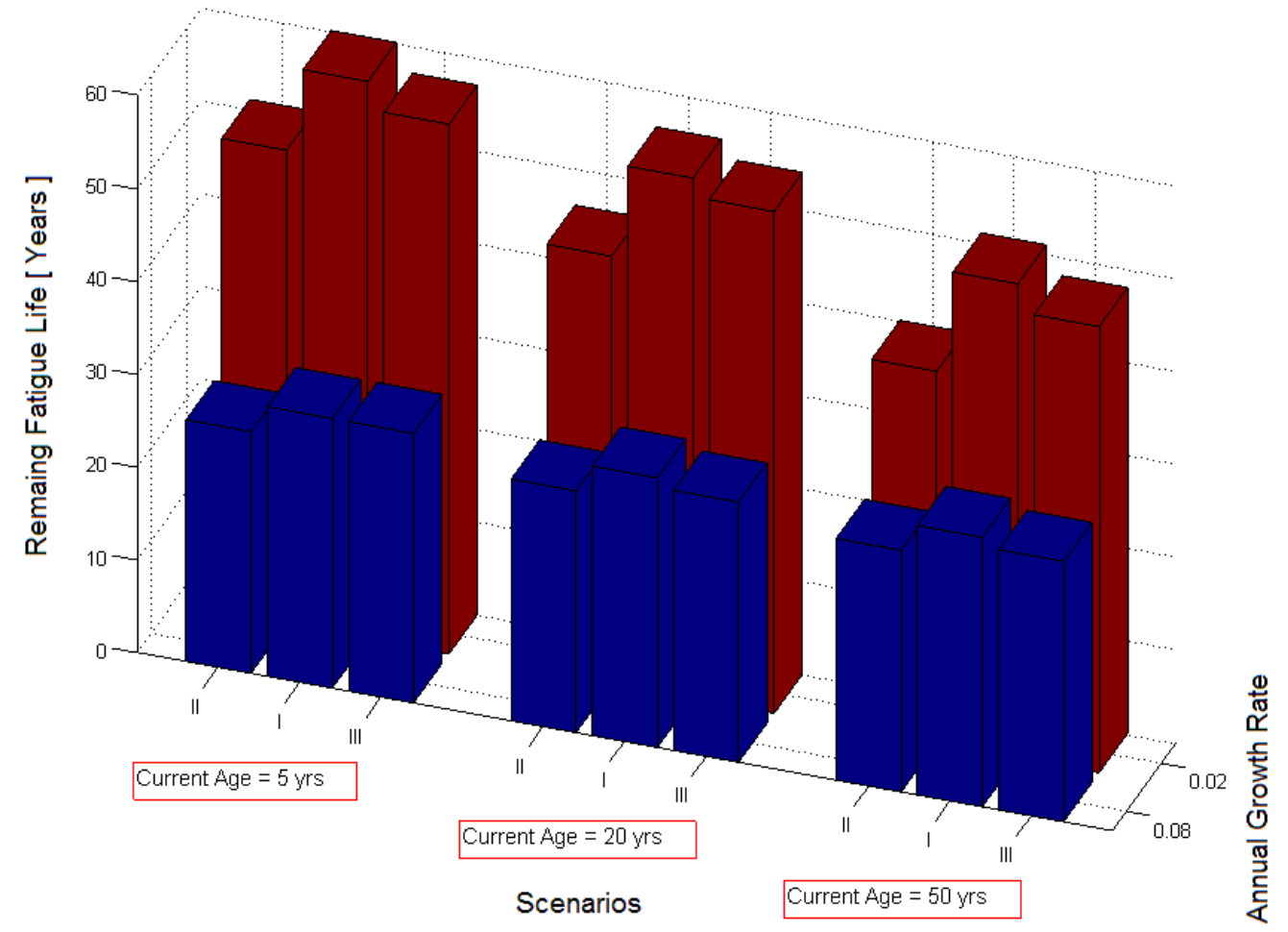

Figure 95. Remaining Fatigue Life of All Scenarios for Three Span Real Bridge 
Table 44. Fatigue Rating of All Three Real Bridges for All Scenarios

\begin{tabular}{|c|c|c|c|c|c|c|c|c|c|c|c|c|}
\hline \multicolumn{13}{|c|}{ Fatigue Rating } \\
\hline & \multicolumn{4}{|c|}{ Type 352 (Scenario I) } & \multicolumn{4}{|c|}{ 9-Axle Turnpike Double (Scenario II) } & \multicolumn{4}{|c|}{ SU4 (Scenario III) } \\
\hline$a^{g}$ & 0.02 & 0.04 & 0.06 & 0.08 & 0.02 & 0.04 & 0.06 & 0.08 & 0.02 & 0.04 & 0.06 & 0.08 \\
\hline \multicolumn{13}{|c|}{ First Real Bridge } \\
\hline 5 & Excellent & Good & Moderate & Moderate & Good & Moderate & Moderate & Fair & Excellent & Good & Moderate & Moderate \\
\hline 10 & Excellent & Good & Moderate & Moderate & Moderate & Moderate & Moderate & Fair & Excellent & Good & Moderate & Moderate \\
\hline 20 & Good & Good & Moderate & Moderate & Moderate & Moderate & Moderate & Fair & Excellent & Good & Moderate & Moderate \\
\hline 30 & Good & Good & Moderate & Moderate & Moderate & Moderate & Moderate & Fair & Excellent & Good & Moderate & Moderate \\
\hline 40 & Good & Moderate & Moderate & Moderate & Moderate & Moderate & Moderate & Fair & Good & Good & Moderate & Moderate \\
\hline 50 & Good & Moderate & Moderate & Moderate & Moderate & Moderate & Moderate & Fair & Good & Good & Moderate & Moderate \\
\hline \multicolumn{13}{|c|}{ Second Real Bridge } \\
\hline 5 & Excellent & Excellent & Excellent & Good & Excellent & Excellent & Good & Good & Excellent & Excellent & Good & Good \\
\hline 10 & Excellent & Excellent & Excellent & Good & Excellent & Excellent & Good & Good & Excellent & Excellent & Good & Good \\
\hline 20 & Excellent & Excellent & Excellent & Good & Excellent & Excellent & Good & Good & Excellent & Excellent & Good & Good \\
\hline 30 & Excellent & Excellent & Excellent & Good & Excellent & Excellent & Good & Good & Excellent & Excellent & Good & Good \\
\hline 40 & Excellent & Excellent & Excellent & Good & Excellent & Excellent & Good & Good & Excellent & Excellent & Good & Good \\
\hline 50 & Excellent & Excellent & Good & Good & Excellent & Good & Good & Good & Excellent & Good & Good & Good \\
\hline \multicolumn{13}{|c|}{ Three Span Continuous Real Bridge } \\
\hline 5 & Good & Moderate & Moderate & Moderate & Good & Moderate & Moderate & Moderate & Good & Moderate & Moderate & Moderate \\
\hline 10 & Good & Moderate & Moderate & Moderate & Good & Moderate & Moderate & Moderate & Good & Moderate & Moderate & Moderate \\
\hline 20 & Good & Moderate & Moderate & Moderate & Good & Moderate & Moderate & Moderate & Good & Moderate & Moderate & Moderate \\
\hline 30 & Good & Moderate & Moderate & Moderate & Good & Moderate & Moderate & Moderate & Good & Moderate & Moderate & Moderate \\
\hline 40 & Good & Moderate & Moderate & Moderate & Moderate & Moderate & Moderate & Moderate & Good & Moderate & Moderate & Moderate \\
\hline 50 & Good & Moderate & Moderate & Moderate & Moderate & Moderate & Moderate & Moderate & Good & Moderate & Moderate & Moderate \\
\hline
\end{tabular}




\section{SUMMARY AND CONCLUSIONS}

In this dissertation, the effects of different types of vehicles on the dynamic response of bridges were studied. Dynamic models and equations of motion, describing the dynamic model of eleven different types of truck were developed. The list of trucks included the currently widely used trucks such as Type $3 S 2$ (FDOT Truck) in addition to some Longer Combination Vehicles (LCV) that can carry much heavier loads but are not being used as often as the other truck types. The simple truck models had been verified in some previous reports and same modeling techniques were used in this research for the LCVs and other new trucks.

In order to model the road surface condition, Power Spectral Density was used to develop different types of road surface conditions. Two different types of bridges (Prestressed Concrete Bridges and Steel Bridges) with five different span lengths ranging from $30 \mathrm{ft}$. to $140 \mathrm{ft}$. were designed based on the current bridge design code. In addition, to study real bridges and continuous bridges, two single span simply supported bridges and a continuous three span bridge were used. The bridge models then were created using the Grid System for all ten different bridges. These models were created in the MATLAB software. The designed bridges were verified by comparing their first natural frequency results to those of first two real bridges.

Using the mass, stiffness and damping matrices of each bridge and also the ODE solver in MATLAB, the different dynamic responses of the bridge such as the deflection and the moment at different points of the bridge were calculated. The interaction between the bridge and the vehicle was also taken into account and time history of different responses of the bridges when different types of trucks were traveling on the bridges 
was recorded. The maximum dynamic forces in the truck tires and suspensions were also obtained.

In the first part, the effects of the trucks traveling on the road and not on the bridge were studied. Two different sets of analysis were performed in order to understand the effects of Long Combination Vehicles (LCVs) on the road surfaces. Different road surface conditions ranging from Very Good to Poor were used in the first part to study the effects of different vehicle categories on the pavement. Impact Factor defined as the ratio between the maximum dynamic and static force in the truck tires was used as an indicator of the vehicle response and it was observed that the values of impact factor could get very high in some cases of poor surface conditions. These values increased when the road surface condition got worse. The values of impact factors were higher for the lighter axles in most cases. The vehicle speed and the vehicle responses was not clearly related. The LCVs had the highest values of impact factor among the three vehicle categories for the better surface conditions but they resulted in smaller impact factors in the relatively worse surface conditions. In the second set of analysis, the effect of a single bump on the road was studied to understand the stability of vehicle models in addition to the impact factors due to bumps. Three different sizes for the bump were used ranging from 1/2" to 2 ". The results showed a good agreement with the conclusions made from the first set. As the bump size got higher the Impact factors got larger for all trucks and LCVs generated the highest values of impact factor, comparing to the other two truck categories, in the cases of small bumps and smallest values in the case of largest bump.

In the second part, the effects of the trucks traveling on the designed bridge were investigated. Different types of results were obtained when calculating the Dynamic 
Amplification Factor (DAF) of the designed bridges. The axle with maximum static load was chosen to calculate DAF. The larger trucks resulted in the smallest values of DAF when traveling on the bridge with Good and Very Good road surface conditions. The Single Unit Trucks resulted in the highest values of DAF in the bridges and the LCVs resulted in the smallest values of DAF.

The reason for the highest values of DAF in the case of Single Unit Trucks category is that the weight of the axles can be higher than the other two cases as it can be seen in the cases of the H-20 and HS-20 trucks. Another factor is that the load is distributed over a smaller length which causes more concentration of load and higher DAFs.

In almost all the cases where the Good and Very Good surface condition were used, the values of DAF were smaller than the $33 \%$ which is suggested by the AASHTO LRFD Design Specifications.

The reason for the difference between the results of the trucks travelling on the road and the bridge can be sought in the interaction of the bridge and the vehicle and the fact that when heavy axles are on the bridge they can cause large displacements on the bridge, which effects the vehicle, where on a road surface, no significant displacement occurs in the pavement and the only input for the vehicle tires is the road surface profile.

The moment created by the passage of the trucks were also recorded and as expected for the longer bridges where all the axles of the trucks happen to be on the bridge, the largest values of moment were achieved. The values for the moment were used to calculate the amount of flexural stress in the bridge members.

In the third part, the dynamic effects of trucks travelling on the real bridges were inspected using two single span simply supported and one three span continuous 
bridges. High frequency results were observed in the case of the Single Unit Trucks comparing to the low frequency results which happened in the case of Truck and Double Trailers. The results for the first and second real bridges which were single span and simply supported show a lot of similarities to the previously designed bridges. Except for a few cases that LCVs show higher DAF values when travelling on higher speeds, the Single Unit Trucks showed the highest values of DAF. In the case of the third real bridge (the three span continuous bridge), the Truck and Double Trailers show slightly higher results in the cases of high and low vehicle speeds on the Very Good surface condition. On the other hand, in the case of Good surface condition, the Single Unit Trucks show the highest values of DAF.

In the Fourth part, fatigue analysis as a measure of the remaining life of the bridges was performed. This analysis was carried out for the designed steel bridge and also the reinforced concrete deck. The formula mentioned in the NCHRP Report 495 [32] for the remaining life of the bridges was used to understand the current status of the bridge. Also a newly suggested factor called Fatigue Serviceability Index (FSI), which is a qualitative measure of bridge fatigue life, was used to study the current state of older bridges [34].

Three different scenarios for the fatigue evaluation of the steel and prestressed concrete bridges were assumed. Some Weigh in Motion (WIM) data reported in the state of Wisconsin [36] was used to find the better option. In the first option, the current traffic on the roads was used to determine the remaining life of the bridge. In the second one, it was assumed that all the Type $3 S 2$ trucks, which formed the majority of the trucks on the road, were replaced by less number of heavier LCV's such as 9-Axle Turnpike Double in a way that the same amount of freight was moved. A third scenario of replacing the Type 
$3 S 2$ trucks with a Single Unit Trucks such as SU4 was also investigated which turned out to be the worst option of all. It was observed that using the larger vehicle (second scenario), in some cases does not change the remaining fatigue life of the bridges and in some cases it slightly decreases the bridge life but this change is not too big to throw away the option of using larger and longer vehicles and in fact using the Fatigue Serviceability Index $(\mathrm{FSI})$, there is almost no change in the Fatigue rating for the two cases.

Different trend was seen when dealing with the reinforced concrete deck fatigue and the remaining fatigue life of the second scenario was higher than the first scenario. In general, the results showed that the future state of the bridges will be improved by using the longer combination vehicles.

In the fifth part, the fatigue assessment of the three real bridges was performed. Same approach and scenarios, which were used for the designed bridges, were employed to calculate the remaining fatigue life of the three real bridges. For the first and second real bridges, using the second scenario did not result in same results as the first scenario and the remaining fatigue life was decreased and the fatigue rating was slightly decreased. In the third real bridge, the second scenario caused the lowest values for the remaining fatigue life but the difference between the three scenarios was not that big and in fact the fatigue ratings of all three scenarios were the same.

To sum up, the results of the remaining fatigue life of the designed and real bridges showed that using Longer Combination Vehicles (LCVS) instead of the regular trucks might in some cases, damage the bridges to some extent, but the multiple environmental and transportational benefits which come from using these larger trucks can outweigh the disadvantages and now that the demand for the freight shipping is going through a 
quick rise, considering the option of using these trucks can help decision makers deal with this issue. Further cost-benefit analysis, including all the environmental, transportational and structural aspects needs to be performed in order to have easier decision making process. 


\section{LIST OF REFERENCES}

[1] U.S. Department of Transportation, "Comprehensive Truck Size and Weight Study Vol. 1," Federal Highway Administration (FHWA), 2000. [Online]. Available: http://www.fhwa.dot.gov/reports/tswstudy/TSWfinal.htm.

[2] Adams, T. et al., "Longer Combination Vehicles: An Estimation of their Benefits and Public Perception of their Use", NationalCenter for Freight \& Infrastructure Research \& Education, University of Wisconsin-Madison, 2012.

[3] Luskin, D.M. and Walton, C.M., "Effects of Truck Size and weights on Highway Infrastructure and operations: A Synthesis Report." TxDOT, CTR, ReportFHWA/TX-0-2122-1, 2001.

[4] USDOT, "Comprehensive Truck Size and Weight Study: Volume II, Issues and Background", Publication FHWA-PL-00-029 (Volume II), USDOT, 2000.

[5] USDOT, "Comprehensive Truck Size and Weight Study, Vol. III: Scenario Analysis", Publication FHWA-PL-00-029 (Volume II), USDOT, 2000.

[6] Puppala, A. J.,Archeewa, E.,Hoyos, L. R.,Nazarian. S.,Saride, S., "Recommendations for Design, Construction, and Maintenance of Bridge Approach Slabs: Synthesis Report." Final Report, Texas Department of Transportation, Austin, TX, Report No. FHWA/TX-09/0-6022-1, 186p, 2009.

[7] AASHTO LRFD Bridge Design Specifications, Second ed., Washington, DC, 2012.

[8] Fafard, M., Bennur, M., Savard, M. "A general multi-axle vehicle model to study the bridge-vehicle interaction," Engineering Computation, vol. 14, no. 5, p. 491-508, 1997.

[9] Chatterjee, P.K., Datta, T.K., Surana, C.S. "Vibration of continuous bridges under moving vehicles," Journal of Sound and Vibration, vol. 169, no. 5, p. 619-632, 1994.

[10] Chompooming, K., Yener, M. "The influence of roadway surface irregularities and vehicle deceleration on bridge dynamics using the method of lines," Journal of Sound and Vibration, vol. 183, no. 4, p. 567-589, 1995.

[11] Fafard, M., Savard, M., Bennur, M. "Dynamic analysis of existing continuous bridge," Journal of Bridge Engineering, vol. 3, no. 1, p. 28-37, 1998.

[12] Henchi, K., Fafardm, M., Talbot, M., Dhatt, G. "An efficient algorithm for dynamic analysis of bridges under moving vehicles using a coupled modal and physical components approach," Journal of Sound and Vibration, vol. 212, no. 4, p. 663-683, 1998. 
[13] Wang, T.L., Huang, D.Z., Shahawy, M. "Dynamic response of multi-girder bridges," Journal of Structural, vol. 118, no. 8, p. 2222-2238, 1993.

[14] Law, S.S., Zhu, X.Q. "Bridge dynamic responses due to road surface roughness and braking of vehicle," Journal of Sound and Vibration, vol. 282, p. 805-830, 2005.

[15] Fafard, M., Laflamme, M., Savard, M., Bennur, M. "Dynamic Analysis Of Existing Continuous Bridge," Journal of Bridge Engineering, vol. 3, no. 1, pp. 28-37, 1998.

[16] AASHTO, Standard specifications for highway bridges, Washington (DC), 2002.

[17] Ontario Ministry of Transportation and Communications, Ontario highway bridge design code, Downsview (Ontario), 1983.

[18] Paultre, P., O. Chaallal, and J, Proulx, "Bridge Dynamics and Dynamic Amplification Factors: A Review of Analytical and Experinmental Findings," Canadian Journal of Civil Engineering, Vol.19, No. 2, PP. 260-278, 1992.

[19] David I. McLean, M. Lee Marsh, "NCHRP Synthesis 266, Dynamic Impact Factors for Bridges," Transportation Research Board (TRB), Washington, D.C. 1998.

[20] Liu, C., Huang, D. Z., Wang, T. L., "Analytical Dynamic Impact Study Based on Correlated Road Roughness," Journal of Computers and Structures, vol. 80, pp. 1639-1650, 2002.

[21] Huang, D.Z., Wang, T.L., Shahawy, M. "Impact studies of multigirder concrete bridges," Journal of Structural Engineering, vol. 119, no. 8, pp. 2387-2402, 1993.

[22] Brady, S.P., O'Brien, E.J. and Znidaric, A. "Effect of Vehicle Velocity on the Dynamic Amplification of a Vehicle Crossing a Simply Supported Bridge," Journal of Bridge Engineering, pp. 241-249, 2006.

[23] Wang, T. L., and Huang, D. Z., "Cable-stayed bridge vibration due to road surface roughness."Structural Engineering, ASCE, 118(5), 1354-1374, 1992.

[24] Huang, D. Z., and Wang, T. L., "Impact analysis of cable-stayed bridges."J. Comput. andStruct., 43(5), 897-908, 1992.

[25] Huang, D. Z., Wang, T. L., and Shahaway, M., "Impact analysis of continuous multigirder bridges due to moving vehicles." J. Struct. Engrg., ASCE,3427-3443 , 1992.

[26] Wang, T. L., Shahawy, M., and Huang, D. Z., "Impact in highway prestressed concrete bridges." J. Comput. And Struct., 44(3), 525-534, 1992.

[27] Dodds, C.J., Robson, J.D., "The Description of Road Surface Roughness," Journal of Sound and Vibration, vol. 31, no. 2, pp. 175-183, 1973. 
[28] Honda, H., Kajikawa, Y., Kobori, T. "Spectra of Road Surface Roughness on Bridges," Journal of the Structural Division, ASCE, vol. 108, pp. 1956-1966, 1982.

[29] MATLAB Release R2012a, The Math Works Inc., Natick, Massachusetts, United States.

[30] NHI/FHWA, "Load and Resistance Factor Design (LRFD) for Highway Bridge Superstructures", Design Manual, NHI Course No. 130081, 130081A-130081D, Publication No. FHWA-NHI-07-035, National Highway Institute, Federal Highway Administration, 1982 pp, 2007.

[31] AASHTO, "Guide Specification for Fatigue Evaluation of Existing Steel Bridges," Washington, DC, 1990.

[32] Fu, G., et al., "NCHRP Report 495: Effect of Truck Weight on Bridge Network Costs," Transportation Research Board of the National Academies, Washington, DC, 2003.

[33] AASHTO, Manual for Bridge Evaluation, Second ed., Washington, D.C, 2011.

[34] Bowman, M. D., et al., "NCHRP Report 721: Fatigue Evaluation of Steel Bridges," Transportation Research Board of the National Academies, Washington, DC, 2012.

[35] Miner, M.A., "Cumulative Damage in Fatigue," Journal of Applied Mechanics, Vol. 12, p. A-159, 1945.

[36] Tabatabai, H., et al., "Statistical Analysis of Heavy Truck Loads Using Wisconsin Weigh-In-Motion Data", National Center for Freight \& Infrastructure Research \& Education, University of Wisconsin, Madison, 2009.

[37] Ozgur, C., "Influence of Cross-Frame Detailing on Curved and Skewed Steel IGirder Bridges”, PhD Dissertation, Georgia Institute of Technology, 2011.

[38] Clough, Ray W., Penzien, J., "Dynamics of Structures", Computers \& Structures, Inc., 2003.

[39] Chen, W.F., Duan, L., "Bridge Engineering Handbook", Technology \& Engineering, 2010.

[40] Goel, R.K., "Earthquake Characteristics of Bridges with Integral Abutments", J Struct Eng, 123 (11), pp. 1435-1443, 1997.

[41] Wang, T. L., Huang, D. Z., "Computer Modeling Analysis in Bridge Evaluation", Research Report No. FL/DOT/RMC/0542-3394 submitted to Florida Department of Transportation, 1992. 
APPENDICES 
First Real Bridge (Project Location)

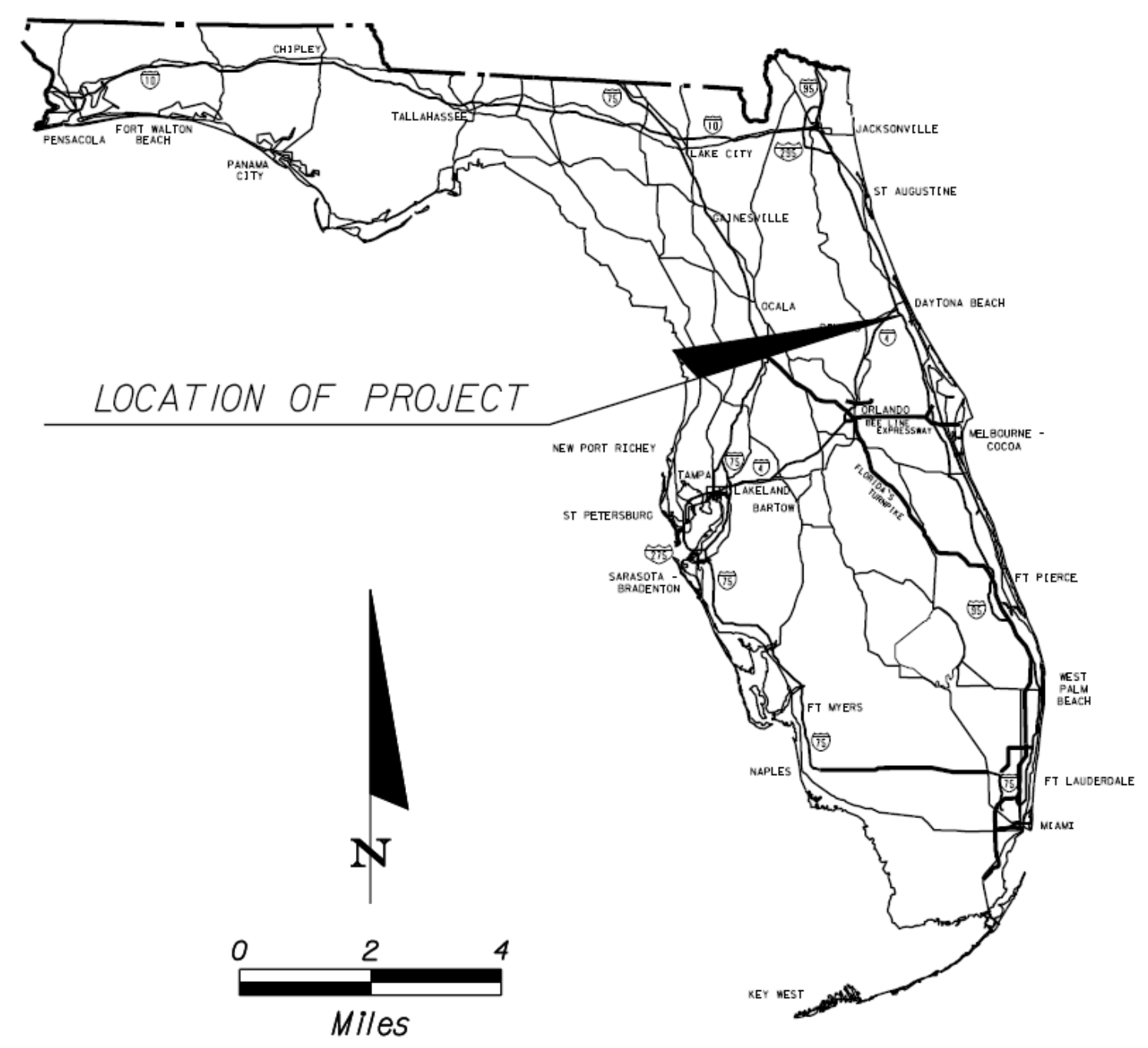


First Real Bridge (Typical Girder Elevation)
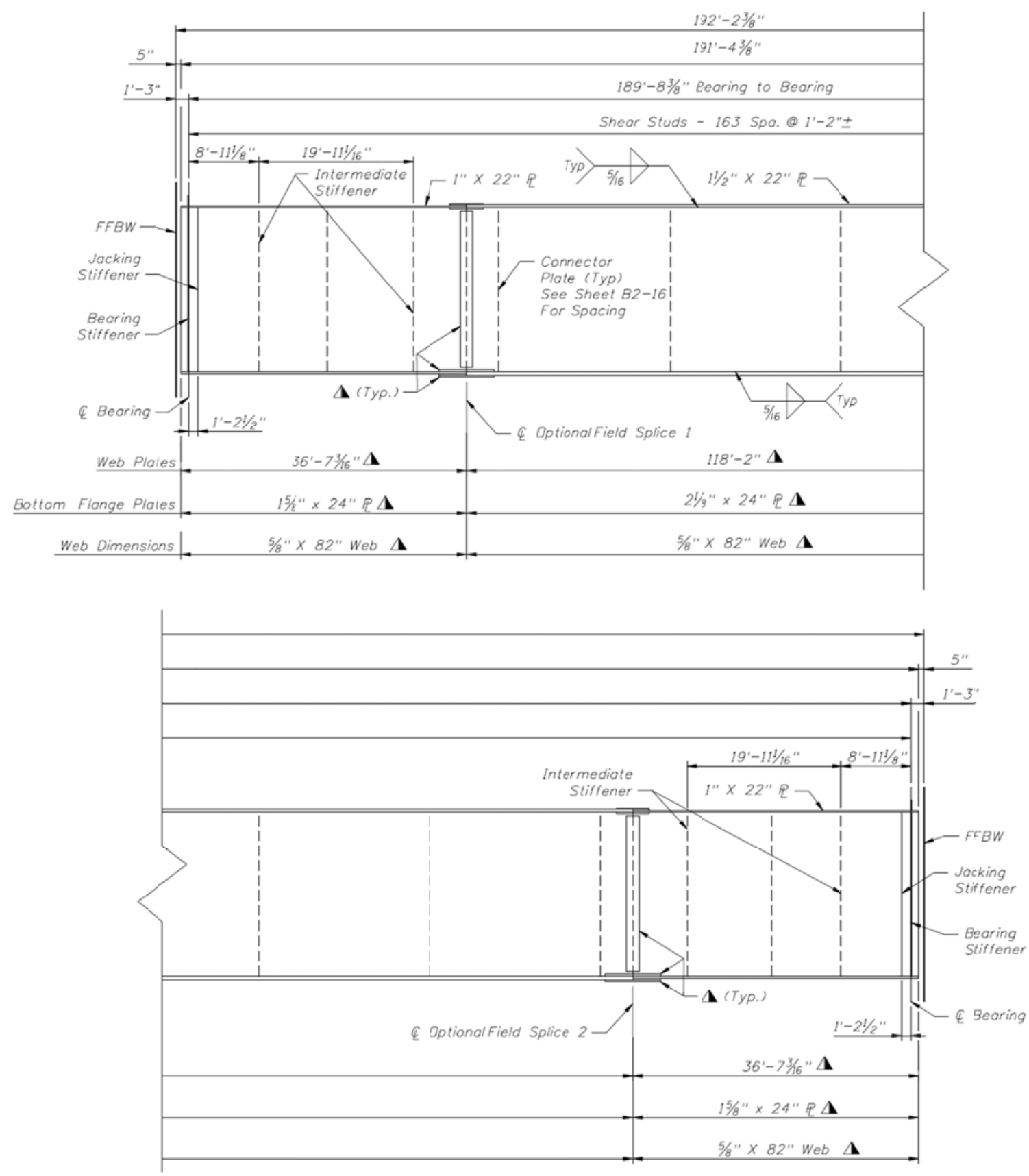
First Real Bridge (Typical Section)

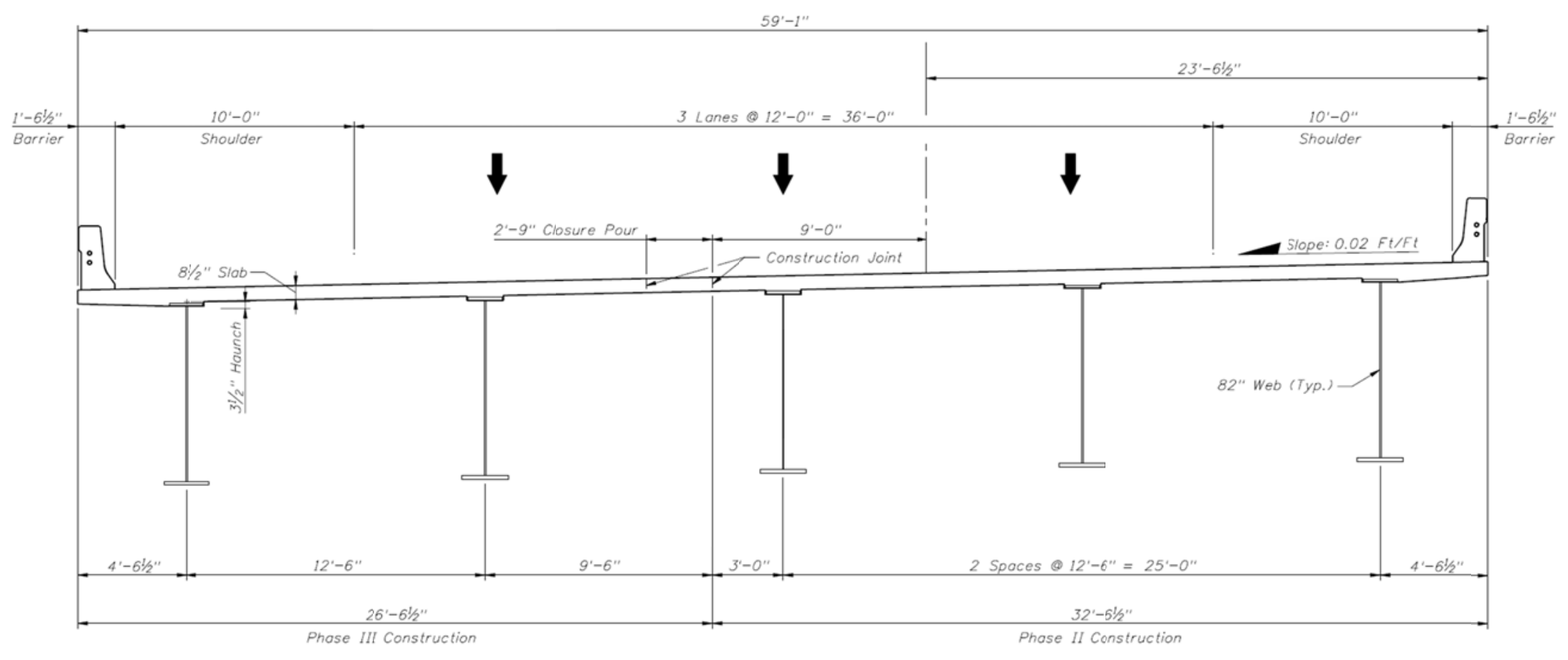


First Real Bridge (Framing Plan)

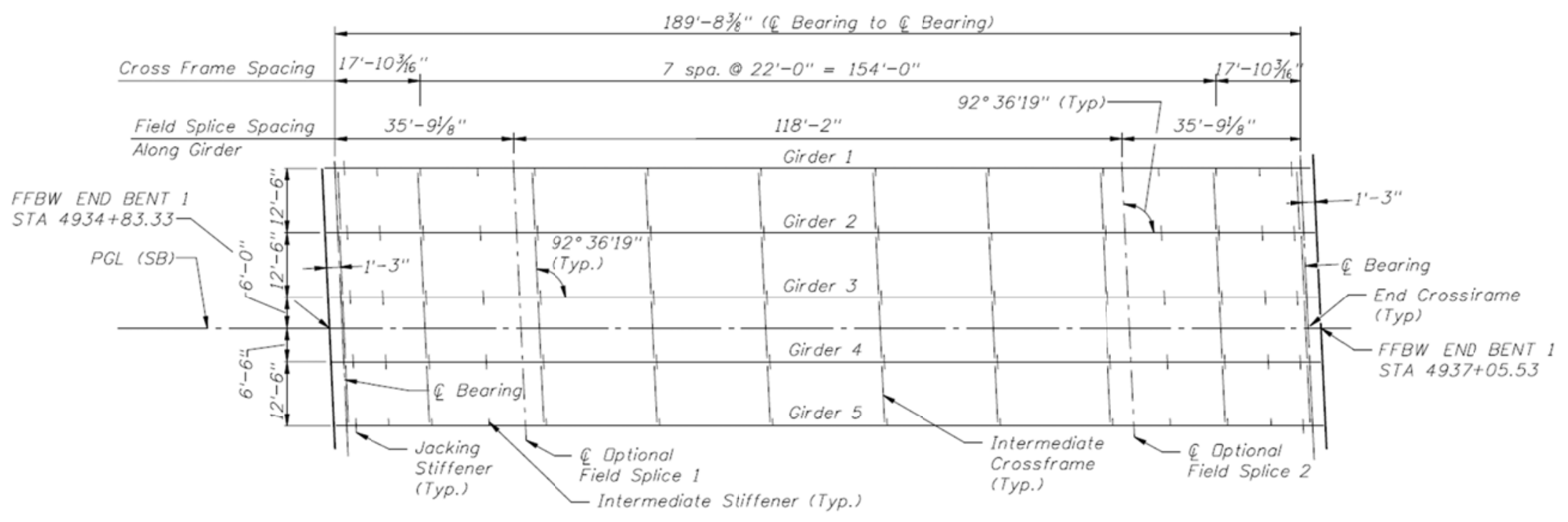


Second Real Bridge (Project Location)

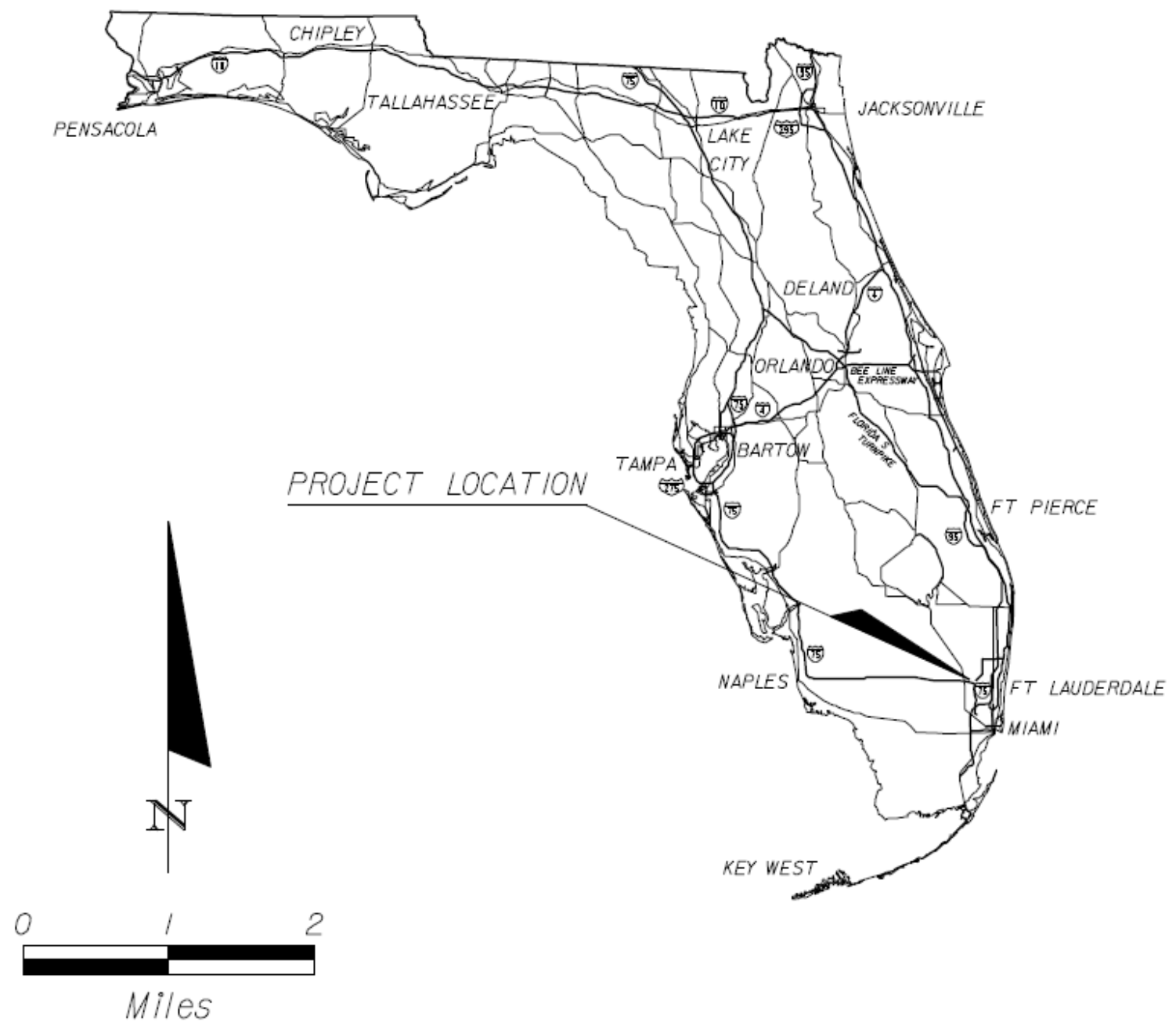


Second Real Bridge (Typical Bridge and $1^{\text {st }} \& 3^{\text {rd }}$ Span Girder Elevations)
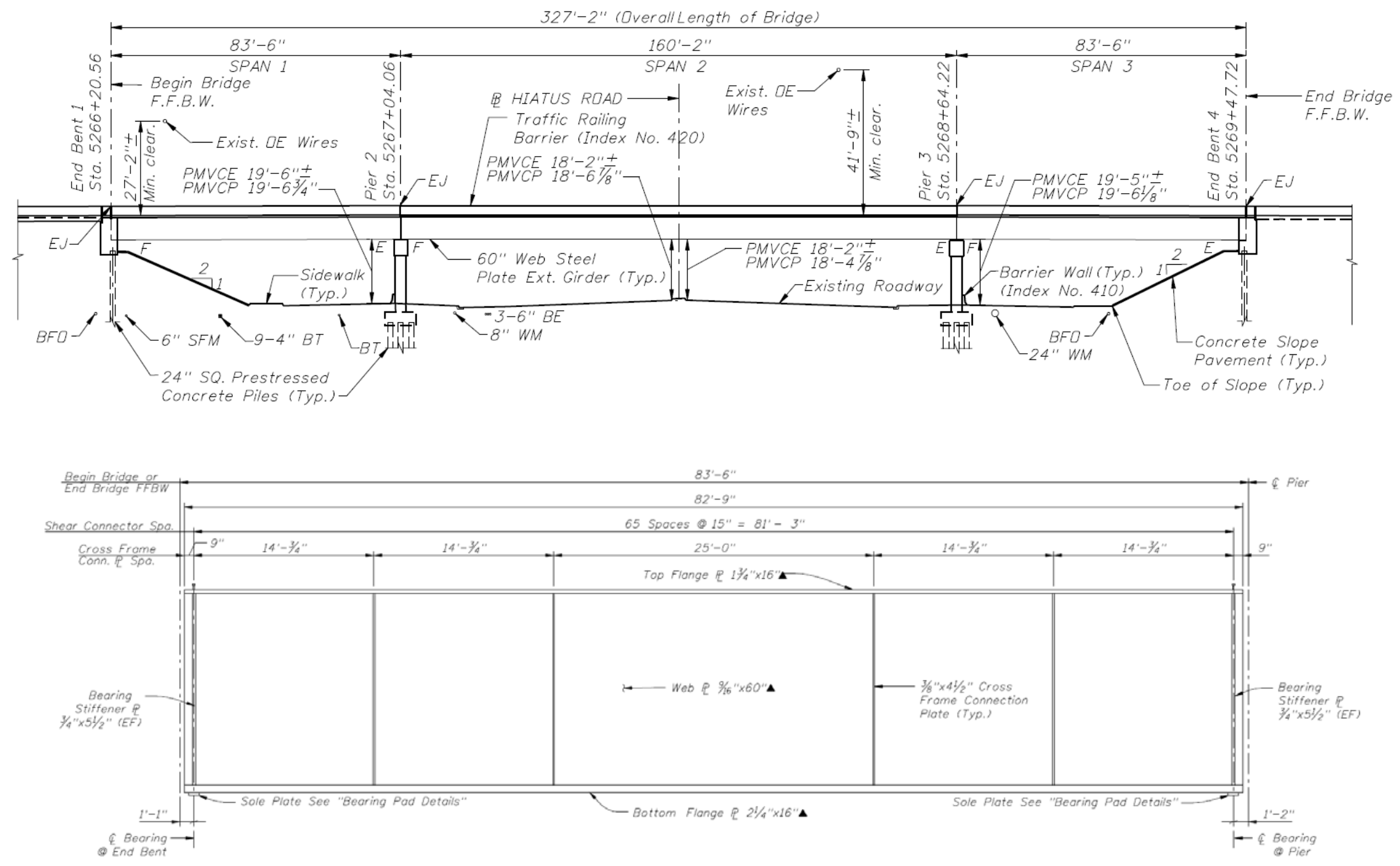
Second Real Bridge (Typical Section of $1^{\text {st }} \& 3^{\text {rd }}$ Spans and Framing Plan)
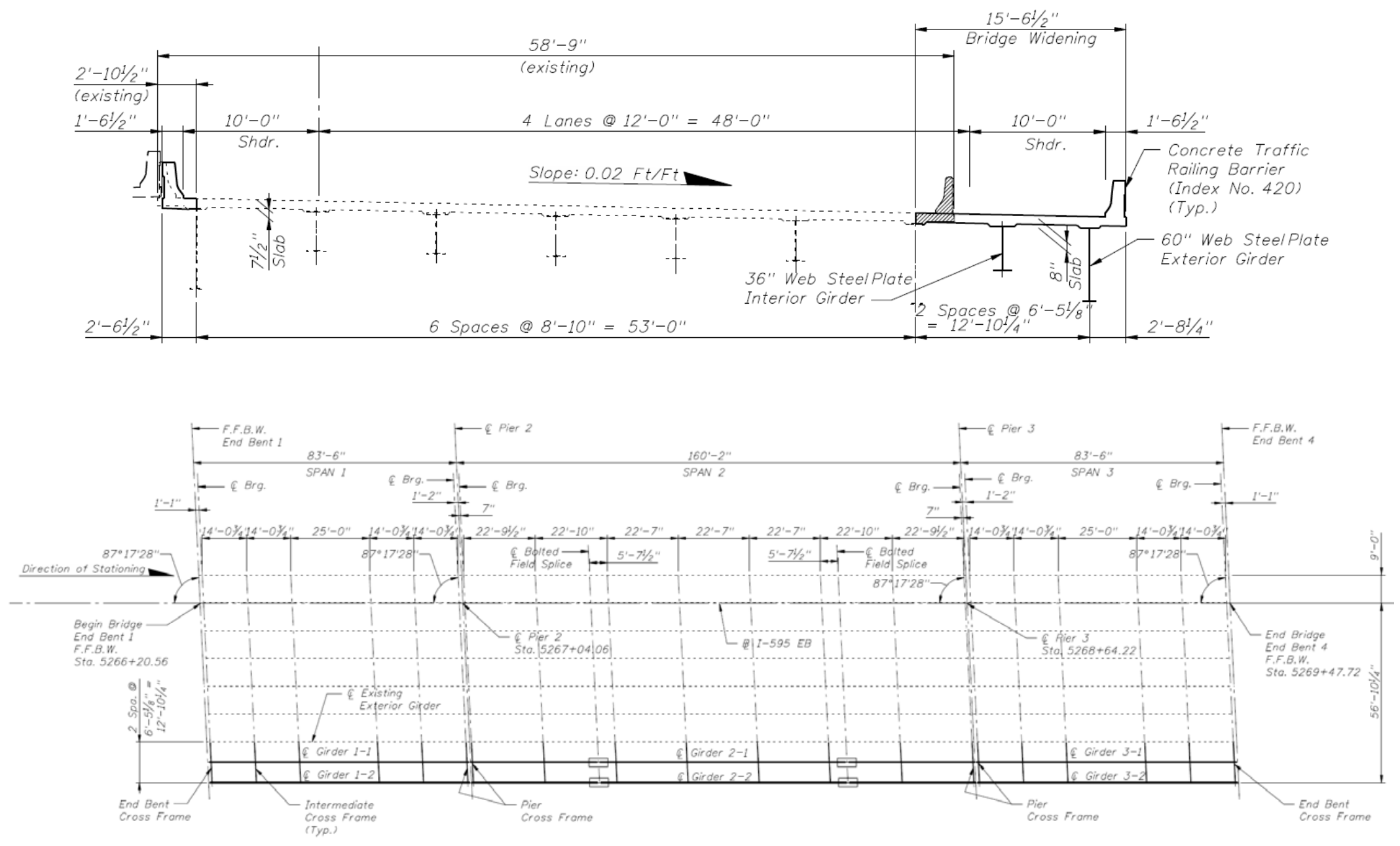
Third Real Bridge (Typical Cross Section) [37]

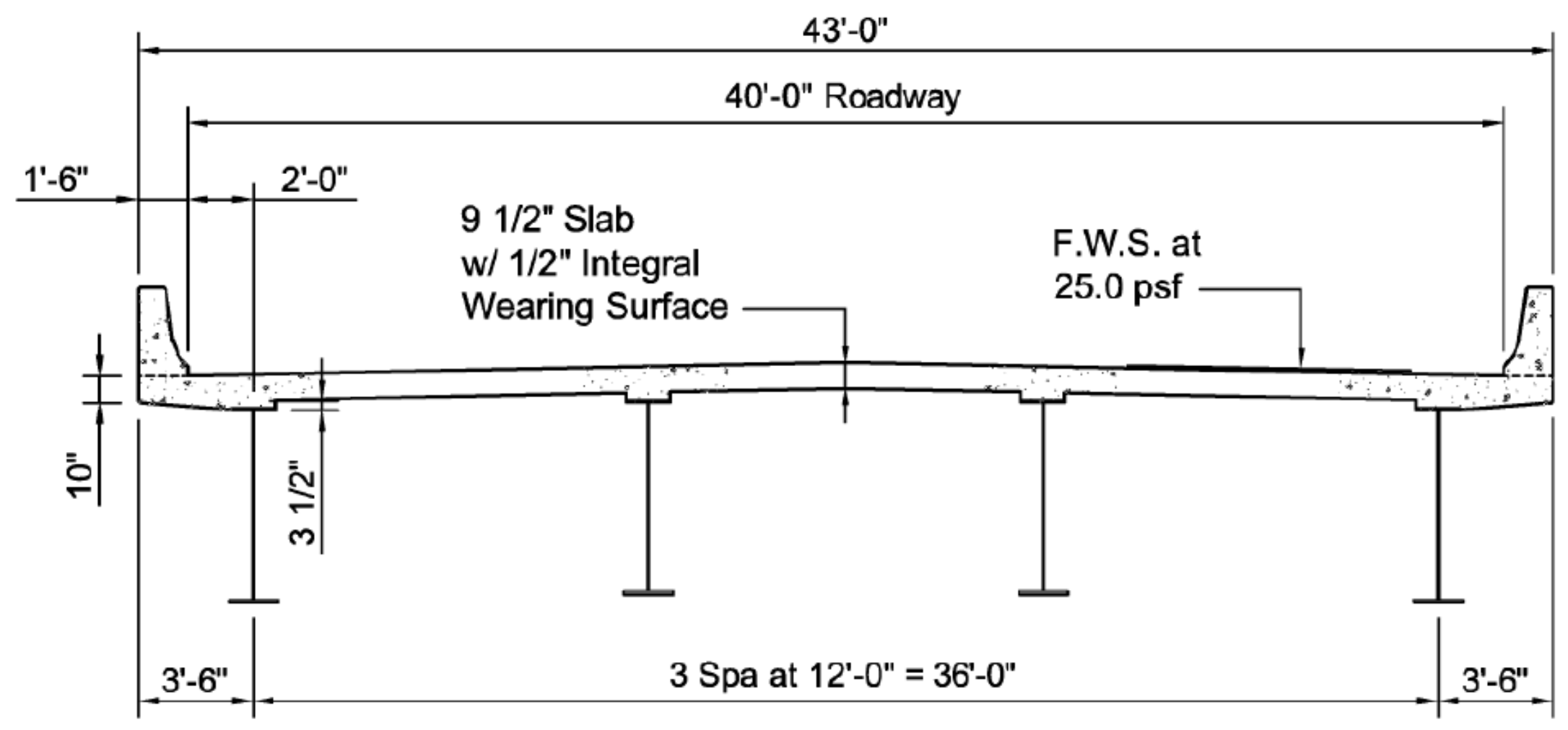


Third Real Bridge (Typical Girder Elevation) [37]
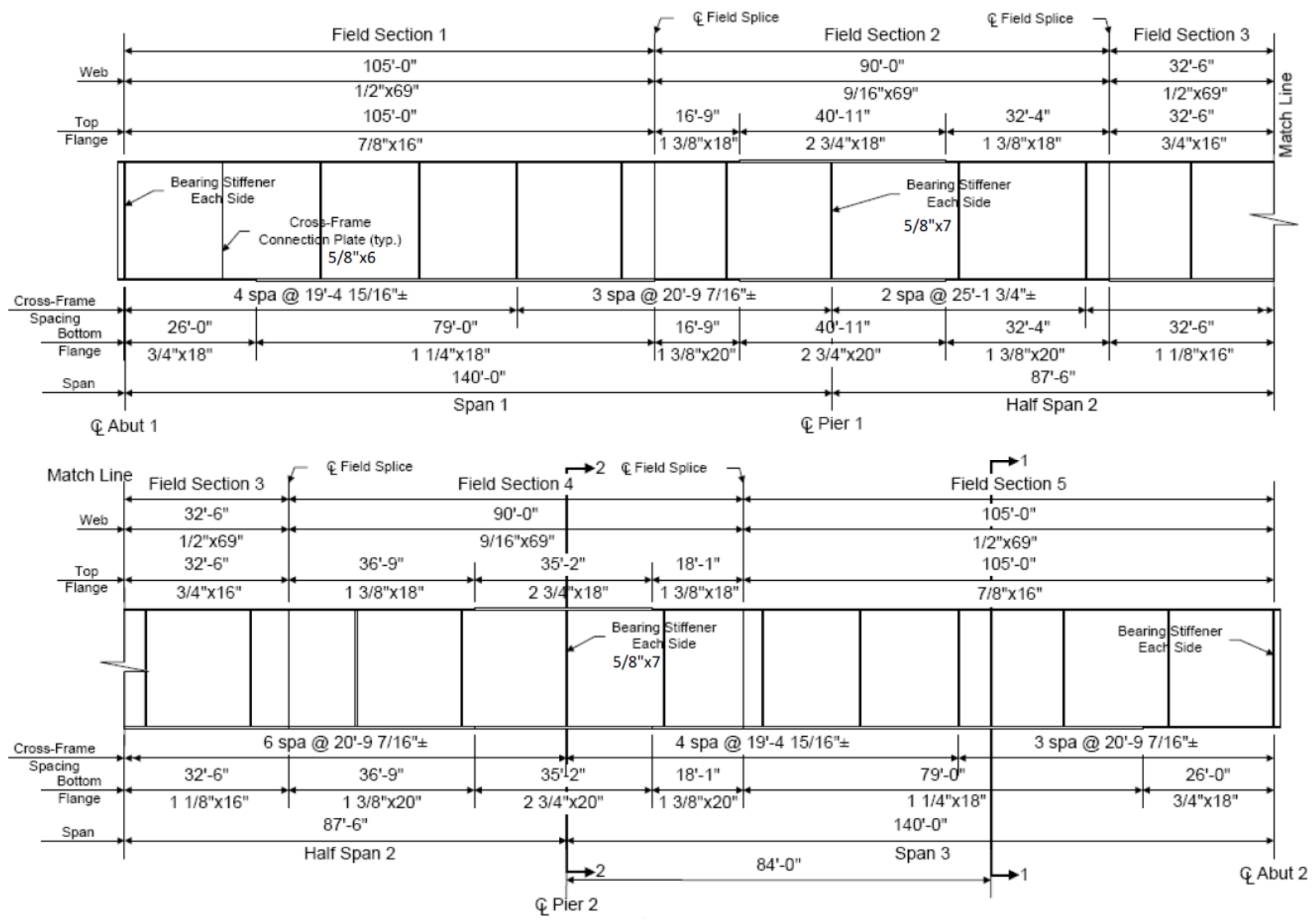
Third Real Bridge (Framing Plan) [37]

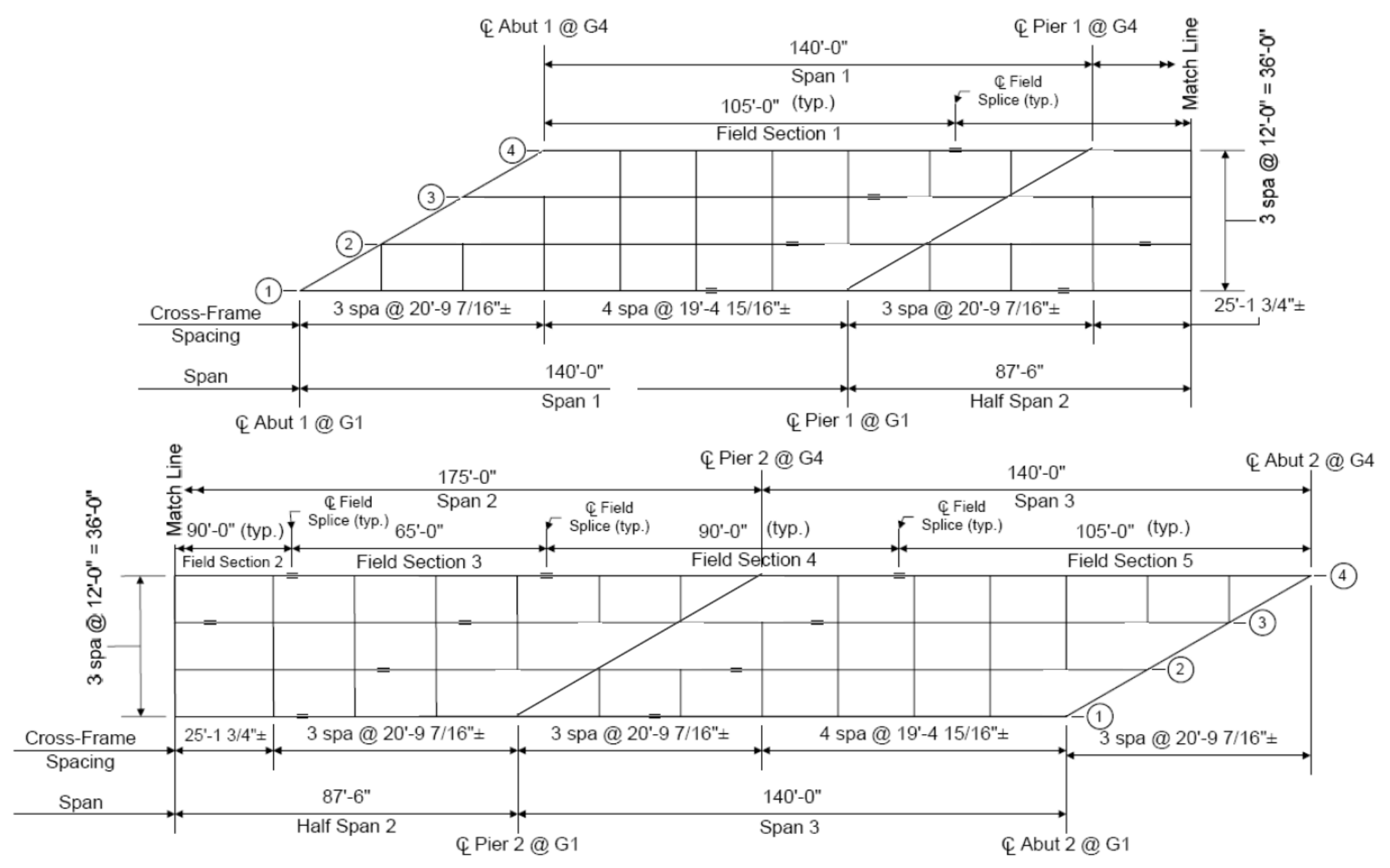




\section{Appendix 2 - Other Vehicles Equations of motion Derivation}

\section{Derivation of Equations of Motion for Type 3 Truck}

There are nine degrees of freedom in total for this type of truck. The degrees of freedom can be seen in Figure 1 and the description of those degrees of freedom can be found in Table 1. Relative Displacements at the locations of the springs are also calculated using the values given in Table 2 .

Table 1. Degrees of Freedom of Type 3 Truck

\begin{tabular}{|c|c|c|l|} 
No. & $\begin{array}{c}\text { Degree of } \\
\text { Freedom }\end{array}$ & $\begin{array}{c}\text { Contributed } \\
\text { Mass }\end{array}$ & \multicolumn{1}{c|}{ Description } \\
$\mathbf{1}$ & $\mathrm{y}_{\mathrm{t} 1}$ & $\mathrm{~m}_{\mathrm{t} 1}$ & Truck vertical displacement and mass \\
$\mathbf{2}$ & $\varphi_{\mathrm{t} 1}$ & $\mathrm{I}_{\mathrm{xt} 1}$ & Truck roll displacement and mass moment of inertia \\
$\mathbf{3}$ & $\theta_{\mathrm{t} 1}$ & $\mathrm{I}_{\mathrm{zt} 1}$ & Truck pitch displacement and mass moment of inertia \\
$\mathbf{4}$ & $\mathrm{y}_{\mathrm{a} 1}$ & $\mathrm{~m}_{\mathrm{a} 1}$ & First axle vertical displacement and mass \\
$\mathbf{5}$ & $\varphi_{\mathrm{a} 1}$ & $\mathrm{I}_{\mathrm{xa} 1}$ & First axle roll displacement and mass moment of inertia \\
$\mathbf{6}$ & $\mathrm{y}_{\mathrm{a} 2}$ & $\mathrm{~m}_{\mathrm{a} 2}$ & Second axle vertical displacement and mass \\
$\mathbf{7}$ & $\varphi_{\mathrm{a} 2}$ & $\mathrm{I}_{\mathrm{xa} 2}$ & Second axle roll displacement and mass moment of inertia \\
$\mathbf{8}$ & $\mathrm{y}_{\mathrm{a} 3}$ & $\mathrm{~m}_{\mathrm{a} 3}$ & Third axle vertical displacement and mass \\
$\mathbf{9}$ & $\varphi_{\mathrm{a} 3}$ & $\mathrm{I}_{\mathrm{xa} 3}$ & Third axle roll displacement and mass moment of inertia \\
\hline
\end{tabular}

Kinetic Energy of the system:

$$
\begin{aligned}
& T=\frac{1}{2} m_{t 1} \dot{y}_{t 1}{ }^{2}+\frac{1}{2} m_{a 1} \dot{y}_{a 1}{ }^{2}+\frac{1}{2} m_{a 2} \dot{y}_{a 2}{ }^{2}+\frac{1}{2} m_{a 3} \dot{y}_{a 3}{ }^{2}+\frac{1}{2} I_{x t 1} \dot{\varphi}_{t 1}{ }^{2}+\frac{1}{2} I_{z t 1} \dot{\theta}_{t 1}{ }^{2}+ \\
& \frac{1}{2} I_{x a 1} \dot{\varphi}_{a 1}{ }^{2}+\frac{1}{2} I_{x a 2} \dot{\varphi}_{a 2}{ }^{2}+\frac{1}{2} I_{x a 3} \dot{\varphi}_{a 3}{ }^{2}
\end{aligned}
$$

Potential Energy of the system:

$$
V=\frac{1}{2} K_{s y 1} U_{s y 1}{ }^{2}+\frac{1}{2} K_{s y 2} U_{s y 2}{ }^{2}+\frac{1}{2} K_{s y 3} U_{s y 3}{ }^{2}+\frac{1}{2} K_{s y 4} U_{s y 4}{ }^{2}+\frac{1}{2} K_{s y 5} U_{s y 5}{ }^{2}+
$$




$$
\begin{aligned}
& \frac{1}{2} K_{s y 6} U_{s y 6}{ }^{2}+\frac{1}{2} K_{t y 1} U_{t y 1}{ }^{2}+\frac{1}{2} K_{t y 2} U_{t y 2}{ }^{2}+\frac{1}{2} K_{t y 3} U_{t y 3}{ }^{2}+\frac{1}{2} K_{t y 4} U_{t y 4}{ }^{2}+ \\
& \frac{1}{2} K_{t y 5} U_{t y 5}{ }^{2}+\frac{1}{2} K_{t y 6} U_{t y 6}{ }^{2}-\left(\left(m_{t 1} g\right) y_{t 1}+\left(m_{a 1} g\right) y_{a 1}+\left(m_{a 2} g\right) y_{a 2}+\right. \\
& \left.\left(m_{a 3} g\right) y_{a 3}\right)+\left(F_{y 1} U_{s y 1}+F_{y 2} U_{s y 2}+F_{y 3} U_{s y 3}+F_{y 4} U_{s y 4}+F_{y 5} U_{s y 5}+F_{y 6} U_{s y 6}\right)
\end{aligned}
$$

Damping Energy of the system:

$$
\begin{aligned}
& D=\frac{1}{2} D_{s y 1} \dot{U}_{s y 1}{ }^{2}+\frac{1}{2} D_{s y 2} \dot{U}_{s y 2}{ }^{2}+\frac{1}{2} D_{s y 3} \dot{U}_{s y 3}{ }^{2}+\frac{1}{2} D_{s y 4} \dot{U}_{s y 4}{ }^{2}+\frac{1}{2} D_{s y 5} \dot{U}_{s y 5}{ }^{2}+ \\
& \frac{1}{2} D_{s y 6} \dot{U}_{s y 6}{ }^{2}+\frac{1}{2} D_{t y 1} \dot{U}_{t y 1}{ }^{2}+\frac{1}{2} D_{t y 2} \dot{U}_{t y 2}{ }^{2}+\frac{1}{2} D_{t y 3} \dot{U}_{t y 3}{ }^{2}+\frac{1}{2} D_{t y 4} \dot{U}_{t y 4}{ }^{2}+ \\
& \frac{1}{2} D_{t y 5} \dot{U}_{t y 5}{ }^{2}+\frac{1}{2} D_{t y 6} \dot{U}_{t y 6}{ }^{2}
\end{aligned}
$$

\begin{tabular}{|c|c|}
\hline \multicolumn{2}{|r|}{ Suspension springs } \\
\hline $\mathbf{U}_{\text {sy1 }}$ & $\left(\mathrm{y}_{\mathrm{t} 1}-\mathrm{y}_{\mathrm{a} 1}\right)+\left(\mathrm{S}_{1} / 2\right)\left(\varphi_{\mathrm{t} 1}-\varphi_{\mathrm{a} 1}\right)+\mathrm{l}_{3} \theta_{\mathrm{t} 1}$ \\
\hline $\mathbf{U}_{\text {sy2 }}$ & $\left(\mathrm{y}_{\mathrm{t} 1}-\mathrm{y}_{\mathrm{a} 1}\right)-\left(\mathrm{S}_{1} / 2\right)\left(\varphi_{\mathrm{t} 1}-\varphi_{\mathrm{a} 1}\right)+\mathrm{l}_{3} \theta_{\mathrm{t} 1}$ \\
\hline $\mathbf{U}_{\text {sy3 }}$ & $\left(\mathrm{y}_{\mathrm{t} 1}-\mathrm{y}_{\mathrm{a} 2}\right)+\left(\mathrm{S}_{2} / 2\right)\left(\varphi_{\mathrm{t} 1}-\varphi_{\mathrm{a} 2}\right)-\mathrm{l}_{4} \theta_{\mathrm{t} 1}$ \\
\hline $\mathbf{U}_{\text {sy4 }}$ & $\left(\mathrm{y}_{\mathrm{t} 1}-\mathrm{y}_{\mathrm{a} 2}\right)-\left(\mathrm{S}_{2} / 2\right)\left(\varphi_{\mathrm{t} 1}-\varphi_{\mathrm{a} 2}\right)-\mathrm{l}_{4} \theta_{\mathrm{t} 1}$ \\
\hline $\mathbf{U}_{\text {sy5 }}$ & $\left(\mathrm{y}_{\mathrm{t} 1}-\mathrm{y}_{\mathrm{a} 3}\right)+\left(\mathrm{S}_{3} / 2\right)\left(\varphi_{\mathrm{t} 1}-\varphi_{\mathrm{a} 3}\right)-\left(\mathrm{l}_{2}+\mathrm{l}_{4}\right) \theta_{\mathrm{t} 1}$ \\
\hline $\mathbf{U}_{\text {sy6 }}$ & $\left(\mathrm{y}_{\mathrm{t} 1}-\mathrm{y}_{\mathrm{a} 3}\right)-\left(\mathrm{S}_{3} / 2\right)\left(\varphi_{\mathrm{t} 1}-\varphi_{\mathrm{a} 3}\right)-\left(\mathrm{l}_{2}+\mathrm{l}_{4}\right) \theta_{\mathrm{t} 1}$ \\
\hline & Tire springs \\
\hline $\mathbf{U}_{\mathrm{ty} \mathbf{1}}$ & $\mathrm{y}_{\mathrm{a} 1}+\left(\mathrm{d}_{1} / 2\right) \varphi_{\mathrm{a} 1}+\mathrm{u}_{\mathrm{SR} 1}$ \\
\hline $\mathbf{U}_{\mathrm{ty} 2}$ & $\mathrm{y}_{\mathrm{a} 1}-\left(\mathrm{d}_{1} / 2\right) \varphi_{\mathrm{a} 1}+\mathrm{u}_{\mathrm{SR} 2}$ \\
\hline $\mathbf{U}_{\mathrm{ty} 3}$ & $\mathrm{y}_{\mathrm{a} 2}+\left(\mathrm{d}_{2} / 2\right) \varphi_{\mathrm{a} 2}+\mathrm{u}_{\mathrm{SR} 3}$ \\
\hline $\mathbf{U}_{\mathrm{ty} 4}$ & $\mathrm{y}_{\mathrm{a} 2}-\left(\mathrm{d}_{2} / 2\right) \varphi_{\mathrm{a} 2}+\mathrm{u}_{\mathrm{SR} 4}$ \\
\hline $\mathbf{U}_{\text {ty5 }}$ & $\mathrm{y}_{\mathrm{a} 3}+\left(\mathrm{d}_{3} / 2\right) \varphi_{\mathrm{a} 3}+\mathrm{u}_{\mathrm{SR} 5}$ \\
\hline $\mathbf{U}_{\mathrm{ty} 6}$ & $\mathrm{y}_{\mathrm{a} 3}-\left(\mathrm{d}_{3} / 2\right) \varphi_{\mathrm{a} 3}+\mathrm{u}_{\mathrm{SR} 6}$ \\
\hline
\end{tabular}

Now the Lagrange's equation is applied to $\mathrm{y}_{\mathrm{t} 1}$ :

$$
\begin{aligned}
& m_{t 1} \ddot{y}_{t 1}+\left[\left(F_{s y 1}+F_{s y 2}+F_{s y 3}+F_{s y 4}+F_{s y 5}+F_{s y 6}\right)+\left(F_{d s y 1}+F_{d s y 2}+F_{d s y 3}+\right.\right. \\
& \left.\left.F_{d s y 4}+F_{d s y 5}+F_{d s y 6}\right)\right]=m_{t 1} g
\end{aligned}
$$

Table 2. Relative Displacements at Spring Locations of Type 3 Truck 
Fị 
Also, by applying the Lagrange's equation to $\theta_{\mathrm{t} 1}$ :

$$
\begin{aligned}
& I_{z t 1} \ddot{\theta}_{t 1}+\left[l_{3}\left(F_{s y 1}+F_{s y 2}\right)-l_{4}\left(F_{s y 3}+F_{s y 4}\right)-\left(l_{2}+l_{4}\right)\left(F_{s y 5}+F_{s y 6}\right)\right]+ \\
& {\left[l_{3}\left(F_{d s y 1}+F_{d s y 2}\right)-l_{4}\left(F_{d s y 3}+F_{d s y 4}\right)-\left(l_{2}+l_{4}\right)\left(F_{d s y 5}+F_{d s y 6}\right)\right]=0}
\end{aligned}
$$

By applying the Lagrange's equation to $\varphi_{\mathrm{t} 1}$ :

$$
\begin{aligned}
& I_{x t 1} \ddot{\varphi}_{t 1}+\left[\left(\frac{s_{1}}{2}\right)\left(F_{s y 1}-F_{s y 2}\right)+\left(\frac{s_{2}}{2}\right)\left(F_{s y 3}-F_{s y 4}\right)+\left(\frac{s_{3}}{2}\right)\left(F_{s y 5}-F_{s y 6}\right)\right]+ \\
& {\left[\left(\frac{s_{1}}{2}\right)\left(F_{d s y 1}-F_{d s y 2}\right)+\left(\frac{s_{2}}{2}\right)\left(F_{d s y 3}-F_{d s y 4}\right)+\left(\frac{s_{3}}{2}\right)\left(F_{d s y 5}-F_{d s y 6}\right)\right]=0}
\end{aligned}
$$

Also the rest of degrees of freedom will be as follows:

$$
\begin{aligned}
& m_{a 1} \ddot{y}_{a 1}-\left(F_{s y 1}+F_{s y 2}\right)+\left(F_{t y 1}+F_{t y 2}\right)-\left(F_{d s y 1}+F_{d s y 2}\right)+\left(F_{d t y 1}+F_{d t y 2}\right)= \\
& m_{a 1} g \\
& I_{x a 1} \ddot{\varphi}_{a 1}-\left(\frac{s_{1}}{2}\right)\left(F_{s y 1}-F_{s y 2}\right)+\left(\frac{d_{1}}{2}\right)\left(F_{t y 1}-F_{t y 2}\right)-\left(\frac{s_{1}}{2}\right)\left(F_{d s y 1}-F_{d s y 2}\right)+ \\
& \left(\frac{d_{1}}{2}\right)\left(F_{d t y 1}-F_{d t y 2}\right)=0 \\
& m_{a 2} \ddot{y}_{a 2}-\left(F_{s y 3}+F_{s y 4}\right)+\left(F_{t y 3}+F_{t y 4}\right)-\left(F_{d s y 3}+F_{d s y 4}\right)+\left(F_{d t y 3}+F_{d t y 4}\right)= \\
& m_{a 2} g \\
& I_{x a 2} \ddot{\varphi}_{a 2}-\left(\frac{s_{2}}{2}\right)\left(F_{s y 3}-F_{s y 4}\right)+\left(\frac{d_{2}}{2}\right)\left(F_{t y 3}-F_{t y 4}\right)-\left(\frac{s_{2}}{2}\right)\left(F_{d s y 3}-F_{d s y 4}\right)+ \\
& \left(\frac{d_{2}}{2}\right)\left(F_{d t y 3}-F_{d t y 4}\right)=0 \\
& m_{a 3} \ddot{y}_{a 3}-\left(F_{s y 5}+F_{s y 6}\right)+\left(F_{t y 5}+F_{t y 6}\right)-\left(F_{d s y 5}+F_{d s y 6}\right)+\left(F_{d t y 5}+F_{d t y 6}\right)= \\
& m_{a 3} g \\
& I_{x a 3} \ddot{\varphi}_{a 3}-\left(\frac{s_{3}}{2}\right)\left(F_{s y 5}-F_{s y 6}\right)+\left(\frac{d_{3}}{2}\right)\left(F_{t y 5}-F_{t y 6}\right)-\left(\frac{s_{3}}{2}\right)\left(F_{d s y 5}-F_{d s y 6}\right)+ \\
& \left(\frac{d_{3}}{2}\right)\left(F_{d t y 5}-F_{d t y 6}\right)=0 \\
& y_{t y}
\end{aligned}
$$




\section{Derivation of Equations of Motion for Type 3S2 Truck (FDOT Truck)}

There are sixteen degrees of freedom in total for this type of truck. The degrees of freedom can be seen in Figure 2 and the description of those degrees of freedom can be found in Table 3. Relative Displacements at the locations of the springs are also calculated using the values given in Table 4.

Kinetic Energy of the system:

$$
\begin{aligned}
& T=\frac{1}{2} m_{t 1} \dot{y}_{t 1}{ }^{2}+\frac{1}{2} m_{a 1} \dot{y}_{a 1}{ }^{2}+\frac{1}{2} m_{a 2} \dot{y}_{a 2}{ }^{2}+\frac{1}{2} m_{a 3} \dot{y}_{a 3}{ }^{2}+\frac{1}{2} m_{a 4} \dot{y}_{a 4}{ }^{2}+\frac{1}{2} m_{a 5} \dot{y}_{a 5}{ }^{2}+ \\
& \frac{1}{2} I_{x t 1} \dot{\varphi}_{t 1}{ }^{2}+\frac{1}{2} I_{z t 1} \dot{\theta}_{t 1}{ }^{2}+\frac{1}{2} I_{x t 2} \dot{\varphi}_{t 2}{ }^{2}+\frac{1}{2} I_{z t 2} \dot{\theta}_{t 2}{ }^{2}+\frac{1}{2} I_{x a 1} \dot{\varphi}_{a 1}{ }^{2}+\frac{1}{2} I_{x a 2} \dot{\varphi}_{a 2}{ }^{2}+ \\
& \frac{1}{2} I_{x a 3} \dot{\varphi}_{a 3}{ }^{2}+\frac{1}{2} I_{x a 4} \dot{\varphi}_{a 4}{ }^{2}+\frac{1}{2} I_{x a 5} \dot{\varphi}_{a 5}{ }^{2}+\frac{1}{2} m_{t 2} \dot{y}_{t 2}{ }^{2}
\end{aligned}
$$

Potential Energy of the system:

$$
\begin{aligned}
& V=\frac{1}{2} K_{s y 1} U_{s y 1}{ }^{2}+\frac{1}{2} K_{s y 2} U_{s y 2}{ }^{2}+\frac{1}{2} K_{s y 3} U_{s y 3}{ }^{2}+\frac{1}{2} K_{s y 4} U_{s y 4}{ }^{2}+\frac{1}{2} K_{s y 5} U_{s y 5}{ }^{2}+ \\
& \frac{1}{2} K_{s y 6} U_{s y 6}{ }^{2}+\frac{1}{2} K_{s y 7} U_{s y 7}{ }^{2}+\frac{1}{2} K_{s y 8} U_{s y 8}{ }^{2}+\frac{1}{2} K_{s y 9} U_{s y 9}{ }^{2}+\frac{1}{2} K_{s y 10} U_{s y 10}{ }^{2}+ \\
& \frac{1}{2} K_{t y 1} U_{t y 1}{ }^{2}+\frac{1}{2} K_{t y 2} U_{t y 2}{ }^{2}+\frac{1}{2} K_{t y 3} U_{t y 3}{ }^{2}+\frac{1}{2} K_{t y 4} U_{t y 4}{ }^{2}+\frac{1}{2} K_{t y 5} U_{t y 5}{ }^{2}+ \\
& \frac{1}{2} K_{t y 6} U_{t y 6}{ }^{2}+\frac{1}{2} K_{t y 7} U_{s y 7}{ }^{2}+\frac{1}{2} K_{t y 8} U_{t y 8}{ }^{2}+\frac{1}{2} K_{t y 9} U_{t y 9}{ }^{2}+\frac{1}{2} K_{t y 10} U_{t y 10}{ }^{2}- \\
& \left(\left(m_{t 1} g\right) y_{t 1}+\left(m_{t 2} g\right) y_{t 2}+\left(m_{a 1} g\right) y_{a 1}+\left(m_{a 2} g\right) y_{a 2}+\left(m_{a 3} g\right) y_{a 3}+\left(m_{a 4} g\right) y_{a 4}+\right. \\
& \left.\left(m_{a 5} g\right) y_{a 5}\right)+\left(F_{y 1} U_{s y 1}+F_{y 2} U_{s y 2}+F_{y 3} U_{s y 3}+F_{y 4} U_{s y 4}+F_{y 5} U_{s y 5}+F_{y 6} U_{s y 6}+\right. \\
& \left.F_{y 7} U_{s y 7}+F_{y 8} U_{s y 8}+F_{y 9} U_{s y 9}+F_{y 10} U_{s y 10}\right)
\end{aligned}
$$

Damping Energy of the system:

$$
\begin{aligned}
& D=\frac{1}{2} D_{s y 1} \dot{U}_{s y 1}{ }^{2}+\frac{1}{2} D_{s y 2} \dot{U}_{s y 2}{ }^{2}+\frac{1}{2} D_{s y 3} \dot{U}_{s y 3}{ }^{2}+\frac{1}{2} D_{s y 4} \dot{U}_{s y 4}{ }^{2}+\frac{1}{2} D_{s y 5} \dot{U}_{s y 5}{ }^{2}+ \\
& \frac{1}{2} D_{s y 6} \dot{U}_{s y 6}{ }^{2}+\frac{1}{2} D_{s y 7} \dot{U}_{s y 7}{ }^{2}+\frac{1}{2} D_{s y 8} \dot{U}_{s y 8}{ }^{2}+\frac{1}{2} D_{s y 9} \dot{U}_{s y 9}{ }^{2}+\frac{1}{2} D_{s y 10} \dot{U}_{s y 10}{ }^{2}+
\end{aligned}
$$




$$
\begin{aligned}
& \frac{1}{2} D_{t y 1} \dot{U}_{t y 1}{ }^{2}+\frac{1}{2} D_{t y 2} \dot{U}_{t y 2}{ }^{2}+\frac{1}{2} D_{t y 3} \dot{U}_{t y 3}{ }^{2}+\frac{1}{2} D_{t y 4} \dot{U}_{t y 4}{ }^{2}+\frac{1}{2} D_{t y 5} \dot{U}_{t y 5}{ }^{2}+ \\
& \frac{1}{2} D_{t y 6} \dot{U}_{t y 6}{ }^{2}+\frac{1}{2} D_{t y 7} \dot{U}_{t y 7}{ }^{2}+\frac{1}{2} D_{t y 8} \dot{U}_{t y 8}{ }^{2}+\frac{1}{2} D_{t y 9} \dot{U}_{t y 9}{ }^{2}+\frac{1}{2} D_{t y 10} \dot{U}_{t y 10}{ }^{2}
\end{aligned}
$$

\begin{tabular}{|c|c|c|c|}
\hline No. & $\begin{array}{l}\text { Degree of } \\
\text { Freedom }\end{array}$ & $\begin{array}{l}\text { Contributed } \\
\text { Mass }\end{array}$ & Description \\
\hline 1 & $\mathrm{y}_{\mathrm{t} 1}$ & $\mathrm{~m}_{\mathrm{t} 1}$ & Tractor vertical displacement and mass \\
\hline 2 & $\varphi_{\mathrm{t} 1}$ & $\mathrm{I}_{\mathrm{xt} 1}$ & Tractor roll displacement and mass moment of inertia \\
\hline 3 & $\theta_{\mathrm{t} 1}$ & $\mathrm{I}_{\mathrm{zt} 1}$ & Tractor pitch displacement and mass moment of inertia \\
\hline 4 & $\mathrm{y}_{\mathrm{t} 2}$ & $\mathrm{~m}_{\mathrm{t} 2}$ & Trailer vertical displacement and mass \\
\hline 5 & $\varphi_{\mathrm{t} 2}$ & $\mathrm{I}_{\mathrm{xt} 2}$ & Trailer roll displacement and mass moment of inertia \\
\hline 6 & $\theta_{\mathrm{t} 2}$ & $\mathrm{I}_{\mathrm{zt} 2}$ & Trailer pitch displacement and mass moment of inertia \\
\hline 7 & $\mathrm{y}_{\mathrm{a} 1}$ & $\mathrm{~m}_{\mathrm{a} 1}$ & Steer axle vertical displacement and mass \\
\hline 8 & $\varphi_{\mathrm{a} 1}$ & $\mathrm{I}_{\mathrm{xa} 1}$ & Steer axle roll displacement and mass moment of inertia \\
\hline 9 & $\mathrm{y}_{\mathrm{a} 2}$ & $\mathrm{~m}_{\mathrm{a} 2}$ & $\begin{array}{l}\text { Vertical displacement and mass of forward axle of tractor } \\
\text { tandem }\end{array}$ \\
\hline 10 & $\varphi_{\mathrm{a} 2}$ & $\mathrm{I}_{\mathrm{xa} 2}$ & $\begin{array}{l}\text { Roll displacement and mass moment of inertia of forward } \\
\text { axle of tractor tandem }\end{array}$ \\
\hline 11 & $\mathrm{y}_{\mathrm{a} 3}$ & $\mathrm{~m}_{\mathrm{a} 3}$ & $\begin{array}{l}\text { Vertical displacement and mass of aft axle of tractor } \\
\text { tandem }\end{array}$ \\
\hline 12 & $\varphi_{\mathrm{a} 3}$ & $\mathrm{I}_{\mathrm{xa} 3}$ & $\begin{array}{l}\text { Roll displacement and mass moment of inertia of aft axle } \\
\text { of tractor tandem }\end{array}$ \\
\hline 13 & $\mathrm{y}_{\mathrm{a} 4}$ & $\mathrm{~m}_{\mathrm{a} 4}$ & $\begin{array}{l}\text { Vertical displacement and mass of forward axle of trailer } \\
\text { tandem }\end{array}$ \\
\hline 14 & $\varphi_{\mathrm{a} 4}$ & $\mathrm{I}_{\mathrm{xa} 4}$ & $\begin{array}{l}\text { Roll displacement and mass moment of inertia of forward } \\
\text { axle of trailer tandem }\end{array}$ \\
\hline 15 & $\mathrm{y}_{\mathrm{a} 5}$ & $\mathrm{~m}_{\mathrm{a} 5}$ & $\begin{array}{l}\text { Vertical displacement and mass of aft axle of trailer } \\
\text { tandem }\end{array}$ \\
\hline 16 & $\varphi_{\mathrm{a} 5}$ & $\mathrm{I}_{\mathrm{xa} 5}$ & $\begin{array}{l}\text { Roll displacement and mass moment of inertia of aft axle } \\
\text { of trailer tandem }\end{array}$ \\
\hline
\end{tabular}

Table 3. Degrees of Freedom of Type 3S2 Truck 
Figure 2. Type $3 S 2$ Dynamic Model (a) Truck Side View (b) Truck Front View 
Table 4. Relative Displacements at Spring Locations of Type 3S2 Truck

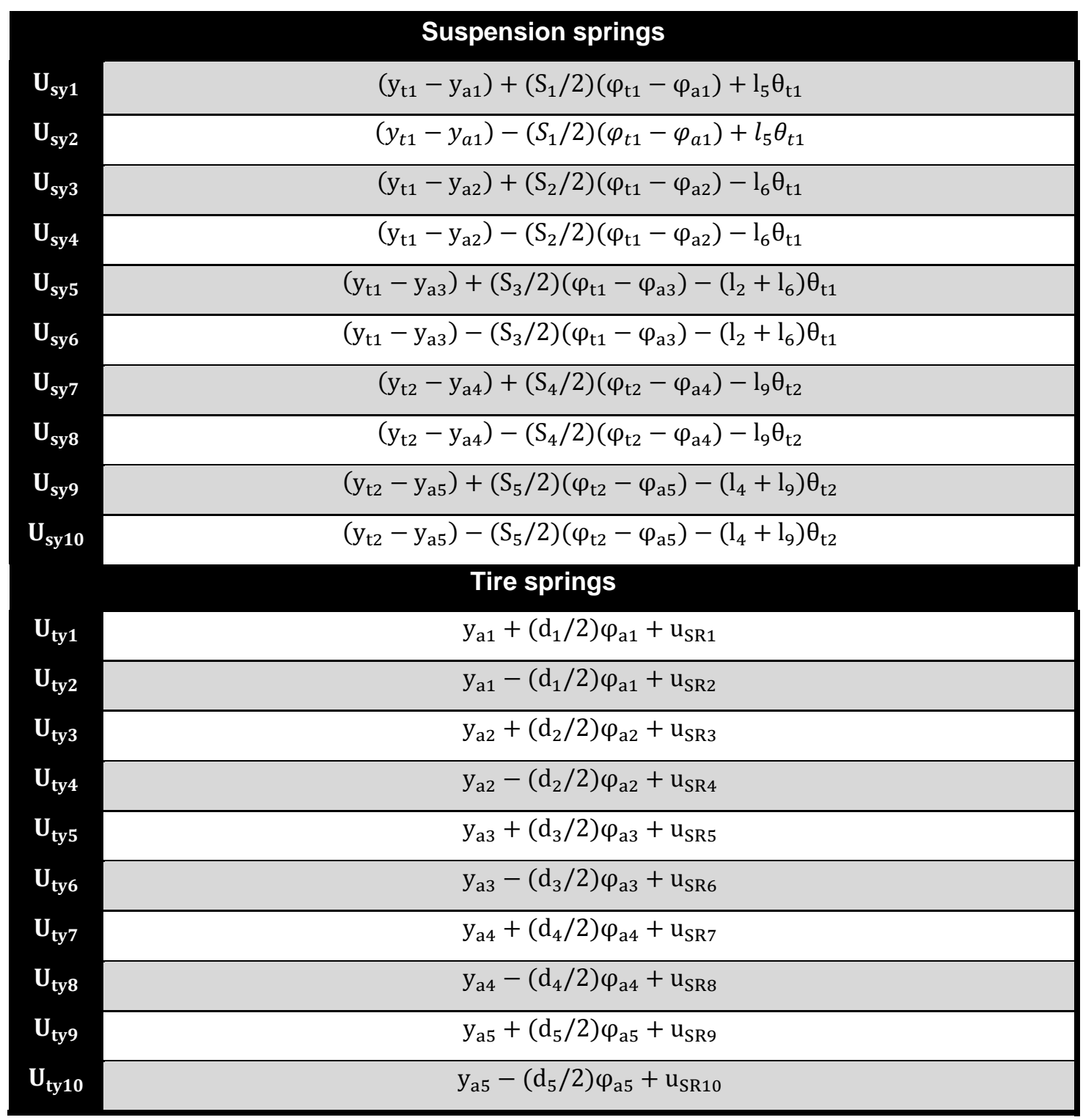

The displacement at the pivot point should stay the same, whether it is calculated from the trailer part or the tractor part,

$y_{t 2}+\theta_{t 2} l_{8}=y_{t 1}-\theta_{t 1} l_{7}$

Thus, by calculating $\theta_{t 2}$ from equation ( 115 ) and substituting in equation ( 112 ), 


$$
\begin{aligned}
& T=\frac{1}{2} m_{t 1} \dot{y}_{t 1}{ }^{2}+\frac{1}{2} m_{a 1} \dot{y}_{a 1}{ }^{2}+\frac{1}{2} m_{a 2} \dot{y}_{a 2}{ }^{2}+\frac{1}{2} m_{a 3} \dot{y}_{a 3}{ }^{2}+\frac{1}{2} m_{a 4} \dot{y}_{a 4}{ }^{2}+\frac{1}{2} m_{a 5} \dot{y}_{a 5}{ }^{2}+ \\
& \frac{1}{2} I_{x t 1} \dot{\varphi}_{t 1}{ }^{2}+\frac{1}{2} I_{z t 1} \dot{\theta}_{t 1}{ }^{2}+\frac{1}{2} I_{x t 2} \dot{\varphi}_{t 2}{ }^{2}+\frac{1}{2} I_{z t 2}\left(\frac{\dot{y}_{t 1}-\dot{y}_{t 2}-\dot{\theta}_{t 1} l_{7}}{l_{8}}\right)^{2}+\frac{1}{2} I_{x a 1} \dot{\varphi}_{a 1}{ }^{2}+ \\
& \frac{1}{2} I_{x a 2} \dot{\varphi}_{a 2}{ }^{2}+\frac{1}{2} I_{x a 3} \dot{\varphi}_{a 3}{ }^{2}+\frac{1}{2} I_{x a 4} \dot{\varphi}_{a 4}{ }^{2}+\frac{1}{2} I_{x a 5} \dot{\varphi}_{a 5}{ }^{2}+\frac{1}{2} m_{t 2} \dot{y}_{t 2}{ }^{2}
\end{aligned}
$$

Same substitution will be applied to the equations ( 113 ) and ( 114 ). Now the Lagrange's equation is applied to $\mathrm{y}_{\mathrm{t} 2}$ :

$$
\begin{aligned}
& {\left[m_{t 2} \ddot{y}_{t 2}-\frac{I_{z t 2}}{l_{8}^{2}}\left(\ddot{y}_{t 1}-\ddot{y}_{t 2}-\ddot{\theta}_{t 1} l_{7}\right)\right]+\left[( 1 + \frac { l _ { 9 } } { l _ { 8 } } ) \left(K_{s y 7} U_{s y 7}+K_{s y 8} U_{s y 8}+F_{y 7}+\right.\right.} \\
& \left.\left.F_{y 8}\right)+\left(1+\frac{l_{4}+l_{9}}{l_{8}}\right)\left(K_{s y 9} U_{s y 9}+K_{s y 10} U_{s y 10}+F_{y 9}+F_{y 10}\right)-\left(m_{t 2} g\right)\right]+ \\
& {\left[\left(1+\frac{l_{9}}{l_{8}}\right)\left(D_{s y 7} \dot{U}_{s y 7}+D_{s y 8} \dot{U}_{s y 8}\right)+\left(1+\frac{l_{4}+l_{9}}{l_{8}}\right)\left(D_{s y 9} \dot{U}_{s y 9}+D_{s y 10} \dot{U}_{s y 10}\right)\right]=0}
\end{aligned}
$$

To simplify the equation some variables are defined as follows:

$$
\begin{aligned}
& S_{a 2}=\frac{I_{z t 2}}{l_{8}^{2}} \\
& S_{c 2}=\frac{I_{z t 2}}{l_{8}{ }^{2}}+m_{t 2}
\end{aligned}
$$

$$
S_{a 3}=\frac{I_{z t 2}}{l_{8}^{2}} l_{7}
$$$$
B_{t 4}=m_{t 2} g-\left(1+\frac{l_{9}}{l_{8}}\right)\left(F_{s y 7}+F_{s y 8}+F_{d s y 7}+F_{d s y 8}\right)-\left(1+\frac{l_{4}+l_{9}}{l_{8}}\right)\left(F_{s y 9}+F_{s y 10}+F_{d s y 9}+\right.
$$

$\left.F_{d s y 10}\right)$

Therefore equation ( 117 ) will be simplified to:

$$
-S_{a 2} \ddot{y}_{t 1}+S_{c 2} \ddot{y}_{t 2}+S_{a 3} \ddot{\theta}_{t 1}=B_{t 4}
$$

By applying the Lagrange's equation to $\mathrm{y}_{\mathrm{t} 1}$ : 


$$
\begin{aligned}
& {\left[m_{t 1} \ddot{y}_{t 1}+\frac{I_{z t 2}}{l_{8}^{2}}\left(\ddot{y}_{t 1}-\ddot{y}_{t 2}-\ddot{\theta}_{t 1} l_{7}\right)\right]+\left[\left(F_{s y 1}+F_{s y 2}+F_{s y 3}+F_{s y 4}+F_{s y 5}+F_{s y 6}\right)-\right.} \\
& \left.\frac{l_{9}}{l_{8}}\left(F_{s y 7}+F_{s y 8}\right)-\frac{l_{9}+l_{4}}{l_{8}}\left(F_{s y 9}+F_{s y 10}\right)-\left(m_{t 1} g\right)\right]+\left[\left(F_{d s y 1}+F_{d s y 2}+F_{d s y 3}+\right.\right. \\
& \left.\left.F_{d s y 4}+F_{d s y 5}+F_{d s y 6}\right)-\frac{l_{9}}{l_{8}}\left(F_{d s y 7}+F_{d s y 8}\right)-\frac{l_{9}+l_{4}}{l_{8}}\left(F_{d s y 9}+F_{d s y 10}\right)\right]=0
\end{aligned}
$$

Again to simplify the equation some variables are defined as follows:

$$
\begin{aligned}
& S_{a 1}=\frac{I_{z t 2}}{l_{8}^{2}}+m_{t 1} \\
& B_{t 1}=m_{t 1} g-\left[\left(F_{s y 1}+F_{s y 2}+F_{s y 3}+F_{s y 4}+F_{s y 5}+F_{s y 6}\right)-\frac{l_{9}}{l_{8}}\left(F_{s y 7}+F_{s y 8}\right)-\frac{l_{9}+l_{4}}{l_{8}}\left(F_{s y 9}+\right.\right. \\
& \left.F_{s y 10}\right)+\left(F_{d s y 1}+F_{d s y 2}+F_{d s y 3}+F_{d s y 4}+F_{d s y 5}+F_{d s y 6}\right)-\frac{l_{9}}{l_{8}}\left(F_{d s y 7}+F_{d s y 8}\right)- \\
& \left.\frac{l_{9}+l_{4}}{l_{8}}\left(F_{d s y 9}+F_{d s y 10}\right)\right]
\end{aligned}
$$

Therefore equation ( 119 ) will be simplified to:

$$
S_{a 1} \ddot{y}_{t 1}-S_{a 2} \ddot{y}_{t 2}-S_{a 3} \ddot{\theta}_{t 1}=B_{t 1}
$$

Also, by applying the Lagrange's equation to $\theta_{\mathrm{t} 1}$ :

$$
\begin{aligned}
& {\left[I_{z t 1} \ddot{\theta}_{t 1}-\frac{I_{z t 2} l_{7}}{l_{8}{ }^{2}}\left(\ddot{y}_{t 1}-\ddot{y}_{t 2}-\ddot{\theta}_{t 1} l_{7}\right)\right]+\left[l_{5}\left(F_{s y 1}+F_{s y 2}\right)-l_{6}\left(F_{s y 3}+F_{s y 4}\right)-\right.} \\
& \left.\left(l_{2}+l_{6}\right)\left(F_{s y 5}+F_{s y 6}\right)+\frac{l_{7} I_{9}}{l_{8}}\left(F_{s y 7}+F_{s y 8}\right)+\frac{l_{7}\left(l_{4}+I_{9}\right)}{l_{8}}\left(F_{s y 9}+F_{s y 10}\right)\right]+\left[l _ { 5 } \left(F_{d s y 1}+\right.\right. \\
& \left.F_{d s y 2}\right)-l_{6}\left(F_{d s y 3}+F_{d s y 4}\right)-\left(l_{2}+l_{6}\right)\left(F_{d s y 5}+F_{d s y 6}\right)+\frac{l_{7} I_{9}}{l_{8}}\left(F_{d s y 7}+F_{d s y 8}\right)+ \\
& \left.\frac{l_{7}\left(l_{4}+I_{9}\right)}{l_{8}}\left(F_{d s y 9}+F_{d s y 10}\right)\right]=0
\end{aligned}
$$

Once again to simplify the equation some variables need to be defined as follows:

$$
S_{b 3}=I_{z t 1}+\frac{I_{z t 2} l_{7}^{2}}{l_{8}{ }^{2}}
$$




$$
\begin{aligned}
& B_{t 3}=-\left[\left[l_{5}\left(F_{s y 1}+F_{s y 2}\right)-l_{6}\left(F_{s y 3}+F_{s y 4}\right)-\left(l_{2}+l_{6}\right)\left(F_{s y 5}+F_{s y 6}\right)+\frac{l_{7} I_{9}}{l_{8}}\left(F_{s y 7}+F_{s y 8}\right)+\right.\right. \\
& \left.\frac{l_{7}\left(l_{4}+I_{9}\right)}{l_{8}}\left(F_{s y 9}+F_{s y 10}\right)\right]+\left[l_{5}\left(F_{d s y 1}+F_{d s y 2}\right)-l_{6}\left(F_{d s y 3}+F_{d s y 4}\right)-\left(l_{2}+l_{6}\right)\left(F_{d s y 5}+\right.\right. \\
& \left.\left.\left.F_{d s y 6}\right)+\frac{l_{7} I_{9}}{l_{8}}\left(F_{d s y 7}+F_{d s y 8}\right)+\frac{l_{7}\left(l_{4}+I_{9}\right)}{l_{8}}\left(F_{d s y 9}+F_{d s y 10}\right)\right]\right]
\end{aligned}
$$

Therefore equation ( 121 ) will be simplified to:

$-S_{a 3} \ddot{y}_{t 1}+S_{a 3} \ddot{y}_{t 2}+S_{b 3} \ddot{\theta}_{t 1}=B_{t 3}$

By adding equations ( 118 ) and ( 120 ),

$\left(S_{a 1}-S_{a 2}\right) \ddot{y}_{t 1}-\left(S_{a 2}-S_{c 2}\right) \ddot{y}_{t 2}=B_{t 1}+B_{t 4}$

Also by multiplying $S_{b 3}$ and $S_{a 3}$ to equations ( 120 ) and ( 122 ) respectively,

$$
\left(S_{a 1} S_{b 3}-S_{a 3}^{2}\right) \ddot{y}_{t 1}-\left(S_{a 2} S_{b 3}-S_{a 3}^{2}\right) \ddot{y}_{t 2}=S_{b 3} B_{t 1}+S_{a 3} B_{t 3}
$$

By defining the following expressions, equations ( 123 ) and ( 124 ) are simplified to equations ( 125 ) and ( 126 ) respectively,

$$
\begin{aligned}
& e_{1}=S_{a 1}-S_{a 2} \\
& e_{2}=S_{a 2}-S_{c 2} \\
& e_{3}=S_{a 1} S_{b 3}-S_{a 3}^{2} \\
& e_{4}=S_{a 2} S_{b 3}-S_{a 3}^{2} \\
& e_{1} \ddot{y}_{t 1}-e_{2} \ddot{y}_{t 2}=B_{t 1}+B_{t 4} \\
& e_{3} \ddot{y}_{t 1}-e_{4} \ddot{y}_{t 2}=S_{b 3} B_{t 1}+S_{a 3} B_{t 3}
\end{aligned}
$$

Solving equations ( 125 ) and ( 126 ) for $\ddot{y}_{t 1}$ and $\ddot{y}_{t 2}$ will lead to: 
$\ddot{y}_{t 1}=\frac{e_{4}\left(B_{t 1}+B_{t 4}\right)-e_{2}\left(S_{b 3} B_{t 1}+S_{a 3} B_{t 3}\right)}{e_{1} e_{4}-e_{2} e_{3}}$

$\ddot{y}_{t 2}=\frac{e_{1}}{e_{2}}\left(\frac{e_{4}\left(B_{t 1}+B_{t 4}\right)-e_{2}\left(S_{b 3} B_{t 1}+S_{a 3} B_{t 3}\right)}{e_{1} e_{4}-e_{2} e_{3}}\right)-\frac{B_{t 1}+B_{t 4}}{e_{2}}$

Substituting equations ( 127 ) and ( 128 ) into equation ( 122 ) will give,

$\ddot{\theta}_{t 1}=\frac{B_{t 3}}{S_{b 3}}+\frac{S_{a 3}}{S_{b 3}}\left(\frac{e_{4}\left(B_{t 1}+B_{t 4}\right)-e_{2}\left(S_{b 3} B_{t 1}+S_{a 3} B_{t 3}\right)}{e_{1} e_{4}-e_{2} e_{3}}\right)-\frac{S_{a 3}}{S_{b 3}}\left(\frac{e_{1}}{e_{2}}\left(\frac{e_{4}\left(B_{t 1}+B_{t 4}\right)-e_{2}\left(S_{b 3} B_{t 1}+S_{a 3} B_{t 3}\right)}{e_{1} e_{4}-e_{2} e_{3}}\right)-\right.$

$\left.\frac{B_{t 1}+B_{t 4}}{e_{2}}\right)$

By applying the Lagrange's equation to $\varphi_{t 1}, \varphi_{t 2}$ :

$$
\begin{aligned}
& I_{x t 1} \ddot{\varphi}_{t 1}+\left[\left(\frac{s_{1}}{2}\right)\left(F_{s y 1}-F_{s y 2}\right)+\left(\frac{s_{2}}{2}\right)\left(F_{s y 3}-F_{s y 4}\right)+\left(\frac{s_{3}}{2}\right)\left(F_{s y 5}-F_{s y 6}\right)\right]+ \\
& {\left[\left(\frac{s_{1}}{2}\right)\left(F_{d s y 1}-F_{d s y 2}\right)+\left(\frac{s_{2}}{2}\right)\left(F_{d s y 3}-F_{d s y 4}\right)+\left(\frac{s_{3}}{2}\right)\left(F_{d s y 5}-F_{d s y 6}\right)\right]=0} \\
& I_{x t 2} \ddot{\varphi}_{t 2}+\left[\left(\frac{s_{4}}{2}\right)\left(F_{s y 7}-F_{s y 8}\right)+\left(\frac{s_{5}}{2}\right)\left(F_{s y 9}-F_{s y 10}\right)\right]+\left[\left(\frac{s_{4}}{2}\right)\left(F_{d s y 7}-F_{d s y 8}\right)+\right. \\
& \left.\left(\frac{s_{5}}{2}\right)\left(F_{d s y 9}-F_{d s y 10}\right)\right]=0
\end{aligned}
$$

Also the rest of degrees of freedom will be as follows:

$$
\begin{aligned}
& m_{a 1} \ddot{y}_{a 1}-\left(F_{s y 1}+F_{s y 2}\right)+\left(F_{t y 1}+F_{t y 2}\right)-\left(F_{d s y 1}+F_{d s y 2}\right)+\left(F_{d t y 1}+F_{d t y 2}\right)= \\
& m_{a 1} g \\
& I_{x a 1} \ddot{\varphi}_{a 1}-\left(\frac{s_{1}}{2}\right)\left(F_{s y 1}-F_{s y 2}\right)+\left(\frac{d_{1}}{2}\right)\left(F_{t y 1}-F_{t y 2}\right)-\left(\frac{s_{1}}{2}\right)\left(F_{d s y 1}-F_{d s y 2}\right)+ \\
& \left(\frac{d_{1}}{2}\right)\left(F_{d t y 1}-F_{d t y 2}\right)=0 \\
& m_{a 2} \ddot{y}_{a 2}-\left(F_{s y 3}+F_{s y 4}\right)+\left(F_{t y 3}+F_{t y 4}\right)-\left(F_{d s y 3}+F_{d s y 4}\right)+\left(F_{d t y 3}+F_{d t y 4}\right)= \\
& m_{a 2} g \\
& I_{x a 2} \ddot{\varphi}_{a 2}-\left(\frac{s_{2}}{2}\right)\left(F_{s y 3}-F_{s y 4}\right)+\left(\frac{d_{2}}{2}\right)\left(F_{t y 3}-F_{t y 4}\right)-\left(\frac{s_{2}}{2}\right)\left(F_{d s y 3}-F_{d s y 4}\right)+ \\
& \left(\frac{d_{2}}{2}\right)\left(F_{d t y 3}-F_{d t y 4}\right)=0
\end{aligned}
$$




$$
\begin{aligned}
& m_{a 3} \ddot{y}_{a 3}-\left(F_{s y 5}+F_{s y 6}\right)+\left(F_{t y 5}+F_{t y 6}\right)-\left(F_{d s y 5}+F_{d s y 6}\right)+\left(F_{d t y 5}+F_{d t y 6}\right)= \\
& m_{a 3} g \\
& I_{x a 3} \ddot{\varphi}_{a 3}-\left(\frac{s_{3}}{2}\right)\left(F_{s y 5}-F_{s y 6}\right)+\left(\frac{d_{3}}{2}\right)\left(F_{t y 5}-F_{t y 6}\right)-\left(\frac{s_{3}}{2}\right)\left(F_{d s y 5}-F_{d s y 6}\right)+ \\
& \left(\frac{d_{3}}{2}\right)\left(F_{d t y 5}-F_{d t y 6}\right)=0 \\
& m_{a 4} \ddot{y}_{a 4}-\left(F_{s y 7}+F_{s y 8}\right)+\left(F_{t y 7}+F_{t y 8}\right)-\left(F_{d s y 7}+F_{d s y 8}\right)+\left(F_{d t y 7}+F_{d t y 8}\right)= \\
& m_{a 4} g \\
& I_{x a 4} \ddot{\varphi}_{a 4}-\left(\frac{s_{4}}{2}\right)\left(F_{s y 7}-F_{s y 8}\right)+\left(\frac{d_{4}}{2}\right)\left(F_{t y 7}-F_{t y 8}\right)-\left(\frac{s_{4}}{2}\right)\left(F_{d s y 7}-F_{d s y 8}\right)+ \\
& \left(\frac{d_{4}}{2}\right)\left(F_{d t y 7}-F_{d t y 8}\right)=0 \\
& m_{a 5} \ddot{y}_{a 5}-\left(F_{s y 9}+F_{s y 10}\right)+\left(F_{t y 9}+F_{t y 10}\right)-\left(F_{d s y 9}+F_{d s y 10}\right)+\left(F_{d t y 9}+F_{d t y 10}\right)= \\
& m_{a 5} g \\
& I_{x a 5} \ddot{\varphi}_{a 5}-\left(\frac{s_{5}}{2}\right)\left(F_{s y 9}-F_{s y 10}\right)+\left(\frac{d_{5}}{2}\right)\left(F_{t y 9}-F_{t y 10}\right)-\left(\frac{s_{5}}{2}\right)\left(F_{d s y 9}-F_{d s y 10}\right)+ \\
& \left(\frac{d_{5}}{2}\right)\left(F_{d t y 9}-F_{d t y 10}\right)=0 \\
& { }_{t y}
\end{aligned}
$$

\section{Derivation of Equations of Motion for Type 3S3 Truck}

There are eighteen degrees of freedom in total for this type of truck. The degrees of freedom can be seen in Figure 3 and the description of those degrees of freedom can be found in Table 5. Relative displacements at the locations of the springs are also calculated using the values given in Table 6.

Kinetic Energy of the system:

$$
\begin{aligned}
& T=\frac{1}{2} m_{t 1} \dot{y}_{t 1}{ }^{2}+\frac{1}{2} m_{a 1} \dot{y}_{a 1}{ }^{2}+\frac{1}{2} m_{a 2} \dot{y}_{a 2}{ }^{2}+\frac{1}{2} m_{a 3} \dot{y}_{a 3}{ }^{2}+\frac{1}{2} m_{a 4} \dot{y}_{a 4}{ }^{2}+\frac{1}{2} m_{a 5} \dot{y}_{a 5}{ }^{2}+ \\
& \frac{1}{2} m_{a 6} \dot{y}_{a 6}{ }^{2}+\frac{1}{2} I_{x t 1} \dot{\varphi}_{t 1}{ }^{2}+\frac{1}{2} I_{z t 1} \dot{\theta}_{t 1}{ }^{2}+\frac{1}{2} I_{x t 2} \dot{\varphi}_{t 2}{ }^{2}+\frac{1}{2} I_{z t 2} \dot{\theta}_{t 2}{ }^{2}+\frac{1}{2} I_{x a 1} \dot{\varphi}_{a 1}{ }^{2}+ \\
& \frac{1}{2} I_{x a 2} \dot{\varphi}_{a 2}{ }^{2}+\frac{1}{2} I_{x a 3} \dot{\varphi}_{a 3}{ }^{2}+\frac{1}{2} I_{x a 4} \dot{\varphi}_{a 4}{ }^{2}+\frac{1}{2} I_{x a 5} \dot{\varphi}_{a 5}{ }^{2}+\frac{1}{2} I_{x a 6} \dot{\varphi}_{a 6}{ }^{2}+\frac{1}{2} m_{t 2} \dot{y}_{t 2}{ }^{2}
\end{aligned}
$$


Table 5. Degrees of Freedom of Type 3S3 Truck

\begin{tabular}{|c|c|c|c|}
\hline No. & $\begin{array}{l}\text { Degree of } \\
\text { Freedom }\end{array}$ & $\begin{array}{l}\text { Contributed } \\
\text { Mass }\end{array}$ & Description \\
\hline 1 & $\mathrm{y}_{\mathrm{t} 1}$ & $\mathrm{~m}_{\mathrm{t} 1}$ & Tractor vertical displacement and mass \\
\hline 2 & $\varphi_{\mathrm{t} 1}$ & $\mathrm{I}_{\mathrm{xt} 1}$ & Tractor roll displacement and mass moment of inertia \\
\hline 3 & $\theta_{\mathrm{t} 1}$ & $\mathrm{I}_{\mathrm{zt} 1}$ & Tractor pitch displacement and mass moment of inertia \\
\hline 4 & $\mathrm{y}_{\mathrm{t} 2}$ & $\mathrm{~m}_{\mathrm{t} 2}$ & Trailer vertical displacement and mass \\
\hline 5 & $\varphi_{\mathrm{t} 2}$ & $\mathrm{I}_{\mathrm{xt} 2}$ & Trailer roll displacement and mass moment of inertia \\
\hline 6 & $\theta_{\mathrm{t} 2}$ & $\mathrm{I}_{\mathrm{zt} 2}$ & Trailer pitch displacement and mass moment of inertia \\
\hline 7 & $\mathrm{y}_{\mathrm{a} 1}$ & $\mathrm{~m}_{\mathrm{a} 1}$ & Steer axle vertical displacement and mass \\
\hline 8 & $\varphi_{\mathrm{a} 1}$ & $\mathrm{I}_{\mathrm{xa} 1}$ & Steer axle roll displacement and mass moment of inertia \\
\hline 9 & $\mathrm{y}_{\mathrm{a} 2}$ & $\mathrm{~m}_{\mathrm{a} 2}$ & $\begin{array}{l}\text { Vertical displacement and mass of forward axle of tractor } \\
\text { tandem }\end{array}$ \\
\hline 10 & $\varphi_{\mathrm{a} 2}$ & $\mathrm{I}_{\mathrm{xa} 2}$ & $\begin{array}{l}\text { Roll displacement and mass moment of inertia of forward } \\
\text { axle of tractor tandem }\end{array}$ \\
\hline 11 & $\mathrm{y}_{\mathrm{a} 3}$ & $\mathrm{~m}_{\mathrm{a} 3}$ & $\begin{array}{l}\text { Vertical displacement and mass of aft axle of tractor } \\
\text { tandem }\end{array}$ \\
\hline 12 & $\varphi_{\mathrm{a} 3}$ & $\mathrm{I}_{\mathrm{xa} 3}$ & $\begin{array}{l}\text { Roll displacement and mass moment of inertia of aft axle } \\
\text { of tractor tandem }\end{array}$ \\
\hline 13 & $\mathrm{y}_{\mathrm{a} 4}$ & $\mathrm{~m}_{\mathrm{a} 4}$ & Vertical displacement and mass of first axle of trailer \\
\hline 14 & $\varphi_{\mathrm{a} 4}$ & $\mathrm{I}_{\mathrm{xa} 4}$ & Roll disp. and mass moment of inertia of first axle of trailer \\
\hline 15 & $\mathrm{y}_{\mathrm{a} 5}$ & $\mathrm{~m}_{\mathrm{a} 5}$ & Vertical disp. and mass of forward axle of trailer tandem \\
\hline 16 & $\varphi_{\mathrm{a} 5}$ & $\mathrm{I}_{\mathrm{xa} 5}$ & $\begin{array}{l}\text { Roll displacement and mass moment of inertia of forward } \\
\text { axle of trailer tandem }\end{array}$ \\
\hline 17 & $\mathrm{y}_{\mathrm{a} 6}$ & $\mathrm{~m}_{\mathrm{a} 6}$ & $\begin{array}{l}\text { Vertical displacement and mass of aft axle of trailer } \\
\text { tandem }\end{array}$ \\
\hline 18 & $\varphi_{\mathrm{a} 6}$ & $\mathrm{I}_{\mathrm{xa} 6}$ & $\begin{array}{l}\text { Roll displacement and mass moment of inertia of aft axle } \\
\text { of trailer tandem }\end{array}$ \\
\hline
\end{tabular}


Table 6. Relative Displacements at Spring Locations of Type 3S3 Truck

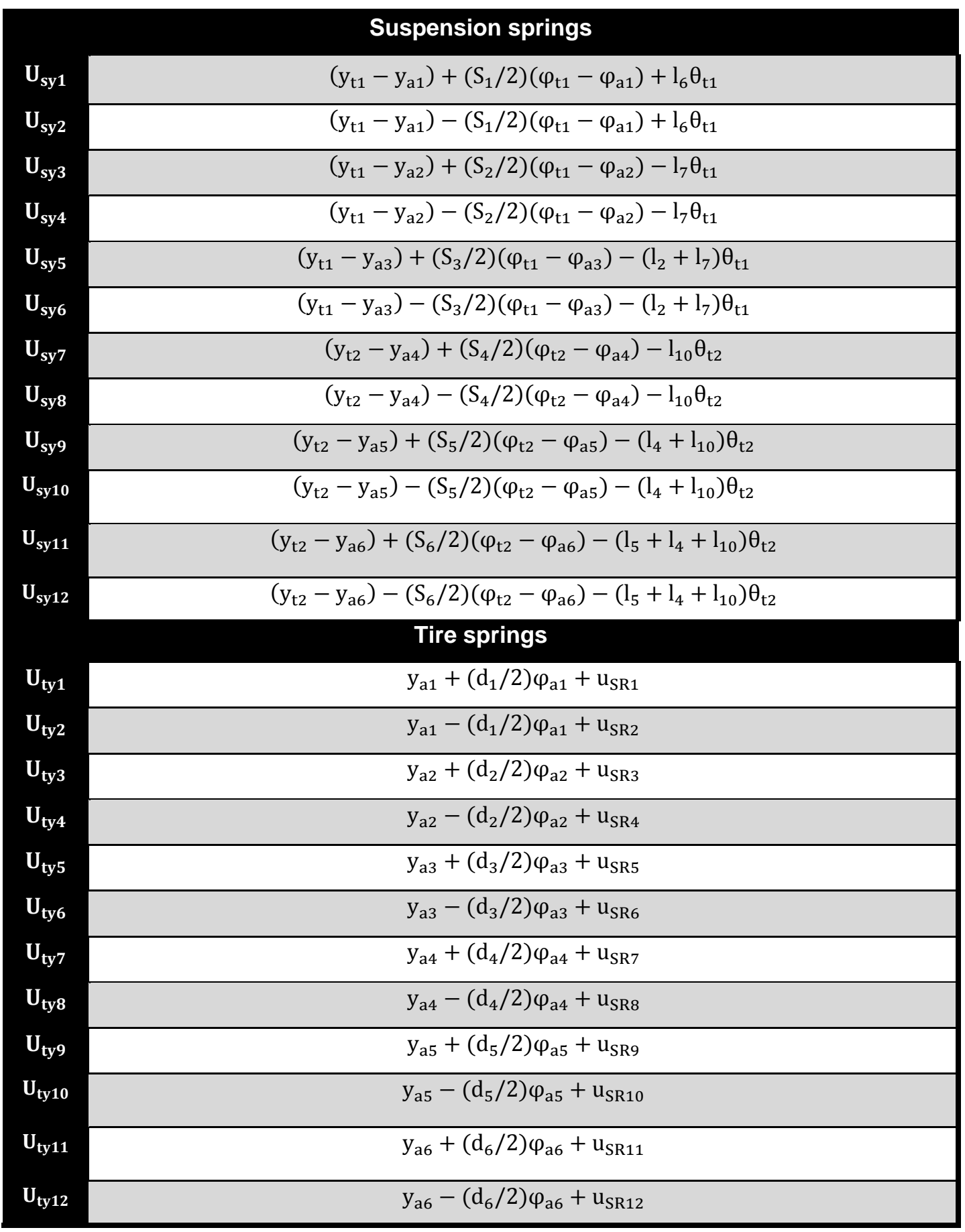


Figure 3. Type 3S3 Dynamic Model (a) Truck Side View (b) Truck Front View 
Potential Energy of the system:

$$
\begin{aligned}
& V=\frac{1}{2} K_{s y 1} U_{s y 1}{ }^{2}+\frac{1}{2} K_{s y 2} U_{s y 2}{ }^{2}+\frac{1}{2} K_{s y 3} U_{s y 3}{ }^{2}+\frac{1}{2} K_{s y 4} U_{s y 4}{ }^{2}+\frac{1}{2} K_{s y 5} U_{s y 5}{ }^{2}+ \\
& \frac{1}{2} K_{s y 6} U_{s y 6}{ }^{2}+\frac{1}{2} K_{s y 7} U_{s y 7}^{2}+\frac{1}{2} K_{s y 8} U_{s y 8}^{2}+\frac{1}{2} K_{s y 9} U_{s y 9}{ }^{2}+\frac{1}{2} K_{s y 10} U_{s y 10}^{2}+ \\
& \frac{1}{2} K_{s y 11} U_{s y 11}^{2}+\frac{1}{2} K_{s y 12} U_{s y 12}^{2}+\frac{1}{2} K_{t y 1} U_{t y 1}{ }^{2}+\frac{1}{2} K_{t y 2} U_{t y 2}{ }^{2}+\frac{1}{2} K_{t y 3} U_{t y 3}{ }^{2}+ \\
& \frac{1}{2} K_{t y 4} U_{t y 4}{ }^{2}+\frac{1}{2} K_{t y 5} U_{t y 5}{ }^{2}+\frac{1}{2} K_{t y 6} U_{t y 6}{ }^{2}+\frac{1}{2} K_{t y 7} U_{s y 7}{ }^{2}+\frac{1}{2} K_{t y 8} U_{t y 8}{ }^{2}+ \\
& \frac{1}{2} K_{t y 9} U_{t y 9}{ }^{2}+\frac{1}{2} K_{t y 10} U_{t y 10}{ }^{2}+\frac{1}{2} K_{t y 11} U_{t y 11}{ }^{2}+\frac{1}{2} K_{t y 12} U_{t y 12}{ }^{2}-\left(\left(m_{t 1} g\right) y_{t 1}+\right. \\
& \left(m_{t 2} g\right) y_{t 2}+\left(m_{a 1} g\right) y_{a 1}+\left(m_{a 2} g\right) y_{a 2}+\left(m_{a 3} g\right) y_{a 3}+\left(m_{a 4} g\right) y_{a 4}+\left(m_{a 5} g\right) y_{a 5}+ \\
& \left.\left(m_{a 6} g\right) y_{a 6}\right)+\left(F_{y 1} U_{s y 1}+F_{y 2} U_{s y 2}+F_{y 3} U_{s y 3}+F_{y 4} U_{s y 4}+F_{y 5} U_{s y 5}+F_{y 6} U_{s y 6}+\right. \\
& \left.F_{y 7} U_{s y 7}+F_{y 8} U_{s y 8}+F_{y 9} U_{s y 9}+F_{y 10} U_{s y 10}+F_{y 11} U_{s y 11}+F_{y 12} U_{s y 12}\right)
\end{aligned}
$$

Damping Energy of the system:

$$
\begin{aligned}
& D=\frac{1}{2} D_{s y 1} \dot{U}_{s y 1}{ }^{2}+\frac{1}{2} D_{s y 2} \dot{U}_{s y 2}{ }^{2}+\frac{1}{2} D_{s y 3} \dot{U}_{s y 3}{ }^{2}+\frac{1}{2} D_{s y 4} \dot{U}_{s y 4}{ }^{2}+\frac{1}{2} D_{s y 5} \dot{U}_{s y 5}{ }^{2}+ \\
& \frac{1}{2} D_{s y 6} \dot{U}_{s y 6}{ }^{2}+\frac{1}{2} D_{s y 7} \dot{U}_{s y 7}{ }^{2}+\frac{1}{2} D_{s y 8} \dot{U}_{s y 8}{ }^{2}+\frac{1}{2} D_{s y 9} \dot{U}_{s y 9}{ }^{2}+\frac{1}{2} D_{s y 10} \dot{U}_{s y 10}{ }^{2}+ \\
& \frac{1}{2} D_{s y 11} \dot{U}_{s y 11}{ }^{2}+\frac{1}{2} D_{s y 12} \dot{U}_{s y 12}{ }^{2}+\frac{1}{2} D_{t y 1} \dot{U}_{t y 1}{ }^{2}+\frac{1}{2} D_{t y 2} \dot{U}_{t y 2}{ }^{2}+\frac{1}{2} D_{t y 3} \dot{U}_{t y 3}{ }^{2}+ \\
& \frac{1}{2} D_{t y 4} \dot{U}_{t y 4}{ }^{2}+\frac{1}{2} D_{t y 5} \dot{U}_{t y 5}{ }^{2}+\frac{1}{2} D_{t y 6} \dot{U}_{t y 6}{ }^{2}+\frac{1}{2} D_{t y 7} \dot{U}_{t y 7}{ }^{2}+\frac{1}{2} D_{t y 8} \dot{U}_{t y 8}{ }^{2}+ \\
& \frac{1}{2} D_{t y 99} \dot{U}_{t y 9}{ }^{2}+\frac{1}{2} D_{t y 10} \dot{U}_{t y 10}{ }^{2}+\frac{1}{2} D_{t y 11} \dot{U}_{t y 11}{ }^{2}+\frac{1}{2} D_{t y 12} \dot{U}_{t y 12}{ }^{2}
\end{aligned}
$$

The displacement at the pivot point should stay the same, whether it is calculated from the trailer part or the tractor part,

$$
y_{t 2}+\theta_{t 2} l_{8}=y_{t 1}-\theta_{t 1} l_{7}
$$

Thus, by calculating $\theta_{t 2}$ from equation ( 145 ) and substituting in equation ( 142 ),

$$
T=\frac{1}{2} m_{t 1} \dot{y}_{t 1}{ }^{2}+\frac{1}{2} m_{a 1} \dot{y}_{a 1}{ }^{2}+\frac{1}{2} m_{a 2} \dot{y}_{a 2}{ }^{2}+\frac{1}{2} m_{a 3} \dot{y}_{a 3}{ }^{2}+\frac{1}{2} m_{a 4} \dot{y}_{a 4}{ }^{2}+\frac{1}{2} m_{a 5} \dot{y}_{a 5}{ }^{2}+
$$




$$
\begin{aligned}
& \frac{1}{2} m_{a 6} \dot{y}_{a 6}{ }^{2}+\frac{1}{2} I_{x t 1} \dot{\varphi}_{t 1}{ }^{2}+\frac{1}{2} I_{z t 1} \dot{\theta}_{t 1}{ }^{2}+\frac{1}{2} I_{x t 2} \dot{\varphi}_{t 2}{ }^{2}+\frac{1}{2} I_{z t 2}\left(\frac{\dot{y}_{t 1}-\dot{y}_{t 2}-\dot{\theta}_{t 1} l_{8}}{l_{9}}\right)^{2}+ \\
& \frac{1}{2} I_{x a 1} \dot{\varphi}_{a 1}{ }^{2}+\frac{1}{2} I_{x a 2} \dot{\varphi}_{a 2}{ }^{2}+\frac{1}{2} I_{x a 3} \dot{\varphi}_{a 3}{ }^{2}+\frac{1}{2} I_{x a 4} \dot{\varphi}_{a 4}{ }^{2}+\frac{1}{2} I_{x a 5} \dot{\varphi}_{a 5}{ }^{2}+\frac{1}{2} I_{x a 6} \dot{\varphi}_{a 6}{ }^{2}+ \\
& \frac{1}{2} m_{t 2} \dot{y}_{t 2}{ }^{2}
\end{aligned}
$$

Same substitution will be applied to the equations ( 143 ) and ( 144 ). Now the Lagrange's equation is applied to $\mathrm{y}_{\mathrm{t} 2}$ :

$$
\begin{aligned}
& {\left[m_{t 2} \ddot{y}_{t 2}-\frac{I_{z t 2}}{l_{9}^{2}}\left(\ddot{y}_{t 1}-\ddot{y}_{t 2}-\ddot{\theta}_{t 1} l_{8}\right)\right]+\left[( 1 + \frac { l _ { 1 0 } } { l _ { 9 } } ) \left(K_{s y 7} U_{s y 7}+K_{s y 8} U_{s y 8}+F_{y 7}+\right.\right.} \\
& \left.F_{y 8}\right)+\left(1+\frac{l_{4}+l_{10}}{l_{9}}\right)\left(K_{s y 9} U_{s y 9}+K_{s y 10} U_{s y 10}+F_{y 9}+F_{y 10}\right)+ \\
& \left.\left(1+\frac{l_{4}+l_{5}+l_{10}}{l_{9}}\right)\left(K_{s y 11} U_{s y 11}+K_{s y 12} U_{s y 12}+F_{y 11}+F_{y 12}\right)-\left(m_{t 2} g\right)\right]+[(1+ \\
& \left.\frac{l_{10}}{l_{9}}\right)\left(D_{s y 7} \dot{U}_{s y 7}+D_{s y 8} \dot{U}_{s y 8}\right)+\left(1+\frac{l_{4}+l_{10}}{l_{9}}\right)\left(D_{s y 9} \dot{U}_{s y 9}+D_{s y 10} \dot{U}_{s y 10}\right)+(1+ \\
& \left.\left.\frac{l_{4}+l_{5}+l_{10}}{l_{9}}\right)\left(D_{s y 11} \dot{U}_{s y 11}+D_{s y 12} \dot{U}_{s y 12}\right)\right]=0
\end{aligned}
$$

To simplify the equation some variables are defined as follows:

$$
\begin{aligned}
& S_{a 2}=\frac{I_{z t 2}}{l_{8}{ }^{2}} \\
& S_{c 2}=\frac{I_{z t 2}}{l_{8}{ }^{2}}+m_{t 2} \\
& S_{a 3}=\frac{I_{z t 2}}{l_{8}{ }^{2}} l_{7} \\
& B_{t 4}=m_{t 2} g-\left(1+\frac{l_{9}}{l_{8}}\right)\left(F_{s y 7}+F_{s y 8}+F_{d s y 7}+F_{d s y 8}\right)-\left(1+\frac{l_{4}+l_{9}}{l_{8}}\right)\left(F_{s y 9}+F_{s y 10}+F_{d s y 9}+\right. \\
& \left.F_{d s y 10}\right)
\end{aligned}
$$

Therefore equation ( 147 ) will be simplified to: 
$-S_{a 2} \ddot{y}_{t 1}+S_{c 2} \ddot{y}_{t 2}+S_{a 3} \ddot{\theta}_{t 1}=B_{t 4}$

By applying the Lagrange's equation to $\mathrm{y}_{\mathrm{t} 1}$ :

$$
\begin{aligned}
& {\left[m_{t 1} \ddot{y}_{t 1}+\frac{I_{z t 2}}{l_{9}^{2}}\left(\ddot{y}_{t 1}-\ddot{y}_{t 2}-\ddot{\theta}_{t 1} l_{8}\right)\right]+\left[\left(F_{s y 1}+F_{s y 2}+F_{s y 3}+F_{s y 4}+F_{s y 5}+F_{s y 6}\right)-\right.} \\
& \left.\frac{l_{10}}{l_{9}}\left(F_{s y 7}+F_{s y 8}\right)-\frac{l_{4}+l_{10}}{l_{9}}\left(F_{s y 9}+F_{s y 10}\right)-\frac{l_{4}+l_{5}+l_{10}}{l_{9}}\left(F_{s y 11}+F_{s y 12}\right)-\left(m_{t 1} g\right)\right]+ \\
& {\left[\left(F_{d s y 1}+F_{d s y 2}+F_{d s y 3}+F_{d s y 4}+F_{d s y 5}+F_{d s y 6}\right)-\frac{l_{10}}{l_{9}}\left(F_{d s y 7}+F_{d s y 8}\right)-\right.} \\
& \left.\frac{l_{4}+l_{10}}{l_{9}}\left(F_{d s y 9}+F_{d s y 10}\right)-\frac{l_{4}+l_{5}+l_{10}}{l_{9}}\left(F_{d s y 11}+F_{d s y 12}\right)\right]=0
\end{aligned}
$$

Again to simplify the equation some variables are defined as follows:

$$
\begin{aligned}
& S_{a 1}=\frac{I_{z t 2}}{l_{9}^{2}}+m_{t 1} \\
& B_{t 1}=m_{t 1} g-\left[\left(F_{s y 1}+F_{s y 2}+F_{s y 3}+F_{s y 4}+F_{s y 5}+F_{s y 6}\right)-\frac{l_{10}}{l_{9}}\left(F_{s y 7}+F_{s y 8}\right)-\frac{l_{4}+l_{10}}{l_{9}}\left(F_{s y 9}+\right.\right. \\
& \left.F_{s y 10}\right)-\frac{l_{4}+l_{5}+l_{10}}{l_{9}}\left(F_{s y 11}+F_{s y 12}\right)+\left(F_{d s y 1}+F_{d s y 2}+F_{d s y 3}+F_{d s y 4}+F_{d s y 5}+F_{d s y 6}\right)- \\
& \left.\frac{l_{10}}{l_{9}}\left(F_{d s y 7}+F_{d s y 8}\right)-\frac{l_{4}+l_{10}}{l_{9}}\left(F_{d s y 9}+F_{d s y 10}\right)-\frac{l_{4}+l_{5}+l_{10}}{l_{9}}\left(F_{d s y 11}+F_{d s y 12}\right)\right]
\end{aligned}
$$

Therefore equation ( 149 ) will be simplified to:

$$
S_{a 1} \ddot{y}_{t 1}-S_{a 2} \ddot{y}_{t 2}-S_{a 3} \ddot{\theta}_{t 1}=B_{t 1}
$$

Also, by applying the Lagrange's equation to $\theta_{\mathrm{t} 1}$ :

$$
\begin{aligned}
& {\left[I_{z t 1} \ddot{\theta}_{t 1}-\frac{I_{z t 2} l_{8}}{l_{9}{ }^{2}}\left(\ddot{y}_{t 1}-\ddot{y}_{t 2}-\ddot{\theta}_{t 1} l_{8}\right)\right]+\left[l_{6}\left(F_{s y 1}+F_{s y 2}\right)-l_{7}\left(F_{s y 3}+F_{s y 4}\right)-\right.} \\
& \left(l_{2}+l_{7}\right)\left(F_{s y 5}+F_{s y 6}\right)+\frac{l_{8} I_{10}}{l_{9}}\left(F_{s y 7}+F_{s y 8}\right)+\frac{l_{8}\left(I_{4}+l_{10}\right)}{l_{9}}\left(F_{s y 9}+F_{s y 10}\right)+ \\
& \left.\frac{l_{8}\left(I_{4}+l_{5}+l_{10}\right)}{l_{9}}\left(F_{s y 11}+F_{s y 12}\right)\right]+\left[l_{6}\left(F_{d s y 1}+F_{d s y 2}\right)-l_{7}\left(F_{d s y 3}+F_{d s y 4}\right)-\right.
\end{aligned}
$$




$$
\begin{aligned}
& \left(l_{2}+l_{7}\right)\left(F_{d s y 5}+F_{d s y 6}\right)+\frac{l_{8} I_{10}}{l_{9}}\left(F_{d s y 7}+F_{d s y 8}\right)+\frac{l_{8}\left(I_{4}+l_{10}\right)}{l_{9}}\left(F_{d s y 9}+F_{d s y 10}\right)+ \\
& \left.\frac{l_{8}\left(I_{4}+l_{5}+l_{10}\right)}{l_{9}}\left(F_{d s y 11}+F_{d s y 12}\right)\right]=0
\end{aligned}
$$

Once again to simplify the equation some variables need to be defined as follows:

$$
\begin{aligned}
& S_{b 3}=I_{z t 1}+\frac{I_{z t 2} l_{8}^{2}}{l_{9}{ }^{2}} \\
& B_{t 3}=-\left[\left[l_{6}\left(F_{s y 1}+F_{s y 2}\right)-l_{7}\left(F_{s y 3}+F_{s y 4}\right)-\left(l_{2}+l_{7}\right)\left(F_{s y 5}+F_{s y 6}\right)+\frac{l_{8} I_{10}}{l_{9}}\left(F_{s y 7}+F_{s y 8}\right)+\right.\right. \\
& \left.\frac{l_{8}\left(I_{4}+l_{10}\right)}{l_{9}}\left(F_{s y 9}+F_{s y 10}\right)+\frac{l_{8}\left(I_{4}+l_{5}+l_{10}\right)}{l_{9}}\left(F_{s y 11}+F_{s y 12}\right)\right]+\left[l_{6}\left(F_{d s y 1}+F_{d s y 2}\right)-l_{7}\left(F_{d s y 3}+\right.\right. \\
& \left.F_{d s y 4}\right)-\left(l_{2}+l_{7}\right)\left(F_{d s y 5}+F_{d s y 6}\right)+\frac{l_{8} I_{10}}{l_{9}}\left(F_{d s y 7}+F_{d s y 8}\right)+\frac{l_{8}\left(I_{4}+l_{10}\right)}{l_{9}}\left(F_{d s y 9}+F_{d s y 10}\right)+ \\
& \left.\left.\frac{l_{8}\left(I_{4}+l_{5}+l_{10}\right)}{l_{9}}\left(F_{d s y 11}+F_{d s y 12}\right)\right]\right]
\end{aligned}
$$

Therefore equation ( 151 ) will be simplified to:

$$
-S_{a 3} \ddot{y}_{t 1}+S_{a 3} \ddot{y}_{t 2}+S_{b 3} \ddot{\theta}_{t 1}=B_{t 3}
$$

By adding equations ( 148 ) and ( 150 ),

$$
\left(S_{a 1}-S_{a 2}\right) \ddot{y}_{t 1}-\left(S_{a 2}-S_{c 2}\right) \ddot{y}_{t 2}=B_{t 1}+B_{t 4}
$$

Also by multiplying $S_{b 3}$ and $S_{a 3}$ to equations ( 150 ) and ( 152 ) respectively,

$$
\left(S_{a 1} S_{b 3}-S_{a 3}^{2}\right) \ddot{y}_{t 1}-\left(S_{a 2} S_{b 3}-S_{a 3}^{2}\right) \ddot{y}_{t 2}=S_{b 3} B_{t 1}+S_{a 3} B_{t 3}
$$

By defining the following expressions, equations ( 153 ) and ( 154 ) are simplified to equations ( 155 ) and ( 156 ) respectively,

$$
\begin{aligned}
& e_{1}=S_{a 1}-S_{a 2} \\
& e_{2}=S_{a 2}-S_{c 2}
\end{aligned}
$$




$$
\begin{aligned}
& e_{3}=S_{a 1} S_{b 3}-S_{a 3}^{2} \\
& e_{4}=S_{a 2} S_{b 3}-S_{a 3}^{2} \\
& e_{1} \ddot{y}_{t 1}-e_{2} \ddot{y}_{t 2}=B_{t 1}+B_{t 4} \\
& e_{3} \ddot{y}_{t 1}-e_{4} \ddot{y}_{t 2}=S_{b 3} B_{t 1}+S_{a 3} B_{t 3}
\end{aligned}
$$

Solving equations ( 155 ) and ( 156 ) for $\ddot{y}_{t 1}$ and $\ddot{y}_{t 2}$ will lead to:

$$
\begin{aligned}
& \ddot{y}_{t 1}=\frac{e_{4}\left(B_{t 1}+B_{t 4}\right)-e_{2}\left(S_{b 3} B_{t 1}+S_{a 3} B_{t 3}\right)}{e_{1} e_{4}-e_{2} e_{3}} \\
& \ddot{y}_{t 2}=\frac{e_{1}}{e_{2}}\left(\frac{e_{4}\left(B_{t 1}+B_{t 4}\right)-e_{2}\left(S_{b 3} B_{t 1}+S_{a 3} B_{t 3}\right)}{e_{1} e_{4}-e_{2} e_{3}}\right)-\frac{B_{t 1}+B_{t 4}}{e_{2}}
\end{aligned}
$$

Substituting equations ( 157 ) and ( 158 ) into equation ( 152 ) will give,

$$
\begin{aligned}
& \ddot{\theta}_{t 1}= \\
& \frac{B_{t 3}}{S_{b 3}}+\frac{S_{a 3}}{S_{b 3}}\left(\frac{e_{4}\left(B_{t 1}+B_{t 4}\right)-e_{2}\left(S_{b 3} B_{t 1}+S_{a 3} B_{t 3}\right)}{e_{1} e_{4}-e_{2} e_{3}}\right)-\frac{S_{a 3}}{S_{b 3}}\left(\frac{e_{1}}{e_{2}}\left(\frac{e_{4}\left(B_{t 1}+B_{t 4}\right)-e_{2}\left(S_{b 3} B_{t 1}+S_{a 3} B_{t 3}\right)}{e_{1} e_{4}-e_{2} e_{3}}\right)-\right. \\
& \left.\frac{B_{t 1}+B_{t 4}}{e_{2}}\right)
\end{aligned}
$$

By applying the Lagrange's equation to $\varphi_{t 1}, \varphi_{t 2}$ :

$$
\begin{aligned}
& I_{x t 1} \ddot{\varphi}_{t 1}+\left[\left(\frac{s_{1}}{2}\right)\left(F_{s y 1}-F_{s y 2}\right)+\left(\frac{s_{2}}{2}\right)\left(F_{s y 3}-F_{s y 4}\right)+\left(\frac{s_{3}}{2}\right)\left(F_{s y 5}-F_{s y 6}\right)\right]+ \\
& {\left[\left(\frac{s_{1}}{2}\right)\left(F_{d s y 1}-F_{d s y 2}\right)+\left(\frac{s_{2}}{2}\right)\left(F_{d s y 3}-F_{d s y 4}\right)+\left(\frac{s_{3}}{2}\right)\left(F_{d s y 5}-F_{d s y 6}\right)\right]=0} \\
& I_{x t 2} \ddot{\varphi}_{t 2}+\left[\left(\frac{s_{4}}{2}\right)\left(F_{s y 7}-F_{s y 8}\right)+\left(\frac{s_{5}}{2}\right)\left(F_{s y 9}-F_{s y 10}\right)+\left(\frac{s_{6}}{2}\right)\left(F_{s y 11}-F_{s y 12}\right)\right]+ \\
& {\left[\left(\frac{s_{4}}{2}\right)\left(F_{d s y 7}-F_{d s y 8}\right)+\left(\frac{s_{5}}{2}\right)\left(F_{d s y 9}-F_{d s y 10}\right)+\left(\frac{s_{6}}{2}\right)\left(F_{d s y 11}-F_{d s y 12}\right)\right]=0}
\end{aligned}
$$

Also the rest of degrees of freedom will be as follows:

$$
\begin{aligned}
& m_{a 1} \ddot{y}_{a 1}-\left(F_{s y 1}+F_{s y 2}\right)+\left(F_{t y 1}+F_{t y 2}\right)-\left(F_{d s y 1}+F_{d s y 2}\right)+\left(F_{d t y 1}+F_{d t y 2}\right)= \\
& m_{a 1} g
\end{aligned}
$$




$$
\begin{aligned}
& I_{x a 1} \ddot{\varphi}_{a 1}-\left(\frac{s_{1}}{2}\right)\left(F_{s y 1}-F_{s y 2}\right)+\left(\frac{d_{1}}{2}\right)\left(F_{t y 1}-F_{t y 2}\right)-\left(\frac{s_{1}}{2}\right)\left(F_{d s y 1}-F_{d s y 2}\right)+ \\
& \left(\frac{d_{1}}{2}\right)\left(F_{d t y 1}-F_{d t y 2}\right)=0 \\
& m_{a 2} \ddot{y}_{a 2}-\left(F_{s y 3}+F_{s y 4}\right)+\left(F_{t y 3}+F_{t y 4}\right)-\left(F_{d s y 3}+F_{d s y 4}\right)+\left(F_{d t y 3}+F_{d t y 4}\right)= \\
& m_{a 2} g \\
& I_{x a 2} \ddot{\varphi}_{a 2}-\left(\frac{s_{2}}{2}\right)\left(F_{s y 3}-F_{s y 4}\right)+\left(\frac{d_{2}}{2}\right)\left(F_{t y 3}-F_{t y 4}\right)-\left(\frac{s_{2}}{2}\right)\left(F_{d s y 3}-F_{d s y 4}\right)+ \\
& \left(\frac{d_{2}}{2}\right)\left(F_{d t y 3}-F_{d t y 4}\right)=0 \\
& m_{a 3} \ddot{y}_{a 3}-\left(F_{s y 5}+F_{s y 6}\right)+\left(F_{t y 5}+F_{t y 6}\right)-\left(F_{d s y 5}+F_{d s y 6}\right)+\left(F_{d t y 5}+F_{d t y 6}\right)= \\
& m_{a 3} g \\
& I_{x a 3} \ddot{\varphi}_{a 3}-\left(\frac{s_{3}}{2}\right)\left(F_{s y 5}-F_{s y 6}\right)+\left(\frac{d_{3}}{2}\right)\left(F_{t y 5}-F_{t y 6}\right)-\left(\frac{s_{3}}{2}\right)\left(F_{d s y 5}-F_{d s y 6}\right)+ \\
& \left(\frac{d_{3}}{2}\right)\left(F_{d t y 5}-F_{d t y 6}\right)=0 \\
& m_{a 4} \ddot{y}_{a 4}-\left(F_{s y 7}+F_{s y 8}\right)+\left(F_{t y 7}+F_{t y 8}\right)-\left(F_{d s y 7}+F_{d s y 8}\right)+\left(F_{d t y 7}+F_{d t y 8}\right)= \\
& m_{a 4} g \\
& I_{x a 4} \ddot{\varphi}_{a 4}-\left(\frac{s_{4}}{2}\right)\left(F_{s y 7}-F_{s y 8}\right)+\left(\frac{d_{4}}{2}\right)\left(F_{t y 7}-F_{t y 8}\right)-\left(\frac{s_{4}}{2}\right)\left(F_{d s y 7}-F_{d s y 8}\right)+ \\
& \left(\frac{d_{4}}{2}\right)\left(F_{d t y 7}-F_{d t y 8}\right)=0 \\
& m_{a 5} \ddot{y}_{a 5}-\left(F_{s y 9}+F_{s y 10}\right)+\left(F_{t y 9}+F_{t y 10}\right)-\left(F_{d s y 9}+F_{d s y 10}\right)+\left(F_{d t y 9}+\right. \\
& \left.F_{d t y 10}\right)=m_{a 5} g \\
& I_{x a 5} \ddot{\varphi}_{a 5}-\left(\frac{s_{5}}{2}\right)\left(F_{s y 9}-F_{s y 10}\right)+\left(\frac{d_{5}}{2}\right)\left(F_{t y 9}-F_{t y 10}\right)-\left(\frac{s_{5}}{2}\right)\left(F_{d s y 9}-F_{d s y 10}\right)+ \\
& \left(\frac{d_{5}}{2}\right)\left(F_{d t y 9}-F_{d t y 10}\right)=0 \\
& m_{a 6} \ddot{y}_{a 6}-\left(F_{s y 11}+F_{s y 12}\right)+\left(F_{t y 11}+F_{t y 12}\right)-\left(F_{d s y 11}+F_{d s y 12}\right)+\left(F_{d t y 11}+\right. \\
& \left.F_{d t y 12}\right)=m_{a 6} g \\
& I_{x a 6} \ddot{\varphi}_{a 6}-\left(\frac{s_{6}}{2}\right)\left(F_{s y 11}-F_{s y 12}\right)+\left(\frac{d_{6}}{2}\right)\left(F_{t y 11}-F_{t y 12}\right)-\left(\frac{s_{6}}{2}\right)\left(F_{d s y 11}-F_{d s y 12}\right)+
\end{aligned}
$$


$\left(\frac{d_{6}}{2}\right)\left(F_{d t y 11}-F_{d t y 12}\right)=0$

\section{Derivation of Equations of Motion for Type 3S1 Truck}

There are fourteen degrees of freedom in total for this type of truck. The degrees of freedom can be seen in Figure 4 and the description of those degrees of freedom can be found in Table 7. Relative Displacements at the locations of the springs are also calculated using the values given in Table 8.

Table 7. Degrees of Freedom of Type 3S1 Truck

\begin{tabular}{|c|c|l|l|}
\hline $\begin{array}{c}\text { No. } \\
\text { Freedom }\end{array}$ & $\begin{array}{c}\text { Degree of } \\
\text { Fass }\end{array}$ & $\begin{array}{c}\text { Contributed } \\
\text { Mascription }\end{array}$ \\
$\mathbf{2}$ & $\mathrm{y}_{\mathrm{t} 1}$ & $\mathrm{~m}_{\mathrm{t} 1}$ & Tractor vertical displacement and mass \\
$\mathbf{3}$ & $\varphi_{\mathrm{t} 1}$ & $\mathrm{I}_{\mathrm{xt} 1}$ & Tractor roll displacement and mass moment of inertia \\
$\mathbf{4}$ & $\theta_{\mathrm{t} 1}$ & $\mathrm{I}_{\mathrm{zt} 1}$ & Tractor pitch displacement and mass moment of inertia \\
$\mathbf{5}$ & $\mathrm{y}_{\mathrm{t} 2}$ & $\mathrm{~m}_{\mathrm{t} 2}$ & Trailer vertical displacement and mass \\
$\mathbf{6}$ & $\varphi_{\mathrm{t} 2}$ & $\mathrm{I}_{\mathrm{xt} 2}$ & Trailer roll displacement and mass moment of inertia \\
$\mathbf{7}$ & $\theta_{\mathrm{t} 2}$ & $\mathrm{I}_{\mathrm{zt} 2}$ & Trailer pitch displacement and mass moment of inertia \\
$\mathbf{8}$ & $\mathrm{y}_{\mathrm{a} 1}$ & $\mathrm{~m}_{\mathrm{a} 1}$ & Steer axle vertical displacement and mass \\
$\mathbf{9}$ & $\varphi_{\mathrm{a} 1}$ & $\mathrm{I}_{\mathrm{xa} 1}$ & Steer axle roll displacement and mass moment of inertia \\
\hline $\mathbf{1 0}$ & $\mathrm{y}_{\mathrm{a} 2}$ & $\mathrm{~m}_{\mathrm{a} 2}$ & Vertical displacement and mass of forward axle of tractor \\
& $\varphi_{\mathrm{a} 2}$ & $\mathrm{I}_{\mathrm{xa} 2}$ & tandem \\
\hline $\mathbf{1 1}$ & $\mathrm{y}_{\mathrm{a} 3}$ & $\mathrm{~m}_{\mathrm{a} 3}$ & Roll displacement and mass moment of inertia of forward \\
$\mathbf{1 2}$ & $\varphi_{\mathrm{a} 3}$ & $\mathrm{I}_{\mathrm{xa} 3}$ & $\begin{array}{l}\text { Roll displacement and mass moment of inertia of aft axle } \\
\text { of tractor tandem }\end{array}$ \\
\hline $\mathbf{1 3}$ & $\mathrm{y}_{\mathrm{a} 4}$ & $\mathrm{~m}_{\mathrm{a} 4}$ & Trailer axle vertical displacement and mass \\
\hline & $\varphi_{\mathrm{a} 4}$ & $\mathrm{I}_{\mathrm{xa} 4}$ & Trailer axle roll displacement and mass moment of inertia \\
\hline
\end{tabular}


Figure 4. Type 3S1 Dynamic Model (a) Truck Side View (b) Truck Front View 
Table 8. Relative Displacements at Spring Locations of Type 3S1 Truck

\begin{tabular}{|c|c|}
\hline & Suspension springs \\
\hline $\mathbf{U}_{\text {sy1 }}$ & $\left(\mathrm{y}_{\mathrm{t} 1}-\mathrm{y}_{\mathrm{a} 1}\right)+\left(\mathrm{S}_{1} / 2\right)\left(\varphi_{\mathrm{t} 1}-\varphi_{\mathrm{a} 1}\right)+\mathrm{l}_{5} \theta_{\mathrm{t} 1}$ \\
\hline $\mathbf{U}_{\text {sy2 }}$ & $\left(\mathrm{y}_{\mathrm{t} 1}-\mathrm{y}_{\mathrm{a} 1}\right)-\left(\mathrm{S}_{1} / 2\right)\left(\varphi_{\mathrm{t} 1}-\varphi_{\mathrm{a} 1}\right)+\mathrm{l}_{5} \theta_{\mathrm{t} 1}$ \\
\hline $\mathbf{U}_{\text {sy3 }}$ & $\left(\mathrm{y}_{\mathrm{t} 1}-\mathrm{y}_{\mathrm{a} 2}\right)+\left(\mathrm{S}_{2} / 2\right)\left(\varphi_{\mathrm{t} 1}-\varphi_{\mathrm{a} 2}\right)-\mathrm{l}_{6} \theta_{\mathrm{t} 1}$ \\
\hline $\mathbf{U}_{\text {sy4 }}$ & $\left(y_{\mathrm{t} 1}-\mathrm{y}_{\mathrm{a} 2}\right)-\left(\mathrm{S}_{2} / 2\right)\left(\varphi_{\mathrm{t} 1}-\varphi_{\mathrm{a} 2}\right)-\mathrm{l}_{6} \theta_{\mathrm{t} 1}$ \\
\hline $\mathbf{U}_{\text {sy5 }}$ & $\left(\mathrm{y}_{\mathrm{t} 1}-\mathrm{y}_{\mathrm{a} 3}\right)+\left(\mathrm{S}_{3} / 2\right)\left(\varphi_{\mathrm{t} 1}-\varphi_{\mathrm{a} 3}\right)-\left(\mathrm{l}_{2}+\mathrm{l}_{6}\right) \theta_{\mathrm{t} 1}$ \\
\hline $\mathbf{U}_{\text {sy6 }}$ & $\left(\mathrm{y}_{\mathrm{t} 1}-\mathrm{y}_{\mathrm{a} 3}\right)-\left(\mathrm{S}_{3} / 2\right)\left(\varphi_{\mathrm{t} 1}-\varphi_{\mathrm{a} 3}\right)-\left(\mathrm{l}_{2}+\mathrm{l}_{6}\right) \theta_{\mathrm{t} 1}$ \\
\hline $\mathbf{U}_{\text {sy7 }}$ & $\left(\mathrm{y}_{\mathrm{t} 2}-\mathrm{y}_{\mathrm{a} 4}\right)+\left(\mathrm{S}_{4} / 2\right)\left(\varphi_{\mathrm{t} 2}-\varphi_{\mathrm{a} 4}\right)-\mathrm{l}_{9} \theta_{\mathrm{t} 2}$ \\
\hline $\mathbf{U}_{\text {sy8 }}$ & $\left(\mathrm{y}_{\mathrm{t} 2}-\mathrm{y}_{\mathrm{a} 4}\right)-\left(\mathrm{S}_{4} / 2\right)\left(\varphi_{\mathrm{t} 2}-\varphi_{\mathrm{a} 4}\right)-\mathrm{l}_{9} \theta_{\mathrm{t} 2}$ \\
\hline & Tire springs \\
\hline $\mathbf{U}_{\text {ty } 1}$ & $\mathrm{y}_{\mathrm{a} 1}+\left(\mathrm{d}_{1} / 2\right) \varphi_{\mathrm{a} 1}+\mathrm{u}_{\mathrm{SR} 1}$ \\
\hline $\mathbf{U}_{\text {ty2 }}$ & $\mathrm{y}_{\mathrm{a} 1}-\left(\mathrm{d}_{1} / 2\right) \varphi_{\mathrm{a} 1}+\mathrm{u}_{\mathrm{SR} 2}$ \\
\hline $\mathbf{U}_{\text {ty3 }}$ & $\mathrm{y}_{\mathrm{a} 2}+\left(\mathrm{d}_{2} / 2\right) \varphi_{\mathrm{a} 2}+\mathrm{u}_{\mathrm{SR} 3}$ \\
\hline $\mathbf{U}_{\text {ty } 4}$ & $\mathrm{y}_{\mathrm{a} 2}-\left(\mathrm{d}_{2} / 2\right) \varphi_{\mathrm{a} 2}+\mathrm{u}_{\mathrm{SR} 4}$ \\
\hline $\mathbf{U}_{\mathrm{ty5}}$ & $\mathrm{y}_{\mathrm{a} 3}+\left(\mathrm{d}_{3} / 2\right) \varphi_{\mathrm{a} 3}+\mathrm{u}_{\mathrm{SR} 5}$ \\
\hline $\mathbf{U}_{\mathrm{ty} 6}$ & $\mathrm{y}_{\mathrm{a} 3}-\left(\mathrm{d}_{3} / 2\right) \varphi_{\mathrm{a} 3}+\mathrm{u}_{\mathrm{SR} 6}$ \\
\hline $\mathbf{U}_{\text {ty7 }}$ & $\mathrm{y}_{\mathrm{a} 4}+\left(\mathrm{d}_{4} / 2\right) \varphi_{\mathrm{a} 4}+\mathrm{u}_{\mathrm{SR} 7}$ \\
\hline $\mathbf{U}_{\text {ty8 }}$ & $\mathrm{y}_{\mathrm{a} 4}-\left(\mathrm{d}_{4} / 2\right) \varphi_{\mathrm{a} 4}+\mathrm{u}_{\mathrm{SR} 8}$ \\
\hline
\end{tabular}

Kinetic Energy of the system:

$$
\begin{aligned}
& T=\frac{1}{2} m_{t 1} \dot{y}_{t 1}{ }^{2}+\frac{1}{2} m_{a 1} \dot{y}_{a 1}{ }^{2}+\frac{1}{2} m_{a 2} \dot{y}_{a 2}{ }^{2}+\frac{1}{2} m_{a 3} \dot{y}_{a 3}{ }^{2}+\frac{1}{2} m_{a 4} \dot{y}_{a 4}{ }^{2}+\frac{1}{2} I_{x t 1} \dot{\varphi}_{t 1}{ }^{2}+ \\
& \frac{1}{2} I_{z t 1} \dot{\theta}_{t 1}{ }^{2}+\frac{1}{2} I_{x t 2} \dot{\varphi}_{t 2}{ }^{2}+\frac{1}{2} I_{z t 2} \dot{\theta}_{t 2}{ }^{2}+\frac{1}{2} I_{x a 1} \dot{\varphi}_{a 1}{ }^{2}+\frac{1}{2} I_{x a 2} \dot{\varphi}_{a 2}{ }^{2}+\frac{1}{2} I_{x a 3} \dot{\varphi}_{a 3}{ }^{2}+ \\
& \frac{1}{2} I_{x a 4} \dot{\varphi}_{a 4}{ }^{2}+\frac{1}{2} m_{t 2} \dot{y}_{t 2}{ }^{2}
\end{aligned}
$$

Potential Energy of the system:

$$
V=\frac{1}{2} K_{s y 1} U_{s y 1}{ }^{2}+\frac{1}{2} K_{s y 2} U_{s y 2}{ }^{2}+\frac{1}{2} K_{s y 3} U_{s y 3}{ }^{2}+\frac{1}{2} K_{s y 4} U_{s y 4}{ }^{2}+\frac{1}{2} K_{s y 5} U_{s y 5}{ }^{2}+
$$




$$
\begin{aligned}
& \frac{1}{2} K_{s y 6} U_{s y 6}{ }^{2}+\frac{1}{2} K_{s y 7} U_{s y 7}{ }^{2}+\frac{1}{2} K_{s y 8} U_{s y 8}{ }^{2}+\frac{1}{2} K_{t y 1} U_{t y 1}{ }^{2}+\frac{1}{2} K_{t y 2} U_{t y 2}{ }^{2}+ \\
& \frac{1}{2} K_{t y 3} U_{t y 3}{ }^{2}+\frac{1}{2} K_{t y 4} U_{t y 4}{ }^{2}+\frac{1}{2} K_{t y 5} U_{t y 5}{ }^{2}+\frac{1}{2} K_{t y 6} U_{t y 6}{ }^{2}+\frac{1}{2} K_{t y 7} U_{s y 7}{ }^{2}+ \\
& \frac{1}{2} K_{t y 8} U_{t y 8}{ }^{2}-\left(\left(m_{t 1} g\right) y_{t 1}+\left(m_{t 2} g\right) y_{t 2}+\left(m_{a 1} g\right) y_{a 1}+\left(m_{a 2} g\right) y_{a 2}+\right. \\
& \left.\left(m_{a 3} g\right) y_{a 3}+\left(m_{a 4} g\right) y_{a 4}\right)+\left(F_{y 1} U_{s y 1}+F_{y 2} U_{s y 2}+F_{y 3} U_{s y 3}+F_{y 4} U_{s y 4}+\right. \\
& \left.F_{y 5} U_{s y 5}+F_{y 6} U_{s y 6}+F_{y 7} U_{s y 7}+F_{y 8} U_{s y 8}\right)
\end{aligned}
$$

Damping Energy of the system:

$$
\begin{aligned}
& D=\frac{1}{2} D_{s y 1} \dot{U}_{s y 1}{ }^{2}+\frac{1}{2} D_{s y 2} \dot{U}_{s y 2}{ }^{2}+\frac{1}{2} D_{s y 3} \dot{U}_{s y 3}{ }^{2}+\frac{1}{2} D_{s y 4} \dot{U}_{s y 4}{ }^{2}+\frac{1}{2} D_{s y 5} \dot{U}_{s y 5}{ }^{2}+ \\
& \frac{1}{2} D_{s y 6} \dot{U}_{s y 6}{ }^{2}+\frac{1}{2} D_{s y 7} \dot{U}_{s y 7}{ }^{2}+\frac{1}{2} D_{s y 8} \dot{U}_{s y 8}{ }^{2}+\frac{1}{2} D_{t y 1} \dot{U}_{t y 1}{ }^{2}+\frac{1}{2} D_{t y 2} \dot{U}_{t y 2}{ }^{2}+ \\
& \frac{1}{2} D_{t y 3} \dot{U}_{t y 3}{ }^{2}+\frac{1}{2} D_{t y 4} \dot{U}_{t y 4}{ }^{2}+\frac{1}{2} D_{t y 5} \dot{U}_{t y 5}{ }^{2}+\frac{1}{2} D_{t y 6} \dot{U}_{t y 6}{ }^{2}+\frac{1}{2} D_{t y 7} \dot{U}_{t y 7}{ }^{2}+ \\
& \frac{1}{2} D_{t y 8} \dot{U}_{t y 8}{ }^{2}
\end{aligned}
$$

Whether it is calculated from the trailer part or the tractor part, the displacement at the pivot point should be the same,

$y_{t 2}+\theta_{t 2} l_{8}=y_{t 1}-\theta_{t 1} l_{7}$

Thus, by calculating $\theta_{t 2}$ from equation ( 177 ) and substituting in equation ( 174 ),

$$
\begin{aligned}
& T=\frac{1}{2} m_{t 1} \dot{y}_{t 1}{ }^{2}+\frac{1}{2} m_{a 1} \dot{y}_{a 1}{ }^{2}+\frac{1}{2} m_{a 2} \dot{y}_{a 2}{ }^{2}+\frac{1}{2} m_{a 3} \dot{y}_{a 3}{ }^{2}+\frac{1}{2} m_{a 4} \dot{y}_{a 4}{ }^{2}+\frac{1}{2} I_{x t 1} \dot{\varphi}_{t 1}{ }^{2}+ \\
& \frac{1}{2} I_{z t 1} \dot{\theta}_{t 1}{ }^{2}+\frac{1}{2} I_{x t 2} \dot{\varphi}_{t 2}{ }^{2}+\frac{1}{2} I_{z t 2}\left(\frac{\dot{y}_{t 1}-\dot{y}_{t 2}-\dot{\theta}_{t 1} l_{7}}{l_{8}}\right)^{2}+\frac{1}{2} I_{x a 1} \dot{\varphi}_{a 1}{ }^{2}+\frac{1}{2} I_{x a 2} \dot{\varphi}_{a 2}{ }^{2}+ \\
& \frac{1}{2} I_{x a 3} \dot{\varphi}_{a 3}{ }^{2}+\frac{1}{2} I_{x a 4} \dot{\varphi}_{a 4}{ }^{2}+\frac{1}{2} m_{t 2} \dot{y}_{t 2}{ }^{2}
\end{aligned}
$$

Same substitution will be applied to the equations ( 175 ) and ( 176 ). Now the Lagrange's equation is applied to $\mathrm{y}_{\mathrm{t} 2}$ : 


$$
\begin{aligned}
& {\left[m_{t 2} \ddot{y}_{t 2}-\frac{I_{z t 2}}{l_{8}^{2}}\left(\ddot{y}_{t 1}-\ddot{y}_{t 2}-\ddot{\theta}_{t 1} l_{7}\right)\right]+\left[( 1 + \frac { l _ { 9 } } { l _ { 8 } } ) \left(K_{s y 7} U_{s y 7}+K_{s y 8} U_{s y 8}+F_{y 7}+\right.\right.} \\
& \left.\left.F_{y 8}\right)+-\left(m_{t 2} g\right)\right]+\left[\left(1+\frac{l_{9}}{l_{8}}\right)\left(D_{s y 7} \dot{U}_{s y 7}+D_{s y 8} \dot{U}_{s y 8}\right)\right]=0
\end{aligned}
$$

To simplify the equation some variables are defined as follows:

$$
\begin{aligned}
& S_{a 2}=\frac{I_{z t 2}}{l_{8}{ }^{2}} \\
& S_{c 2}=\frac{I_{z t 2}}{l_{8}{ }^{2}}+m_{t 2} \\
& S_{a 3}=\frac{I_{z t 2}}{l_{8}{ }^{2}} l_{7} \\
& B_{t 4}=m_{t 2} g-\left(1+\frac{l_{9}}{l_{8}}\right)\left(F_{s y 7}+F_{s y 8}+F_{d s y 7}+F_{d s y 8}\right)
\end{aligned}
$$

Therefore equation ( 179 ) will be simplified to:

$$
-S_{a 2} \ddot{y}_{t 1}+S_{c 2} \ddot{y}_{t 2}+S_{a 3} \ddot{\theta}_{t 1}=B_{t 4}
$$

By applying the Lagrange's equation to $\mathrm{y}_{\mathrm{t} 1}$ :

$$
\begin{aligned}
& {\left[m_{t 1} \ddot{y}_{t 1}+\frac{I_{z t 2}}{l_{8}^{2}}\left(\ddot{y}_{t 1}-\ddot{y}_{t 2}-\ddot{\theta}_{t 1} l_{7}\right)\right]+\left[\left(F_{s y 1}+F_{s y 2}+F_{s y 3}+F_{s y 4}+F_{s y 5}+F_{s y 6}\right)-\right.} \\
& \left.\frac{l_{9}}{l_{8}}\left(F_{s y 7}+F_{s y 8}\right)-\left(m_{t 1} g\right)\right]+\left[\left(F_{d s y 1}+F_{d s y 2}+F_{d s y 3}+F_{d s y 4}+F_{d s y 5}+F_{d s y 6}\right)-\right. \\
& \left.\frac{l_{9}}{l_{8}}\left(F_{d s y 7}+F_{d s y 8}\right)\right]=0
\end{aligned}
$$

Again to simplify the equation some variables are defined as follows:

$$
S_{a 1}=\frac{I_{z t 2}}{l_{8}^{2}}+m_{t 1}
$$




$$
\begin{aligned}
& B_{t 1}=m_{t 1} g-\left[\left(F_{s y 1}+F_{s y 2}+F_{s y 3}+F_{s y 4}+F_{s y 5}+F_{s y 6}\right)-\frac{l_{9}}{l_{8}}\left(F_{s y 7}+F_{s y 8}\right)+\left(F_{d s y 1}+\right.\right. \\
& \left.\left.F_{d s y 2}+F_{d s y 3}+F_{d s y 4}+F_{d s y 5}+F_{d s y 6}\right)-\frac{l_{9}}{l_{8}}\left(F_{d s y 7}+F_{d s y 8}\right)\right]
\end{aligned}
$$

Therefore equation ( 181 ) will be simplified to:

$S_{a 1} \ddot{y}_{t 1}-S_{a 2} \ddot{y}_{t 2}-S_{a 3} \ddot{\theta}_{t 1}=B_{t 1}$

Also, by applying the Lagrange's equation to $\theta_{\mathrm{t} 1}$ :

$$
\begin{aligned}
& {\left[I_{z t 1} \ddot{\theta}_{t 1}-\frac{I_{z t 2} l_{7}}{l_{8}{ }^{2}}\left(\ddot{y}_{t 1}-\ddot{y}_{t 2}-\ddot{\theta}_{t 1} l_{7}\right)\right]+\left[l_{5}\left(F_{s y 1}+F_{s y 2}\right)-l_{6}\left(F_{s y 3}+F_{s y 4}\right)-\right.} \\
& \left.\left(l_{2}+l_{6}\right)\left(F_{s y 5}+F_{s y 6}\right)+\frac{l_{7} I_{9}}{l_{8}}\left(F_{s y 7}+F_{s y 8}\right)\right]+\left[l_{5}\left(F_{d s y 1}+F_{d s y 2}\right)-l_{6}\left(F_{d s y 3}+\right.\right. \\
& \left.\left.F_{d s y 4}\right)-\left(l_{2}+l_{6}\right)\left(F_{d s y 5}+F_{d s y 6}\right)+\frac{l_{7} I_{9}}{l_{8}}\left(F_{d s y 7}+F_{d s y 8}\right)\right]=0
\end{aligned}
$$

Once again to simplify the equation some variables need to be defined as follows:

$$
\begin{aligned}
& S_{b 3}=I_{z t 1}+\frac{I_{z t 2} l_{7}^{2}}{l_{8}{ }^{2}} \\
& B_{t 3}=-\left[\left[l_{5}\left(F_{s y 1}+F_{s y 2}\right)-l_{6}\left(F_{s y 3}+F_{s y 4}\right)-\left(l_{2}+l_{6}\right)\left(F_{s y 5}+F_{s y 6}\right)+\frac{l_{7} I_{9}}{l_{8}}\left(F_{s y 7}+F_{s y 8}\right)\right]+\right. \\
& \left.\left[l_{5}\left(F_{d s y 1}+F_{d s y 2}\right)-l_{6}\left(F_{d s y 3}+F_{d s y 4}\right)-\left(l_{2}+l_{6}\right)\left(F_{d s y 5}+F_{d s y 6}\right)+\frac{l_{7} I_{9}}{l_{8}}\left(F_{d s y 7}+F_{d s y 8}\right)\right]\right]
\end{aligned}
$$

Therefore equation ( 183 ) will be simplified to:

$$
-S_{a 3} \ddot{y}_{t 1}+S_{a 3} \ddot{y}_{t 2}+S_{b 3} \ddot{\theta}_{t 1}=B_{t 3}
$$

By adding equations ( 180 ) and ( 182 ),

$$
\left(S_{a 1}-S_{a 2}\right) \ddot{y}_{t 1}-\left(S_{a 2}-S_{c 2}\right) \ddot{y}_{t 2}=B_{t 1}+B_{t 4}
$$

Also by multiplying $S_{b 3}$ and $S_{a 3}$ to equations ( 182 ) and ( 184 ) respectively, 
$\left(S_{a 1} S_{b 3}-S_{a 3}{ }^{2}\right) \ddot{y}_{t 1}-\left(S_{a 2} S_{b 3}-S_{a 3}{ }^{2}\right) \ddot{y}_{t 2}=S_{b 3} B_{t 1}+S_{a 3} B_{t 3}$

By defining the following expressions, equations ( 185 ) and ( 186 ) are simplified to equations ( 187 ) and ( 188 ) respectively,

$e_{1}=S_{a 1}-S_{a 2}$

$e_{2}=S_{a 2}-S_{c 2}$

$e_{3}=S_{a 1} S_{b 3}-S_{a 3}^{2}$

$e_{4}=S_{a 2} S_{b 3}-S_{a 3}^{2}$

$e_{1} \ddot{y}_{t 1}-e_{2} \ddot{y}_{t 2}=B_{t 1}+B_{t 4}$

$e_{3} \ddot{y}_{t 1}-e_{4} \ddot{y}_{t 2}=S_{b 3} B_{t 1}+S_{a 3} B_{t 3}$

Solving equations ( 187 ) and ( 188 ) for $\ddot{y}_{t 1}$ and $\ddot{y}_{t 2}$ will lead to:

$\ddot{y}_{t 1}=\frac{e_{4}\left(B_{t 1}+B_{t 4}\right)-e_{2}\left(S_{b 3} B_{t 1}+S_{a 3} B_{t 3}\right)}{e_{1} e_{4}-e_{2} e_{3}}$

$\ddot{y}_{t 2}=\frac{e_{1}}{e_{2}}\left(\frac{e_{4}\left(B_{t 1}+B_{t 4}\right)-e_{2}\left(S_{b_{3}} B_{t 1}+S_{a 3} B_{t 3}\right)}{e_{1} e_{4}-e_{2} e_{3}}\right)-\frac{B_{t 1}+B_{t 4}}{e_{2}}$

Substituting equations ( 189 ) and ( 190 ) into equation ( 184 ) will give,

$\ddot{\theta}_{t 1}=$

$\frac{B_{t 3}}{S_{b 3}}+\frac{S_{a 3}}{S_{b 3}}\left(\frac{e_{4}\left(B_{t 1}+B_{t 4}\right)-e_{2}\left(S_{b 3} B_{t 1}+S_{a 3} B_{t 3}\right)}{e_{1} e_{4}-e_{2} e_{3}}\right)-\frac{S_{a 3}}{S_{b 3}}\left(\frac{e_{1}}{e_{2}}\left(\frac{e_{4}\left(B_{t 1}+B_{t 4}\right)-e_{2}\left(S_{b 3} B_{t 1}+S_{a 3} B_{t 3}\right)}{e_{1} e_{4}-e_{2} e_{3}}\right)-\right.$

$\left.\frac{B_{t 1}+B_{t 4}}{e_{2}}\right)$

By applying the Lagrange's equation to $\varphi_{t 1}, \varphi_{t 2}$ :

$I_{x t 1} \ddot{\varphi}_{t 1}+\left[\left(\frac{s_{1}}{2}\right)\left(F_{s y 1}-F_{s y 2}\right)+\left(\frac{s_{2}}{2}\right)\left(F_{s y 3}-F_{s y 4}\right)+\left(\frac{s_{3}}{2}\right)\left(F_{s y 5}-F_{s y 6}\right)\right]+$ 


$$
\begin{aligned}
& {\left[\left(\frac{s_{1}}{2}\right)\left(F_{d s y 1}-F_{d s y 2}\right)+\left(\frac{s_{2}}{2}\right)\left(F_{d s y 3}-F_{d s y 4}\right)+\left(\frac{s_{3}}{2}\right)\left(F_{d s y 5}-F_{d s y 6}\right)\right]=0} \\
& I_{x t 2} \ddot{\varphi}_{t 2}+\left(\frac{s_{4}}{2}\right)\left(F_{s y 7}-F_{s y 8}\right)+\left(\frac{s_{4}}{2}\right)\left(F_{d s y 7}-F_{d s y 8}\right)=0
\end{aligned}
$$

Also the rest of degrees of freedom will be as follows:

$$
\begin{aligned}
& m_{a 1} \ddot{y}_{a 1}-\left(F_{s y 1}+F_{s y 2}\right)+\left(F_{t y 1}+F_{t y 2}\right)-\left(F_{d s y 1}+F_{d s y 2}\right)+\left(F_{d t y 1}+F_{d t y 2}\right)= \\
& m_{a 1} g \\
& I_{x a 1} \ddot{\varphi}_{a 1}-\left(\frac{s_{1}}{2}\right)\left(F_{s y 1}-F_{s y 2}\right)+\left(\frac{d_{1}}{2}\right)\left(F_{t y 1}-F_{t y 2}\right)-\left(\frac{s_{1}}{2}\right)\left(F_{d s y 1}-F_{d s y 2}\right)+ \\
& \left(\frac{d_{1}}{2}\right)\left(F_{d t y 1}-F_{d t y 2}\right)=0 \\
& m_{a 2} \ddot{y}_{a 2}-\left(F_{s y 3}+F_{s y 4}\right)+\left(F_{t y 3}+F_{t y 4}\right)-\left(F_{d s y 3}+F_{d s y 4}\right)+\left(F_{d t y 3}+F_{d t y 4}\right)= \\
& m_{a 2} g \\
& I_{x a 2} \ddot{\varphi}_{a 2}-\left(\frac{s_{2}}{2}\right)\left(F_{s y 3}-F_{s y 4}\right)+\left(\frac{d_{2}}{2}\right)\left(F_{t y 3}-F_{t y 4}\right)-\left(\frac{s_{2}}{2}\right)\left(F_{d s y 3}-F_{d s y 4}\right)+ \\
& \left(\frac{d_{2}}{2}\right)\left(F_{d t y 3}-F_{d t y 4}\right)=0 \\
& m_{a 3} \ddot{y}_{a 3}-\left(F_{s y 5}+F_{s y 6}\right)+\left(F_{t y 5}+F_{t y 6}\right)-\left(F_{d s y 5}+F_{d s y 6}\right)+\left(F_{d t y 5}+F_{d t y 6}\right)= \\
& m_{a 3} g \\
& I_{x a 3} \ddot{\varphi}_{a 3}-\left(\frac{s_{3}}{2}\right)\left(F_{s y 5}-F_{s y 6}\right)+\left(\frac{d_{3}}{2}\right)\left(F_{t y 5}-F_{t y 6}\right)-\left(\frac{s_{3}}{2}\right)\left(F_{d s y 5}-F_{d s y 6}\right)+ \\
& I_{x a 4} \ddot{\varphi}_{a 4}-\left(\frac{s_{4}}{2}\right)\left(F_{s y 7}-F_{s y 8}\right)+\left(\frac{d_{4}}{2}\right)\left(F_{t y 7}-F_{t y 8}\right)-\left(\frac{s_{4}}{2}\right)\left(F_{d s y 7}-F_{d s y 8}\right)+ \\
& \left(\frac{d_{3}}{2}\right)\left(F_{d t y 5}-F_{d t y 6}\right)=0 \\
& m_{a 4} \ddot{y}_{a 4}-\left(F_{d t y 7}-F_{d t y 8}\right)=0 \\
& m_{a 4} g \\
& \left.F_{s y 8}\right)+\left(F_{t y 7}+F_{t y 8}\right)-\left(F_{d s y 7}+F_{d s y 8}\right)+\left(F_{d t y 7}+F_{d t y 8}\right)= \\
&
\end{aligned}
$$




\section{Derivation of Equations of Motion for Type 2S2 Truck}

There are fourteen degrees of freedom in total for this type of truck. The degrees of freedom can be seen in Figure 5 and the description of those degrees of freedom can be found in Table 9.

Relative Displacements at the locations of the springs are also calculated using the values given in Table 10 .

Table 9. Degrees of Freedom of Type 2S2 Truck

\begin{tabular}{|c|c|l|l|}
$\begin{array}{c}\text { No. } \\
\text { Freedom }\end{array}$ & $\begin{array}{c}\text { Degree of } \\
\text { Mass }\end{array}$ & \multicolumn{1}{c|}{$\begin{array}{l}\text { Contributed } \\
\text { Mescription }\end{array}$} \\
$\mathbf{2}$ & $\mathrm{y}_{\mathrm{t} 1}$ & $\mathrm{~m}_{\mathrm{t} 1}$ & Tractor vertical displacement and mass \\
$\mathbf{3}$ & $\varphi_{\mathrm{t} 1}$ & $\mathrm{I}_{\mathrm{xt} 1}$ & Tractor roll displacement and mass moment of inertia \\
$\mathbf{4}$ & $\theta_{\mathrm{t} 1}$ & $\mathrm{I}_{\mathrm{zt} 1}$ & Tractor pitch displacement and mass moment of inertia \\
$\mathbf{5}$ & $\mathrm{y}_{\mathrm{t} 2}$ & $\mathrm{~m}_{\mathrm{t} 2}$ & Trailer vertical displacement and mass \\
$\mathbf{6}$ & $\varphi_{\mathrm{t} 2}$ & $\mathrm{I}_{\mathrm{xt} 2}$ & Trailer roll displacement and mass moment of inertia \\
$\mathbf{7}$ & $\theta_{\mathrm{t} 2}$ & $\mathrm{I}_{\mathrm{zt} 2}$ & Trailer pitch displacement and mass moment of inertia \\
$\mathbf{8}$ & $\mathrm{y}_{\mathrm{a} 1}$ & $\mathrm{~m}_{\mathrm{a} 1}$ & Steer axle vertical displacement and mass \\
$\mathbf{9}$ & $\varphi_{\mathrm{a} 1}$ & $\mathrm{I}_{\mathrm{xa} 1}$ & Steer axle roll displacement and mass moment of inertia \\
\hline $\mathbf{1 0}$ & $\mathrm{y}_{\mathrm{a} 2}$ & $\mathrm{~m}_{\mathrm{a} 2}$ & Tractor second axle vertical displacement and mass \\
\hline $\mathbf{1 1}$ & $\varphi_{\mathrm{a} 2}$ & $\mathrm{I}_{\mathrm{xa} 2}$ & $\begin{array}{l}\text { Tractor second axle roll displacement and mass moment } \\
\text { of inertia }\end{array}$ \\
\hline $\mathbf{1 2}$ & $\mathrm{y}_{\mathrm{a} 3}$ & $\mathrm{~m}_{\mathrm{a} 3}$ & $\begin{array}{l}\text { Vertical displacement and mass of forward axle of trailer } \\
\text { tandem }\end{array}$ \\
\hline $\mathbf{1 3}$ & $\varphi_{\mathrm{a} 3}$ & $\mathrm{I}_{\mathrm{xa} 3}$ & $\begin{array}{l}\text { Roll displacement and mass moment of inertia of forward } \\
\text { axle of trailer tandem }\end{array}$ \\
\hline & $\mathrm{y}_{\mathrm{a} 4}$ & $\mathrm{~m}_{\mathrm{a} 4}$ & $\begin{array}{l}\text { Vertical displacement and mass of aft axle of trailer } \\
\text { tandem }\end{array}$ \\
\hline
\end{tabular}


Figure 5. Type 2S2 Dynamic Model (a) Truck Side View (b) Truck Front View 
Table 10. Relative Displacements at Spring Locations of Type 2S2 Truck

\begin{tabular}{|c|c|}
\hline & Suspension springs \\
\hline $\mathbf{U}_{\text {sy1 }}$ & $\left(\mathrm{y}_{\mathrm{t} 1}-\mathrm{y}_{\mathrm{a} 1}\right)+\left(\mathrm{S}_{1} / 2\right)\left(\varphi_{\mathrm{t} 1}-\varphi_{\mathrm{a} 1}\right)+\mathrm{l}_{5} \theta_{\mathrm{t} 1}$ \\
\hline $\mathbf{U}_{\text {sy2 }}$ & $\left(\mathrm{y}_{\mathrm{t} 1}-\mathrm{y}_{\mathrm{a} 1}\right)-\left(\mathrm{S}_{1} / 2\right)\left(\varphi_{\mathrm{t} 1}-\varphi_{\mathrm{a} 1}\right)+\mathrm{l}_{5} \theta_{\mathrm{t} 1}$ \\
\hline $\mathbf{U}_{\text {sy3 }}$ & $\left(\mathrm{y}_{\mathrm{t} 1}-\mathrm{y}_{\mathrm{a} 2}\right)+\left(\mathrm{S}_{2} / 2\right)\left(\varphi_{\mathrm{t} 1}-\varphi_{\mathrm{a} 2}\right)-\mathrm{l}_{6} \theta_{\mathrm{t} 1}$ \\
\hline $\mathbf{U}_{\text {sy4 }}$ & $\left(y_{\mathrm{t} 1}-y_{\mathrm{a} 2}\right)-\left(\mathrm{S}_{2} / 2\right)\left(\varphi_{\mathrm{t} 1}-\varphi_{\mathrm{a} 2}\right)-\mathrm{l}_{6} \theta_{\mathrm{t} 1}$ \\
\hline $\mathbf{U}_{\text {sy5 }}$ & $\left(\mathrm{y}_{\mathrm{t} 2}-\mathrm{y}_{\mathrm{a} 3}\right)+\left(\mathrm{S}_{3} / 2\right)\left(\varphi_{\mathrm{t} 2}-\varphi_{\mathrm{a} 3}\right)-\mathrm{l}_{9} \theta_{\mathrm{t} 2}$ \\
\hline $\mathbf{U}_{\text {sy6 }}$ & $\left(\mathrm{y}_{\mathrm{t} 2}-\mathrm{y}_{\mathrm{a} 3}\right)-\left(\mathrm{S}_{3} / 2\right)\left(\varphi_{\mathrm{t} 2}-\varphi_{\mathrm{a} 3}\right)-\mathrm{l}_{9} \theta_{\mathrm{t} 2}$ \\
\hline $\mathbf{U}_{\text {sy7 }}$ & $\left.\mathrm{t} t 2_{2} \mathrm{y}_{\mathrm{a} 4}\right)+\left(\mathrm{S}_{4} / 2\right)\left(\varphi_{\mathrm{t} 2}-\varphi_{\mathrm{a} 4}\right)-\left(\mathrm{l}_{4}+\mathrm{l}_{9}\right) \theta_{\mathrm{t} 2}$ \\
\hline $\mathbf{U}_{\text {sy8 }}$ & $\left.\mathrm{t} t 2_{2}-\mathrm{y}_{\mathrm{a} 4}\right)-\left(\mathrm{S}_{4} / 2\right)\left(\varphi_{\mathrm{t} 2}-\varphi_{\mathrm{a} 4}\right)-\left(\mathrm{l}_{4}+\mathrm{l}_{9}\right) \theta_{\mathrm{t} 2}$ \\
\hline & Tire springs \\
\hline $\mathbf{U}_{\mathrm{ty} \mathbf{1}}$ & $\mathrm{y}_{\mathrm{a} 1}+\left(\mathrm{d}_{1} / 2\right) \varphi_{\mathrm{a} 1}+\mathrm{u}_{\mathrm{SR} 1}$ \\
\hline $\mathbf{U}_{\mathrm{ty} 2}$ & $\mathrm{y}_{\mathrm{a} 1}-\left(\mathrm{d}_{1} / 2\right) \varphi_{\mathrm{a} 1}+\mathrm{u}_{\mathrm{SR} 2}$ \\
\hline $\mathbf{U}_{\mathrm{ty} 3}$ & $\mathrm{y}_{\mathrm{a} 2}+\left(\mathrm{d}_{2} / 2\right) \varphi_{\mathrm{a} 2}+\mathrm{u}_{\mathrm{SR} 3}$ \\
\hline $\mathbf{U}_{\text {ty4 }}$ & $\mathrm{y}_{\mathrm{a} 2}-\left(\mathrm{d}_{2} / 2\right) \varphi_{\mathrm{a} 2}+\mathrm{u}_{\mathrm{SR} 4}$ \\
\hline $\mathbf{U}_{\text {ty5 }}$ & $\mathrm{y}_{\mathrm{a} 3}+\left(\mathrm{d}_{3} / 2\right) \varphi_{\mathrm{a} 3}+\mathrm{u}_{\mathrm{SR} 5}$ \\
\hline $\mathbf{U}_{\mathrm{ty} 6}$ & $\mathrm{y}_{\mathrm{a} 3}-\left(\mathrm{d}_{3} / 2\right) \varphi_{\mathrm{a} 3}+\mathrm{u}_{\mathrm{SR} 6}$ \\
\hline $\mathbf{U}_{\mathrm{ty} 7}$ & $\mathrm{y}_{\mathrm{a} 4}+\left(\mathrm{d}_{4} / 2\right) \varphi_{\mathrm{a} 4}+\mathrm{u}_{\mathrm{SR} 7}$ \\
\hline $\mathbf{U}_{\mathrm{ty8}}$ & $\mathrm{y}_{\mathrm{a} 4}-\left(\mathrm{d}_{4} / 2\right) \varphi_{\mathrm{a} 4}+\mathrm{u}_{\mathrm{SR} 8}$ \\
\hline
\end{tabular}

Kinetic Energy of the system:

$$
\begin{aligned}
& T=\frac{1}{2} m_{t 1} \dot{y}_{t 1}{ }^{2}+\frac{1}{2} m_{a 1} \dot{y}_{a 1}{ }^{2}+\frac{1}{2} m_{a 2} \dot{y}_{a 2}{ }^{2}+\frac{1}{2} m_{a 3} \dot{y}_{a 3}{ }^{2}+\frac{1}{2} m_{a 4} \dot{y}_{a 4}{ }^{2}+\frac{1}{2} I_{x t 1} \dot{\varphi}_{t 1}{ }^{2}+ \\
& \frac{1}{2} I_{z t 1} \dot{\theta}_{t 1}{ }^{2}+\frac{1}{2} I_{x t 2} \dot{\varphi}_{t 2}{ }^{2}+\frac{1}{2} I_{z t 2} \dot{\theta}_{t 2}{ }^{2}+\frac{1}{2} I_{x a 1} \dot{\varphi}_{a 1}{ }^{2}+\frac{1}{2} I_{x a 2} \dot{\varphi}_{a 2}{ }^{2}+\frac{1}{2} I_{x a 3} \dot{\varphi}_{a 3}{ }^{2}+ \\
& \frac{1}{2} I_{x a 4} \dot{\varphi}_{a 4}{ }^{2}+\frac{1}{2} m_{t 2} \dot{y}_{t 2}{ }^{2}
\end{aligned}
$$

Potential Energy of the system:

$$
V=\frac{1}{2} K_{s y 1} U_{s y 1}{ }^{2}+\frac{1}{2} K_{s y 2} U_{s y 2}{ }^{2}+\frac{1}{2} K_{s y 3} U_{s y 3}{ }^{2}+\frac{1}{2} K_{s y 4} U_{s y 4}{ }^{2}+\frac{1}{2} K_{s y 5} U_{s y 5}{ }^{2}+
$$




$$
\begin{aligned}
& \frac{1}{2} K_{s y 6} U_{s y 6}{ }^{2}+\frac{1}{2} K_{s y 7} U_{s y 7}{ }^{2}+\frac{1}{2} K_{s y 8} U_{s y 8}{ }^{2}+\frac{1}{2} K_{t y 1} U_{t y 1}{ }^{2}+\frac{1}{2} K_{t y 2} U_{t y 2}{ }^{2}+ \\
& \frac{1}{2} K_{t y 3} U_{t y 3}{ }^{2}+\frac{1}{2} K_{t y 4} U_{t y 4}{ }^{2}+\frac{1}{2} K_{t y 5} U_{t y 5}{ }^{2}+\frac{1}{2} K_{t y 6} U_{t y 6}{ }^{2}+\frac{1}{2} K_{t y 7} U_{s y 7}{ }^{2}+ \\
& \frac{1}{2} K_{t y 8} U_{t y 8}{ }^{2}-\left(\left(m_{t 1} g\right) y_{t 1}+\left(m_{t 2} g\right) y_{t 2}+\left(m_{a 1} g\right) y_{a 1}+\left(m_{a 2} g\right) y_{a 2}+\right. \\
& \left.\left(m_{a 3} g\right) y_{a 3}+\left(m_{a 4} g\right) y_{a 4}\right)+\left(F_{y 1} U_{s y 1}+F_{y 2} U_{s y 2}+F_{y 3} U_{s y 3}+F_{y 4} U_{s y 4}+\right. \\
& \left.F_{y 5} U_{s y 5}+F_{y 6} U_{s y 6}+F_{y 7} U_{s y 7}+F_{y 8} U_{s y 8}\right)
\end{aligned}
$$

Damping Energy of the system:

$$
\begin{aligned}
& D=\frac{1}{2} D_{s y 1} \dot{U}_{s y 1}{ }^{2}+\frac{1}{2} D_{s y 2} \dot{U}_{s y 2}{ }^{2}+\frac{1}{2} D_{s y 3} \dot{U}_{s y 3}{ }^{2}+\frac{1}{2} D_{s y 4} \dot{U}_{s y 4}{ }^{2}+\frac{1}{2} D_{s y 5} \dot{U}_{s y 5}{ }^{2}+ \\
& \frac{1}{2} D_{s y 6} \dot{U}_{s y 6}{ }^{2}+\frac{1}{2} D_{s y 7} \dot{U}_{s y 7}{ }^{2}+\frac{1}{2} D_{s y 8} \dot{U}_{s y 8}{ }^{2}+\frac{1}{2} D_{t y 1} \dot{U}_{t y 1}{ }^{2}+\frac{1}{2} D_{t y 2} \dot{U}_{t y 2}{ }^{2}+ \\
& \frac{1}{2} D_{t y 3} \dot{U}_{t y 3}{ }^{2}+\frac{1}{2} D_{t y 4} \dot{U}_{t y 4}{ }^{2}+\frac{1}{2} D_{t y 5} \dot{U}_{t y 5}{ }^{2}+\frac{1}{2} D_{t y 6} \dot{U}_{t y 6}{ }^{2}+\frac{1}{2} D_{t y 7} \dot{U}_{t y 7}{ }^{2}+ \\
& \frac{1}{2} D_{t y 8} \dot{U}_{t y 8}{ }^{2}
\end{aligned}
$$

Whether it is calculated from the trailer part or the tractor part, the displacement at the pivot point should be the same,

$y_{t 2}+\theta_{t 2} l_{8}=y_{t 1}-\theta_{t 1} l_{7}$

Thus, by calculating $\theta_{t 2}$ from equation ( 205 ) and substituting in equation ( 202 ),

$$
\begin{aligned}
& T=\frac{1}{2} m_{t 1} \dot{y}_{t 1}{ }^{2}+\frac{1}{2} m_{a 1} \dot{y}_{a 1}{ }^{2}+\frac{1}{2} m_{a 2} \dot{y}_{a 2}{ }^{2}+\frac{1}{2} m_{a 3} \dot{y}_{a 3}{ }^{2}+\frac{1}{2} m_{a 4} \dot{y}_{a 4}{ }^{2}+\frac{1}{2} I_{x t 1} \dot{\varphi}_{t 1}{ }^{2}+ \\
& \frac{1}{2} I_{z t 1} \dot{\theta}_{t 1}{ }^{2}+\frac{1}{2} I_{x t 2} \dot{\varphi}_{t 2}{ }^{2}+\frac{1}{2} I_{z t 2}\left(\frac{\dot{y}_{t 1}-\dot{y}_{t 2}-\dot{\theta}_{t 1} l_{7}}{l_{8}}\right)^{2}+\frac{1}{2} I_{x a 1} \dot{\varphi}_{a 1}{ }^{2}+\frac{1}{2} I_{x a 2} \dot{\varphi}_{a 2}{ }^{2}+ \\
& \frac{1}{2} I_{x a 3} \dot{\varphi}_{a 3}{ }^{2}+\frac{1}{2} I_{x a 4} \dot{\varphi}_{a 4}{ }^{2}+\frac{1}{2} m_{t 2} \dot{y}_{t 2}{ }^{2}
\end{aligned}
$$

Same substitution will be applied to the equations ( 203 ) and ( 204 ). Now the Lagrange's equation is applied to $\mathrm{y}_{\mathrm{t} 2}$ : 


$$
\begin{aligned}
& {\left[m_{t 2} \ddot{y}_{t 2}-\frac{I_{t t 2}}{l_{8}^{2}}\left(\ddot{y}_{t 1}-\ddot{y}_{t 2}-\ddot{\theta}_{t 1} l_{7}\right)\right]+\left[\left(1+\frac{l_{9}}{l_{8}}\right)\left(F_{s y 5}+F_{s y 6}\right)+\left(1+\frac{l_{4}+l_{9}}{l_{8}}\right)\left(F_{s y 7}+\right.\right.} \\
& \left.\left.F_{s y 8}\right)-\left(m_{t 2} g\right)\right]+\left[\left(1+\frac{l_{9}}{l_{8}}\right)\left(F_{d s y 5}+F_{d s y 6}\right)+\left(1+\frac{l_{4}+l_{9}}{l_{8}}\right)\left(F_{d s y 7}+F_{d s y 8}\right)\right]=0
\end{aligned}
$$

To simplify the equation some variables are defined as follows:

$$
\begin{aligned}
& S_{a 2}=\frac{I_{z t 2}}{l_{8}^{2}} \\
& S_{c 2}=\frac{I_{z t 2}}{l_{8}^{2}}+m_{t 2} \\
& S_{a 3}=\frac{I_{z t 2}}{l_{8}^{2}} l_{7} \\
& B_{t 4}=m_{t 2} g-\left(1+\frac{l_{9}}{l_{8}}\right)\left(F_{s y 5}+F_{s y 6}+F_{d s y 5}+F_{d s y 6}\right)-\left(1+\frac{l_{4}+l_{9}}{l_{8}}\right)\left(F_{s y 7}+F_{s y 8}+F_{d s y 7}+\right. \\
& \left.F_{d s y 8}\right)
\end{aligned}
$$

Therefore equation ( 207 ) will be simplified to:

$$
-S_{a 2} \ddot{y}_{t 1}+S_{c 2} \ddot{y}_{t 2}+S_{a 3} \ddot{\theta}_{t 1}=B_{t 4}
$$

By applying the Lagrange's equation to $\mathrm{y}_{\mathrm{t} 1}$ :

$$
\begin{aligned}
& {\left[m_{t 1} \ddot{y}_{t 1}+\frac{I_{t t 2}}{l_{8}^{2}}\left(\ddot{y}_{t 1}-\ddot{y}_{t 2}-\ddot{\theta}_{t 1} l_{7}\right)\right]+\left[\left(F_{s y 1}+F_{s y 2}+F_{s y 3}+F_{s y 4}\right)-\frac{l_{9}}{l_{8}}\left(F_{s y 5}+\right.\right.} \\
& \left.\left.F_{s y 6}\right)-\frac{l_{9}+l_{4}}{l_{8}}\left(F_{s y 7}+F_{s y 8}\right)-\left(m_{t 1} g\right)\right]+\left[\left(F_{d s y 1}+F_{d s y 2}+F_{d s y 3}+F_{d s y 4}\right)-\right. \\
& \left.\frac{l_{9}}{l_{8}}\left(F_{d s y 5}+F_{d s y 6}\right)-\frac{l_{9}+l_{4}}{l_{8}}\left(F_{d s y 7}+F_{d s y 8}\right)\right]=0
\end{aligned}
$$

Again to simplify the equation some variables are defined as follows:

$$
S_{a 1}=\frac{I_{z t 2}}{l_{8}{ }^{2}}+m_{t 1}
$$




$$
\begin{aligned}
& B_{t 1}=m_{t 1} g-\left[\left(F_{s y 1}+F_{s y 2}+F_{s y 3}+F_{s y 4}\right)-\frac{l_{9}}{l_{8}}\left(F_{s y 5}+F_{s y 6}\right)-\frac{l_{9}+l_{4}}{l_{8}}\left(F_{s y 7}+F_{s y 8}\right)+\right. \\
& \left.\left(F_{d s y 1}+F_{d s y 2}+F_{d s y 3}+F_{d s y 4}\right)-\frac{l_{9}}{l_{8}}\left(F_{d s y 5}+F_{d s y 6}\right)-\frac{l_{9}+l_{4}}{l_{8}}\left(F_{d s y 7}+F_{d s y 8}\right)\right]
\end{aligned}
$$

Therefore equation ( 209 ) will be simplified to:

$S_{a 1} \ddot{y}_{t 1}-S_{a 2} \ddot{y}_{t 2}-S_{a 3} \ddot{\theta}_{t 1}=B_{t 1}$

Also, by applying the Lagrange's equation to $\theta_{\mathrm{t} 1}$ :

$$
\begin{aligned}
& {\left[I_{z t 1} \ddot{\theta}_{t 1}-\frac{I_{z t 2} l_{7}}{l_{8}{ }^{2}}\left(\ddot{y}_{t 1}-\ddot{y}_{t 2}-\ddot{\theta}_{t 1} l_{7}\right)\right]+\left[l_{5}\left(F_{s y 1}+F_{s y 2}\right)-l_{6}\left(F_{s y 3}+F_{s y 4}\right)+\right.} \\
& \left.\frac{l_{7} I_{9}}{l_{8}}\left(F_{s y 5}+F_{s y 6}\right)+\frac{l_{7}\left(l_{4}+I_{9}\right)}{l_{8}}\left(F_{s y 7}+F_{s y 8}\right)\right]+\left[l_{5}\left(F_{d s y 1}+F_{d s y 2}\right)-l_{6}\left(F_{d s y 3}+\right.\right. \\
& \left.\left.F_{d s y 4}\right)+\frac{l_{7} I_{9}}{l_{8}}\left(F_{d s y 5}+F_{d s y 6}\right)+\frac{l_{7}\left(l_{4}+I_{9}\right)}{l_{8}}\left(F_{d s y 7}+F_{d s y 8}\right)\right]=0
\end{aligned}
$$

Once again to simplify the equation some variables need to be defined as follows:

$$
\begin{aligned}
& S_{b 3}=I_{z t 1}+\frac{I_{z t 2} l_{7}^{2}}{l_{8}^{2}} \\
& B_{t 3}=-\left[\left[l_{5}\left(F_{s y 1}+F_{s y 2}\right)-l_{6}\left(F_{s y 3}+F_{s y 4}\right)+\frac{l_{7} I_{9}}{l_{8}}\left(F_{s y 5}+F_{s y 6}\right)+\frac{l_{7}\left(l_{4}+I_{9}\right)}{l_{8}}\left(F_{s y 7}+F_{s y 8}\right)\right]+\right. \\
& \left.\left[l_{5}\left(F_{d s y 1}+F_{d s y 2}\right)-l_{6}\left(F_{d s y 3}+F_{d s y 4}\right)+\frac{l_{7} I_{9}}{l_{8}}\left(F_{d s y 5}+F_{d s y 6}\right)+\frac{l_{7}\left(l_{4}+I_{9}\right)}{l_{8}}\left(F_{d s y 7}+F_{d s y 8}\right)\right]\right]
\end{aligned}
$$

Therefore equation ( 211 ) will be simplified to:

$-S_{a 3} \ddot{y}_{t 1}+S_{a 3} \ddot{y}_{t 2}+S_{b 3} \ddot{\theta}_{t 1}=B_{t 3}$

By adding equations ( 208 ) and ( 210 ),

$$
\left(S_{a 1}-S_{a 2}\right) \ddot{y}_{t 1}-\left(S_{a 2}-S_{c 2}\right) \ddot{y}_{t 2}=B_{t 1}+B_{t 4}
$$

Also by multiplying $S_{b 3}$ and $S_{a 3}$ to equations ( 210 ) and ( 212 ) respectively, 
$\left(S_{a 1} S_{b 3}-S_{a 3}{ }^{2}\right) \ddot{y}_{t 1}-\left(S_{a 2} S_{b 3}-S_{a 3}{ }^{2}\right) \ddot{y}_{t 2}=S_{b 3} B_{t 1}+S_{a 3} B_{t 3}$

By defining the following expressions, equations ( 213 ) and ( 214 ) are simplified to equations ( 215 ) and ( 216 ) respectively,

$e_{1}=S_{a 1}-S_{a 2}$

$e_{2}=S_{a 2}-S_{c 2}$

$e_{3}=S_{a 1} S_{b 3}-S_{a 3}^{2}$

$e_{4}=S_{a 2} S_{b 3}-S_{a 3}^{2}$

$e_{1} \ddot{y}_{t 1}-e_{2} \ddot{y}_{t 2}=B_{t 1}+B_{t 4}$

$e_{3} \ddot{y}_{t 1}-e_{4} \ddot{y}_{t 2}=S_{b 3} B_{t 1}+S_{a 3} B_{t 3}$

Solving equations ( 215 ) and ( 216 ) for $\ddot{y}_{t 1}$ and $\ddot{y}_{t 2}$ will lead to:

$\ddot{y}_{t 1}=\frac{e_{4}\left(B_{t 1}+B_{t 4}\right)-e_{2}\left(S_{b 3} B_{t 1}+S_{a 3} B_{t 3}\right)}{e_{1} e_{4}-e_{2} e_{3}}$

$\ddot{y}_{t 2}=\frac{e_{1}}{e_{2}}\left(\frac{e_{4}\left(B_{t 1}+B_{t 4}\right)-e_{2}\left(S_{b 3} B_{t 1}+S_{a 3} B_{t 3}\right)}{e_{1} e_{4}-e_{2} e_{3}}\right)-\frac{B_{t 1}+B_{t 4}}{e_{2}}$

Substituting equations ( 217 ) and ( 218 ) into equation ( 212 ) will give,

$$
\begin{aligned}
\ddot{\theta}_{t 1}=\frac{B_{t 3}}{S_{b 3}}+\frac{S_{a 3}}{S_{b 3}} & \left(\frac{e_{4}\left(B_{t 1}+B_{t 4}\right)-e_{2}\left(S_{b 3} B_{t 1}+S_{a 3} B_{t 3}\right)}{e_{1} e_{4}-e_{2} e_{3}}\right) \\
& -\frac{S_{a 3}}{S_{b 3}}\left(\frac{e_{1}}{e_{2}}\left(\frac{e_{4}\left(B_{t 1}+B_{t 4}\right)-e_{2}\left(S_{b 3} B_{t 1}+S_{a 3} B_{t 3}\right)}{e_{1} e_{4}-e_{2} e_{3}}\right)-\frac{B_{t 1}+B_{t 4}}{e_{2}}\right)
\end{aligned}
$$

By applying the Lagrange's equation to $\varphi_{t 1}, \varphi_{t 2}$ :

$$
\begin{aligned}
& I_{x t 1} \ddot{\varphi}_{t 1}+\left[\left(\frac{s_{1}}{2}\right)\left(F_{s y 1}-F_{s y 2}\right)+\left(\frac{s_{2}}{2}\right)\left(F_{s y 3}-F_{s y 4}\right)\right]+\left[\left(\frac{s_{1}}{2}\right)\left(F_{d s y 1}-F_{d s y 2}\right)+\right. \\
& \left.\left(\frac{s_{2}}{2}\right)\left(F_{d s y 3}-F_{d s y 4}\right)\right]=0
\end{aligned}
$$




$$
\begin{aligned}
& I_{x t 2} \ddot{\varphi}_{t 2}+\left[\left(\frac{s_{3}}{2}\right)\left(F_{s y 5}-F_{s y 6}\right)+\left(\frac{s_{4}}{2}\right)\left(F_{s y 7}-F_{s y 8}\right)\right]+\left[\left(\frac{s_{3}}{2}\right)\left(F_{d s y 5}-F_{d s y 6}\right)+\right. \\
& \left.\left(\frac{s_{4}}{2}\right)\left(F_{d s y 7}-F_{d s y 8}\right)\right]=0
\end{aligned}
$$

Also the rest of degrees of freedom will be as follows:

$$
\begin{aligned}
& m_{a 1} \ddot{y}_{a 1}-\left(F_{s y 1}+F_{s y 2}\right)+\left(F_{t y 1}+F_{t y 2}\right)-\left(F_{d s y 1}+F_{d s y 2}\right)+\left(F_{d t y 1}+F_{d t y 2}\right)= \\
& m_{a 1} g \\
& I_{x a 1} \ddot{\varphi}_{a 1}-\left(\frac{s_{1}}{2}\right)\left(F_{s y 1}-F_{s y 2}\right)+\left(\frac{d_{1}}{2}\right)\left(F_{t y 1}-F_{t y 2}\right)-\left(\frac{s_{1}}{2}\right)\left(F_{d s y 1}-F_{d s y 2}\right)+ \\
& \left(\frac{d_{1}}{2}\right)\left(F_{d t y 1}-F_{d t y 2}\right)=0 \\
& m_{a 2} \ddot{y}_{a 2}-\left(F_{s y 3}+F_{s y 4}\right)+\left(F_{t y 3}+F_{t y 4}\right)-\left(F_{d s y 3}+F_{d s y 4}\right)+\left(F_{d t y 3}+F_{d t y 4}\right)= \\
& m_{a 2} g \\
& I_{x a 2} \ddot{\varphi}_{a 2}-\left(\frac{s_{2}}{2}\right)\left(F_{s y 3}-F_{s y 4}\right)+\left(\frac{d_{2}}{2}\right)\left(F_{t y 3}-F_{t y 4}\right)-\left(\frac{s_{2}}{2}\right)\left(F_{d s y 3}-F_{d s y 4}\right)+ \\
& \left(\frac{d_{2}}{2}\right)\left(F_{d t y 3}-F_{d t y 4}\right)=0 \\
& m_{a 3} \ddot{y}_{a 3}-\left(F_{s y 5}+F_{s y 6}\right)+\left(F_{t y 5}+F_{t y 6}\right)-\left(F_{d s y 5}+F_{d s y 6}\right)+\left(F_{d t y 5}+F_{d t y 6}\right)= \\
& m_{a 3} g \\
& I_{x a 3} \ddot{\varphi}_{a 3}-\left(\frac{s_{3}}{2}\right)\left(F_{s y 5}-F_{s y 6}\right)+\left(\frac{d_{3}}{2}\right)\left(F_{t y 5}-F_{t y 6}\right)-\left(\frac{s_{3}}{2}\right)\left(F_{d s y 5}-F_{d s y 6}\right)+ \\
& \left(\frac{d_{3}}{2}\right)\left(F_{d t y 5}-F_{d t y 6}\right)=0 \\
& m_{a 4} \ddot{y}_{a 4}-\left(F_{s y 7}+F_{s y 8}\right)+\left(F_{t y 7}+F_{t y 8}\right)-\left(F_{d s y 7}+F_{d s y 8}\right)+\left(F_{d t y 7}+F_{d t y 8}\right)= \\
& m_{a 4} g \\
& I_{x a 4} \ddot{\varphi}_{a 4}-\left(\frac{s_{4}}{2}\right)\left(F_{s y 7}-F_{s y 8}\right)+\left(\frac{d_{4}}{2}\right)\left(F_{t y 7}-F_{t y 8}\right)-\left(\frac{s_{4}}{2}\right)\left(F_{d s y 7}-F_{d s y 8}\right)+ \\
& \left(\frac{d_{4}}{2}\right)\left(F_{d t y 7}-F_{d t y 8}\right)=0
\end{aligned}
$$




\section{Derivation of Equations of Motion for SU4 Truck}

There are eleven degrees of freedom in total for this type of truck. The degrees of freedom can be seen in Figure 6 and the description of those degrees of freedom can be found in Table 11. Relative Displacements at the locations of the springs are also calculated using the values given in Table 12.

Table 11. Degrees of Freedom of SU4 Truck

\begin{tabular}{|c|c|c|c|}
\hline No. & $\begin{array}{l}\text { Degree of } \\
\text { Freedom }\end{array}$ & $\begin{array}{l}\text { Contributed } \\
\text { Mass }\end{array}$ & Description \\
\hline 1 & $\mathrm{y}_{\mathrm{t} 1}$ & $\mathrm{~m}_{\mathrm{t} 1}$ & Truck vertical displacement and mass \\
\hline 2 & $\varphi_{\mathrm{t} 1}$ & $\mathrm{I}_{\mathrm{xt} 1}$ & Truck roll displacement and mass moment of inertia \\
\hline 3 & $\theta_{\mathrm{t} 1}$ & $\mathrm{I}_{\mathrm{zt} 1}$ & Truck pitch displacement and mass moment of inertia \\
\hline 4 & $\mathrm{y}_{\mathrm{a} 1}$ & $\mathrm{~m}_{\mathrm{a} 1}$ & Steer axle vertical displacement and mass \\
\hline 5 & $\varphi_{\mathrm{a} 1}$ & $\mathrm{I}_{\mathrm{xa} 1}$ & Steer axle roll displacement and mass moment of inertia \\
\hline 6 & $\mathrm{y}_{\mathrm{a} 2}$ & $\mathrm{~m}_{\mathrm{a} 2}$ & Vertical displacement and mass of 1 st axle of truck tridem \\
\hline 7 & $\varphi_{\mathrm{a} 2}$ & $\mathrm{I}_{\mathrm{xa} 2}$ & $\begin{array}{l}\text { Roll displacement and mass moment of inertia of 1st axle } \\
\text { of truck tridem }\end{array}$ \\
\hline 8 & $\mathrm{y}_{\mathrm{a} 3}$ & $\mathrm{~m}_{\mathrm{a} 3}$ & Vertical displacement and mass of 2 nd axle of truck tridem \\
\hline 9 & $\varphi_{\mathrm{a} 3}$ & $\mathrm{I}_{\mathrm{xa} 3}$ & $\begin{array}{l}\text { Roll displacement and mass moment of inertia of } 2 \text { nd axle } \\
\text { of truck tridem }\end{array}$ \\
\hline 10 & $\mathrm{y}_{\mathrm{a} 4}$ & $\mathrm{~m}_{\mathrm{a} 4}$ & $\begin{array}{l}\text { Fourth axle vertical displacement and mass of 3rd axle of } \\
\text { truck tridem }\end{array}$ \\
\hline 11 & $\varphi_{\mathrm{a} 4}$ & $\mathrm{I}_{\mathrm{xa} 4}$ & $\begin{array}{l}\text { Roll displacement and mass moment of inertia of 3rd axle } \\
\text { of truck tridem }\end{array}$ \\
\hline
\end{tabular}

Kinetic Energy of the system:

$$
\begin{aligned}
& T=\frac{1}{2} m_{t 1} \dot{y}_{t 1}{ }^{2}+\frac{1}{2} m_{a 1} \dot{y}_{a 1}{ }^{2}+\frac{1}{2} m_{a 2} \dot{y}_{a 2}{ }^{2}+\frac{1}{2} m_{a 3} \dot{y}_{a 3}{ }^{2}+\frac{1}{2} m_{a 4} \dot{y}_{a 4}{ }^{2}+\frac{1}{2} I_{x t 1} \dot{\varphi}_{t 1}{ }^{2}+ \\
& \frac{1}{2} I_{z t 1} \dot{\theta}_{t 1}{ }^{2}+\frac{1}{2} I_{x a 1} \dot{\varphi}_{a 1}{ }^{2}+\frac{1}{2} I_{x a 2} \dot{\varphi}_{a 2}{ }^{2}+\frac{1}{2} I_{x a 3} \dot{\varphi}_{a 3}{ }^{2}+\frac{1}{2} I_{x a 4} \dot{\varphi}_{a 4}{ }^{2}
\end{aligned}
$$


Figure 6. SU4 Truck Dynamic Model (a) Truck Side View (b) Truck Front View 
Table 12. Relative Displacements at Spring Locations of SU4 Truck

\begin{tabular}{|c|c|}
\hline & Suspension springs \\
\hline $\mathrm{U}_{\mathrm{sy} 1}$ & $\left(\mathrm{y}_{\mathrm{t} 1}-\mathrm{y}_{\mathrm{a} 1}\right)+\left(\mathrm{S}_{1} / 2\right)\left(\varphi_{\mathrm{t} 1}-\varphi_{\mathrm{a} 1}\right)+\mathrm{l}_{4} \theta_{\mathrm{t} 1}$ \\
\hline $\mathrm{U}_{\text {sy2 }}$ & $\left(y_{\mathrm{t} 1}-\mathrm{y}_{\mathrm{a} 1}\right)-\left(\mathrm{S}_{1} / 2\right)\left(\varphi_{\mathrm{t} 1}-\varphi_{\mathrm{a} 1}\right)+\mathrm{l}_{4} \theta_{\mathrm{t} 1}$ \\
\hline $\mathbf{U}_{\text {sy3 }}$ & $\left(y_{\mathrm{t} 1}-\mathrm{y}_{\mathrm{a} 2}\right)+\left(\mathrm{S}_{2} / 2\right)\left(\varphi_{\mathrm{t} 1}-\varphi_{\mathrm{a} 2}\right)-\mathrm{l}_{5} \theta_{\mathrm{t} 1}$ \\
\hline $\mathbf{U}_{\text {sy4 }}$ & $\left(\mathrm{y}_{\mathrm{t} 1}-\mathrm{y}_{\mathrm{a} 2}\right)-\left(\mathrm{S}_{2} / 2\right)\left(\varphi_{\mathrm{t} 1}-\varphi_{\mathrm{a} 2}\right)-\mathrm{l}_{5} \theta_{\mathrm{t} 1}$ \\
\hline $\mathbf{U}_{\text {sy5 }}$ & $\left(\mathrm{y}_{\mathrm{t} 1}-\mathrm{y}_{\mathrm{a} 3}\right)+\left(\mathrm{S}_{3} / 2\right)\left(\varphi_{\mathrm{t} 1}-\varphi_{\mathrm{a} 3}\right)-\left(\mathrm{l}_{2}+\mathrm{l}_{5}\right) \theta_{\mathrm{t} 1}$ \\
\hline $\mathbf{U}_{\text {sy } 6}$ & $\left(\mathrm{y}_{\mathrm{t} 1}-\mathrm{y}_{\mathrm{a} 3}\right)-\left(\mathrm{S}_{3} / 2\right)\left(\varphi_{\mathrm{t} 1}-\varphi_{\mathrm{a} 3}\right)-\left(\mathrm{l}_{2}+\mathrm{l}_{5}\right) \theta_{\mathrm{t} 1}$ \\
\hline $\mathbf{U}_{\text {sy }}$ & $\left(y_{\mathrm{t} 1}-\mathrm{y}_{\mathrm{a} 4}\right)+\left(\mathrm{S}_{4} / 2\right)\left(\varphi_{\mathrm{t} 1}-\varphi_{\mathrm{a} 4}\right)-\left(\mathrm{l}_{2}+\mathrm{l}_{3}+\mathrm{l}_{5}\right) \theta_{\mathrm{t} 1}$ \\
\hline $\mathbf{U}_{\text {sy8 }}$ & $\left(y_{\mathrm{t} 1}-\mathrm{y}_{\mathrm{a} 4}\right)-\left(\mathrm{S}_{4} / 2\right)\left(\varphi_{\mathrm{t} 1}-\varphi_{\mathrm{a} 4}\right)-\left(\mathrm{l}_{2}+\mathrm{l}_{3}+\mathrm{l}_{5}\right) \theta_{\mathrm{t} 1}$ \\
\hline & Tire springs \\
\hline $\mathrm{U}_{\mathrm{ty} 1}$ & $\mathrm{y}_{\mathrm{a} 1}+\left(\mathrm{d}_{1} / 2\right) \varphi_{\mathrm{a} 1}+\mathrm{u}_{\mathrm{SR} 1}$ \\
\hline $\mathrm{U}_{\mathrm{ty} 2}$ & $\mathrm{y}_{\mathrm{a} 1}-\left(\mathrm{d}_{1} / 2\right) \varphi_{\mathrm{a} 1}+\mathrm{u}_{\mathrm{SR} 2}$ \\
\hline $\mathbf{U}_{\mathrm{ty} 3}$ & $\mathrm{y}_{\mathrm{a} 2}+\left(\mathrm{d}_{2} / 2\right) \varphi_{\mathrm{a} 2}+\mathrm{u}_{\mathrm{SR} 3}$ \\
\hline $\mathbf{U}_{\mathrm{ty} 4}$ & $\mathrm{y}_{\mathrm{a} 2}-\left(\mathrm{d}_{2} / 2\right) \varphi_{\mathrm{a} 2}+\mathrm{u}_{\mathrm{SR} 4}$ \\
\hline $\mathbf{U}_{\mathrm{ty} 5}$ & $\mathrm{y}_{\mathrm{a} 3}+\left(\mathrm{d}_{3} / 2\right) \varphi_{\mathrm{a} 3}+\mathrm{u}_{\mathrm{SR} 5}$ \\
\hline $\mathbf{U}_{\mathrm{ty} 6}$ & $\mathrm{y}_{\mathrm{a} 3}-\left(\mathrm{d}_{3} / 2\right) \varphi_{\mathrm{a} 3}+\mathrm{u}_{\mathrm{SR} 6}$ \\
\hline $\mathbf{U}_{\mathrm{ty} 7}$ & $\mathrm{y}_{\mathrm{a} 4}+\left(\mathrm{d}_{4} / 2\right) \varphi_{\mathrm{a} 4}+\mathrm{u}_{\mathrm{SR} 7}$ \\
\hline $\mathbf{U}_{\text {ty8 }}$ & $\mathrm{y}_{\mathrm{a} 4}-\left(\mathrm{d}_{4} / 2\right) \varphi_{\mathrm{a} 4}+\mathrm{u}_{\mathrm{SR} 8}$ \\
\hline
\end{tabular}

Potential Energy of the system:

$$
\begin{aligned}
& V=\frac{1}{2} K_{s y 1} U_{s y 1}{ }^{2}+\frac{1}{2} K_{s y 2} U_{s y 2}{ }^{2}+\frac{1}{2} K_{s y 3} U_{s y 3}{ }^{2}+\frac{1}{2} K_{s y 4} U_{s y 4}{ }^{2}+\frac{1}{2} K_{s y 5} U_{s y 5}{ }^{2}+ \\
& \frac{1}{2} K_{s y 6} U_{s y 6}{ }^{2}+\frac{1}{2} K_{s y 7} U_{s y 7}{ }^{2}+\frac{1}{2} K_{s y 8} U_{s y 8}{ }^{2}+\frac{1}{2} K_{t y 1} U_{t y 1}{ }^{2}+\frac{1}{2} K_{t y 2} U_{t y 2}{ }^{2}+ \\
& \frac{1}{2} K_{t y 3} U_{t y 3}{ }^{2}+\frac{1}{2} K_{t y 4} U_{t y 4}{ }^{2}+\frac{1}{2} K_{t y 5} U_{t y 5}{ }^{2}+\frac{1}{2} K_{t y 6} U_{t y 6}{ }^{2}+\frac{1}{2} K_{t y 7} U_{t y 7}{ }^{2}+ \\
& \frac{1}{2} K_{t y 8} U_{t y 8}{ }^{2}-\left(\left(m_{t 1} g\right) y_{t 1}+\left(m_{a 1} g\right) y_{a 1}+\left(m_{a 2} g\right) y_{a 2}+\left(m_{a 3} g\right) y_{a 3}+\right. \\
& \left.\left(m_{a 4} g\right) y_{a 4}\right)+\left(F_{y 1} U_{s y 1}+F_{y 2} U_{s y 2}+F_{y 3} U_{s y 3}+F_{y 4} U_{s y 4}+F_{y 5} U_{s y 5}+F_{y 6} U_{s y 6}+\right.
\end{aligned}
$$


$\left.F_{y 7} U_{s y 7}+F_{y 8} U_{s y 8}\right)$

Damping Energy of the system:

$D=\frac{1}{2} D_{s y 1} \dot{U}_{s y 1}{ }^{2}+\frac{1}{2} D_{s y 2} \dot{U}_{s y 2}{ }^{2}+\frac{1}{2} D_{s y 3} \dot{U}_{s y 3}{ }^{2}+\frac{1}{2} D_{s y 4} \dot{U}_{s y 4}{ }^{2}+\frac{1}{2} D_{s y 5} \dot{U}_{s y 5}{ }^{2}+$

$\frac{1}{2} D_{s y 6} \dot{U}_{s y 6}{ }^{2}+\frac{1}{2} D_{s y 7} \dot{U}_{s y 7}{ }^{2}+\frac{1}{2} D_{s y 8} \dot{U}_{s y 8}{ }^{2}+\frac{1}{2} D_{t y 1} \dot{U}_{t y 1}{ }^{2}+\frac{1}{2} D_{t y 2} \dot{U}_{t y 2}{ }^{2}+$

$\frac{1}{2} D_{t y 3} \dot{U}_{t y 3}{ }^{2}+\frac{1}{2} D_{t y 4} \dot{U}_{t y 4}{ }^{2}+\frac{1}{2} D_{t y 5} \dot{U}_{t y 5}{ }^{2}+\frac{1}{2} D_{t y 6} \dot{U}_{t y 6}{ }^{2}+\frac{1}{2} D_{t y 7} \dot{U}_{t y 7}{ }^{2}+$

$\frac{1}{2} D_{t y 8} \dot{U}_{t y 8}^{2}$

Now the Lagrange's equation is applied to $\mathrm{y}_{\mathrm{t} 1}$ :

$m_{t 1} \ddot{y}_{t 1}+\left[\left(F_{s y 1}+F_{s y 2}+F_{s y 3}+F_{s y 4}+F_{s y 5}+F_{s y 6}+F_{s y 7}+F_{s y 8}\right)+\left(F_{d s y 1}+\right.\right.$

$\left.\left.F_{d s y 2}+F_{d s y 3}+F_{d s y 4}+F_{d s y 5}+F_{d s y 6}+F_{d s y 7}+F_{d s y 8}\right)\right]=m_{t 1} g$

Also, by applying the Lagrange's equation to $\theta_{\mathrm{t} 1}$ :

$I_{z t 1} \ddot{\theta}_{t 1}+\left[l_{4}\left(F_{s y 1}+F_{s y 2}\right)-l_{5}\left(F_{s y 3}+F_{s y 4}\right)-\left(l_{2}+l_{5}\right)\left(F_{s y 5}+F_{s y 6}\right)-\right.$

$\left.\left(l_{2}+l_{3}+l_{5}\right)\left(F_{s y 7}+F_{s y 8}\right)\right]+\left[l_{4}\left(F_{d s y 1}+F_{d s y 2}\right)-l_{5}\left(F_{d s y 3}+F_{d s y 4}\right)-\right.$

$\left.\left(l_{2}+l_{5}\right)\left(F_{d s y 5}+F_{d s y 6}\right)-\left(l_{2}+l_{3}+l_{5}\right)\left(F_{d s y 7}+F_{d s y 8}\right)\right]=0$

By applying the Lagrange's equation to $\varphi_{\mathrm{t} 1}$ :

$I_{x t 1} \ddot{\varphi}_{t 1}+\left[\left(\frac{s_{1}}{2}\right)\left(F_{s y 1}-F_{s y 2}\right)+\left(\frac{s_{2}}{2}\right)\left(F_{s y 3}-F_{s y 4}\right)+\left(\frac{s_{3}}{2}\right)\left(F_{s y 5}-F_{s y 6}\right)+\right.$

$\left.\left(\frac{s_{4}}{2}\right)\left(F_{s y 7}-F_{s y 8}\right)\right]+\left[\left(\frac{s_{1}}{2}\right)\left(F_{d s y 1}-F_{d s y 2}\right)+\left(\frac{s_{2}}{2}\right)\left(F_{d s y 3}-F_{d s y 4}\right)+\left(\frac{s_{3}}{2}\right)\left(F_{d s y 5}-\right.\right.$

$\left.\left.F_{d s y 6}\right)+\left(\frac{s_{4}}{2}\right)\left(F_{d s y 7}-F_{d s y 8}\right)\right]=0$

Also the rest of degrees of freedom will be as follows:

$m_{a 1} \ddot{y}_{a 1}-\left(F_{s y 1}+F_{s y 2}\right)+\left(F_{t y 1}+F_{t y 2}\right)-\left(F_{d s y 1}+F_{d s y 2}\right)+\left(F_{d t y 1}+F_{d t y 2}\right)=$ $m_{a 1} g$ 


$$
\begin{aligned}
& I_{x a 1} \ddot{\varphi}_{a 1}-\left(\frac{s_{1}}{2}\right)\left(F_{s y 1}-F_{s y 2}\right)+\left(\frac{d_{1}}{2}\right)\left(F_{t y 1}-F_{t y 2}\right)-\left(\frac{s_{1}}{2}\right)\left(F_{d s y 1}-F_{d s y 2}\right)+ \\
& \left(\frac{d_{1}}{2}\right)\left(F_{d t y 1}-F_{d t y 2}\right)=0 \\
& m_{a 2} \ddot{y}_{a 2}-\left(F_{s y 3}+F_{s y 4}\right)+\left(F_{t y 3}+F_{t y 4}\right)-\left(F_{d s y 3}+F_{d s y 4}\right)+\left(F_{d t y 3}+F_{d t y 4}\right)= \\
& m_{a 2} g \\
& I_{x a 2} \ddot{\varphi}_{a 2}-\left(\frac{s_{2}}{2}\right)\left(F_{s y 3}-F_{s y 4}\right)+\left(\frac{d_{2}}{2}\right)\left(F_{t y 3}-F_{t y 4}\right)-\left(\frac{s_{2}}{2}\right)\left(F_{d s y 3}-F_{d s y 4}\right)+ \\
& \left(\frac{d_{2}}{2}\right)\left(F_{d t y 3}-F_{d t y 4}\right)=0 \\
& m_{a 3} \ddot{y}_{a 3}-\left(F_{s y 5}+F_{s y 6}\right)+\left(F_{t y 5}+F_{t y 6}\right)-\left(F_{d s y 5}+F_{d s y 6}\right)+\left(F_{d t y 5}+F_{d t y 6}\right)= \\
& m_{a 3} g \\
& I_{x a 3} \ddot{\varphi}_{a 3}-\left(\frac{s_{3}}{2}\right)\left(F_{s y 5}-F_{s y 6}\right)+\left(\frac{d_{3}}{2}\right)\left(F_{t y 5}-F_{t y 6}\right)-\left(\frac{s_{3}}{2}\right)\left(F_{d s y 5}-F_{d s y 6}\right)+ \\
& \left(\frac{d_{3}}{2}\right)\left(F_{d t y 5}-F_{d t y 6}\right)=0 \\
& m_{a 4} \ddot{y}_{a 4}-\left(F_{s y 7}+F_{s y 8}\right)+\left(F_{t y 7}+F_{t y 8}\right)-\left(F_{d s y 7}+F_{d s y 8}\right)+\left(F_{d t y 7}+F_{d t y 8}\right)= \\
& m_{a 4} g \\
& I_{x a 4} \ddot{\varphi}_{a 4}-\left(\frac{d_{4}}{2}\right)\left(F_{d t y 7}-F_{d t y 8}\right)=0 \\
& \left.F_{s y 7}-F_{s y 8}\right)+\left(\frac{d_{4}}{2}\right)\left(F_{t y 7}-F_{t y 8}\right)-\left(\frac{s_{4}}{2}\right)\left(F_{d s y 7}-F_{d s y 8}\right)+ \\
&
\end{aligned}
$$

Derivation of Equations of Motion for 7-Axle Rocky Mountain Double

There are twenty three degrees of freedom in total for this type of truck. The degrees of freedom can be seen in Figure 7 and the description of those degrees of freedom can be found in Table 13. Relative Displacements at the locations of the springs are also calculated using the values given in Table 14.

Kinetic Energy of the system:

$$
T=\frac{1}{2} m_{t 1} \dot{y}_{t 1}{ }^{2}+\frac{1}{2} m_{a 1} \dot{y}_{a 1}{ }^{2}+\frac{1}{2} m_{a 2} \dot{y}_{a 2}{ }^{2}+\frac{1}{2} m_{a 3} \dot{y}_{a 3}{ }^{2}+\frac{1}{2} m_{a 4} \dot{y}_{a 4}{ }^{2}+\frac{1}{2} m_{a 5} \dot{y}_{a 5}{ }^{2}+
$$




$$
\begin{aligned}
& \frac{1}{2} m_{a 6} \dot{y}_{a 6}{ }^{2}+\frac{1}{2} m_{a 7} \dot{y}_{a 7}{ }^{2}+\frac{1}{2} I_{x t 1} \dot{\varphi}_{t 1}{ }^{2}+\frac{1}{2} I_{z t 1} \dot{\theta}_{t 1}{ }^{2}+\frac{1}{2} I_{x t 2} \dot{\varphi}_{t 2}{ }^{2}+\frac{1}{2} I_{z t 2} \dot{\theta}_{t 2}{ }^{2}+ \\
& \frac{1}{2} I_{x t 3} \dot{\varphi}_{t 3}{ }^{2}+\frac{1}{2} I_{z t 3} \dot{\theta}_{t 3}{ }^{2}+\frac{1}{2} I_{x a 1} \dot{\varphi}_{a 1}{ }^{2}+\frac{1}{2} I_{x a 2} \dot{\varphi}_{a 2}{ }^{2}+\frac{1}{2} I_{x a 3} \dot{\varphi}_{a 3}{ }^{2}+\frac{1}{2} I_{x a 4} \dot{\varphi}_{a 4}{ }^{2}+ \\
& \frac{1}{2} I_{x a 5} \dot{\varphi}_{a 5}{ }^{2}+\frac{1}{2} I_{x a 6} \dot{\varphi}_{a 6}{ }^{2}+\frac{1}{2} I_{x a 7} \dot{\varphi}_{a 7}{ }^{2}+\frac{1}{2} m_{t 2} \dot{y}_{t 2}{ }^{2}+\frac{1}{2} m_{t 3} \dot{y}_{t 3}{ }^{2}
\end{aligned}
$$

\begin{tabular}{|c|c|c|c|}
\hline No. & $\begin{array}{l}\text { Degree of } \\
\text { Freedom }\end{array}$ & $\begin{array}{l}\text { Contrib. } \\
\text { Mass }\end{array}$ & Description \\
\hline 1 & $\mathrm{y}_{\mathrm{t} 1}$ & $\mathrm{~m}_{\mathrm{t} 1}$ & Tractor vertical displacement and mass \\
\hline 2 & $\varphi_{\mathrm{t} 1}$ & $\mathrm{I}_{\mathrm{xt} 1}$ & Tractor roll displacement and mass moment of inertia \\
\hline 3 & $\theta_{\mathrm{t} 1}$ & $\mathrm{I}_{\mathrm{zt} 1}$ & Tractor pitch displacement and mass moment of inertia \\
\hline 4 & $\mathrm{y}_{\mathrm{t} 2}$ & $\mathrm{~m}_{\mathrm{t} 2}$ & Semi-trailer vertical displacement and mass \\
\hline 5 & $\varphi_{\mathrm{t} 2}$ & $\mathrm{I}_{\mathrm{xt} 2}$ & Semi-trailer roll displacement and mass moment of inertia \\
\hline 6 & $\theta_{\mathrm{t} 2}$ & $\mathrm{I}_{\mathrm{zt} 2}$ & Semi-trailer pitch displacement and mass moment of inertia \\
\hline 7 & $\mathrm{y}_{\mathrm{t} 3}$ & $\mathrm{~m}_{\mathrm{t} 3}$ & Trailer vertical displacement and mass \\
\hline 8 & $\varphi_{\mathrm{t} 3}$ & $\mathrm{I}_{\mathrm{xt} 3}$ & Trailer roll displacement and mass moment of inertia \\
\hline 9 & $\theta_{\mathrm{t} 3}$ & $\mathrm{I}_{\mathrm{zt} 3}$ & Trailer pitch displacement and mass moment of inertia \\
\hline 10 & $\mathrm{y}_{\mathrm{a} 1}$ & $\mathrm{~m}_{\mathrm{a} 1}$ & Steer axle vertical displacement and mass \\
\hline 11 & $\varphi_{\mathrm{a} 1}$ & $\mathrm{I}_{\mathrm{xa} 1}$ & Steer axle roll displacement and mass moment of inertia \\
\hline 12 & $\mathrm{y}_{\mathrm{a} 2}$ & $\mathrm{~m}_{\mathrm{a} 2}$ & Vertical displacement and mass of forward axle of tractor tandem \\
\hline 13 & $\varphi_{\mathrm{a} 2}$ & $\mathrm{I}_{\mathrm{xa} 2}$ & $\begin{array}{l}\text { Roll displacement and mass moment of inertia of forward axle of } \\
\text { tractor tandem }\end{array}$ \\
\hline 14 & $\mathrm{y}_{\mathrm{a} 3}$ & $\mathrm{~m}_{\mathrm{a} 3}$ & Vertical displacement and mass of aft axle of tractor tandem \\
\hline 15 & $\varphi_{\mathrm{a} 3}$ & $\mathrm{I}_{\mathrm{xa} 3}$ & $\begin{array}{l}\text { Roll displacement and mass moment of inertia of aft axle of tractor } \\
\text { tandem }\end{array}$ \\
\hline 16 & $\mathrm{y}_{\mathrm{a} 4}$ & $\mathrm{~m}_{\mathrm{a} 4}$ & Vertical displacement and mass of 1st axle of 1st trailer \\
\hline 17 & $\varphi_{\mathrm{a} 4}$ & $\mathrm{I}_{\mathrm{xa} 4}$ & Roll displacement and mass moment of inertia of 1 st axle of $1 \mathrm{st}$ trailer \\
\hline 18 & $\mathrm{y}_{\mathrm{a} 5}$ & $\mathrm{~m}_{\mathrm{a} 5}$ & Vertical displacement and mass of 2 nd axle of 1 st trailer \\
\hline 19 & $\varphi_{\mathrm{a} 5}$ & $\mathrm{I}_{\mathrm{xa5}}$ & Roll displacement and mass moment of inertia of 2 nd axle of 1 st trailer \\
\hline 20 & $\mathrm{y}_{\mathrm{a} 6}$ & $\mathrm{~m}_{\mathrm{a} 6}$ & Vertical displacement and mass of 1st axle of 2nd trailer \\
\hline 21 & $\varphi_{\mathrm{a} 6}$ & $\mathrm{I}_{\mathrm{xa6}}$ & Roll displacement and mass moment of inertia of 1 st axle of 2 nd trailer \\
\hline 22 & $\mathrm{y}_{\mathrm{a} 7}$ & $\mathrm{~m}_{\mathrm{a} 7}$ & Vertical displacement and mass of 2 nd axle of 2 nd trailer \\
\hline 23 & $\varphi_{\mathrm{a} 7}$ & $\mathrm{I}_{\mathrm{xa} 7}$ & $\begin{array}{l}\text { Roll displacement and mass moment of inertia of } 2 \text { nd axle of } 2 \text { nd } \\
\text { trailer }\end{array}$ \\
\hline
\end{tabular}

Table 13. Degrees of Freedom of 7-Axle Rocky Mountain Double 
Table 14. Relative Displacements at Spring Locations of 7-Axle Rocky Mountain Double

\begin{tabular}{|c|c|}
\hline & Suspension springs \\
\hline $\mathbf{U}_{\text {sy1 }}$ & $\left(\mathrm{y}_{\mathrm{t} 1}-\mathrm{y}_{\mathrm{a} 1}\right)+\left(\mathrm{S}_{1} / 2\right)\left(\varphi_{\mathrm{t} 1}-\varphi_{\mathrm{a} 1}\right)+\mathrm{l}_{7} \theta_{\mathrm{t} 1}$ \\
\hline $\mathbf{U}_{\text {sy2 }}$ & $\left(\mathrm{y}_{\mathrm{t} 1}-\mathrm{y}_{\mathrm{a} 1}\right)-\left(\mathrm{S}_{1} / 2\right)\left(\varphi_{\mathrm{t} 1}-\varphi_{\mathrm{a} 1}\right)+\mathrm{l}_{7} \theta_{\mathrm{t} 1}$ \\
\hline $\mathbf{U}_{\text {sy3 }}$ & $\left(\mathrm{y}_{\mathrm{t} 1}-\mathrm{y}_{\mathrm{a} 2}\right)+\left(\mathrm{S}_{2} / 2\right)\left(\varphi_{\mathrm{t} 1}-\varphi_{\mathrm{a} 2}\right)-\mathrm{l}_{8} \theta_{\mathrm{t} 1}$ \\
\hline $\mathbf{U}_{\mathrm{sy} 4}$ & $\left(\mathrm{y}_{\mathrm{t} 1}-\mathrm{y}_{\mathrm{a} 2}\right)-\left(\mathrm{S}_{2} / 2\right)\left(\varphi_{\mathrm{t} 1}-\varphi_{\mathrm{a} 2}\right)-\mathrm{l}_{8} \theta_{\mathrm{t} 1}$ \\
\hline $\mathrm{U}_{\text {sy5 }}$ & $\left(\mathrm{y}_{\mathrm{t} 1}-\mathrm{y}_{\mathrm{a} 3}\right)+\left(\mathrm{S}_{3} / 2\right)\left(\varphi_{\mathrm{t} 1}-\varphi_{\mathrm{a} 3}\right)-\left(\mathrm{l}_{2}+\mathrm{l}_{8}\right) \theta_{\mathrm{t} 1}$ \\
\hline $\mathbf{U}_{\text {sy6 }}$ & $\left(\mathrm{y}_{\mathrm{t} 1}-\mathrm{y}_{\mathrm{a} 3}\right)-\left(\mathrm{S}_{3} / 2\right)\left(\varphi_{\mathrm{t} 1}-\varphi_{\mathrm{a} 3}\right)-\left(\mathrm{l}_{2}+\mathrm{l}_{8}\right) \theta_{\mathrm{t} 1}$ \\
\hline $\mathbf{U}_{\text {sy7 }}$ & $\left(\mathrm{y}_{\mathrm{t} 2}-\mathrm{y}_{\mathrm{a} 4}\right)+\left(\mathrm{S}_{4} / 2\right)\left(\varphi_{\mathrm{t} 2}-\varphi_{\mathrm{a} 4}\right)-\mathrm{l}_{11} \theta_{\mathrm{t} 2}$ \\
\hline $\mathbf{U}_{\text {sy8 }}$ & $\left(\mathrm{y}_{\mathrm{t} 2}-\mathrm{y}_{\mathrm{a} 4}\right)-\left(\mathrm{S}_{4} / 2\right)\left(\varphi_{\mathrm{t} 2}-\varphi_{\mathrm{a} 4}\right)-\mathrm{l}_{11} \theta_{\mathrm{t} 2}$ \\
\hline $\mathbf{U}_{\text {sy9 }}$ & $\left(\mathrm{y}_{\mathrm{t} 2}-\mathrm{y}_{\mathrm{a} 5}\right)+\left(\mathrm{S}_{5} / 2\right)\left(\varphi_{\mathrm{t} 2}-\varphi_{\mathrm{a} 5}\right)-\left(\mathrm{l}_{4}+\mathrm{l}_{11}\right) \theta_{\mathrm{t} 2}$ \\
\hline $\mathbf{U}_{\text {sy10 }}$ & $\left(\mathrm{y}_{\mathrm{t} 2}-\mathrm{y}_{\mathrm{a} 5}\right)-\left(\mathrm{S}_{5} / 2\right)\left(\varphi_{\mathrm{t} 2}-\varphi_{\mathrm{a} 5}\right)-\left(\mathrm{l}_{4}+\mathrm{l}_{11}\right) \theta_{\mathrm{t} 2}$ \\
\hline $\mathbf{U}_{\text {sy11 }}$ & $\left(\mathrm{y}_{\mathrm{t} 3}-\mathrm{y}_{\mathrm{a} 6}\right)+\left(\mathrm{S}_{6} / 2\right)\left(\varphi_{\mathrm{t} 3}-\varphi_{\mathrm{a} 6}\right)+\mathrm{l}_{12} \theta_{\mathrm{t} 3}$ \\
\hline $\mathbf{U}_{\text {sy12 }}$ & $\left(\mathrm{y}_{\mathrm{t} 3}-\mathrm{y}_{\mathrm{a} 6}\right)-\left(\mathrm{S}_{6} / 2\right)\left(\varphi_{\mathrm{t} 3}-\varphi_{\mathrm{a} 6}\right)+\mathrm{l}_{12} \theta_{\mathrm{t} 3}$ \\
\hline $\mathbf{U}_{\text {sy13 }}$ & $\left(\mathrm{y}_{\mathrm{t} 3}-\mathrm{y}_{\mathrm{a} 7}\right)+\left(\mathrm{S}_{7} / 2\right)\left(\varphi_{\mathrm{t} 3}-\varphi_{\mathrm{a} 7}\right)-\mathrm{l}_{13} \theta_{\mathrm{t} 3}$ \\
\hline $\mathbf{U}_{\text {sy14 }}$ & $\left(\mathrm{y}_{\mathrm{t} 3}-\mathrm{y}_{\mathrm{a} 7}\right)-\left(\mathrm{S}_{7} / 2\right)\left(\varphi_{\mathrm{t} 3}-\varphi_{\mathrm{a} 7}\right)-\mathrm{l}_{13} \theta_{\mathrm{t} 3}$ \\
\hline & Tire springs \\
\hline $\mathbf{U}_{\mathrm{ty} 1}$ & $\mathrm{y}_{\mathrm{a} 1}+\left(\mathrm{d}_{1} / 2\right) \varphi_{\mathrm{a} 1}+\mathrm{u}_{\mathrm{SR} 1}$ \\
\hline $\mathbf{U}_{\mathrm{ty} 2}$ & $\mathrm{y}_{\mathrm{a} 1}-\left(\mathrm{d}_{1} / 2\right) \varphi_{\mathrm{a} 1}+\mathrm{u}_{\mathrm{SR} 2}$ \\
\hline $\mathbf{U}_{\mathrm{ty} 3}$ & $\mathrm{y}_{\mathrm{a} 2}+\left(\mathrm{d}_{2} / 2\right) \varphi_{\mathrm{a} 2}+\mathrm{u}_{\mathrm{SR} 3}$ \\
\hline $\mathbf{U}_{\text {ty } 4}$ & $\mathrm{y}_{\mathrm{a} 2}-\left(\mathrm{d}_{2} / 2\right) \varphi_{\mathrm{a} 2}+\mathrm{u}_{\mathrm{SR} 4}$ \\
\hline $\mathbf{U}_{\text {ty5 }}$ & $\mathrm{y}_{\mathrm{a} 3}+\left(\mathrm{d}_{3} / 2\right) \varphi_{\mathrm{a} 3}+\mathrm{u}_{\mathrm{SR} 5}$ \\
\hline $\mathbf{U}_{\mathrm{ty} 6}$ & $\mathrm{y}_{\mathrm{a} 3}-\left(\mathrm{d}_{3} / 2\right) \varphi_{\mathrm{a} 3}+\mathrm{u}_{\mathrm{SR} 6}$ \\
\hline $\mathbf{U}_{\text {ty7 }}$ & $\mathrm{y}_{\mathrm{a} 4}+\left(\mathrm{d}_{4} / 2\right) \varphi_{\mathrm{a} 4}+\mathrm{u}_{\mathrm{SR} 7}$ \\
\hline $\mathbf{U}_{\mathrm{ty} 8}$ & $\mathrm{y}_{\mathrm{a} 4}-\left(\mathrm{d}_{4} / 2\right) \varphi_{\mathrm{a} 4}+\mathrm{u}_{\mathrm{SR} 8}$ \\
\hline $\mathbf{U}_{\text {ty9 }}$ & $\mathrm{y}_{\mathrm{a} 5}+\left(\mathrm{d}_{5} / 2\right) \varphi_{\mathrm{a} 5}+\mathrm{u}_{\mathrm{SR} 9}$ \\
\hline $\mathbf{U}_{\text {ty10 }}$ & $\mathrm{y}_{\mathrm{a} 5}-\left(\mathrm{d}_{5} / 2\right) \varphi_{\mathrm{a} 5}+\mathrm{u}_{\mathrm{SR} 10}$ \\
\hline $\mathbf{U}_{\mathrm{ty} 11}$ & $\mathrm{y}_{\mathrm{a} 6}+\left(\mathrm{d}_{6} / 2\right) \varphi_{\mathrm{a} 6}+\mathrm{u}_{\mathrm{SR} 11}$ \\
\hline $\mathbf{U}_{\mathrm{ty} 12}$ & $\mathrm{y}_{\mathrm{a} 6}-\left(\mathrm{d}_{6} / 2\right) \varphi_{\mathrm{a} 6}+\mathrm{u}_{\mathrm{SR} 12}$ \\
\hline $\mathbf{U}_{\mathrm{ty} 13}$ & $\mathrm{y}_{\mathrm{a} 7}+\left(\mathrm{d}_{7} / 2\right) \varphi_{\mathrm{a} 7}+\mathrm{u}_{\mathrm{SR} 13}$ \\
\hline $\mathbf{U}_{\mathrm{ty} 14}$ & $\mathrm{y}_{\mathrm{a} 7}-\left(\mathrm{d}_{7} / 2\right) \varphi_{\mathrm{a} 7}+\mathrm{u}_{\mathrm{SR} 14}$ \\
\hline
\end{tabular}


Figure 7. Seven Axle Rocky Mountain Double Dynamic Model (a) Truck Side View (b) Truck Front View 
Potential Energy of the system:

$$
\begin{aligned}
& V=\frac{1}{2} K_{s y 1} U_{s y 1}{ }^{2}+\frac{1}{2} K_{s y 2} U_{s y 2}{ }^{2}+\frac{1}{2} K_{s y 3} U_{s y 3}{ }^{2}+\frac{1}{2} K_{s y 4} U_{s y 4}{ }^{2}+\frac{1}{2} K_{s y 5} U_{s y 5}{ }^{2}+ \\
& \frac{1}{2} K_{s y 6} U_{s y 6}{ }^{2}+\frac{1}{2} K_{s y 7}{U_{s y 7}}^{2}+\frac{1}{2} K_{s y 8} U_{s y 8}{ }^{2}+\frac{1}{2} K_{s y 9} U_{s y 9}{ }^{2}+\frac{1}{2} K_{s y 10} U_{s y 10}{ }^{2}+ \\
& \frac{1}{2} K_{s y 11} U_{s y 11}{ }^{2}+\frac{1}{2} K_{s y 12} U_{s y 12}{ }^{2}+\frac{1}{2} K_{s y 13} U_{s y 13}{ }^{2}+\frac{1}{2} K_{s y 14} U_{s y 14}{ }^{2}+\frac{1}{2} K_{t y 1} U_{t y 1}{ }^{2}+ \\
& \frac{1}{2} K_{t y 2} U_{t y 2}{ }^{2}+\frac{1}{2} K_{t y 3} U_{t y 3}{ }^{2}+\frac{1}{2} K_{t y 4} U_{t y 4}{ }^{2}+\frac{1}{2} K_{t y 5} U_{t y 5}{ }^{2}+\frac{1}{2} K_{t y 6} U_{t y 6}{ }^{2}+ \\
& \frac{1}{2} K_{t y 7} U_{s y 7}{ }^{2}+\frac{1}{2} K_{t y 8} U_{t y 8}{ }^{2}+\frac{1}{2} K_{t y 9} U_{t y 9}{ }^{2}+\frac{1}{2} K_{t y 10} U_{t y 10}{ }^{2}+\frac{1}{2} K_{t y 11} U_{t y 11}{ }^{2}+ \\
& \frac{1}{2} K_{t y 12} U_{t y 12}{ }^{2}+\frac{1}{2} K_{t y 13} U_{t y 13}{ }^{2}+\frac{1}{2} K_{t y 14} U_{t y 14}{ }^{2}-\left(\left(m_{t 1} g\right) y_{t 1}+\left(m_{t 2} g\right) y_{t 2}+\right. \\
& \left(m_{t 3} g\right) y_{t 3}+\left(m_{a 1} g\right) y_{a 1}+\left(m_{a 2} g\right) y_{a 2}+\left(m_{a 3} g\right) y_{a 3}+\left(m_{a 4} g\right) y_{a 4}+ \\
& \left.\left(m_{a 5} g\right) y_{a 5}+\left(m_{a 6} g\right) y_{a 6}+\left(m_{a 7} g\right) y_{a 7}\right)+\left(F_{y 1} U_{s y 1}+F_{y 2} U_{s y 2}+F_{y 3} U_{s y 3}+\right. \\
& F_{y 4} U_{s y 4}+F_{y 5} U_{s y 5}+F_{y 6} U_{s y 6}+F_{y 7} U_{s y 7}+F_{y 8} U_{s y 8}+F_{y 9} U_{s y 9}+F_{y 10} U_{s y 10}+ \\
& \left.F_{y 11} U_{s y 11}+F_{y 12} U_{s y 12}+F_{y 13} U_{s y 13}+F_{y 14} U_{s y 14}\right)
\end{aligned}
$$

\section{Damping Energy of the system:}

$$
\begin{aligned}
& D=\frac{1}{2} D_{s y 1} \dot{U}_{s y 1}{ }^{2}+\frac{1}{2} D_{s y 2} \dot{U}_{s y 2}{ }^{2}+\frac{1}{2} D_{s y 3} \dot{U}_{s y 3}{ }^{2}+\frac{1}{2} D_{s y 4} \dot{U}_{s y 4}{ }^{2}+\frac{1}{2} D_{s y 5} \dot{U}_{s y 5}{ }^{2}+ \\
& \frac{1}{2} D_{s y 6} \dot{U}_{s y 6}{ }^{2}+\frac{1}{2} D_{s y 7} \dot{U}_{s y 7}{ }^{2}+\frac{1}{2} D_{s y 8} \dot{U}_{s y 8}{ }^{2}+\frac{1}{2} D_{s y 9} \dot{U}_{s y 9}{ }^{2}+\frac{1}{2} D_{s y 10} \dot{U}_{s y 10}{ }^{2}+ \\
& \frac{1}{2} D_{s y 11} \dot{U}_{s y 11}{ }^{2}+\frac{1}{2} D_{s y 12} \dot{U}_{s y 12}{ }^{2}+\frac{1}{2} D_{s y 13} \dot{U}_{s y 13}{ }^{2}+\frac{1}{2} D_{s y 14} \dot{U}_{s y 14}{ }^{2}+\frac{1}{2} D_{t y 1} \dot{U}_{t y 1}{ }^{2}+ \\
& \frac{1}{2} D_{t y 2} \dot{U}_{t y 2}{ }^{2}+\frac{1}{2} D_{t y 3} \dot{U}_{t y 3}{ }^{2}+\frac{1}{2} D_{t y 4} \dot{U}_{t y 4}{ }^{2}+\frac{1}{2} D_{t y 5} \dot{U}_{t y 5}{ }^{2}+\frac{1}{2} D_{t y 6} \dot{U}_{t y 6}{ }^{2}+ \\
& \frac{1}{2} D_{t y 7} \dot{U}_{t y 7}{ }^{2}+\frac{1}{2} D_{t y 8} \dot{U}_{t y 8}{ }^{2}+\frac{1}{2} D_{t y 9} \dot{U}_{t y 9}{ }^{2}+\frac{1}{2} D_{t y 10} \dot{U}_{t y 10}{ }^{2}+\frac{1}{2} D_{t y 11} \dot{U}_{t y 11}{ }^{2}+ \\
& \frac{1}{2} D_{t y 12} \dot{U}_{t y 12}{ }^{2}+\frac{1}{2} D_{t y 13} \dot{U}_{t y 13}{ }^{2}+\frac{1}{2} D_{t y 14} \dot{U}_{t y 14}{ }^{2}
\end{aligned}
$$

The displacement at the pivot point should stay the same, whether it is calculated from the trailer part or the tractor part, 
$y_{t 2}+\theta_{t 2} l_{10}=y_{t 1}-\theta_{t 1} l_{9}$

Thus, by substituting $\theta_{\mathrm{t} 2}$ from equation ( 247 ) in equation ( 244 ),

$$
\begin{aligned}
& T=\frac{1}{2} m_{t 1} \dot{y}_{t 1}{ }^{2}+\frac{1}{2} m_{a 1} \dot{y}_{a 1}{ }^{2}+\frac{1}{2} m_{a 2} \dot{y}_{a 2}{ }^{2}+\frac{1}{2} m_{a 3} \dot{y}_{a 3}{ }^{2}+\frac{1}{2} m_{a 4} \dot{y}_{a 4}{ }^{2}+\frac{1}{2} m_{a 5} \dot{y}_{a 5}{ }^{2}+ \\
& \frac{1}{2} m_{a 6} \dot{y}_{a 6}{ }^{2}+\frac{1}{2} m_{a 7} \dot{y}_{a 7}{ }^{2}+\frac{1}{2} I_{x t 1} \dot{\varphi}_{t 1}{ }^{2}+\frac{1}{2} I_{z t 1} \dot{\theta}_{t 1}{ }^{2}+\frac{1}{2} I_{x t 2} \dot{\varphi}_{t 2}{ }^{2}+ \\
& \frac{1}{2} I_{z t 2}\left(\frac{\dot{y}_{t 1}-\dot{y}_{t 2}-\dot{\theta}_{t 1} l_{9}}{l_{10}}\right)^{2}+\frac{1}{2} I_{x t 3} \dot{\varphi}_{t 3}{ }^{2}+\frac{1}{2} I_{z t 3} \dot{\theta}_{t 3}{ }^{2}+\frac{1}{2} I_{x a 1} \dot{\varphi}_{a 1}{ }^{2}+\frac{1}{2} I_{x a 2} \dot{\varphi}_{a 2}{ }^{2}+ \\
& \frac{1}{2} I_{x a 3} \dot{\varphi}_{a 3}{ }^{2}+\frac{1}{2} I_{x a 4} \dot{\varphi}_{a 4}{ }^{2}+\frac{1}{2} I_{x a 5} \dot{\varphi}_{a 5}{ }^{2}+\frac{1}{2} I_{x a 6} \dot{\varphi}_{a 6}{ }^{2}+\frac{1}{2} I_{x a 7} \dot{\varphi}_{a 7}{ }^{2}+\frac{1}{2} m_{t 2} \dot{y}_{t 2}{ }^{2}+ \\
& \frac{1}{2} m_{t 3} \dot{y}_{t 3}{ }^{2}
\end{aligned}
$$

Same substitution will be applied to the equations ( 245 ) and ( 246 ). Now the Lagrange's equation is applied to $\mathrm{y}_{\mathrm{t} 2}$ :

$$
\begin{aligned}
& {\left[m_{t 2} \ddot{y}_{t 2}-\frac{I_{z t 2}}{l_{10}^{2}}\left(\ddot{y}_{t 1}-\ddot{y}_{t 2}-\ddot{\theta}_{t 1} l_{9}\right)\right]+} \\
& {\left[\left(1+\frac{l_{11}}{l_{10}}\right)\left(F_{s y 7}+F_{s y 8}\right)+\left(1+\frac{l_{4}+l_{11}}{l_{10}}\right)\left(F_{s y 9}+F_{s y 10}\right)-\left(m_{t 2} g\right)\right]+[(1+} \\
& \left.\left.\frac{l_{11}}{l_{10}}\right)\left(F_{d s y 7}+F_{d s y 8}\right)+\left(1+\frac{l_{4}+l_{11}}{l_{10}}\right)\left(F_{d s y 9}+F_{d s y 10}\right)\right]=0
\end{aligned}
$$

To simplify the equation some variables are defined as follows:

$$
\begin{aligned}
& \mathrm{S}_{\mathrm{a} 2}=\frac{\mathrm{I}_{\mathrm{zt} 2}}{\mathrm{l}_{10}{ }^{2}} \\
& \mathrm{~S}_{\mathrm{c} 2}=\frac{\mathrm{I}_{\mathrm{zt} 2}}{l_{10}{ }^{2}}+\mathrm{m}_{\mathrm{t} 2} \\
& \mathrm{~S}_{\mathrm{a} 3}=\frac{\mathrm{I}_{\mathrm{zt} 2}}{l_{10}{ }^{2}} l_{9} \\
& B_{t 4}=m_{t 2} g-\left(1+\frac{l_{11}}{l_{10}}\right)\left(F_{s y 7}+F_{s y 8}+F_{d s y 7}+F_{d s y 8}\right)-\left(1+\frac{l_{4}+l_{11}}{l_{10}}\right)\left(F_{s y 9}+F_{s y 10}+F_{d s y 9}+\right. \\
& \left.F_{d s y 10}\right)
\end{aligned}
$$


Therefore equation ( 249 ) will be simplified to:

$-S_{a 2} \ddot{y}_{t 1}+S_{c 2} \ddot{y}_{t 2}+S_{a 3} \ddot{\theta}_{t 1}=B_{t 4}$

By applying the Lagrange's equation to $\mathrm{y}_{\mathrm{t} 1}$ :

$$
\begin{aligned}
& {\left[m_{t 1} \ddot{y}_{t 1}+\frac{I_{z t 2}}{l_{10}}\left(\ddot{y}_{t 1}-\ddot{y}_{t 2}-\ddot{\theta}_{t 1} l_{9}\right)\right]+\left[\left(F_{s y 1}+F_{s y 2}+F_{s y 3}+F_{s y 4}+F_{s y 5}+F_{s y 6}\right)-\right.} \\
& \left.\frac{l_{11}}{l_{10}}\left(F_{s y 7}+F_{s y 8}\right)-\frac{l_{4}+l_{11}}{l_{10}}\left(F_{s y 9}+F_{s y 10}\right)-\left(m_{t 1} g\right)\right]+\left[\left(F_{d s y 1}+F_{d s y 2}+F_{d s y 3}+\right.\right. \\
& \left.\left.F_{d s y 4}+F_{d s y 5}+F_{d s y 6}\right)-\frac{l_{11}}{l_{10}}\left(F_{d s y 7}+F_{d s y 8}\right)-\frac{l_{4}+l_{11}}{l_{10}}\left(F_{d s y 9}+F_{d s y 10}\right)\right]=0
\end{aligned}
$$

Again to simplify the equation some variables are defined as follows:

$$
\begin{aligned}
& S_{a 1}=\frac{I_{z t 2}}{l_{10}^{2}}+m_{t 1} \\
& B_{t 1}=m_{t 1} g-\left[\left(F_{s y 1}+F_{s y 2}+F_{s y 3}+F_{s y 4}+F_{s y 5}+F_{s y 6}\right)-\frac{l_{11}}{l_{10}}\left(F_{s y 7}+F_{s y 8}\right)-\frac{l_{4}+l_{11}}{l_{10}}\left(F_{s y 9}+\right.\right. \\
& \left.F_{s y 10}\right)+\left(F_{d s y 1}+F_{d s y 2}+F_{d s y 3}+F_{d s y 4}+F_{d s y 5}+F_{d s y 6}\right)-\frac{l_{11}}{l_{10}}\left(F_{d s y 7}+F_{d s y 8}\right)- \\
& \left.\frac{l_{4}+l_{11}}{l_{10}}\left(F_{d s y 9}+F_{d s y 10}\right)\right]
\end{aligned}
$$

Therefore equation ( 251 ) will be simplified to:

$$
S_{a 1} \ddot{y}_{t 1}-S_{a 2} \ddot{y}_{t 2}-S_{a 3} \ddot{\theta}_{t 1}=B_{t 1}
$$

Also, by applying the Lagrange's equation to $\theta_{\mathrm{t} 1}$ :

$$
\begin{aligned}
& {\left[I_{z t 1} \ddot{\theta}_{t 1}-\frac{I_{z t 2} l_{9}}{l_{10}{ }^{2}}\left(\ddot{y}_{t 1}-\ddot{y}_{t 2}-\ddot{\theta}_{t 1} l_{9}\right)\right]+\left[l_{7}\left(F_{s y 1}+F_{s y 2}\right)-l_{8}\left(F_{s y 3}+F_{s y 4}\right)-\right.} \\
& \left.\left(l_{2}+l_{8}\right)\left(F_{s y 5}+F_{s y 6}\right)+\frac{l_{9} I_{11}}{l_{10}}\left(F_{s y 7}+F_{s y 8}\right)+\frac{l_{9}\left(l_{4}+I_{11}\right)}{l_{10}}\left(F_{s y 9}+F_{s y 10}\right)\right]+ \\
& {\left[l_{7}\left(F_{d s y 1}+F_{d s y 2}\right)-l_{8}\left(F_{d s y 3}+F_{d s y 4}\right)-\left(l_{2}+l_{8}\right)\left(F_{d s y 5}+F_{d s y 6}\right)+\frac{l_{9} I_{11}}{l_{10}}\left(F_{d s y 7}+\right.\right.}
\end{aligned}
$$


$\left.\left.F_{d s y 8}\right)+\frac{l_{9}\left(l_{4}+I_{11}\right)}{l_{10}}\left(F_{d s y 9}+F_{d s y 10}\right)\right]=0$

Once again to simplify the equation some variables need to be defined as follows:

$\mathrm{S}_{\mathrm{b} 3}=\mathrm{I}_{\mathrm{zt} 1}+\frac{\mathrm{I}_{\mathrm{zt} 2} \mathrm{l}_{9}}{\mathrm{l}_{10}{ }^{2}}$

$B_{t 3}=-\left[\left[l_{7}\left(F_{s y 1}+F_{s y 2}\right)-l_{8}\left(F_{s y 3}+F_{s y 4}\right)-\left(l_{2}+l_{8}\right)\left(F_{s y 5}+F_{s y 6}\right)+\frac{l_{9} I_{11}}{l_{10}}\left(F_{s y 7}+F_{s y 8}\right)+\right.\right.$

$\left.\frac{l_{9}\left(l_{4}+l_{11}\right)}{l_{10}}\left(F_{s y 9}+F_{s y 10}\right)\right]+\left[l_{7}\left(F_{d s y 1}+F_{d s y 2}\right)-l_{8}\left(F_{d s y 3}+F_{d s y 4}\right)-\left(l_{2}+l_{8}\right)\left(F_{d s y 5}+\right.\right.$

$\left.\left.\left.F_{d s y 6}\right)+\frac{l_{9} I_{11}}{l_{10}}\left(F_{d s y 7}+F_{d s y 8}\right)+\frac{l_{9}\left(l_{4}+I_{11}\right)}{l_{10}}\left(F_{d s y 9}+F_{d s y 10}\right)\right]\right]$

Therefore equation ( 253 ) will be simplified to:

$-S_{a 3} \ddot{y}_{t 1}+S_{a 3} \ddot{y}_{t 2}+S_{b 3} \ddot{\theta}_{t 1}=B_{t 3}$

By adding equations ( 250 ) and ( 252 ),

$\left(S_{a 1}-S_{a 2}\right) \ddot{y}_{t 1}-\left(S_{a 2}-S_{c 2}\right) \ddot{y}_{t 2}=B_{t 1}+B_{t 4}$

Also by multiplying $\mathrm{S}_{\mathrm{b} 3}$ and $\mathrm{S}_{\mathrm{a} 3}$ to equations ( 254 ) and ( 255 ), respectively,

$\left(S_{a 1} S_{b 3}-S_{a 3}^{2}\right) \ddot{y}_{t 1}-\left(S_{a 2} S_{b 3}-S_{a 3}^{2}\right) \ddot{y}_{t 2}=S_{b 3} B_{t 1}+S_{a 3} B_{t 3}$

By defining the following expressions, equations ( 255 ) and ( 256 ) are simplified to equations ( 257 ) and ( 258 ), respectively,

$$
\begin{aligned}
& e_{1}=S_{a 1}-S_{a 2} \\
& e_{2}=S_{a 2}-S_{c 2} \\
& e_{3}=S_{a 1} S_{b 3}-S_{a 3}^{2} \\
& e_{4}=S_{a 2} S_{b 3}-S_{a 3}^{2}
\end{aligned}
$$


$e_{1} \ddot{y}_{t 1}-e_{2} \ddot{y}_{t 2}=B_{t 1}+B_{t 4}$

$e_{3} \ddot{y}_{t 1}-e_{4} \ddot{y}_{t 2}=S_{b 3} B_{t 1}+S_{a 3} B_{t 3}$

Solving equations ( 257 ) and ( 258 ) for $\ddot{y}_{\mathrm{t} 1}$ and $\ddot{y}_{\mathrm{t} 2}$ will lead to:

$\ddot{y}_{t 1}=\frac{e_{4}\left(B_{t 1}+B_{t 4}\right)-e_{2}\left(S_{b 3} B_{t 1}+S_{a 3} B_{t 3}\right)}{e_{1} e_{4}-e_{2} e_{3}}$

$\ddot{y}_{t 2}=\frac{e_{1}}{e_{2}}\left(\frac{e_{4}\left(B_{t 1}+B_{t 4}\right)-e_{2}\left(S_{b 3} B_{t 1}+S_{a 3} B_{t 3}\right)}{e_{1} e_{4}-e_{2} e_{3}}\right)-\frac{B_{t 1}+B_{t 4}}{e_{2}}$

Substituting equations ( 259 ) and ( 260 ) into equation ( 254 ) will give,

$$
\begin{aligned}
& \ddot{\theta}_{t 1}= \\
& \frac{B_{t 3}}{S_{b 3}}+\frac{S_{a 3}}{S_{b 3}}\left(\frac{e_{4}\left(B_{t 1}+B_{t 4}\right)-e_{2}\left(S_{b 3} B_{t 1}+S_{a 3} B_{t 3}\right)}{e_{1} e_{4}-e_{2} e_{3}}\right)-\frac{S_{a 3}}{S_{b 3}}\left(\frac{e_{1}}{e_{2}}\left(\frac{e_{4}\left(B_{t 1}+B_{t 4}\right)-e_{2}\left(S_{b 3} B_{t 1}+S_{a 3} B_{t 3}\right)}{e_{1} e_{4}-e_{2} e_{3}}\right)-\right. \\
& \left.\frac{B_{t 1}+B_{t 4}}{e_{2}}\right)
\end{aligned}
$$

By applying the Lagrange's equation to $\varphi_{\mathrm{t} 1}, \varphi_{\mathrm{t} 2}, \varphi_{\mathrm{t} 3}, \mathrm{y}_{\mathrm{t} 3}, \theta_{\mathrm{t} 3}$ :

$$
\begin{aligned}
& I_{x t 1} \ddot{\varphi}_{t 1}+\left[\left(\frac{s_{1}}{2}\right)\left(F_{s y 1}-F_{s y 2}\right)+\left(\frac{s_{2}}{2}\right)\left(F_{s y 3}-F_{s y 4}\right)+\left(\frac{s_{3}}{2}\right)\left(F_{s y 5}-F_{s y 6}\right)\right]+ \\
& {\left[\left(\frac{s_{1}}{2}\right)\left(F_{d s y 1}-F_{d s y 2}\right)+\left(\frac{s_{2}}{2}\right)\left(F_{d s y 3}-F_{d s y 4}\right)+\left(\frac{s_{3}}{2}\right)\left(F_{d s y 5}-F_{d s y 6}\right)\right]=0} \\
& I_{x t 2} \ddot{\varphi}_{t 2}+\left[\left(\frac{s_{4}}{2}\right)\left(F_{s y 7}-F_{s y 8}\right)+\left(\frac{s_{5}}{2}\right)\left(F_{s y 9}-F_{s y 10}\right)\right]+\left[\left(\frac{s_{4}}{2}\right)\left(F_{d s y 7}-F_{d s y 8}\right)+\right. \\
& \left.\left(\frac{s_{5}}{2}\right)\left(F_{d s y 9}-F_{d s y 10}\right)\right]=0 \\
& I_{x t 3} \ddot{\varphi}_{t 3}+\left[\left(\frac{s_{6}}{2}\right)\left(F_{s y 11}-F_{s y 12}\right)+\left(\frac{s_{7}}{2}\right)\left(F_{s y 13}-F_{s y 14}\right)\right]+\left[\left(\frac{s_{6}}{2}\right)\left(F_{d s y 11}-F_{d s y 12}\right)+\right. \\
& \left.\left(\frac{s_{7}}{2}\right)\left(F_{d s y 13}-F_{d s y 14}\right)\right]=0 \\
& m_{t 3} \ddot{y}_{t 3}+\left(F_{s y 11}+F_{s y 12}+F_{s y 13}+F_{s y 14}\right)+\left(F_{d s y 11}+F_{d s y 12}+F_{d s y 13}+F_{d s y 14}\right)- \\
& m_{t 3} g=0 \\
& I_{z t 3} \ddot{\theta}_{t 3}+\left[l_{12}\left(F_{s y 11}+F_{s y 12}\right)-l_{13}\left(F_{s y 13}+F_{s y 14}\right)\right]+\left[l_{12}\left(F_{d s y 11}+F_{d s y 12}\right)-\right. \\
& \left.l_{13}\left(F_{d s y 13}+F_{d s y 14}\right)\right]=0
\end{aligned}
$$


The rest of degrees of freedom will be as follows:

$$
\begin{aligned}
& m_{a 1} \ddot{y}_{a 1}-\left(F_{s y 1}+F_{s y 2}\right)+\left(F_{t y 1}+F_{t y 2}\right)-\left(F_{d s y 1}+F_{d s y 2}\right)+\left(F_{d t y 1}+F_{d t y 2}\right)= \\
& m_{a 1} g \\
& I_{x a 1} \ddot{\varphi}_{a 1}-\left(\frac{s_{1}}{2}\right)\left(F_{s y 1}-F_{s y 2}\right)+\left(\frac{d_{1}}{2}\right)\left(F_{t y 1}-F_{t y 2}\right)-\left(\frac{s_{1}}{2}\right)\left(F_{d s y 1}-F_{d s y 2}\right)+ \\
& \left(\frac{d_{1}}{2}\right)\left(F_{d t y 1}-F_{d t y 2}\right)=0 \\
& m_{a 2} \ddot{y}_{a 2}-\left(F_{s y 3}+F_{s y 4}\right)+\left(F_{t y 3}+F_{t y 4}\right)-\left(F_{d s y 3}+F_{d s y 4}\right)+\left(F_{d t y 3}+F_{d t y 4}\right)= \\
& m_{a 2} g \\
& I_{x a 2} \ddot{\varphi}_{a 2}-\left(\frac{s_{2}}{2}\right)\left(F_{s y 3}-F_{s y 4}\right)+\left(\frac{d_{2}}{2}\right)\left(F_{t y 3}-F_{t y 4}\right)-\left(\frac{s_{2}}{2}\right)\left(F_{d s y 3}-F_{d s y 4}\right)+ \\
& \left(\frac{d_{2}}{2}\right)\left(F_{d t y 3}-F_{d t y 4}\right)=0 \\
& m_{a 3} \ddot{y}_{a 3}-\left(F_{s y 5}+F_{s y 6}\right)+\left(F_{t y 5}+F_{t y 6}\right)-\left(F_{d s y 5}+F_{d s y 6}\right)+\left(F_{d t y 5}+F_{d t y 6}\right)= \\
& m_{a 3} g \\
& I_{x a 3} \ddot{\varphi}_{a 3}-\left(\frac{s_{3}}{2}\right)\left(F_{s y 5}-F_{s y 6}\right)+\left(\frac{d_{3}}{2}\right)\left(F_{t y 5}-F_{t y 6}\right)-\left(\frac{s_{3}}{2}\right)\left(F_{d s y 5}-F_{d s y 6}\right)+ \\
& \left.F_{d t y 10}\right)=m_{a 5} g \\
& \left(\frac{d_{3}}{2}\right)\left(F_{d t y 5}-F_{d t y 6}\right)=0 \\
& m_{a 4} \ddot{y}_{a 4}-\left(F_{s y 7}+F_{s y 8}\right)+\left(F_{t y 7}+F_{t y 8}\right)-\left(F_{d s y 7}+F_{d s y 8}\right)+\left(F_{d t y 7}+F_{d t y 8}\right)= \\
& m_{a 4} g \\
& \left(\ddot{\varphi}_{a 4}-\left(\frac{s_{4}}{2}\right)\left(F_{s y 7}-F_{s y 8}\right)+\left(\frac{d_{4}}{2}\right)\left(F_{t y 7}-F_{t y 8}\right)-\left(\frac{s_{4}}{2}\right)\left(F_{d s y 7}-F_{d s y 8}\right)+\right. \\
& \ddot{y}_{a 5}-\left(F_{s y 9}+F_{s y 10}\right)+\left(F_{t y 9}+F_{t y 10}\right)-\left(F_{d s y 9}+F_{d s y 10}\right)+\left(F_{d t y 9}+\right. \\
&
\end{aligned}
$$




$$
\begin{aligned}
& I_{x a 5} \ddot{\varphi}_{a 5}-\left(\frac{s_{5}}{2}\right)\left(F_{s y 9}-F_{s y 10}\right)+\left(\frac{d_{5}}{2}\right)\left(F_{t y 9}-F_{t y 10}\right)-\left(\frac{s_{5}}{2}\right)\left(F_{d s y 9}-F_{d s y 10}\right)+ \\
& \left(\frac{d_{5}}{2}\right)\left(F_{d t y 9}-F_{d t y 10}\right)=0 \\
& m_{a 6} \ddot{y}_{a 6}-\left(F_{s y 11}+F_{s y 12}\right)+\left(F_{t y 11}+F_{t y 12}\right)-\left(F_{d s y 11}+F_{d s y 12}\right)+\left(F_{d t y 11}+\right. \\
& \left.F_{d t y 12}\right)=m_{a 6} g \\
& I_{x a 6} \ddot{\varphi}_{a 6}-\left(\frac{s_{6}}{2}\right)\left(F_{s y 11}-F_{s y 12}\right)+\left(\frac{d_{6}}{2}\right)\left(F_{t y 11}-F_{t y 12}\right)-\left(\frac{s_{6}}{2}\right)\left(F_{d s y 11}-F_{d s y 12}\right)+ \\
& \left(\frac{d_{6}}{2}\right)\left(F_{d t y 11}-F_{d t y 12}\right)=0 \\
& m_{a 7} \ddot{y}_{a 7}-\left(F_{s y 13}+F_{s y 14}\right)+\left(F_{t y 13}+F_{t y 14}\right)-\left(F_{d s y 13}+F_{d s y 14}\right)+\left(F_{d t y 13}+\right. \\
& \left.F_{d t y 14}\right)=m_{a 7} g \\
& I_{x a 7} \ddot{\varphi}_{a 7}-\left(\frac{s_{7}}{2}\right)\left(F_{s y 13}-F_{s y 14}\right)+\left(\frac{d_{7}}{2}\right)\left(F_{t y 13}-F_{t y 14}\right)-\left(\frac{s_{7}}{2}\right)\left(F_{d s y 13}-F_{d s y 14}\right)+ \\
& \left(\frac{d_{7}}{2}\right)\left(F_{d t y 13}-F_{d t y 14}\right)=0
\end{aligned}
$$

Derivation of Equations of Motion for 8 Axle B-Train Double

There are twenty five degrees of freedom in total for this type of truck. The degrees of freedom can be seen in Figure 8 and the description of those degrees of freedom can be found in Table 15. Relative Displacements at the locations of the springs are also calculated using the values given in Table 16. 
Table 15. Degrees of Freedom of 8 Axle B-Train Double

\begin{tabular}{|c|c|c|c|}
\hline No. & $\begin{array}{l}\text { Degree of } \\
\text { Freedom }\end{array}$ & $\begin{array}{l}\text { Contrib. } \\
\text { Mass }\end{array}$ & Description \\
\hline 1 & $\mathrm{y}_{\mathrm{t} 1}$ & $\mathrm{~m}_{\mathrm{t} 1}$ & Tractor vertical displacement and mass \\
\hline 2 & $\varphi_{\mathrm{t} 1}$ & $\mathrm{I}_{\mathrm{xt} 1}$ & Tractor roll displacement and mass moment of inertia \\
\hline 3 & $\theta_{\mathrm{t} 1}$ & $\mathrm{I}_{\mathrm{zt} 1}$ & Tractor pitch displacement and mass moment of inertia \\
\hline 4 & $\mathrm{y}_{\mathrm{t} 2}$ & $\mathrm{~m}_{\mathrm{t} 2}$ & Semi-trailer vertical displacement and mass \\
\hline 5 & $\varphi_{\mathrm{t} 2}$ & $\mathrm{I}_{\mathrm{xt} 2}$ & Semi-trailer roll displacement and mass moment of inertia \\
\hline 6 & $\theta_{\mathrm{t} 2}$ & $\mathrm{I}_{\mathrm{zt} 2}$ & Semi-trailer pitch displacement and mass moment of inertia \\
\hline 7 & $\mathrm{y}_{\mathrm{t} 3}$ & $\mathrm{~m}_{\mathrm{t} 3}$ & Trailer vertical displacement and mass \\
\hline 8 & $\varphi_{\mathrm{t} 3}$ & $\mathrm{I}_{\mathrm{xt} 3}$ & Trailer roll displacement and mass moment of inertia \\
\hline 9 & $\theta_{\mathrm{t} 3}$ & $\mathrm{I}_{\mathrm{zt} 3}$ & Trailer pitch displacement and mass moment of inertia \\
\hline 10 & $\mathrm{y}_{\mathrm{a} 1}$ & $\mathrm{~m}_{\mathrm{a} 1}$ & Steer axle vertical displacement and mass \\
\hline 11 & $\varphi_{\mathrm{a} 1}$ & $\mathrm{I}_{\mathrm{xa} 1}$ & Steer axle roll displacement and mass moment of inertia \\
\hline 12 & $\mathrm{y}_{\mathrm{a} 2}$ & $\mathrm{~m}_{\mathrm{a} 2}$ & Vertical displacement and mass of forward axle of tractor tandem \\
\hline 13 & $\varphi_{\mathrm{a} 2}$ & $\mathrm{I}_{\mathrm{xa} 2}$ & $\begin{array}{l}\text { Roll displacement and mass moment of inertia of forward axle of } \\
\text { tractor tandem }\end{array}$ \\
\hline 14 & $\mathrm{y}_{\mathrm{a} 3}$ & $\mathrm{~m}_{\mathrm{a} 3}$ & Vertical displacement and mass of aft axle of tractor tandem \\
\hline 15 & $\varphi_{\mathrm{a} 3}$ & $\mathrm{I}_{\mathrm{xa} 3}$ & $\begin{array}{l}\text { Roll displacement and mass moment of inertia of aft axle of tractor } \\
\text { tandem }\end{array}$ \\
\hline 16 & $\mathrm{y}_{\mathrm{a} 4}$ & $\mathrm{~m}_{\mathrm{a} 4}$ & Vertical displacement and mass of first axle of first trailer \\
\hline 17 & $\varphi_{\mathrm{a} 4}$ & $\mathrm{I}_{\mathrm{xa} 4}$ & $\begin{array}{l}\text { Roll displacement and mass moment of inertia of first axle of first } \\
\text { trailer }\end{array}$ \\
\hline 18 & $\mathrm{y}_{\mathrm{a} 5}$ & $\mathrm{~m}_{\mathrm{a} 5}$ & Vertical displacement and mass of second axle of first trailer \\
\hline 19 & $\varphi_{\mathrm{a} 5}$ & $\mathrm{I}_{\mathrm{xa} 5}$ & $\begin{array}{l}\text { Roll displacement and mass moment of inertia of second axle of first } \\
\text { trailer }\end{array}$ \\
\hline 20 & $\mathrm{y}_{\mathrm{a} 6}$ & $\mathrm{~m}_{\mathrm{a} 6}$ & Vertical displacement and mass of first axle of second trailer \\
\hline 21 & $\varphi_{\mathrm{a} 6}$ & $\mathrm{I}_{\mathrm{xa} 6}$ & $\begin{array}{l}\text { Roll displacement and mass moment of inertia of first axle of second } \\
\text { trailer }\end{array}$ \\
\hline 22 & $\mathrm{y}_{\mathrm{a} 7}$ & $\mathrm{~m}_{\mathrm{a} 7}$ & Vertical displacement and mass of second axle of second trailer \\
\hline 23 & $\varphi_{\mathrm{a} 7}$ & $\mathrm{I}_{\mathrm{xa} 7}$ & $\begin{array}{l}\text { Roll displacement and mass moment of inertia of second axle of } \\
\text { second trailer }\end{array}$ \\
\hline 24 & $\mathrm{y}_{\mathrm{a} 8}$ & $\mathrm{~m}_{\mathrm{a} 8}$ & Vertical displacement and mass of third axle of second trailer \\
\hline 25 & $\varphi_{\mathrm{a} 8}$ & $\mathrm{I}_{\mathrm{xa} 8}$ & $\begin{array}{l}\text { Roll displacement and mass moment of inertia of third axle of second } \\
\text { trailer }\end{array}$ \\
\hline
\end{tabular}


Table 16. Relative Displacements at Spring Locations of 8 Axle Turnpike Double

\begin{tabular}{|c|c|}
\hline & Suspension springs \\
\hline $\mathbf{U}_{\text {sy1 }}$ & $\left(\mathrm{y}_{\mathrm{t} 1}-\mathrm{y}_{\mathrm{a} 1}\right)+\left(\mathrm{S}_{1} / 2\right)\left(\varphi_{\mathrm{t} 1}-\varphi_{\mathrm{a} 1}\right)+\mathrm{l}_{7} \theta_{\mathrm{t} 1}$ \\
\hline $\mathbf{U}_{\text {sy2 }}$ & $\left(\mathrm{y}_{\mathrm{t} 1}-\mathrm{y}_{\mathrm{a} 1}\right)-\left(\mathrm{S}_{1} / 2\right)\left(\varphi_{\mathrm{t} 1}-\varphi_{\mathrm{a} 1}\right)+\mathrm{l}_{7} \theta_{\mathrm{t} 1}$ \\
\hline $\mathbf{U}_{\mathrm{sy} 3}$ & $\left(\mathrm{y}_{\mathrm{t} 1}-\mathrm{y}_{\mathrm{a} 2}\right)+\left(\mathrm{S}_{2} / 2\right)\left(\varphi_{\mathrm{t} 1}-\varphi_{\mathrm{a} 2}\right)-\mathrm{l}_{8} \theta_{\mathrm{t} 1}$ \\
\hline $\mathbf{U}_{\text {sy4 }}$ & $\left(\mathrm{y}_{\mathrm{t} 1}-\mathrm{y}_{\mathrm{a} 2}\right)-\left(\mathrm{S}_{2} / 2\right)\left(\varphi_{\mathrm{t} 1}-\varphi_{\mathrm{a} 2}\right)-\mathrm{l}_{8} \theta_{\mathrm{t} 1}$ \\
\hline $\mathbf{U}_{\text {sy5 }}$ & $\left(\mathrm{y}_{\mathrm{t} 1}-\mathrm{y}_{\mathrm{a} 3}\right)+\left(\mathrm{S}_{3} / 2\right)\left(\varphi_{\mathrm{t} 1}-\varphi_{\mathrm{a} 3}\right)-\left(\mathrm{l}_{2}+\mathrm{l}_{8}\right) \theta_{\mathrm{t} 1}$ \\
\hline $\mathbf{U}_{\text {sy6 }}$ & $\left(\mathrm{y}_{\mathrm{t} 1}-\mathrm{y}_{\mathrm{a} 3}\right)-\left(\mathrm{S}_{3} / 2\right)\left(\varphi_{\mathrm{t} 1}-\varphi_{\mathrm{a} 3}\right)-\left(\mathrm{l}_{2}+\mathrm{l}_{8}\right) \theta_{\mathrm{t} 1}$ \\
\hline $\mathbf{U}_{\text {sy7 }}$ & $\left(\mathrm{y}_{\mathrm{t} 2}-\mathrm{y}_{\mathrm{a} 4}\right)+\left(\mathrm{S}_{4} / 2\right)\left(\varphi_{\mathrm{t} 2}-\varphi_{\mathrm{a} 4}\right)-\mathrm{l}_{11} \theta_{\mathrm{t} 2}$ \\
\hline $\mathbf{U}_{\text {sy8 }}$ & $\left(\mathrm{y}_{\mathrm{t} 2}-\mathrm{y}_{\mathrm{a} 4}\right)-\left(\mathrm{S}_{4} / 2\right)\left(\varphi_{\mathrm{t} 2}-\varphi_{\mathrm{a} 4}\right)-\mathrm{l}_{11} \theta_{\mathrm{t} 2}$ \\
\hline $\mathbf{U}_{\text {sy9 }}$ & $\left(\mathrm{y}_{\mathrm{t} 2}-\mathrm{y}_{\mathrm{a} 5}\right)+\left(\mathrm{S}_{5} / 2\right)\left(\varphi_{\mathrm{t} 2}-\varphi_{\mathrm{a} 5}\right)-\left(\mathrm{l}_{4}+\mathrm{l}_{11}\right) \theta_{\mathrm{t} 2}$ \\
\hline $\mathbf{U}_{\text {sy10 }}$ & $\left(\mathrm{y}_{\mathrm{t} 2}-\mathrm{y}_{\mathrm{a} 5}\right)-\left(\mathrm{S}_{5} / 2\right)\left(\varphi_{\mathrm{t} 2}-\varphi_{\mathrm{a} 5}\right)-\left(\mathrm{l}_{4}+\mathrm{l}_{11}\right) \theta_{\mathrm{t} 2}$ \\
\hline $\mathbf{U}_{\text {sy11 }}$ & $\left(\mathrm{y}_{\mathrm{t} 3}-\mathrm{y}_{\mathrm{a} 6}\right)+\left(\mathrm{S}_{6} / 2\right)\left(\varphi_{\mathrm{t} 3}-\varphi_{\mathrm{a} 6}\right)+\mathrm{l}_{13} \theta_{\mathrm{t} 3}$ \\
\hline $\mathbf{U}_{\mathrm{sy} 12}$ & $\left(\mathrm{y}_{\mathrm{t} 3}-\mathrm{y}_{\mathrm{a} 6}\right)-\left(\mathrm{S}_{6} / 2\right)\left(\varphi_{\mathrm{t} 3}-\varphi_{\mathrm{a} 6}\right)+\mathrm{l}_{13} \theta_{\mathrm{t} 3}$ \\
\hline $\mathbf{U}_{\mathrm{sy} 13}$ & $\left(\mathrm{y}_{\mathrm{t} 3}-\mathrm{y}_{\mathrm{a} 7}\right)+\left(\mathrm{S}_{7} / 2\right)\left(\varphi_{\mathrm{t} 3}-\varphi_{\mathrm{a} 7}\right)-\mathrm{l}_{14} \theta_{\mathrm{t} 3}$ \\
\hline $\mathbf{U}_{\text {sy14 }}$ & $\left(\mathrm{y}_{\mathrm{t} 3}-\mathrm{y}_{\mathrm{a} 7}\right)-\left(\mathrm{S}_{7} / 2\right)\left(\varphi_{\mathrm{t} 3}-\varphi_{\mathrm{a} 7}\right)-\mathrm{l}_{14} \theta_{\mathrm{t} 3}$ \\
\hline $\mathbf{U}_{\mathrm{sy} 15}$ & $\left(\mathrm{y}_{\mathrm{t} 3}-\mathrm{y}_{\mathrm{a} 8}\right)+\left(\mathrm{S}_{8} / 2\right)\left(\varphi_{\mathrm{t} 3}-\varphi_{\mathrm{a} 8}\right)-\left(\mathrm{l}_{14}+\mathrm{l}_{12}\right) \theta_{\mathrm{t} 3}$ \\
\hline $\mathbf{U}_{\text {sy16 }}$ & $\left(\mathrm{y}_{\mathrm{t} 3}-\mathrm{y}_{\mathrm{a} 8}\right)-\left(\mathrm{S}_{8} / 2\right)\left(\varphi_{\mathrm{t} 3}-\varphi_{\mathrm{a} 8}\right)-\left(\mathrm{l}_{14}+\mathrm{l}_{12}\right) \theta_{\mathrm{t} 3}$ \\
\hline & Tire springs \\
\hline $\mathbf{U}_{\text {ty1 }}$ & $\mathrm{y}_{\mathrm{a} 1}+\left(\mathrm{d}_{1} / 2\right) \varphi_{\mathrm{a} 1}+\mathrm{u}_{\mathrm{SR} 1}$ \\
\hline $\mathbf{U}_{\mathrm{ty} 2}$ & $\mathrm{y}_{\mathrm{a} 1}-\left(\mathrm{d}_{1} / 2\right) \varphi_{\mathrm{a} 1}+\mathrm{u}_{\mathrm{SR} 2}$ \\
\hline $\mathbf{U}_{\mathrm{ty} 3}$ & $\mathrm{y}_{\mathrm{a} 2}+\left(\mathrm{d}_{2} / 2\right) \varphi_{\mathrm{a} 2}+\mathrm{u}_{\mathrm{SR} 3}$ \\
\hline $\mathbf{U}_{\mathrm{ty} 4}$ & $\mathrm{y}_{\mathrm{a} 2}-\left(\mathrm{d}_{2} / 2\right) \varphi_{\mathrm{a} 2}+\mathrm{u}_{\mathrm{SR} 4}$ \\
\hline $\mathbf{U}_{\text {ty5 }}$ & $\mathrm{y}_{\mathrm{a} 3}+\left(\mathrm{d}_{3} / 2\right) \varphi_{\mathrm{a} 3}+\mathrm{u}_{\mathrm{SR} 5}$ \\
\hline $\mathbf{U}_{\text {ty6 }}$ & $\mathrm{y}_{\mathrm{a} 3}-\left(\mathrm{d}_{3} / 2\right) \varphi_{\mathrm{a} 3}+\mathrm{u}_{\mathrm{SR} 6}$ \\
\hline $\mathbf{U}_{\text {ty } 7}$ & $\mathrm{y}_{\mathrm{a} 4}+\left(\mathrm{d}_{4} / 2\right) \varphi_{\mathrm{a} 4}+\mathrm{u}_{\mathrm{SR} 7}$ \\
\hline $\mathbf{U}_{\text {ty8 }}$ & $\mathrm{y}_{\mathrm{a} 4}-\left(\mathrm{d}_{4} / 2\right) \varphi_{\mathrm{a} 4}+\mathrm{u}_{\mathrm{SR} 8}$ \\
\hline$U_{\text {ty9 }}$ & $\mathrm{y}_{\mathrm{a} 5}+\left(\mathrm{d}_{5} / 2\right) \varphi_{\mathrm{a} 5}+\mathrm{u}_{\mathrm{SR} 9}$ \\
\hline $\mathbf{U}_{\mathrm{ty} 10}$ & $\mathrm{y}_{\mathrm{a} 5}-\left(\mathrm{d}_{5} / 2\right) \varphi_{\mathrm{a} 5}+\mathrm{u}_{\mathrm{SR} 10}$ \\
\hline $\mathbf{U}_{\text {ty11 }}$ & $\mathrm{y}_{\mathrm{a} 6}+\left(\mathrm{d}_{6} / 2\right) \varphi_{\mathrm{a} 6}+\mathrm{u}_{\mathrm{SR} 11}$ \\
\hline $\mathbf{U}_{\mathrm{ty} 12}$ & $\mathrm{y}_{\mathrm{a} 6}-\left(\mathrm{d}_{6} / 2\right) \varphi_{\mathrm{a} 6}+\mathrm{u}_{\mathrm{SR} 12}$ \\
\hline
\end{tabular}




\begin{tabular}{|c|c|}
\hline $\mathbf{U}_{\mathrm{ty} 13}$ & $\mathrm{y}_{\mathrm{a} 7}+\left(\mathrm{d}_{7} / 2\right) \varphi_{\mathrm{a} 7}+\mathrm{u}_{\mathrm{SR} 13}$ \\
\cline { 2 - 2 } $\mathbf{U}_{\mathrm{ty} 14}$ & $\mathrm{y}_{\mathrm{a} 7}-\left(\mathrm{d}_{7} / 2\right) \varphi_{\mathrm{a} 7}+\mathrm{u}_{\mathrm{SR} 14}$ \\
\hline $\mathbf{U}_{\mathrm{ty} 15}$ & $\mathrm{y}_{\mathrm{a} 8}+\left(\mathrm{d}_{8} / 2\right) \varphi_{\mathrm{a} 8}+\mathrm{u}_{\mathrm{SR} 15}$ \\
\hline $\mathbf{U}_{\mathrm{ty} 16}$ & $\mathrm{y}_{\mathrm{a} 8}-\left(\mathrm{d}_{8} / 2\right) \varphi_{\mathrm{a} 8}+\mathrm{u}_{\mathrm{SR} 16}$ \\
\hline
\end{tabular}

Kinetic Energy of the system:

$$
\begin{aligned}
& T=\frac{1}{2} m_{t 1} \dot{y}_{t 1}{ }^{2}+\frac{1}{2} m_{a 1} \dot{y}_{a 1}{ }^{2}+\frac{1}{2} m_{a 2} \dot{y}_{a 2}{ }^{2}+\frac{1}{2} m_{a 3} \dot{y}_{a 3}{ }^{2}+\frac{1}{2} m_{a 4} \dot{y}_{a 4}{ }^{2}+\frac{1}{2} m_{a 5} \dot{y}_{a 5}{ }^{2}+ \\
& \frac{1}{2} m_{a 6} \dot{y}_{a 6}{ }^{2}+\frac{1}{2} m_{a 7} \dot{y}_{a 7}{ }^{2}+\frac{1}{2} m_{a 8} \dot{y}_{a 8}{ }^{2}+\frac{1}{2} I_{x t 1} \dot{\varphi}_{t 1}{ }^{2}+\frac{1}{2} I_{z t 1} \dot{\theta}_{t 1}{ }^{2}+\frac{1}{2} I_{x t 2} \dot{\varphi}_{t 2}{ }^{2}+ \\
& \frac{1}{2} I_{z t 2} \dot{\theta}_{t 2}{ }^{2}+\frac{1}{2} I_{x t 3} \dot{\varphi}_{t 3}{ }^{2}+\frac{1}{2} I_{z t 3} \dot{\theta}_{t 3}{ }^{2}+\frac{1}{2} I_{x a 1} \dot{\varphi}_{a 1}{ }^{2}+\frac{1}{2} I_{x a 2} \dot{\varphi}_{a 2}{ }^{2}+\frac{1}{2} I_{x a 3} \dot{\varphi}_{a 3}{ }^{2}+ \\
& \frac{1}{2} I_{x a 4} \dot{\varphi}_{a 4}{ }^{2}+\frac{1}{2} I_{x a 5} \dot{\varphi}_{a 5}{ }^{2}+\frac{1}{2} I_{x a 6} \dot{\varphi}_{a 6}{ }^{2}+\frac{1}{2} I_{x a 7} \dot{\varphi}_{a 7}{ }^{2}+\frac{1}{2} I_{x a 8} \dot{\varphi}_{a 8}{ }^{2}+\frac{1}{2} m_{t 2} \dot{y}_{t 2}{ }^{2}+ \\
& \frac{1}{2} m_{t 3} \dot{y}_{t 3}{ }^{2}
\end{aligned}
$$

\section{Damping Energy of the system:}

$$
\begin{aligned}
& D=\frac{1}{2} D_{s y 1} \dot{U}_{s y 1}{ }^{2}+\frac{1}{2} D_{s y 2} \dot{U}_{s y 2}{ }^{2}+\frac{1}{2} D_{s y 3} \dot{U}_{s y 3}{ }^{2}+\frac{1}{2} D_{s y 4} \dot{U}_{s y 4}{ }^{2}+\frac{1}{2} D_{s y 5} \dot{U}_{s y 5}{ }^{2}+ \\
& \frac{1}{2} D_{s y 6} \dot{U}_{s y 6}{ }^{2}+\frac{1}{2} D_{s y 7} \dot{U}_{s y 7}{ }^{2}+\frac{1}{2} D_{s y 8} \dot{U}_{s y 8}{ }^{2}+\frac{1}{2} D_{s y 9} \dot{U}_{s y 9}{ }^{2}+\frac{1}{2} D_{s y 10} \dot{U}_{s y 10}{ }^{2}+ \\
& \frac{1}{2} D_{s y 11} \dot{U}_{s y 11}{ }^{2}+\frac{1}{2} D_{s y 12} \dot{U}_{s y 12}{ }^{2}+\frac{1}{2} D_{s y 13} \dot{U}_{s y 13}{ }^{2}+\frac{1}{2} D_{s y 14} \dot{U}_{s y 14}{ }^{2}+\frac{1}{2} D_{s y 15} \dot{U}_{s y 15}{ }^{2}+ \\
& \frac{1}{2} D_{s y 16} \dot{U}_{s y 16}{ }^{2}+\frac{1}{2} D_{t y 1} \dot{U}_{t y 1}{ }^{2}+\frac{1}{2} D_{t y 2} \dot{U}_{t y 2}{ }^{2}+\frac{1}{2} D_{t y 3} \dot{U}_{t y 3}{ }^{2}+\frac{1}{2} D_{t y 4} \dot{U}_{t y 4}{ }^{2}+ \\
& \frac{1}{2} D_{t y 5} \dot{U}_{t y 5}{ }^{2}+\frac{1}{2} D_{t y 6} \dot{U}_{t y 6}{ }^{2}+\frac{1}{2} D_{t y 7} \dot{U}_{t y 7}{ }^{2}+\frac{1}{2} D_{t y 8} \dot{U}_{t y 8}{ }^{2}+\frac{1}{2} D_{t y 9} \dot{U}_{t y 9}{ }^{2}+ \\
& \frac{1}{2} D_{t y 10} \dot{U}_{t y 10}{ }^{2}+\frac{1}{2} D_{t y 11} \dot{U}_{t y 11}{ }^{2}+\frac{1}{2} D_{t y 12} \dot{U}_{t y 12}{ }^{2}+\frac{1}{2} D_{t y 13} \dot{U}_{t y 13}{ }^{2}+\frac{1}{2} D_{t y 14} \dot{U}_{t y 14}{ }^{2}+ \\
& \frac{1}{2} D_{t y 15} \dot{U}_{t y 15}{ }^{2}+\frac{1}{2} D_{t y 16} \dot{U}_{t y 16}{ }^{2}
\end{aligned}
$$


Figure 8. Eight Axle Turnpike Double Dynamic Model (a) Truck Side View (b) Truck Front View 
Potential Energy of the system:

$$
\begin{aligned}
& V=\frac{1}{2} K_{s y 1} U_{s y 1}{ }^{2}+\frac{1}{2} K_{s y 2} U_{s y 2}{ }^{2}+\frac{1}{2} K_{s y 3} U_{s y 3}{ }^{2}+\frac{1}{2} K_{s y 4} U_{s y 4}{ }^{2}+\frac{1}{2} K_{s y 5} U_{s y 5}{ }^{2}+ \\
& \frac{1}{2} K_{s y 6} U_{s y 6}{ }^{2}+\frac{1}{2} K_{s y 7} U_{s y 7}{ }^{2}+\frac{1}{2} K_{s y 8} U_{s y 8}{ }^{2}+\frac{1}{2} K_{s y 9} U_{s y 9}{ }^{2}+\frac{1}{2} K_{s y 10} U_{s y 10}{ }^{2}+ \\
& \frac{1}{2} K_{s y 11} U_{s y 11}{ }^{2}+\frac{1}{2} K_{s y 12} U_{s y 12}{ }^{2}+\frac{1}{2} K_{s y 13} U_{s y 13}{ }^{2}+\frac{1}{2} K_{s y 14} U_{s y 14}{ }^{2}+ \\
& \frac{1}{2} K_{s y 15} U_{s y 15}{ }^{2}+\frac{1}{2} K_{s y 16} U_{s y 16}{ }^{2}+\frac{1}{2} K_{t y 1} U_{t y 1}{ }^{2}+\frac{1}{2} K_{t y 2} U_{t y 2}{ }^{2}+\frac{1}{2} K_{t y 3} U_{t y 3}{ }^{2}+ \\
& \frac{1}{2} K_{t y 4} U_{t y 4}{ }^{2}+\frac{1}{2} K_{t y 5} U_{t y 5}{ }^{2}+\frac{1}{2} K_{t y 6} U_{t y 6}{ }^{2}+\frac{1}{2} K_{t y 7} U_{s y 7}{ }^{2}+\frac{1}{2} K_{t y 8} U_{t y 8}{ }^{2}+ \\
& \frac{1}{2} K_{t y 9} U_{t y 9}{ }^{2}+\frac{1}{2} K_{t y 10} U_{t y 10}{ }^{2}+\frac{1}{2} K_{t y 11} U_{t y 11}{ }^{2}+\frac{1}{2} K_{t y 12} U_{t y 12}{ }^{2}+\frac{1}{2} K_{t y 13} U_{t y 13}{ }^{2}+ \\
& \frac{1}{2} K_{t y 14} U_{t y 14}{ }^{2}+\frac{1}{2} K_{t y 15} U_{t y 15}{ }^{2}+\frac{1}{2} K_{t y 16} U_{t y 16}{ }^{2}-\left(\left(m_{t 1} g\right) y_{t 1}+\left(m_{t 2} g\right) y_{t 2}+\right. \\
& \left(m_{t 3} g\right) y_{t 3}+\left(m_{a 1} g\right) y_{a 1}+\left(m_{a 2} g\right) y_{a 2}+\left(m_{a 3} g\right) y_{a 3}+\left(m_{a 4} g\right) y_{a 4}+ \\
& \left.\left(m_{a 5} g\right) y_{a 5}+\left(m_{a 6} g\right) y_{a 6}+\left(m_{a 7} g\right) y_{a 7}+\left(m_{a 8} g\right) y_{a 8}\right)+\left(F_{y 1} U_{s y 1}+F_{y 2} U_{s y 2}+\right. \\
& F_{y 3} U_{s y 3}+F_{y 4} U_{s y 4}+F_{y 5} U_{s y 5}+F_{y 6} U_{s y 6}+F_{y 7} U_{s y 7}+F_{y 8} U_{s y 8}+F_{y 9} U_{s y 9}+ \\
& F_{y 10} U_{s y 10}+F_{y 11} U_{s y 11}+F_{y 12} U_{s y 12}+F_{y 13} U_{s y 13}+F_{y 14} U_{s y 14}+F_{y 15} U_{s y 15}+ \\
& \left.F_{y 16} U_{s y 16}\right)
\end{aligned}
$$

The displacement at the pivot point should stay the same, whether it is calculated from the trailer part or the tractor part,

$$
y_{t 2}+\theta_{t 2} l_{10}=y_{t 1}-\theta_{t 1} l_{9}
$$

Thus, by substituting $\theta_{\mathrm{t} 2}$ from equation ( 284 ) in equation ( 281 ),

$$
\begin{aligned}
& T=\frac{1}{2} m_{t 1} \dot{y}_{t 1}^{2}+\frac{1}{2} m_{a 1} \dot{y}_{a 1}^{2}+\frac{1}{2} m_{a 2} \dot{y}_{a 2}{ }^{2}+\frac{1}{2} m_{a 3} \dot{y}_{a 3}{ }^{2}+\frac{1}{2} m_{a 4} \dot{y}_{a 4}{ }^{2}+\frac{1}{2} m_{a 5} \dot{y}_{a 5}{ }^{2}+ \\
& \frac{1}{2} m_{a 6} \dot{y}_{a 6}{ }^{2}+\frac{1}{2} m_{a 7} \dot{y}_{a 7}{ }^{2}+\frac{1}{2} m_{a 8} \dot{y}_{a 8}{ }^{2}+\frac{1}{2} I_{x t 1} \dot{\varphi}_{t 1}{ }^{2}+\frac{1}{2} I_{z t 1} \dot{\theta}_{t 1}{ }^{2}+\frac{1}{2} I_{x t 2} \dot{\varphi}_{t 2}{ }^{2}+ \\
& \frac{1}{2} I_{z t 2}\left(\frac{\dot{y}_{t 1}-\dot{y}_{t 2}-\dot{\theta}_{t 1} l_{9}}{l_{10}}\right)^{2}+\frac{1}{2} I_{x t 3} \dot{\varphi}_{t 3}{ }^{2}+\frac{1}{2} I_{z t 3} \dot{\theta}_{t 3}{ }^{2}+\frac{1}{2} I_{x a 1} \dot{\varphi}_{a 1}{ }^{2}+\frac{1}{2} I_{x a 2} \dot{\varphi}_{a 2}{ }^{2}+
\end{aligned}
$$


$\frac{1}{2} I_{x a 3} \dot{\varphi}_{a 3}{ }^{2}+\frac{1}{2} I_{x a 4} \dot{\varphi}_{a 4}{ }^{2}+\frac{1}{2} I_{x a 5} \dot{\varphi}_{a 5}{ }^{2}+\frac{1}{2} I_{x a 6} \dot{\varphi}_{a 6}{ }^{2}+\frac{1}{2} I_{x a 7} \dot{\varphi}_{a 7}{ }^{2}+\frac{1}{2} I_{x a 8} \dot{\varphi}_{a 8}{ }^{2}+$

$\frac{1}{2} m_{t 2} \dot{y}_{t 2}^{2}+\frac{1}{2} m_{t 3} \dot{y}_{t 3}^{2}$

Same substitution will be applied to the equations ( 282 ) and ( 283 ). Now the Lagrange's equation is applied to $\mathrm{y}_{\mathrm{t} 2}$ :

$\left[m_{t 2} \ddot{y}_{t 2}-\frac{I_{z t 2}}{l_{10}}\left(\ddot{y}_{t 1}-\ddot{y}_{t 2}-\ddot{\theta}_{t 1} l_{9}\right)\right]+$

$\left[\left(1+\frac{l_{11}}{l_{10}}\right)\left(F_{s y 7}+F_{s y 8}\right)+\left(1+\frac{l_{4}+l_{11}}{l_{10}}\right)\left(F_{s y 9}+F_{s y 10}\right)-\left(m_{t 2} g\right)\right]+[(1+$

$\left.\left.\frac{l_{11}}{l_{10}}\right)\left(F_{d s y 7}+F_{d s y 8}\right)+\left(1+\frac{l_{4}+l_{11}}{l_{10}}\right)\left(F_{d s y 9}+F_{d s y 10}\right)\right]=0$

To simplify the equation some variables are defined as follows:

$\mathrm{S}_{\mathrm{a} 2}=\frac{\mathrm{I}_{\mathrm{zt} 2}}{\mathrm{l}_{10}{ }^{2}}$

$\mathrm{S}_{\mathrm{c} 2}=\frac{\mathrm{I}_{\mathrm{zt} 2}}{\mathrm{l}_{10}^{2}}+\mathrm{m}_{\mathrm{t} 2}$

$\mathrm{S}_{\mathrm{a} 3}=\frac{\mathrm{I}_{\mathrm{zt} 2}}{\mathrm{l}_{10}{ }^{2}} \mathrm{l}_{9}$

$B_{t 4}=m_{t 2} g-\left[\left(1+\frac{l_{11}}{l_{10}}\right)\left(F_{s y 7}+F_{s y 8}+F_{d s y 7}+F_{d s y 8}\right)+\left(1+\frac{l_{4}+l_{11}}{l_{10}}\right)\left(F_{s y 9}+F_{s y 10}+F_{d s y 9}+\right.\right.$

$\left.\left.F_{d s y 10}\right)\right]$

Therefore equation ( 286 ) will be simplified to:

$-S_{\mathrm{a} 2} \ddot{y}_{\mathrm{t} 1}+\mathrm{S}_{\mathrm{c} 2} \ddot{y}_{\mathrm{t} 2}+\mathrm{S}_{\mathrm{a} 3} \ddot{\theta}_{\mathrm{t} 1}=\mathrm{B}_{\mathrm{t} 4}$

By applying the Lagrange's equation to $\mathrm{y}_{\mathrm{t} 1}$ :

$\left[m_{t 1} \ddot{y}_{t 1}+\frac{I_{z t 2}}{l_{10}{ }^{2}}\left(\ddot{y}_{t 1}-\ddot{y}_{t 2}-\ddot{\theta}_{t 1} l_{9}\right)\right]+\left[\left(F_{s y 1}+F_{s y 2}+F_{s y 3}+F_{s y 4}+F_{s y 5}+F_{s y 6}\right)-\right.$ 


$$
\begin{aligned}
& \left.\frac{l_{11}}{l_{10}}\left(F_{s y 7}+F_{s y 8}\right)-\frac{l_{4}+l_{11}}{l_{10}}\left(F_{s y 9}+F_{s y 10}\right)-\left(m_{t 1} g\right)\right]+\left[\left(F_{d s y 1}+F_{d s y 2}+F_{d s y 3}+\right.\right. \\
& \left.\left.F_{d s y 4}+F_{d s y 5}+F_{d s y 6}\right)-\frac{l_{11}}{l_{10}}\left(F_{d s y 7}+F_{d s y 8}\right)-\frac{l_{4}+l_{11}}{l_{10}}\left(F_{d s y 9}+F_{d s y 10}\right)\right]=0
\end{aligned}
$$

Again to simplify the equation some variables are defined as follows:

$$
\begin{aligned}
& \mathrm{S}_{\mathrm{a} 1}=\frac{\mathrm{I}_{\mathrm{zt} 2}}{\mathrm{l}_{10}^{2}}+\mathrm{m}_{\mathrm{t} 1} \\
& B_{t 1}=m_{t 1} g-\left[\left(F_{s y 1}+F_{s y 2}+F_{s y 3}+F_{s y 4}+F_{s y 5}+F_{s y 6}\right)-\frac{l_{11}}{l_{10}}\left(F_{s y 7}+F_{s y 8}\right)-\frac{l_{4}+l_{11}}{l_{10}}\left(F_{s y 9}+\right.\right. \\
& \left.F_{s y 10}\right)+\left(F_{d s y 1}+F_{d s y 2}+F_{d s y 3}+F_{d s y 4}+F_{d s y 5}+F_{d s y 6}\right)-\frac{l_{11}}{l_{10}}\left(F_{d s y 7}+F_{d s y 8}\right)- \\
& \left.\frac{l_{4}+l_{11}}{l_{10}}\left(F_{d s y 9}+F_{d s y 10}\right)\right]
\end{aligned}
$$

Therefore equation ( 288 ) will be simplified to:

$\mathrm{S}_{\mathrm{a} 1} \ddot{\mathrm{y}}_{\mathrm{t} 1}-\mathrm{S}_{\mathrm{a} 2} \ddot{\mathrm{y}}_{\mathrm{t} 2}-\mathrm{S}_{\mathrm{a} 3} \ddot{\theta}_{\mathrm{t} 1}=\mathrm{B}_{\mathrm{t} 1}$

Also, by applying the Lagrange's equation to $\theta_{\mathrm{t} 1}$ :

$$
\begin{aligned}
& {\left[I_{z t 1} \ddot{\theta}_{t 1}-\frac{I_{z t 2} l_{9}}{l_{10}{ }^{2}}\left(\ddot{y}_{t 1}-\ddot{y}_{t 2}-\ddot{\theta}_{t 1} l_{9}\right)\right]+\left[l_{7}\left(F_{s y 1}+F_{s y 2}\right)-l_{8}\left(F_{s y 3}+F_{s y 4}\right)-\right.} \\
& \left.\left(l_{2}+l_{8}\right)\left(F_{s y 5}+F_{s y 6}\right)+\frac{l_{9} I_{11}}{l_{10}}\left(F_{s y 7}+F_{s y 8}\right)+\frac{l_{9}\left(l_{4}+I_{11}\right)}{l_{10}}\left(F_{s y 9}+F_{s y 10}\right)\right]+ \\
& {\left[l_{7}\left(F_{d s y 1}+F_{d s y 2}\right)-l_{8}\left(F_{d s y 3}+F_{d s y 4}\right)-\left(l_{2}+l_{8}\right)\left(F_{d s y 5}+F_{d s y 6}\right)+\frac{l_{9} I_{11}}{l_{10}}\left(F_{d s y 7}+\right.\right.} \\
& \left.\left.F_{d s y 8}\right)+\frac{l_{9}\left(l_{4}+I_{11}\right)}{l_{10}}\left(F_{d s y 9}+F_{d s y 10}\right)\right]=0
\end{aligned}
$$

Once again to simplify the equation some variables need to be defined as follows:

$$
\mathrm{S}_{\mathrm{b} 3}=\mathrm{I}_{\mathrm{zt} 1}+\frac{\mathrm{I}_{\mathrm{zt} 2} \mathrm{l}_{9}}{\mathrm{l}_{10}^{2}}
$$




$$
\begin{aligned}
& B_{t 3}=-\left[\left[l_{7}\left(F_{s y 1}+F_{s y 2}\right)-l_{8}\left(F_{s y 3}+F_{s y 4}\right)-\left(l_{2}+l_{8}\right)\left(F_{s y 5}+F_{s y 6}\right)+\frac{l_{9} I_{11}}{l_{10}}\left(F_{s y 7}+F_{s y 8}\right)+\right.\right. \\
& \left.\frac{l_{9}\left(l_{4}+I_{11}\right)}{l_{10}}\left(F_{s y 9}+F_{s y 10}\right)\right]+\left[l_{7}\left(F_{d s y 1}+F_{d s y 2}\right)-l_{8}\left(F_{d s y 3}+F_{d s y 4}\right)-\left(l_{2}+l_{8}\right)\left(F_{d s y 5}+\right.\right. \\
& \left.\left.\left.F_{d s y 6}\right)+\frac{l_{9} I_{11}}{l_{10}}\left(F_{d s y 7}+F_{d s y 8}\right)+\frac{l_{9}\left(l_{4}+I_{11}\right)}{l_{10}}\left(F_{d s y 9}+F_{d s y 10}\right)\right]\right]
\end{aligned}
$$

Therefore equation ( 290 ) will be simplified to:

$$
-S_{\mathrm{a} 3} \ddot{y}_{\mathrm{t} 1}+\mathrm{S}_{\mathrm{a} 3} \ddot{\mathrm{y}}_{\mathrm{t} 2}+\mathrm{S}_{\mathrm{b} 3} \ddot{\theta}_{\mathrm{t} 1}=\mathrm{B}_{\mathrm{t} 3}
$$

By adding equations ( 287 ) and ( 289 ),

$$
\left(S_{\mathrm{a} 1}-\mathrm{S}_{\mathrm{a} 2}\right) \ddot{y}_{\mathrm{t} 1}-\left(\mathrm{S}_{\mathrm{a} 2}-\mathrm{S}_{\mathrm{c} 2}\right) \ddot{y}_{\mathrm{t} 2}=\mathrm{B}_{\mathrm{t} 1}+\mathrm{B}_{\mathrm{t} 4}
$$

Also by multiplying $\mathrm{S}_{\mathrm{b} 3}$ and $\mathrm{S}_{\mathrm{a} 3}$ to equations ( 291 ) and ( 292 ), respectively,

$$
\left(\mathrm{S}_{\mathrm{a} 1} \mathrm{~S}_{\mathrm{b} 3}-\mathrm{S}_{\mathrm{a} 3}^{2}\right) \ddot{\mathrm{y}}_{\mathrm{t} 1}-\left(\mathrm{S}_{\mathrm{a} 2} \mathrm{~S}_{\mathrm{b} 3}-\mathrm{S}_{\mathrm{a} 3}^{2}\right) \ddot{\mathrm{y}}_{\mathrm{t} 2}=\mathrm{S}_{\mathrm{b} 3} \mathrm{~B}_{\mathrm{t} 1}+\mathrm{S}_{\mathrm{a} 3} \mathrm{~B}_{\mathrm{t} 3}
$$

By defining the following expressions, equations ( 292 ) and ( 293 ) are simplified to equations ( 294 ) and ( 295 ), respectively,

$$
\begin{aligned}
& \mathrm{e}_{1}=\mathrm{S}_{\mathrm{a} 1}-\mathrm{S}_{\mathrm{a} 2} \\
& \mathrm{e}_{2}=\mathrm{S}_{\mathrm{a} 2}-\mathrm{S}_{\mathrm{c} 2} \\
& \mathrm{e}_{3}=\mathrm{S}_{\mathrm{a} 1} \mathrm{~S}_{\mathrm{b} 3}-\mathrm{S}_{\mathrm{a} 3}^{2} \\
& \mathrm{e}_{4}=\mathrm{S}_{\mathrm{a} 2} \mathrm{~S}_{\mathrm{b} 3}-\mathrm{S}_{\mathrm{a} 3}{ }^{2} \\
& \mathrm{e}_{1} \ddot{\mathrm{y}}_{\mathrm{t} 1}-\mathrm{e}_{2} \ddot{\mathrm{y}}_{\mathrm{t} 2}=\mathrm{B}_{\mathrm{t} 1}+\mathrm{B}_{\mathrm{t} 4} \\
& \mathrm{e}_{3} \ddot{\mathrm{y}}_{\mathrm{t} 1}-\mathrm{e}_{4} \ddot{\mathrm{y}}_{\mathrm{t} 2}=\mathrm{S}_{\mathrm{b} 3} \mathrm{~B}_{\mathrm{t} 1}+\mathrm{S}_{\mathrm{a} 3} \mathrm{~B}_{\mathrm{t} 3}
\end{aligned}
$$

Solving equations ( 294 ) and ( 295 ) for $\ddot{y}_{\mathrm{t} 1}$ and $\ddot{y}_{\mathrm{t} 2}$ will lead to: 
$\ddot{y}_{t 1}=\frac{e_{4}\left(B_{t 1}+B_{t 4}\right)-e_{2}\left(S_{b 3} B_{t 1}+S_{a 3} B_{t 3}\right)}{e_{1} e_{4}-e_{2} e_{3}}$

$\ddot{y}_{t 2}=\frac{e_{1}}{e_{2}}\left(\frac{e_{4}\left(B_{t 1}+B_{t 4}\right)-e_{2}\left(S_{b 3} B_{t 1}+S_{a 3} B_{t 3}\right)}{e_{1} e_{4}-e_{2} e_{3}}\right)-\frac{B_{t 1}+B_{t 4}}{e_{2}}$

Substituting equations ( 296 ) and ( 297 ) into equation ( 291 ) will give,

$$
\begin{aligned}
& \ddot{\theta}_{t 1}= \\
& \frac{B_{t 3}}{S_{b 3}}+\frac{S_{a 3}}{S_{b 3}}\left(\frac{e_{4}\left(B_{t 1}+B_{t 4}\right)-e_{2}\left(S_{b 3} B_{t 1}+S_{a 3} B_{t 3}\right)}{e_{1} e_{4}-e_{2} e_{3}}\right)-\frac{S_{a 3}}{S_{b 3}}\left(\frac{e_{1}}{e_{2}}\left(\frac{e_{4}\left(B_{t 1}+B_{t 4}\right)-e_{2}\left(S_{b 3} B_{t 1}+S_{a 3} B_{t 3}\right)}{e_{1} e_{4}-e_{2} e_{3}}\right)-\right. \\
& \left.\frac{B_{t 1}+B_{t 4}}{e_{2}}\right)
\end{aligned}
$$

By applying the Lagrange's equation to $\varphi_{\mathrm{t} 1}, \varphi_{\mathrm{t} 2}, \varphi_{\mathrm{t} 3}, \mathrm{y}_{\mathrm{t} 3}, \theta_{\mathrm{t} 3}$ :

$$
\begin{aligned}
& I_{x t 1} \ddot{\varphi}_{t 1}+\left[\left(\frac{s_{1}}{2}\right)\left(F_{s y 1}-F_{s y 2}\right)+\left(\frac{s_{2}}{2}\right)\left(F_{s y 3}-F_{s y 4}\right)+\left(\frac{s_{3}}{2}\right)\left(F_{s y 5}-F_{s y 6}\right)\right]+ \\
& {\left[\left(\frac{s_{1}}{2}\right)\left(F_{d s y 1}-F_{d s y 2}\right)+\left(\frac{s_{2}}{2}\right)\left(F_{d s y 3}-F_{d s y 4}\right)+\left(\frac{s_{3}}{2}\right)\left(F_{d s y 5}-F_{d s y 6}\right)\right]=0} \\
& I_{x t 2} \ddot{\varphi}_{t 2}+\left[\left(\frac{s_{4}}{2}\right)\left(F_{s y 7}-F_{s y 8}\right)+\left(\frac{s_{5}}{2}\right)\left(F_{s y 9}-F_{s y 10}\right)\right]+\left[\left(\frac{s_{4}}{2}\right)\left(F_{d s y 7}-F_{d s y 8}\right)+\right. \\
& \left.\left(\frac{s_{5}}{2}\right)\left(F_{d s y 9}-F_{d s y 10}\right)\right]=0 \\
& I_{x t 3} \ddot{\varphi}_{t 3}+\left[\left(\frac{s_{6}}{2}\right)\left(F_{s y 11}-F_{s y 12}\right)+\left(\frac{s_{7}}{2}\right)\left(F_{s y 13}-F_{s y 14}\right)+\left(\frac{s_{8}}{2}\right)\left(F_{s y 15}-F_{s y 16}\right)\right]+ \\
& {\left[\left(\frac{s_{6}}{2}\right)\left(F_{d s y 11}-F_{d s y 12}\right)+\left(\frac{s_{7}}{2}\right)\left(F_{d s y 13}-F_{d s y 14}\right)+\left(\frac{s_{8}}{2}\right)\left(F_{d s y 15}-F_{d s y 16}\right)\right]=0} \\
& m_{t 3} \ddot{y}_{t 3}+\left(F_{s y 11}+F_{s y 12}+F_{s y 13}+F_{s y 14}+F_{s y 15}+F_{s y 16}\right)+\left(F_{d s y 11}+F_{d s y 12}+\right. \\
& \left.F_{d s y 13}+F_{d s y 14}+F_{d s y 15}+F_{d s y 16}\right)-m_{t 3} g=0 \\
& I_{z t 3} \ddot{\theta}_{t 3}+\left[l_{13}\left(F_{s y 11}+F_{s y 12}\right)-l_{14}\left(F_{s y 13}+F_{s y 14}\right)-\left(l_{14}+l_{12}\right)\left(F_{s y 15}+F_{s y 16}\right)\right]+ \\
& {\left[l_{13}\left(F_{d s y 11}+F_{d s y 12}\right)-l_{14}\left(F_{d s y 13}+F_{d s y 14}\right)-\left(l_{14}+l_{12}\right)\left(F_{d s y 15}+F_{d s y 16}\right)\right]=0}
\end{aligned}
$$

The rest of degrees of freedom will be as follows: 


$$
\begin{aligned}
& m_{a 1} \ddot{y}_{a 1}-\left(F_{s y 1}+F_{s y 2}\right)+\left(F_{t y 1}+F_{t y 2}\right)-\left(F_{d s y 1}+F_{d s y 2}\right)+\left(F_{d t y 1}+F_{d t y 2}\right)= \\
& m_{a 1} g \\
& I_{x a 1} \ddot{\varphi}_{a 1}-\left(\frac{s_{1}}{2}\right)\left(F_{s y 1}-F_{s y 2}\right)+\left(\frac{d_{1}}{2}\right)\left(F_{t y 1}-F_{t y 2}\right)-\left(\frac{s_{1}}{2}\right)\left(F_{d s y 1}-F_{d s y 2}\right)+ \\
& \left(\frac{d_{1}}{2}\right)\left(F_{d t y 1}-F_{d t y 2}\right)=0 \\
& m_{a 2} \ddot{y}_{a 2}-\left(F_{s y 3}+F_{s y 4}\right)+\left(F_{t y 3}+F_{t y 4}\right)-\left(F_{d s y 3}+F_{d s y 4}\right)+\left(F_{d t y 3}+F_{d t y 4}\right)= \\
& m_{a 2} g \\
& I_{x a 2} \ddot{\varphi}_{a 2}-\left(\frac{s_{2}}{2}\right)\left(F_{s y 3}-F_{s y 4}\right)+\left(\frac{d_{2}}{2}\right)\left(F_{t y 3}-F_{t y 4}\right)-\left(\frac{s_{2}}{2}\right)\left(F_{d s y 3}-F_{d s y 4}\right)+ \\
& \left(\frac{d_{2}}{2}\right)\left(F_{d t y 3}-F_{d t y 4}\right)=0 \\
& m_{a 3} \ddot{y}_{a 3}-\left(F_{s y 5}+F_{s y 6}\right)+\left(F_{t y 5}+F_{t y 6}\right)-\left(F_{d s y 5}+F_{d s y 6}\right)+\left(F_{d t y 5}+F_{d t y 6}\right)= \\
& m_{a 3} g \\
& I_{x a 3} \ddot{\varphi}_{a 3}-\left(\frac{s_{3}}{2}\right)\left(F_{s y 5}-F_{s y 6}\right)+\left(\frac{d_{3}}{2}\right)\left(F_{t y 5}-F_{t y 6}\right)-\left(\frac{s_{3}}{2}\right)\left(F_{d s y 5}-F_{d s y 6}\right)+ \\
& \left(\frac{d_{3}}{2}\right)\left(F_{d t y 5}-F_{d t y 6}\right)=0 \\
& m_{a 4} \ddot{y}_{a 4}-\left(F_{s y 7}+F_{s y 8}\right)+\left(F_{t y 7}+F_{t y 8}\right)-\left(F_{d s y 7}+F_{d s y 8}\right)+\left(F_{d t y 7}+F_{d t y 8}\right)= \\
& m_{a 4} g \\
& I_{x a 4} \ddot{\varphi}_{a 4}-\left(\frac{s_{4}}{2}\right)\left(F_{s y 7}-F_{s y 8}\right)+\left(\frac{d_{4}}{2}\right)\left(F_{t y 7}-F_{t y 8}\right)-\left(\frac{s_{4}}{2}\right)\left(F_{d s y 7}-F_{d s y 8}\right)+ \\
& \left(\frac{d_{4}}{2}\right)\left(F_{d t y 7}-F_{d t y 8}\right)=0 \\
& m_{a 5} \ddot{y}_{a 5}-\left(F_{s y 9}+F_{s y 10}\right)+\left(F_{t y 9}+F_{t y 10}\right)-\left(F_{d s y 9}+F_{d s y 10}\right)+\left(F_{d t y 9}+F_{d t y 10}\right)= \\
& m_{a 5} g \\
& I_{x a 5} \ddot{\varphi}_{a 5}-\left(\frac{s_{5}}{2}\right)\left(F_{s y 9}-F_{s y 10}\right)+\left(\frac{d_{5}}{2}\right)\left(F_{t y 9}-F_{t y 10}\right)-\left(\frac{s_{5}}{2}\right)\left(F_{d s y 9}-F_{d s y 10}\right)+ \\
& \left(\frac{d_{5}}{2}\right)\left(F_{d t y 9}-F_{d t y 10}\right)=0
\end{aligned}
$$




$$
\begin{aligned}
& m_{a 6} \ddot{y}_{a 6}-\left(F_{s y 11}+F_{s y 12}\right)+\left(F_{t y 11}+F_{t y 12}\right)-\left(F_{d s y 11}+F_{d s y 12}\right)+\left(F_{d t y 11}+\right. \\
& \left.F_{d t y 12}\right)=m_{a 6} g \\
& I_{x a 6} \ddot{\varphi}_{a 6}-\left(\frac{s_{6}}{2}\right)\left(F_{s y 11}-F_{s y 12}\right)+\left(\frac{d_{6}}{2}\right)\left(F_{t y 11}-F_{t y 12}\right)-\left(\frac{s_{6}}{2}\right)\left(F_{d s y 11}-F_{d s y 12}\right)+ \\
& \left(\frac{d_{6}}{2}\right)\left(F_{d t y 11}-F_{d t y 12}\right)=0 \\
& m_{a 7} \ddot{y}_{a 7}-\left(F_{s y 13}+F_{s y 14}\right)+\left(F_{t y 13}+F_{t y 14}\right)-\left(F_{d s y 13}+F_{d s y 14}\right)+\left(F_{d t y 13}+\right. \\
& \left.F_{d t y 14}\right)=m_{a 7} g \\
& I_{x a 7} \ddot{\varphi}_{a 7}-\left(\frac{s_{7}}{2}\right)\left(F_{s y 13}-F_{s y 14}\right)+\left(\frac{d_{7}}{2}\right)\left(F_{t y 13}-F_{t y 14}\right)-\left(\frac{s_{7}}{2}\right)\left(F_{d s y 13}-F_{d s y 14}\right)+ \\
& \left(\frac{d_{7}}{2}\right)\left(F_{d t y 13}-F_{d t y 14}\right)=0 \\
& m_{a 8} \ddot{y}_{a 8}-\left(F_{s y 15}+F_{s y 16}\right)+\left(F_{t y 15}+F_{t y 16}\right)-\left(F_{d s y 15}+F_{d s y 16}\right)+\left(F_{d t y 15}+\right. \\
& \left.F_{d t y 16}\right)=m_{a 8} g \\
& I_{x a 8} \ddot{\varphi}_{a 8}-\left(\frac{s_{8}}{2}\right)\left(F_{s y 15}-F_{s y 16}\right)+\left(\frac{d_{8}}{2}\right)\left(F_{t y 15}-F_{t y 16}\right)-\left(\frac{s_{8}}{2}\right)\left(F_{d s y 15}-F_{d s y 16}\right)+ \\
& \left(\frac{d_{8}}{2}\right)\left(F_{d t y 15}-F_{d t y 16}\right)=0
\end{aligned}
$$


VITA

ARASH TARIGHI

Born, Tehran, Iran

2003-2007

B.SC. Civil Engineering

Sharif University of Technology

Tehran, Iran

2008-2010

M.S. Civil Engineering

Sharif University of Technology

Tehran, Iran

2011-2015

Ph.D. Candidate, Teaching and Research Assistant

Florida International University

Miami, FL

\section{PUBLICATIONS AND PRESENTATIONS}

Tarighi, A., Wang, T. (2014) Dynamic Modeling of Long Combination Vehicles. International Journal of Sciences: Basic and Applied Research (IJSBAR), Volume 17, Nov. 2014, pp 330-345.

Tarighi, A., Wang, T. (2015) Dynamic Effects of Long Combination Vehicles (LCVs) on Designed Steel and Prestressed Concrete Bridges and Comparing to the Real Bridges (To be submitted).

Tarighi, A., Wang, T. (2015) Fatigue Analysis of Single Span Designed Steel and Concrete Bridges due to Long Combination Vehicles (LCVS) (To be submitted).

Tarighi, A., Wang, T. (2015) Dynamic Analysis and Fatigue Assessment of a Multiple Span Continuous Steel Bridge (To be submitted).

Tarighi, A., Wang, T. (2014) Fatigue Life Evaluation of Steel Girder Bridges Due to Doubling Heavy Vehicles. GSAW Poster Session, Florida International University. 